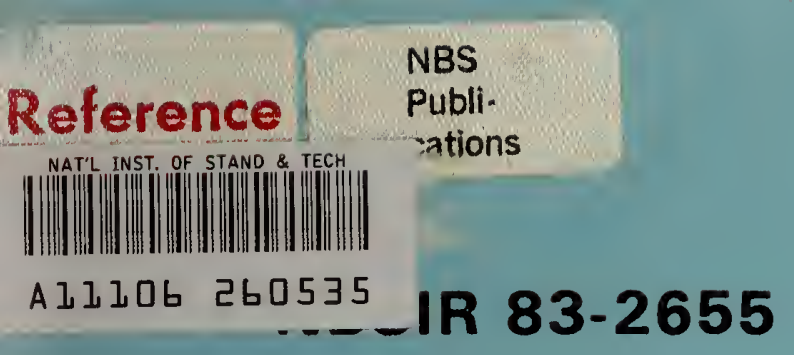

\title{
Thermal Analysis Research Program Reference Manual
}

U.S. DEPARTMENT OF COMMERCE National Bureau of Standards National Engineering Laboratory Building Physics Division

Washington, DC 20234

March 1983

Sponsored by

National Bureau of Standards

and

Building Energy Sciences Branch

affice of Building Energy Research and Development U.S. Department of Energy

Washington, DC 20545 


$$
\text { NTRL - PB83194225 }
$$


NBSIR 83-2655

...

THERMAL ANALYSIS RESEARCH

PROGRAM REFERENCE MANUAL

George N. Walton

U.S. DEPARTMENT OF COMMERCE

National Bureau of Standards

National Engineering Laboratory

Building Physics Division

Washington, DC 20234

March 1983

Sponsored by

National Bureau of Standards

and

Building Energy Sciences Branch

Office of Building Energy Research and Development

U.S. Department of Energy

Washington, DC 20545

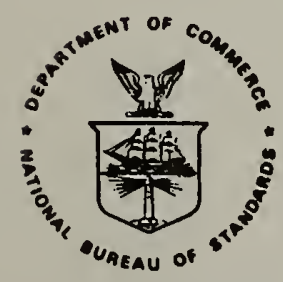

U.S. DEPARTMENT OF COMMERCE, Malcolm Baldrige, Secretary NATIONAL BUREAU OF STANDARDS, Ernest Ambler, Director 



\section{ABSTRACT}

The Thermal Analysis Research Program (TARP) has been developed as a research tool for the thermal analysis of bulldings. It especially alms to study the interactions of many complex heat transfer phenomena. TARP uses the detalled heat balance method for the simultaneous calculation of the energy requirements of multiple rooms. Interroom conductive and convective processes are simulated in deta1l. Th1s program reference manual describes the algorithms, 1nput, output, and program structure of TARP. The program is written to be portable and modiflable. It 18 written in FORTRAN 77 and has run on CDC and UNIVAC computers. Future expansions of the program are anticipated, particularly for the simultaneous simulation of the equipment performance and building thermal response.

Keywords: bullding energy analysis; load calculations; computer modeling; bullding heat transfer. 


\section{PREFACE}

This report is one of a serles documenting NBS research and analysis efforts in developing energy and cost data to support the Department of Energy/National Bureau of Standards Measurements Program. It was prepared by the Thermal Analysis Group, Bullding Physics Division, Center for Bullding Technology, National Engineering Laboratory, National Bureau of Standards (NBS). Th1s work was Jolntly sponsored by NBS and the Department of Energy (DoE). The development of multiroom air flow modeling was supported by DoE/NBS Task Order A008 under Interagency agreement No. EA-77-A-01-6010. Th1s report describes a computer program whlch was written as part of an effort to develop a comprehensive modeling technique for predicting the simultaneous transfer of alr, molsture, and heat in and through multiroom bulldings.

The author wishes to acknowledge the support and direction given by Dr. T. Kusuda, Thermal Analys1s Group Leader.

The computer program described in th1s report 18 intended for research purposes only. It is furnished by the government and 18 accepted and used by any reclpient with the expressed understanding that the United Stated Government makes no warranty, expressed or 1mplled, concerning the accuracy, completeness, rel1abllity, usability, or sultablifty for any particular purpose of the information and data contalned in this program or furnished in connection therewith, and the Unfted States shall be under no llabllity whatsoever to any person by reason of any use made thereof. 
I. INTRODUCTION $\ldots \ldots \ldots \ldots \ldots \ldots \ldots \ldots \ldots \ldots \ldots \ldots \ldots \ldots \ldots \ldots \ldots \ldots \ldots \ldots \ldots \ldots \ldots \ldots \ldots, \ldots \ldots \ldots$

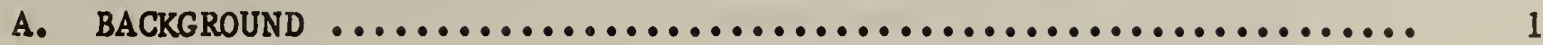

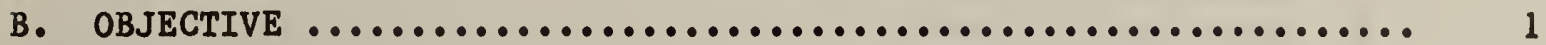

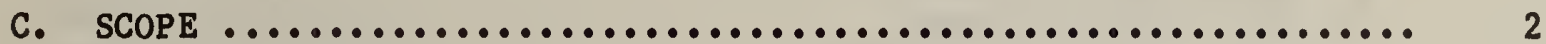

II. PROGRAM OVERVIEW $\ldots \ldots \ldots \ldots \ldots \ldots \ldots \ldots \ldots \ldots \ldots \ldots \ldots \ldots \ldots \ldots \ldots \ldots \ldots \ldots \ldots \ldots \ldots . . \ldots$

A. SIMULATION CAPABILITIES $\ldots \ldots \ldots \ldots \ldots \ldots \ldots \ldots \ldots \ldots \ldots \ldots \ldots \ldots \ldots \ldots \ldots$

B. PROGRAM STRUCTURE .................................. 3

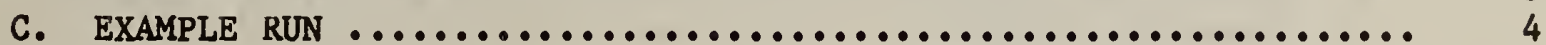

III. ALGORITHMS ............................................ 13

A. INTRODUCTION $\ldots \ldots \ldots \ldots \ldots \ldots \ldots \ldots \ldots \ldots \ldots \ldots \ldots \ldots \ldots \ldots \ldots \ldots \ldots \ldots \ldots \ldots \ldots \ldots . \ldots \ldots$

1. The Heat Balance Method .............................. 13

2. Table of Symbols ................................ 13

B. ENVIRONMENT ....................................... 16

1. Time ......................................... 16

2. Psychrometrics $\ldots \ldots \ldots \ldots \ldots \ldots \ldots \ldots \ldots \ldots \ldots \ldots \ldots \ldots \ldots \ldots \ldots \ldots \ldots \ldots \ldots, 18$

3. Temperatures $\ldots \ldots \ldots \ldots \ldots \ldots \ldots \ldots \ldots \ldots \ldots \ldots \ldots \ldots \ldots \ldots \ldots \ldots \ldots \ldots \ldots . \ldots . \ldots \ldots$

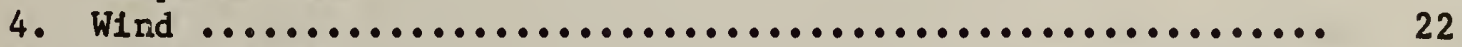

5. Solar radiation ................................. 22

C. TRANSIENT HEAT CONDUCTION $\ldots \ldots \ldots \ldots \ldots \ldots \ldots \ldots \ldots \ldots \ldots \ldots \ldots \ldots \ldots \ldots \ldots . . \ldots . \ldots 26$

1. Use of Conduction Transfer Functions ................. 26

2. Calculation of Conduction Transfer Functions ........... 27

D. WINDOW OPTICS ...................................... 29

1. Optical Coefficients ............................ 29

2. Shading Coefficients ............................ 30

3. Uncoated Pane Optics .............................. 31

4. Reflective Coatings ............................. 33

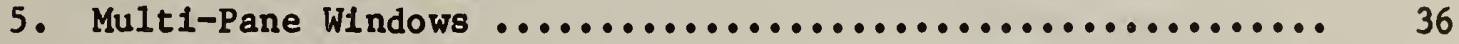

6. Diffuse Radiation ............................... 37

7. Interlor Shading Devices $\ldots \ldots \ldots \ldots \ldots \ldots \ldots \ldots \ldots \ldots \ldots \ldots \ldots \ldots . \ldots \ldots$

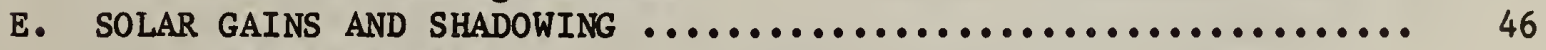

1. Surface Geometry ................................ 46

2. Shadow Projection ............................... 47

3. Homogeneous Coordinates ......................... 48

4. Overlapping Shadows .............................. 49

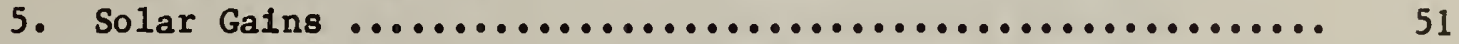

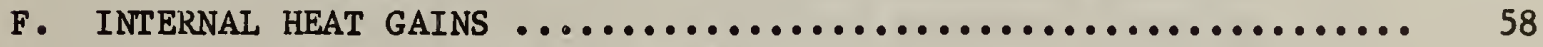

1. Sources and Types of Gains ....................... 58

2. Distribution of $\operatorname{Radiant}$ Gains $\ldots \ldots \ldots \ldots \ldots \ldots \ldots \ldots \ldots \ldots \ldots \ldots$

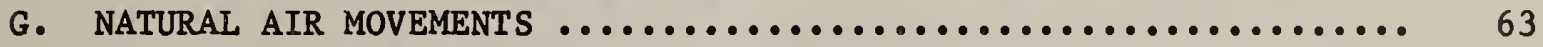

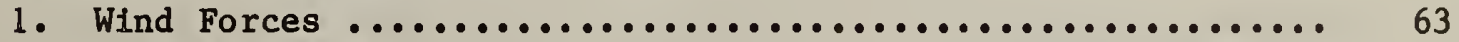

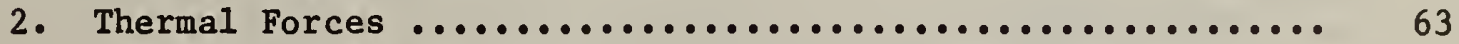

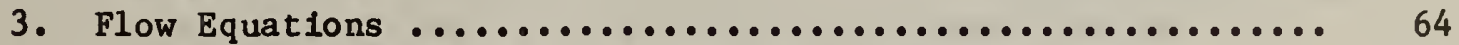

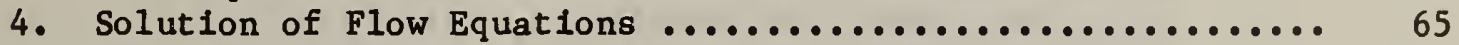

H. ROOM RADIANT INTERCHANGE ........................... 68

1. Detalled Radiant Interchange .......................... 68

2. MRT Network Algorithm .......................... 68 
I. SURFACE OUTSIDE HEAT BALANCES $\ldots \ldots \ldots \ldots \ldots \ldots \ldots \ldots \ldots \ldots \ldots \ldots \ldots \ldots \ldots$

1. Simple Surface Conductance ........................ 71

2. Detalled Surface Conductance ....................... 71

3. Basic Heat Balances ................................. 74

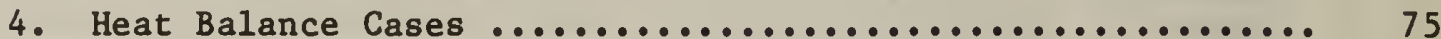

J. SURFACE INSIDE HEAT BALANCES $\ldots \ldots \ldots \ldots \ldots \ldots \ldots \ldots \ldots \ldots \ldots \ldots \ldots \ldots \ldots . \ldots \ldots$

1. Simple Convection Coefficient ....................... 79

2. Detalled Natural Convection Coefficlent ................ 79

3. Basic Heat Balance .............................. 80

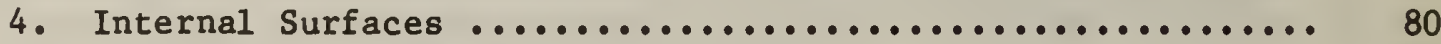

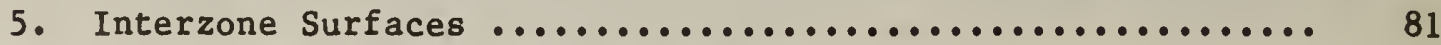

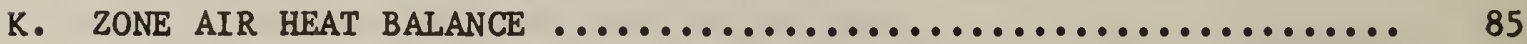

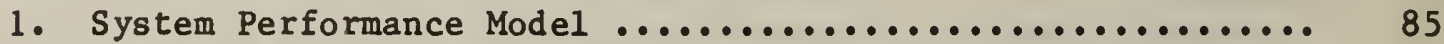

2. Simple Infiltration Model $\ldots \ldots \ldots \ldots \ldots \ldots \ldots \ldots \ldots \ldots \ldots \ldots \ldots \ldots . \ldots \ldots$

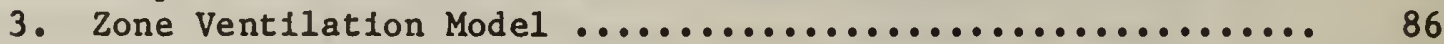

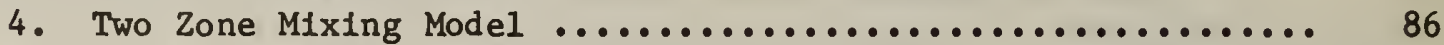

5. Whole House Fan Model ............................ 87

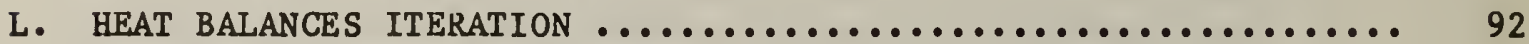

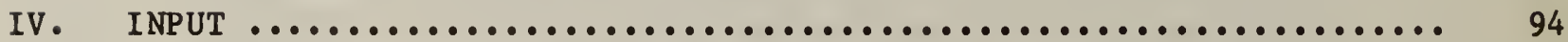

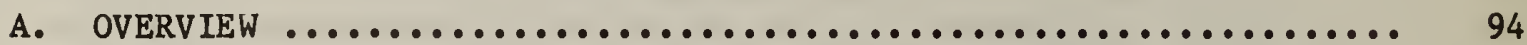

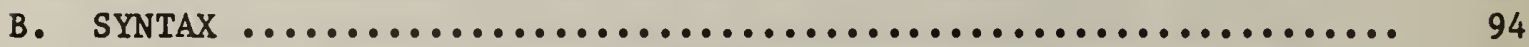

1. BNF Description ....................................... 95

2. English Description .............................. 95

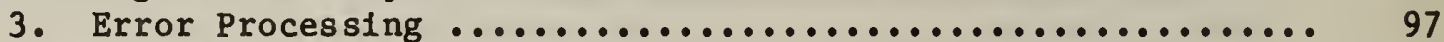

c. INPUT DETAILS $\ldots \ldots \ldots \ldots \ldots \ldots \ldots \ldots \ldots \ldots \ldots \ldots \ldots \ldots \ldots \ldots \ldots \ldots \ldots \ldots \ldots . \ldots \ldots$

1. Project Section ................................ 98

2. Library Section ................................ 102

3. Building Section ............................... 108

4. Zone Section .................................. 111

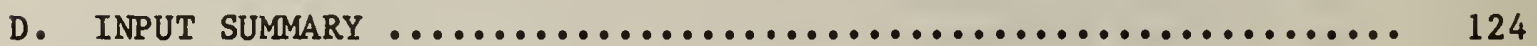

E. ZONE TEMPERATURE CONTROL .......................... 127

F. GEOMETRIC DATA ................................. 136

1. Surface Coordinate System ....................... 136

2. Window and Door Subsurfaces ...................... 137

3. Shadowlng Subsurfaces ........................... 137

4. Zone Coordinate System ........................... 138

5. Bullding Coordinate System ....................... 138

6. Detached Shadowing Surfaces ........................ 139

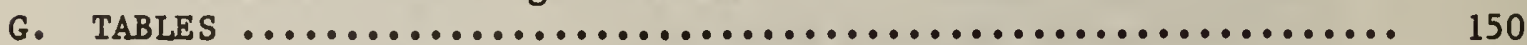

1. Shadowing Dates ............................... 150

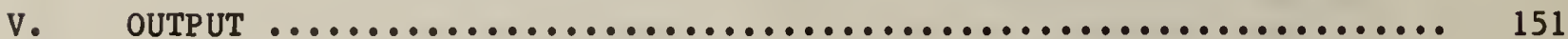

A. INPUT REPORTS ................................... 151

1. Default Reports ................................ 151

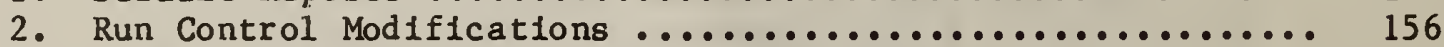

3. Numbered Reports ................................ 160

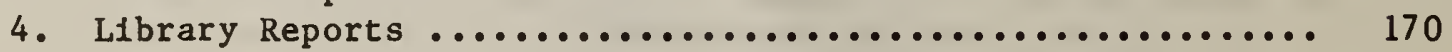




\section{Page}

B. LOADS REPORTS ................................... 176

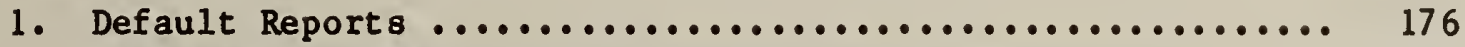

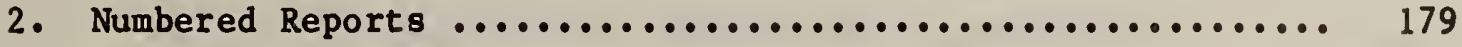

VI. COMPUTER PROGRAM ....................................... 197

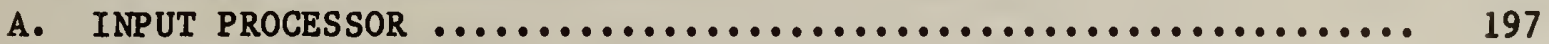

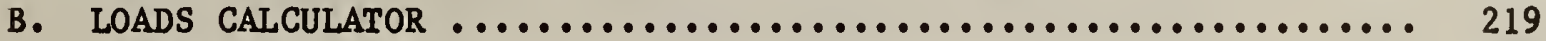

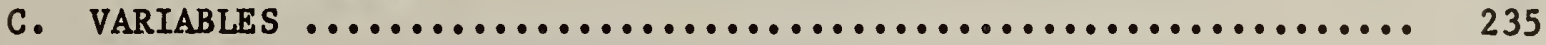

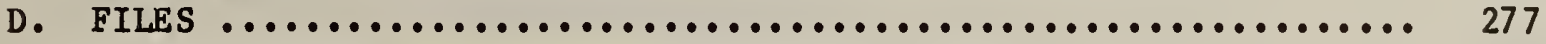


Figure II.1

F1gure II.2

Figure II.3

Figure II.4

Figure III.D.I

FIgure III.D.

Figure III.D.4

Figure III.D.

Figure III.D.

Figure III.E

Figure III.E.2

Figure III.E.3

Figure III.E.4

Figure III.E.5

Figure III.E.6

Figure III.F.1

Figure III.F.2

Figure III.G.I

F1gure III.G.2

Figure III.G.3 Pressure relationships for envelope surfaces

Figure III.I.1 Thermal network for simple outside surface coefficients . 


\section{LIST OF FIGURES (cont.)}

Page

Figure III.I.2 Thermal network for detalled outside surface

coefficient ...............................

Figure III.I.3 Thermal network for outside movable insulation ........ 78

Figure III.J.1 Inside surface thermal network ................... 84

Figure III.J.2 Inside movable insulation thermal network ........... 84

Figure III.K.1 Zone temperature control profile .................. 89

Figure III.K.2 Ventilation control profile: $T_{a}$ higher than TV ...... 90

Figure III.K.3 Ventilation control profile: $T_{a}$ lower than TV ....... 90

Figure III.K.4 Ventilation and heating control profiles ........... 91

Figure III.K.5 Ventilation and cooling control profiles ........... 91

Figure IV.E.1 Simple control profile with deadband .............. 131

Figure IV.E.2 Normalized control profile ...................... 132

Figure IV.E.3 Control profile for three-deck miultizone systems ..... 133

Figure IV.E.4 Control profile for multizone system ................ 134

Figure IV.E.5 Control profile for VAV system .................... 135

Figure IV.F.1 Rectangle ................................. 140

Figure IV.F.2 Triangle .................................. 140

Figure IV.F.3 Quadrilateral ............................... 140

Figure IV.F.4 Window/door subsurface ......................... 140

Figure IV.F.5 Overhang $\ldots \ldots \ldots \ldots \ldots \ldots \ldots \ldots \ldots \ldots \ldots \ldots \ldots \ldots \ldots \ldots \ldots \ldots$

Figure IV.F.6 Left fin ................................ 141

Figure IV.F.7 Right fin .............................. 141

Figure IV.F.8 Projection .............................. 141

Figure IV.F.9 Zone coordinate system: tilted surfaces ........... 142 


\section{LIST OF FIGURES (cont.)}

$\underline{\text { Page }}$

Figure IV.F.10 Zone coordinate system: flat roof $\ldots \ldots \ldots \ldots \ldots \ldots \ldots \ldots$

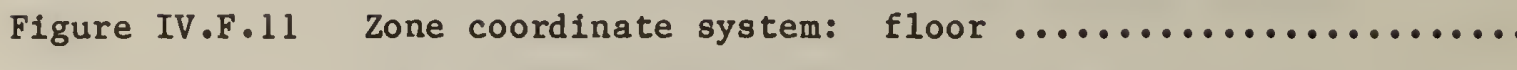

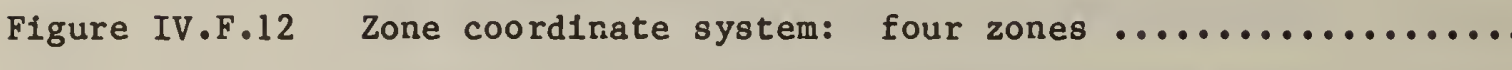

Figure IV.F.13 Portion of building with similar zones ............ 146

Figure IV.F.14 Zone 3 described by rotation and translation of zone

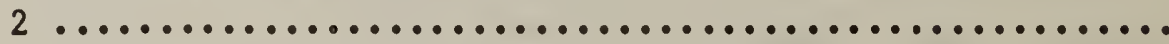

Figure IV.F.15 Zone 4 described by mirror imaging and translation of

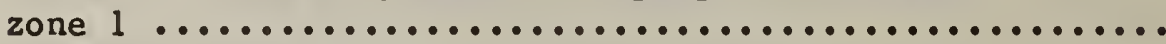

Figure IV.F.16 Zone 4 described by mirror imaging, rotation and

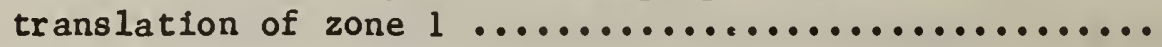

Figure V.1

Sample default output $\ldots \ldots \ldots \ldots \ldots \ldots \ldots \ldots \ldots \ldots \ldots \ldots \ldots$

Figure V.2

Sample error messages

Figure V.3

Double spacing

Figure V.4

Cross references

Figure V.5

Two reports using metric unfts $\ldots \ldots \ldots \ldots \ldots \ldots \ldots \ldots$

Figure V.6

Dump of project control data .................... 160

Figure $V .7$

Dump of 1 ibrary control data $\ldots \ldots \ldots \ldots \ldots \ldots \ldots \ldots \ldots \ldots$

Figure V.8

Dump of weather data...

Figure V.9

Dump of CTF calculations for massive construct ........

Figure V.10

Dump of optical calculations

164

Figure V.11

Dump of shadowing surface data...

Figure V.12

Dump of zone data

Figure V.13

Dump of cross reference values

Figure V.14

Day-schedule reports

170

Figure V.15

Week-schedule reports

171 


\section{LIST OF FIGURES (cont.)}

$\underline{\text { Page }}$

Figure V.16

Materials report

171

F1gure V.17

Constructs report

172

Figure V.18

Construct report for a window

Figure V.19

Control profiles reports

174

Figure V.20

Control day-schedule reports

Figure V.21

Control week-schedule reports

Figure V.22

Default loads calculation output

Figure V.23

Dump of SINPFL

Figure V.24

Zone description report

Figure V.25

Results of shadowing calculations

Figure V.26

Shadowing combinations report

Figure V.27

Dump of shadowing calculations

Figure V.28

Hourly Dump of zone loads

Figure V.29

Dump of zone loads calculations 195

Figure VI.A.1

Tree structure of input processor program 214

Figure VI.B.1

Tree structure of the loads calculator program 232 


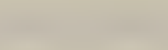




\section{INTRODUCTION}

\section{I.A BACKGROUND}

The effort to encourage the design, construction, and retrofit of energy conserving buildings will be strengthened by the development of comprehensive methods for evaluating the thermal effectiveness of those buildings. Since the development of research programs such as NBSLD [1], there has been a proliferation of public and private energy analysis computer programs. Computer assisted analysis is increasingly used in building design. Public domain research programs have served as sources of validated algorithms and of simulated performance for the testing of the design programs. The majority of current building thermal simulation computer programs are based upon single room methods. It was assumed that the conditions in one room were not significantly affected by conditions in another. This was a good assumption because the low cost of energy made it common practice to keep near constant temperatures in all rooms. Similarly, occupant comfort was not a significant consideration in the early programs because sufficient energy would always be available to achleve comfort. Detalled analysis of moisture migration was unnecesary because molsture could always be mechanically removed to maintain comfort or prevent condensation. The increasing cost of energy has led to the use of natural heating and cooling techniques which have gone beyond those assumptions. Significant variations in room temperatures can be expected as unoccupied rooms are left unheated and uncooled or as "sun spaces" are built on homes to help heat them by natural convection. Increased temperature ranges are allowed in work areas with occupants expected to adjust amounts of clothing to maintain comfort. Natural ventilation cooling might lead to significant moisture problems. Many other phenomena are poorly understood or inadequately modeled in existing programs. Simulation of the complex interactions among the many phenomena in real buildings is especially important.

An 1mproved research-oriented program is needed to allow the detalled study of simultaneous air, heat, and moisture transfer in and through a building with complex internal architecture. Such a research program must be easily expandable to test the simulation of new features. This requirement 1mplies that the program should have a simple structure and be well-documented. The program should also be able to handle simple or very complex problems efficiently, and it should be portable so that many researchers can use it.

\section{I.B OBJECTIVES}

The objective of this effort is to develop a state-of-the-art researchoriented computer program for the thermal analysis of buildings together with the documentation necessary for its use.

This computer program is called the Thermal Analysis Research Program (TARP). The name was chosen to emphasize that this is to be more than an energy/loads predictor. It aims is to study the interactions of many factors of the thermal performance of bulldings. Also, features which would have enhanced the usability of the program for bullding designers and engineers have given way to research features. In its present version it is capable of 
computing room loads and temperatures by simultaneously considering conduction and alr movements between all rooms in a bullding. Th1s program provides the framework for the integration of many more advanced simulation features.

\section{I.C SCOPE}

Th1s report is the documentation of the algorithms, user-1nterface, and computer code of TARP in 1ts present form. It provides a detalled description of the structure and mathematical methods of the program. It is not intended to be a tutorial for persons who are totally unfamiliar with energy analysis programs and methods.

Chapter II is an introduction to the capabilities, structure, and use of the program.

Chapter III reviews the algorithms that the program uses to compute the bullding energy and alr flows.

Chapter IV explains how bulldings are described by the input language.

Chapter V describes the various output reports avallable to the user.

Chapter VI gives the Information necessary to understand (and hence modify) the computer code.

Th1s report uses an outline organization to serve two purposes. It w111 allow easier updating of the documentation as the program evolves. It also allows a simple way to handle the many cross-references within the report. Any of the chapters may refer to detalls of the 1nput or algorithms. The form of an input reference 1s: (3.2.5). It may consist of 1,2 , or 3 numbers separated by periods. It refers to the detalled input description in chapter IV, section C. The full reference may be considered (IV.C.3.2.5) with the "IV.C" 1mplied. The form of an algorithm reference 1s: (B.2.4). It consists of a letter and optional numbers and refers to information in chapter III. The full reference may be considered (III.B.2.4). section.

References are Indicated by brackets and are listed at the end of each

\section{REFERENCES}

[1] Kusuda, T., "NBSLD, the Computer Porgram for Heat1ng and Cooling Loads in Buildings," NBS Bullding Sclence Serles 69, (July 1976). 
The Thermal Analysis Research Program uses detailed heat balance techniques to compute room loads. It may be used to evaluate single "design" days or it may use up to one year of measured weather data. A large number of occupant usage features may be scheduled with hourly, dally, and seasonal variations. The effects of temperature drifts in response to various control strategies can be accurately evaluated. Input and output may be in English or metric units. Other capabilities can be grouped by the three modes of heat transfer.

Conduction: Transient conduction effects are modeled by "conduction transfer functions" which are extensions of response factors. They model the heat storage effects of walls, furnishings, and partitions between rooms. Movable insulation is closely approximated by a massless insulation model with appropriate controls which may be applied over windows or walls.

Radiation: The transmittance and absorptance of windows 18 computed from the optical properties of the window panes. There may be up to four panes which may be heat absorbing or have reflective films. Shading coefficients may be used for windows which cannot be described in terms of their components. The shadowing and distribution of sunlight on surfaces may be calculated in several levels of detail up to the amount of light transmitted through windows onto each surface of the room. The effects of emissivity are modeled for both interior and exterior surfaces. There is a simple model to account for the energy savings of daylighting.

Convection: The program uses variable interior and exterior convection coefficients as functions of temperature difference and system induced flow velocity when appropriate. It can compute infiltration and the natural flow of air between rooms caused by wind and thermal forces. There is an alternative simple model for infiltration with options of ventilation cooling, a whole house fan, and controlled air mixing betwen two rooms.

TARP is an evolutionary development of the BLAST [1,2] computer program. BLAST is a user, rather than research, oriented program with equipment simulation capabilities not included in TARP. TARP provides more detailed models for air movement and multiroom analysis. It is also more portable and easier to modify.

\section{II.B PROGRAM STRUCTURE}

The program is written almost entirely in FORTRAN 77. This is a standard language which has been or is being implemented on most large and medium size computers. The handling of character data and direct access files help to make this language machine independent. The TARP should be portable except for some conversions from single to double precision and replacing the use of BLAST weather tapes. The PARAMETER feature of FORTRAN 77 is used extensively in modifiable array dimensions so the TARP can handle different size problems. 
The TARP is divided into two subprograms: the input processor (IP) and the loads calculator (LC). This structure is illustrated in figure II.1. The IP checks the user input, prepares input files for the LC, and reports the array sizes that the LC will require. The LC performs the building loads simulation and reports the results. This separation of subprograms allows a reduction in computer core requirements. The IP uses minimal array sizes because it processes the input one element (surface, schedule, material, etc.) at a time. The LC uses large arrays which consider these elements simultaneously. The IP and LC may be run as separate jobs when it is necessary to recompile the LC for correct array sizes, or they may be run as a single job if the LC is known to have sufficiently large arrays.

The input processor is divided into four major sections. These correspond to the input language sections (III.C) which they process. This sectioning allows further reductions in core requirements by the use of overlays (or segments). A small input processor is important to allow the fast job turn-around necessary to quickly debug the user input deck. Each section contains several subroutines which process the input language "keys" plus others for special elements of certain keys. The largest of these special routines are the two groups of subroutines which evaluate the conduction transfer functions and the window optics.

The loads calculator is divided into three sections. The first reads the input file created by the IP and fills the LC arrays. It checks for sufficient array space and performs some checks which require that all data for the problem description be present in the arrays. The second section uses the geometric and optical descriptions of the building surfces to compute solar gain factors for various periods of the year. The third section does the actual heat balances necessary to compute the multi-room loads. It does this on an hour-by-hour basis.

\section{II.C EXAMPLE RUN}

The following example calculation is designed to show how a building can be simulated with TARP. The building configuration was chosen to emphasize interzone effects. It is a "passive solar" design as shown in figure 2. The building is a townhouse configuration with 8 inch thick masonry walls separating it from identical units to the east and west. The gross floor area is 1584 $\mathrm{ft}^{2}$. The exterior walls and roof are wood frame construction with insulation $R$ values of 19 and 30 respectively. The house is divided into three major zones: a north zone for bedrooms, a center zone for the main living area, and a south zone for the kitchen/utility area. Each zone has a different internal gain profile consistant with its function. At the top of the center zone is a southfacing $120 \mathrm{ft}^{2}$ double pane clerestory which is intended to allow sun to shine directly onto the 8 inch thick masonry wall which separates the north and center zones. The south exterior walls includes $80 \mathrm{ft}^{2}$ (23 percent of wall area) of double pane window where the sun is intended to shine directly on the uncarpeted slab floor. The north and center zones have carpet on the slab. The partition between the south and center zones is a nonmassive wood frame and drywall construction. 
The TARP input for the example is shown in figure 3. The input begins by describing project data in the first nine lines between "PROJECT [" and "]". A project description is given; the location is described; ground temperatures are given. Then there is a description of the weather between "DDY(" and ")" on the following line. This sets up a mild, late winter condition when the solar and internal gains nearly offset the infiltration and conduction losses. The low temperature (LOW) for the day is $30 \mathrm{~F}$ and the high (HIGH) is 50F. A clear sky (CLR) for 21 February (DATE) is assumed. A $15 \mathrm{mph}$ (WS=1320 ft/min) wind blows from the northwest $(D I R=315)$.

The next section is called the "LIBRARY". It is used to define certain features which are referred to by the name in later sections of the input. The first few entries in the library section begin with "DS" which stands for dayschedule. A day-schedule is a list of 24 values, one for each hour of the day. The third day-schedule is given the name "ON" to indicate that it is being used to describe the occupancy schedule in the north zone. This day-schedule is used in the week-schedule (WS) which has the name "OCCN". A week-schedule is a collection of day-schedules, one for each day of the week plus holidays and other special days. The command $W D=O N$ will assign day-schedule $0 N$ to all week days. The same day-schedule will also apply for other day types by default since no other day types are specified. Building materials (MATL) are described in a similar manner. The first material is a gypsum wallboard given the name "GYP", and having a conductivity (K) of $.42 \mathrm{Btu} / \mathrm{h} \cdot \mathrm{ft} \cdot \mathrm{F}$, a density (D) of 45 $1 \mathrm{bm} / \mathrm{ft}^{3}$, and a specific heat (CP) of $0.3 \mathrm{Btu} / 1 \mathrm{bf}$. The wallboard is used in the first wall construction (CONS) named "WL-I". This lists the thickness and name of each material layer in the wall listed from outside to inside. There is $0.0521 \mathrm{ft}$ (.625 in) of GYP as the inside surface. The final entries in the library ("CPFL", "CDS", and "CWS") describe the control of the zone temperatures.

The "BUILDING" section gives commands controlling the heat balance simulation and descriptions of the roof overhangs.

There are three "ZONE" sections to describe the three zones of the example building. Each zone is identified by a user supplied name, e.g., "NORTH". Activities related to the entire zone are the temperature control (CTRL) and people (PEO), lights (LIT), and equipment (EQP) loads. There are three people maximum $(C A P=3)$ in the zone. The hourly number of people is determined by that maximum and the previously defined week-schedule (WS=0CCN). The other activities have similar capacities and schedules. The rest of the zone description defines the surfaces, both envelope and internal, of the zone. The mass (MASS) of furnishings is handled by a single surface of appropriate density and area. "SRF" then describes most of the north wall of the zone as an exterior (EX), opaque (OP), base surface (BS). It is made of the previously defined WL-I construction. The wall faces north ( $A Z M=0)$ and is $41 \mathrm{ft}$ long by $8 \mathrm{ft}$ high (SIZE). It is located relative to the other surfaces of the building by the origin (ORG) command. The next line of input specifies a window on the wall. The window is an exterior (EX), transparent (TR), subsurface (SS) made of the WDW2 construction. Its size is made to represent all windows on the north wall. Openings in the wall for identification are combined into a single area under the "AFS" command. The next surface command describes the remainder of 
the north wall: the portion at the studs wh1ch is construction WL-S. Four lines later there is a description of the massive partition described as an interior (IN), opaque (OP), base surface (BS). It is thermally connected to the center zone by the command "ZONE=CENTER".

F1gure 4 shows the computed loads for the sample run. The report is headed by the profect, location, and environment descriptions. Then the following values are presented for each zone: Total heating and cooling requirements, peak heat and cooling loads, maximum zone alr temperatures, hours at peak heating capac1ty (HX), other heating hours (HT), vent1lating hours (V), cooling (below peak capac1ty) hours (CL), and hours at peak cooling capacity (CX). Bullding-wide values are summarized by the line labeled "TOTAL:". These values include the total heating and cooling requirements for all zones, the peak colncident heating and cooling loads, and maximum and minimum of all zone temperatures. The hour and day are reported for the occurance of the peak loads and temperatures.

This example was not intended to provide complete instruction. The user should read the remalnder of the program documentation before attempting to run TARP.

\section{REFERENCES}

[1] Hittle, D. C., "The Bullding Loads Analysis and System Thermodynamics (BLAST) Program, Version 2.0: User Manual", CERL Technical Report E-153, (Construction Engineering Research Laboratory, 1979).

[2] Herron, D., Walton, G., Lawrle, L., "Bullding Loads Analysis and System Thermodynamics (BLAST) Program Users Manual -- Volume One Supplement (Version 3.0), CERL Technical Report E-171, (Construction Engineering Research Laboratory, 1981). 


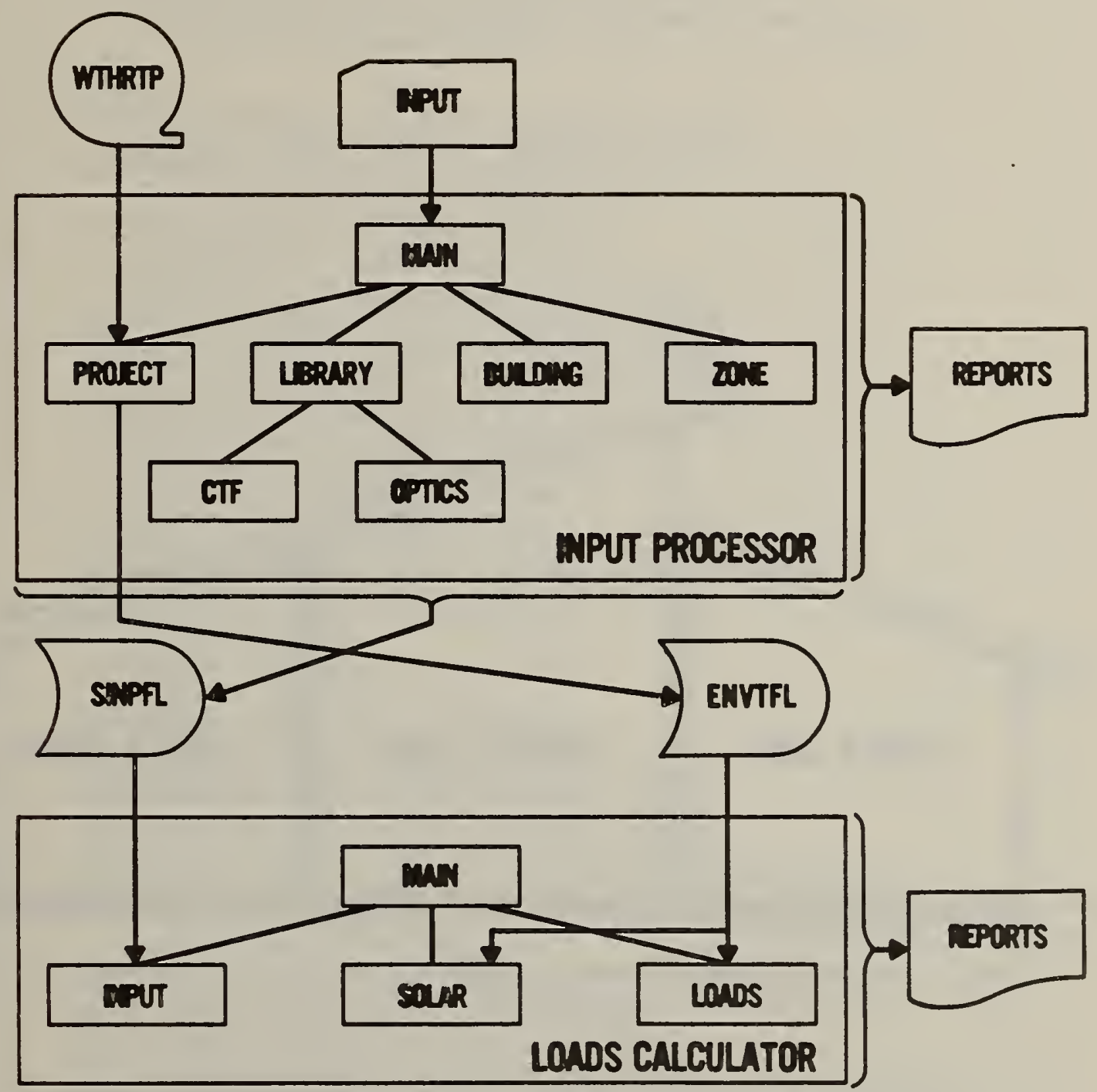

Figure II.1 Structure of the Thermal Analysis Research Program 


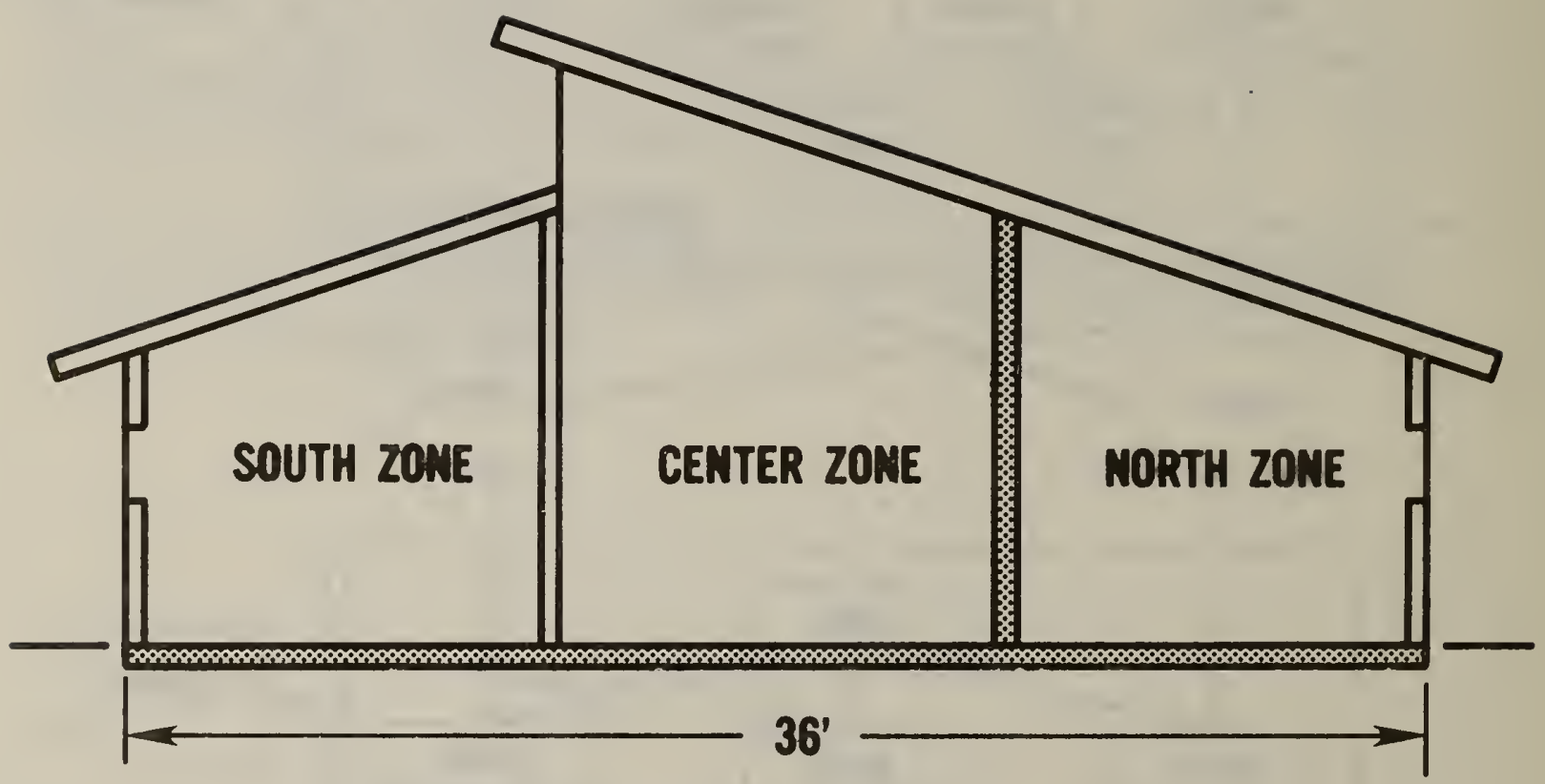

Figure II.2 House configuration for example problem 


\section{PROJECT}

RC (DEM/UIN=ENGLISH/UOUT $=E N G L I S H /$

DESC='THERMAL MASS TEST - SIMULTANEOUS ZONES, DIRECT SUN') RPT ( RINOS $=9$ )

LOC ( DESC $=$ 'COLUMBIA, MO,'/LATD $=38.9 / L O N G=92.3 / T Z=6$ )

GRND (GRT $=40,42,48,55,62,67,70,69,63,55,48,42)$

DDY (DESC $=$ 'MILD WINTER'/HIGH $=50 / L O W=30 / W B=40 / D A T E=21 \mathrm{FEB} /$

了 $C L R=1$. $/ \mathrm{MON} / \mathrm{WS}=1320 / \mathrm{DIR}=315$ )

LIBRARY [

DS (NAME $=$ NONE $/ D E S C=' Z E R O$ ALL HOURS'/FFC $=24 * 0$ )

DS (NAME $=F U L L / D E S C=$ ' ONE ALL HOURS'/FFC=24*1)

IIS (NAME $=$ ON/DESC $=$ ' NORTH OCCUPANCY'/

FFC $=6 * 1, .5, .16,8 * 0,4 * .16,2 * .33, .67,1)$

DS (NAME $=0 C / D E S C=$ 'CENTER OCCUPANCY'

$F F C=16 * 0,3 * .17, .67, .5, .67, .17,0)$

DS (NAME $=0 S /$ LESC $=$ ' SOUTH OCCUPANCY'/

FFC $=6 * 0, .5, .5,8 * 0,2 *, 33, .67,2 *, 16,3 * 0)$

WS (NAME $=0 C C N /$ IIESC $=$ ' NORTH OCCUFANCY'/WD=ON)

WS (NAME $=0 C C C / D E S C=$ 'CENTER OCCUPANCY'/WD=OC)

WS (NAME $=0 C C S / D E S C=$ 'SOUTH OCCUPANCY'/WD=OS)

DS (NAME = LN/DESC = 'NORTH LIGHTING'/

FFC $=6 * 0, .7, .7,8 * 0,2 *, 33,4 * .7, .4,0)$

IIS (NAME =LC/UESC $=$ 'CENTER LIGHTING'/

$F F C=16 * 0, .5,5 *, 7, .3,0)$

DS (NAME $=$ LS $/$ DESC $=$ ' SOUTH LIGHTING'/

$F F C=6 * 0, .7, .7,8 * 0,5 * .7,3 * 0)$

WS (NAME $=$ LITN/DESC $=$ 'NORTH LIGHTING'/WD $=L N$ )

WS (NAME $=$ LITC/DESC $=$ 'CENTER LIGHTING'/WD=LC)

WS (NAME $=$ LITS/DESC $=$ ' SOUTH LIGHTING'/WD=LS)

DS (NAME $=E N / D E S C=$ 'NORTH EQUIFMENT'/

$F F C=20 * 0,3 * 1,0)$

IIS (NAME $=E C / D E S C=$ 'CENTER EQUIPMENT'/

$F F C=16 * 0,4 * 1,4 * 0)$

DS (NAME $=E S / D E S C=$ ' SOUTH EQUIFMENT'/

$F F C=6 * .3,2 * 1,8 *, 3,2 * 1,3 *, 7,3 *, 3)$

WS (NAME =EQF'N/DESC $=$ ' NORTH EQUIPMENT'/WD=EN)

WS (NAME $=E Q P C / D E S C=$ 'CENTER EQUIPMENT'/WD=EC)

WS (NAME =EQFS/IIESC $=$ ' SOUTH EQUIPMENT'/WD=ES)

WS (NAME $=$ CONST $/$ DESC $=$ ' CONSTANT $100 \%$ ' $/ A L L=F U L L$ )

MATL (NAME $=$ GYP/DESC $=$ ' GYPSUM WALLBDARD'/K=.42/D=45, /CP = .3)

MATL (NAKE $=W\left[I-S / D E S C=' S O F T W O D D^{\prime} / K=.0675 / D=32, / C P=.33\right)$

MATL (NAME $=S H T H / D E S C=$ ' INTERMEDIATE DENSITY BUILDING BOARD SHEATHING', $K=.034 / D=22 . / C P=.31)$

MATL (NAME $=C-H W / D E S C=$ 'HEAUY CONCRETE' $/ K=1.0 / C P=, 2 / D=140$, )

MATL (NAME =B1/DESC='AIRSPACE RESISTANCE'/R=.91/AIR)

MATL (NAME $=R 5 / D E S C=$ 'R5 POLYSTYRENE'/R=5,)

MATL (NAME $=R 19 / D E S C=$ 'R19 INSULATION'/R=19.)

MATL (NAME $=R 30 /$ DESC $=$ 'R30 INSULATION'/R=30.)

MATL (NAME $=S P D S / D E S C=' S T A N D A R D$ GLASS'/GLASS $/ R=.0236 / T R N S=.86)$

$M A T L\left(N A M E=A S H / D E S C={ }^{\prime}\right.$ ASPHALT SHINGLES' $/ K=18,16 / D=70 / C P=.3$ )

$M A T L(N A M E=D I R T / K=, 1 / D=65, / A=, 70)$

Figure II.3 TARP input for example problem 


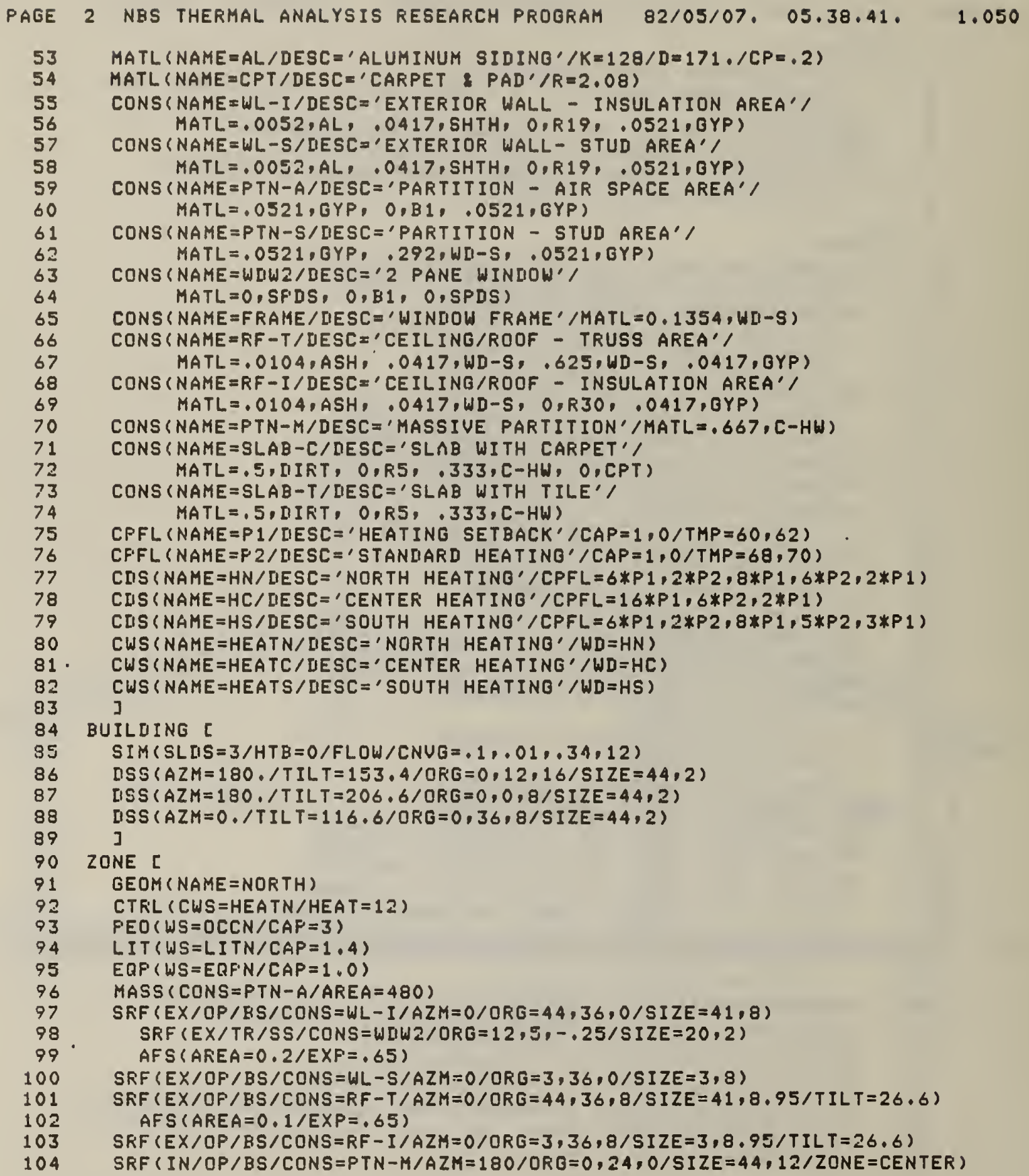

Figure II.3 (continued) 
105

106

107

108

109

110

111

112

113

114

115

116

117

118

119

120

121

122

123

124

125

126

127

128

129

130

131

132

133

134

135

136

137

138

139

140

141

142

143

144

145

146

147

148

149

AFS (AREA $=0.5 / E X P=.50)$

$S R F(I N / D P / B S / C D N S=P T N-M / A Z M=270 / O R G=0,36,0 / U R T S=12,0,12,12,0,8)$ $S R F(I N / O P / B S / C O N S=P T N-M / A Z M=90 / O R G=44,24,0 /$ VRT $8=12,0,12,8,0,12)$ $S R F(E X / O P / B S / C D N S=S L A B-C / A Z M=180 / O R G=0,36,0 / S I Z E=44,12 / T I L T=180)$ $\operatorname{DSC}(T G P=1)$

ZONE

GEOM (NAME =CENTER)

$C T R L(C W S=H E A T C / H E A T=12$ )

$F E D(W S=D C C C / C A P=3$ )

LIT $(W S=L I T C / C A P=1,4)$

$E Q P(W S=E Q P C / C A P=1.0)$

MASS ( $C D N S=P T N-A / A R E A=480)$

SRF ( $E X / D P / B S / C D N S=F R A M E / A Z H=180 / O R G=0,12,12 / S I Z E=44,3$ ) SRF $(E X / T R / S S / C O N S=W D W 2 / O R G=2,0,-, \cdot 25 / S I Z E=40,3)$ AF $S(A R E A=0.25 / E X P=.65)$

$S F F(E X / D P / B S / C D N S=R F-T / A Z M=0 / O R G=44,24,12 / S I Z E=41,8,95 / T I L T=26,6)$ AFS ( $A R E A=0.1 / E X P=.65$ )

$S R F(E X / D P / B S / C D N S=R F-I / A Z M=0 / O R G=3,24,12 / S I Z E=3,8,95 / T I L T=26,6)$ SRF ( IN $/ O P / B S / C D N S=P T N-A / A Z M=180 / D R G=3,12,0 / S I Z E=41,12 / Z O N E=S O U T H)$ AFS (AREA $=0.5 / E X P=.50)$

$S R F(I N / O F / B S / C O N S=F T N-S / A Z H=180 / O R G=0,12,0 / 5 I Z E=3,12 / Z O N E=S D U T H)$

$S R F(I N / O P / B S / C O N S=P T N-M / A Z M=0 / O R G=14,24,0 / S I Z E=44,12 / Z O N E=N O R T H)$ AFS $(A R E A=0.5 / E X F=.50)$

$S R F(I N / O P / B S / C O N S=P T N-M / A Z M=270 / O R G=0,24,0 / U R T S=12,0,12,16,0,12)$ $S R F(I N / D P / B S / C O N S=P T N-M / A Z M=90 / D R G=44,12,0 /$ URT $=12,0,12,12 i 0,16)$ $S R F(E X / O P / B S / C O N S=S L A B-C / A Z M=180 / D R G=0,24,0 / S I Z E=44,12 / T I L T=180)$ 3 OSC $(T G P=1)$

ZONE [

GEDM (NAKE $=$ SOUTH)

CTRL ( $C W S=H E A T S / H E A T=12)$

$F \cdot E O(W S=O C C S / C A F:=3$ )

LIT (WS $=$ LITS $/ C A P=1,4$ )

$E Q F \cdot(W S=E R P S / C A P=9,4 / L O S T=, 4)$

MASS ( $C O N S=P T N-A / A R E A=480)$

SRF (EX/OP $/ B S / C D N S=W L-I / A Z M=180 / O R G=0,0,0 / 5 I Z E=41,8)$ $S R F(E X / T R / S S / C O N S=W D W 2 / O R G=12,3,-.25 / S I Z E=20,4)$ AFS ( $A K E A=0.2 / E X P=.65$ )

$S R F(E X / O P / B S / C D N S=W L-S / A Z M=180 / O R G=41,0,0 / S I Z E=3,8)$

$S R F(E X / D P / B S / C D N S=R F-T / A Z M=180 / D R G=0,0,8 / S I Z E=41,8,95 / T I L T=26,6)$ AFS (AREA $=0.1 / E X P=.65)$

$S R F(E X / O F / B S / C D N S=R F-I / A Z M=180 / D R G=41,0,8 / S I Z E=3,8,95 / T I L T=26,6)$

$S R F(I N / O P / B S / C O N S=P T N-A / A Z M=0 / O R G=44,12,0 / S I Z E=41,12 / Z O N E=C E N T E R)$ AF $S(A R E A=0.5 / E X P=.50)$

SRF ( IN/OF" $/ E S / C O N S=P T N-S / A Z M=0 / O R G=3,12,0 / S I Z E=3,12 / Z O N E=C E N T E R$ )

SRF ( IN $/ O P / B S / C O N S=P T N-K / A Z M=270 / O R G=0,12,0 /$ UTS $=12,0,12,8,0,12$ ) $S R F(I N / O P / B S / C O N S=P T N-M / A Z M=90 / D R G=44,0,0 /$ VTS $=12,0,12,12,0,8)$ $S R F(E X / O P / 8 S / C O N S=S L A B-T / A Z M=180 / O R G=0,12,0 / S I Z E=44,12 / T I L T=180)$ ] $O S C(T G P=1)$

Figure II.3 (concluded) 


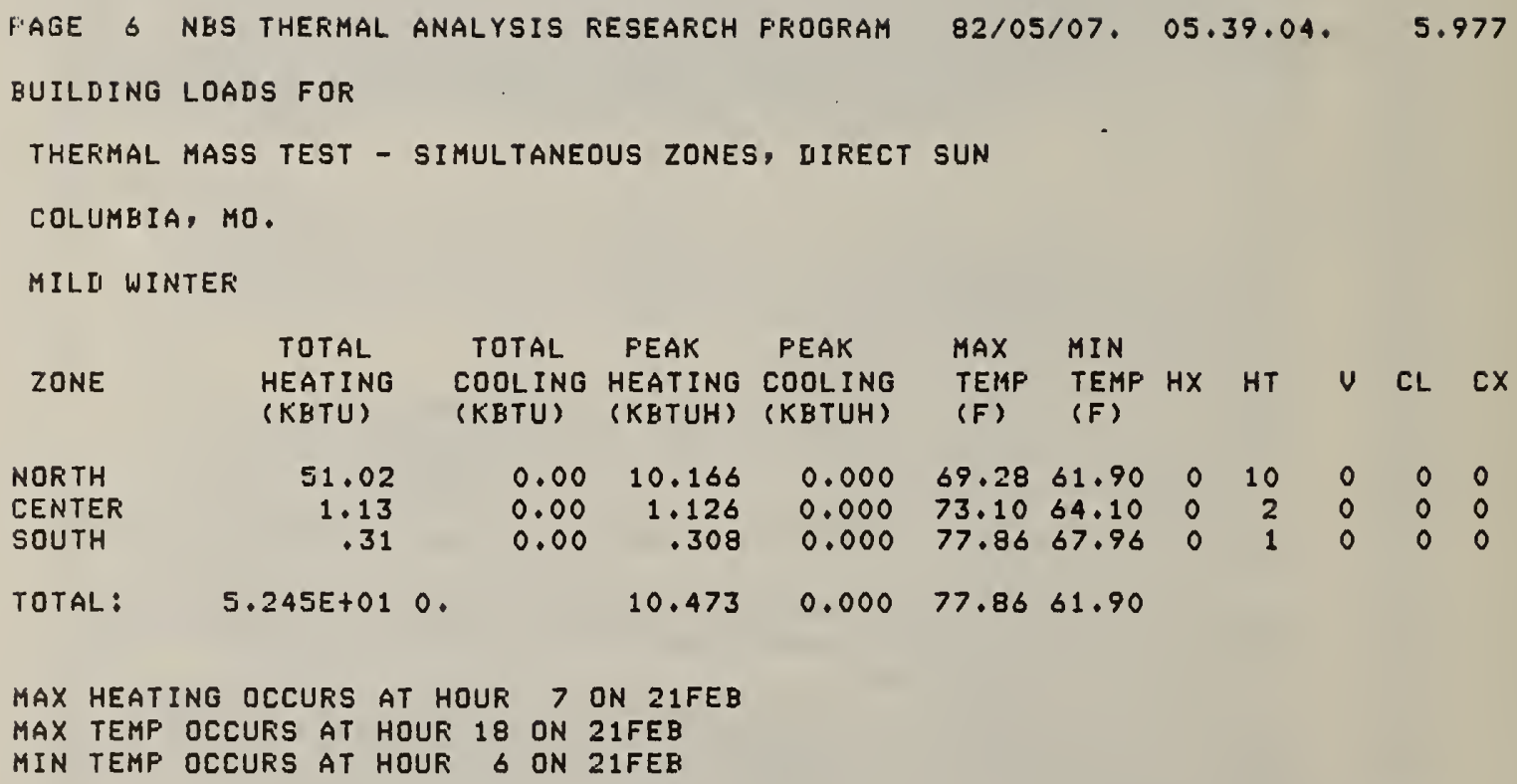

Figure II.4 Calculated loads for example problem 
III.

ALGORITHMS

III.A INTRODUCTION

III.A.1 THE HEAT BALANCE METHOD

TARP is a large collection of algorithms which perform a simultaneous evaluation of multi-room temperatures and energy requirements as affected by dynamic external and internal thermal conditions. The overall simulation process is best explained in terms of a single room. The calculation of the room air temperature is based on a heat balance on the room air. The convective gains from the room surfaces and internal sources plus the sensible gain from incoming air plus the energy added by the air handling system must equal zero.

$$
C E+\Sigma H C_{1} * S_{i} *\left(T_{1}-T Z\right)+\sum F_{j}^{*} C_{p} *\left(T S_{j}-T Z\right)+L=0 \text { (A.1.1) }
$$

where

$$
\begin{aligned}
& \mathrm{CE}=\text { energy convected from internal sources } \\
& \mathrm{S} 1=\text { area of surface } 1 \\
& \mathrm{HC}_{\mathbf{1}}=\text { convection coefficient of surface } 1 \\
& \mathrm{~T}_{1}=\text { temperature of surface } 1 \\
& \mathrm{TZ}=\text { room air temperature } \\
& \mathrm{F}_{j}=\text { mass flow of air through opening } \mathrm{j} \\
& \mathrm{Cp}_{\mathrm{p}}=\text { specific heat of air } \\
& \mathrm{TS}_{j}=\text { temperature of the air through opening } j \\
& \mathrm{~L}=\text { energy from the air handling system }
\end{aligned}
$$

The summations apply to all surfaces/openings which are part of the room. The values of the surface temperatures, $T_{1}$, are obtained by evaluating a heat balance at every surface of the room using an assumed room temperature. A better estimate of the room temperature is then obtained by solving equation A.1.1 for TZ. Repeating this process leads to successively better approximations of the surface and air temperatures. The process is rapidly convergent. Multiple rooms can be handled within the iterative scheme given an appropriate data structure and proper heat balances on the surfaces between rooms. Multiple rooms are thermally connected by conductive, convective, and radiative heat transfer. The following sections describe the algorithms for the various heat transfer mechanisms and thermal driving functions which culminate in multi-room heat balances.

III.A.2 TABLE OF SYMBOLS

The following symbols are used frequently in the algorithm descriptions. Symbols which are local to an algorithm are defined as they occur. 
Subscripts:

Subscripts may be omitted if context is clear.

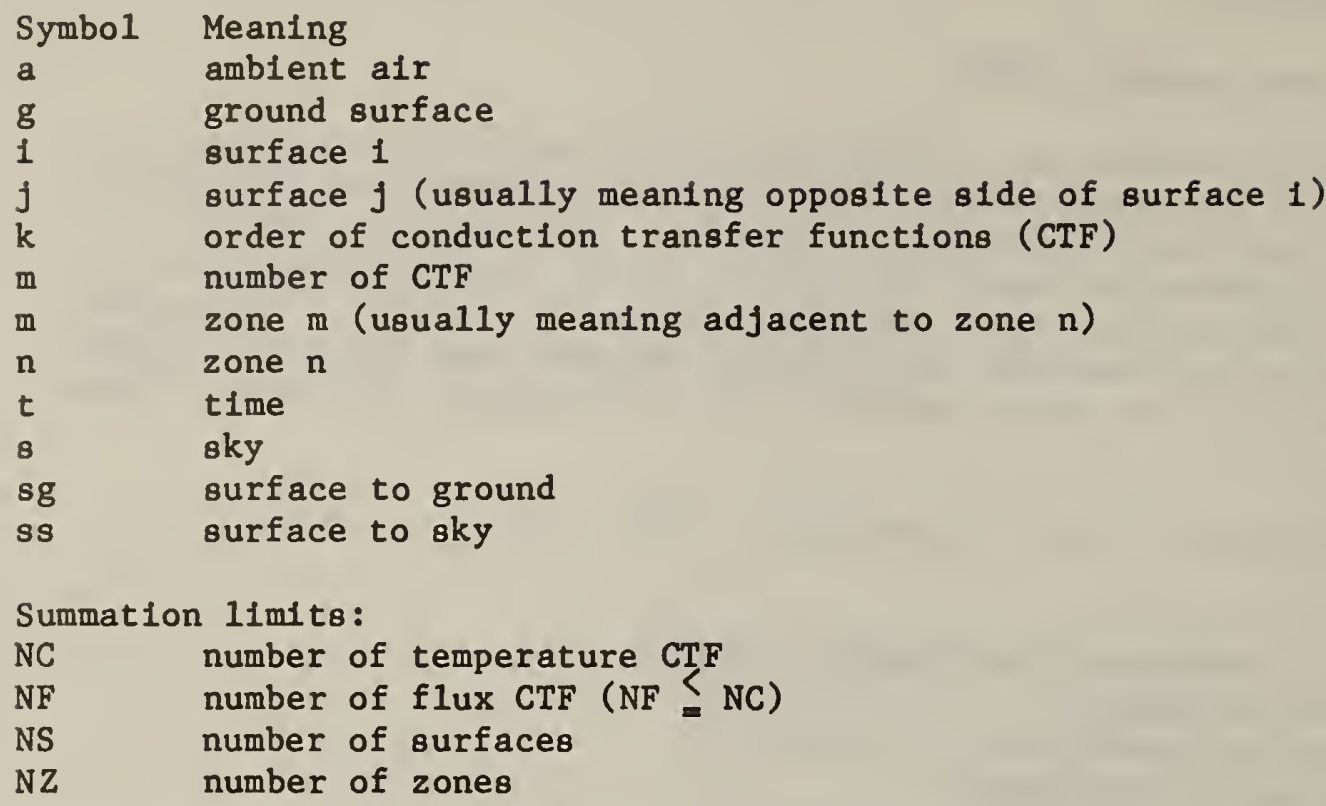

\section{Parameters:}

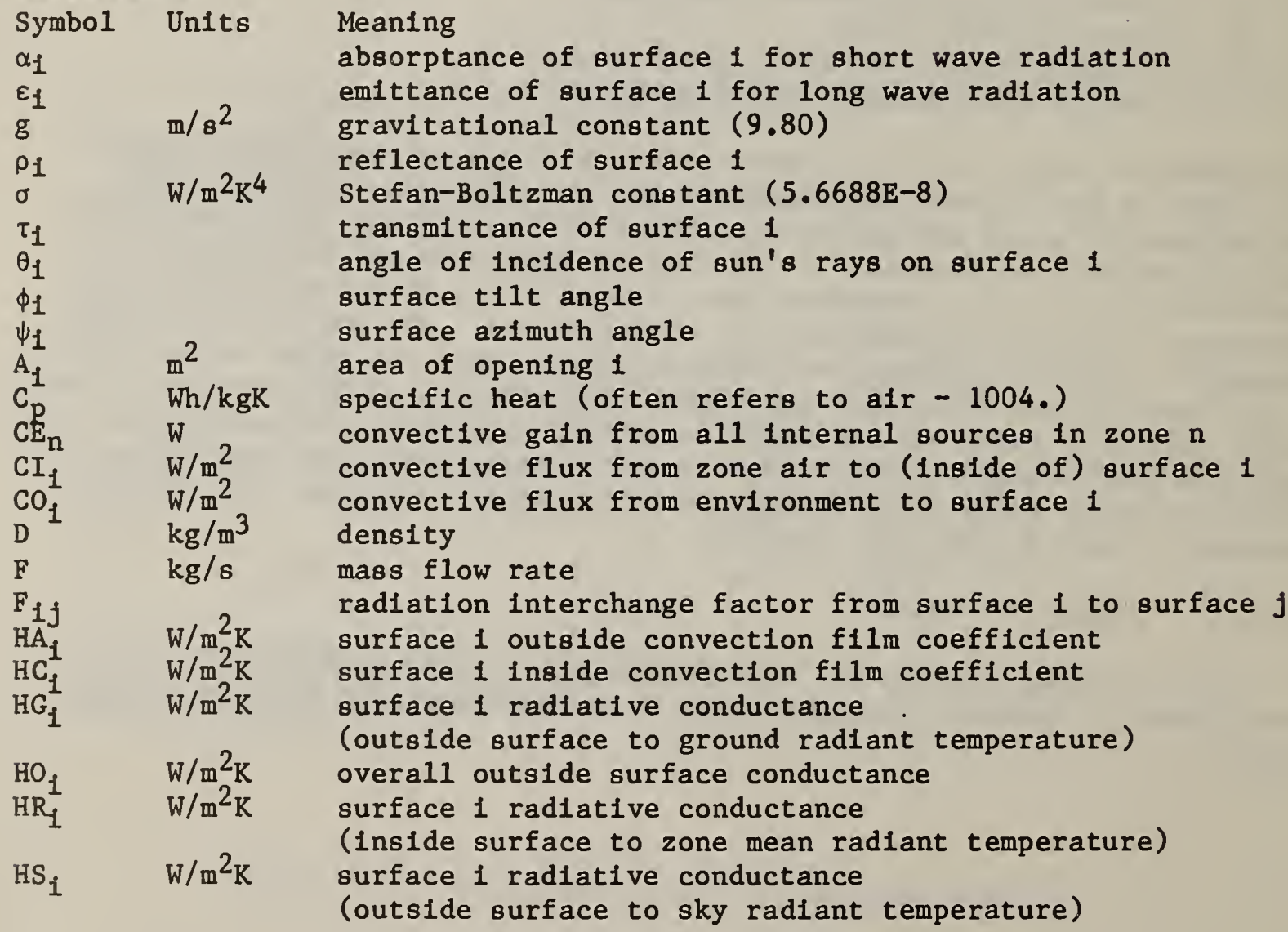




\begin{tabular}{|c|c|c|}
\hline$I_{b}$ & $\mathrm{~W} / \mathrm{m}^{2}$ & intensity of solar beam (direct) radiation \\
\hline & $\mathrm{W} / \mathrm{m}^{2}$ & Intensity of solar diffuse radiation \\
\hline & $\mathrm{W} / \mathrm{m}^{2}$ & intensity of sky diffuse radiation (sky brightness) \\
\hline & $W / m^{2}$ & intensity of ground reflected radiation \\
\hline & $\mathrm{W} / \mathrm{m}^{2}$ & $\begin{array}{l}\text { flux referring CTF } \\
\text { inward conductive flux at inside of surface } 1 \text { at time } t\end{array}$ \\
\hline$K_{I} P_{1, t}, t$ & $\mathrm{~W} / \mathrm{m}^{2}$ & $\begin{array}{l}\text { portion of inward conductive flux based on previous } \\
\text { temperature and flux history terms }\end{array}$ \\
\hline & $\mathrm{W} / \mathrm{m}^{2}$ & outward conductive flux at outside of surface 1 at time \\
\hline & $\mathrm{W} / \mathrm{m}^{2}$ & $\begin{array}{l}\text { portion of outward conductive flux based on previous } \\
\text { temperature and flux history terms }\end{array}$ \\
\hline$M$ & $\mathrm{~W} / \mathrm{K}$ & capacitance rate (mass flow times specific heat) \\
\hline & $\mathrm{N} / \mathrm{m}^{2}$ & pressure \\
\hline PB & $\mathrm{N} / \mathrm{m}^{2}$ & barometric pressure \\
\hline $\mathrm{PS}_{1}$ & $\mathrm{~N} / \mathrm{m}^{2}$ & pressure difference across surface 1 due to stack effect \\
\hline $\mathrm{PW}_{1}^{1}$ & $\mathrm{~N} / \mathrm{m}^{2}$ & pressure difference across surface 1 due to wind \\
\hline$Q I_{i}^{\perp}$ & $\mathrm{W} / \mathrm{m}^{2}$ & total radiant flux absorbed at inside of surface 1 \\
\hline $\mathrm{QL}_{n}^{\perp}$ & W & total long wave radiation created in zone $n$ \\
\hline QLI & $\mathrm{W} / \mathrm{m}^{2}$ & long wave radiant flux absorbed at inside of surface 1 \\
\hline $\mathrm{QO}_{1}$ & $\mathrm{~W} / \mathrm{m}^{2}$ & total radiant flux absorbed at outside of surface $i$ \\
\hline $\mathrm{QS}_{\mathrm{n}}$ & $=12$ & $\begin{array}{l}\text { total diffuse short wave radiation entering } \\
\text { and created in zone } n\end{array}$ \\
\hline $\mathrm{QSI}_{1}$ & $\mathrm{~W} / \mathrm{m}^{2}$ & short wave radiant flux absorbed at Inside of surface 1 \\
\hline & $\begin{array}{l}W / m^{2} \\
m^{2}\end{array}$ & $\begin{array}{l}\text { short wave radiant flux absorbed at outside of surface } 1 \\
\text { area of surface } 1\end{array}$ \\
\hline $\mathrm{T}^{\perp}$ & C & temperature \\
\hline$\underline{T}$ & $\mathrm{~K}$ & absolute temperature $(=\mathrm{T}+273.15 \mathrm{~K})$ \\
\hline$\overline{\mathrm{T}}_{\mathrm{a}}$ & C & temperature of outside (amblent) alr \\
\hline $\mathrm{T}_{\mathrm{g}}$ & C & ground surface (radiant) temperature \\
\hline $\mathrm{TI}_{i, t}$ & C & temperature of inside of surface 1 at time $t$ \\
\hline & C & $\begin{array}{l}\text { temperature of movable insulation } \\
\text { (zone side or outside depending on placement) }\end{array}$ \\
\hline $\mathrm{TO}_{\mathbf{i}, \mathrm{t}}$ & C & temperature of outside of surface 1 at time $t$ \\
\hline & C & mean radiant temperature of zone $n$ \\
\hline $\mathrm{T}_{\mathbf{8}}$ & C & sky radiant temperature \\
\hline$T Z_{n}$ & & temperature of zone alr \\
\hline U & $\mathrm{W} / \mathrm{m}^{2} \mathrm{~K}$ & conductance (U-value) of a construct \\
\hline & $\begin{array}{l}\mathrm{W} / \mathrm{m}^{2} \mathrm{~K} \\
\mathrm{~m} / \mathrm{s}\end{array}$ & $\begin{array}{l}\text { conductance of movable insulation on surface } 1 \\
\text { wind speed (measured value) }\end{array}$ \\
\hline $\mathrm{v}_{\mathrm{az}}$ & $\mathrm{m} / \mathrm{s}$ & wind speed at height $z$ \\
\hline & $\mathrm{m} / \mathrm{s}$ & $\begin{array}{l}\text { wind speed relative to surface at height } z \\
\text { and orientation } \psi\end{array}$ \\
\hline $\mathrm{X}$ & m & $\mathrm{X}$-coordinate of a point \\
\hline$x_{1}$ & & flow exponent \\
\hline$x_{i, m}$ & $\mathrm{~W} / \mathrm{m}^{2} \mathrm{~K}$ & outside (eXterior) CTF \\
\hline & $\begin{array}{l}\mathrm{m} \\
\mathrm{W} / \mathrm{m}^{2} \mathrm{~K}\end{array}$ & $\begin{array}{l}\text { Y-coordinate of a point } \\
\text { cross CTF }\end{array}$ \\
\hline $\mathrm{z}^{1, \mathrm{~m}}$ & & Z-coordinate of a point \\
\hline Z & & height (of surface 1 or zone $n$ ) \\
\hline $\mathrm{z}_{\mathrm{i}, \mathrm{m}}$ & $\mathrm{W} / \mathrm{m}^{2} \mathrm{~K}$ & inside (Zone) CTF \\
\hline
\end{tabular}


III.B.I TIME

III.B.1.1 TIME OF DAY

Currently, TARP uses a one hour time step. The time from midnight to 1:00 AM 1s hour number 1 ; from 1:00 to $2: 00$ AM 1s hour 2 ; ...; and from 11:00 PM to midnight 1s hour 24. The hour number $\left(t_{s}\right)$ is used as an 1ndex in the program to select array elements. Most driving functions, such as solar radiation, wind, and scheduled activities, use their average values for the hour. Temperatures are for the mid-point of the hour. The one hour time step was chosen because it is the shortest for which weather data 18 commonly avallable, and 1t 18 possibly the longest for significant detall in the thermal analysis. The time step can be changed by slight modification of the program, primarlly in the handling of day ( 24 hour) schedules.

During some portions of the year, daylight savings time (DST) is in effect. DST hour numbers $\left(t_{d}\right)$ are given by: $t_{d}=t_{8}+1$. TARP responds to DST by operating scheduled activities according to td hour numbers and the environmentally controlled activities and parameters according to $t_{s}$ hours.

\section{III.B.1.2 DATES}

The TARP includes a package of routines to compute dates in various forms for different calculational needs. All use integer arithmetic (remainders of divisions are truncated). The starting values are the year (YR), month (MO) and day-of-month (DM). For example the date December 31 , 1980 has $Y R=1980$ (all 4 digits required), $M O=12$, and $D M=31$. The leap year 1ndicator (LY) is determined by the YR. LY = I If YR is a leap year, 0 if it is not. A year is not a leap year if it is not evenly divisible by 4 , or if it is evenly divisible by 100 but not 400 . Otherwise, it is a leap year. Note that $L Y(1900)=0$ and $L Y(2000)=1$. The number of days in each month (LM) is given by

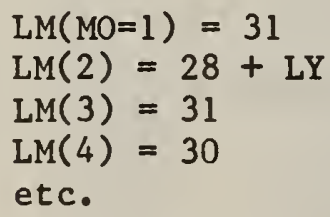

The day-of-year number (DY) is a continuous count of days beginning at 1 January. It can be computed by

$$
D Y=D M+\sum_{m=0}^{M O-1} L M(m)
$$

For $M O=1$, the sum is zero. 
The Julian date (JD) is the most powerful date representation. It is a continuous count of days from 1 January 4713 B.C. Any number of days added to or subtracted from a JD is a valid JD. The following algorithms [1] convert between conventional and Jullan dates:

$$
\begin{aligned}
& L=(M O-14) / 12 \\
& J D=D M-32075+1461 *(Y E A R+4800+L) / 4 \\
& +367 *(\mathrm{MO}-2-12 * \mathrm{~L}) / 12 \\
& -3 *((\text { YEAR }+4900+L) / 100) / 4 \\
& \mathrm{~J}=\mathrm{JD}+68569 \\
& \mathrm{~N}=4 * \mathrm{~J} / 146097 \\
& \mathrm{~K}=\mathrm{J}-(146097 * \mathrm{~N}+3) / 4 \\
& \text { YEAR }^{\prime}=4000 *(\mathrm{~K}+1) / 1461001 \\
& \mathrm{~L}=\mathrm{K}-1461 \text { * YEAR' / } 4+31 \\
& \mathrm{MO}^{\prime}=80 * \mathrm{~L} / 2447 \\
& \mathrm{DM}=\mathrm{I}-2447 * \mathrm{MO}^{\prime} / 80 \\
& \mathrm{M}=\mathrm{MO}^{\prime} / 11 \\
& \mathrm{MO}=\mathrm{MO}^{\prime}+2-12 * \mathrm{M} \\
& \text { YEAR }=100 *(\mathrm{~N}-49)+\mathrm{YEAR}^{\prime}+\mathrm{M}
\end{aligned}
$$

The cyclic date $(C D)$ is used in TARP to represent time periods which begin and end certain functions. They are given by

$$
\mathrm{CD}=32 * \mathrm{MO}+\mathrm{DM}
$$

The inverse relationships are equally simple.

$$
\begin{aligned}
& M O=C D / 32 \\
& D M=\operatorname{MOD}(C D, 32)
\end{aligned}
$$

where

$$
\begin{aligned}
\operatorname{MOD}(A, B) & =\text { the remainder of } A / B \\
& =A-(A / B) *_{B} \quad(M O D \text { is a FORTRAN intrinsic function) }
\end{aligned}
$$

It is easy to use cyclic dates to determine if CD lies within a period from $\mathrm{CD} 1$ through $\mathrm{CD} 2$, inclusive.

If $(C D 2>C D 1)$, then $(C D>C D 1$ and $C D<C D 2)$ for $C D$ to be in the period. If $(C D 1>C D 2)$, then $(C D>C D 1$ or $C D<C D 2)$ for $C D$ to be in the period.

(B.1.6)

A number such as 94 can be a valid cyclic date even though it represents an impossible conventional date - 30 February. This date can be used to end activities on the last day of February without considering leap year. The logic of B.1.6 still works because 1 March has cyclic date 97.

Day-of-week numbers (DW) are assigned according to: Sunday $=1$, Monday $=2, \ldots$. , Saturday $=7$. DW is given from JD by:

$$
\mathrm{DW}=\mathrm{MOD}(\mathrm{JD}+1,7)+1
$$


Building activities typlcally differ on holldays from normal schedules. The standard U. S. federal holidays are:

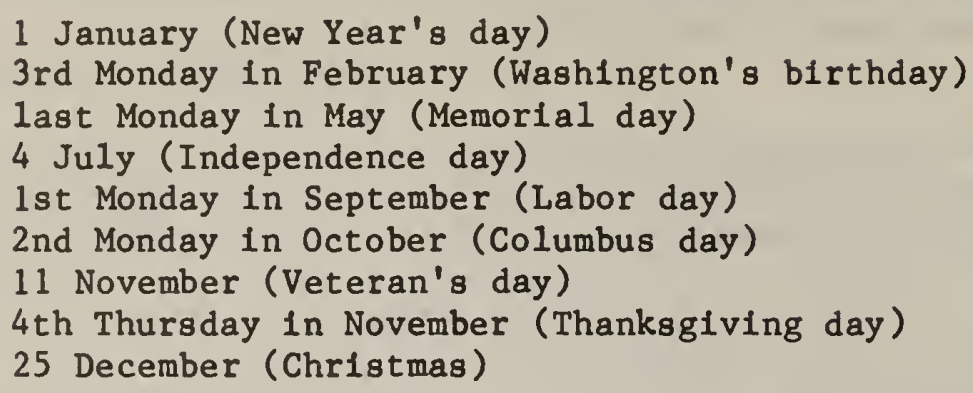

If any of the four holldays with dates fall on a weekend, the nearest Friday or Monday becomes a holiday. Five tests can describe the federal holldays (given that MO is correct).

Mth (DW=N) in the month:

$$
\operatorname{If}(D W=N \text { and }(D M+6) / 7=M), D M \text { is the holiday. }
$$

Last ( $D W=N)$ in the month:

$$
\text { If }(D W=N \text { and } D M>(L M-7)), D M \text { is the holiday. }
$$

Dated hollday (DM=J) on weekday:

$$
\text { If }(D M=J \text { and } D W \neq 1 \text { and } D W \neq 7) \text {, DM } 1 \text { s the holiday. (B.1.8c) }
$$

Dated hollday on Saturday:

$$
\text { If }(D M=J-1 \text { and } D W=6), D M 1 s \text { the holiday. }
$$

Dated holiday on Sunday:

$$
\text { If }(D M=J+1 \text { and } D W=2), D M \text { is the holiday. }
$$

A test is also needed for the New Year's holiday on Friday, 31 December.

Daylight savings time is in effect from the last Sunday in April through the Saturday before the last Sunday in October.

\section{III.B.2 PSYCHRONETRICS}

The following algorithms are used to calculate the properties of moist a1r. They are presented as a package, but not all are required by TARP. The psychrometric package gives four ways to compute the humidity ratio depending on available information. Other values can then be computed from the humidity ratio, dry-bulb temperature, and barometric presure. The following nomenclature is used in the psychrometric package. 


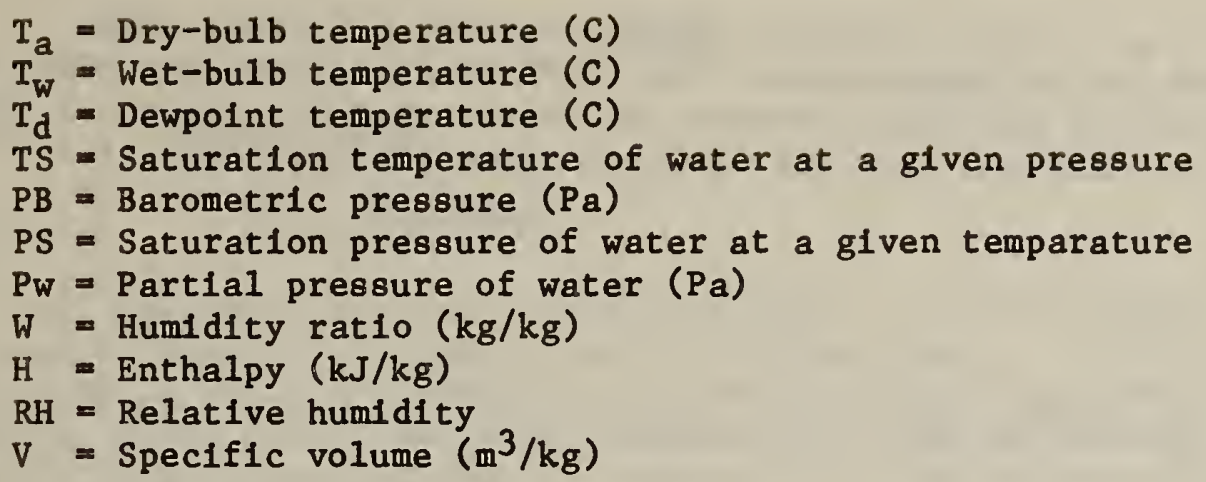

TS and PS are computed from polynomial expressions obtained by fits to the detailed correlation [2]. These expressions are of the form

$$
Y(X)=A_{0}+A_{1} * X+A_{2} * X^{2}+\ldots+A_{N} * X^{N}
$$

The coefficients for computing PS(T) ( $+0.02 \%)$ are:

\begin{tabular}{|c|c|c|c|c|c|c|}
\hline Range & of $T$ & $\mathbf{A}_{0}$ & $\mathbf{A}_{1}$ & $\mathrm{~A}_{2}$ & $\mathrm{~A}_{3}$ & $\mathrm{~A}_{4}$ \\
\hline 70. & -60 & 187.72756 & 9.7388459 & . 19227592 & .0017092958 & $5.7638449 E-6$ \\
\hline 60. $t$ & & 304. & 17. & & & 1.4989 \\
\hline 50. t & -3 & 456. & 30. & & & \\
\hline 35. & -20 & 578.2 & 43.8491 & $1 .$. & & .00 \\
\hline-20 & 0 & 611.12442 & $50.242 C$ & $18540^{\circ}$ & .037851608 & .00036358829 \\
\hline 0 & 20 & 617.57030 & 44.8571 & 5995 & .024895 & .00041888641 \\
\hline 20. & 40 & 30450 & 34.7350 & 2,1525 & .00 & .00069389647 \\
\hline 40 & 70 & 188 & -75 & 6.0 & -.0 & .0010572251 \\
\hline 70. to & & 10003.937 & $-537 \cdot 34244$ & 15.931817 & -.15349268 & .0014076596 \\
\hline
\end{tabular}

The coefficients for computing TS(P) ( $+0.005 \mathrm{C})$ are:

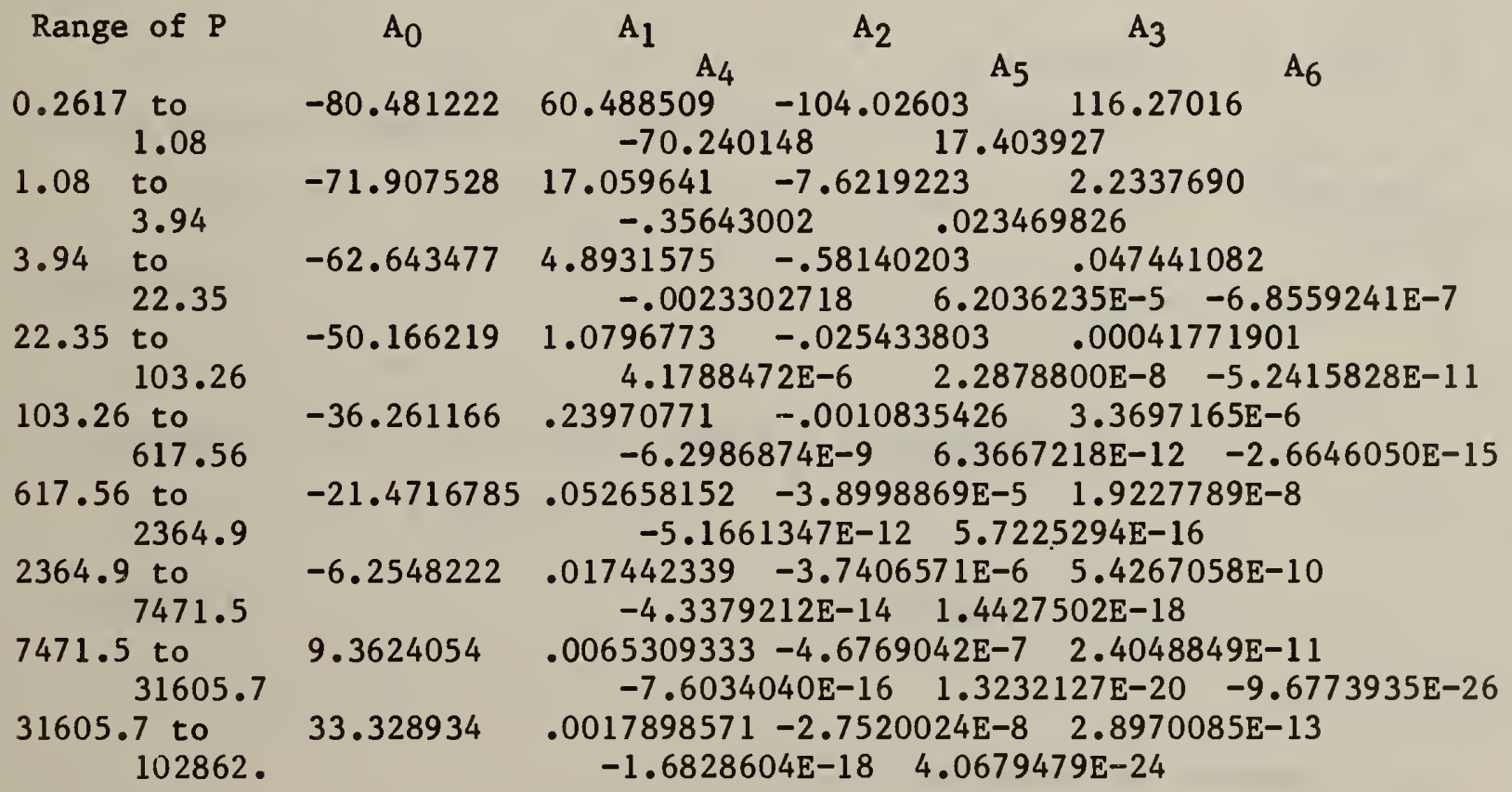


The polynomials are faster than the ASHRAE detalled algorfthm which involves a logarithm and an exponential. The other relationships are based on the 1deal gas law and are generally accurate to better than 0.7 percent. The humidity ratio may be obtalned from one of the following algorithms [3].

$\mathrm{W}\left(\mathrm{T}_{\mathrm{d}}, \mathrm{PB}\right)$

$$
\begin{aligned}
& \mathrm{P}_{\mathrm{W}}=\mathrm{PS}\left(\mathrm{T}_{\mathrm{d}}\right) \\
& \mathrm{W}=0.62198 * \mathrm{P}_{\mathrm{W}} /\left(\mathrm{PB}-\mathrm{P}_{\mathrm{W}}\right)
\end{aligned}
$$

$W\left(T_{a}, T_{w}, P B\right)$

$$
\begin{aligned}
\mathrm{P}^{\prime} & =\operatorname{PS}\left(\mathrm{T}_{\mathrm{W}}\right) \\
\mathrm{W}^{\prime} & =0.62198 * \mathrm{P}^{\prime} /\left(\mathrm{PB}-\mathrm{P}^{\prime}\right) \\
\mathrm{W}= & {\left[\left(2501.2 .381 * \mathrm{~T}_{\mathrm{W}}\right) * \mathrm{~W}^{\prime}-\left(\mathrm{T}_{\mathrm{a}}-\mathrm{T}_{\mathrm{W}}\right)\right] } \\
& /\left(2501 .+1.805 * \mathrm{~T}_{\mathrm{a}}-4.18 * \mathrm{~T}_{\mathrm{W}}\right)
\end{aligned}
$$

$\mathrm{W}\left(\mathrm{T}_{\mathrm{a}}, \mathrm{RH}, \mathrm{PB}\right)$

$$
\begin{aligned}
& \mathrm{P}_{\mathrm{W}}=\mathrm{RH} * \mathrm{PS}\left(\mathrm{T}_{\mathrm{a}}\right) \\
& \mathrm{W}=0.62198 * \mathrm{P}_{\mathrm{W}} /\left(\mathrm{PB}-\mathrm{P}_{\mathrm{W}}\right)
\end{aligned}
$$

$\mathrm{W}\left(\mathrm{T}_{\mathrm{a}}, \mathrm{H}\right)$

$$
\mathrm{W}=\left(\mathrm{H}-\mathrm{T}_{\mathrm{a}}\right) /\left(2501 \cdot+1.805 * \mathrm{~T}_{\mathrm{a}}\right)
$$

The following values may be computed when the humidity ratio is known. $\mathrm{T}_{\mathrm{d}}(\mathrm{W}, \mathrm{PB})$

$$
\begin{aligned}
& \mathrm{P}_{\mathrm{w}}=\mathrm{PB} * \mathrm{~W} /(0.62198+\mathrm{W}) \\
& \mathrm{T}_{\mathrm{d}}=\mathrm{TS}\left(\mathrm{P}_{\mathrm{w}}\right)
\end{aligned}
$$

$R H\left(T_{a}, T_{d}\right)$

$$
R H=P S\left(T_{d}\right) / P S\left(T_{a}\right)
$$

$\mathrm{V}\left(\mathrm{T}_{\mathrm{a}}, \mathrm{W}, \mathrm{PB}\right)$

$$
\mathrm{V}=287.055 *(1 .+1.6078 * \mathrm{~W}) * \mathrm{~T}_{\mathrm{a}} / \mathrm{PB}
$$

$\mathrm{H}(\mathrm{T} a, \mathrm{~W})$

$$
\mathrm{H}=\mathrm{T}_{\mathrm{a}}+\mathrm{W} *\left(2501 .+1.805 * \mathrm{~T}_{\mathrm{a}}\right)
$$

$\mathrm{T}_{\mathrm{w}}\left(\mathrm{T}_{\mathrm{a}}, \mathrm{W}, \mathrm{PB}\right)$

$\mathrm{T}_{\mathrm{W}}$ is computed by 1terating (B.2.3). 


\section{III.B.3.1 AIR TEMPERATURES}

All temperatures occur on the half-hour. Dry bulb temperature and barometric pressure are read from the weather tape. The wet bulb temperature, dew point, or relative humldity are also read to allow computation of the humidity ratio and the wet bulb temperature. For design days a temperature profile is generated between the maximum $\left(\mathrm{Ta}^{+}\right)$and minimum $\left(\mathrm{T}_{\mathrm{a}}{ }^{-}\right.$) temperatures for the day according to

$$
T_{a t}=T_{a}^{+}-f_{t} *\left(T_{a}^{+}-T_{a}^{-}\right)
$$

where $f_{t}$ is given by

$\begin{array}{rrrrrrrrrrrrr}\mathrm{t}: & 1 & 2 & 3 & 4 & 5 & 6 & 7 & 8 & 9 & 10 & 11 & 12 \\ \mathrm{f}: & .85 & .90 & .94 & .98 & 1.0 & .99 & .95 & .89 & .78 & .64 & .48 & .31 \\ \mathrm{t:} & 13 & 14 & 15 & 16 & 17 & 18 & 19 & 20 & 21 & 22 & 23 & 24 \\ \mathrm{f:} & .17 & .06 & .00 & .01 & .07 & .16 & .23 & .41 & .53 & .63 & .72 & .79\end{array}$

These values were obtain by interpolating between the hourly temperatures given by ASHRAE [4]. This profile is for summer days. For design days the user also gives $\mathrm{PB}$ and $\mathrm{T}_{\mathrm{w}}$ corresponding to $\mathrm{T}^{+}{ }^{+}$. A humidity ratio is computed from these and used with $\mathrm{T}_{\mathrm{a}}$ and $\mathrm{PB}$ to compute $\mathrm{Tw}$ for every hour.

\section{III.B.3.2 SKY TEMPERATURE}

The net thermal radiative flux between a horizontal surface and the sky $\left(Q_{\mathrm{sS}}\right)$ is given by

$$
\mathrm{Q}_{\mathrm{SS}}=\varepsilon_{1} *\left(\sigma * \mathrm{TO}_{1}^{4}-\varepsilon_{\mathrm{S}} * \sigma * \mathrm{~T}_{\mathrm{a}}{ }^{4}\right)
$$

with $\varepsilon_{S}$, the sky emmisivity, given by the correlation [5]

$$
\varepsilon_{s}=\left[0.787+.764 * \ln \left(T_{d} / 273\right)\right] *\left(1+.0224 * N-.0035 * N^{2}+.00028 * N^{3}\right)
$$

where

$$
\mathrm{N}=\text { tenths cloud cover }
$$

TARP uses a slightly different formula for computing $Q_{S S}$.

$$
Q_{s s}=\varepsilon_{i} * \sigma *\left(\mathrm{TO}_{i}^{4}-\mathrm{T}_{\mathrm{s}}^{4}\right)
$$

so that

$$
\mathrm{T}_{\mathrm{s}}=4 \sqrt{ } \varepsilon_{\mathrm{s}} * \mathrm{~T}_{\mathrm{a}}
$$


The user specifies monthly ground temperatures. Useful advice for the selection of ground temperatures is a subject of ongoing research.

III.B. 4 WIND

Wind speed increases with helght according to the formula

$$
V=V_{0} * \beta *\left(z / z_{0}\right)^{\alpha}
$$

where

$\mathrm{V}_{0}=$ wind speed at standard conditions

$\mathrm{Z}=$ height being considered

$\mathrm{Z}_{\mathrm{o}}=$ standard height of wind measurements ( $10 \mathrm{~m}$ )

$\alpha, \beta$ terrain dependent coefficients given below.

Terrain Parameters for Standard Terrain Classes [6]

\begin{tabular}{clcc} 
Class & \multicolumn{1}{c}{ Description } & $\alpha$ & $\beta$ \\
1 & $\begin{array}{l}\text { ocean or other body of water with at } \\
\text { least 5km of unrestricted expanse } \\
\text { flat terrain with some lsolated obs- } \\
\text { tacles (bulldings or trees well }\end{array}$ & 0.10 & 0.15 \\
$\quad \begin{array}{l}\text { separated from each other) } \\
\text { rural areas with low buildings, }\end{array}$ & 0.20 & 1.00 \\
3 & $\begin{array}{l}\text { trees, etc. } \\
\text { urban, industrial, or forest area }\end{array}$ & 0.25 & 0.67 \\
5 & $\begin{array}{l}\text { center of large city (Manhattan) } \\
5\end{array}$ & 0.35 & 0.47
\end{tabular}

Wind speeds are usually measured at class 2 sites (alrports). Therefore, the reported velocity is $V_{0}$. Eq $(B .4 .1)$ can be rearranged to compute $V_{0}$ for $V$ measured at non-standard sites.

\section{III.B.5 SOLAR RADIATION}

The general factors in determining solar position and solar radiation intensity are described by ASHRAE [7]. Most of that information is not repeated in the following discussion.

\section{III.B.5.1 SOLAR POSITION}

The solar position is described in terms of three direction cosines which are convenient for determining the angle of incidence of the sun's rays on a bullding surface (E.2.2). The following procedure is used to determine the direction cosines. The values of the solar declination angle, $\delta$, the equation of time, $\varepsilon$, and the distance form the earth to the sun, $R$ (in $\mathrm{AU}: 1 \mathrm{AU}=149,504,000 \mathrm{~km}$ ) are determined by a U.S. Naval Observatory algorithm [8]. 
For a given JD, compute the number of centuries since 1900 .

$T=(J D-2415020.5) / 36525$.

Then compute the following fundamental angles (in degrees).

Mean anomaly of the sun:

$G=385.475833+35999.049750 T-0.000150 T^{2}$

Mean longitude of the sun:

$\mathrm{L}=279.696678+36000.768920 \mathrm{~T}+0.000303 \mathrm{~T}^{2}$

Mean longitude of the moon:

$C=270.434164+481267.883144 \mathrm{~T}-0.001133 \mathrm{~T}^{2}$

Longitude of the ascending node of the moon's orbit:

$\mathrm{N}=259.183275-1934.142008 \mathrm{~T}+0.002078 \mathrm{~T}^{2}$

Mean anomaly of Venus:

$\mathrm{V}=212.603219+58517.803875 \mathrm{~T}+0.0001286 \mathrm{~T}^{2}$

Mean anomaly of Mars:

$M=319.529425+19139.858500 \mathrm{~T}+0.000181 \mathrm{~T}^{2}$

Mean anomaly of Jupiter:

$J=225.444651+3034.906654 \mathrm{~T}$

(B.5.2g)

Then compute the following values.

$$
\begin{aligned}
\theta & =0.397930 \sin (\mathrm{L})+0.009999 \sin (G-L)+0.003334 \sin (G+L) \\
& -0.000208 \mathrm{~T} \sin (\mathrm{L})+0.000042 \sin (2 \mathrm{G}+\mathrm{L})-0.000040 \cos (\mathrm{L}) \\
& -0.000039 \sin (\mathrm{N}-\mathrm{L})-0.000030 \mathrm{~T} \sin (G-\mathrm{L})-0.000014 \sin (2 \mathrm{G}-\mathrm{L}) \\
& -0.000010 \cos (\mathrm{G}-\mathrm{L}-\mathrm{J})-0.000010 \mathrm{~T} \sin (\mathrm{G}+\mathrm{L}) \\
\rho & =1.000421-0.033503 \cos (\mathrm{G})-0.000140 \cos (2 \mathrm{G}) \\
& +0.000084 \mathrm{~T} \cos (\mathrm{G})-0.000033 \sin (\mathrm{G}-\mathrm{J})+0.000027 \sin (2 \mathrm{G}-2 \mathrm{~V}) \\
\phi & =-0.041295 \sin (2 \mathrm{~L})+0.032116 \sin (\mathrm{G})-0.001038 \sin (\mathrm{G}-2 \mathrm{~L}) \\
& -0.000346 \sin (\mathrm{G}+2 \mathrm{~L})-0.000095-0.000080 \mathrm{~T} \sin (\mathrm{G}) \\
& -0.000079 \sin (\mathrm{N})+0.000068 \sin (2 \mathrm{G})+0.000046 \mathrm{~T} \sin (2 \mathrm{~L}) \\
& +0.000030 \sin (\mathrm{C}-\mathrm{L})-0.000025 \cos (\mathrm{G}-\mathrm{J})+0.000024 \sin (4 \mathrm{G}-8 \mathrm{PI}+3 \mathrm{~J}) \\
& -0.000019 \sin (\mathrm{G}-\mathrm{V})-0.000017 \cos (2 \mathrm{G}-2 \mathrm{~V})
\end{aligned}
$$

The maximum error in $\theta$ or $\phi$ is $.0001 \mathrm{AU}$ and the maximum error in $\rho$ is .0001 $\mathrm{AU}^{2}$ for the years 1800 through 2100. This is more accurate than is needed for building thermal analysis. Equations $(B .5 .3 a-c)$ can be truncated with some loss in accuracy. That loss can be estimated by the sum of the magnitudes of the truncated coefficients. TARP uses the first 4,4 , and 5 terms of these equations, respectively. With the shortened equations, only $G$ and $L$ are evaluated.

Then compute the solar declination angle, equation of time, and the earth-sun distance.

$$
\begin{aligned}
& \delta=\arcsin (\theta / \sqrt{\rho}) \\
& \varepsilon=-\arcsin \left(\phi / \sqrt{\rho-\theta^{2}}\right) / 15 .
\end{aligned}
$$

[hours] 


$$
R=\sqrt{\rho}
$$

The hour angle, $\mathrm{H}$, 18 the number of hours from solar noon.

$$
H=15\left(12-t_{B}-\varepsilon-T Z\right)+\text { LONG }
$$

where

$t_{s}=$ standard time (hours) at midpoint of the timestep

$\mathrm{TZ}=$ time zone number $(1.3 .4)$

LONG $=$ longitude $(1.3 .3)$

The solar direction cosines can be determined from these values plus the latitude, $\lambda$ (north positive, south negative), of the site.

$$
\begin{aligned}
& \mathrm{CS}_{1}=\cos \delta \operatorname{sinH} \\
& \mathrm{CS}_{2}=\sin \delta \cos \lambda-\cos \delta \sin \lambda \cos H \\
& \mathrm{CS}_{3}=\sin \delta \sin \lambda+\cos \delta \cos \lambda \cos H
\end{aligned}
$$

(B.5.6C)

$\mathrm{CS}_{3}$ is the cosine of the solar zenith angle which also equals the sine of the solar altitude angle. The solar azimuth angle, $\psi$ (relative to north), can be determined from

$$
\begin{aligned}
& \sin \psi=\mathrm{Cs}_{1} / \sqrt{1-\mathrm{Cs}_{3}{ }^{2}} \\
& \cos \psi=\mathrm{Cs}_{2} / \sqrt{1-\mathrm{Cs}_{3}{ }^{2}}
\end{aligned}
$$

These angle calculations apply for the northern and southern hemispheres.

\section{III.B.5.2 SOLAR INTENSITY}

The calculation of direct normal solar intensity, $I_{b}$, and diffuse solar intensity, $I_{S}$, for clear design days is exactly as described in [7].

$$
\begin{aligned}
& I_{b}=A e^{-B / C S_{3}} \\
& I_{s}=C * I_{b}
\end{aligned}
$$

The values of A, B, and C are calculated by a truncated Fourfer series fit to the data in Table 1 of [7]. Seasonal effects implicit in that table would not apply to the southern hemisphere. When the clearness number is less than 0.75 , it is assumed to represent the ratio $\mathrm{k}_{\mathrm{T}}$ defined as

$$
k_{T}=I / I_{0}
$$

where

$I=$ the total solar radiation on a horizontal surface

$$
\left(=I_{b} * \mathrm{CS}_{3}+I_{s}\right)
$$


$I_{0}=$ the solar radiation on a horizontal surface above the earth's atmosphere $\left[=\left(I_{s c} / R^{2}\right) * \mathrm{CS}_{3}\right]$

$I_{s c}=$ the solar constant $\left(1353 \mathrm{~W} / \mathrm{m}^{2}\right)$

On such cloudy design days the following correlation [9] 1s used.

$$
I_{s} / I=\begin{array}{ll}
1.0-0.249 k_{T} & k_{T}<0.35 \\
1.557-1.84 k_{T} & 0.35<k_{T}<0.75 \\
0.177 & k_{T}>0.75
\end{array}
$$

Weather tape data 18 used by means of the BLAST program weather f1le processor. For transportabllity, a version of th1s processor should be incorporated into TARP. Th1s version should include the most current solar radiation correlations.

\section{REFERENCES}

[1] Fliegel, H. and Van Flandern, T., "A Mach1ne Algor1thm for Processing Calender Dates," Communicat1ons of the ACM, Vol. 11, No. 10 (October 1968), p. 657.

[2] ASHRAE Handbook - 1981 Fundamentals (ASHRAE, 1981), p 5.2.

[3] ASHRAE Handbook - 1981 Fundamentals (ASHRAE, 1981), pp 5.3-5.5.

[4] ASHRAE Handbook - 1981 Fundamentals (ASHRAE, 1981), p 26.6, table 3.

[5] Clark, G. and Allen, C., "The Est1mation of Atmospher1c Radiation for Clear and Cloudy Skies," Proceedings of the 2nd National Passive Solar Conference (AS/ISES, 1978), Pp. 675-678.

[6] ASHRAE Handbook - 1981 Fundamentals (ASHRAE, 1981), p 22.15, table 7.

[7] ASHRAE Handbook - 1981 Fundamentals (ASHRAE, 1981), pp 27.2-9.

[8] Doggett, L. E., Kaplan, G. H., and Seldelmann, P. K., Almanac for Computers for the year 1978, (Un1ted States Naval Observatory, 1978) pp Al1-17.

[9] Org111, J. F., and Hollands, K. G. T., "Correlation Equation for Hourly Diffuse Radiation on a Horizontal Surface", Solar Energy 19 (Pergamon Press, 1977), p 358. 


\section{III.C.1 USE OF CONDUCTION TRANSFER FUNCTIONS}

The conventional equation for calculating steady state heat flux from the inside to the outside of a wall is

$$
K O=U *(T I-T O)
$$

This equation is valid only when the wall is non-massive or when the 1nside or outside temperatures are constant in time. In the more common and complex situation where transient effects cannot be safely ignored, heat conduction calculations which properly account for the dynamic effects must be utilized. The methodology implemented in TARP 18 based on the standard response factor technique [1] developed by Stephenson and Mttalas [2] and Kusuda [3] modified for efficiency according to a suggestion by Peavy [4]. The modified response factors are called "conduction transfer functions" (CTF). The heat conduction at (and toward) the inside surface at time $t$ is given by:

$$
K I_{t}=\sum_{m=0}^{N T} Y_{m} * T O_{t-m}-\sum_{m=0}^{N T} Z_{m} * T I_{t-m}+\sum_{k=1}^{N F} J_{k} * K I_{t-k}
$$

The heat conduction flux at (and toward) the outside surface is

$$
K O_{t}=\sum_{m=0}^{N T} Y_{m} * T I_{t-m}-\sum_{m=0}^{N T} X_{m} * T O_{t-m}+\sum_{k=1}^{N F} J_{k} * K O_{t-k}
$$

TARP uses the convention that the X CTF refer to outside (or eXterior) surface temperatures, and that the $\mathrm{Z}$ CTF refer to Inside (or Zone side) temperatures as in [1]. The opposite convention is often used in other programs.

The current inside and outside conductive fluxes are functions of the current inside and outside temperatures plus a factor containing the previous temperatures and fluxes. TARP Inftializes the temperature and flux histories by starting from a steady state and repeatedly calculating the building thermal performance for the first day of the simulation period until essentially equal results are achieved. Equation $(C .1 .2)$ can be rewritten to emphasize the unknown values at time $t$.

$$
K I_{t}=Y_{0} * T O_{t}-Z_{0} * T I_{t}+K I P_{t}
$$

where

$$
\mathrm{KIP}_{\mathrm{t}}=\sum_{\mathrm{m}=1}^{\mathrm{NT}} \mathrm{Y}_{\mathrm{m}}{ }^{\mathrm{T}} \mathrm{TO} \mathrm{O}_{\mathrm{t}-\mathrm{m}}-\sum_{\mathrm{m}=1}^{\mathrm{NT}} \mathrm{Z}_{\mathrm{m}}{ }^{\mathrm{T}} \mathrm{TI} \mathrm{I}_{\mathrm{t}-\mathrm{m}}+\sum_{\mathrm{k}=1}^{\mathrm{NF}} \mathrm{J}_{\mathrm{j}} * \mathrm{KI} \mathrm{I}_{\mathrm{t}-\mathrm{k}}
$$

Equation (C.1.3) may be similarly rewritten.

$$
\mathrm{KO}_{\mathrm{t}}=\mathrm{Y}_{\mathrm{O}} * \mathrm{TI} \mathrm{I}_{\mathrm{t}}-\mathrm{X}_{0}{ }^{*} \mathrm{TO} \mathrm{O}_{\mathrm{t}}+\mathrm{KOP}_{\mathrm{t}}
$$


where

$$
\mathrm{KOP}_{t}=\sum_{m=1}^{N T} \mathrm{Y}_{m} * T I_{t-m}-\sum_{m=1}^{N T} \mathrm{X}_{m} * T O_{t-m}+\sum_{k=1}^{N F} J_{k} * K O_{t-k}
$$

For lightwelght surfaces, such as sheet metal or thin glass, there are no CTF terms for $\mathrm{m}>1$ or $\mathrm{k}>0$. In that case $\mathrm{X}_{0}=\mathrm{Y}_{0}=\mathrm{Z}_{0}=\mathrm{U}$, and equations (C.1.4) and $(c .1 .6)$ both reduce to equation (c.1.1). Alr cavities are handled by massless 'slabs' which have only thermal resistance. This resistance cannot be described as temperature dependent. The conductive properties of a multipane window are described in this manner and appropriate conduction transfer functions are computed.

\section{III.C.2 CALCULATION OF CONDUCTION TRANSFER FUNCTIONS}

The CTF method is based upon the exact solution of a triangular temperature pulse on elther side of the wall. A series of triangular temperature pulses can be superposed to produce a good approximation of a continuous temperature function. The triangular pulse is solved by a Laplace transform. TARP follows the calculation technique used in BLAST [5] and described in detail by Hittle [6]. That description is quite lengthy and is not repeated here.

One useful property of the CTF is that the steady state conductance of the wall is related to the CTF by

$$
\begin{aligned}
U & =\sum_{m=0}^{N T} X_{m} /\left(1-\sum_{k=1}^{N F} J_{k}\right) \\
& =\sum_{m=0}^{N T} Y_{m} /\left(1-\sum_{k=1}^{N F} J_{k}\right) \\
& =\sum_{m=0}^{N T} Z_{m} /\left(1-\sum_{j=1}^{N F} J_{k}\right)
\end{aligned}
$$

This provides the method for determining the number of CTF terms to produce the desired accuracy.

\section{REFERENCES}

[1] ASHRAE Handbook - 1981 Fundamentals (ASHRAE, 1981), pp 23.09-23.10.

[2] Stephenson, D. G. and Mitalas, G. P., "Cooling Load Calculation by Thermal Response Factor Method", ASHRAE Transactions, Vol 73 (ASHRAE, 1967).

[3] Kusuda, T., "Thermal Response Factors for Multilayer Structures of Various Heat Conduction Systems", ASHRAE Transactions, Vol 75 (ASHRAE, 1969), p 246.

[4] B. A. Peavy, "A Note on Response Factors and Conduction Transfer Functions", ASHRAE Transactions, Vol 84 (ASHRAE, 1978), pp 688-690. 
[5] Hittle, D. C., "The Bullding Load Analysis and System Thermodynamics (BLAST) Program, Version 2.0: Users Manual", CERL Techn1cal Report E-153. (Construction Engineering Research Laboratory, 1979).

[6] Hittle, D. C., "Calculating Bullding Heat1ng and Cooling Loads Using the Frequency Response of Mult1layered Slabs", CERL Technical Manuscript E-169 (Construction Eng1neering Research Laboratory, 1981), pp 20-70. 
Windows are thermally critical elements of the building envelope. They are difficult to insulate and produce much greater conductive gains and losses than corresponding wall areas. Most can be opened to provide ventilation, but then they are significant sources of infiltration. The unique characteristic of windows is the transmission of light (short wavelength thermal radiation) directly into the building. This transmitted light is usually a desirable heat gain in the winter and an undesirable gain in the summer. It also provides natural lighting inside the building. The following sections describe the TARP optical algorithms.

\section{III.D.1 OPTICAL COEFFICIENTS}

Figure D.1 shows how the solar-optical properties of typical uncoated glazing materials vary with the incident angle of the light [1]. As the incident angle increases from $\theta=0$ degrees (normal incidence), the transmittance decreases, reflectance increases, and absorptance first increases due to the lengthened optical path through the glass and then decreases as more incident radiation is reflected away. These properties also vary with the wavelength of the incident radiation. The total solar radiation incident on a window ( $Q$ ) is composed of beam and diffuse components,

$$
Q=I_{b} * \cos \theta+I_{d}
$$

The beam component $\left(I_{b}\right)$ comes directly fom the sun and is incident at angle $\theta$. The diffuse component $\left(I_{d}\right.$ ) comes uniformly from all directions. Some of the incident radiation is transmitted according to

$$
\mathrm{QT}=\mathrm{T}_{\mathrm{b}} * \mathrm{I}_{\mathrm{b}} * \cos \theta+\mathrm{T}_{\mathrm{d}} * \mathrm{I}_{\mathrm{d}}
$$

where

$T_{b}$ is the beam transmittance at $\theta$ and

$\mathrm{T}_{\mathrm{d}}$ is the transmittance for diffuse radiation.

Some is absorbed according to

$$
Q A=A_{b} * I_{b} * \cos \theta+A_{d} * I_{d}
$$

where $A_{b}$ and $A_{d}$ are the beam and diffuse absorptances. If an internal shade is present, it also absorbs radiation with absorptances $A S_{b}$ and $A S_{d}$.

$$
\mathrm{QS}=\mathrm{AS}_{\mathrm{b}} * \mathrm{I}_{\mathrm{b}} * \cos \theta+\mathrm{AS}_{\mathrm{d}} * \mathrm{I}_{\mathrm{d}}
$$

The energy absorbed in the shade is convected directly to the room air. The energy absorbed in the glass is convected both into the room and to the outside according to proportions (neglecting the thermal resistance of the glass which is small compared to HI and HO) defined by 


$$
\mathrm{QA}_{\text {in }}=\mathrm{QA} * \mathrm{HI} /(\mathrm{HI}+\mathrm{HO})
$$

and

$$
\mathrm{QA}_{\text {out }}=\mathrm{QA} \text { * } \mathrm{HO} /(\mathrm{HI}+\mathrm{HO})
$$

where

$H I=$ inside surface heat transfer coeficient and

HO = outside surface heat transfer coefficient.

The expressions become more complicated for a two pane window.

$$
\mathrm{QA}_{\text {in }}=\mathrm{QAI} *(\mathrm{U} / \mathrm{HO}+\mathrm{U} / \mathrm{HS})+\mathrm{QAO} * \mathrm{U} / \mathrm{HO}
$$

and

$$
\mathrm{QA}_{\mathrm{out}}=\mathrm{QAI} * \mathrm{U} / \mathrm{HI}+\mathrm{QAO} *(\mathrm{U} / \mathrm{HI}+\mathrm{U} / \mathrm{HS})
$$

where

$\mathrm{U}=1 /(1 / \mathrm{HO}+1 / \mathrm{HS}+1 / \mathrm{HI})$,

HS = heat transfer coefficient of the air gap,

QAI = energy absorbed in the outer pane and

$\mathrm{QAO}=$ energy absorbed in the outer pane.

In TARP a consistant description of absorption in single and multi pane windows is achieved by separating QA into equal components, QAI and QAO, for the single pane window. HS is then the U-value of the glass. The actual distribution of the QAI qnd QAO is handled by the more general surface heat balance equations (I.3.2) and $(J .3 .2)$.

The angle dependent properties of $\mathrm{T}_{\mathrm{d}}, \mathrm{AO}_{\mathrm{d}}, A I_{\mathrm{d}}$, and $\mathrm{AS}_{\mathrm{d}}$ are represented by polynomial equations in terms of $\cos \theta$. Two ranges of $\cos \theta$ are used for greater accuracy, so each property (X) has two equations

and

$$
X=c_{0}+c_{1} \cos \theta+c_{2}(\cos \theta)^{2}+\ldots+c_{4}(\cos \theta)^{4}[\cos \theta>0.5] \quad \text { (D.1.7a) }
$$

$$
\mathrm{X}=\mathrm{d}_{1} \cos \theta+\mathrm{d}_{2}(\cos \theta)^{2}+\ldots+\mathrm{c}_{6}(\cos \theta)^{6} \quad[\cos \theta<0.5] \quad \text { (D.1.7b) }
$$

The coefficients $c_{1}$ and $d_{1}$ are determined by curve fits to optical values computed by methods described in the following sections. TARP also computes transmittance and absorptances for diffuse radiation.

\section{III.D.2 SHADING COEFFICIENTS}

The solar optical properties of windows are often described by a shading coefficient, SC, [2] which is defined as

$$
\begin{aligned}
\text { SC }= & \text { Solar Heat Gain of Window / } \\
& \text { Solar Heat Gain of Reference Glass }
\end{aligned}
$$


For single glazing this is

$$
\begin{aligned}
\mathrm{SC}= & {[\mathrm{QT}+\mathrm{QA} *(\mathrm{HO}+\mathrm{HI}) / \mathrm{HO}] / } \\
& {\left[\mathrm{QT}_{\mathrm{dsa}}+\mathrm{QA}_{\mathrm{dsa}} *(\mathrm{HO}+\mathrm{HI}) / \mathrm{HO}\right] }
\end{aligned}
$$

where

$$
\begin{aligned}
& \mathrm{QT}=\text { radiation transmitted } \\
& \mathrm{QT}_{\mathrm{dsa}}=\mathrm{QT} \text { of DSA glass } \\
& \mathrm{QA}=\text { radiation absorbed } \\
& \mathrm{QA}_{\mathrm{dsa}}=\mathrm{QA} \text { of DSA glass } \\
& \mathrm{HO}=\text { outside surface heat transfer coefficient }\left(=22.7 \mathrm{~W} / \mathrm{m}^{2} \mathrm{k}\right) \\
& \mathrm{HI}=\text { Inside surface heat transfer coefficlent }\left(=8.3 \mathrm{~W} / \mathrm{m}^{2} \mathrm{~K}\right)
\end{aligned}
$$

The reference glazing material is double-strength sheet glass (DSA) with 0.86 transmittance, 0.08 reflectance, and 0.06 absorptance at normal incidence.

A shading coefficient is implemented in TARP by multiplying SC times the $c_{1}$ and $d_{1}$ of $(D .1 .7)$ computed for the reference glass. This gives correct steady state solar gains, but does not give correct proportions of transmitted and absorbed radiation (esecially for heat absorbing glasses). Correct proportions are necessary in dynamic simulation because the absorbed component produces an instantaneous convective gain to the space while the transmitted component is first absorbed by the surfaces of the space and produces a delayed gain. Therefore, the shading coefficlent method is not recommended unless data for the following detailed method is unavallable.

\section{III.D.3 UNCOATED PANE OPTICS}

When a ray of light reaches a smooth interface between two non-conducting media, part of the ray is reflected and part is refracted as in figure D.2. The angle of reflection equals the angle of incidence $\left(\theta_{1}\right)$. The angle of refraction $\left(\theta_{2}\right)$ is given by Snell's law:

$$
\mathrm{n}_{1} * \sin \theta_{1}=\mathrm{n}_{2} * \sin \theta_{2}
$$

where $n_{1}$ and $n_{2}$ are the indexes of refraction of the two media. The refractive index of air is effectively equal to unity. The refractive index of glass is dependent on both the composition of the glass and the wavelength of the light. The variation is small for typical wavelengths between 0.3 and 3.0 microns, but it is enough for a glass prism to separate a ray of white light into the spectrum of colors.

Reflectance is the ratio of the energy reflected from the interface to the energy incident upon it. The electromagnetic description of light shows that reflectance depends on the polarization of the incident light. The two components of polarization are perpendicular to the plane of incidence (also called transverse electric or TE) and parallel to the plane of incidence (called transverse magnetic or TM). A simple formula [3] for reflectance at the interface shown in figure $D .2$ is

$$
\rho=\left[\left(p_{1}-p_{2}\right) /\left(p_{1}+p_{2}\right)\right]^{2}
$$



$\mathrm{p}_{1}=\cos \theta_{1} \star \mathrm{n}_{1}$
for TE light
$(D .3 .2 a)$

and

$$
\mathrm{P}_{1}=\cos \theta_{1} / \mathrm{n}_{1} \quad \text { for } \operatorname{TM} 11 \mathrm{ght}
$$

Unpolarized light may be considered to consist of one half TE and one half TM polarized light. (D.3.2) is a computationally simpler form of the more familiar Fresnel equations.

The fraction of light transmitted through the interface is given by

$$
\tau=\left(p_{2} / p_{1}\right) *\left[2 * p_{1} /\left(p_{1}+p_{2}\right)\right]^{2}
$$

with the same polarization dependent values for $\mathrm{p}$ as above. It is easier to calculate transmittance from the simple energy balance: $\tau=1-p$.

Glass absorbs light passing through it in proportion to the intensity of the 1ight. The fraction of light $\left(\tau_{g}\right)$ transmitted through a given distance (x) of glass is given by the exponential decay formula

$$
\tau_{g}=e^{-k x}
$$

where $k$ is the extinction coefficient of the glass. The value of $k$ is wavelength dependent but independent of polarization. The fraction of light absorbed is ag = 1 - tg. For a glass plate of thickness $\mathrm{L}$, the distance the light travels in passing from one side to the other $18 x=L / \cos \theta_{2}$. Therefore,

$$
\tau_{g}=e^{-k L / \cos \theta} 2
$$

A ray of light incident on a sheet of glass will be both reflected and refracted at the front surface. Part of the refracted component will be absorbed in the glass before reaching the back surface where it is again reflected and refracted. This continues unt1l all the light is either absorbed or escapes from the front or back surfaces of the glass. Figure D. 3 shows the first several reflections of the incident light ray. Summation of the transmitted, reflected, and absorbed components of the incident ray give the total transmittance $(t)$, reflectance $(r)$, and absorptance (a) of the sheet of glass. These values must be determined separately for both polarization components. $\rho, \tau(=1-\rho), \tau g$, and $\alpha_{g}\left(=1-\tau_{g}\right)$ are functions of the angle of Incidence and wavelength of the light. They are identical at both sides of the glass.

Single pane transmittance:

$$
\begin{aligned}
t & =(1-\rho)^{2} \tau_{g}+(1-\rho)^{2} \rho^{2} \tau_{g}{ }^{3}+(1-\rho)^{2}{ }^{4} \tau_{g}{ }^{5}+\ldots \\
& =(1-\rho)^{2} \tau_{g}\left(1+\rho^{2} \tau_{g}{ }^{2}+\rho^{4} \tau_{g} 4+\ldots\right) \\
& =\tau^{2} \tau_{g} /\left(1-\rho^{2} \tau_{g}{ }^{2}\right)
\end{aligned}
$$


Single pane reflectance:

$$
\begin{aligned}
r & =\rho+(1-\rho)^{2} \rho \tau_{g}{ }^{2}+(1-\rho)^{2} \rho^{3} \tau_{g}{ }^{4}+\ldots \\
& =\rho+(1-\rho) 2 \rho \tau{ }^{2}\left(1+\rho^{2} \tau_{g}{ }^{2}+\rho^{4} \tau_{g}^{4}+\ldots\right) \\
& =\rho+\tau^{2} \rho \tau_{g}{ }^{2} /\left(1-\rho^{2} \tau_{g}{ }^{2}\right)
\end{aligned}
$$

Single pane absorptance:

$$
\begin{aligned}
a= & \left.(1-\rho)-(1-\rho) \tau_{g}\right]+\left[(1-\rho) \rho \tau_{g}-(1-\rho) \rho \tau_{g}{ }^{2}\right]+\left[(1-\rho) \rho^{2} \tau_{g}{ }^{2}-(1-\rho) \rho^{2} \tau_{g}{ }^{3}\right]+\ldots \\
& =(1-\rho)\left(1-\tau_{g}\right)\left(1+\rho \tau_{g}+\rho^{2} \tau_{g}{ }^{2}+\ldots\right) \\
& =\tau \alpha_{g} /\left(1-\rho \tau_{g}\right)
\end{aligned}
$$

The energy balance $(t+r+a=1)$ allows any one of the three components to be computed from the other two, or it allows a check for the consistancy of all three.

The extinction coefficient of a pane of glass can be computed from the thickness, normal incidence transmittance, and index of refraction. At normal incidence

$$
\begin{aligned}
\rho & =\left[\left(n_{1}-n_{2}\right) /\left(n_{1}+n_{2}\right)\right]^{2} \\
& =[(n-1) /(n+1)]^{2} \text { for air and glass }
\end{aligned}
$$

and

$$
t=\left[(1-\rho)^{2} \tau_{g}\right] /\left[1-\rho^{2} \tau_{g}^{2}\right]
$$

which combine to give a quadratic equation for $\tau_{g}$. The solution of that equation is

$$
\tau_{\mathrm{g}}=\left(-\mathrm{B}+\sqrt{\mathrm{B}^{2}+4 \mathrm{C}}\right) / 2
$$

where $B=(1-\rho)^{2} /\left(\rho^{2} t\right)$ and $C=1 / \rho^{2}$. Finally, from (D.3.5)

$$
k=-\ln \left(\tau_{g}\right) / L
$$

This provides a means of describing the glass pane in terms of simply measurable optical properties and makes it unnecessary to use the less exact shading coefficients when those properties are known.

\section{III.D.4 REFLECTIVE COATINGS}

A metallic film will be treated as a thin, smooth coating on one side of the pane of glass. Let medium 1 be the air, medium 2 the film, and medium 3 the glass substrate. The mathematical treatment of the optics of a metallic film $[4,5]$ is based on the index of refraction of the metal being a complex number (complex numbers indicated by $\sim$ ) 


$$
\tilde{\mathrm{n}}_{2}=\mathrm{n}_{2}-1 \mathrm{k}_{2} \quad[1=\sqrt{-1}]
$$

where $n_{2}$ is the (real) index of refraction and $k_{2}$ is the extinction coefficient.

Snell's law st1ll applies, but 1 t leads to a complex value of $\cos \theta_{2}=$ $x+1 y$. Let

and

$$
c=\left[\left(n_{1} *_{\sin \theta_{1}} *_{n_{2}}\right) /\left(n_{2}{ }^{2}+k_{2}{ }^{2}\right)\right]^{2}
$$

Then

$$
d=\left[\left(n_{1} * \sin \theta_{1} * k_{2}\right) /\left(n_{2}{ }^{2}+k_{2}{ }^{2}\right)\right]^{2}
$$

$$
x=\sqrt{1-c+d+\sqrt{(1-c+d)^{2}+4^{\star} c^{\star} d} / 2}
$$

and

$$
y=c * k_{2} /\left(x * n_{2}\right)
$$

The amplitude (not energy) reflectance at the interface between media 1 and $\mathrm{f}$ for light incident from medium 1 is given by

$$
\begin{aligned}
\tilde{p}_{1 j} & =\left(\tilde{p}_{1}-\tilde{p}_{j}\right) /\left(\tilde{p}_{1}+\tilde{p}_{j}\right) & & \text { (D.4.3a) } \\
\tilde{p}_{1} & =\cos \sigma_{1} * \tilde{n}_{1} & & \text { [TE polarization] } \\
\tilde{p}_{1} & =\tilde{n}_{1} / \cos \sigma_{1} & & \text { [TM polarization] }
\end{aligned}
$$

The amplitude transmittance at an interface is given by

$$
\tilde{\tau}_{1 j}=2 * \tilde{p}_{1} /\left(\tilde{p}_{1}+\tilde{p}_{j}\right)
$$

Note that $\tilde{\rho}_{j 1}=-\tilde{\rho}_{1 j}$ and $\tilde{\tau}_{1 j} * \tilde{\tau}_{j 1}=1-\tilde{\rho}_{1 j}^{2}$.

Amplitude transmittance $\left(\tilde{\tau}_{f}\right)$ within the metallic film is based on 1 ts phase thickness defined as

$$
\widetilde{d}=2 * \pi * D * \tilde{\mathrm{n}}_{2} * \cos \tilde{\theta}_{2} / \lambda
$$

where

$$
\begin{aligned}
& D=\text { thickness of the film and } \\
& \lambda=\text { wavelength of the } 11 \text { ght }
\end{aligned}
$$

so that

$$
\tilde{\tau}_{f}=e^{-1 \tilde{d}} \quad[1=\sqrt{-1}]
$$

Considerations of multiple reflections within the film leads to expressions for the total amplitude reflectance and transmittance. For light incident from medium 1 the expressions are

$$
\tilde{\rho}_{13}=\left(\tilde{\rho}_{12}+\tilde{\rho}_{23} * \tilde{\tau}_{f}^{2}\right) /\left(1+\tilde{\rho}_{12} * \tilde{\rho}_{23} * \widetilde{\tau}_{f}^{2}\right)
$$

and 


$$
\tilde{\tau}_{13}=\tilde{\tau}_{12} * \tilde{\tau}_{23} * \tilde{\tau}_{f} /\left(1+\tilde{\rho}_{12} * \tilde{\rho}_{23} * \tilde{\tau}_{f}^{2}\right)
$$

Reverse the subscripts for light incldent from medium 3.

The energy reflectance and transmittance are given by

and$$
\rho_{13}=\tilde{\rho}_{13} * \bar{\rho}_{13}
$$

$$
\tau_{13}=\tilde{\tau}_{13} * \bar{\tau}_{13} * \tilde{\mathrm{p}}_{3} / \tilde{\mathrm{p}}_{1}
$$

where $\bar{\rho}$ and $\bar{\tau}$ are the complex conjugates of $\tilde{\rho}$ and $\tilde{\tau}$. Energy is absorbed in the metallic film $\left(\rho_{13}+\tau_{13}<1\right)$.

Most of the above expression are complex. Rather than expanding them to get solutions in terms of real numbers, it is easier to let the computer evaluate the expressions by using complex arthmetic.

Coated glass has the same multiple reflection property as uncoated glass. Derivation of the total reflectance, transmittance, and absorptance is complicated by the fact that reflectances at the coatings depend on the direction of incidence. Again consider a light ray incident from the left (as was done in figure D.3). Properties $(\rho, \tau)$ for both the left and right surfaces of the glass are dependent on whether the light is incident from the left or right. Consider the left side to be the "front" and the right side to be the "back" of the glass. The following subscripts specify these conditions:

1: light incident on the left side from the left

2: light incident on the left side from the right

3: light incident on right side from the right (none)

4: light incident on right side from the left

so that for light incident from the front (superscript f)

and

$$
\mathrm{r}^{\mathrm{f}}=\rho_{1}+\rho_{4} \tau_{1} \tau_{2} \tau_{\mathrm{g}}{ }^{2} /\left(1-\rho_{2} \rho_{4} \tau_{\mathrm{g}}{ }^{2}\right)
$$

$$
\mathrm{t}^{\mathrm{f}}=\tau_{1} \tau_{4} \tau_{\mathrm{g}} /\left(1-\rho_{2} \rho_{4} \tau_{\mathrm{g}}{ }^{2}\right)
$$

A simple exchange of subscripts $(1: 3$ and $2: 4)$ will give the expressions for light incident from the back (superscript b).

and

$$
\mathrm{r}^{\mathrm{b}}=\rho_{3}+\rho_{2} \tau_{3} \tau_{4} \tau_{\mathrm{g}}{ }^{2} /\left(1-\rho_{4} \rho_{2} \tau_{\mathrm{g}}{ }^{2}\right)
$$

$$
t^{b}=\tau_{3} \tau_{2} \tau_{g} /\left(1-\rho_{4} \rho_{2} \tau_{g}{ }^{2}\right)
$$

Since light is absorbed in the glass and in the coatings on either side, it is easiest to compute absorptance from the energy balance: $a=1-r-t$. If both sides of the glass are uncoated, $\rho_{1}=\rho_{2}=\rho_{3}=\rho_{4}$, and $\tau_{1}=\tau_{2}=\tau_{3}=\tau_{4}$ and equations (D.4.8a and $b$ and D.4.9a and $b$ ) reduce to (D.3.7) and (D.3.6). 


\section{III.D.5 MULTI-PANE WINDOWS}

The optical properties of a combination of two panes of glass can be determined from the properties of the component single panes. The values for the TE and TM polarization components must be determined separately and then added according to the relative proportions of each component [6].

Flgure D.4 shows two panes of glass with fluxes of light golng to both the rlght (I) and to the left $(\mathrm{J})$. The radiation fluxes are made up of all transmitted and inter-reflected components. Let

$t_{n}=$ transmittance of pane $n$ (as an individual pane)

$a_{n}^{f}=$ absorptance of pane $n$ for flux from left (front)

$a_{n}{ }^{b}=$ absorptance of pane $n$ for flux from right (back)

$r_{n} f=$ reflectance of pane $n$ for light from the left (front)

$r_{n}{ }^{b}=$ reflectance of pane $n$ for 11ght from the right (back)

then

$$
\begin{aligned}
& J_{1}=I_{1} * r_{2} f+J_{2} * t_{2} \\
& J_{0}=I_{0} * r_{1} f+J_{1} * t_{1} \\
& I_{2}=I_{1} * t_{2}+J_{2} * r_{2}^{b} \\
& I_{1}=I_{0} * t_{1}+J_{1} * r_{1}^{b}
\end{aligned}
$$

The optical properties for light incldent only from the front are given by setting $J_{2}=0$, and substituting (D.5.1a-d) Into the following definitions.

$$
\begin{aligned}
T^{f} & =I_{2} / I_{0} \\
& =B * t_{2} \\
R^{f} & =J_{0} / I_{0} \\
& =r_{1}^{f}+B * r_{2}^{f} * t_{1} \\
A_{1}^{f} & =\left(a_{1}^{f} * I_{0}+a_{1}^{b}{ }^{b} J_{1}\right) / I_{0} \\
& =a_{1}^{f}+B * r_{2}^{f} * a_{1}^{b} \\
A_{2} f & =a_{2}^{f} * I_{1} / I_{0} \\
& =B * a_{2} f
\end{aligned}
$$

where 


$$
B=t_{1} /\left(1-r_{1}^{b} * r_{2}^{f}\right)
$$

For light incident from the back, set $I_{0}=0$, to obtain

$$
\begin{aligned}
& \mathrm{T}^{\mathrm{b}}=\mathrm{J}_{0} / \mathrm{J}_{2}=\mathrm{C} * \mathrm{t}_{1} \\
& \mathrm{R}^{\mathrm{b}}=\mathrm{I}_{2} / \mathrm{J}_{2}=\mathrm{r}_{2}^{\mathrm{b}}+\mathrm{C} * \mathrm{r}_{1}^{\mathrm{b}} * \mathrm{t}_{2} \\
& A_{2}^{b}=\left(a_{2}^{b} * J_{2}+a_{2} f * I_{1}\right) / J_{2}=a_{2}^{b}+c * r_{1}^{b} * a_{2}^{f} \\
& A_{1}^{b}=a_{1}^{b} * J_{1} / J_{2}=C * a_{1}^{b}
\end{aligned}
$$

where

$$
c=t_{2} /\left(1-r_{2} f * r_{1}^{b}\right)
$$

Note that $\mathrm{T}^{\mathrm{f}}=\mathrm{T}^{\mathrm{b}}$. All other front and back coefficients may be different.

Simflar heat balances can be set up for triple glazing. They lead to the following equations for front radiation.

$$
\begin{aligned}
& T^{f}=E * D * t_{3} \\
& R^{f}=r_{1}^{f}+E * t_{1} *\left(r_{2}^{f}+D * r_{3}^{f} * t_{2}\right) \\
& A_{1}^{f}=a_{1}^{f}+a_{1}^{b} * E *\left(r_{2} f+D * r_{3} f * t_{2}\right) \\
& A_{2}^{f}=E *\left(a_{2}^{f}+a_{2}^{b} * D * r_{3}^{f}\right) \\
& A_{3}^{f}=a_{3}^{f} * E * D \\
& D=t_{2} /\left(1-r_{2}^{b} * r_{3}^{f}\right) \\
& E=t_{1} /\left(1-r_{1}^{b} * r_{2}^{f}-D * r_{1}^{b} * r_{3}{ }^{f} * t_{2}\right)
\end{aligned}
$$

There is a similar set of equations for radiation incident from the back. TARP also uses expressions for quadruple glazing, which are not repeated here.

\section{III.D.6 DIFFUSE RADIATION}

Diffuse radiation is considered to be of uniform intensity from all directions and to be unpolarized (equal amounts of TE and TM polarizations). Consider a small area, $\mathrm{dA}_{1}$, under a hemisphere of uniform brightness I (figure D.5). The energy recelved is given by [7]

$$
\mathrm{dQ}=\mathrm{I} \mathrm{dA}_{1} \cos \theta \mathrm{d} \Omega
$$

where 
$\mathrm{dQ} / \mathrm{dA}_{1}=$ energy per unit area

$\mathrm{d} \Omega=$ the differential solid angle $=\mathrm{dA}_{2} / \mathrm{r}^{2}$

$=2 \pi(r \sin \theta) r d \theta / r 2$

Let $X(\theta)$ be the transmittance, reflectance, or absorptance for beam radiation of a system of glass panes. Then the diffuse property, $X_{d}$, is given by

$$
X_{d}=\int_{0}^{\pi / 2} X(\theta) 2 \pi I \sin \theta \cos \theta d \theta / \int_{0}^{\pi / 2} 2 \pi I \sin \theta \cos \theta d \theta
$$

The integral is evaluated by Simpson's method using beam values of $x(\theta)$ at appropriate $\theta$.

\section{III.D.7 INTERIOR SHADING DEVICES}

Windows commonly have drapes or blinds in addition to the panes of glass discussed so far. In TARP such interior shading devices are modeled as diffusely transmitting ( $t s)$, reflecting ( $r s$ ) and absorbing (as) surfaces. When an interior shading device 1 s added to the glazing system, a new set of interreflected components is created (figure D.6). The total forward flux on the shade is $I_{s}\left(=I_{0} * T^{f}+J_{s} * R_{d}^{b}\right)$. Note that we are interested in the diffuse back reflectance of the panes of glass. The total (diffusely) transmited flux through the shade is $I_{t}=I_{s} * t_{s}$. The total leftward flux is $J_{s}=I_{s} * r_{s}$. Therefore, $I_{s}=I_{0} * T_{f} /\left(1-r_{s} * R_{d}^{b}\right)$, and the total transmitted flux $1 s$

$$
I_{t}=I_{0} * T_{f} * t_{s} /\left(1-r_{s} * R_{d}^{b}\right)
$$

The total shade absorptance is

$$
A_{s}=I_{s} * a_{s} / I_{0}=T^{f} * t_{s} * a_{s} /\left(1-r_{s} * R_{d}^{b}\right)
$$

The total forward absorptance of each pane of glass is modified by

$$
\begin{aligned}
A_{n}{ }^{f} & =A_{n}{ }^{f}+J_{s} * A_{n d}{ }^{b} \\
& =A_{n}{ }^{f}+A_{n d}{ }^{b} * T^{f} * r_{s} /\left(1-r_{s} * R_{d}{ }^{b}\right)
\end{aligned}
$$

Thus in the evaluation of the optical properties of a pane/shade system, it is first necessary to compute the diffuse back absorptance of each pane in the glass system by integrating beam $A_{n}{ }^{b}$ over $\theta$. Then the pane/shade beam transmittance and absorptances are computed at the angles to be used in the optical properties curve fits. Finally the pane/shade diffuse properties can be computed.

\section{REFERENCES}

[1] ASHRAE Handbook - 1981 Fundamentals (ASHRAE, 1981), p 27.14. [2] ASHRAE Handbook - 1981 Fundamentals (ASHRAE, 1981), pp 27.14-17. 
[3] Born, M., and Wolf, E., Princlples of Optics, 4th ed, (Pergamon Press, 1970), pp 36-42.

[4] Heavens, 0. S., Optical Propert1es of Th1n Sol1d F1lms, (Academic Press, 1955), pp 51-58.

[5] Born, M., and Wolf, E., Princlples of Opt1cs, 4th ed, (Pergamon Press, 1970), pp 627-632.

[6] Hottel, H. C., and Sarofim, A. F., Radlative Transfer, (McGraw-Hill, 1967), p 197, f1g 5-12.

[7] Kreith, F., Principles of Heat Transfer, 3rd ed. (Intext Educational Publishers, 1973), pp 230-231. 

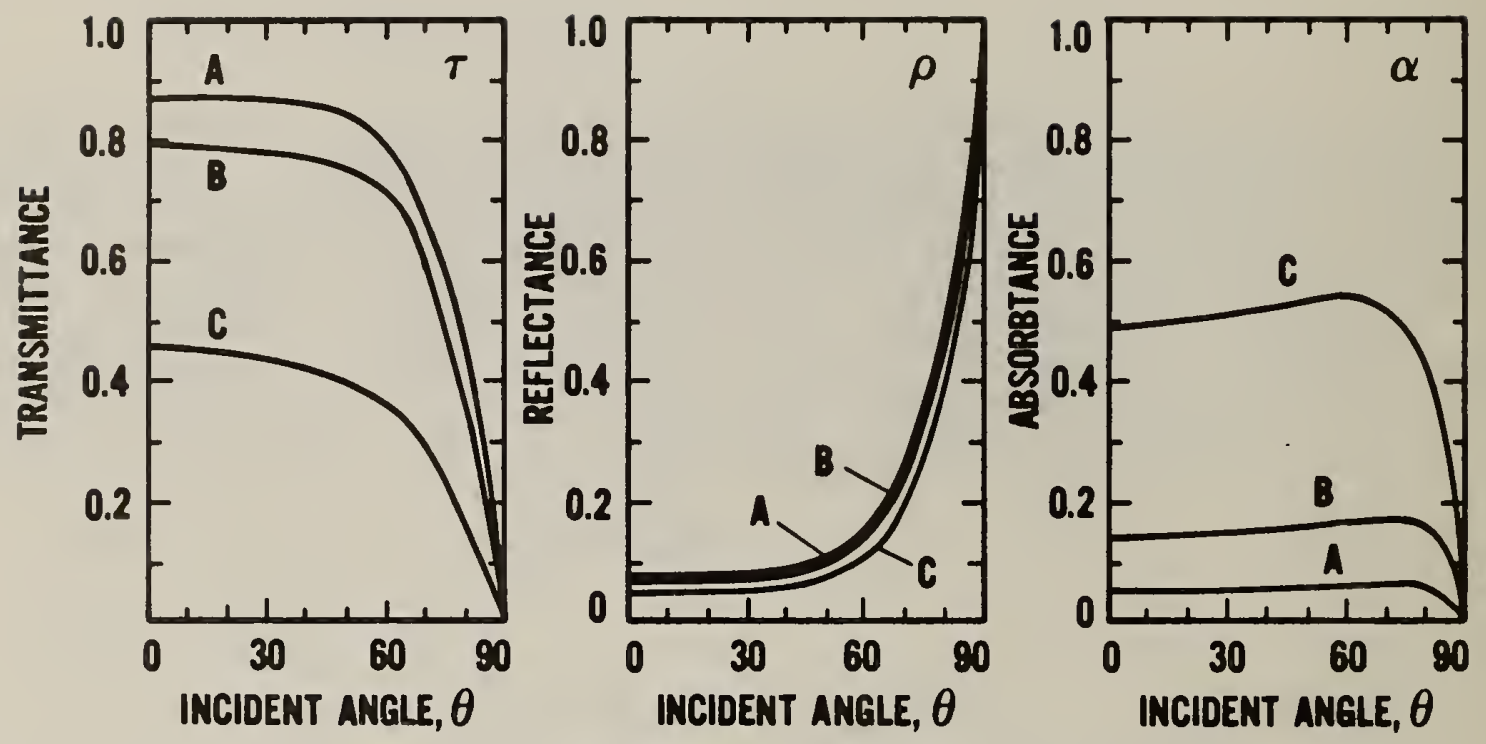

$A=D S A$ glass
$B=6 \mathrm{~mm}(0.25$ in $)$ clear glass
$C=6 \mathrm{~mm}(0.25$ in $)$ heat absorbing glass

Figure IIL.D.1 Variation of solar-optical properties with angle of incidence 


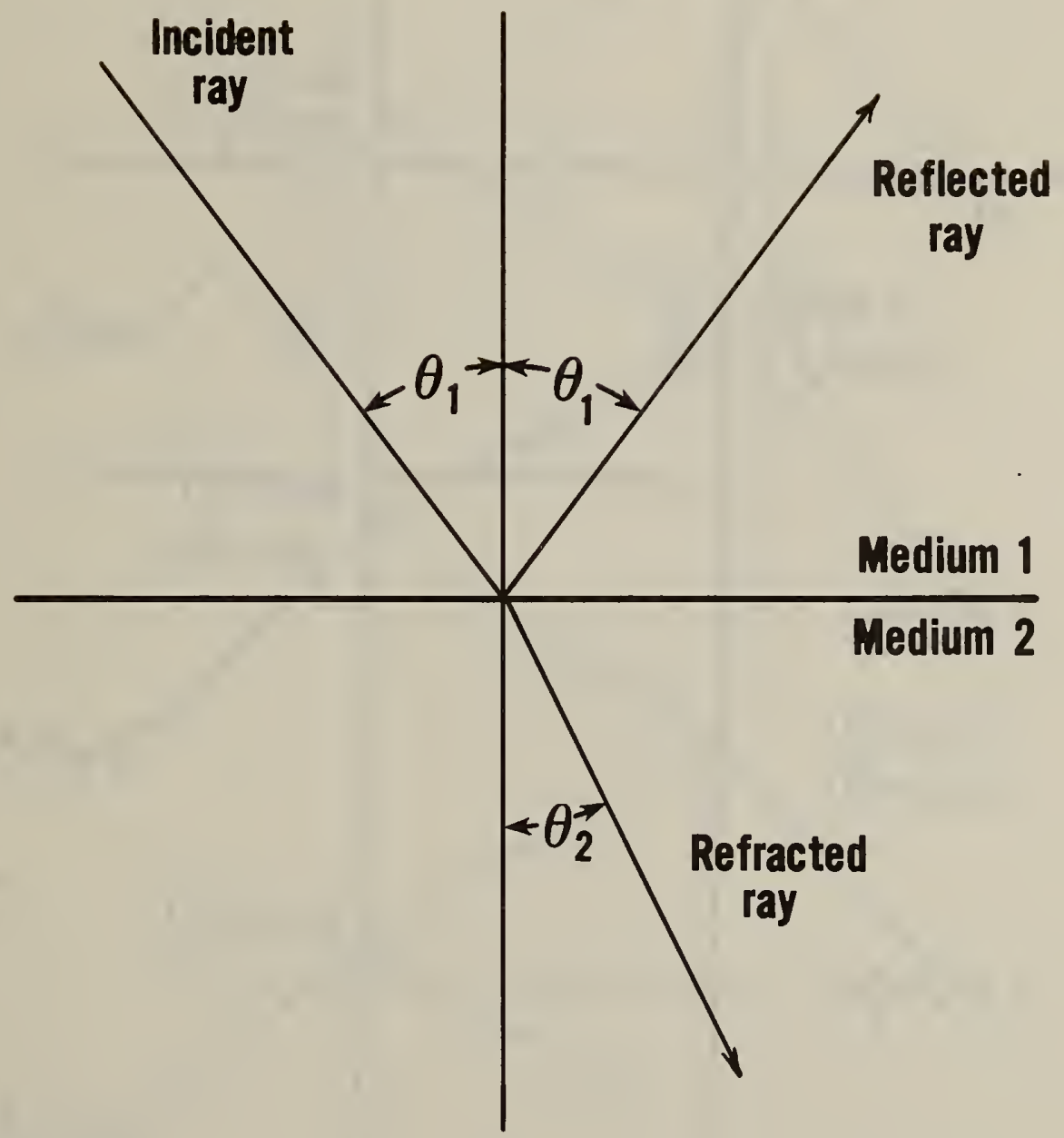

Figure III.D.2 Reflection and refraction at an interface 


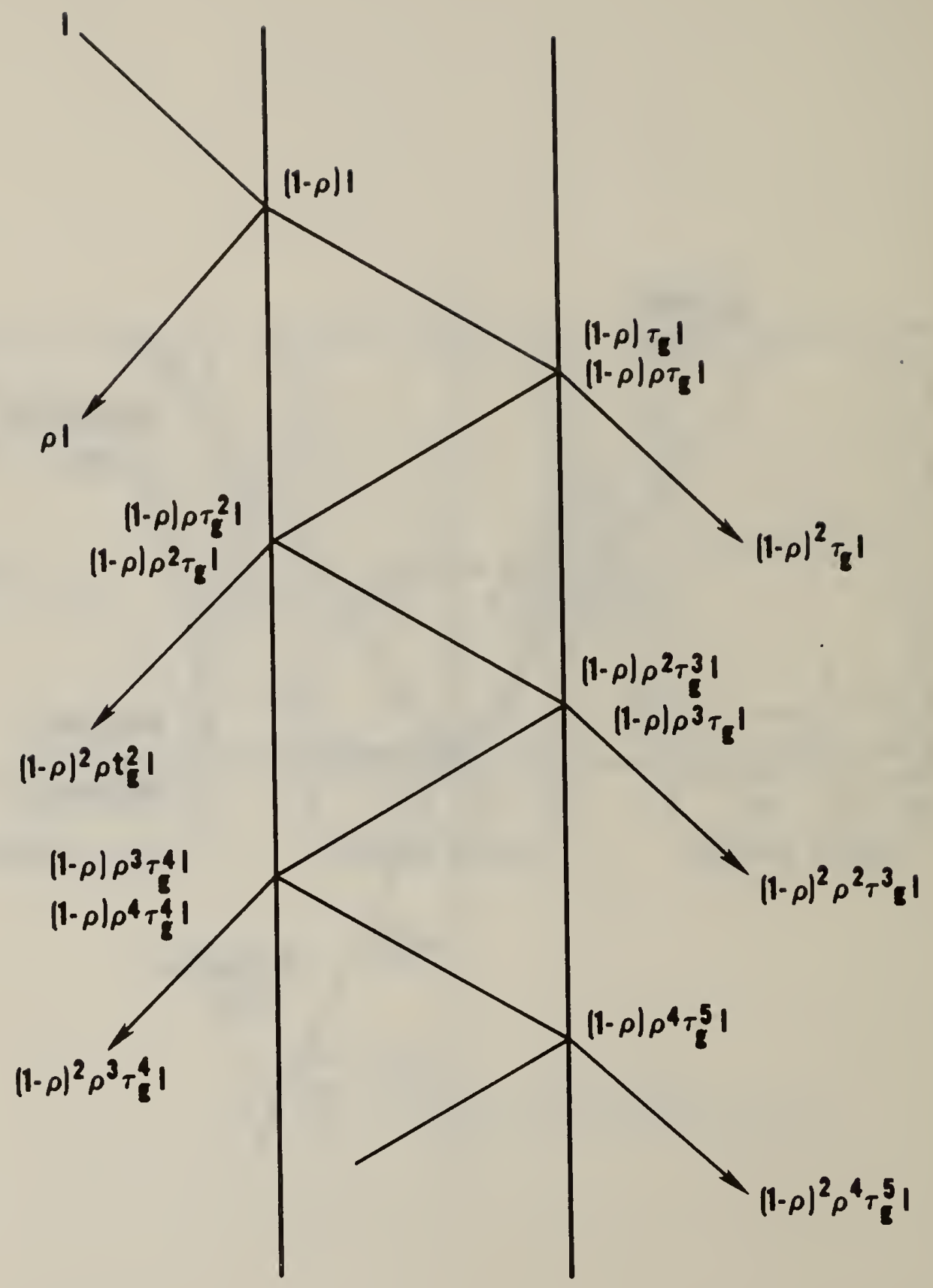

Figure III.D.3 Multiple reflections in a pane of glass 


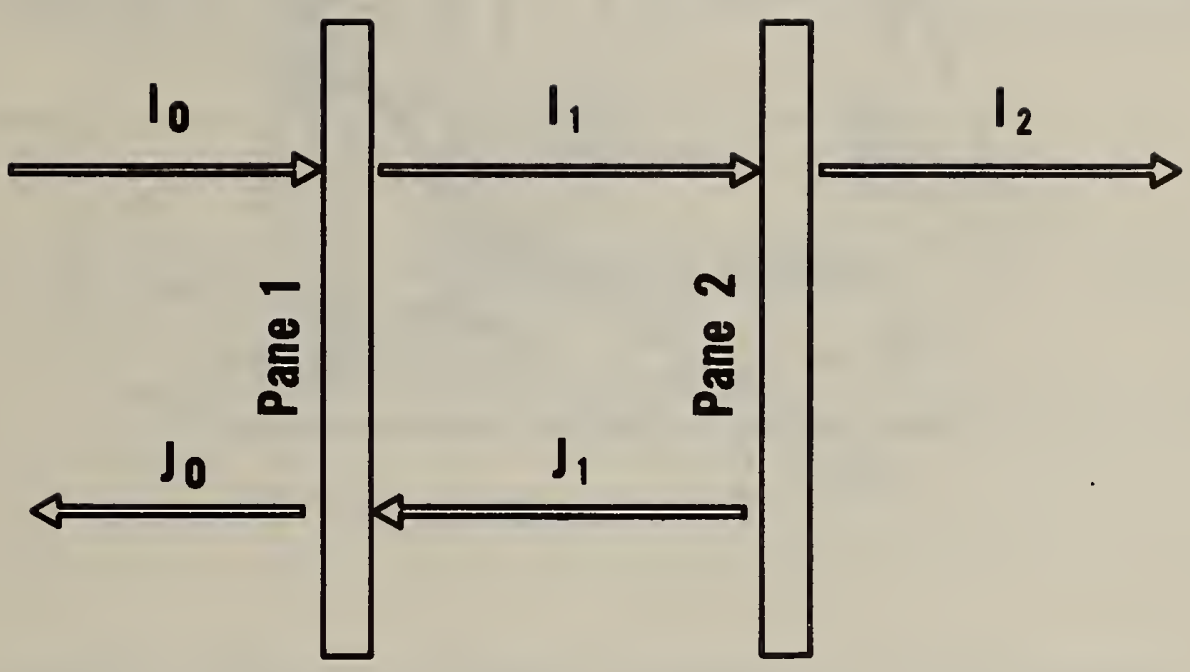

Figure III.D.4 Two-pane window system 


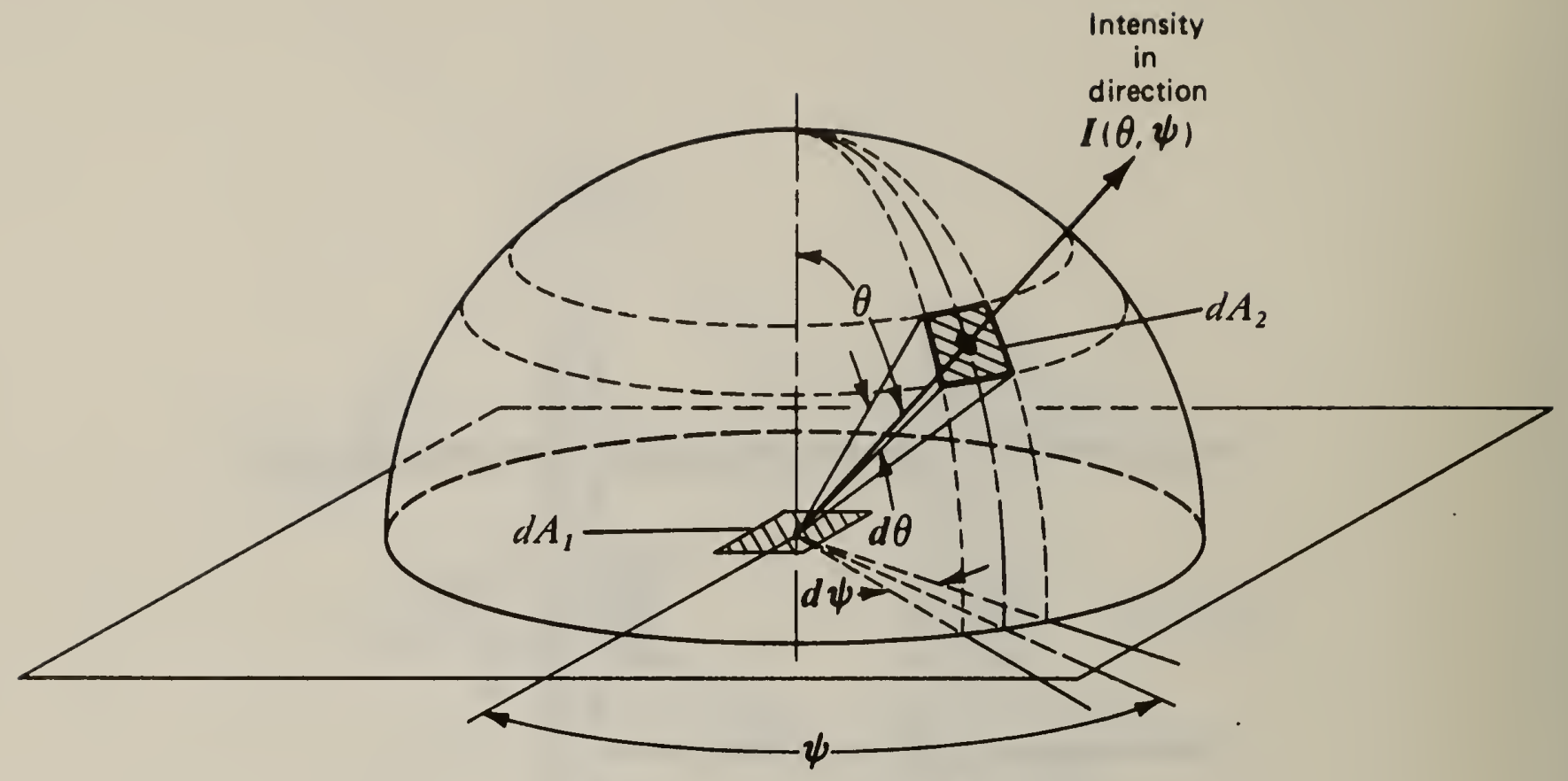

Figure III.D.5 Coordinate system for diffuse radiation 


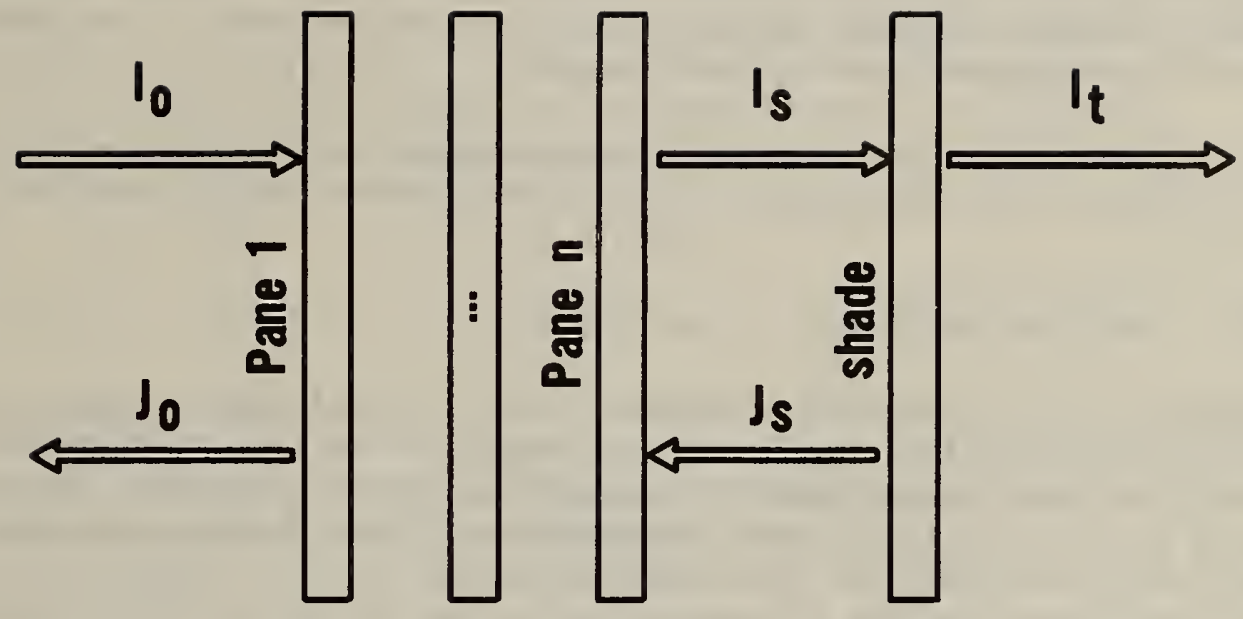

Figure III.D.6 Window system with interior shade 


\section{III.E SOLAR GAINS AND SHADOWING}

When assessing heat gains in bulldings due to solar radiation, it is necessary to know how much of each part of the bullding 1 s shaded and how much is in direct sunlight. As an example, figure E.l shows a flat roofed, L-shaped structure with a window in each of the visible sides. The sun is to the right so that walls 1 and 3 and windows a and $c$ are completely shaded, and wall 4 and window d are completely sunlit. Wall 2 and window b are partially shaded. The sunlit area of each surface changes as the position of the sun changes during the day. The purpose of the TARP shadow algorithm is to compute such sunlit areas.

The shadow algorithm is based on coordinate transformation methods similar to Groth and Lokmanhekim [1] and the shadow overlap method of Walton [2].

\section{III.E.1 SURFACE GEOMETRY}

Shadow calculations first require that the bullding surfaces be described geometrically. Surfaces are described by the coordinates of their vertices in a three dimensional Cartesian coordinate system. This "global" coordinate system has the X-axis pointing east, the Y-axis pointing north, and the $Z$-axis pointing up. The azlmuth angle $(\psi)$ of a surface is the angle froin the north axis to the projection onto the X-Y plane of a normal to the surface (clockwise positive). The surface tilt angle $(\phi)$ is the angle between the Z-axis and the normal to the surface. The vertices are recorded in counter-clockwise sequence (as the surface is viewed from outside its zone).

TARP input allows the user to specify a rotation of $\psi_{b}$ degrees of the "building" coordinate system from the global coordinate system. The global coordinates of zone orlgins are related to the bullding relative coordinates by

$$
\begin{array}{ll}
\mathrm{X}_{\mathrm{zO}}=\mathrm{X}_{\mathrm{br}} * \cos \psi_{\mathrm{b}}-\mathrm{Y}_{\mathrm{br}} * \sin \psi_{\mathrm{b}} & \text { (E.1.1a) } \\
\mathrm{Y}_{\mathrm{zO}}=\mathrm{X}_{\mathrm{br}} * \sin \psi_{\mathrm{b}}+\mathrm{Y}_{\mathrm{br}} * \cos \psi_{\mathrm{b}} & \text { (E.1.1b) } \\
\mathrm{Z}_{\mathrm{zO}}=\mathrm{Z}_{\mathrm{br}} & \text { (E.1.1c) }
\end{array}
$$

The user is also permitted to rotate a zone $\psi_{z}$ degrees relative to the building coordinate system. Origins of zone surfaces are then given realtive to the $z$ one coordinate system. The global coordinates of the surface origins are given by

$$
\begin{aligned}
& \mathrm{X}_{\mathrm{SO}}=\mathrm{X}_{\mathrm{ZO}}+\mathrm{X}_{\mathrm{Zr}} * \cos \psi_{\mathrm{z}}-\mathrm{Y}_{\mathrm{zr}} * \sin \psi_{\mathrm{Z}} \\
& \mathrm{Y}_{\mathrm{SO}}=\mathrm{Y}_{\mathrm{zO}}+\mathrm{X}_{\mathrm{zr}} * \sin \psi \mathrm{z}+\mathrm{Y}_{\mathrm{zr}} * \cos \psi_{\mathrm{Z}} \\
& \mathrm{Z}_{\mathrm{SO}}=\mathrm{Z}_{\mathrm{zO}}+\mathrm{Z}_{\mathrm{zr}}
\end{aligned}
$$


A surface azimuth angle relative to the zone coordinate system $\left(\psi_{8}\right)$ is converted to a global azimuth by

$$
\psi=\psi_{\mathrm{s}}+\psi_{\mathrm{z}}+\psi_{\mathrm{b}}
$$

The surface tilt angle $(\phi)$ is not changed by these rotations about the Z-axis.

The coordinates of the surface vertices are given in a coordinate system in the plane of the surface relative to the second vertex as shown for four surfaces in figure E.2. The X-axis of the surface coordinate system is a horizontal line through the second vertex. The global coordinates of the surface vertices are given by

$$
\begin{aligned}
& \mathrm{X}=\mathrm{X}_{\mathrm{SO}}-\mathrm{X}_{\mathrm{Sr}} * \cos \psi-\mathrm{Y}_{\mathrm{sr}} * \sin \psi * \cos \phi \\
& \mathrm{Y}=\mathrm{Y}_{\mathrm{SO}}+\mathrm{X}_{\mathrm{Sr}} * \sin \psi-\mathrm{Y}_{\mathrm{sr}} * \cos \psi * \cos \phi \\
& \mathrm{Z}=\mathrm{Z}_{\mathrm{SO}}+\mathrm{Y}_{\mathrm{sr}} * \sin \phi
\end{aligned}
$$

Vertices in the global coordinate system can be transformed to the coordinate system relative to a given surface by

$$
\begin{aligned}
& X^{\prime}=X-X_{\text {So }} \\
& Y^{\prime}=Y-Y_{S O} \\
& Z^{\prime}=Z-Z_{S o} \\
& X_{S r}=-X^{\prime} * \cos \psi+Y^{\prime} * \sin \psi \\
& Y_{S r}=-X^{\prime} * \sin \psi * \cos \phi-Y^{\prime} * \cos \psi * \cos \phi+Z^{\prime} * \sin \phi \\
& Z_{S r}=X^{\prime} * \sin \psi * \sin \phi+Y^{\prime} * \cos \psi * \sin \phi+Z^{\prime} * \cos \phi
\end{aligned}
$$

III.E. 2

\section{SHADOW PROJECTION}

All architectural forms are represented by plane polygons. This can give good accuracy even for curved surfaces: a sphere can be approximated by the 20 nodes of an icosohedron with only 3 percent error in the shadow area cast by the sphere. Consider how a solid object, which is composed of a set of enclosing plane polygons, casts a shadow. Figure E.3 shows a box shaped structure on a horizontal surface. The structure consists of a top (surface 1) and four vertical surfaces ( 2 and 3 visible to the observer and 4 and 5 not visible). The sun is positioned behind and to the right of the structure and a shadow is cast onto the horizontal surface (the ground). Surfaces 1, 4, and 5 are in sunlight; 2 and 3 are in shade. It is possible to think of the structure's shadow as the combination of shadows cast by surfaces $1,2,3,4$ and 5 or by 1,4 and 5 , or by surfaces 2 and 3 . This last combination of shadow casting surfaces is the simplest. In the TARP shadow algorithm every surface is considered to be one of the surfaces which 
enclose a solid, and only those surfaces which are not sunlit at a given hour are considered shadowing surfaces. surface:

The expressions in eq (E.1.6f) are the direction cosines of the

$$
\begin{aligned}
& \mathrm{CW}_{1}=\sin \psi * \sin \phi \\
& \mathrm{CW}_{2}=\cos \psi * \sin \phi \\
& \mathrm{CW}_{3}=\cos \phi
\end{aligned}
$$

The cosine of the angle of incidence of the sun's rays on the surface are given by the dot product of surface and sun (B.3.3) direction cosines.

$$
\cos \theta=\mathrm{CS}_{1} * \mathrm{CW}_{1}+\mathrm{CS}_{2} * \mathrm{CW}_{2}+\mathrm{CS}_{3} * \mathrm{CW}_{3}
$$

If $\cos \theta$ is less than zero, the sun is behind the surface.

A shadow is projected from the vertices of the shadowing surface (SS) along the direction of the sun's rays to the plane of the shadow recelving surface (RS). If any vertices of the SS are below the plane of the RS $(z<0)$, a false shadow is cast as in figure E.3. The "submerged" portion of the SS must be clipped off before projection. This is done by finding, through Iinear interpolation, the points on the perfmeter of the SS which intersect the plane of the RS. These points become new vertices of the SS, which together with the other positive vertices define a clipped SS which casts only a real shadow.

A vertex located at $(x, y, z)$ relative to the RS coordinate system casts a shadow to a point in the plane of the RS given by

where

$$
\begin{aligned}
& x^{\prime}=x-z * a / \cos \theta \\
& y^{\prime}=y-z * b / \cos \theta
\end{aligned}
$$

and

$$
\mathrm{a}=\sin \psi * \mathrm{Cs}_{1}-\cos \psi * \mathrm{Cs}_{2}
$$

$\mathrm{b}=-\cos \psi * \cos \phi * \operatorname{cs}_{1}-\sin \psi * \cos \phi * \operatorname{cs}_{2}+\sin \phi * \operatorname{cs}_{3}$

\section{III.E.3 HOMOGENEOUS COORDINATES}

Two-dimensional homogeneous coordinate techniques are used to determine the vertices of shadow overlaps. In homogeneous coordinates, points and lines are represented by a single form which allows simple vector operations between those forms [3]. A point $(X, Y)$ is represented by a three element vector $(\mathrm{x}, \mathrm{y}, \mathrm{w})$ where $\mathrm{x}=\mathrm{w}^{*} \mathrm{X}, \mathrm{y}=\mathrm{w}^{*} \mathrm{Y}$, and $\mathrm{w}$ is any real number except zero. $\mathrm{A}$ line is also represented by a three element vector $(a, b, c)$. The directed line $(a, b, c)$ from point $\left(x_{1}, y_{1}, w_{1}\right)$ to point $\left(x_{2}, y_{2}, w_{2}\right)$ is given by

$$
(a, b, c)=\left(x_{1}, y_{1}, w_{1}\right) \operatorname{cross}\left(x_{2}, y_{2}, w_{2}\right)
$$


The sequence in the cross product is a convention to determine sign. The condition that a point $(x, y, w)$ lie on a line $(a, b, c)$ is that

$$
(a, b, c) \operatorname{dot}(x, y, w)=0
$$

Normalize the representation of a point by dividing by $w$. Then if

$$
(\mathrm{a}, \mathrm{b}, \mathrm{c}) \operatorname{dot}(\mathrm{x} / \mathrm{w}, \mathrm{y} / \mathrm{w}, 1)>0
$$

the point is to the left of the line, and if it is less than zero, the point is to the right of the line. The intercept $(x, y, w)$ of line $\left(a_{1}, b_{1}, c_{1}\right)$ and line $\left(a_{2}, b_{2}, c_{2}\right)$ is given by

$$
(x, y, w)=\left(a_{1}, b_{1}, c_{1}\right) \operatorname{cross}\left(a_{2}, b_{2}, c_{2}\right)
$$

Note that the use of homogeneous coordinates as outlined above provides a consistant method and notation for defining points and lines, for determining intercepts, and for determining whether a point lies to the left, to the right, or on a line. Normalization provides the means for transforming to and from homogeneous notation and Cartesian coordinates. Thus, if $(X, Y)$ is a Cartesian coordinate pair, its homogeneous coordinates are $(X, Y, 1)$. Similarly, the homogeneous coordinates $(x, y, w)$ can be transformed to the Cartesian point with coordinates $(x / w, y / w)$.

\section{III.E.4 OVERLAPPING SHADOWS}

After transforming the shadows onto the plane of the receiving surface, the basic job of the shadow algorithm is to determine the area of the overlap between the polygons representing the shadows and the polygon representing the receiving surface.

There is considerable simplification if only convex (no interior angle $>180$ ) polygons are considered. The overlap between two convex polygons is another convex polygon. Coordinate and projection transformations of a convex polygon produce another convex polygon. Any non-convex polygon can be constructed as a sum of convex ones.

The vertices which define the overlap between two convex polygons, A and $B$, consist of:

1) the vertices of $A$ enclosed by $B$,

2) the vertices of $B$ enclosed by $A$,

3) and the intercepts of the sides of $A$ with the sides of $B$.

In figure E.4a point $a$ is the result of rule 1 , point $c$ is the result of rule 2 , and points $b$ and $d$ result from rule 3 . The overlap of $A$ and $B$ is the polygon $a-b-c-d$. Figure $E .4 b$ shows an overlap where all of the vertices of $A$ are enclosed by $B$. Figure $E .4 C$ shows an overlap defined only by the intercepts of $A$ and $B$. Figure E.4d shows a more complex overlap. 
Coordinate transformation retains the order of the vertices of a polygon, while a projection reverses the order. The sequence of vertices of the recelving polygons should be reversed so 1 t and all shadow polygons will have the same sequence.

A point is enclosed by a clockwise, convex polygon if it lies to the right of all sides (or does not lie to the left of any side) of the polygon. The intercept of two sides may not lie beyond the ends of elther side. These are "Ilne segments" rather than "lines". It is possible to tell if line segments $A$ and $B$ intercept within their end points by noting that the ends of A must 11e on both sldes of $B$, and the ends of $B$ must 11 e on both sides of $A$ as shown in figure E.5. This should be done before the intercept is calculated.

Once the vertices are determined, they must be sorted into clockwise order for the area to be computed. Given a plane polygon of $n$ sequential vertices $\left(x_{1}, y_{1}\right),\left(x_{2}, y_{2}\right), \ldots,\left(x_{n}, y_{n}\right)$, 1ts area is given by [4]

$$
A=\left(x_{1} y_{2}+x_{2} y_{3}+\ldots+x_{n-1} y_{n}+x_{n} y_{1}-y_{1} x_{2}-y_{2} x_{3}-\ldots-y_{n} x_{1}\right) / 2
$$

The area is positive if the vertices are counter-clockwise and negative if they are clockwise.

If two shadows overlap the recelving surface, they may also overlap each other as in figure E.6. The vertices of this overlap can be computed. The areas of all overlaps can be computed. The total sunlit area can be expressed as the sum of all polygon areas given a proper sign on each of the areas. The following convention was adopted:

recelving surface

overlap between shadow and recelving overlap between two shadows

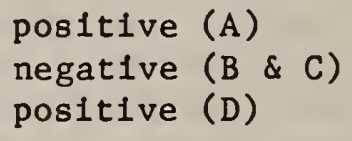

positive (A)

positive (D)

and so on through multiple overlaps where the sign of the overlap area is the product of the slgns of the overlapping areas.

Partially transparent shadowing surfaces can also be modeled by giving a transparency $(\tau)$ to every shadowing polygon. Let $\tau$ of the recelving polygon be one. Then the $\tau$ of every overlap of polygons 1 and $j$ is the product of $\tau_{1}$ and $\tau_{j}$. The shaded area 1 s then computed by summing $A_{1} *\left(1-\tau_{1}\right)$ for all overlap polygons.

It is easy to determine the sunlit area of a window once all the shadow and overlap vertices on the wall have been computed. Consider wall 2 of figure E.1. First the wall is considered a simple rectangle and the window on it is ignored. The shadow overlapping is performed and the sunlit portion of the gross wall area is computed. Then the window rectangle is overlapped with the shadow to determine 1 ts sunlit area. The sunlit area of the window is subtracted from the gross wall sunlit area to determine the net wall sunlit 
area. During this calculation it is not necessary to recompute the shadows, because they were precisely determined on the wall.

\section{III.E.5 SOLAR GAINS}

The total solar gain on any exterior surface is a combination of the absorption of direct and diffuse solar radiation given by

$$
\mathrm{QSO}=\alpha *\left(I_{\mathrm{b}} * \cos \theta * \mathrm{~S}_{\mathrm{s}} / \mathrm{S}+\mathrm{I}_{\mathrm{s}} * \mathrm{~F}_{\mathrm{SS}}+\mathrm{I}_{\mathrm{g}} * \mathrm{~F}_{\mathrm{sg}}\right)
$$

where

$$
\begin{aligned}
& \alpha=\text { solar absorptance of the surface } \\
& \theta \quad=\text { angle of incidence of the sun's rays } \\
& \mathrm{S}=\text { area of the surface } \\
& \mathrm{S}_{\mathrm{s}}=\text { sunlit area } \\
& \mathrm{I}_{\mathrm{b}}=\text { intensity of beam (direct) radiation } \\
& \mathrm{I}_{\mathrm{S}}=\text { intensity of sky diffuse radiation } \\
& \mathrm{I}_{\mathrm{g}}=\text { intensity of ground reflected diffuse radiation } \\
& \mathrm{F}_{\mathrm{S}}=\text { angle factor between the surface and the sky } \\
& \mathrm{F}_{\mathrm{Sg}}=\text { angle factor between the surface and the ground }
\end{aligned}
$$

For the surface of a building located on a featureless plain

and

$$
\mathrm{F}_{\mathrm{SS}}=(1+\cos \phi) / 2
$$

$$
\mathrm{F}_{\mathrm{Sg}}=(1-\cos \phi) / 2
$$

These values can be modified by the user.

For a window the absorptance, $\alpha$, is divided into components $\alpha_{b}$ (for beam radiation) and $\alpha_{d}$ (for diffuse radiation) as described in section D. A similar expression describes the transmittance of solar radiation into the zone. In its default mode, TARP assumes that all transmitted beam radiation is incident on the floor. The floor absorbs a fraction of that radiation equal to the floor inside solar absorptance. The unabsorbed portion of the beam radiation is combined with the diffuse radiation and then evenly distributed over all surfaces as described in section F.2. In the detailed mode, TARP computes the beam radiation distribution on all surfaces.

\section{REFERENCES}

[1] Groth, C. C., and Lokmanhekim, M., "Shadow - A New Technique for the Calculation of Shadow Shapes and Areas by Digital Computer, "Second Hawaii International Conference on System Sciences, (Honolulu, HI, January 22-24, 1969).

[2] Walton, G. N., "The Application of Homogeneous Coordinates to Shadowing Calculations", ASHRAE Transactions, Vol 84 (ASHRAE, 1978), Part I.

[3] Newman, M. W., and Sproul, R. F., Principles of Interactive Computer Graphics, (McGraw-Hi11, 1973).

[4] Selby, S. M., ed., Standard Mathematical Tables, 22nd Edition, (CRC Press, 1974) p 369. 

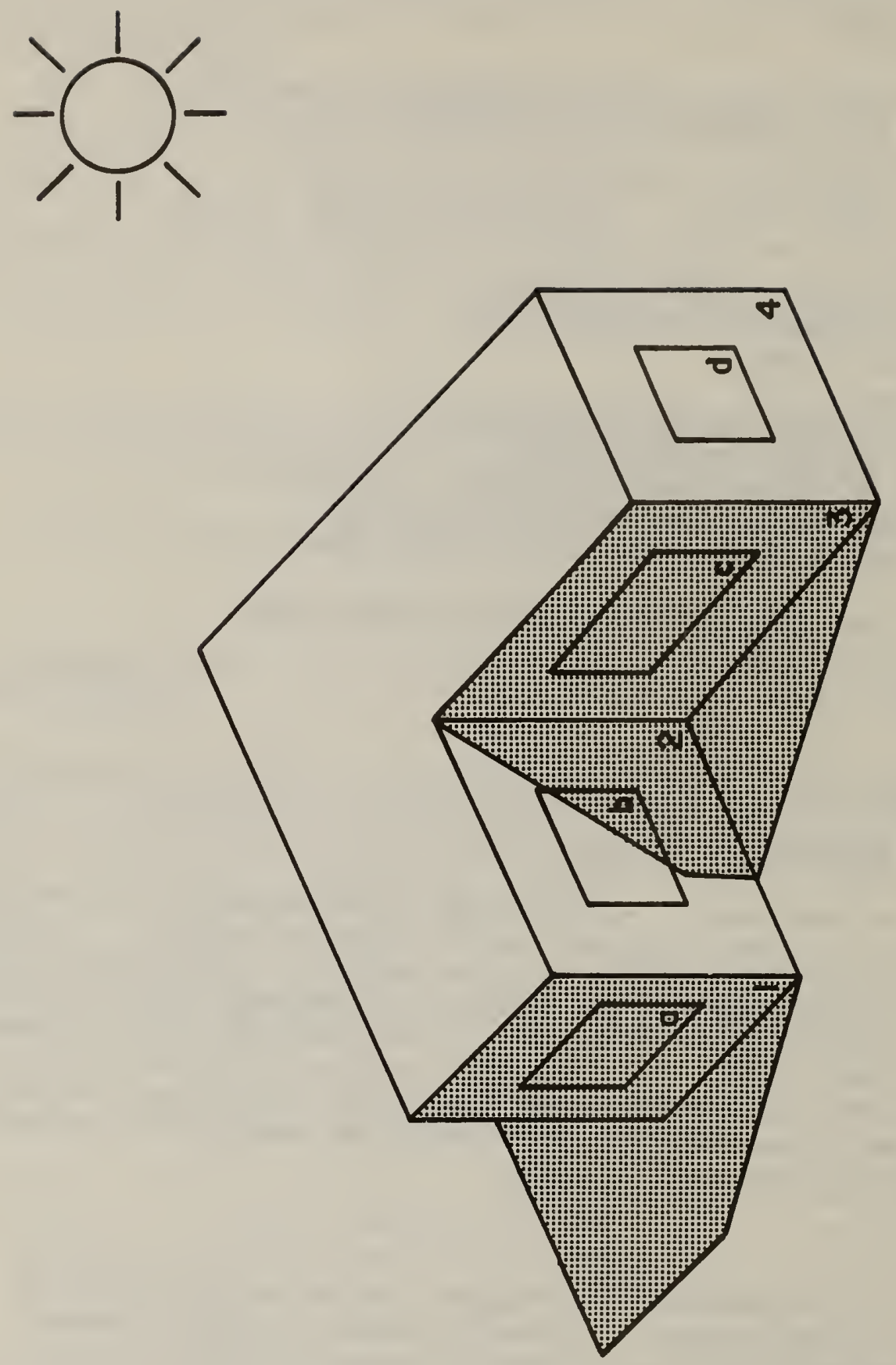

 


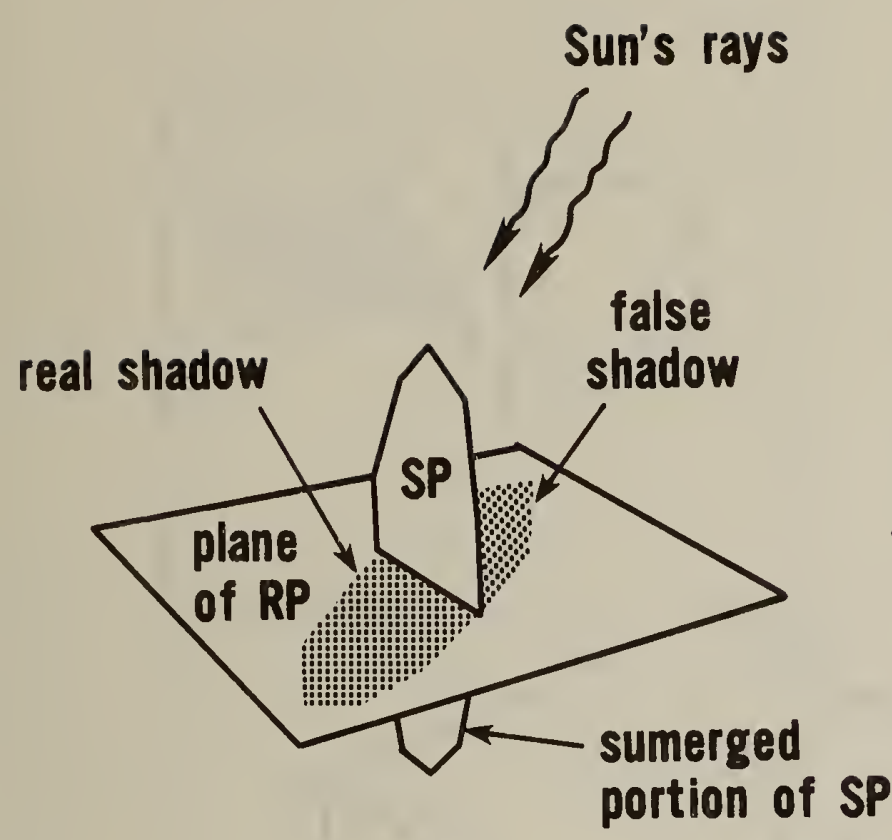

BEFORE CLIPPING

\section{real}

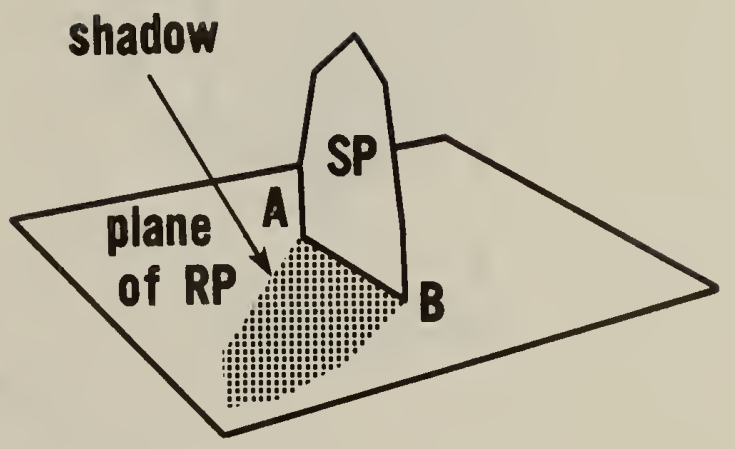

Sun's rays

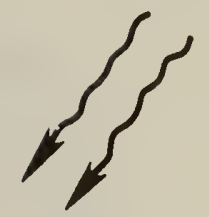

.



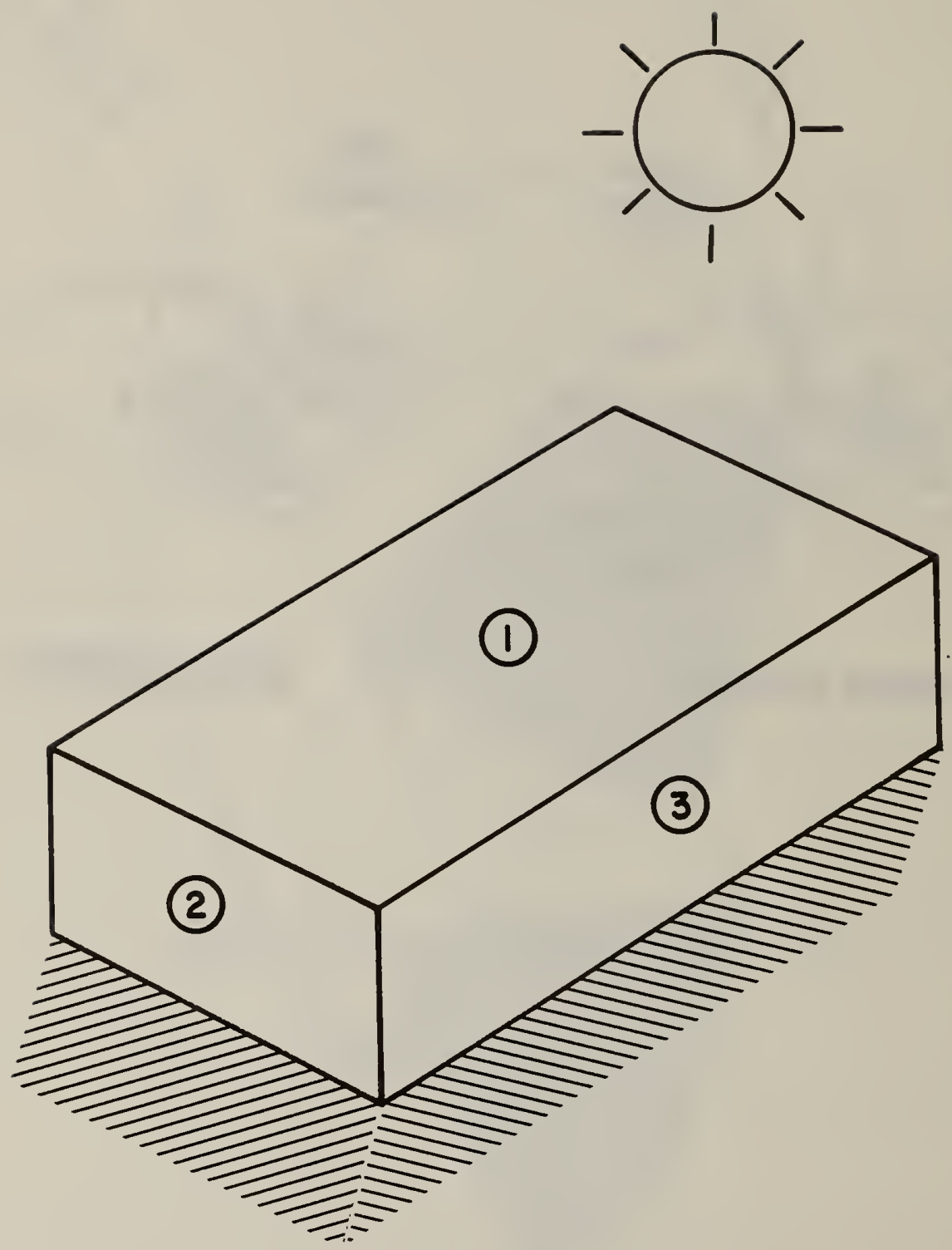

Figure III.E.3 Shadow casting surfaces 


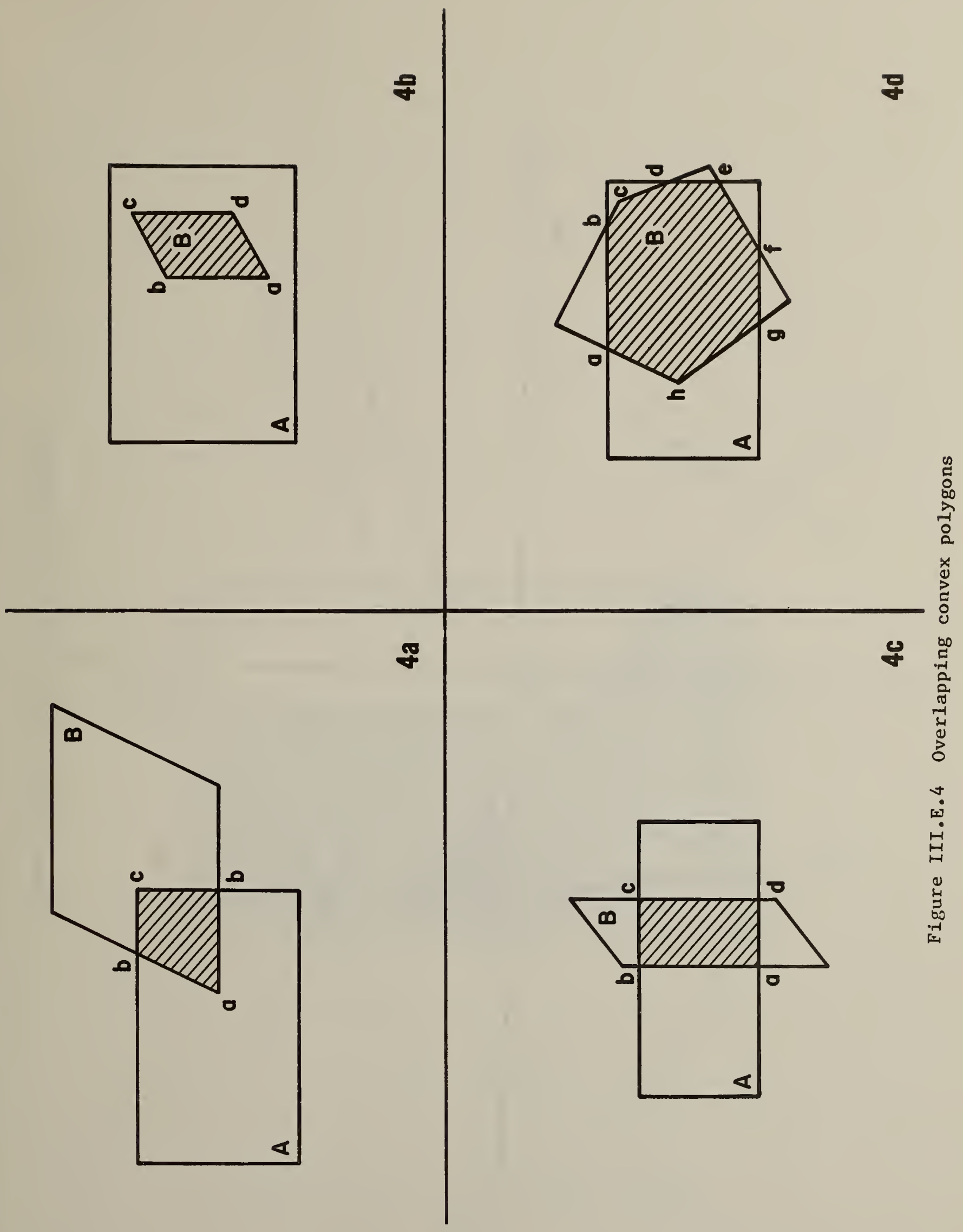




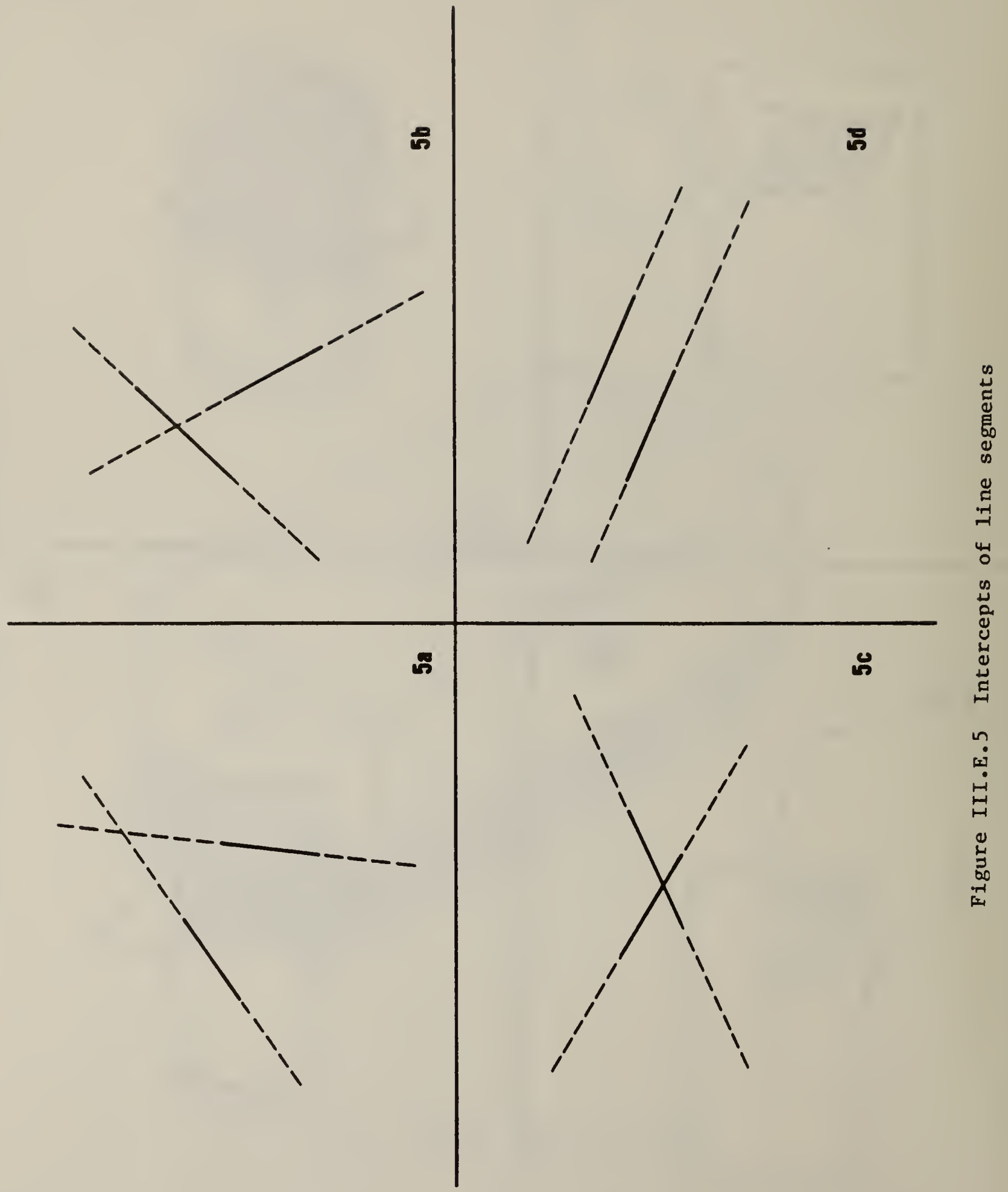




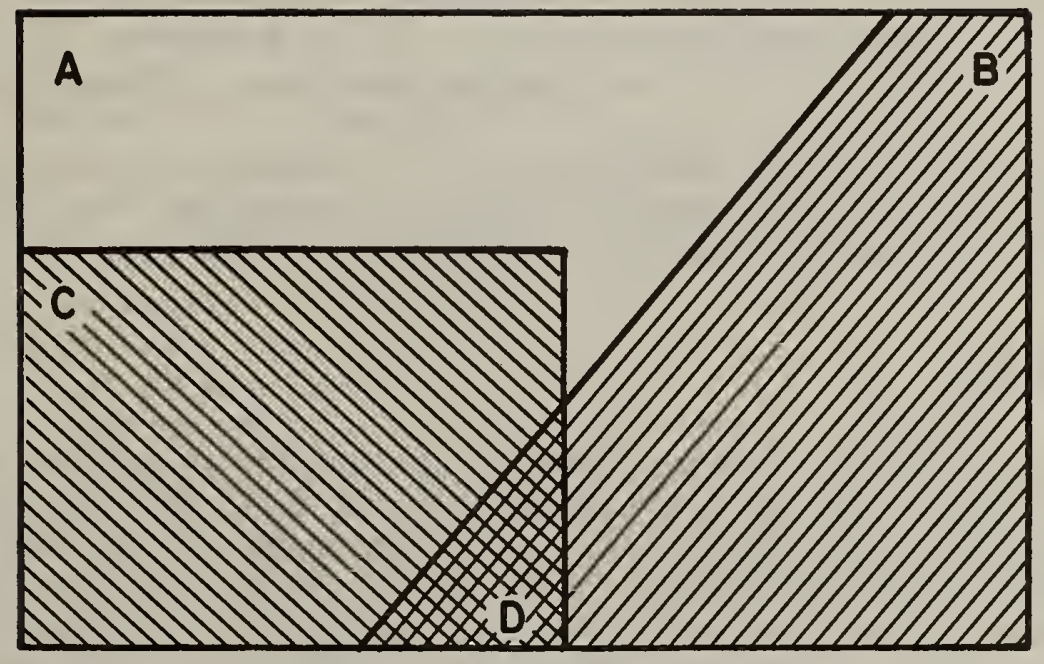

Figure III.E.6 Multiple shadow overlaps 
Internal heat gains from 11ghts, people, and equipment of various types are usually significant elements in the zone thermal balance. TARP allows the user to specify heat gains from equipment of various types, lights, occupants, and baseboard heat controlled by outdoor temperature. The total heat gain is made up of convective, radiant, and latent gains in various proportions from each of these sources. Convective gains are instantaneous additions of heat to the zone air. Radiant gains are distributed on the surfaces of the zone, where they are first absorbed and then released back into the room (and some fraction conducted through the surface) according to the surface heat balances (section I). Latent galns must be handled by ventilation or air conditioning equipment. Recommended heat gains for many items of equipment are given by ASHRAE [1]. These recommendations include the sensible (convective plus radiative) and latent proportions. Sensible gains from equipment are predominately radiant. The user can specify the heat gains and proportions appropriate for any type of equipment. The gains from lights, people, and baseboard heat are slightly more complicated.

\section{III.F.1.1 LIGHTS}

Radiant gains from lights must be handled differently from other radiant gains for reasons described in F.2. It is necessary to divide the total radiant gains into visible and thermal portions. The total electric input to typical incandescent lights is converted into 10 percent visible radiation, 80 percent thermal radiation and 10 pecent convective gain. The electric input to typical flourescent lights is converted into 20 percent visible radiation, 20 percent thermal radiation, and 60 percent convective gain [2].

\section{III.E.1.2 PEOPLE}

Heat is generated in the human body by oxidation at a rate called the metabolic rate. This heat is dissipated from the body surface and respiratory tract by a combination of radiation, convection, and evaporation. The relative portions of sensible (radiation plus convection) and latent (evaporation) heat from people is a complex function of the metabolic rate and environmental conditions. TARP uses a polynomial function to divide the total metabolic heat gain into sensible and latent portions. That function is based upon a fit to data [3] at average adjusted metabolic rates of $350,400,450,500,750,850,1000$, and $1450 \mathrm{Btu} / \mathrm{h}$ each at temperatures of $70,75,78,80$, and $82 \mathrm{~F}$. Sensible gains of 0 at $96 \mathrm{~F}$ and sensible gains equal to the metabolic rate at $30 \mathrm{~F}$ were assumed in order to give reasonable values beyond the reported temperature range. The original data for the polynomial was in English units, but the following correlation is in metric units. 


$$
\begin{aligned}
\mathrm{S} & =6.461927+.946892 * \mathrm{M}+.0000255737 * \mathrm{M}^{2} \\
& +7.139322 * \mathrm{~T}-.0627909 * \mathrm{~T} * \mathrm{M}+.0000589172 * \mathrm{~T} * \mathrm{M}^{2} \\
& -.198550 * \mathrm{~T}^{2}+.000940018 * \mathrm{~T}^{2} * \mathrm{M}-.00000149532 * \mathrm{~T}^{2} * \mathrm{M}^{2}
\end{aligned}
$$

where

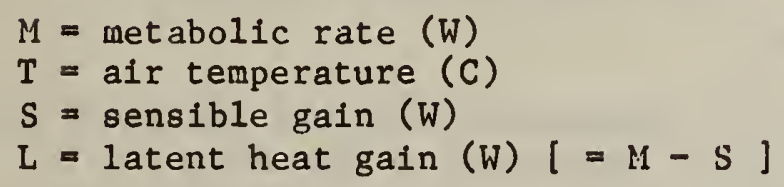

This function is compared to the original data points in figure F.1. The radiant fraction of the sensible gain is determined by the user.

\section{III.F.1.3 BASEBOARD HEAT}

Outdoor temperature controlled baseboard heat adds energy to the zone according a control profile as in figure $\mathrm{F} .2$. At $\mathrm{T}_{\mathrm{a}}=\mathrm{T}_{2}$, the baseboard heat gain is $Q_{2}$. For $T_{a}>T_{2}$, there is no heat gain. For $T_{a}<T_{1}$, a naximum amount of energy, $\mathrm{Q}_{1}$, is added to the zone. There is proportional control between those temperatures:

$$
Q=Q_{2}-\left(Q_{2}-Q_{1}\right) *\left(T_{2}-T_{a}\right) /\left(T_{2}-T_{1}\right)
$$

\section{III.F.2 DISTRIBUTION OF RADIANT GAINS}

It is useful to consider the distribution of short wavelength (including visible) radiant energy separate from long wavelength (thermal) radiant energy because many materials have different optical porperties at the different wavelenghts. An extreme example is glass which is opaque to the long wavelengths and transparent to the short. Properties of materials vary across the entire spectrum of wavelengths. In TARP, all radiant

interactions are represented in terms of only two wavelengths: "short" and "long". Short wavelength refers to the distribution given by a $\sim 6000 \mathrm{~K}$ black body source such as the sun. Long wavelengths refer to radiation from $\sim 300 \mathrm{~K}$ sources such as walls or people. there is negligible overlap between these two distributions. Solne sources, such as lights, must be considered as emitting both long and short wavelength radiation in proportions which approximate their actual effects on room surfaces.

Long wavelength radiation from all internal sources, such as people, lights, and equipment, is combined and then uniformly distributed over all surfaces according to $(\mathrm{H}, 2.5)$.

Some fraction of the beam solar radiation transmitted into the zone is directly absorbed by the interior surfaces according to the solar distribution algorithm (3.1.5) selected by the user. The beam radiation not directly absorbed, plus the diffuse sky and ground-reflected radiation, plus the short wavelength radiation from lights are combined and distributed over the surfaces of the zone according to: 


$$
Q S I_{1}=Q S_{n} * \alpha_{1} / \sum_{1=1}^{N S} S_{1} *\left(1-\rho_{1}\right)
$$

If all surfaces of the room are opaque, the radiation is distributed in proportion to the area*absorptance product of each surface. For surfaces which are transparent, $\rho_{1}=1-\alpha_{1}-\tau_{1}$. That fraction of radiation represented by $\tau_{1}$ is lost from the zone.

The transmittance and absorptance of transparent surfaces (windows) are calculated as in section $D$ based on optical properties of the window material layers. The total absorptance of the window $1 \mathrm{~s}$ computed for the interior shading device, the inside surface, and the outside surface for diffuse solar radiation incident froin outside the zone. Those absorptances are used for short wavelength radiation incident from inside the zone. In most cases, this should not cause significant error. When movable insulation covers the window, the radiation which would have been transmitted is absorbed at the outer surface of the window (thermally equal to the inside surface of the insulation).

\section{REFERENCES}

[1] ASHRAE Handbook - 1981 Fundamentals (ASHRAE, 1981), pp 26.26-26.28.

[2] Handbook of Air Conditioning System Design (Carrier Air Conditioning Company, McGraw H111, 1965), pp 1-99 to 1-100.

[3] Handbook of Air Conditioning System Design (Carrier Air Conditioning Company, McGraw H111, 1965), p 1-100, Table 48. 


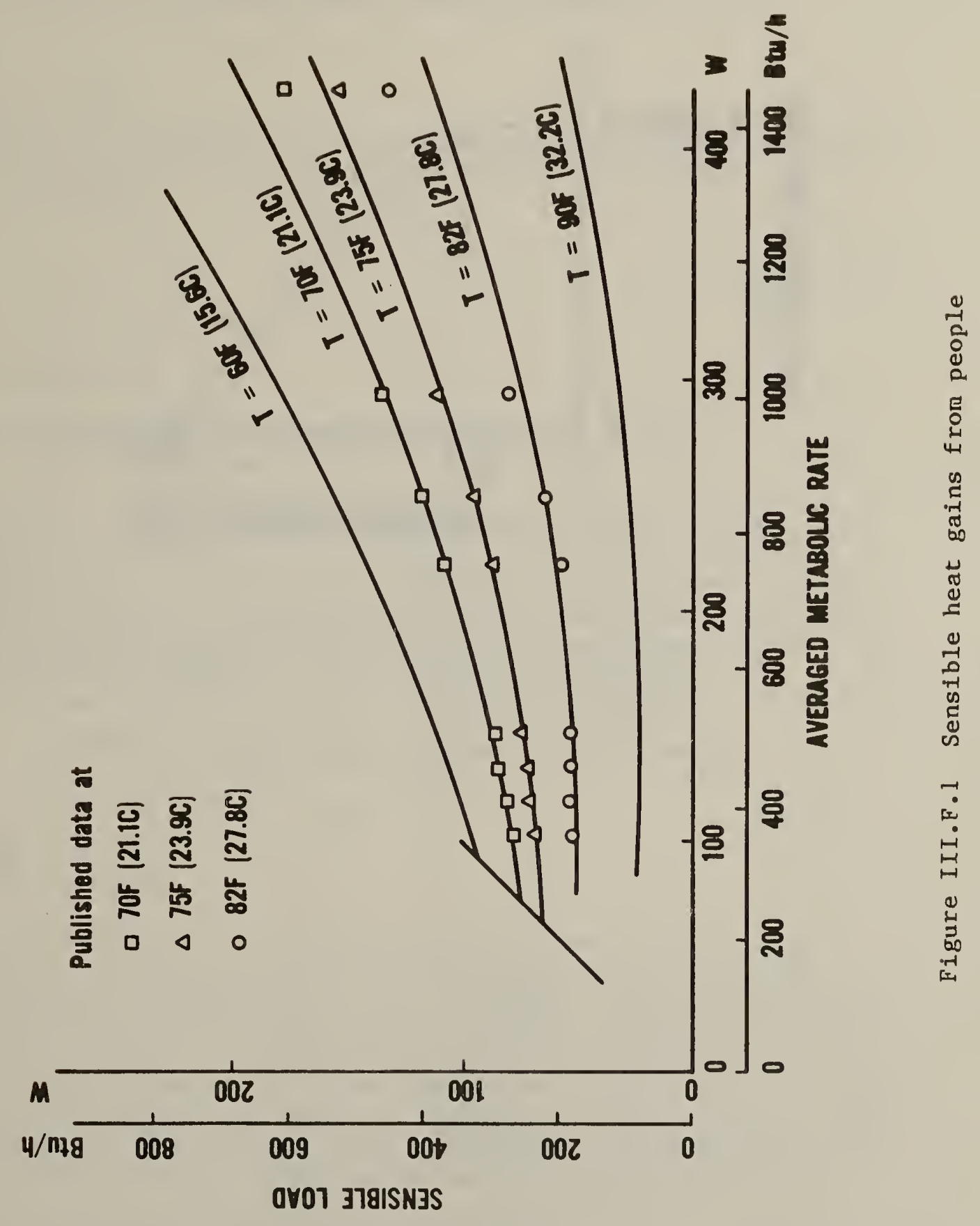




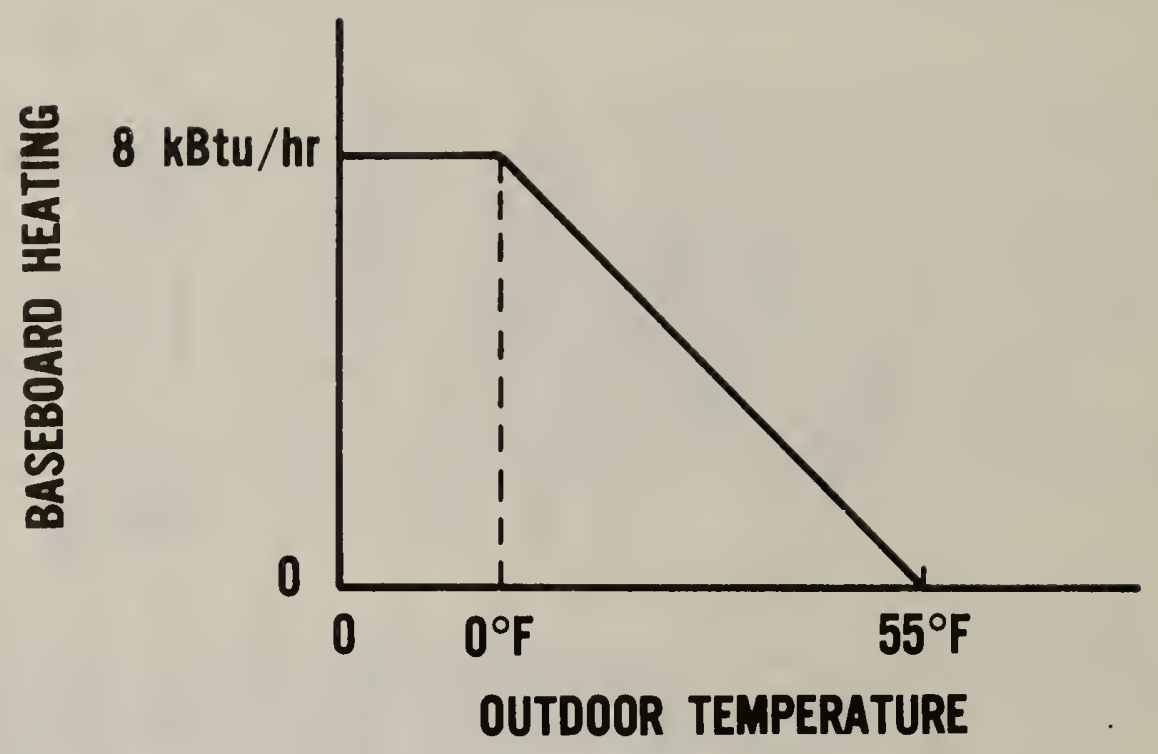

Figure III.F.2 Baseboard heat control profile 
Most building surfaces contain openings, either large or small, which permit the movement of air through them whenever there is a pressure difference across the surface. Pressure differences arise from naturally occurring wind and thermal forces. The following discussion of air movements emphasizes the relationships to basic principles of fluid mechanics.

III.G. 1 WIND FORCES

Wind pressures on surfaces are proportional to the velocity head of the undisturbed air stream [1]. The wind pressure is thus calculated from Bernoulli's equation as

$$
\mathrm{PW}_{1}^{\prime}=0.5 * \mathrm{D}_{\mathrm{a}} * \mathrm{~V}^{2}
$$

The density of air is given by

$$
\mathrm{D}_{\mathrm{a}}=0.0034838 * \mathrm{~PB} / \underline{\mathrm{T}_{\mathrm{a}}}
$$

The wind speed is evaluated at the highest point of the surface using the wind speed to height correlation (B.3.1).

Wind direction effects are dependent on the building's configuration and its relationship to surrounding structures. No single correlation can truly model directional effects on all buildings or even the effects on a single building in different environments. The following correlation is a compromise derived by averaging several published correlations [2, 3 ]. It accounts for the trends observed in wind pressure measurements. Let $\mathrm{Y}=$ angle of incidence of wind on the surface $(0<=\mathrm{Y}<=180$.

$$
\begin{aligned}
& \operatorname{If}(\mathrm{Y}<=90 .) \quad \mathrm{PW}_{1}=(.75-1.05 * \mathrm{Y} / 90 .) * \mathrm{PW}_{\mathrm{I}}{ }^{\prime} \\
& \operatorname{If}(\mathrm{Y}>=90 .) \quad \mathrm{PW}_{1}=(0.15 * \mathrm{Y} / 90 .-.45) * \mathrm{PW}_{\mathrm{I}}{ }^{\prime}
\end{aligned}
$$

\section{III.G.2 THERMAL FORCES}

Temperature differences cause air density differences which cause bouyancy (or "stack") effects. The magnitude of the force on a submerged surface (all surfaces are submerged in air) is equal to the area times the pressure at the centroid of the area. It is therefore necessary to know the pressure at the centroids and the locations of those centroids. The effect of air density on the pressure on any surface can be considered by a single simple formula. The pressure at height $\mathrm{Zl}$ is equal to the pressure at height Z2 plus fluid density times the graviational constant $\left(9.80 \mathrm{~m} / \mathrm{s}^{2}\right)$ times ( $\mathrm{Z2}$ Z1). Figure G.1 shows a surface separating two vertically adjacent zones.

The pressure difference $(\Delta P)$ across the surface 1 s $P j-P i$. It is more useful to know this $\Delta \mathrm{P}$ in terms of zone pressures $\mathrm{Pm}$ and $\mathrm{Pn}$ : 


$$
\begin{aligned}
& P_{j}=P_{m}+D_{m} * g *\left(Z_{m}-Z_{j}\right) \\
& P_{1}=P_{n}+D_{n} * g *\left(Z_{n}-Z_{1}\right)
\end{aligned}
$$

The same formulae apply to a vertical surface as in figure G.2. They also apply to an envelope surface where $P_{j}$ is the pressure of the outside a1r (figure G.3). Ambient alr variables are substituted for the zone m variables:

$$
P_{j}=P_{a}+D_{a} * g *\left(Z_{a}-Z_{j}\right)
$$

$Z_{a}$ is the reference height for air pressure measurements. Its location is arbitrary. The zone reference heights, $z_{n}$ and $z_{m}$, are also arbitrary. All are chosen for convenient or physically meaningful representation.

The pressure difference across surface $i$ is

where

$$
\begin{aligned}
\Delta P & =P_{j}-P_{1} \\
& =P_{m}-P_{n}+D_{m} * g *\left(Z_{m}-Z_{j}\right)-D_{n} * g *\left(Z_{n}-Z_{i}\right) \\
& =P_{m}-P_{n}+P S_{i}
\end{aligned}
$$

$$
\mathrm{PS}_{\mathrm{i}}=\mathrm{D}_{\mathrm{m}} * \mathrm{~g} *\left(Z_{\mathrm{m}}-\mathrm{Z}_{\mathrm{j}}\right)-\mathrm{D}_{\mathrm{n}} * \mathrm{~g} *\left(\mathrm{Z}_{\mathrm{n}}-\mathrm{Z}_{\mathrm{i}}\right)
$$

is the "stack pressure" on surface 1 .

The height of the centrold of a triangle or rectangle is the average of the heights of the vertices. Since the stack effect also occurs within the thickness of a horizontal surface and since it is necessary to leave no building internal height unaccounted, $z_{1}$ and $z_{j}$ in figure $G .1$ should both be replaced by their average.

\section{III.G.3 FLOW EQUATIONS} equation

The flow through small openings in a surface is based on the orifice

$$
\mathrm{F}=\mathrm{C} * \mathrm{~A} * \mathrm{D} * \sqrt{2 * \Delta \mathrm{P} / \mathrm{D}}
$$

where $A$ is the observed opening area and where the flow coefficient, $C$, is a function of the Reynolds number and the ratio of the opening size to the entire surface. When the opening is small, $C$ equals 0.6 for a wide range of Reynolds numbers [4]. TARP assumes this value of C. The user may modify $C$ by using an effective flow area (FA) which differs fron the actual proportional opening area. Experimental results indicate that flow through real surfaces is a combination of orifice flow $(F \alpha \sqrt{\Delta P})$ and capillary flow $(F \propto \Delta P)$ with an exponent of about 0.65 [5]. In order to retain the concept of opening area and provide a simple grouping of all other terms in (G.3.1), C is multiplied by $\sqrt{2}$ and $D$ divided by $\sqrt{D}$ to give: 


$$
\mathrm{F}_{1}=0.848 * \mathrm{FA}_{1} * \sqrt{\mathrm{D}} *(\Delta \mathrm{P})^{\mathrm{X} 1}
$$

where $F_{1}$ is the effective flow area of the openings in the surface, $D$ is the density of incoming air, and $X_{1}$ is the flow exponent. The pressure difference for envelope surfaces is

$$
\Delta \mathrm{P}=\mathrm{PW}_{1}+\mathrm{PS}_{1}-\mathrm{P}_{\mathrm{n}}
$$

and the $\Delta \mathrm{P}$ for interzone surfaces is

$$
\Delta \mathrm{P}=\mathrm{PS}_{\mathrm{i}}+\mathrm{P}_{\mathrm{m}}-\mathrm{P}_{\mathrm{n}}
$$

The surface flow equation becomes

or

$$
\begin{array}{ll}
\mathrm{F}_{1}=0.848 * \mathrm{FA}_{1} * / \mathrm{D}_{\mathrm{m}} *(\Delta \mathrm{P})^{\mathrm{Xi}} & (\Delta \mathrm{P}>0) \\
\mathrm{F}_{1}=-.848 * \mathrm{FA}_{1} * / \mathrm{D}_{\mathrm{n}} *(-\Delta \mathrm{P})^{\mathrm{XI}} & (\Delta \mathrm{P}<0)
\end{array}
$$

For each zone there must be a mass balance

$$
F_{s}+\sum F_{1}=0
$$

where $F_{s}$ is the net mass flow into the zone from the air handling system and the $F_{1}$ are the flows through openings in the zone envelope surfaces. These mass balances form a system of non-1inear algebraic equations which can be solved for the zone pressures.

\section{III.G.4 SOLUTION OF THE FLOW EQUATIONS}

In some schemes for the evaluation of these simultaneous equations it is important to know the following partial derivatives:

$$
\begin{aligned}
& \frac{\partial F_{1}}{\partial P_{n}}=-X_{1} * F_{i} / \Delta P \\
& \frac{\partial F_{i}}{\partial P_{m}}=X_{1} * F_{1} / \Delta P
\end{aligned}
$$$$
\text { (interzone surface) }
$$

or

$$
\frac{\partial F_{1}}{\partial P_{m}}=0 \quad \text { (envelope surface) }
$$

Note that it is not necessary to evaluate $(\Delta P)(X i-1)$ to compute these derivatives. Note also that as $\Delta \mathrm{P}$ approaches zero these derivatives cannot be evaluated. This condition applies for large openings which cannot support a large pressure difference (except with very high flow rates). This is a potential source of trouble which must be considered. 
These equations have been successfully solved by a modified Newton's method in all cases tested. A standard Newton's method was found to sometimes give very slow convergence because of overcorrections during the 1teration. The modification reduces the Newton correction when this problem appears to occur.

\section{REFERENCES}

[1] ASHRAE Handbook - 1981 Fundamentals (ASHRAE, 1981), p 22.3.

[2] Shaw, C. Y. and Tamura, G. T., "The Calculation of Air Infiltration Rates Caused by Wind and Stack Action for Tall Bulldings", ASHRAE Transactions, Vol 83 (ASHRAE, 1977), part 2.

[3] Shaw, C. Y., "A Method for Predicting Infiltration Rates for a Ta11 Building Surrounded by Lower Structures of Uniform Helght", ASHRAE Transactions, Vo1. 85 (ASHRAE, 1979), part 1.

[4] ASHRAE Handbook - 1981 Fundamentals (ASHRAE, 1981), p 4.13, Fig 18.

[5] ASHRAE Handbook - 1981 Fundamentals (ASHRAE, 1981), p 22.8. 


$$
\mathrm{F}_{1}=0.848 * \mathrm{FA}_{1} * \sqrt{\mathrm{D}} *(\Delta \mathrm{P})^{\mathrm{Xi}}
$$

where $F A_{1}$ is the effective flow area of the openings in the surface, $D$ is the density of incoming air, and $X_{i}$ is the flow exponent. The pressure difference for envelope surfaces is

$$
\Delta \mathrm{P}=\mathrm{PW}_{\mathrm{i}}+\mathrm{PS}_{\mathrm{i}}-\mathrm{P}_{\mathrm{n}}
$$

and the $\Delta \mathrm{P}$ for interzone surfaces is

$$
\Delta \mathrm{P}=\mathrm{PS}_{\mathrm{I}}+\mathrm{P}_{\mathrm{m}}-\mathrm{P}_{\mathrm{n}}
$$

The surface flow equation becomes

or

$$
\begin{array}{ll}
\mathrm{F}_{1}=0.848 * \mathrm{FA}_{1} * / \mathrm{D}_{\mathrm{m}} *(\Delta \mathrm{P})^{\mathrm{Xi}} & (\Delta \mathrm{P}>0) \\
\mathrm{F}_{1}=-.848 * \mathrm{FA}_{1} * / \mathrm{D}_{\mathrm{n}} *(-\Delta \mathrm{P})^{\mathrm{Xi}} & (\Delta \mathrm{P}<0)
\end{array}
$$

For each zone there must be a mass balance

$$
F_{S}+\sum F_{1}=0
$$

where $F_{S}$ is the net mass flow into the zone from the air handling system and the $F_{1}$ are the flows through openings in the zone envelope surfaces. These mass balances form a system of non-linear algebraic equations which can be solved for the zone pressures.

\section{III.G.4 SOLUTION OF THE FLOW EQUATIONS}

In some schemes for the evaluation of these simultaneous equations it is important to know the following partial derivatives:

$$
\begin{aligned}
& \frac{\partial F_{i}}{\partial P_{n}}=-X_{i} * F_{i} / \Delta P \\
& \frac{\partial F_{i}}{\partial P_{m}}=X_{i} * F_{i} / \Delta P \quad \text { (interzone surface) }
\end{aligned}
$$

or

$$
\frac{\partial F_{i}}{\partial P_{m}}=0 \quad \text { (envelope surface) }
$$

Note that it is not necessary to evaluate $(\Delta P)(X i-1)$ to compute these derivatives. Note also that as $\Delta \mathrm{P}$ approaches zero these derivatives cannot be evaluated. This condition applies for large openings which cannot support a large pressure difference (except with very high flow rates). This is a potential source of trouble which must be considered. 
These equations have been successfully solved by a modified Newton's method in all cases tested. A standard Newton's method was found to sometimes give very slow convergence because of overcorrections during the iteration. The modification reduces the Newton correction when this problem appears to occur.

\section{REFERENCES}

[1] ASHRAE Handbook - 1981 Fundamentals (ASHRAE, 1981), p 22.3.

[2] Shaw, C. Y. and Tamura, G. T., "The Calculation of Air Infiltration Rates Caused by Wind and Stack Action for Tall Buildings", ASHRAE Transactions, Vo1 83 (ASHRAE, 1977), part 2.

[3] Shaw, C. Y., "A Method for Predicting Infiltration Rates for a Tall Bullding Surrounded by Lower Structures of Uniform Height", ASHRAE Transactions, Vol. 85 (ASHRAE, 1979), part 1.

[4] ASHRAE Handbook - 1981 Fundamentals (ASHRAE, 1981), p 4.13, Fig 18.

[5] ASHRAE Handbook - 1981 Fundamentals (ASHRAE, 1981), p 22.8. 

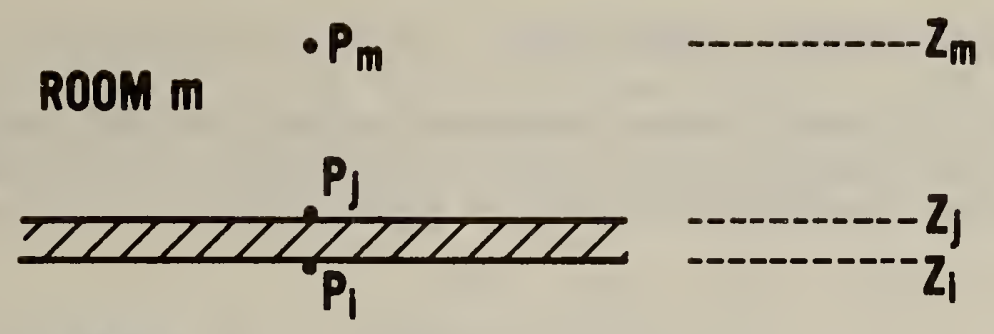

ROOM n

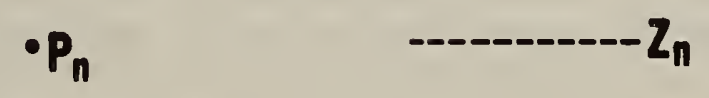

F1gure III.G.1 Pressure relationships for vertically adjacent zones

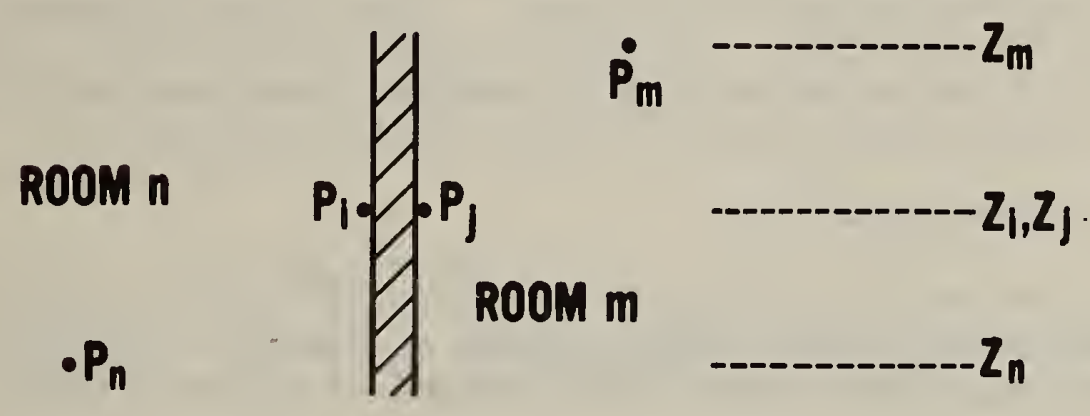

Figure III.G.2 Pressure relationships for horizontally adjacent zones
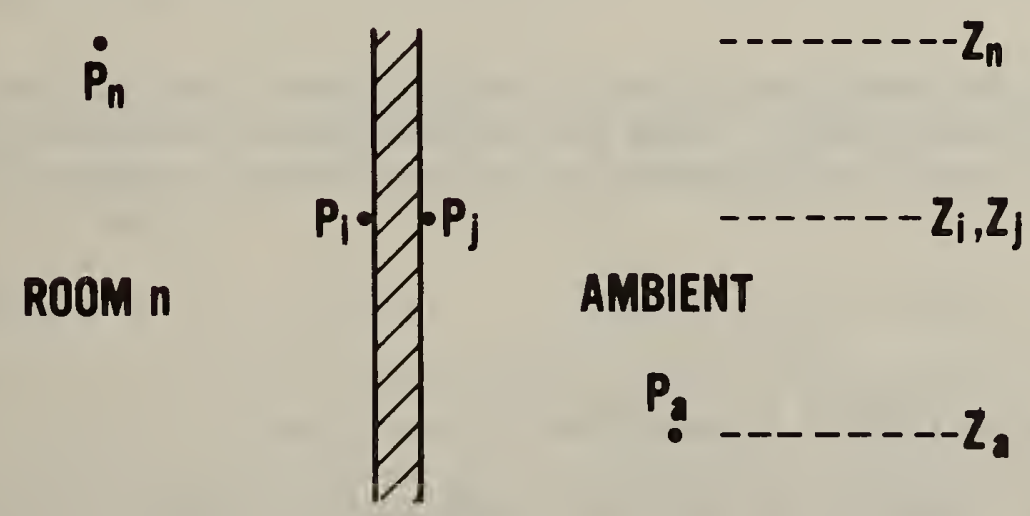

Figure III.G.3 Pressure relationships for envelope surfaces 


\section{III.H.I DETAILED RADIANT INTERCHANGE}

The surfaces of a room form an enclosure where they exchange energy with the room air by convection and directly with each other by radiation. The net radiant flux absorbed by surface 1 is given by

$$
Q I_{1}=\sum_{j} F_{1 j} *\left(\underline{T}_{j}^{4}-\underline{T}_{1}^{4}\right)+Q L I_{1}+Q S I_{1}
$$

This expression is not usually substituted into the surface heat balance equations since the $\mathrm{T}^{4}$ terms would make the equations nonlinear and difficult to solve. The radiation interchange factor, $F_{i j}$ (which includes geometry and radiocity factors) is difficult to calculate for rooms with arbitrary geometry. Since each surface interacts with all other surfaces of the room (total of $N$ surfaces) there are $\mathrm{N}^{2}$ interactions to be considered. This requires a time consuming solution technique. Quicker solutions are possible by linearizing and assuming constant radiative and convective coefficients for all surfaces [1]. Alternate methods are available which use mean radiant temperature instead of the detailed radiant interchange. These methods allow efficient treatment of the problem without assuming constant coefficients. They so significantly affect the solution time for problems with many surfaces that they make simultaneous heat balances for many rooms feasible [2].

\section{III.H.2 MRT NETWORK ALGORITHM}

In the TARP radiant interchange between room surfaces is based on the mean radiant temperature network (MRTN) method of Joseph A. Carrol1 [3]. Surfaces radiatively interact with an $\mathbb{M} T$ instead of directly with each other.

$$
Q I_{i}=H R_{i} *\left(T R_{n}-T_{i}\right)
$$

where $\mathrm{HR}_{1}$ is a radiative conductance. This gives $\mathrm{N}$ instead of $\mathrm{N}^{2}$ interactions. The time required to solve the inside surface heat balances is reduced froin order $\mathrm{N}^{2}$ to order $\mathrm{N}$. The effects of $\mathrm{QLI}_{i}$ and $\mathrm{QSI}_{i}$ are discussed below.

Since the $M R T$ includes the effect of all surfaces, coupling the surface to the MRT couples it to itself. The MRT network method includes a factor $F_{i}$, the "MRT view factor", which compensates for the self weight of surface 1. in the MRT.

$$
F_{i}=1 /\left[1-S_{i} * F_{i} /\left(\sum_{j} S_{j} * F_{j}\right)\right]
$$

This expression can be solved iteratively.

The effects of surface emittance are modeled by a surface resistance in the radiative conductance. 


$$
H R_{1}=4 \sigma^{*} \underline{T}^{3} /\left[1 / F_{1}+\left(1-\varepsilon_{1}\right) / \varepsilon_{1}\right]
$$

Near room temperature the radiative couplings between surfaces vary by about 1 percent per degree $C$ variation in the mean radiant temperature. The TARP allows a quick mode of calculating the radiant interchange which uses a constant $T(=296 \mathrm{~K}=23 \mathrm{C})$ for evaluating $H R_{1}$. A more accurate model uses the following algorithm to account for the non-linearity of the detalled equation.

1. Initialize all the HRI for a temperature of $27 \mathrm{C}$ :

$$
H R_{1}=6.13 /\left[1 / F_{1}+\left(1-\varepsilon_{1}\right) / \varepsilon_{1}\right]
$$

2. At each iteration first adjust all

$$
H R_{1}=\left(0.865+0.005 * T_{1}\right) * H R_{1}
$$

3. Then evaluate

$$
\mathrm{TRL}_{\mathrm{n}}=\Sigma H \mathrm{HR}_{1} * \mathrm{~A}_{1} * \mathrm{~T}_{1} / \Sigma \mathrm{HR}_{1} * \mathrm{~A}_{1}
$$

where the sum applies to all surfaces of room $n$

4. Then again adjust all

$$
H R_{1}=\left(0.865+0.005 * \mathrm{TRL}_{\mathrm{n}}\right) * \mathrm{HR}_{1}
$$

This method scales each $\mathrm{HR}_{1}$ by two factors nearly proportional to $\mathrm{T}^{1.5}$, and estimates the radiant fluxes to within about 1 percent for surfaces between $0 \mathrm{C}$ and $50 \mathrm{C}$.

In addition to the radiation from other surfaces, there is longwave radiation from various energy sources in the room. The effect of these radiant sources can be factored into the MRT and the radiant flux automatically distributed over the room surfaces.

$$
\mathrm{TR}_{\mathrm{n}}=\left(\Sigma H \mathrm{HR}_{1} * \mathrm{~S}_{1} * \mathrm{~T}_{\mathrm{i}}+\mathrm{QL}_{\mathrm{n}}\right) / \sum \mathrm{HR}_{1} * \mathrm{~S}_{\mathrm{i}}
$$

Shortwave radiation, such as from the sun and lights, should not be handled by this modification of the MRT because the room surfaces can have entirely different emissivites for short and long wavelength radiation. Therefore, H.2.1 should be written:

$$
Q I_{i}=H R_{i} *\left(T R_{n}-T_{i}\right)+Q S I_{i}
$$

The MRTN method of Carroll is slightly more accurate than the "balanced mean radiant temperature" (MRTB) method of Walton. In addition it can easily handle multiple reflections and air emittance effects. However, when IRTN is used in the TARP iterative heat balance, it is slower than MRTB. A single MRTN iteration is slightly faster than MRTB, but more are required. This is because MRTN updates $\mathrm{TR}_{\mathrm{n}}$ once per heat balance iteration of all 
surfaces while MRTB updates $\mathrm{TR}_{\mathrm{n}}$ for each surface during the heat balance 1teration. The effect is the same as Jacobi versus Gauss-Seldel 1teration [4]. The MRTN method was chosen over MRTB because of its accuracy and potential for future expansion. It thus became important to find a method to reduce the number of iterations to regain speed similar to MRTB. This method is described in section $L$.

\section{REFERENCES}

[1] Sowe11, E.F., and Walton, G.N., "Efficient Computation of Zone Loads", ASHRAE Transactions Vol 86 (1980), Part I.

[2] Walton, G. N., "A New Algorithm for Radiant Interchange in Room Loads Calculations", ASHRAE Transactions Vol 86 (1980), Part II.

[3] Carroll, J. A., "An 'MRT Method' of Computing Radiant Energy Exchange in Rooms", Proceedings of the 2nd Systems Simulation and Economics Analysis Conference (1980).

[4] Conte, S. D., and de Boor, C., Elementary Numerical Analysis: An Algorithmic Approach, (McGraw-Hi11, 1972), pp 166-167. 


\section{III.I.1 SIMPLE SURFACE CONDUCTANCE}

The convective plus radiative heat flux from a surface to the environment may be represented by:

$$
\text { . } \mathrm{CO}+\mathrm{QO}=\mathrm{HO} *\left(\mathrm{TO}-\mathrm{T}_{\mathrm{a}}\right)+\mathrm{QSO}
$$

The surface coefficient, HO, accounts for both convection and longwave radiant interchange. QSO is the absorbed shortwave radiant flux. A simple correlation for HO uses a polynomial expression [1] based on an ASHRAE relationship [2] which relates the surface coefficient $\left(\mathrm{W} / \mathrm{m}^{2} \mathrm{~K}\right)$ to wind speed $(\mathrm{m} / \mathrm{s})$ and surface roughness.

$$
\mathrm{H}_{0}=\mathrm{A}_{0}+\mathrm{A}_{1} * \mathrm{~V}_{\mathrm{a}}+\mathrm{A}_{2} * \mathrm{~V}_{\mathrm{a}}^{2}
$$

The values of the coefficients are determined by the surface roughness:

\begin{tabular}{ccccl}
$\begin{array}{c}\text { Roughness } \\
\text { Index }\end{array}$ & \multicolumn{1}{c}{$\mathrm{A}_{0}$} & $\mathrm{~A}_{1}$ & \multicolumn{1}{c}{$\mathrm{A}_{2}$} & Example Material \\
1 & 11.58 & 5.894 & 0.0 & Stucco \\
2 & 12.49 & 4.065 & 0.028 & Brick, rough plaster \\
3 & 10.79 & 4.192 & 0.0 & Concrete \\
4 & 8.23 & 4.00 & -0.057 & Clear pine \\
5 & 10.22 & 3.10 & 0.0 & Smooth plaster \\
6 & 8.23 & 3.33 & -0.036 & Glass, paint on pine
\end{tabular}

$\mathrm{Va}$ is the reported wind speed unmodified for surface height or orientation. This is reasonable for estimating design loads, but it needs improvement for detailed simulations.

Rain causes the surface temperature to rapidly approach the water temperature. TARP models this by setting HO to $1000 . \mathrm{W} / \mathrm{m}^{2} \mathrm{~K}$ and replacing Ta in (I.1.1) by the wet bulb temperature.

\section{III.I.2 DETAILED SURFACE CONDUCTANCE}

A detailed description of the outside surface coefficient must include components of forced convection $\left(H_{f}\right)$, natural convection $\left(H_{n}\right)$, and radiant interchange $\left(H_{r}\right)$. These are affected by surface size, shape, location, orientation, and many features in the surrounding environment. All of these effects are open to further study [3]. The following algorithms have been combined (perhaps not justifiably) to allow the user to study the effects of certain details in the outside conductance algorithm on relative zone conditions. They show the kind of details that can be considered in TARP. They will be progressively enhanced as better algorithms are developed. 
III.I.2.1

Wind velocity tends to increase at increasing heights above the ground. The relationship for this increase is described in $B .3$.

$$
\mathrm{v}_{\mathrm{az}}=\mathrm{v}_{\mathrm{a}} *_{\mathrm{b}} *\left(\mathrm{z} / \mathrm{z}_{\mathrm{o}}\right)^{\mathrm{a}}
$$

Studies of the effect of surface shape on $\mathrm{H}_{f}$ give the following correlation [4].

or

$$
\text { St } * \mathrm{Pr}^{2 / 3}=0.86 * \mathrm{Re}^{-1 / 2}
$$

$$
\mathrm{H}_{\mathrm{f}}=0.86 * \mathrm{D}_{\mathrm{a}} * \mathrm{C}_{\mathrm{p}} * \mathrm{P}_{\mathrm{r}}-2 / 3 *\left(.25 * \mathrm{~V}_{\mathrm{az}} * \mathrm{C} * \mathrm{v} / \mathrm{A}\right)^{1 / 2}
$$

where

$$
\begin{aligned}
& \mathrm{St}=\text { Stanton number }\left(\mathrm{H}_{\mathrm{f}} / \mathrm{D}_{\mathrm{a}} \mathrm{C}_{\mathrm{p}} \mathrm{V}_{\mathrm{z}}\right) \\
& \mathrm{Pr}=\text { Prandtl number }\left(\mathrm{C}_{\mathrm{p}} \nu / \mathrm{k}\right) \\
& \mathrm{Re}=\text { Reynolds number }\left(4 \mathrm{~V}_{\mathrm{az}} \mathrm{A} / \mathrm{C} \mathrm{\nu}\right) \\
& \mathrm{A}=\text { surface area } \\
& \mathrm{C}=\text { surface circumference } \\
& \mathrm{D}_{\mathrm{a}}=\text { density of air } \\
& \mathrm{C}_{\mathrm{p}}=\text { specific heat of air } \\
& \mathrm{V}_{\mathrm{az}}=\text { free stream wind velocity (at helght of surface) } \\
& \nu=\text { kinematic viscosity }
\end{aligned}
$$

For air $\operatorname{Pr}^{-2 / 3}=1.245, C_{p}=1004 \mathrm{~J} / \mathrm{Kg} \mathrm{K}$, and $D_{a} \sqrt{v} \cong 0.00472 \mathrm{Kg} / \mathrm{s} \mathrm{m}^{5 / 2}$ which combine to give

$$
\mathrm{H}_{\mathrm{f}}=2.537 * \sqrt{\mathrm{C} / \mathrm{A}} * \sqrt{\mathrm{V}_{\mathrm{az}}}
$$

The local value of $\mathrm{H}_{\mathrm{f}}$ was found to be greatest near the edges of the surface where the thermal boundary layer is thinnest. Therefore, to avoid computing too large a value for small subsurfaces (windows and doors), TARP uses the same C/A for the subsurfaces as for the wall they are on.

There is as yet no definitive study giving an algorithm for wind direction effects. Therefore, it was decided to follow the suggestion of Cole [5] and multiply $\mathrm{H}_{f}$ by a wind direction modifier, $W_{f}$, of one half for the leeward surfaces. Wf equals one for windward surfaces. In TARP leeward is defined as greater than 100 degrees from normal incidence.

A simple surace roughness multiplier, $R_{f}$, was developed from the ASHRAE graph of surface conductances [6]. At 0 mph all lines on this graph intercept at about $1.9 \mathrm{Btu} / \mathrm{hrft}^{2} \mathrm{~F}$. The correlations for the six roughnesses are nearly linear. Therefore, a simple roughness multiplier was constructed by subtracting 1.9 from all values of $\mathrm{H}$ ( at $25 \mathrm{mph}$ ) and dividing by the quantity [ $\mathrm{H}$ (of roughness 6 at $25 \mathrm{mph}$ ) -1.9 ] as summarized below. 


$\begin{array}{ccc}\text { Roughness } & H(\text { at } 25 \mathrm{mph}) & \mathrm{R}_{\mathrm{f}} \\ 1 & 13.6 & 2.1 \\ 2 & 10.8 & 1.67 \\ 3 & 10.1 & 1.52 \\ 4 & 8.0 & 1.13 \\ 5 & 7.9 & 1.11 \\ 6 & 7.3 & 1.00\end{array}$

III.I.2.2 NATURAL CONVECTION

There must be a natural convection component in the overall surface coefficient to account for the convection which exists at zero wind velocity. The same expressions are used for outside natural convection as for inside convection (J.2).

$$
\begin{array}{ll}
\text { Heat flow up: } & \left.H_{n}=9.482 * \sqrt[3]{|\mathrm{TO}-\mathrm{Ta}| /(7.238-|\cos \phi|}\right) \\
\text { Heat flow down: } & \left.H_{\mathrm{n}}=1.810 * \sqrt[3]{|\mathrm{TO}-\mathrm{Ta}| /(1.381+|\cos \phi|}\right)
\end{array}
$$

This component is assumed to be present at all wind speeds.

\section{III.I.2.3 RADIAN'T INTERCHANGE}

There is radiant interchange between the surface and the sky, and between the surface and the ground surface or adjacent structures. The effective temperature of the ground surface is assumed to be equal to $T_{a}$ (pending further algorithn development). The effective temperature of any point in the sky depends on the optical path length through the atmosphere. Section B.3 describes the algorithm which computes the effective sky temperature which would be seen by a horizontal surface. For tilted surfaces the radiant interchange coefficient $\left(H_{r}\right)$ must be divided into three parts: one (HS) to sky temperature, one (HG) to ground surface temperature, and one ( $\mathrm{Ha}$ ) to air temperature.

$$
\begin{aligned}
& \mathrm{Ha}=\sigma * \varepsilon * \mathrm{~F}_{\mathrm{SS}} *(1-\cos (\phi / 2)) *\left(\underline{\mathrm{TO}}^{4}-\underline{\mathrm{T}}_{\mathrm{a}}^{4}\right) /\left|\underline{\mathrm{TO}}-\underline{\mathrm{T}}_{\mathrm{a}}\right| \\
& \mathrm{HS}=\sigma * \varepsilon * \mathrm{~F}_{\mathrm{SS}} * \cos (\phi / 2) *\left(\underline{\mathrm{TO}}{ }^{4}-\underline{\mathrm{T}}_{\mathrm{S}}^{4}\right) /\left|\underline{\mathrm{TO}}-\underline{\mathrm{T}}_{\mathrm{S}}\right| \\
& \mathrm{HG}=\sigma * \varepsilon * \mathrm{~F}_{\mathrm{Sg}} *\left(\underline{\mathrm{TO}}^{4}-\underline{\mathrm{T}}_{\mathrm{g}}^{4}\right) /\left|\mathrm{TO}-\underline{\mathrm{T}}_{\mathrm{g}}\right|
\end{aligned}
$$

Pending further research, TARP assumes the ground surface temperature, $\mathrm{T}_{\mathrm{g}}$, equals the air temperature, $\mathrm{T}_{\mathrm{a}}$. This three component split of $\mathrm{H}_{\mathrm{r}}$ must still be validated or modified by experimental data. It produces proper results for horizontal surfaces. It causes a vertical surface to radiate to an effective temperature of $\left(.35 \mathrm{~T}_{s}+.65 \mathrm{~T}_{\mathrm{a}}\right)$. TARP allows for radiant exchange to surfaces of buidings to be represented by the user-specified values of $\mathrm{F}_{\mathrm{ss}}$ and $\mathrm{F}_{\mathrm{sg}}$. Other building surfaces can be expected to have about the same temperature as the surface in question. Therefore, there is no net radiant transfer to it, and the view factor to all other building surfaces is represented by $1-F_{s s}-F_{s g}$. 
Since the expressions for $\mathrm{Hn}$ and $\mathrm{Hr}$ are used to evaluate TO, the most. recent value of TO is used in their calculation. The three factors combine to give the following expression for combined convective and radiative flux.

$$
\mathrm{CO}+\mathrm{QO}=\left(\mathrm{H}_{\mathrm{f}} * \mathrm{~W}_{\mathrm{f}} * \mathrm{R}_{\mathrm{f}}+\mathrm{H}_{\mathrm{n}}+\mathrm{HA}\right) *\left(\mathrm{~T}_{\mathrm{a}}-\mathrm{TO}\right)+\mathrm{HS}^{*}\left(\mathrm{~T}_{\mathrm{S}}-\mathrm{TO}\right)+\mathrm{HG} *\left(\mathrm{~T}_{\mathrm{g}}-\mathrm{TO}\right)+\mathrm{QSO}
$$

\section{III.I.3 BASIC HEAT BALANCES}

A heat balance must exist at the outside surface-air interface. The incoming conductive, convective, and radiative fluxes must sum to zero:

$$
\mathrm{KO}+\mathrm{CO}+\mathrm{QO}=\mathrm{O}
$$

In contrast to the internal surface heat balance which treats all surfaces simultaneously, the external thermal balance for each surface is performed independent of all other surfaces. This implies that there is no direct interaction between the individual surfaces.

The TARP includes four possible representations for the basic outside surface heat balance. The first two depend on which of the optional surface conductance algorithms the user selects. The simple outside surface conductance (I.1) which includes both the convective and thermal interchange between the surface and the environment in a single coefficient, is represented by the thermal network in figure I.1. (I.3.1) can be expressed in terms of $(C .1 .6)$ and $(1.1 .1)$ as

$$
\mathrm{KOP}_{t}+\mathrm{Y}_{0} * \mathrm{TI}_{\mathrm{t}}-\mathrm{X}_{0} * \mathrm{TO}_{\mathrm{t}}+\mathrm{HO} *\left(\mathrm{~T}_{\mathrm{a}}-\mathrm{TO}_{\mathrm{t}}\right)+\mathrm{QSO}=0
$$

This can be solved for the outside surface temperature.

$$
\mathrm{TO}_{\mathrm{t}}=\left(\mathrm{KOP} \mathrm{T}_{\mathrm{t}}+\mathrm{QSO}+\mathrm{Y}_{0} * \mathrm{TI}_{\mathrm{t}}+\mathrm{HO} * \mathrm{~T}_{\mathrm{a}}\right) /\left(\mathrm{X}_{\mathrm{O}}+\mathrm{HO}\right)
$$

The detailed outside surface conductance model (I.2) considers convection and radiant interchange with the sky and with the ground as separate factors. Its use in the outside thermal balance is shown in figure I.2. In this case (I.3.1) can be expanded according to (C.1.6) and (I.2.7) to give

$$
\begin{aligned}
& \mathrm{KOP}_{\mathrm{t}}+\mathrm{Y}_{0} * \mathrm{TI}_{\mathrm{t}}-\mathrm{X}_{0} * \mathrm{TO}_{\mathrm{t}}+\mathrm{HA} *\left(\mathrm{~T}_{\mathrm{a}}-\mathrm{TO}_{\mathrm{t}}\right) \\
& +\mathrm{HS} *\left(\mathrm{~T}_{\mathrm{S}}-\mathrm{TO}_{\mathrm{t}}\right)+\mathrm{HG} *\left(\mathrm{~T}_{\mathrm{g}}-\mathrm{TO}_{\mathrm{t}}\right)+\mathrm{QSO}=0
\end{aligned}
$$

This can be solved for the outside surface temperature:

$$
\begin{aligned}
\mathrm{TO}_{t}= & \left(\mathrm{KOP}_{\mathrm{t}}+\mathrm{QSO}+\mathrm{YO} * \mathrm{TI}_{\mathrm{t}}+\mathrm{HA} * \mathrm{~T}_{\mathrm{a}}+\mathrm{HS} * \mathrm{~T}_{\mathrm{S}}+\mathrm{HG}^{*} \mathrm{~T}_{\mathrm{g}}\right) \\
& /\left(\mathrm{X}_{0}+\mathrm{HA}+\mathrm{HS}+\mathrm{HG}\right)
\end{aligned}
$$


The third and fourth representations occur when the outside surface has been covered with a movable insulation. The insulation has a conductance of UM. This case is represented by the thermal network in figure I.3. The insulation must be massless because 1 t is not generally possible to perform a correct thermal balance at the juncture of two surfaces each modeled by CTF.

The equation for the thermal balance betwen the surface and the insulation is

$$
\mathrm{KOP}_{\mathrm{t}}+\mathrm{Y}_{0} * \mathrm{TI}_{\mathrm{t}}-\mathrm{X}_{0} * \mathrm{TO}_{\mathrm{t}}+\mathrm{UI} *\left(\mathrm{TM}-\mathrm{TO}_{\mathrm{t}}\right)+\mathrm{QSO}=0
$$

which can be rewritten to solve for TO:

$$
\mathrm{TO}_{\mathrm{t}}=\left(\mathrm{KOP}_{\mathrm{t}}+\mathrm{QSO}+\mathrm{Y}_{0} * \mathrm{TI}_{\mathrm{t}}+\mathrm{UM} * \mathrm{TM}\right) /\left(\mathrm{X}_{0}+\mathrm{UM}\right)
$$

Depending on whether or not the detalled or simple algorlthm for surface conductance is being used, there are two expresions for TM, the outside temperature of the Insulation. For the simple conductance:

$$
\mathrm{TM}=\left(\mathrm{QSM}+\mathrm{UM}^{*} \mathrm{TO}_{\mathrm{t}}+\mathrm{HO}^{*} \mathrm{~T}_{\mathrm{a}}\right) /(\mathrm{UM}+\mathrm{HO})
$$

For the detailed conductance:

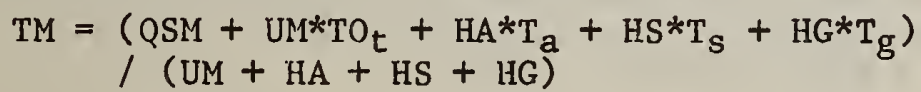

In this case the values of $\mathrm{HA}$, HS, and HG must be found by using an estimated value of TM in place of TO in (I.2).

\section{III.I.4 HEAT BALANCE CASES}

$\mathrm{TO}_{\mathrm{t}}$ and $\mathrm{TI}_{\mathrm{t}}$ are related through the $\mathrm{Y}_{0} \mathrm{CTF}$. However, $\mathrm{TI}_{t}$ is also unknown. While it is possible to combine the outside and inside surface heat balances to compute $\mathrm{TO}_{t}$ and $\mathrm{TI}_{t}$ simultaneously, the TARP uses a simpler procedure where $\mathrm{TO}_{t}$ is based on a previous value of $\mathrm{TI}$. When $\mathrm{Y}_{0}$ is small, as occurs in well insulated or very massive surfaces, $\mathrm{TI}_{\mathrm{t}}$ can be replaced by $\mathrm{TI}_{\mathrm{t}-1}$ (which is known from the previous hour's heat balance) without significantly effecting the value of $\mathrm{TO}_{\mathrm{t}}$. When $\mathrm{Y}_{0}$ is large, TO and $\mathrm{TI}$ can be so strongly coupled that separate outside and inside heat balances do not work because the environment and zone temperatures have negligible influence on the heat balances. The TARP uses the inside surface heat balance to couple $\mathrm{TO}_{t}$ with $\mathrm{TZ}$ and $\mathrm{TR}$. These two temperatures are less strongly influenced by TO and allow a reasonable heat balance. On the first heat balance iteration, TZ and TR are the values at time $t-1$. The user may optionally require that $\mathrm{TO}_{t}$ be recomputed with every iteration of $\mathrm{TI}_{t}$. In this case $\mathrm{TZ}$ and $\mathrm{TR}$ have the values from the previous iteration, and a true simultaneous solution is achieved. In most conventional construction, recomputing $\mathrm{TO}_{t}$ does not significantly change the computed zone loads and temperatures. The inside surface heat balance is given by $(\mathrm{J} .3 .3)$ which is repeated here.

$$
\begin{aligned}
T I_{t}= & \left(K I P_{t}+Q S I+H C * T Z+H R * T R+Y_{0} * T O\right) \\
& /\left(Z_{0}+H C+H R\right)
\end{aligned}
$$


The surface heat balances can be combined in eight ways according to conditions for calculation of the outside surface temperature. Compute

$$
\begin{aligned}
& F_{1}=Y_{0} /\left(\mathrm{Z}_{0}+\mathrm{HI}+\mathrm{HR}\right)^{\prime} \\
& F_{2}=\mathrm{UM} /(\mathrm{UM}+\mathrm{HO}) \\
& \mathrm{F}_{3}=\mathrm{UM} /(\mathrm{UM}+\mathrm{HA}+\mathrm{HS}+\mathrm{HG})
\end{aligned}
$$

as needed for the following cases.

CASE 1: Yo small, simple conductance, no movable insulation. From equation $(\mathrm{I} .3 .3)$ :

$$
\mathrm{TO}_{\mathrm{t}}=\left(\mathrm{KOP}_{\mathrm{t}}+\mathrm{QSO}+\mathrm{Y}_{0} * \mathrm{TI}_{\mathrm{t}-1}+\mathrm{HO}^{*} \mathrm{~T}_{\mathrm{a}}\right) /\left(\mathrm{X}_{0}+\mathrm{HO}\right)
$$

CASE 2: $Y_{0}$ not small, simple conductance, no movable insulation. From (I.3.3) and $(I .4 .1)$ :

$$
\begin{aligned}
\mathrm{TO}_{\mathrm{t}}= & {\left[\mathrm{KOP} \mathrm{P}_{\mathrm{t}}+\mathrm{QSO}+\mathrm{HO} \mathrm{H}_{\mathrm{a}}+\mathrm{F}_{1} *\left(\mathrm{KIP}_{\mathrm{t}}+\mathrm{QSI}+\mathrm{HI} \mathrm{T}^{*} \mathrm{TZ}+\mathrm{HR}{ }^{*} \mathrm{TR}\right)\right] } \\
& /\left(\mathrm{X}_{0}+\mathrm{HO}-\mathrm{F}_{1} * \mathrm{Y}_{0}\right)
\end{aligned}
$$

CASE 3: Yo small, detailed conductance, no movable insulation. From (I.3.4):

$$
\begin{aligned}
\mathrm{TO}_{\mathrm{t}}= & \left(\mathrm{KOP}_{\mathrm{t}}+\mathrm{QSO}+\mathrm{Y}_{0} * \mathrm{TI}_{\mathrm{t}-1}+\mathrm{HA}^{*} \mathrm{~T}_{\mathrm{a}}+\mathrm{HS}^{*} \mathrm{~T}_{\mathrm{S}}+\mathrm{HG}^{*} \mathrm{~T}_{\mathrm{g}}\right) \\
& /\left(\mathrm{X}_{0}+\mathrm{HA}+\mathrm{HS}+\mathrm{HG}\right)
\end{aligned}
$$

CASE 4: Yo not small, detailed conductance, no movable insulation. From $(I .3 .4)$ and $(I .4 .1)$ :

$$
\begin{aligned}
\mathrm{TO}_{\mathrm{t}}= & {\left[\mathrm{KOP}_{\mathrm{t}}+\mathrm{QSO}+\mathrm{HA}^{*} \mathrm{~T}_{\mathrm{a}}+\mathrm{HS}^{*} \mathrm{~T}_{\mathrm{s}}+\mathrm{HG}^{*} \mathrm{~T} g\right.} \\
& \left.+\mathrm{F}_{1} *\left(\mathrm{KIP}_{\mathrm{t}}+\mathrm{QSI}+\mathrm{HI} * \mathrm{TZ}+\mathrm{HR} * \mathrm{TR}\right)\right] \\
& /\left(\mathrm{X}_{0}+\mathrm{HA}+\mathrm{HS}+\mathrm{HG}-\mathrm{F}_{1} * \mathrm{Y}_{0}\right)
\end{aligned}
$$

CASE 5: $Y_{0}$ small, simple conductance, with movable insulation. From (I.3.7) and $(I .3 .8)$ :

$$
\begin{aligned}
\mathrm{TO}_{\mathrm{t}}= & {\left[\mathrm{KOP}_{\mathrm{t}}+\mathrm{QSO}+\mathrm{Y}_{0} * \mathrm{TI} \mathrm{I}_{\mathrm{t}-1}+\mathrm{F}_{2} *(\mathrm{QSM}+\mathrm{HO} * \mathrm{TM})\right] } \\
& /\left(\mathrm{X}_{0}+\mathrm{UM}-\mathrm{F}_{2} * \mathrm{UM}\right)
\end{aligned}
$$

CASE 6: Y Y not small, simple conductance, with movable insulation. From $(I .3 .7),(I .3 .8)$, and $(I .4 .1)$ :

$$
\begin{aligned}
\mathrm{TO}_{\mathrm{t}}= & {\left[\mathrm{KOP}_{\mathrm{t}}+\mathrm{QSO}+\mathrm{F}_{2} *\left(\mathrm{QSM}+\mathrm{HO} * \mathrm{~T}_{\mathrm{a}}\right)+\mathrm{F}_{1} *\left(\mathrm{KIP}_{\mathrm{t}}+\mathrm{QSI}+\mathrm{HI} * \mathrm{TZ}+\mathrm{HR} * \mathrm{TR}\right)\right] } \\
& /\left(\mathrm{X}_{0}+\mathrm{UM}-\mathrm{F}_{2} * \mathrm{UM}-\mathrm{F}_{1} * \mathrm{Y}_{0}\right)
\end{aligned}
$$


CASE 7: Yo smal1, detailed conductance, with movable insulation. From (I.3.7) and $(1.3 .9)$ :

$$
\begin{aligned}
\mathrm{TO}_{\mathrm{t}}= & {\left[\mathrm{KOP}_{\mathrm{t}}+\mathrm{QSO}+\mathrm{Y}_{0} * \mathrm{TI}_{\mathrm{t}-1}+\mathrm{F}_{3} *\left(\mathrm{QSM}+\mathrm{HA} * \mathrm{~T}_{\mathrm{a}}+\mathrm{HS}^{*} \mathrm{~T}_{\mathrm{S}}+\mathrm{HG}^{*} \mathrm{~T}_{\mathrm{g}}\right)\right] } \\
& /\left(\mathrm{X}_{0}+\mathrm{UM}-\mathrm{F}_{3} * \mathrm{UM}\right)
\end{aligned}
$$

CASE 8: Y Y not small, detalled conductance, with movable insulation. From $(I .3 .7),(1.3 .9)$, and $(I .4 .1)$ :

$$
\begin{aligned}
\mathrm{TO}_{\mathrm{t}}= & {\left[\mathrm{KOP}_{\mathrm{t}}+\mathrm{QSO}+\mathrm{F}_{1} *\left(\mathrm{KIP}_{\mathrm{t}}+\mathrm{QSI}+\mathrm{HI} * \mathrm{TZ}+\mathrm{HR} \mathrm{TR}^{*}\right)\right.} \\
& \left.+\mathrm{F}_{3} *\left(\mathrm{QSM}+\mathrm{HA}^{*} \mathrm{~T}_{\mathrm{a}}+\mathrm{HS}^{*} \mathrm{~T}_{\mathrm{s}}+\mathrm{HG} \mathrm{T}_{\mathrm{g}}\right)\right] \\
& /\left(\mathrm{X}_{0}+\mathrm{UM}-\mathrm{F}_{3} * \mathrm{UM}-\mathrm{F}_{1} * \mathrm{Y}_{0}\right)
\end{aligned}
$$

REFERENCES

[1] T. Kusuda, "NBSLD, the Computer Program for Heating and Cooling Loads in Bulldings," NBS Bullding Science Series 69, (July 1967), p 66a.

[2] ASHRAE Handbook - 1981 Fundamentals (ASHRAE, 1981), p 23.2, Figure 1.

[3] R. J. Cole and N. S. Sturrock, "The Convective Heat Exhcange at the External Surface of Buildings", Bullding and Environment, Vol 12 (1977) pp 207-214.

[4] E. M. Sparrow, J. W. Ramsey, and E. A. Mass, "Effect of Finite Width on Heat Transfer and Fluid Flow about an Inclined Rectangular Plate," Journal of Heat Transfer, Vo1 101 (May 1979), p 204.

[5] R. J. Cole and N. S. Sturrock, "The Convective Heat Exchange at the External Surface of Buildings", Bullding and Environment, Vol 12 (1977), p 212 .

[6] ASHRAE Handbook - 1981 Fundamentals, (ASHRAE, 1981), p 23.2, Figure 1. 


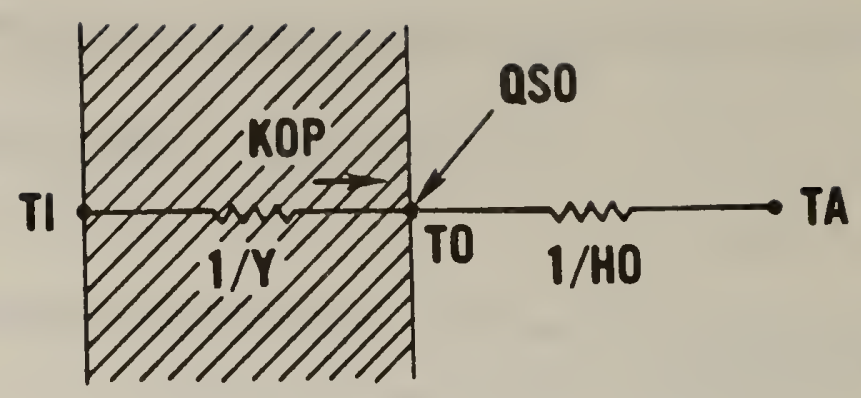

Figure III.I.1 Thermal network for simple outside surface coefficient

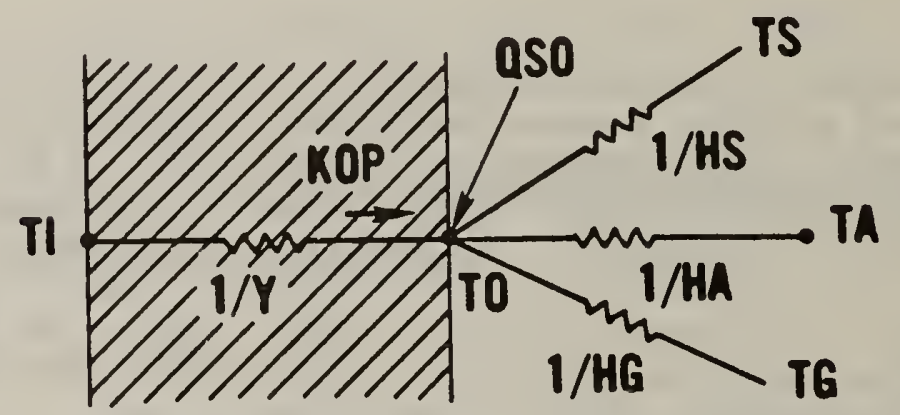

Figure III.I.2 Thermal network for detailed outside surface coefficient

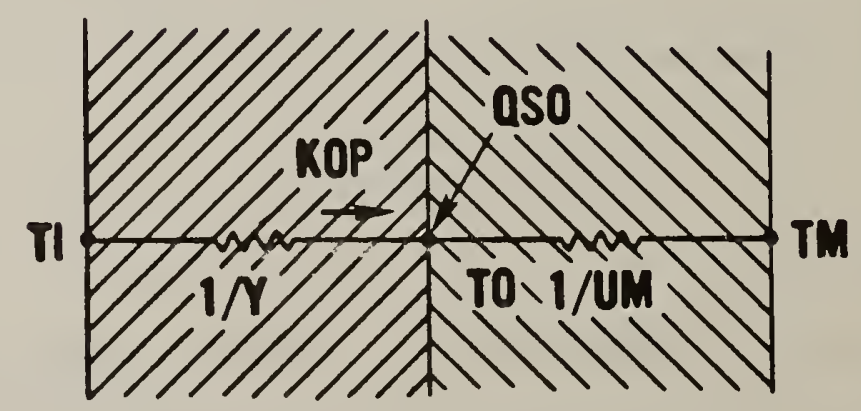

Figure III.I.3 Thermal network for outside movable insulation 
III.J

SURFACE INSIDE HEAT BALANCES

III.J.1 SIMPLE CONVECTION COEFFICIENT

The convective heat flux from the zone air to a surface is given by:

$C I=H C *(T I-T Z)$

$(\mathrm{J} \cdot 1.1)$

The coefficient for natural convection heat transfer is based on data from ASHRAE [1]. The ASHRAE values are for combined convection and radiation, so a radiative component of ( 1.02 times emissivity of 0.9$)$ is subtracted from the tabulated values which are then converted to metric. When warm air is below a cool horizontal surface (or cool air above a warm surface), there is more convective mixing than for air next to a veritcal surface. Conversely, when cool air is below a warm surface (or warm air above a cool surface) there is reduced convection.

$\begin{array}{lll}\mathrm{HC}\left(\mathrm{W} / \mathrm{m}^{2} \mathrm{~K}\right) & \begin{array}{l}\text { Type of } \\ \text { Heat Flow }\end{array} & \text { Surface T11t } \\ 4.043 & \text { enhanced } & 157.5 \text { to } 180 \text { or } 0 \text { to } 22.5 \text { degrees } \\ 3.873 & \text { enhanced } & 112.5 \text { to } 157.5 \text { or } 22.5 \text { to } 67.5 \text { degrees } \\ 3.078 & \text { normal } & 67.5 \text { to } 112.5 \text { degrees (vertical surface) } \\ 2.283 & \text { reduced } & 22.5 \text { to } 67.5 \text { or } 112.5 \text { to } 157.5 \text { degrees } \\ 0.920 & \text { reduced } & 0 \text { to } 22.5 \text { or } 157.5 \text { to } 180 \text { degrees }\end{array}$

When the air handling system is moving air through the zone, a single value of $6.14 \mathrm{~W} / \mathrm{m}^{2} \mathrm{~K}\left(=2.0-1.02 * 0.90 \mathrm{Btu} / \mathrm{h} * \mathrm{ft}^{2} * \mathrm{~F}\right)$ should be used for $\mathrm{HI}$.

III.J.2 DETAILED NATURAL CONVECTION COEFFICIENT

ASHRAE has the following expressions for natural convection from large surfaces [2].

$$
\begin{array}{lll}
\mathrm{HC}\left(\mathrm{W} / \mathrm{m}^{2} \mathrm{~K}\right) & \text { Direction of Heat Flow } \\
1.52 * \sqrt[3]{|\mathrm{TZ}-\mathrm{TI}|} & \text { Upward } & (\mathrm{J} .2 .1 \mathrm{a}) \\
1.31 * \sqrt[3]{|\mathrm{TZ}-\mathrm{TI}|} & \text { Horizontal } & (\mathrm{J} .2 .1 \mathrm{~b}) \\
0.76 * \sqrt[3]{|\mathrm{TZ}-\mathrm{TI}|} & \text { Downward } & (\mathrm{J} .2 .1 \mathrm{c})
\end{array}
$$$$
1.31 * \sqrt[3]{|\mathrm{TZ}-\mathrm{TI}|} \quad \text { Horizontal (J.2.1b) }
$$

It may be noted that these expressions are inconsistant with the values given for the simple algorithm.

To account for all surface tilts, the following expressions are used.

Heat flow horizontal or upward:

$$
\mathrm{HC}=9.482 * \sqrt[3]{|\mathrm{TZ}-\mathrm{TI}|} /(7.238-|\cos \phi|)
$$


Heat flow horizontal or downward:

$$
\mathrm{HC}=1.810 * \sqrt[3]{\mid \mathrm{TZ}-\mathrm{TI}} \mid /(1.382+|\cos \phi|)
$$

\section{III.J.3 BASIC HEAT BALANCE}

A heat balance must exist at the inside surface-air interface. The incoming convective, radiative, and conductive fluxes must sum to zero:

$$
C I_{1}+Q I_{1}+K I_{1}=0.0
$$

This equation can be expanded according to the descriptions of convection ( $\mathrm{J} .1$ and $\mathrm{J} .2)$, radiation $(\mathrm{F} .2 .6)$, and conduction (C.1.4) and as shown in figure J.l to give

$\mathrm{HC}_{1} *\left(\mathrm{TZ}_{\mathrm{n}}-\mathrm{TI}_{1}\right)+\mathrm{HR}_{1} *\left(\mathrm{TR}_{\mathrm{n}}-\mathrm{TI}_{1}\right)+\mathrm{QSI}_{1}+\mathrm{KIP}_{1}+\mathrm{Y}_{0,1} * \mathrm{TO}_{1}-\mathrm{Z}_{0,1} * \mathrm{TI}_{1}=0.0$

Interior surface temperatures of envelope surfaces are computed by rearranging (J.3.2):

$$
\begin{aligned}
T I_{1}= & \left(H C_{1} * T Z_{\mathrm{n}}+H R_{1} * \mathrm{TR}_{\mathrm{n}}+O \mathrm{SI}_{1}+\mathrm{KIP}_{1}+\mathrm{Y}_{0,1} * \mathrm{TO}_{1}\right) \\
& /\left(\mathrm{HC}_{1}+H R_{1}+\mathrm{Z}_{0,1}\right)
\end{aligned}
$$

The value of $\mathrm{TO}_{1}$ must have been previously calculated by the methods in section 1.4 .

The following two partial derivatives are useful in improving the rate of convergence of the heat balance iterations.

$$
\begin{aligned}
& \frac{\partial \mathrm{TI}_{1}}{\partial \mathrm{TZ}_{\mathrm{n}}}=\mathrm{HC}_{1} /\left(\mathrm{HC}_{1}+\mathrm{HR}_{1}+\mathrm{Z}_{0,1}\right) \\
& \frac{\partial \mathrm{TI}_{1}}{\partial \mathrm{TR}_{\mathrm{n}}}=\mathrm{HR}_{1} /\left(\mathrm{HC}_{1}+\mathrm{HR}_{1}+\mathrm{Z}_{0,1}\right)
\end{aligned}
$$

III.J.4 INTERIJAL SURFACES

Internal masses and partitions separating identically conditioned zones can be treated as surfaces with equal inside and outside temperatures. In that case Equation (J.3.2) may be rearranged to give:

$$
\begin{aligned}
\mathrm{TI}_{1}= & \left(\mathrm{HC}_{1} * \mathrm{~T} \mathrm{Z}_{\mathrm{n}}+\mathrm{HR}_{1} * \mathrm{TR}_{\mathrm{n}}+\mathrm{QSI}_{1}+\mathrm{KIP}_{1}\right) \\
& /\left(\mathrm{HC}_{1}+\mathrm{HR}_{1}+\mathrm{Z}_{0,1}-\mathrm{Y}_{0,1}\right)
\end{aligned}
$$

The partial derivatives are

$$
\frac{\partial \mathrm{TI}_{i}}{\partial \mathrm{TZ}_{\mathrm{n}}}=\mathrm{HC}_{i} /\left(\mathrm{HC}_{i}+\mathrm{HR}_{\mathrm{i}}+\mathrm{Z}_{0, i}-\mathrm{Y}_{0, i}\right)
$$


and

$$
\frac{\partial T I_{1}}{\partial T R_{n}}=H R_{1} /\left(H C_{1}+H R_{1}+Z_{0,1}-Y_{0,1}\right)
$$

\section{III.J.5 INTERZONE SURFACES}

In the TARP interzone surfaces are permitted to have movable insulation. This creates another set of basic heat balances at the air-insulation and the insulation-surface interfaces (figure J.2). The inside heat balances (with movable insulation) are

$$
\begin{aligned}
& \mathrm{HC}_{1} *\left(\mathrm{TZ}_{\mathrm{n}}-\mathrm{TM}_{1}\right)+\mathrm{HR}_{1} *\left(\mathrm{TR}_{\mathrm{n}}-\mathrm{TM}_{1}\right)+\mathrm{UM}_{1} *\left(\mathrm{TI}_{1}-\mathrm{TM}_{1}\right)+\mathrm{QSM}_{1}=0.0 \quad(\mathrm{~J} .5 .1) \\
& \mathrm{KIP}_{1}+\mathrm{Y}_{0,1} * \mathrm{TO}_{1}-\mathrm{Z}_{0,1} * \mathrm{TI}_{1}+\mathrm{UM}_{1} *\left(\mathrm{TM}_{1}-\mathrm{TI}_{1}\right)+\mathrm{QSI}_{1}=0.0 \quad \text { (J.5.2) }
\end{aligned}
$$

A similar set of equations exist for the far side of the surface (described as surface $j$ adjacent to zone $m$ ). The far side heat balance (without movable insulation) is

$$
H C_{j} *\left(T Z_{m}-T I_{j}\right)+H R_{j} *\left(T R_{m}-T I_{j}\right)+Q S I_{j}+K I P_{j}+Y_{0, j} * T O_{j}-Z_{0, j} * T I_{j}=0.0
$$

The far side heat balances (with movable insulation) are

$$
\begin{aligned}
& H C_{j} *\left(T Z_{m}-T M_{j}\right)+H R_{j} *\left(T R_{m}-T_{j}\right)+U M_{j} *\left(T I_{j}-T M_{j}\right)+Q S M_{j}=0.0 \text { (J.5.4) } \\
& \mathrm{KIP}_{\mathrm{j}}+\mathrm{Y}_{0, j}{ }^{*} \mathrm{TO}_{\mathrm{j}}-\mathrm{Z}_{0, j}{ }^{*} \mathrm{TI} I_{j}+\mathrm{UH}_{\mathrm{j}} *\left(\mathrm{TM}_{\mathrm{j}}-\mathrm{TI}_{\mathrm{j}}\right)+\mathrm{QSI} \mathrm{I}_{\mathrm{j}}=0.0 \quad \text { (J.5.5) }
\end{aligned}
$$

The following relationships apply because $i$ and $j$ refer to opposite sides of the same surface:

$$
\begin{aligned}
& \mathrm{TI}_{i}=\mathrm{TO}_{j} ; \quad \mathrm{TO}_{i}=\mathrm{TI}_{j} ; \quad \mathrm{KIP}_{\mathbf{i}}=\mathrm{KOP}_{j} ; \mathrm{KOP}_{i}=\mathrm{KIP} \mathrm{P}_{j} ; \\
& \mathrm{Z}_{0, j}=\mathrm{X}_{0, i}\left(=\mathrm{X}_{0}\right) ; \quad \mathrm{Y}_{0, j}=\mathrm{Y}_{0, i}\left(=\mathrm{Y}_{0}\right) .
\end{aligned}
$$

The placement of insulation on either side leads to four basic cases. Compute

$$
\begin{aligned}
& F_{1}=Y_{0} /\left(X_{0}+H C_{j}+H R_{j}\right) \\
& F_{2}=U M_{i} /\left(U M_{i}+H C_{i}+H R_{i}\right) \\
& F_{3}=U M_{j} /\left(U M_{j}+H C_{j}+H R_{j}\right) \\
& F_{4}=Y_{0} /\left(X_{0}+U M_{j}-F_{3} * U M_{j}\right)
\end{aligned}
$$

as needed for the cases below.

CASE 1: No movable insulation on either side. From equations (J.3.2) and $(\mathrm{J} .5 .3)$ : 


$$
\begin{aligned}
\mathrm{TI}_{1}= & {\left[\mathrm{HC}_{1} * \mathrm{TZ} \mathrm{Z}_{\mathrm{n}}+\mathrm{HR}_{1} * \mathrm{TR}_{\mathrm{n}}+\mathrm{QSI_{i }}+\mathrm{KIP}_{\mathrm{i}}+\right.} \\
& \left.\mathrm{F}_{1} *\left(H \mathrm{HC}_{j} * \mathrm{TZ}_{\mathrm{m}}+\mathrm{HR}_{\mathrm{j}} * \mathrm{TR}_{\mathrm{m}}+\mathrm{QSI_{j }}+\mathrm{KIP_{j }}\right)\right] \\
/ & \left(\mathrm{Z}_{0}+\mathrm{HC}_{1}+\mathrm{HR}_{1}-\mathrm{F}_{1} * \mathrm{Y}_{0}\right)
\end{aligned}
$$

The partial derivatives are:

$$
\frac{\partial \mathrm{TI}_{1}}{\partial \mathrm{TZ}_{\mathrm{n}}}=\mathrm{HC}_{1} /\left(\mathrm{HC}_{1}+\mathrm{HR}_{1}+\mathrm{Z}_{0}-\mathrm{F}_{1} * \mathrm{Y}_{0}\right)
$$

and

$$
\frac{\partial \mathrm{TI}_{1}}{\partial \mathrm{TR}}=\mathrm{HR}_{1} /\left(\mathrm{HC}_{1}+\mathrm{HR}_{1}+\mathrm{Z}_{0}-\mathrm{F}_{1} * \mathrm{Y}_{0}\right)
$$

CASE 2: Movable insulation on near side only. From equations (J.5.1), $(\mathrm{J} .5 .2)$, and $(\mathrm{J} .5 .3)$ :

$$
\begin{aligned}
& T I_{1}=\left[K I P_{1}+Q S I_{1}+F_{1} *\left(H C_{j} * T Z_{m}+H R_{j} * T R_{m}+Q S I_{j}+K I P_{j}\right)\right. \\
& \left.+\mathrm{F}_{2} *\left(\mathrm{HC}_{1} * \mathrm{~T} \mathrm{Z}_{\mathrm{n}}+\mathrm{HR}_{1} * \mathrm{TR} \mathrm{R}_{\mathrm{n}}+\mathrm{QSH}_{1}\right)\right] \\
& \text { / }\left(\mathrm{Z}_{0}+U \mathrm{U}_{1}-\mathrm{F}_{1} * \mathrm{Y}_{0}-\mathrm{F}_{2} * U \mathrm{M}_{1}\right) \\
& \mathrm{TM}_{\mathrm{i}}=\mathrm{F}_{2} *\left[\mathrm{TI} \mathrm{I}_{\mathrm{i}}+\left(\mathrm{HC}_{1} * \mathrm{TZ} \mathrm{Z}_{\mathrm{n}}+\mathrm{HR}_{1} * \mathrm{TR} \mathrm{R}_{\mathrm{n}}+\mathrm{QSM_{1 }}\right) / \mathrm{UM} \mathrm{M}_{1}\right]
\end{aligned}
$$

Since $\mathrm{UM}_{1}$ should be small, the partial derivatives are:

$$
\frac{\partial T I_{1}}{\partial T Z_{n}}=\mathrm{HC}_{1} /\left(\mathrm{HC}_{1}+\mathrm{HR}_{1}+\mathrm{UM}_{1}\right)
$$

and

$$
\frac{\partial \mathrm{TI}_{1}}{\partial \mathrm{TR}}=\mathrm{HR}_{1} /\left(\mathrm{HC}_{1}+\mathrm{HR}_{1}+\mathrm{UM}_{1}\right)
$$

CASE 3: Movable insulation on far side only. From equations (J.3.2), $(\mathrm{J} .5 .4)$, and $(\mathrm{J} .5 .5)$ :

$$
\begin{aligned}
& \mathrm{TI}_{1}=\left\{\mathrm{HC}_{\mathrm{i}}{ }^{*} \mathrm{~T} \mathrm{Z}_{\mathrm{n}}+\mathrm{HR}_{\mathrm{i}} \mathrm{TR}_{\mathrm{n}}+\mathrm{KIP_{1 }}+\mathrm{QSI}_{\mathrm{i}}\right. \\
& \left.+\mathrm{F}_{4} *\left[\mathrm{KIP}_{\mathrm{j}}+\mathrm{QSI}_{\mathrm{j}}+\mathrm{F}_{3} *\left(\mathrm{HC}_{\mathrm{j}} * \mathrm{TZ} \mathrm{m}_{\mathrm{m}}+\mathrm{HR}_{\mathrm{j}} * \mathrm{TR}_{\mathrm{m}}+\mathrm{QSH}_{\mathrm{j}}\right)\right]\right] \\
& /\left(\mathrm{Z}_{0}+\mathrm{HC}_{1}+\mathrm{HR}_{1}-\mathrm{F}_{4} * \mathrm{Y}_{0}\right)
\end{aligned}
$$

The partial derivatives are given by (J.5.8a) and (J.5.8b).

CASE 4: Movable insulation on both sides. $Q_{S I}$ and $Q_{S I}$ are both zero because the insulation is assumed opaque. From equations (J.5.1), (J.5.2), $(J .5 .4)$ and $(J .5 .5)$ : 


$$
\begin{aligned}
& \mathrm{TI}_{1}=\left\{\mathrm{KIP}_{i}+\mathrm{F}_{4} *\left[\mathrm{KIP}_{\mathrm{j}}+\mathrm{F}_{3} *\left(\mathrm{HC}_{\mathrm{j}} * \mathrm{TZ}_{\mathrm{m}}+\mathrm{HR}_{\mathrm{j}} \mathrm{TR}_{\mathrm{m}}+\mathrm{QSI}_{\mathrm{j}}\right)\right]\right. \\
& \left.+\mathrm{F}_{2} *\left(\mathrm{HC}_{\mathrm{i}} * \mathrm{TZ} \mathrm{Z}_{\mathrm{n}}+\mathrm{HR}_{\mathrm{i}} * \mathrm{TR}_{\mathrm{n}}+\mathrm{QSM}_{\mathrm{i}}\right)\right\} \\
& /\left(Z_{0}+U M_{j}-F_{4} * Y_{0}-F_{2} * U M_{i}\right) \\
& \mathrm{TM}_{1}=\mathrm{F}_{2} *\left[\mathrm{TI}_{\mathrm{i}}+\left(\mathrm{HC}_{\mathrm{i}} * \mathrm{TZ} \mathrm{Z}_{\mathrm{n}}+\mathrm{HR}_{\mathrm{i}} * \mathrm{TR}_{\mathrm{n}}+\mathrm{QSM_{1 }}\right) / \mathrm{UM}_{1}\right]
\end{aligned}
$$

The partial derivatives are given by (J.5.10a) and (J.5.10b). REFERENCES

[1] ASHRAE Handbook - 1981 Fundamentals (ASHRAE, 1981), p 23.12, Table 1.

[2] ASHRAE Handbook - 1981 Fundamentals (ASHRAE, 1981), p 2.12, Table 5. 


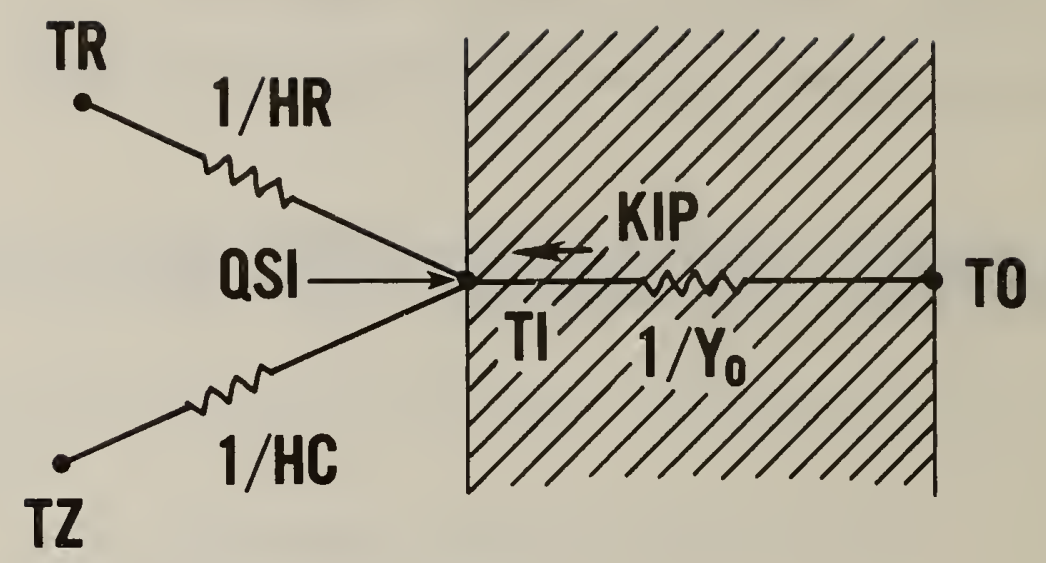

Figure III.J.1 Inside surface thermal network

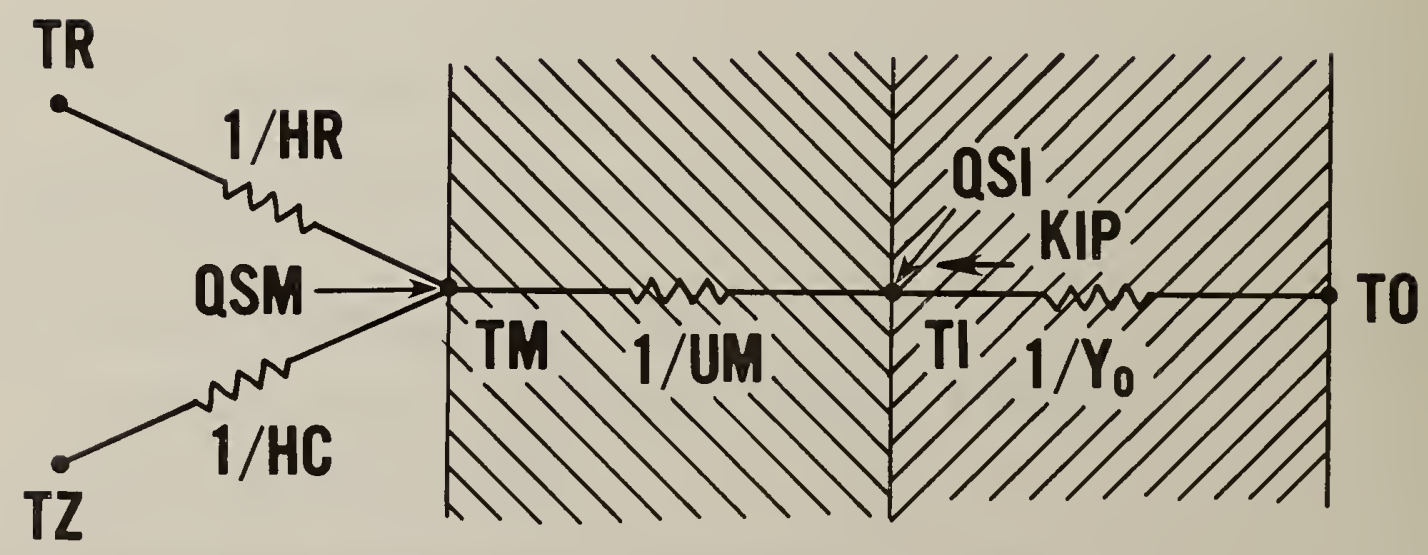

Figure III.J.2 Inside movable insulation thermal network 
The calculation of the zone air temperature is based on a heat balance on the zone alr. The convective gains from the room surfaces and internal sources plus the sensible gain from incoming air plus the energy added by the alr handling system must equal zero.

$$
C E+\sum H C_{1} * S_{1} *\left(T_{1}-T Z\right)+\sum F_{j} * C_{p} *\left(T S_{j}-T Z\right)+L=0
$$

The summations apply to all surfaces which are part of the zone.

The system performance model (III.K.1) may be used with the detalled natural air movement model (III.G) if the supply and exhaust air flows of every zone are equal (that is, Fs in equation (G.3.5) must be zero). The simple air movement models (III.K.2 through III.K.5) may not be used simulatneously with the detalled air novement model.

III.K.1 SYSTEM PERFORMANCE MODEL

The energy from the system is based on the user defined control profile which approximates the performance of the actual system. The control profile consists of a set of control points which define the heating or cooling capacity of the system as a function of the control temperature as in figure K.l. Control range $\mathrm{p}$ is between temperatures $\mathrm{T}_{\mathrm{p}}$ and $\mathrm{T}_{\mathrm{p}+1}$. The control profile is linear between the control points. Simple proportionality gives

$$
\mathrm{L}_{\mathrm{f}}=\mathrm{L}_{\mathrm{p}}+\left(\mathrm{T}-\mathrm{T}_{\mathrm{p}}\right) *\left(\mathrm{~L}_{\mathrm{p}+1}-\mathrm{L}_{\mathrm{p}}\right) /\left(\mathrm{T}_{\mathrm{p}+1}-\mathrm{T}_{\mathrm{p}}\right)
$$

This can be rearranged to

$$
\mathrm{L}=\mathrm{LT} * \mathrm{~T}+\mathrm{LC}
$$

where

$$
\mathrm{LT}=\left(\mathrm{L}_{\mathrm{p}+1}-\mathrm{L}_{\mathrm{p}}\right) /\left(\mathrm{T}_{\mathrm{p}+1}-\mathrm{T}_{\mathrm{p}}\right) \text { and } \mathrm{LC}=\mathrm{L}_{\mathrm{p}}-\mathrm{LT}^{*} \mathrm{~T}_{\mathrm{p}}
$$

The control temperature consists of both the air and the mean radiant temperatures according to the formula

$$
\mathrm{T}=\beta * \mathrm{TR}+(1-\beta) * \mathrm{TZ}
$$

where $\beta$ is the user defined radiant fraction. When this expression is substituted into the zone air heat balance, it gives the following expression for computing the zone air temperature

$$
\begin{aligned}
\mathrm{TZ}= & {\left[\mathrm{CE}+\mathrm{SUM} \mathrm{HC}_{1}{ }^{*} \mathrm{~S}_{1}{ }^{*} \mathrm{~T}_{i}+\operatorname{SUM} \mathrm{F}_{\mathrm{j}}{ }^{*} \mathrm{C}_{\mathrm{p}}{ }^{*} \mathrm{TS}_{j}+\beta^{*} \mathrm{LT}{ }^{*} \mathrm{TR}+\mathrm{LC}\right] } \\
& /\left[\text { SUM } \mathrm{HC}_{i}{ }^{*} \mathrm{~S}_{i}+\operatorname{SUM} \mathrm{F}_{j}{ }^{*} \mathrm{C}_{\mathrm{p}}-(1-\beta) * \mathrm{LT}\right]
\end{aligned}
$$


An equation for the mass flow of infiltration alr can be developed from measured values in similar structures [1]. The TARP assumes a correlation of the form

$$
F I=\left(A_{0}+A_{1} *\left|T Z-T_{a}\right|+A_{2} * V+A_{3} * V^{2}\right) * D_{a}
$$

This correlation accounts for stack effects in the temperature difference term and wind effects in the two velocity terms. Equation (K.1.4) siinplifies to

$$
\begin{aligned}
\mathrm{TZ}= & {\left[\mathrm{CE}+\sum \mathrm{HC}_{1}{ }^{*} \mathrm{~S}_{1}{ }^{*} \mathrm{~T}_{1}+\mathrm{FI}{ }^{*} \mathrm{C}_{\mathrm{p}}{ }^{*} \mathrm{~T}_{\mathrm{a}}+\beta{ }^{*} \mathrm{LT} \mathrm{T}^{*} \mathrm{TR}+\mathrm{LC}\right] } \\
& \left./ \Sigma \mathrm{HC}_{1}{ }^{*} \mathrm{~S}_{1}+\mathrm{FI} \mathrm{C}_{\mathrm{p}}-(1-\beta) * \mathrm{LT}\right]
\end{aligned}
$$

ILI.K.3 ZONE VENTILATION MODEL

'The heating effect of ventilation alr is given by

$$
L V=F V * C_{p} *\left(T_{a}-T Z\right)
$$

TARP ventilation operates by creation of a ventilation profile similar to the zone temperature control profile. A new ventilation profile is created every hour as the amblent temperature changes. No point on the ventilation profile is permitted to overlap the heating or cooling portions of the control profile. This assumes the same fan is used for ventilation and heating or at least that two separate fans are managed by the same controller.

Several types of ventilation profile are possible. Figure K.2 shows a profile when the amblent temperature $\left(\mathrm{T}_{\mathrm{a}}\right)$ is higher than the desired temperature (TV). No cooling occurs until the zone air temperature exceeds TA.

When $T_{a}$ is less than TV, there is a cooling capacity at TV. A small ramp between $T V$ and $T V+0.01$ is created for stability of the heat balance iterations as in figure K.3.

When there is a heating control profile and the desired ventilation temperature is below the point which inftiates heating, the TARP revises TV to above that point as in figure $\mathrm{K} .4$.

When there is a cooling control profile, the ventilation profile is not permitted to extend upward Into the cooling temperature range (f1gure K.5).

IIL.K.4 TWO ZONE MIXING MODEL

A simple model can be developed to describe the forced mixing of air between two zones with simple controls. A mass flow of up to FM will exist from zone $\mathrm{m}$ to zone $\mathrm{n}$ when $\mathrm{TZ}_{\mathrm{m}}-\mathrm{TZ} \mathrm{Z}_{\mathrm{n}}>\mathrm{T} \mathrm{T}$. It is assumed that an equal return flow exists from zone $n$ to $\mathrm{m}$. Since the two zone alr temperatures 
are intimately coupled, it is best to seek an exact simultaneous solution. The description of that solution is simplified by rearranging equation $(K .2 .2)$ to

$$
B_{n} * T Z_{n}=A_{n}
$$

where

$$
\begin{aligned}
& A_{n}=C E_{n}+\sum H C_{1} * T I_{1}+F I_{n} * C p_{n} * T_{a}+\beta * L T_{n} * T R_{n}+L C_{n} \\
& B_{n}=\sum H C_{1}+F I_{n}{ }^{*} C_{p n}-(1-\beta) * L T_{n}
\end{aligned}
$$

A similar equation exists for zone $m$. The effect of an interzone air flow is given by the two equations

$$
\begin{aligned}
& \left(B_{n}+M M\right) * T Z_{n}=A_{n}+M M * T Z_{m} \\
& \left(B_{m}+M M\right) * T Z_{m}=A_{m}+M M * T Z_{n}
\end{aligned}
$$

where $M=F M * C_{p}$.

There are three possible conditions for the interzone air flow. First is that $T Z_{m}-T Z_{n}<T D$ and therefore $M M=0$. Second 1 s that the maximum flow rate st111 leaves $\mathrm{TZ}_{\mathrm{m}}-\mathrm{T} \mathrm{Z}_{\mathrm{n}}>\mathrm{TD}$. S1multaneous solution of equations $(\mathrm{K} .4 .2 \mathrm{a})$ and $(\mathrm{K} .4 .2 \mathrm{~b})$ gives

$$
\begin{aligned}
& T Z_{n}=\left(A_{n}+F_{1} * A_{m}\right) /\left(B_{n}+M M-F_{1} * M M\right) \\
& T Z_{m}=\left(A_{m}+M M_{1} * Z_{n}\right) /\left(B_{m}+M M\right)
\end{aligned}
$$

where $F_{1}=M M /\left(B_{m}+M M\right)$

The third case occurs when no flow gives $T Z_{m}-T Z_{n}>T D$ and full flow would cause $T Z_{1 n}-T Z_{n}<T D$. It is then necessary to solve for the partial flow during the hour which will cause $\mathrm{T} Z_{\mathrm{m}}-\mathrm{T} \mathrm{Z}_{\mathrm{n}}=\mathrm{TD}$. This gives

$$
\begin{aligned}
& M M=\left[A_{m}-B_{1 n} *\left(T D+A_{n} / B_{n}\right)\right] /\left[T D * B_{m} / B_{n}+T D\right] \\
& T Z_{n}=\left(A_{n}+M * T D\right) / B_{n} \\
& T Z_{n}=T Z_{n}+T D
\end{aligned}
$$

III.K.5 WHOLE HOUSE FAN MODEL

A model similar to the zone mixing model (III.K.4) can be developed which describes the effects of a fan moving air only from zone $n$ to zone $m$ with movement of air to and from ambient completing the mass balance. Such a case is the exhaust of house air into its attic. A simple control scheme allows a mass flow of up to $\mathrm{FF}$ whenever $\mathrm{TZ} Z_{\mathrm{n}}>\mathrm{TD}>\mathrm{T}_{\mathrm{a}}$. The effect of the air flow on the zone energy balances is given by 


$$
\left(B_{n}+M F\right) * T Z_{n}=A_{n}+M F * T A
$$

and

$$
\left(B_{m}+M F\right) * T Z_{m}=A_{m}+M F * T Z_{n}
$$

where

$$
\mathrm{MF}=\mathrm{FF} * \mathrm{C}_{\mathrm{p}}
$$

sinflar to equations $(K .4 .2)$.

There are three possible conditions for the interzone air flow. First is that $\mathrm{TD}<\mathrm{T}_{\mathrm{a}}$ or $\mathrm{TZ}_{\mathrm{n}}<\mathrm{TD}$ which gives $\mathrm{MF}=0$. Second is that the maximum flow leaves $\mathrm{TZ}_{\mathrm{Ia}}>\mathrm{TD}$. Direct solution of equations $\mathrm{la}$ and $\mathrm{Ib}$ gives

$$
\begin{aligned}
& \mathrm{T} Z_{n}=\left(A_{n}+M F * T A\right) /\left(B_{n}+M F\right) \\
& T Z_{m}=\left(A_{m}+M F * T Z_{n}\right) /\left(B_{m}+M F\right)
\end{aligned}
$$

The third case occurs when no flow gives $T Z_{n}>T D$ and full flow would cause $T Z_{\mathrm{n}}<\mathrm{TD}$. It is then necessary to solve for the partial flow during the hour which causes $T Z_{n}=T D$.

$$
\begin{aligned}
& \mathrm{MF}=\left(\mathrm{A}_{\mathrm{n}}-\mathrm{B}_{\mathrm{n}} * \mathrm{TD}\right) /\left(\mathrm{TD}-\mathrm{T}_{\mathrm{a}}\right) \\
& \mathrm{TZ} \mathrm{Z}_{\mathrm{n}}=\mathrm{TD} \\
& \mathrm{TZ} \mathrm{Z}_{\mathrm{m}}=\left(A_{\mathrm{m}}+M \mathrm{~F} * \mathrm{~T} \mathrm{Z}_{\mathrm{n}}\right) /\left(\mathrm{B}_{\mathrm{m}}+\mathrm{MF}\right)
\end{aligned}
$$

REFERENCES

[1] Coblenz, C. W. and Achenbach, P. R., "Fleld Measurements of Ten Flectrically-Heated Houses", ASHRAE Transactions (ASHRAE, 1963), pp 358-365. 


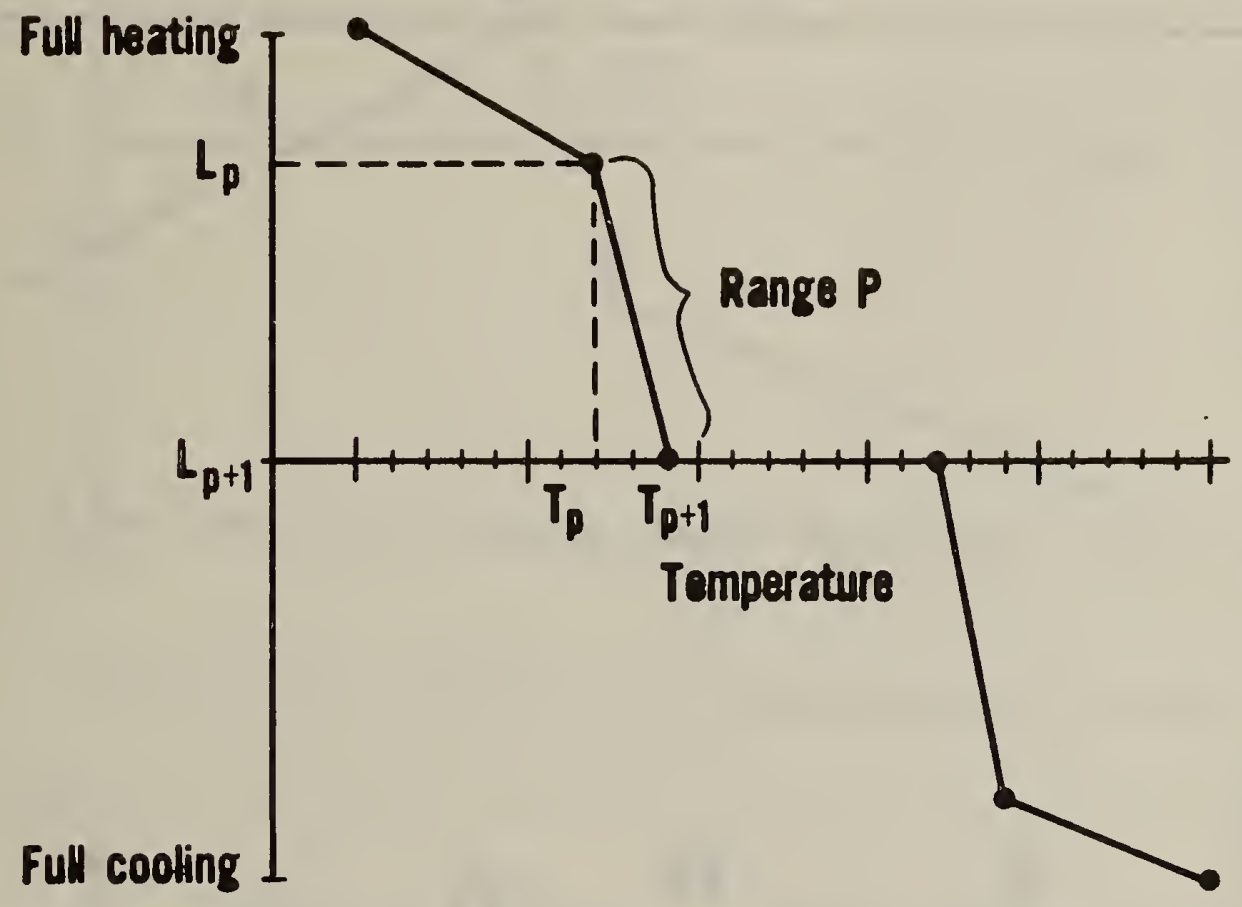

Figure III.K.l Zone temperature control profile 


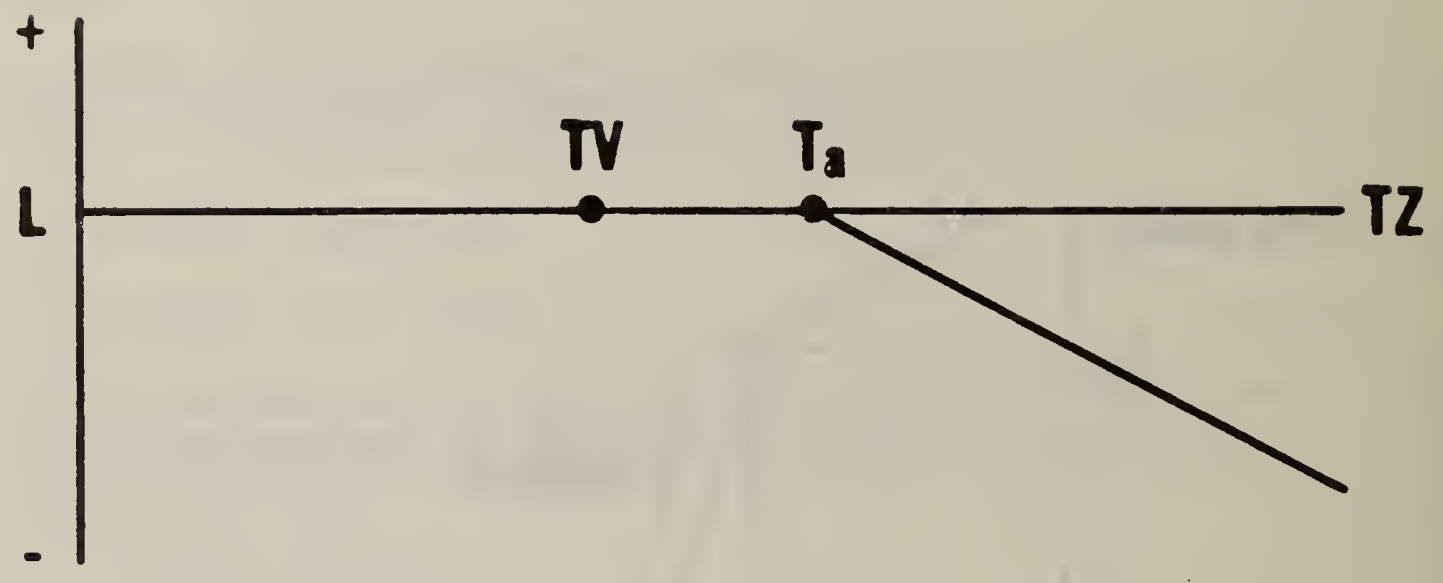

Figure III.K.2 Ventilation control profile: $T_{a}$ higher than TV

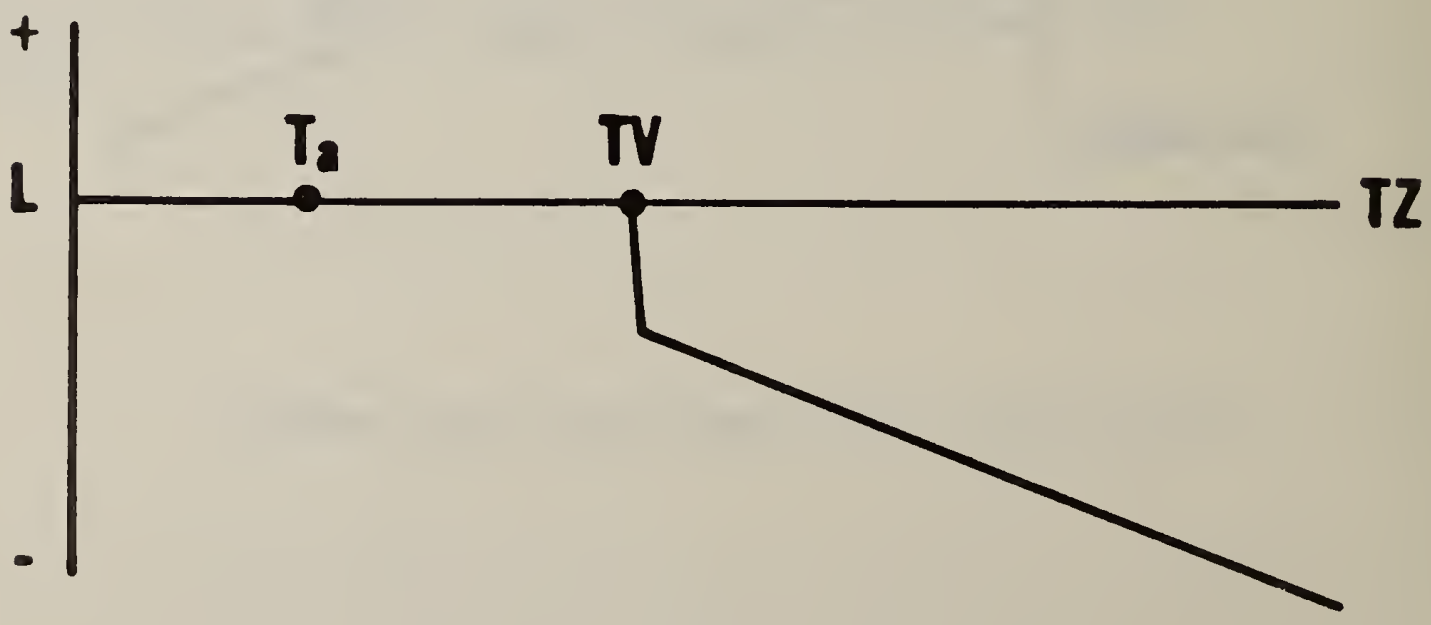

Figure III.K.3 Ventilation control profile: $T_{a}$ higher than TV 


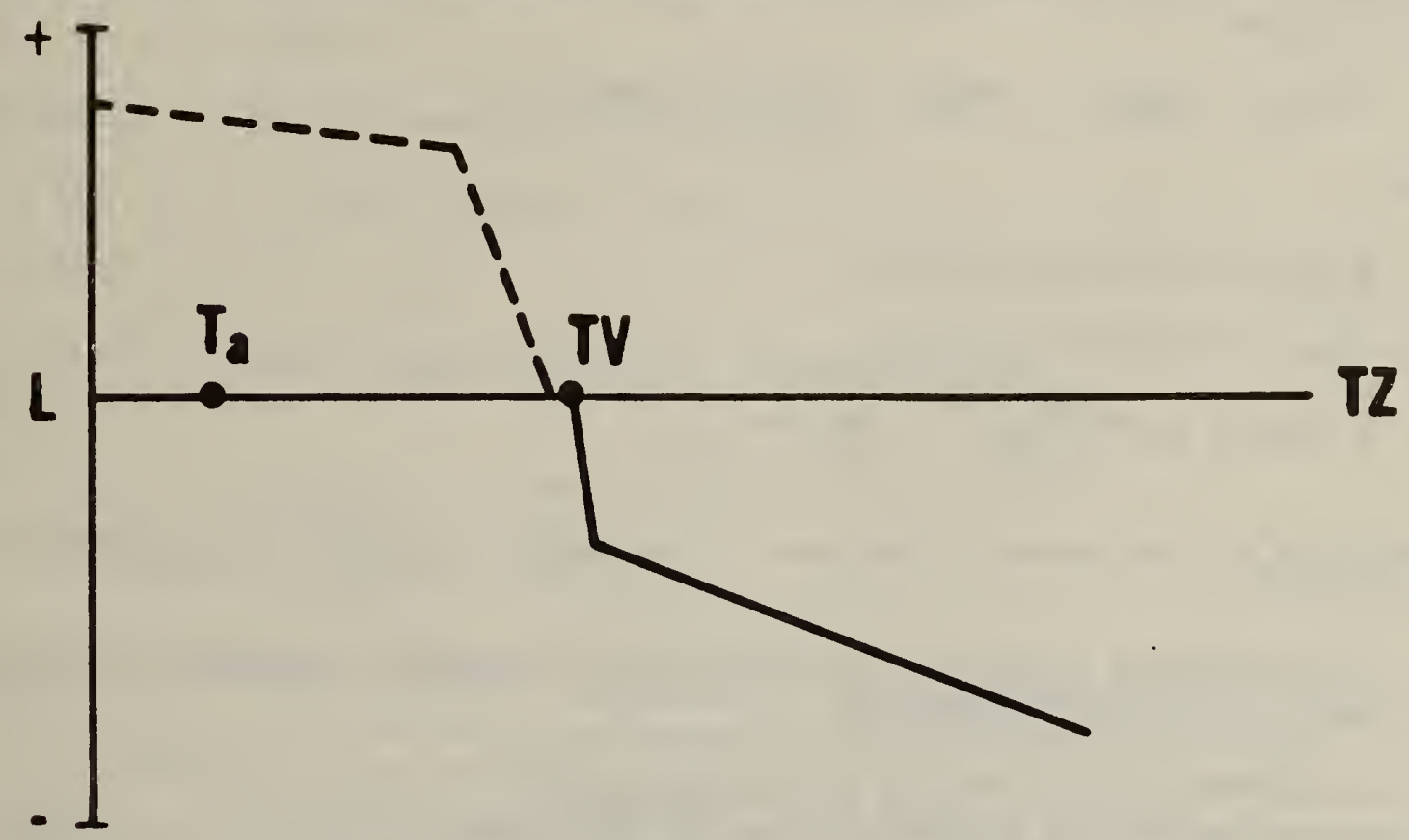

Figure III.K.4 Ventilation and heating control profiles

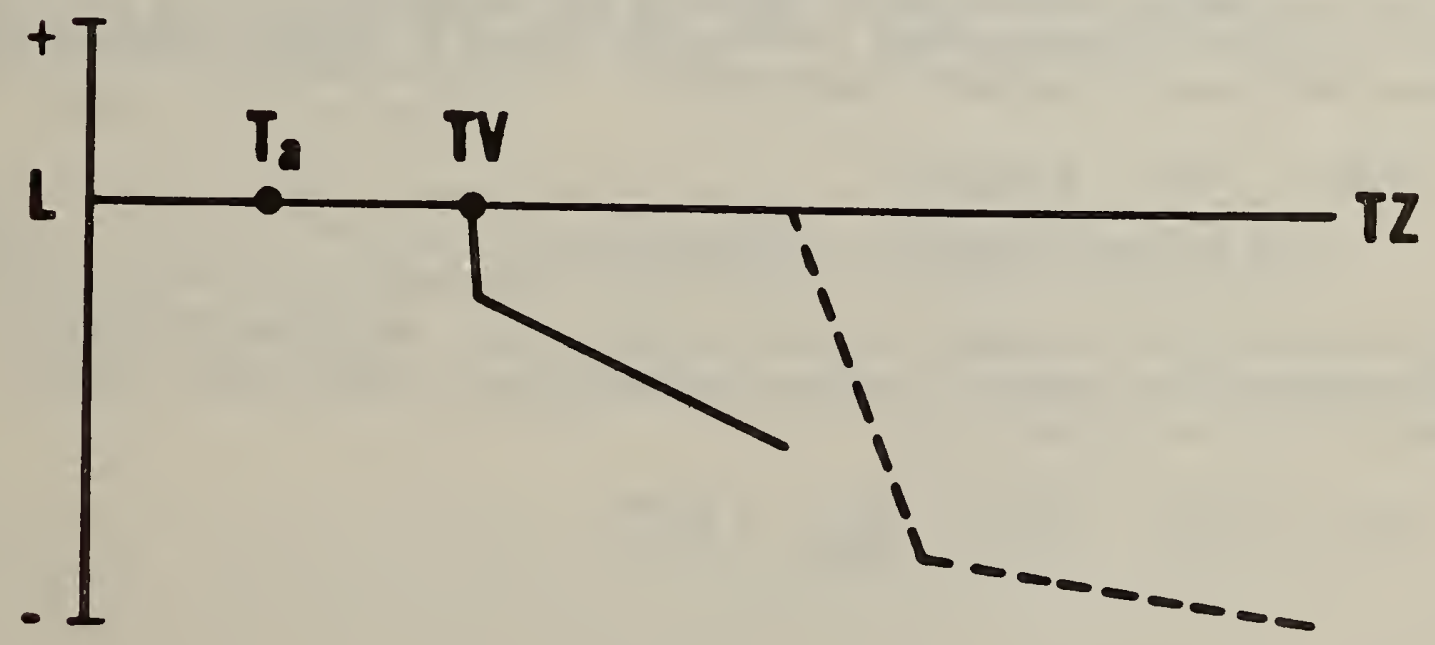

Figure III.K.5 Ventilation and cooling control profiles 
In any zone the alr temperature, mean radiant temperature, and the surface temperatures are intimately related. A change in any one will cause changes in all of the others. Those secondary changes should be predictable.

It was observed that, with the zone alr temperature held nearly constant by a large heating capacity, there was a regular pattern in successive radiant temperature values during the heat balance iterations for a given hour.

$$
\left(T R_{k+2}-T R_{k+1}\right) /\left(T R_{k+1}-T R_{k}\right)=\text { constant }
$$

where

$k$ is the 1teration number.

The value of that constant is

$$
\Sigma\left(H R_{1} * S_{1} * \frac{\left.\partial T I_{1}\right)}{\partial T R_{n}} / \Sigma\left(H R_{1} * S_{1}\right)\right.
$$

with 1 for all surfaces of the zone. The partial derivatives are described in section $\mathrm{J}$.

The following logic led to a method for improved convergence for fixed or floating zone air temperature.

(1) Do the first 1teration in the normal manner.

(2) During the second iteration a new TR is computed (H.2.5). It is $\Delta T R 0$ greater (negative value means less) than the f1rst 1teration TR.

(3) By 1tself, this would cause an increase of $\alpha^{*} \Delta T R_{0}$ in the value of $T R$ in the next 1teration. $\alpha$ is the constant given by (L.1.2).

(4) It also causes an increase in the zone alr temperature due to increased convective gain. Assuming that the average change in surface temperatures equals the change in radiant temperature

$$
\begin{aligned}
\Delta \mathrm{TZ}_{0}= & \Delta \mathrm{TR}_{0} * \Sigma \mathrm{HC}_{1} * \mathrm{~S}_{1} / \\
& {\left[\Sigma \mathrm{HC}_{1} * \mathrm{~S}_{1}+\Sigma \mathrm{F}_{j} * \mathrm{C}_{\mathrm{p}}-(1-\beta) * \mathrm{LT}\right] }
\end{aligned}
$$

(5) Increasing $T Z$ w111 then Increase the TI because of convective gain. Again assuming the change in surface temperatures is about equal to the change in radiant temperature

$$
\Delta \mathrm{TR}_{1}=\Delta \mathrm{TZ}_{0} * \Sigma \mathrm{HC}_{1} * \mathrm{~S}_{1} * \frac{\partial \mathrm{TI}_{1}}{\partial \mathrm{TZ} \mathrm{n}} / \Sigma \mathrm{HC}_{1} * \mathrm{~S}^{1}
$$




$$
\begin{aligned}
& =\Delta \mathrm{TR}_{0} * \Sigma \mathrm{HC}_{1} * \mathrm{~S}_{i} * \frac{\partial \mathrm{TI}_{i}}{\partial \mathrm{TZ}_{\mathrm{n}}} / \\
& {\left[\Sigma \mathrm{HC}_{i} * \mathrm{~S}_{i}+\Sigma \mathrm{F}_{j} * \mathrm{C}_{\mathrm{p}}-(1-\beta) L \mathrm{~T}\right]} \\
& =\gamma * \Delta \mathrm{TR}_{0}
\end{aligned}
$$

(6) Combine the changes in radiant temperature in (3) and (5) to give the total change in TR for one iteration.

$$
\Delta \mathrm{TR}_{2}=(\alpha+\gamma) * \Delta \mathrm{TR}_{0}
$$

The total change in TR over several iterations is

$$
\begin{aligned}
\Delta \mathrm{TR} & =\Delta \mathrm{TR}_{0} *\left[1+(\alpha+\gamma)+(\alpha+\gamma)^{2}+(\alpha+\gamma)^{3}+\ldots\right] \\
& =\Delta \mathrm{TR}_{0} /(1-\alpha-\gamma)
\end{aligned}
$$

(7) Similarly, the total change in zone air temperature is given by

$$
\begin{aligned}
\Delta \mathrm{TZ}= & {\left[\Delta \mathrm{TR}_{0} * \Sigma \mathrm{HC}_{\mathrm{i}}{ }^{*} \mathrm{~S}_{\mathrm{i}}\right) *\left[(\alpha+\gamma)+(\alpha+\gamma)^{2}+\ldots\right] / } \\
& {\left[\Sigma \mathrm{HC}_{\mathrm{i}} * \mathrm{~S}_{\mathrm{i}}+\Sigma \mathrm{F}_{\mathrm{j}} * \mathrm{C}_{\mathrm{p}}-(1-\beta) * \mathrm{LT}\right] }
\end{aligned}
$$

(8) The current estimates of TR and TZ are therefore increased by $\triangle T R$ and $\triangle T Z$, respectively. Then the surface temperatures and resulting new zone air temperature are calculated in the normal manner. For the convergence test the new $\mathrm{TZ}$ is compared to the predicted value of $\mathrm{TZ}$ instead of the previous iteration value. If the two temperatures (or associated heating/cooling load) are sufficiently close, the solution has converged.

On the first iteration of a given hour, many parameters may have changed from the previous hour. These parameters include the delayed conductive gains and radiant and scheduled loads. These are additional factors which must be included in the convergence algorithm. So far that has only been partially successful.

Sample results of the convergence improvement algorithm for a single zone showed a reduction from an average of 7.6 to 2.3 iterations per hour in the floating temperature mode and from 5.4 to 2.1 iterations per hour in the fixed temperature mode. 
IV. INPUT

IV.A OVERVIEW

It is intended that the TARP input deck be an on-1ine file which is created and modified by a text editing system. It can also be a deck of punched cards. There is a simple, consistant input structure. The input is based on a keyword system (keyword = value) to produce a free-format, self-descriptive input. In some ways it is simflar to NAMELIST input which is a feature of sone versions of FORTRAN. The keywords have been kept short (usually less than 5 letters) to reduce the amount of typing that must be done. The keyword system is organlzed in a loglcal hierarchy which groups related concepts and data. Defaulting is used extensively. This applies to individual values and to groups of values representing entire elements of bullding operation or description. Some groups of often used data can be named and then used many times by referring to the name.

This input method was chosen from the following four basic alternatives.

1. Columns or lines of numbers for simple fixed or free format FORTRAN reading.

2. A free-format, self-descriptive language such as used by BLAST or DOE.

3. A prompting, fully interactive system.

4. A graphic, Interactive system.

Method 4 could not be used because of 1 ts equipment and programming time requirements. The complexity of describing bullding geometry may make it the logical cholce of input for a user-orlented loads prograin. Simple FORTRAN reads (method 1) are easy to program and produce a small, fast computer program. However, it is difficult to incorporate simple defaulting and optional input. It is also difficult to understand and correct the input without running it through the input processor. Self-descriptive input (method 2) can be critlcised as taking too long to prepare and presenting more opportunttes for error because of the additional words used to describe the numbers. But defaulting is easy to incorporate, and the user can understand the input deck directly after only a 11ttle practice. Prompting, interactive input (method 3) can be of great help to the beginning user. The large number of values involved in a complete building description can make full prompting tedious. The prompting system must allow for changing the input after it has been used for a loads calculation. This method may be worth the programming time 1 t would take to implement.

\section{IV.B INPUT LANGUAGE SYNTAX}

Several goals were assisted by the development of a slmple, consistant input structure. That input structure may be considered a language and the relationships of the components of a language are called "syntax". The following pages describe the input syntax in two ways. First is the Backus-Naur Form (BNF) which is traditional to computer science. Second is 
an English description of the same features for those who are unfamiliar with BNF.

IV.B.1 BNF DESCRIPTION

1. 〈INPUT DECK $\rangle::=\langle$ SECTION $\rangle\{\langle$ SECTION $\rangle\}$

2. 〈SECTION $\rangle::=\langle$ SECTION NAME $\rangle[\langle\mathrm{KEY}\rangle\{\langle\mathrm{KEY}\rangle\}]$

3. $\langle\mathrm{KEY}\rangle::=\langle\mathrm{KEY}$ NAME $\rangle(\langle\mathrm{SUBKEY}\rangle\{\langle\mathrm{SUBKEY}\rangle\})$

4. 〈SUBKEY $>::=\langle$ SUBKEY NAME $\rangle / \mid$ $\langle$ SUBKEY NAME $\rangle=\langle$ DATA $\{,\langle$ DATA $\rangle\} /$

5. $\langle\mathrm{DATA}\rangle::=\langle\mathrm{NAME}\rangle|\langle\mathrm{INTEGER}\rangle|\langle\mathrm{REAL}\rangle|\langle\mathrm{DATE}\rangle|\langle\mathrm{DESCRIPTION}\rangle$

6. $\langle$ NAME $\rangle::=\langle$ CHAR $\rangle\langle\langle$ CHAR $\rangle|\langle N U L L\rangle\}$

7. 〈UNS INTEGER $::=\langle$ DIGIT $\rangle\langle$ DIGIT $\rangle \mid\langle N U L L\rangle\}$

8. 〈INTEGER〉 : := 〈UNS INTEGER〉 | - 〈UNS INTEGER〉

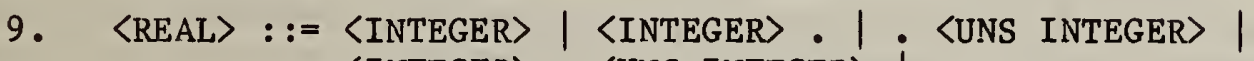
$\langle$ INTEGER $\rangle$. 〈UNS INTEGER

〈INTEGER〉 . 〈UNS INTEGER〉 E 〈INTEGER〉

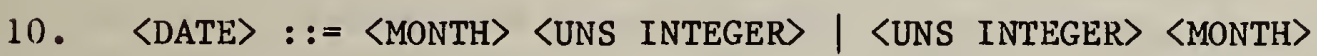

11. $\langle$ DESCRIPTION $\rangle::=$ ' $\{\langle$ CHAR $\rangle \mid\langle$ SYMBOL $\rangle \mid\langle$ NULL $\rangle\}$ '

12. 〈CHAR $\rangle::=\langle$ LETTER $\rangle \mid\langle$ DIGIT $\rangle|-|$.

13. 〈SYMBOL $>::=|=1|,(\mid)|\$| * \mid[\mid]$

14. 〈NULL $\rangle::=\langle$ BLANK $\rangle \mid+$

15. 〈LETTER $>::=$ A $\mid$ B $|\ldots|$ Y | Z

16. $\langle$ DIGIT $\rangle::=0|1| \ldots|c| c$

17. 〈MONTH〉::= JAN $\mid$ FEB $|\ldots|$ NOV | DEC

18. 〈COIMENT $\rangle::=\$ \mid) \mid]\{\langle$ CHAR $\rangle \mid\langle$ SYMBOL $\rangle \mid\langle$ NULL $\rangle\}$ END-OF-LINE

IV.B.2 ENGLISH DESCRIPTION

1. The TARP input deck consists of several sections. There are present1y four sections: PROJECT, LIBRARY, BUILDING, and ZONE.

2. Each section consists of a section name and one or more keys enclosed in brackets. 
3. A key is a key name and one or more subkeys enclosed in parentheses.

4. A subkey consists of a subkey naine or a subkey name, an equals sign, one or more data values, and a terminating slash. When only a subkey name is called for, entry of that name enables some option. Most subkeys introduce one or more elements of data. Multiple data values are separated by commas.

5. There are five different data types. Only descriptions may be longer than 10 non-null characters.

6. A name consists of characters.

7. An unsigned integer consists of digits.

8. An integer is an unsigned integer for positive values or an unsigned integer preceeded by a minus sign for negative values.

9. There are five distinct representations for real numbers. Note that a decimal point is not necessary and that exponential notation is possible.

10. Dates consist of a month name and a day number.

11. A description is a string of characters and other symbols enclosed in apostrophes. It may be up to 100 characters long, including nulls and symbols. An apostrophe may not occur within the string.

12. "Characters" are letters, digits, hyphen (ininus), and period.

13. There are several generally recognized symbols in FORTRAN 77 . These symbols are used as punctuation in the input language. Most systems also provide other symbols which may be used in those language elements which use "symbols" such as ", \%, @, etc.

14. The blank and plus sign are nulls. They are ignored by the input reader. Therefore, elements of the language may be separated by blanks to improve readability. The plus sign does not affect the value or character count of a number.

15. Letters are the 26 letters of the alphabet.

16. Digits are the 10 numerals.

17. Months are first three letter abbreviations of the 12 months.

18. Comments begin with a dollar sign or at the end of a key or end of a section and continue to the end of the line. They may be included on lines with input or on separate lines. 


\section{Other features:}

Successive identical subkey values "..., $\langle\mathrm{DATA}\rangle,\langle\mathrm{DATA}\rangle,\langle\mathrm{DATA}\rangle, \ldots$ may be replaced by "..., $\langle$ UNSIGNED INTEGER $\rangle *\langle$ DATA $\rangle, \ldots$ ".

A line of input may be up to 80 characters long. Input features may be continued on succeeding lines. Punctuation determines the end of all input features except comments, which terminate at the end of the line.

The final subkey slash before ending a section may be dropped. That is, "/ )" may be replaced by ")". The slash may be considered a separator rather than a terminator.

\section{IV.B.3 ERROR PROCESSING}

The TARP handles incorrect input by reporting the error and then skipping to the next readable input. It makes no attempt to correct the input error. It is more important for the user to correctly type punctuation than names or values. The approximate order of importance of punctuation is: ' $\$[$ ] ( ) / = , Similarly, section names are more important than key names which are more important than subkey names which are more important than data. For example, an incorrect data value would cause the program to not process only that value, but an incorrect subkey name causes the program to skip all values following it (because the program cannot know to which subkey they apply) and go to the next subkey; which will be after the next "/". Similarly, an incorrect key name causes the program to skip the entire key including all its subkeys. The key name will have to be corrected and another run made to find any errors in the subkeys. The punctuation is critical because it determines where the input skipping stops. The program must then find a recognizable name or another skip will occur. Thus the brackets and parentheses are nore important than slashes because an error in them causes more skipped input. The apostrophe and dollar sign are most critical because descriptions and comments can include punctuation symbols which could totally confuse the input reader. Although this process sounds complex, the consistancy of the syntax makes it very easy for the user to check punctuation before submitting the input to the computer. The input deck can be debugged in a small number of runs because the entire deck will be processed during every run instead of quitting at the first error. 
The input must be made meaningful by defining the "vocabulary" of names and data which fill in the syntax. Every section, key, and subkey is discussed below. Each subkey description is headed by a line containing $81 x$ elements :

1. The section, key, and subkey numbers (e.g. 2.4.1). These serve in cross-referencing to other input. Several related subkeys may be grouped under one subkey number.

2. The subkey name, "=", data types. The data types mean: $n=$ name, $r=$ real, 1 = integer, $d$ = date, desc = description.

3. The default. Dimensional values are in metric units. Immediately below is the value in English units.

4. The units. "-" means dimensionless. English units are given below the metric units.

5. The status. "reqd" means a value must be given. "opt" means a value is optional; otherwise the default will be used. "cond" means conditional. One of several values must be chosen or a value must be chosen if some other input has been set.

6. The permitted range of the data value.

\section{IV.C.1 PROJECT SECTION}

\section{PROJECT [ Project Section.}

This section is required. It also must be first. It creates the data that relates to the entire project: weather data and various input/output controls.

1.1 RC ( Run control parameters.

This key is optional, but if it is used it must be first.

\subsubsection{DESC = 'desc' blank - opt}

This description will appear on the loads reports.

\subsubsection{SYNTAX no
This subkey causes the input processor to do only a "syntax check".} Syntax and typing errors are 1isted. This avolds many of the calculations that are normally done, so that the processor can run quicker and with less core, but it does not produce a simulation input file (SINPFL) for the loads program.

1.1.3 DEIS no - opt This subkey will enable the printing of more detalled error messages. It may be useful in the early debug phase or for the inexperienced user. 
$1.1 .42 \mathrm{SPC}$ no opt This w111 cause double spacing. A blank 11 ne will be inserted between each user input line which is echoed in the input processor report. This enhances readability.

1.1 .5 XREF no - opt The input processor will report the sequence number of every major input element. This will aid in locating the input that may be causing errors in the loads calculation. See V.A.2.3 for further detalls.

\section{1 .6 OLDW no - opt}

This subkey may be used if a environment file (ENVTFL) has been prepared and saved in a previous run. It causes keys $1.3,1.4,1.5$, and 1.6 to be skipped, saving the time that would be spent preparing a new identical environment file.

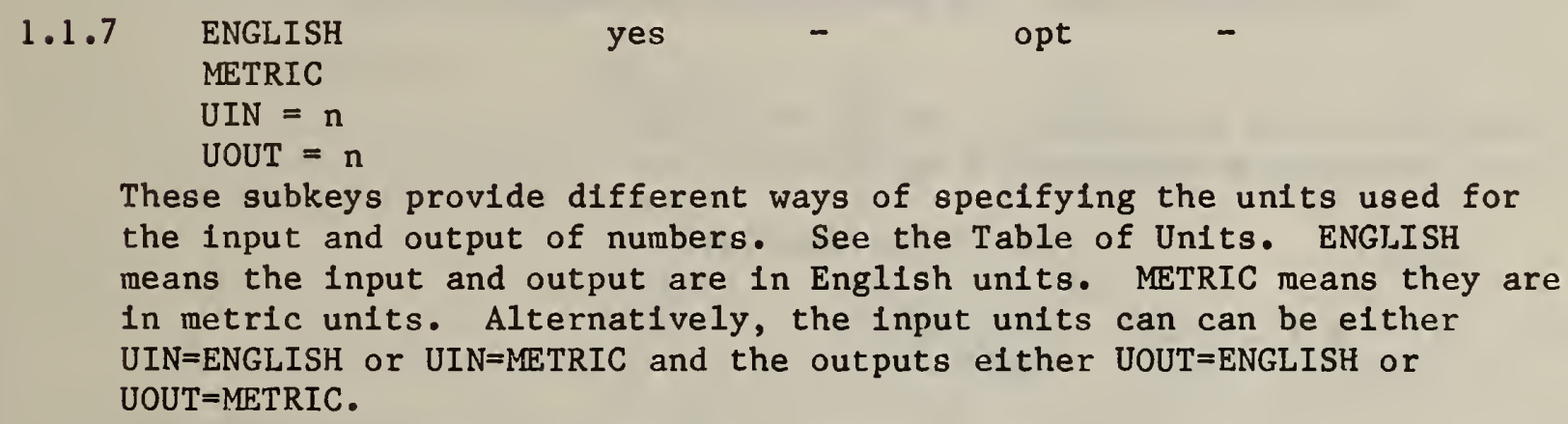

These subkeys provide different ways of specifying the units used for the input and output of numbers. See the Table of Units. ENGILISH means the input and output are in English units. METRIC means they are in metric units. Alternatively, the input units can can be either UIN=ENGLISH or UIN=METRIC and the outputs either UOUT=ENGLISH or UOUT=METRIC.

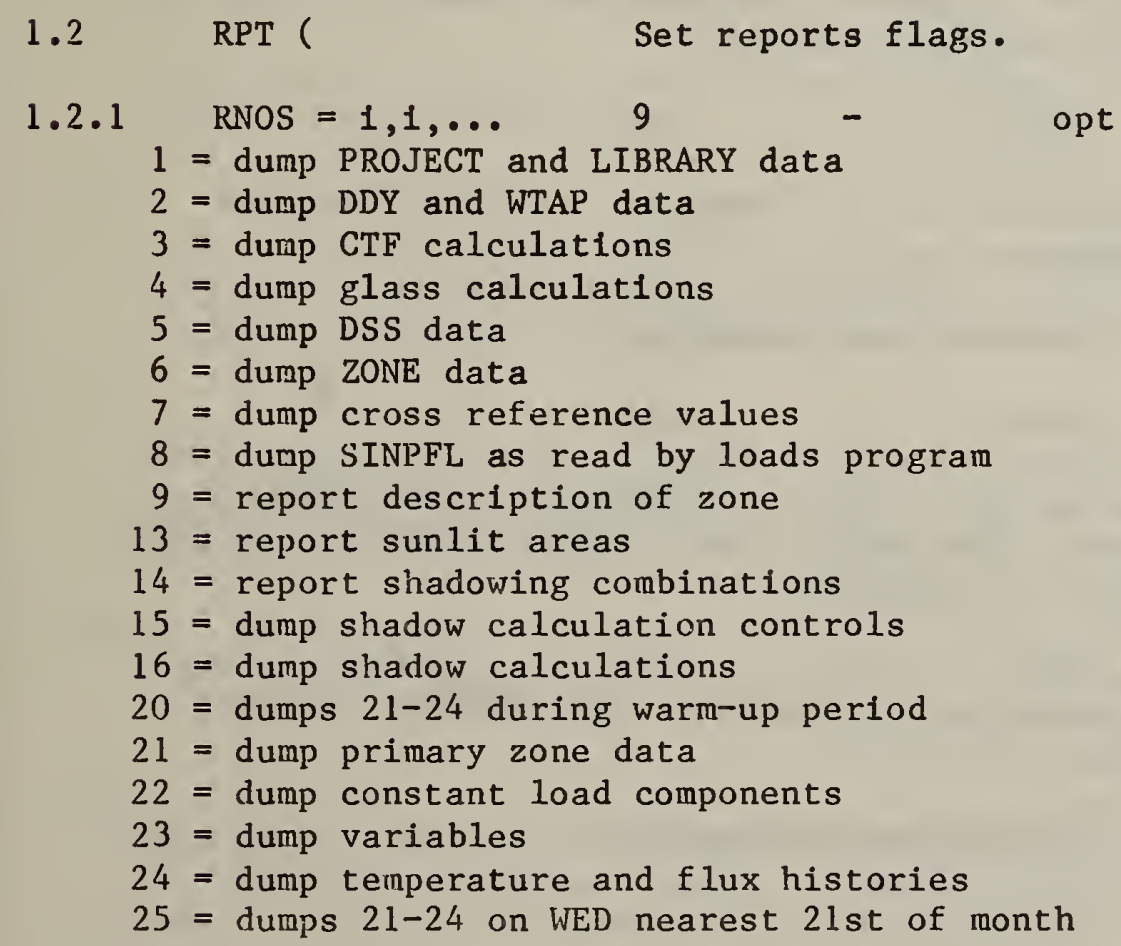


1.3 LOC ( Location.

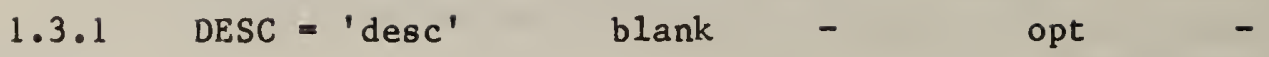

1.3.2 LATD $=r \quad 40 . \quad$ degrees opt $\quad-90 .<=r<=90$. The latitude of the site. Degrees north is positive.

1.3.3 LONG $=r \quad 90 . \quad$ degrees opt $\quad-180 .<=r<=180$. The longltude of the site. Degrees west 18 positive.

1.3.4 $\mathrm{TZ}=\mathrm{r}$ 6. - cond $0 .<=\mathrm{r}<=24$. The time zone number of the site. The Unfted States eastern time zone is 5 and the Pacific time zone is 8 .

1.3.5 ALT $=r$
The alt1tude of the site. Not used by the program.

1.3.6 TER = $1 \quad 2 \quad-\quad$ opt $\quad 1<=1<=3$

Type of terraln 18 used only with HO $=2(3.1 .6)$.

Type numbers are as described in III.B.4.

1.4 GRND ( Ground parameters.

$1.4 .1 \quad G R T=r, r, \ldots\langle 12\rangle \quad 12 * 12.78 \mathrm{C} \quad$ opt $12 * 55$. F

Ground temperatures for the 12 months starting with January. They are used only with other side coefficlents ( 4.3$)$.

1.4.2 MWT $=\mathrm{r}, \mathrm{r}, \ldots<12\rangle \quad 12 * 12.78 \mathrm{C} \quad$ opt

$12 * 55 . \quad F$

Make-up water temperatures for the 12 months starting with January.

Not yet used by the program.

1.5 WTAP ( Weather tape parameters.

1.5.1 DESC = 'desc' blank - opt -

1.5.2 SKIP = 1 o - opt $0<=1<=365$

Sk1p this number of days on the weather tape before starting to process days for the environment file (ENVTFL).

1.5.3 DAYS $=1 \quad 365 \quad$ opt $\quad 1<=1$

Process this number of days from the weather tape (WTHRTP) to the environment file (ENVTFL).
1.6 DDY (
Design day description.
1.6.1 DESC $={ }^{\prime} \operatorname{desc}{ }^{\prime}$
blank
opt 

1.6.2 $\mathrm{HIGH}=\mathrm{r}$
35.0
C
opt
95.0
F
-

High temperature for the design day.
1.6.3 LOW $=r$
22.78
C
opt
LOW $=\mathrm{HIGH}$

Low temperature for the day.
$1.6 .4 \quad W B=r$
25.56
C
opt
$78.0 \quad F$

Wet bulb temperature at the time of the day's high temperature. This

temperature must be psychrometrically possible.

1.6.5 DATE $=\mathrm{d}$
The date determines the solar position and length of daylight.
1.6.6 PRES $=\mathrm{r}$
100000. $\mathrm{Pa}$
opt
401.5 in $\mathrm{H} 20$

The absolute barometric pressure at the site is used in the psychrometric calculations.
1.6 .7 WS $=r$
3.353
$\mathrm{m} / \mathrm{s}$
opt
660. $\mathrm{ft} / \mathrm{min}$
$-$

The default wind speed is 7.5 miles per hour. ( $1 \mathrm{mph}=88 \mathrm{ft} / \mathrm{min})$

1.6.8 $\mathrm{DIR}=\mathrm{r} \quad 270 . \quad$ degrees opt $-360 .<=\mathrm{r}<=360$.

Wind direction: north $=0$ degrees, clockwise is positive. The default wind is from the west.
1.6.9 CLR $=\mathrm{r}$
1.0
opt
$0 .<=r$

The total solar radiation on a horizontal surface is the ASHRAE clear sky amount times this clearness number. The proportion of beam and diffuse radiation changes according to a correlation function.

1.6.10 RAIN no - opt

RAIN causes the outside temperatures of surfaces exposed to ambient to be set to the wet bulb temperature. This models the cooling effect of rain on the building.

1.6.11 SNOW
SNOW causes the ground reflectance to be increased from its default of
0.2 to 0.7 . This gives a much higher diffuse solar gain to the zones.

1.6.12 SUN ... MON - opt -

The day of the week determines which day-schedules (2.2) and control day-schedules (2.6) are used. Allowable day names are: SUN, MON, TUE, WEV, THU, FRI, SAT, HOL, SP1, SP2, SP3, SP4. 
2. LIBRARY L Library Section.

The library simplifies input by grouping relatively large amounts of data by name. That name can be referenced later in the input process instead of again specifying all the data. This produces economies when items are used several times. There are seven types of library data: day-schedules (DS), week-schedules(WS), materials (MATL), constructs (CONS), control profiles (CPFL), control day-schedules (CDS), and control week-schedules (CWS).

2.1 LIB (

$2.1 .1 \quad$ NAME $=n$ Not yet used.

2.1.2 NDS $=1$

NWS $=1$

NMATL $=1$

NCONS $=1$

NCPFL $=1$

NCDS $=1$

NCWS $=1$
Library control parameters.

blank - opt

$\begin{array}{llll}16 & - & \text { opt } & - \\ 16 & - & \text { opt } & - \\ 16 & - & \text { opt } & - \\ 16 & - & \text { opt } & - \\ 16 & - & \text { opt } & - \\ 16 & - & \text { opt } & - \\ 16 & \text { - } & \text { opt } & -\end{array}$

These subkeys control the number of library elements which can be defined. Library names are stored in an array which is 256 elements long. The total number of named library elements cannot exceed 256. The sum of these subkeys (Including those left to default) cannot exceed 256 .

$\begin{array}{clllll}2.1 .3 & \text { ALL } & \text { no } & - & \text { opt } & - \\ \text { DS } & \text { no } & - & \text { opt } & - \\ \text { WS } & \text { no } & - & \text { opt } & - \\ \text { MATL } & \text { no } & - & \text { opt } & - \\ \text { CONS } & \text { no } & - & \text { opt } & - \\ \text { CPFL } & \text { no } & - & \text { opt } & - \\ \text { CDS } & \text { no } & - & \text { opt } & - \\ \text { CWS } & \text { no } & - & \text { opt } & -\end{array}$

These eight subkeys control the printing of library data. The eight individual names will each produce reports for that class of library data. ALL will cause all eight classes to be reported.

2.2 DS ( Day-schedules. A day-schedule is a set of 24 numbers used to provide an hourly variation in some building parameter.

2.2.1 NAIE $=n$
Each day-schedule name must be different from all other day-schedule names. 
2.2.2 DESC $=$ 'desc' blank - opt

A description will more fully describe the purpose of the schedule. It will appear in the day-schedule report.

$2.2 .3 \quad F F C=r, r, \ldots<24\rangle \quad 24 * 1.0 \quad-\quad$ opt $0 .\langle=R<=1$. Fraction of full capacity. 24 values are required: one for each hour of the day. They may range from zero to one. A zero value can be replaced by $O F F$ and $O N$ can be used in place of one. This may be more intuitive for day-schedules which are controlling the on/off operation of something.

2.3 WS ( Week-schedules.

A week-schedule is a set of 12 day-schedules: one for each day of the week, one for holldays, and one for each of 4 special day types (SP1, $\mathrm{SP} 2, \mathrm{SP} 3$, and SP4). It is referenced by name in subsequent building input.

2.3.1 NAME $=\mathrm{n} \quad$ blank - reqd

Each week-schedule must have a name different from all other week-schedule names.

2.3.2 DESC = 'desc' blank - opt

A description is useful in more fully describing the schedule, but its use is optional.

2.3.3 WD =n blank - cond Set weekday (Monday through Friday) pointers to the named day-schedule. That day-schedule must have been previously defined (2.2). Other options are:
$\mathrm{WE}=\mathrm{n}$
$\mathrm{ALL}=\mathrm{n}$
SUN $=n$
MON $=n$
Set weekend (SAT \& SUN) pointers.
Set all 12 pointers.
Set Sunday pointer only
Set Monday pointer only.

and sinilarly for $T U E=n$, WED $=n, T H U=n, F R I=n, S A T=n, S P 1=n$, $\mathrm{SP} 2=\mathrm{n}, \mathrm{SP} 3=\mathrm{n}$, and $\mathrm{SP} 4=\mathrm{n}$. At least one day must be defined (other pointers w111 be set by default rules).

2.4 MATL ( Materials.

These describe the materials used in the walls, windows, floors, etc., of the building. Conductive, optical and surface properties can be described. The user must define the conductive properties ( $K, C H$, and $\mathrm{D}$ ) or $\mathrm{R}$.
2.4.1 NAME $=\mathrm{n}$
blank
$-$
reqd
Each material must have a unique name.

$\begin{array}{llllll}2.4 .2 & \text { DESC }=\text { 'desc }^{\prime} & \text { blank } & - & \text { opt } & - \\ 2.4 .3 & \mathrm{~K}=\mathrm{r} & 0 . & \mathrm{W} / \mathrm{m} * \mathrm{~K} \quad \text { cond } & 0 .<\mathrm{r} \\ & & 0 . & \mathrm{Btu} / \mathrm{hr} * \mathrm{ft} * \mathrm{~F} & \end{array}$

Conductivity. 
2.4.4 $\quad \mathrm{CP}=\mathrm{r}$

Specific heat.

$2.4 .5 \quad D=r$

Density.

$2.4 .6 \quad R=r$

Thermal resistance ( $R$-value).

\section{$\mathrm{kJ} / \mathrm{kg} * \mathrm{~K}$ cond} $\mathrm{Btu} / 1 \mathrm{bm} * \mathrm{~F}$
$0 .<r$ $\mathrm{kg} / \mathrm{m}^{3}$ cond

$\begin{array}{ll}0 . & \mathrm{kg} / \mathrm{m}^{3} \\ 0 . & \mathrm{bm} / \mathrm{ft}^{3}\end{array}$

$0 .<r$

cond

$\mathrm{m}^{2} \star \mathrm{K} / \mathrm{W}$ cond $0 .<\mathrm{r}$ $h r * f t^{2 \star F / B t u}$

$2.4 .7 \quad A=r$

.75

Absorptance (and emittance)

75 - opt

$0 .<=r<=1$.

$2.4 .8 \quad E=r$

.90

-

opt

$0 .<r<1$.

Emittance (and absorptance) for thermal wavelength radiation.

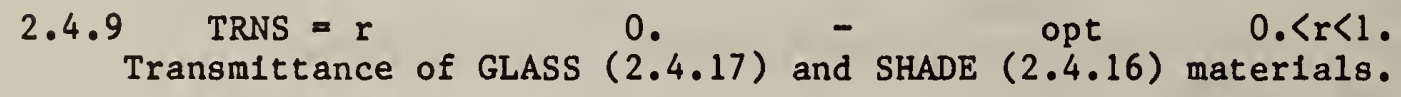

$2.4 .10 \quad I R=r \quad 1.52 \quad-\quad-\quad$ opt $\quad 1 .<r<2$. Index of refraction of GLASS (2.4.17) materials.

\subsubsection{FTRN = r $\quad 0 . \quad$ opt $0 .<r<1$.}

This is the transmittance of a sheet of GLASS $(2.4 .17)$ with a thin metallic film on the inside surface.

It must be used in conjunction with TRNS (2.4.9) which is the transmittance of the glass without the film.

FTRN must be less than TRNS.

The thickness of the film is computed from those values and IR (2.4.10) with optical properties of aluminum assumed for the f1lm.

$2.4 .12 \quad R E F=r$

Reflectance of a SHADE $(2.4 .16)$

opt $\quad 0 .<r<1$.

\section{$\begin{array}{llllll}2.4 .13 & S C=r & 0 & \text { opt } & 0 .<r<1.14\end{array}$}

The ASHRAE defined shading coefficlent of a window. This must be used with GLASS (2.4.17). All other optical properties are 1gnored.

\section{$2.4 .14 \quad \mathrm{RGH}=1 \quad 2 \quad$ opt $\quad 1<=1<=6$}

The roughness index interacts with the wind speed to determine the outside convection coefficient. Index values:

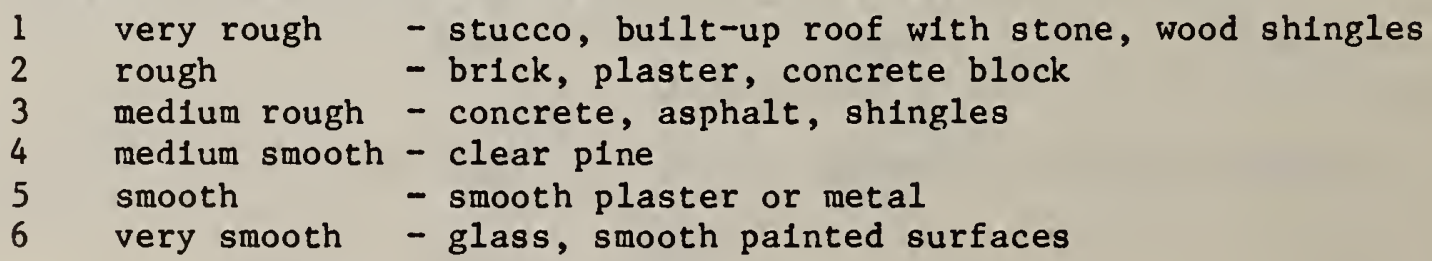


2.4.15 AIR

This subkey must be used if the material is to used as an air layer. in any transparent construct. The optical algorithms assume that the glass panes are separated by air layers. Those air layers automatically have TRNS $=1$ and $I R=1$.

2.4.16 SHADE

cond

This indicates that the material is an interior shade in transparent constructs. It must have information on TRNS (2.4.9) and REF (2.4.12). Conductive properties need not be defined because they will not be used.

\subsubsection{GLASS}

cond

This subkey indicates the glass panes in a transparent construct. A GLASS material must have conductive properties and optical properties chosen from: (TRNS, IR) or (TRNS, IR, FTRN) or (SC). The program assumes that multiple panes are separated by air layers for the optical calculations.

2.5

CONS

Constructs.

Constructs are the wall and window sections, described in terms of their constituent layers, that make up the building.

2.5.1 $\quad \mathrm{NAME}=\mathrm{n}$
Every construct must have a name different from all other constructs.

2.5.2 DESC $=$ 'desc' ' $^{\text {blank }}$ - opt
A description will appear in the construct report to more fully describe the construct.

2.5 .3

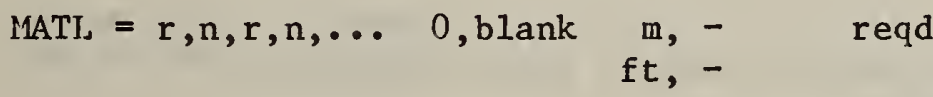

This subkey describes the material layers which form the construct. The values are pairs of (thickness, name of material) from the outside to the inside layer. Layers which are described by R-value $(2.4 .6)$ must be given a thickness to maintain the proper sequence of values. The value of that thickness is not used in the conductivity calculations, so even a zero is adequate.

$2.5 .4 \quad \mathrm{OA}=\mathrm{r} \quad-\quad$ opt $\quad 0 .<=\mathrm{r}<=1$. Outside absorptance (and emittance) for solar radiation. If no value is given, the default is the absorptance (2.4.7) of the outside (first) layer.
$2.5 .5 \quad O E=r$
opt
$0 .<=r<=1$.

Outside emittance (and absorptance) for thermal radiation. If no value is given, the default is the emittance (2.4.8) of the outside (first) layer. 


\section{$2.5 .6 \quad$ ORGH $=1$}

opt

$1<=1<=6$

This describes the roughness of the outs1de surface. It has the values of subkey 2.4.14. If no value is given, the default is the roughness of the outer layer.

\subsubsection{IA $=\mathrm{r}$}

opt

$0 .<=\mathrm{r}<=1$.

Inside absorptance (and emfttance) for solar radiation. If no value is given, the default is the absorptance (2.4.7) of the inside (last)

layer.

2.5 .8 IE $=\mathrm{r}$ - $\quad$ opt $\quad 0 .<=r<=1$. Inside emittance (and absorptance) for thermal radiation. If no value is given, the default is the emfttance (2.4.8) of the inside (last) layer.

2.6 CPFL ( Control profiles. Control profiles relate the capacity of the alr handing system to the zone temperature.

2.6.1 NAME $=n \quad$ blank - reqd
Every control profile must have a unfque name.

2.6.2 DESC = 'desc' blank - opt The description more fully describes the control profile.

2.6.3 $\operatorname{TMP}=\mathrm{r}, \mathrm{r}, \ldots \quad-\quad \mathrm{C} \quad \mathrm{F} \quad$ reqd

This subkey is a list of the control point temperatures which make up the control profile. See IV.E on control profiles.

2.6.4 CAP $=\mathrm{r}, \mathrm{r}, \ldots$ - $\quad-\quad$ reqd $-1 .<\mathrm{r}<=1$. This subkey is a list of the control point capacities which make up the control profile. Each capacity is matched to the control temperature (2.6.3). There may be no more than eight capacitles in the profile. See IV.E on control profiles.

2.7 CDS ( Control day-schedules.

A control day-schedule is a set of 24 control profiles.

2.7.1 NAME = $\mathrm{n}$ blank Each control day-schedule name must be different from all other control day-schedule names.

2.7.2 DESC = 'desc' blank - opt A description will more fully describe the purpose of the control day-schedule. It will appear in the day-schedule report.

2.7.3 CPFL $=n, n, \ldots \quad$ blank - $\quad$ reqd 24 profile names are required: one for each hour of the day. They must have been previously defined $(2.6)$. 
2.8

CWS (

Control week-schedules.

A control week-schedule is a set of 12 control day-schedules: one for each day of the week, one for holidays, and one for each of 4 special day types (SP1, SP2, SP3, and SP4). It is referenced by name in subsequent building input.

2.8.1 NAME $=\mathrm{n} \quad$ blank - reqd Each control week-schedule must have a name different from all other control week-schedule names.

2.8.2 DESC $=$ 'desc' blank - opt A description is useful in more fully describing the schedule, but its use is optional.

2.8.3 $\mathrm{WD}=\mathrm{n} \quad$ blank - cond Set weekday (Monday through Friday) pointers to the named control day-schedule. That control day-schedule must have been previously defined (2.7). Other options are:

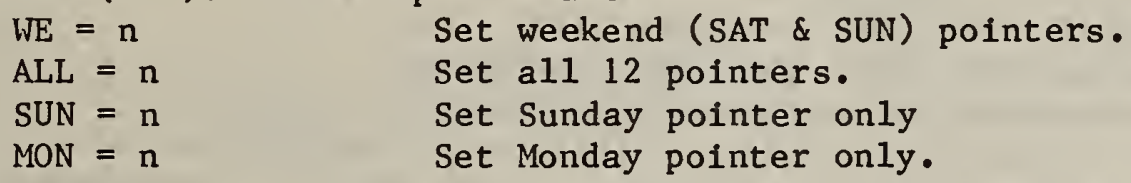

and similarly for TUE $=n$, WED $=n$, THU $=n, F R I=n, S A T=n, S P 1=n$, $\mathrm{SP} 2=\mathrm{n}, \mathrm{SP} 3=\mathrm{n}$, and $\mathrm{SP} 4=\mathrm{n}$. At least one day must be defined (other pointers will be set by default rules). 
3.

$$
\text { BUILDING [ Building Section. }
$$

This section describes features referring to all zones of the building. The entire section is optional. If used, it must occur before any zone (section 4.) descriptions.

3.1 SIM ( Simulation control parameters.

If this key is used, it must occur before any detached shadowing surfaces $(3.2)$. It may not be used more than once.

$3.1 .1 \quad N=r \quad 0.0 \quad$ degrees opt $\quad-360 .<=r<=360$. Degrees from true north to the north axis of bullding coordinate system (IV.F.5). Clockwise is positive.

3.1 .2 SLDS $=1 \quad 0 \quad-\quad$ opt $\quad 0<=1<=3$

Solar distribution algorithm:

0 = shading from 'SHD' surfaces only;

1 = shading from 'SHD' and 'DSS' surfaces;

2 = shading from all surfaces including other zones;

$3=2+$ distribution of beam radiation on interior surfaces. The surfaces of each zone must form a simple convex envelope.

$\begin{array}{lll}3.1 .3 \quad \mathrm{CNVG}=\mathrm{r}, \mathrm{r}, \mathrm{r}, 1 & .056, .01, .1,6 & \mathrm{C},-, \mathrm{W},- \\ & .1, .01, .34,6 & \mathrm{~F},-, \mathrm{Btu} / \mathrm{hr},-\end{array}$

Heat balance iteration convergence limits:

First variable = temperature convergence: when there is no heating or cooling load successive iterations of zone air temperature must be within $r$ degrees.

Second variable = loads convergence: when there is a load, successive iterations of loads must be $(1-\operatorname{load}(n) /(\operatorname{load}(n-1))<r$.

Third number = minimur load: when $\operatorname{load}(n)<r$, the next iteration would cause division by a small number. Therefore convergence is assumed. Convergence is also assumed if $|\operatorname{load}(n)-\operatorname{load}(n-1)|<r$. Fourth number = maximum number of iterations. Then record occurance of non-convergence and go to next time step.

It is not necesary to give all 4 numbers, but to set the third number the first two must also be given.

$3.1 .4 \quad$ FLOW $=1 \quad 12 \quad-\quad$ opt $0<1$

This subkey indicates that the loads processor will use the detailed alr flow algorithm (III.G). It may be used without the value. The value specifies the maximum number of iterations: Run terminates if this number is exceeded because the heat balance is not valid if the flows are not balanced. Two other air flow convergence parameters are set as functions of the heat balance parameters (3.1.3). Relative flow convergence $=$ realtive loads convergence. Absolute flow convergence $=.00005 *$ mininum load. 
$3.1 .5 \quad$ нтВ $=1 \quad 0 \quad$ opt $1=0,1$, or 2 Solve surface heat balances using only a single calculation of the outside surface temperature ( 0 or 1 ) or by iterating the outside temperatures simultaneously with the inside surface temperatures to convergence (2). The simpler mean radiant temperature (H.2.3) is used with HTB $=0$ and the more detailed MRT (H.2.H) is used with 1 or 2 .

3.1 .6 HO $=1 \quad 0 \quad$ opt $\quad 1=0$ or 2 Compute exterior convection coefficient using simple (0) or detailed (1) algoritmh (I.1 and I.2).
3.1 .7 HI $=1$
$0 \quad-\quad$ opt
$1=0$ or 1

Compute interior convection coefficient using simple $(0)$ or detalled

(2) algorithm ( J.1 and J.2).

3.2

DSS (

Detached shadowing surfaces.

Shadows from these surfaces are not used unless SLDS >0 (3.1.2).

3.2.1 AZM $=\mathrm{r} \quad 0 \quad$ degrees opt $\quad-360 .<=r<=360$. Azimuth (facing) angle of surface relative to building coordinate system. For example, north $=0$, east $=90$, south $=180$, west $=270$ or $-90$.
3.2.2 TILT $=r$
90
degrees
opt
$0 .<=\mathrm{r}<=180$.

Tilt of surface $(0=$ facing upward like flat roof; $90=$ vertical; 180

= facing downward like floor).
3.2.3 $x=r$
0.
ft
$\mathrm{Y}=\mathbf{r}$
0 .
opt
0.
ft
$z=r$
0 .
0 .
ft
opt
opt
ORG $=r, r, r$

Coordinates of lower left corner of surface relative to building coordinate system. ORG provides a simpler way of describing all 3 coordinates at once (ORG $=\mathrm{X}, \mathrm{Y}, \mathrm{Z})$. See IV.F on geonetric data.

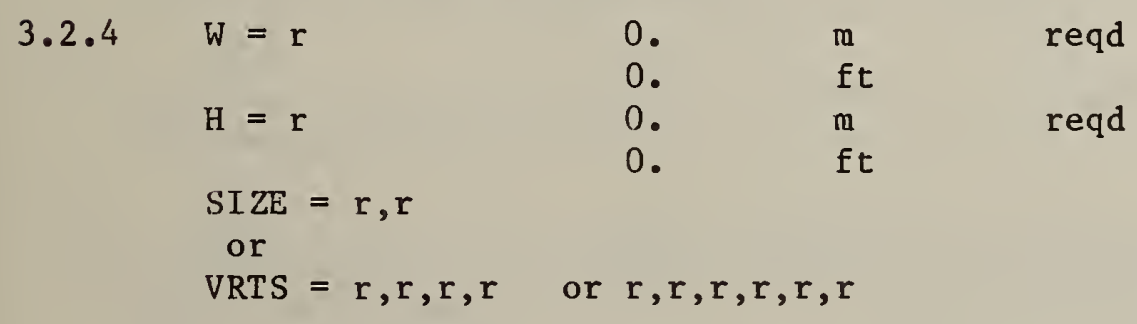

The first two forms specify the width and height of a rectangular surface $(S I Z E=W, H)$. The last form is for triangles or quadrilaterals. The first pair of numbers are the surface relative $x-y$ coordinates of the first vertex counter-clockwise from the lower left vertex. The subsequent pairs of numbers are the coordinates 
of the remaining vertices in counterclockwise sequence. See IV.F on geometric data.

3.2.5 TRNS $=\mathrm{r} \quad$ 0. - opt $0 .<r<=1$.

Transmittance of the shadowing surface.

$\begin{array}{llll}3.2 .6 & \text { FROM }=\mathrm{d} & \text { 1JAN } & - \\ & \text { THRU }=\mathrm{d} & \text { 3IDEC } & \text { opt }\end{array}$

The surface may apply for only part of the year. Any dates may be used, but for greatest efficlency dates should be chosen from the shadowing surface dates table. 
4. ZONE [

Zone Section.

A zone is a space under the control of one thermostat (or uncontrolled) where the air can be considered well mixed. The zone is composed of surfaces which connect it to the environment or to other zones, scheduled internal loads, and air temperature control strategy. There may be multiple zone sections. They must appear after the PROJECT, LIBRARY, and BUILDING sections.

4.1 GEOM ( Zone geometry

This key is required and must be the first key in the zone section. It may not be used more than once.

4.1.1 INAME $=\mathrm{n} \quad$ blank - reqd Each zone must have a unique name.

4.1.2 $N=r \quad 0.0 \quad$ degrees opt $\quad-360 .<=r<=360$. Degrees from building north axis to north axis of zone coordinate system. Clockwise is positive.

4.1.3 $\mathrm{X}=\mathrm{r}$

$Y=r$

$z=r$

$\mathrm{ORG}=\mathrm{r}, \mathrm{r}, \mathrm{r}$
0 m opt

0 . ft

0 . m

$0 . \mathrm{ft}$

$0 . \quad \mathrm{m}$

0 . $\mathrm{ft}$ opt

opt 
4.2.2 $\quad \mathrm{CAP}=$

0

cond

$0 .<r$

Enter the number of occupants.

4.2.3 $\quad \mathrm{ACT}=\mathrm{r}$

0.1318

$\mathrm{kW}$

opt

$.102<=r<=.425$

.450

$\mathrm{kBtu} / \mathrm{hr}$

$.35<=r<=1.45$

Enter the activity level. The program will divide this number into latent and sensible portions based on room alr temperature.

4.2.4 $\mathrm{RAD}=\mathrm{r} \quad .5 \quad-\quad$ opt $\quad 0 .<=\mathrm{r}<=1$.

This is the fraction of the sensible heat gain which is radiated to the room surfaces. The rest is convected to the room alr.

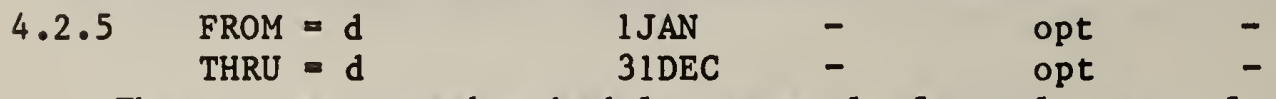

The occupancy week-schedule may apply for only part of the year. The schedule used by another PEO key may not overlap.

4.3 LIT ( Heat galns from 11ghts.

The total heat gain from 11 ghts is divided into several fractions and each is handled differently. The convective fraction is 1.-RA-RAD-VIS. It may not be less than zero.

4.3.1 WS $=\mathrm{n}$ - $\quad$ - reqd -

The total lighting energy is modifled by the week-schedule element (2.3) for the appropriate day and hour (clock t1me).
4.3.2 $\quad \mathrm{CAP}=\mathrm{r}$
0.
$\mathrm{kW}$
reqd
$0 .<r$
$0 . \quad \mathrm{kBtu} / \mathrm{hr}$

CAP is the peak power consumption (capacity) of the zone lights.
4.3.3 $R A=r$
0 .
opt
$0 .<=\mathrm{r}<=1$.

This is the fraction of the total 11ghting energy which goes directly into the return air instead of into the zone. This can occur with vented light fixtures.

4.3.4 RAD = . $20 \quad$ - opt $\quad 0 .<=r<=1$.

This is the fraction which can be considered long-wave radiant energy. It interacts with zone surfaces according to their inside emittance (2.5.8). The default fraction is typical of flourescent lights. A value of 0.80 is appropriate for incandescent lights.

4.3.5 VIS = r . $20 \quad$ opt $\quad 0 .<=r<=1$.

This is the fraction which can be considered short-wave (or visible) radiant energy. It interacts with the room surfaces according to their inside absorptance $(2 \cdot 5.7)$. It can leave the zone through transparent surfaces without creating a load. The default is typical of flourescent lights. For incandescent lights 0.10 is an appropriate value.

4.3.6 REP = r $\quad 0.0$ opt -

This is the fraction of lighting energy which can be replaced by daylight $(4 \cdot 10)$. 

$\begin{array}{ll}\text { 4.3.7 FROM } & =\mathrm{d} \\ \text { THRU } & =\mathrm{d}\end{array}$
$1 \mathrm{JAN}$
$31 \mathrm{DEC}$
opt

The lighting week-schedule may be applied to only part of the year.

The schedules used by other LIT keys may overlap. This allows a simple way to combine lighting from different sources as might be necessary to describe area and task lighting.

4.4

EQP (

Heat gains from equipment.

EQP describes the heat gains from various types of equipment. The convective fraction of that gain is 1.-LAT-RAD-LOST. It may not be less than zero.

4.4.1 WS $=\mathrm{n}$

The equipment is selected from the library of week-schedules (2.3).

The schedule refers to clock time.
4.4.2 $\mathrm{CAP}=\mathrm{r}$
0.
$\mathrm{kW}$
0 .
$\mathrm{kBTU} / \mathrm{hr}$
reqd
$0 .<r$

CAP is the peak power consumption of the equipment. A negative

capacity is permitted. It can describe a process which cools the $z$ one. A zero capacity is meaningless.
4.4.3 LAT $=\mathrm{r}$
0 .
opt
$0 .<=r<=1$.

This is the latent fraction, $i . e .$, the fraction of energy used to add water vapor to the zone air.
4.4.4 RAD = r
.3
opt
$0 .<=r<=1$.

This is the radiant fraction which is treated as long-wave radiation.
4.4.5 LOST $=\mathrm{r}$
0 .
opt
$0 .<=r<=1$.

The fraction lost allows the user to add energy to the total zone and building consumption without effecting the zone loads. For example, it might be used to account for outside lighting.
$4.4 \cdot 6$
FROM $=\mathrm{d}$
THRU $=\mathrm{d}$
1 JAN
$-$
opt
opt
Time periods for multiple EQP keys may overlap.
4.4.7 EL
GS
ST
HW
OTHR
electricity
gas
steam
hot water
other
cond
cond
cond
cond
cond

These simple subkeys identify the energy source of the equipment. They allow summing of the building energy requirements by energy type. One of them must be given. OTHR allows a load to occur in the zone without adding to the energy requirements.

4.5

Simple infiltration - Algorithm K.2.

INF allows scheduling of infiltration with simple temperature and wind 
speed dependencies. It may not be used with the detalled air flow option $(3.1 .4)$.

4.5.1 WS $=\mathrm{n} \quad-\quad$ - $\quad$ reqd -

The infiltration schedule is selected from the library of week-schedules $(2.3)$. The schedule refers to clock time.
4.5.2 $\quad \mathrm{CAP}=\mathrm{x}$
0 .
$\mathrm{m}^{3} / \mathrm{s}$
reqd
$0 .<r$
0 .
$\mathrm{ft}^{3} / \mathrm{min}$

Enter the peak infiltration volume flow rate. The user must convert "air changes" to volume flow rate.

$\begin{array}{rlllll}4.5 .3 & \mathrm{C}=\mathrm{r} & .606 & - & \text { opt } & - \\ \mathrm{T}=\mathrm{r} & .03636 & 1 / \mathrm{C} & \text { opt } & - \\ \mathrm{V}=\mathrm{r} & .0202 & 1 / \mathrm{F} & & \\ & .1177 & \mathrm{~s} / \mathrm{m} & \text { opt } & - \\ \mathrm{VV}=\mathrm{r} & .000598 & \mathrm{mIn} / \mathrm{ft} & & \\ & 0 . & (\mathrm{s} / \mathrm{m})^{2} & \text { opt } & -\end{array}$

The scheduled infiltration is modified by the factor:

$\left(C+T *|T Z-T A|+V * S P D+V V * S P D^{2}\right)$

where $\mathrm{TZ}=$ zone air temperature

$\mathrm{TA}=$ ambient air temperature

SPD = wind speed

The default values are for a $7.5 \mathrm{mph}$ wind and 0 temperature difference. Users who wish to have a constant infiltration should set $C$ to 1 and the other coefficients to 0 .

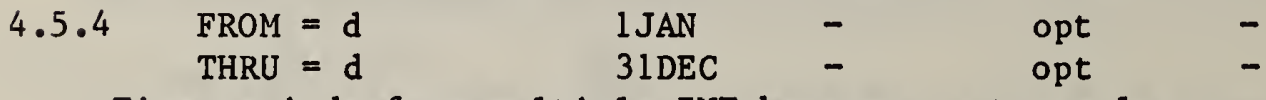

Time periods from multiple INF keys may not overlap.

4.6 VENT ( Ventilation - Algorithm K.3.

Ventilation describes the use of unconditioned outside air to cool the zone. It may also be used to precool the zone during unoccupied hours. It may not be used with the detalled air flow option (3.1.4).

4.6.1 WS $=\mathrm{n}$
The ventilation schedule is chosen from the library of week-schedules (2.3). The schedule refers to clock time.
4.6.2 $\quad \mathrm{CAP}=\mathrm{r}$
0 .
$\mathrm{m}^{3} / \mathrm{s}$
reqd
$0 .<r$ $\mathrm{ft}^{3} / \mathrm{min}$

Enter the peak volumetric flow rate.

4.6.3 MIN $=r$
This causes ventilation to seek to bring the zone air temperature down to the value given. If this subkey is used, do not use MAX (4.6.4). 
4.6.4 MAX = r 90. $\quad$ C $\quad$ opt

This causes ventilation to occur whenever the zone air temperature is greater than this value. If this subkey is used, do not use MII $(4.6 .3)$.
4.6.5 $\mathrm{TD}=\mathrm{r}$
2. $\quad \mathrm{K}$
opt
$0 .<=r$

This requires that the outside air be TD degrees cooler than the inside air before ventilation can occur.

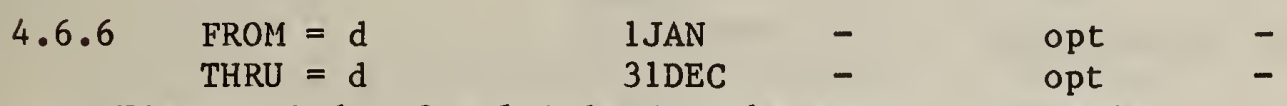

Time periods of multiple VENT keys may not overlap.

4.7 MIX ( Two zone mixing - Algorithm K.4.

MIX simulates the controlled mixing of two zones such as occurs in attached sunspace designs. It may not be used with the detailed air flow option $(3.1 .4)$.

4.7.1 WS $=\mathrm{n}$
The mixing schedule is chosen from the library of week-schedules $(2.3)$. The schedule refers to clock time.
4.7.2 $\quad \mathrm{CAP}=\mathrm{r}$
0 .
$\mathrm{m}^{3} / \mathrm{s}$
reqd
$0 .<r$
0 .
$\mathrm{ft}^{3} / \mathrm{min}$

Enter the peak volumetric flow rate. The mass flow will be based on standard $(1.2 \mathrm{~kg} / \mathrm{m} 3)$ air.
$4 \cdot 7 \cdot 3$
$\mathrm{TD}=\mathrm{r}$
0.
K
opt
$0 .<=r$

There is mixing with the adjacent zone whenever the zone air temperature is TD greater than the adjacent zone. When TD is zero, there is always mixing (as controlled by the schedule).

4.7.4 ZONE = n $\quad-\quad$ - $\quad$ reqd

Give the name of the adjacent zone.
4.7.5 FROM $=\mathrm{d}$
1 JAN
THRU $=d$
31DEC -
opt

Time periods of multiple MIX subkeys may not overlap.

4.8 FAN ( Whole house fan - Algorithm K.5.

Fan simulates a whole house fan which exhausts house air into the attic. It may not be used with the detailed air flow option (3.1.4).

4.8.1 WS $=\mathrm{n} \quad$ - $\quad-\quad$ reqd

The fan schedule is chosen from the library of week-schedules (2.3).

The schedule refers to clock time. 


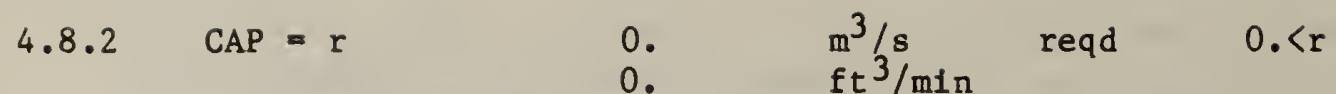

Enter the peak volumetric flow rate. The mass flow will be based on standard $(1.2 \mathrm{~kg} / \mathrm{m} 3)$ air.
4.8.3 $T=r$
0.
C
reqd
$0 .<=r$
0 .
F

The FAN will seek to cool the zone air temperature to $\mathrm{T}$.

4.8.4 ZONE = $\mathrm{n} \quad-\quad$ - $\quad-\quad$ reqd

Give the name of the adjacent (attic) zone.

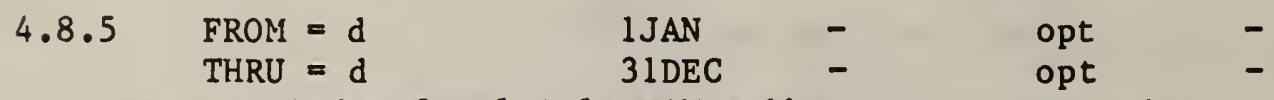

Time periods of multiple FAN subkeys may not overlap.

4.9 CTRL ( Zone control - Algorithm K.1.

Details of zone temperature control are described in IV.E.

4.9.1 CWS $=n$
The control schedule is sectected from the library of control

week-schedules (2.8). The control profile is referenced by clock time.

4.9.2 HEAT $=\mathrm{r} \quad 1 . \mathrm{E} 6 \quad \mathrm{~kW} \quad$ opt $\quad 0 .<=\mathrm{r}$

Enter the peak heating capacity.

4.9.3 COOL $=r \quad$ l.E6 kW $\quad$ opt $0 . \ll r$

Enter the peak cooling capacity.

4.9.4 $\mathrm{RAD}=\mathrm{r} \quad 0 . \quad-\quad$ opt $\quad 0 .<=\mathrm{r}<1$.

The control profile refers to a control temperature which is defined as $(1-R A D) * T Z+R A D * T R$ where $T Z$ is the zone air temperature and $T R$ is the zone mean radiant temperature.

$\begin{array}{llllll}4.9 .5 & \text { FROM }=\mathrm{d} & 1 \mathrm{JAN} & - & \text { opt } & - \\ \text { THRU } & =\mathrm{d} & 31 \mathrm{DEC} & - & \text { opt }\end{array}$

It is common to operate with different control profiles during different seasons as heating or cooling capacities are shut off. The time periods from multiple CTRL keys may not overlap.

4.10 DLTC Daylighting.

The program uses a very simple model to estimate the savings in lighting energy by using daylighting. All DLT keys should appear in the zone description before any LIT keys.

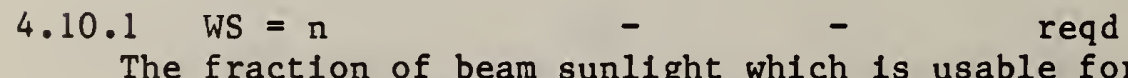
by the week-schedule (2.3) element for the hour (standard time). 

$4 \cdot 10.2 \quad$ BEAM $=r$
0 .
opt
$0 .<=r<=1$.

This is the fraction of beam sunlight entering the zone which can be used to offset the visible energy from the lights.
4.10.3 DIFF $=r$
0 .
opt
$0 .<=r<=1$.

This $1 \mathrm{~s}$ the fraction of diffuse sunlight entering the zone which can be used to offset the visible energy from lights.
4.10.4 FROM $=\mathrm{n}$
THRU $=\mathrm{d}$
1 JAN
$31 \mathrm{DEC}$
opt
opt
Time periods from multiple DLT keys may not overlap.

\subsection{BBH ( Baseboard heat.}

This key describes a system which adds heat to the zone based on the outside alr temperature.

\subsection{1 .1 WS $=\mathrm{n} \quad$ - $\quad$ - $\quad$ reqd}

The peak heating capacity avalable at any hour (clock time) is modified by the baseboard heating schedule selected from the week-schedule library (2.3).
4.11.2 $\quad \mathrm{CAP}=\mathrm{r}, \mathrm{r}$
$0 ., 0$.
$\mathrm{kW}$
reqd
$0 .<=r$

The first value is the peak heating capacity. The second value is the mininum heating capacity at the shut-off temperature. Two values are required.

\subsubsection{TMP $=\mathrm{r}, \mathrm{r} \quad 0 ., 0 . \quad \mathrm{C} \quad$ reqd}

The first value is the highest temperature at which the system gives full heating capacity. The second value is the maximum temperature for which the system produces any heat (the shut-off temperature). Both values are required.
$4.11 .4 \quad \operatorname{RAD}=\mathrm{r}$
3
opt
$0 .<=r<=1$.

This is the radiant fraction which is treated as long-wave radiation.
$4.11 .5 \quad$ FROM $=\mathrm{d}$
THRU $=\mathrm{d}$
$1 \mathrm{JAN}$
$31 \mathrm{DEC}$
$-$
opt
opt
Time periods froin multiple BBH keys may not overlap.
$\begin{array}{ll}4.11 .6 & \mathrm{ST} \\ \mathrm{HW}\end{array}$
$\begin{array}{lll}- & - & \text { cond } \\ - & - & \text { cond }\end{array}$

These refer to the source of heating energy: steam or hot water. One or the other must be given.

\subsection{IASS ( Internal mass.}

Internal masses are modeled by the internal surface algorithms. The only difference from the treatment of a partition is that the internal mass is not given a location in the zone and, therefore, beam sunlight cannot fall directly on it. 
4.12.1 CONS $=\mathrm{n}$
Select the composition of the mass from the constructs library (2.5) $(2.5)$.
4.12.2 AREA $=r$
0.
$\mathrm{m}^{2}$
0 .
$\mathrm{ft}^{2}$
reqd
$0 .<r$

The mass must be given an area.

4.13 SRF (

Heat transfer surfaces.

All zone surfaces which conduct or store heat (except internal nass;

4.12) are described by this key.

\subsubsection{CONS $=\mathrm{n} \quad$ - $\quad$ - reqd}

Select the composition of the surface from the constructs library (2.5).

$\begin{aligned} & 4.13 .2 \text { EX } \\ & \text { IN } \\ & \text { OP } \\ & \text { TR } \\ & \text { BS } \\ & \text { SS }\end{aligned}$

$\begin{array}{llll}- & - & \text { cond } & - \\ - & - & \text { cond } & - \\ - & - & \text { cond } & - \\ - & - & \text { cond } & - \\ - & - & \text { cond } & - \\ - & - & \text { cond } & -\end{array}$

The user must specify the following three factors: Is this an Exterior or INterior surface? Is the surface OPaque or TRansparent? Are its coordinates defined as a Base Surface or a SubSurface? (The. coordinates of a subsurface are defined relative to the most recently described base surface.) There are eight combinations of these factors. Three of those are not permitted because of various algorithmic restrictions in the program. The following table explains the three factors in terms of the common English names for such surfaces (at three basic tilt angles).

\begin{tabular}{|c|c|c|c|c|c|c|c|}
\hline $\mathrm{EX} / \mathrm{IN}$ & OP/TR & $\mathrm{BS} / \mathrm{SS}$ & $90 \mathrm{deg}$ & & $0 \mathrm{deg}$ & & $180 \mathrm{deg}$ \\
\hline EX & OP & BS & wall & & roof & & - \\
\hline EX & $O P$ & SS & door & & - & & - \\
\hline EX & TR & BS & $\star * \star$ & not & permitted & *** & \\
\hline EX & TR & SS & window & & skylight & & - \\
\hline IN & $O P$ & BS & partitio & & cell1ng & & floor \\
\hline IN & $O P$ & SS & $\star * *$ & not & permitted & *** & \\
\hline IN & TR & BS & - & & - & & - \\
\hline IN & TR & SS & $* * *$ & not & permitted & *** & \\
\hline
\end{tabular}

4.13.3 $\mathrm{AZM}=\mathrm{r} \quad 180 . \quad$ degrees opt $\quad-360 .<=\mathrm{r}<=360$. Azimuth (facing) angle of the surface relative to the zone coordinate system. North $=0$; clockwise positive. This is used fo base surfaces only. Subsurfaces face the same direction as their base surface.

4.13.4 TILT $=r \quad 90 . \quad$ degrees opt $0 .<=r<=180$. T1lt of surface ( 0 = facing upward like flat roof; 90 = vertical; 180 = facing downward like floor). This is used for base surfaces only. Subsurfaces have the same tilt as their base surface. 


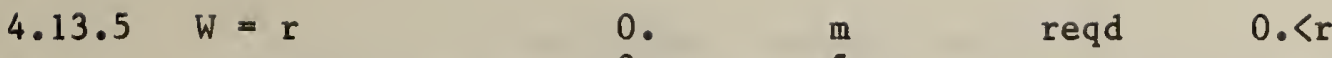

$$
\begin{aligned}
& H=r \quad 0 . \quad m \quad r e q d \quad 0 .<r \\
& \begin{array}{l}
\text { SIZE }=r, r \\
\text { VRTS }=r, r, r, r \quad \text { or } \quad \text { VRTS }=r, r, r, r, r, r
\end{array}
\end{aligned}
$$

The first two forms specify the width and height of a rectangular surface ( $S I Z E=W, H$ ). The last form is for triangles or quadrilaterals. The first pair of numbers are the surface relative $x-y$ coordinates of the first vertex counter-clockwise from the lower left vertex. The subsequent pairs of numbers are the coordinates of the remaining vertices in counter-clockwise sequence. See IV.F on geometric data.

$\begin{array}{rlll}4.13 .6 \quad \mathrm{X}=\mathrm{r} & 0 . & \mathrm{m} \\ \mathrm{Y}=\mathrm{r} & 0 . & \mathrm{ft} \\ \mathrm{Z}=\mathrm{r} & 0 . & \mathrm{m} \\ & 0 . & \mathrm{ft} \\ & 0 . & \mathrm{m} \\ & 0 . & \mathrm{ft}\end{array}$

$\begin{array}{lll}\text { mt } & \text { opt } & \text { - } \\ \text { m } & \text { opt } & - \\ \text { m } & \text { opt } & -\end{array}$

$O R G=r, r, r$

For base surfaces (BS - 4.13.2) these are the coordinates of the lower left corner of the surface relative to the zone coordinate system. The base surface origin is not used in the simple shadow calculation mode (3.1.2). For subsurfaces (SS - 4.13.2) these are the coordinates relative to the lower left corner of the base surface. The $Z$ coordinate is the amount of the setback. ORG provides a simpler way of describing all three coordinates at once (ORG $=\mathrm{X}, \mathrm{Y}, \mathrm{Z}$ ). See IV.F on geometric data.
4.13.7 FSS $=r$
.5
opt
$0 .<r<=1$.

FSS is the angle factor between the surface and the sky. It is used in determining the intensity of diffuse sky radiation incident on the surface. If FSS is not specified, it is computed from the TILT $(4.13 .4)$ angle: $\mathrm{FSS}=(1+\cos (t 11 t)) / 2$.
4.13.8 FSG $=r$
.5
opt
$0 .<=r<=1$.

FSG is the angle factor between the surface and the ground. It is used in determining the intensity of diffuse ground reflected radiation on the surface. If FSG is not specified, it is computed from the tilt $(4.13 .4)$ angle: $F S G=(1-\cos (t 11 t)) / 2$.

4.13.9 ZONE $=\mathrm{n} \quad$ blank - opt This is the name of the zone on the other side of the surface from the current zone. The program will check for that zone to have a surface which refers to this zone. That is, a single partition (or ceiling or floor) which is between two zones, must must be described in each zone. The program checks that these two surfaces have the same area and U-value. It makes a partial check on the conduction transfer functions. Remember that constructs are defined from the outer to the inner layer and, therefore, asymmetric interzone partitions will have to be defined twice to be referenced from the different zones. 
4.14 AFS ( Alr flow surface - Algorithm G

AFS describes the crack area and other openings in the base surface which are used in the detalled air movement simulation. FLOW (3.1.4) must have been specified. The base surface must be elther an exterior surface or an interzone surface $(4.13 .2$ and 4.13 .9$)$. The AFS assumes the azimuth of the base surface for computing wind direction effects. When the AFS applies to an interzone surface, there must be an identical AFS specified for the appropriate base surface in the adjacent zone.

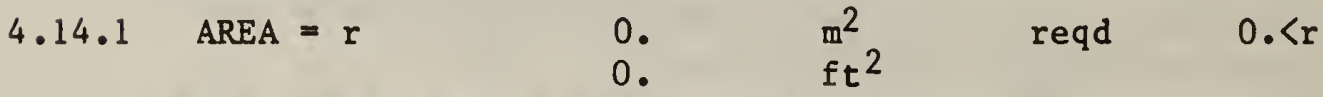

This is the effective area of the opening.

4.14.2 $\quad \operatorname{EXP}=\mathrm{r} \quad .65 \quad-\quad$ opt $.5<=\mathrm{r}<=1$.

EXP is the flow expontent. It 18 typically .65 for exterior walls and

.50 for interzone openings.

$4.14 .3 \quad \mathrm{zS}=\mathrm{r} \quad-\quad \mathrm{m} \quad$ opt

This is the height of the centroid of the surface or opening relative to the zone origin (G.2). The default value 18 the average of the helghts of the vertices of the base surface.

$4.14 .4 \quad \mathrm{ZT}=\mathrm{r} \quad-\mathrm{m} \quad \mathrm{m}$

This is the height at which the wind speed is evaluated for the opening

(G.1). The default value is the highest vertex of the base surface.

4.15 SHD ( Shadowing subsurfaces.

SHD describe simple shadowing surfaces which apply to the most recently defined base surface (BS - 4.13.2) and all of its subsurfaces. The base surface must be an exterior (EX) surface unmodified by OSC $(4.16)$.

4.15 .1 OHNG

LFIN

RFIN

PROJ

$\begin{array}{llll}- & - & \text { cond } & - \\ - & - & \text { cond } & - \\ - & - & \text { cond } & -\end{array}$

There are four configurations for these features: overhang, left $\mathrm{fln}$, right fin, and projection. See IV.F for detalls.

$\begin{array}{llllll}4.15 .2 & W=r & 0 . & m & \text { reqd } & 0 .<=r \\ & H=r & 0 . & \text { ft } & & \\ & & 0 . & m & \text { reqd } & 0 .<=r\end{array}$

$S I Z E=r, r$

These subkeys specify the width and height of the rectangular shadowing surface. SIZE is a shorter description (SIZE $=W, H$ ). See IV.F on geometric data. 


$\begin{array}{rlllll}4.15 .3 & \mathrm{X}=\mathrm{r} & 0 . & \mathrm{m} & \text { opt } & - \\ \mathrm{Y}=\mathrm{r} & 0 . & \mathrm{ft} & & - \\ \mathrm{Z}=\mathrm{r} & 0 . & \mathrm{m} & \text { opt } & - \\ & 0 . & \mathrm{ft} & & \\ & 0 . & \mathrm{m} & \text { opt } & 0 .<=\mathrm{r}\end{array}$

The positioning of the shadowing subsurface is given relative to the base surface coordinate system. See IV.F on geometric data.
4.15.4 TRNS $=r$
0.
opt
$0 .<=r<1$.

Transmittance of the shadowing surface.
4.15.5 $\quad$ FROM $=\mathrm{d}$
THRU $=d$
$\begin{array}{ll}\text { 1JAN } & - \\ 31 \mathrm{DEC} & -\end{array}$
$\begin{array}{ll}\text { opt } & - \\ \text { opt } & -\end{array}$

The surface may apply for only part of the year. Any dates may be used, but for greatest efficiency dates should be chosen from the shadowing surface dates table (IV.G.1).

\subsection{OSC ( Other side coefficients.}

OSC provides a means of approximating conditions on the outside of a surface where it is not desirable (or possible) to simulate those conditions. The OSC key applies to the most recently described surface. That surface should be EX / OP / BS (4.13.2). It should also have no shadowing or heat transfer subsurfaces. Other side coefficients establish an outside temperature which is a function of several factors. The temperature is computed from the formula:

$$
\begin{aligned}
& \mathrm{T}=\left(\mathrm{TZP} * \mathrm{TZ}+\mathrm{TAP} * \mathrm{TA}+\mathrm{CTP} \mathrm{CT}^{*}+\mathrm{TGP} * \mathrm{GRT}+\mathrm{WSP} * \mathrm{SPD} * \mathrm{TA}\right) \\
& /\left(\mathrm{TZP}+\mathrm{TAP}+\mathrm{TGP}+W \mathrm{WP}^{*} \mathrm{SPD}\right)
\end{aligned}
$$

where $\mathrm{TZ}=$ most recent value of zone air temperature

$\mathrm{TA}=$ ambient air temperature

GRT = ground temperature $(1.4 .1)$

SPD $=$ wind speed

and the other factors are user defined as described below. At least one of the factors in the divisor of the equation must be defined nonzero.
4.16.1 НО $=r$
0.
$\mathrm{W} / \mathrm{m}^{2} \mathrm{~K}$
$\mathrm{Btu} / \mathrm{hr} * \mathrm{ft} \mathrm{C}^{\mathrm{F}}$
$0 .<=r$

This is the value of the outside surface convection coefficient. If it is zero, the OSC temperature is the surface outside temperature. If it is not zero, The OSC temperature is an air temperature which is used with the convection coefficient to compute the outside surface temperature.
4.16.2 TZP $=\mathrm{r}$
0.
opt
Zone temperature part.
$\begin{array}{rl}\text { 4.16.3 TAP }=r & 0 . \\ \text { Ambient air temperature part. }\end{array}$
opt 
4.16.4 CT $=r$

0.

Constant temperature.

4.16.5 CTP $=$

0.

Constant temperature part.

4.16.6 TGP $=r$

Ground temperature part.

$4 \cdot 16.7 \quad$ WSP $=r$

0.

Wind speed part.

C

opt

F

$-$

$-$

$\mathrm{s} / \mathrm{m}$

$\mathrm{min} / \mathrm{ft}$ opt

opt

opt

4.17 EMI

Exterior movable insulation.

Exterior movable insulation is applied to the most recently defined surface. That surface must have been defined as exterior (EX; 4.13.2) and not modifled by subsequent OSC (4.16). EMI may apply to either massless or massive surfaces. EMI is opaque and can prevent solar gains through windows.

\subsubsection{CONS $=\mathrm{n} \quad-\quad-\quad$ reqd}

The movable insulation 18 chosen from the constructs 11brary. The movable insulation algorithm handles only massless insulation. It uses the U-value, outer solar and thermal absorptances and roughness of the construct.
$4.17 .2 \quad$ DS $=\mathrm{n}$
SNUP
SNDN

$\begin{array}{llll}- & - & \text { cond } & \text { - } \\ - & - & \text { cond } & \text { cond }\end{array}$

One of three methods must be chosen for control of the EMI. The first is reference to a day-schedule (2.2). A value of zero means no EMI for that hour (standard time) and a one means the EMI is in effect. Fractional values in the day-schedule modify the $\mathrm{R}$-value. Any schedule value greater than zero causes sunlight to be absorbed on the EMI rather than on the surface. Second is SNUP which means the EMI is in effect whenever the sun is above the horizon. SNDN means the EMI is in effect when the sun is below the horizon.

\subsubsection{FROM $=\mathrm{d}$ \\ THRU $=\mathrm{d}$ \\ $1 \mathrm{JAN}$ \\ $-$ \\ opt}

The EMI may apply for only part of the year. It may be desirable to use different controls during different seasons. Any dates may be used, but since the EMI effects the solar gain calculations, dates should be chosen from the table of shadowing surface dates (IV.G.1) for greatest efficiency. Time perlods from multiple EMI subkeys may not overlap. 
4.18 IMI ( Interior movable insulation. Interior movable insulation applies to interzone surfaces only. That is, the most recently defined surface should be interior (IN; 4.13.2) and have an other side zone name $(4.13 .9)$.

4.18.1 CONS $=\mathrm{n}$
The movable insulation is chosen from the constructs library. The movable insulation algorlthm handles only massless insulation.

$\begin{array}{clllll}4.18 .2 & \text { DS }=\mathrm{n} & - & - & \text { cond } & - \\ \text { GAIN } & - & - & \text { cond } & - \\ \text { LOSS } & - & - & \text { cond }\end{array}$

One of three methods must be chosen for control of the IMI. First is reference to a day-schedule (2.2). A value of zero means no IMI for that hour (clock time) and a one means the IMI is in effect. Fraction values in the day-schedule modify the $R$-value. The second method is GAIN which causes the IMI to be in effect whenever the surface temperature is greater than the zone control temperature (4.9.4). LOSS is the inverse of the GAIN operation.
4.18.3 FROM $=\mathrm{d}$
$1 \mathrm{JAN}$
opt -

THRU $=\mathrm{d}$
Since IMI does not effect the zone's solar gain, the dates need not refer to the shadowing surface dates. Time periods from multiple IMI subkeys may not overlap. 
This summary of the input language is intended to serve as a reminder of the syntax and all the keywords. As the user becomes more famillar with the input, he will use this summary more and the detalled input description (IV.C) less. It may be desirable to copy these pages and place them near the computer terminal.

Data types:

$\mathrm{n}=$ name, $\mathrm{r}=$ real, 1 = integer, $\mathrm{d}=$ date, desc $=$ description

1. PROJECT [

$1.1 \quad \mathrm{RC}\left(\mathrm{DESC}=\operatorname{desc}^{\prime} / \mathrm{SYNTAX} / \mathrm{DEM} / \mathrm{2SPC} / \mathrm{XREF} / \mathrm{OLDW} /\right.$ ENGLISH / METRIC / UIN $=\mathrm{n} /$ UOUT $=\mathrm{n}$ )

$1.2 \quad \operatorname{RPT}(\operatorname{RNOS}=1, \ldots)$

1.3 LOC ( DESC $={ }^{\prime d e s c}$ ' LATD $=r /$ LONG $=r / T Z=r / A L T=r /$ $\mathrm{TER}=1$ )

1.4 GRND $(G R T=r, \ldots\langle 12\rangle / \mathrm{MWT}=\mathrm{r}, \ldots\langle 12\rangle)$

$1.5 \operatorname{WTAP}\left(\operatorname{DESC}=\operatorname{desc}^{\prime} / \mathrm{SKIP}=1 / \mathrm{DAYS}=1\right)$

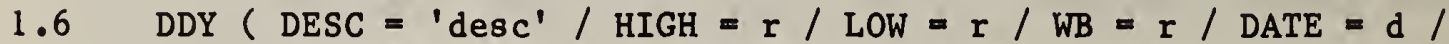
$\mathrm{PRES}=\mathbf{r} / \mathrm{WS}=\mathbf{r} / \mathrm{DIR}=\mathrm{r} / \mathrm{CLR}=\mathrm{r} / \mathrm{RAIN} / \mathrm{SNOW} /$ SUN / MON / TUE / WED / THU / FRI / SAT / HOL / SP1 / SP2 / SP3 / SP4 )

]

2. LIBRARY [

2.1 LIB ( NAME $=n /$ NDS $=1 /$ NWS $=1 /$ NMATL $=1 /$ NCONS $=1 /$ NCPFL $=1 /$ NCDS $=1 /$ NCWS $=1 /$ ALL $/$ DS $/$ WS / MATL / CONS / CPFL / CDS / CWS )

2.2 DS $\left(\right.$ NAME $\left.=n / D E S C={ }^{\prime} \operatorname{desc} ' / F F=r, \ldots\langle 24\rangle\right)$

2.3 WS ( NAME $=n / D E S C='$ desc' $/ W D=n / W E=n /$ ALL $=n /$ SUN $=n /$ MON $=n /$ TUE $=n /$ WED $=n /$ THU $=n /$ FRI $=n /$ $\mathrm{SAT}=\mathrm{n} / \mathrm{HOL}=\mathrm{n} / \mathrm{SP} 1=\mathrm{n} / \mathrm{SP} 2=\mathrm{n} / \mathrm{SP} 3=\mathrm{n} / \mathrm{SP} 4=\mathrm{n})$

2.4 MATL ( NAME $=\mathrm{n} / \mathrm{DESC}=\operatorname{desc}^{\prime} / \mathrm{K}=\mathrm{r} / \mathrm{CP}=\mathrm{r} / \mathrm{D}=\mathrm{r} /$ $\mathrm{R}=\mathrm{r} / \mathrm{A}=\mathrm{r} / \mathrm{E}=\mathrm{r} / \mathrm{TRNS}=\mathrm{r} / \mathrm{IR}=\mathrm{r} /$ FTRN $=\mathrm{r} /$ $\mathrm{REF}=\mathrm{r} / \mathrm{SC}=\mathrm{r} / \mathrm{RGH}=1 / \mathrm{AIR} / \mathrm{SHADE} /$ GLASS $)$

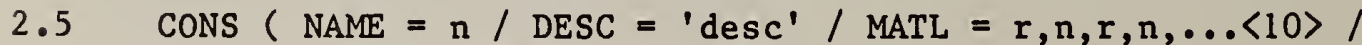
$\mathrm{OA}=\mathrm{r} / \mathrm{OE}=\mathrm{r} / \mathrm{ORGH}=1 / \mathrm{IA}=\mathrm{r} / \mathrm{IE}=\mathrm{r}$ ) 
2.6 CPFL ( NAME $\left.=\mathrm{n} / \mathrm{DESC}={ }^{\prime} \mathrm{desc}^{\prime} / \mathrm{TMP}=\mathrm{r}, \ldots\langle 8\rangle / \mathrm{CAP}=\mathrm{r}, \ldots\langle 8\rangle\right)$

$2.7 \operatorname{CDS}\left(\mathrm{NAME}=\mathrm{n} / \mathrm{DESC}=\operatorname{desc}^{\prime} / \mathrm{CPFL}=\mathrm{n}, \ldots\langle 24\rangle\right)$

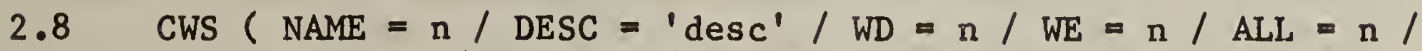
SUN $=n /$ MON $=n /$ TUE $=n /$ WED $=n /$ THU $=n /$ FRI $=n /$ $\mathrm{SAT}=\mathrm{n} / \mathrm{HOL}=\mathrm{n} / \mathrm{SP} 1=\mathrm{n} / \mathrm{SP} 2=\mathrm{n} / \mathrm{SP} 3=\mathrm{n} / \mathrm{SP} 4=\mathrm{n})$

]

3. BUILDING [

$3.1 \operatorname{SIM}(N=\mathrm{r} / \mathrm{SLDS}=1 / \mathrm{CNVG}=\mathrm{r}, \mathrm{r}, \mathrm{r}, 1 /$ FLOW $=1 /$ $\mathrm{HTB}=1 / \mathrm{HO}=1 / \mathrm{HI}=1$ )

3.2 DSS ( $A Z M=r / T I L T=r / X=r / Y=r / Z=r / O R G=r, r, r /$ $\mathrm{W}=\mathrm{r} / \mathrm{H}=\mathrm{r} / \mathrm{SIZE}=\mathrm{r}, \mathrm{r} / \mathrm{VRTS}=\mathrm{r}, \ldots\langle 4$ or 6$\rangle /$

] TRNS $=\mathrm{r} /$ FROM $=\mathrm{d} /$ THRU $=\mathrm{d}$ )

4. ZONE [

4.1 GEOM ( NAME $=\mathrm{n} / \mathrm{N}=\mathrm{r} / \mathrm{X}=\mathrm{r} / \mathrm{Y}=\mathrm{r} / \mathrm{z}=\mathrm{r} /$ ORG $=\mathrm{r}, \mathrm{r}, \mathrm{r} /$ CLHT $=r /$ MIRX / MIRY )

4.2 $\mathrm{PEO}(\mathrm{WS}=\mathrm{n} / \mathrm{CAP}=\mathrm{r} / \mathrm{ACT}=\mathrm{r} / \mathrm{RAD}=\mathrm{r} /$ FROM $=\mathrm{d} / \mathrm{THRU}=\mathrm{d}$ )

4.3 LIT ( WS $=\mathrm{n} / \mathrm{CAP}=\mathrm{r} / \mathrm{RA}=\mathrm{r} / \mathrm{RAD}=\mathrm{r} / \mathrm{VIS}=\mathrm{r} / \mathrm{REP}=\mathrm{r} /$ FROM $=d /$ THRU $=d$ )

4.4 $\mathrm{EQP}(\mathrm{WS}=\mathrm{n} / \mathrm{CAP}=\mathrm{r} / \mathrm{LAT}=\mathrm{r} / \mathrm{RAD}=\mathrm{r} / \mathrm{LOST}=\mathrm{r} /$ FROM $=\mathrm{d} / \mathrm{THRU}=\mathrm{d} / \mathrm{EL} / \mathrm{GS} / \mathrm{ST} / \mathrm{HW} /$ OTHR $)$

4.5 INF ( WS $=\mathrm{n} / \mathrm{CAP}=\mathrm{r} / \mathrm{C}=\mathrm{r} / \mathrm{T}=\mathrm{r} / \mathrm{V}=\mathrm{r} / \mathrm{VV}=\mathrm{r} /$ FROM $=\mathrm{d} /$ THRU $=\mathrm{d}$ )

4.6 VENT ( $\mathrm{WS}=\mathrm{n} / \mathrm{CAP}=\mathrm{r} / \mathrm{MIN}=\mathrm{r} / \mathrm{MAX}=\mathrm{r} / \mathrm{TD}=\mathrm{r} /$

$$
\text { FROM }=\mathrm{d} / \text { THRU }=\mathrm{d})
$$

4.7 MIX ( WS $=\mathrm{n} / \mathrm{CAP}=\mathrm{r} / \mathrm{TD}=\mathrm{r} / \mathrm{ZONE}=\mathrm{n} / \mathrm{FROM}=\mathrm{d} / \mathrm{THRU}=\mathrm{d})$

4.8 FAN ( WS $=\mathrm{n} / \mathrm{CAP}=\mathrm{r} / \mathrm{T}=\mathrm{r} / \mathrm{ZONE}=\mathrm{n} / \mathrm{FROM}=\mathrm{d} / \mathrm{THRU}=\mathrm{d}$ )

4.9 CTRL ( CWS $=\mathrm{n} / \mathrm{HEAT}=\mathrm{r} / \mathrm{COOL}=\mathrm{r} / \mathrm{RAD}=\mathrm{r} /$ FROM $=\mathrm{d} /$ THRU $=\mathrm{d}$ )

4.10 DLT ( WS $=\mathrm{n} / \mathrm{BEAM}=\mathrm{r} / \mathrm{DIFF}=\mathrm{r} / \mathrm{FROM}=\mathrm{d} / \mathrm{THRU}=\mathrm{d})$

4.11 $\mathrm{BBH}(\mathrm{WS}=\mathrm{n} / \mathrm{CAP}=\mathrm{r}, \mathrm{r} / \mathrm{TMP}=\mathrm{r}, \mathrm{r} / \mathrm{RAD}=\mathrm{r} / \mathrm{FROM}=\mathrm{d} /$ THRU $=\mathrm{d} / \mathrm{ST} / \mathrm{HW}$ ) 
4.12 MASS ( CONS $=\mathrm{n} / \mathrm{AREA}=\mathrm{r}$ )

4.13 SRF ( CONS $=\mathrm{n} / \mathrm{EX} / \mathrm{IN} / \mathrm{OP} / \mathrm{TR} / \mathrm{BS} / \mathrm{SS} / \mathrm{AZM}=\mathrm{r} / \mathrm{TILT}=\mathrm{r} /$ $W=r / H=r / S I Z E=r, r /$ VRTS $=r, \ldots\langle 4$ or 6$\rangle / X=r /$ $Y=r / Z=r /$ ORG $=r, r, r / F S=r / F S G=r /$ ZONE $=n$ )

$4.14 \operatorname{AFS}(\operatorname{AREA}=r / \operatorname{EXP}=r / Z S=r / Z T=r)$

4.15 SHD ( OHNG / LFIN / RFIN / PROJ / W $=\mathbf{r} / \mathrm{H}=\mathbf{r} /$

SIZE $=r, r / X=r / Y=r / Z=r / O R G=r, r, r /$

TRNS $=r /$ FROM $=d /$ THRU $=d$ )

4.16 OSC (

4.17 EMI ( CONS $=\mathrm{n} / \mathrm{DS}=\mathrm{n} / \mathrm{SNUP} / \mathrm{SNDN} /$ FROM $=\mathrm{d} /$ THRU $=\mathrm{d})$

4.18 IMI ( CONS $=\mathrm{n} / \mathrm{DS}=\mathrm{n} /$ GAIN / LOSS / FROM $=\mathrm{d} /$ THRU $=\mathrm{d}$ ) 
The zone air temperature is determined by the interaction of the energy flows in the zone and the operation of the air conditioning system. The present version of the TARP does not include detailed system models. The operation of the system is modeled by control profiles like those in the loads section of the BLAST program [1] from which much of the following discussion is taken. A control profile relates the zone air temperature to the capability of the system to add or remove heat from the zone. The use of the control profile in the zone air heat balance is described in III.K.1. Figure E.l shows a simple control profile which can either heat or cool the zone.

Point 1 might occur on a winter day. At that point, the room is at 68 $\mathrm{F}(20.0 \mathrm{C})$ and the heat loss from the room air exactly equals the room heating capacity available at $68 \mathrm{~F}$. In this example, the room heating load (= heat delivered to the room air) is $40.0 \mathrm{kBtu} / \mathrm{hr}(11.7 \mathrm{~kW})$.

Point 2 might occur on a mild day in the spring or fall. At this point (73 F [22.8 C]), no room heating or cooling is accomplished by the building fan system (although heating or cooling energy may be consumed to condition ventilation air). For the heat balance to occur at point 2, convective heat gains caused by such factors as lights or occupancy must be balanced by convective heat losses to room surfaces or by infiltration. The load at point 2 is zero.

Point 3 shows a cooling condition. Here heat gains to the room air are balanced by cooling capacity avallable at the balance point temperature.

The control profile can be described in terms of the temperatures and heating/cooling capacities at control points $A, B, C$, and D. Simple linear proportionality is assumed between the control points. At temperatures below point $A$, the heating capacity is constant. The cooling capacity is constant above point $D$. The control profile is described in two phases in TARP. The full heating and cooling capacities are given for each zone (4.9.2 and 4.9.3). The shape of the profile is described in the library section by normalizing the control point capacities (divide heating capacities by the full heating capacity; divide cooling capacities by the full cooling capacity, the result being set negative). This allows the same profile to be used in many zones which have identical control temperatures but different full capacities. Full heating and cooling capacities can then be adjusted independently of each other. The control profile in figure E.1 normalizes to that in figure $\mathrm{E} .2$ which could be described by the input language $(2.6)$ as:

$$
\text { CPFL（NAME }=\mathrm{Cl} / \mathrm{TMP}=67,69,77,79 / \mathrm{CAP}=1,0,0,-1)
$$

The tempertures and capacities of the control points must be given in the sequence shown. Very steep profiles are possible. The user may set two successive control temperatures equal to each other to hold the room temperature constant. TARP will make the second $0.01 \mathrm{C}$ greater than the first to permit the air heat balance calculations. 
System type can subtly affect room temperature control profiles. For example, assume that a package DX (direct expansion) condensing unit with electric heat has been selected to serve the zone whose control strategy is shown in figure E.1. Futher assume that the unit delivers $3850 \mathrm{cfm}$ $\left(1.82 \mathrm{~m}^{3} / \mathrm{s}\right)$ to the space, that the cooling coll was selected to allow $55 \mathrm{~F}$ $(12.8 \mathrm{C})$ air to be delivered at the design sensible load of $100 \mathrm{kBtu} / \mathrm{hr}$ $(29.3 \mathrm{~kW})$, and that the heating coll was selected to deliver $86.2 \mathrm{~F}$ (30.1 C) air at the design heating load of $80 \mathrm{kBtu} / \mathrm{hr}(23.4 \mathrm{~kW})$. In this case, figure E.1 closely approximates the achieved room temperature control. The room thermostat w111 modulate the condensing unit from "off" to "full" capacity through as many capacity control steps as are avallable on the unit. This modulation will occur in a roughly linear fashion as the balance point room temperature varies from 77 to $79 \mathrm{~F}$ (25 to $26.1 \mathrm{C})$. The heating will be similarly modulated between 69 and $67 \mathrm{~F}$ (20.6 and $19.4 \mathrm{C})$, and both heating and cooling will be "off" between 69 and $77 \mathrm{~F}$ (20.6 and $25 \mathrm{C}$ ). Since the condensing unit's maximum heating and cooling capacity are approximately constant, the unit adds or removes fixed quantities of heat whenever the room temperature is below $67 \mathrm{~F}(19.4 \mathrm{C})$ or above $79 \mathrm{~F}(26.1 \mathrm{C})$.

If a single-zone drawthrough unit served by hot and chilled water is selected, the control strategy of figure E.l may require a slight revision. When room temperature remains between 67 and $79 \mathrm{~F}(19.4$ and $26.1 \mathrm{C})$, figure E.1 is correct. However, as long as the boller and chiller serving the colls in the fan unit can deliver constant temperature hot and chilled water, the maximum capacity of the heating and cooling colls is not independent of room temperature. For example, as the room temperature rises toward $79 \mathrm{~F}(26.1 \mathrm{C})$, the room thermostat opens the cooling coll's chilled water valve until the valve 18 fully opened at $79 \mathrm{~F}(26.1 \mathrm{C})$. If room heat gains are sufficient, the room alr temperature will continue to rise; but as it rises, the temperature of the air entering the coll also rises. Therefore, the cooling capacity of the coll gradually increases. The capacities below point $A$ and above point $D$ of figure $E .1$ are not constant, but are slowly increasing. Coll catalog data can be used to determine the change in coll capacity.

Figure E.3 shows the equivalent control profile that should be used if a three-deck multizone unit is selected to serve several zones with the same thermostat throttling ranges and deadband. The rationale for selecting this profile is:

1. Range C-D is the thermostat deadband in which air delivered to the zone passes through the bypass deck and is neither heated nor cooled.

2. In range $B-C$, air from the hot deck and the bypass deck of the $f$ an system are mixed to meet zone heating requirements. This is the heating throttling range for the thermostat. At its lower end $(67 \mathrm{~F}[19.4 \mathrm{C}])$, all air to the zone comes through the hot deck and is delivered to the zone at the hot deck tempeature (86.2 F [30.1 C], for example). 
3. If heat losses are severe, the room temperature may fall into range A-B. In this range, alr entering the room comes from the hot deck only. As long as the fan system heating coll is not overloaded, the air is supplied to the zone at constant temperature. However, the amount of heat added to the room air continues to increase as the room air temperature falls. The amount of heat added per hour can be calculated from the following formula:

$$
L=F * C_{p} *(T s-T Z)
$$

where

$F=$ mass flow rate of alr supplied by the fan system to the room

$C p=$ spectfic heat of air

Ts = supply air temperature to the room (the hot deck temperature)

$\mathrm{TZ}=$ air temperature in the room

For this system, $F$ and $C p$ are constant and $T s$ is constant for range $A-B$. Therefore, as room temperature (TZ) falls, the heat added to the room increases Iinearly as shown in figure E.3. cooling.

4. Ranges $D-E$ and $E-F$ are analogous to ranges $B-C$ and $A-B$, but are for

The TARP description of the profile in figure E.3 is:

CPFL ( NAME $=\mathrm{C} 2$ / $\mathrm{TMP}=60,67,69,77,79,85 / \mathrm{CAP}=1, .73,0,-0,-.8,-1)$

When defining a control profile like the one shown in figure E.3, users should select arbitrary low and high room temperatures to establish the full heating and cooling $(+1$ and -1$)$ points on the profile. In the example above, 60 and $85 \mathrm{~F}$ ( 15.6 and $29.4 \mathrm{C}$ ) were selected. When specifying corresponding heating and cooling capacities for each zone, the "design" capacity generally should not be used. Capacity should correspond with the selected low and high temperatures.

In the DX condensing unit, single-zone drawthrough, and three-deck multizone examples, load calculations will yield identical results when the control profiles shown in figures E.I or E.3 are used, provided that the temperature in the space stays between 67 and $79 \mathrm{~F}(19.4$ and $26.1 \mathrm{C})$ during the hours when the conrtol profile is in effect. Fortunately, most systems are designed with sufficient capacity to maintain comfort conditions, and users need be concerned about room temperature control characteristics which are outside the range of the thermostat only when the heating or cooling system has been indavertantly or deliberately undersized.

The same reasoning used for the three-deck multizone system can be used to construct control profiles for spaces served by conventional mult1-zone, dual duct, or reheat systems (see flgure E.4). Ranges $A-B$ and $C-D$ correspond to ranges $A-B$ and $E-F$ of figure $E .3$, respectively. Range $B-C$ covers the temperature range where the mixing box, zone dampers, or reheat coils are modulated by the room thermostat. The TARP description of such a profile is: 
CPFL ( $\mathrm{NAME}=\mathrm{C} 3 / \mathrm{TMP}=60,73,77,85 / \mathrm{CAP}=1, .58,-.74,-1)$

No deadband is possible with these profiles so they cannot be approximated by profiles of the type shown in figures E.I and E.3.

Figure E.5 shows a typical control profile for a VAV (variable air volume) system with reheat. It was constructed based on the assumption that $3850 \mathrm{cfm}\left(1.82 \mathrm{~m}^{3} / \mathrm{s}\right)$ of $55 \mathrm{~F}(12.8 \mathrm{C})$ delivery alr $1 \mathrm{~s}$ to be supplied to the zone with the VAV dampers fully open at $79 \mathrm{~F}(26.1 \mathrm{C})$. The dampers close to 20 percent of full flow at $77 \mathrm{~F}(25 \mathrm{C})$. Reheat is to operate between 69 and $67 \mathrm{~F}$ (20.6 to $19.4 \mathrm{C}$ ), and the reheat coll w1ll dellver alr at $140 \mathrm{~F}$ (60 C) when fully energized. The following temperatures and capacities define the control profile:

Temperature
F $(\mathrm{C})$
$60.0(15.6)$
$67.0(19.4)$
$69.0(20.6)$
$77.0(25.0)$
$79.0(26.1)$
$85.0(29.4)$

Capac1ty
kBtu/hr(kW)
$66(19.3)$
$61(17.9)$
$-12(-3.5)$
$-18(-5.3)$
$-100(-29.3)$
$-125(-36.6)$

Normal1zed
Capac1ty
1.0
.91
-.09
-.15
-.80
-1.0

The TARP input for this profile 1s:

CPFL（NAME=C4 / TMP $=60,67,69,77,79,85 / \mathrm{CAP}=1, .91 .-.09,-.15,-.8,-1)$ REFERENCES

[1] Hittle, D. C., BLAST, Version 2.0: Users Manual, Vo1 1, U. S. Army Construction Engineering Research Laboratory, Technical Report E-153 (Champalgn IL, 1979), pp 41-46. 


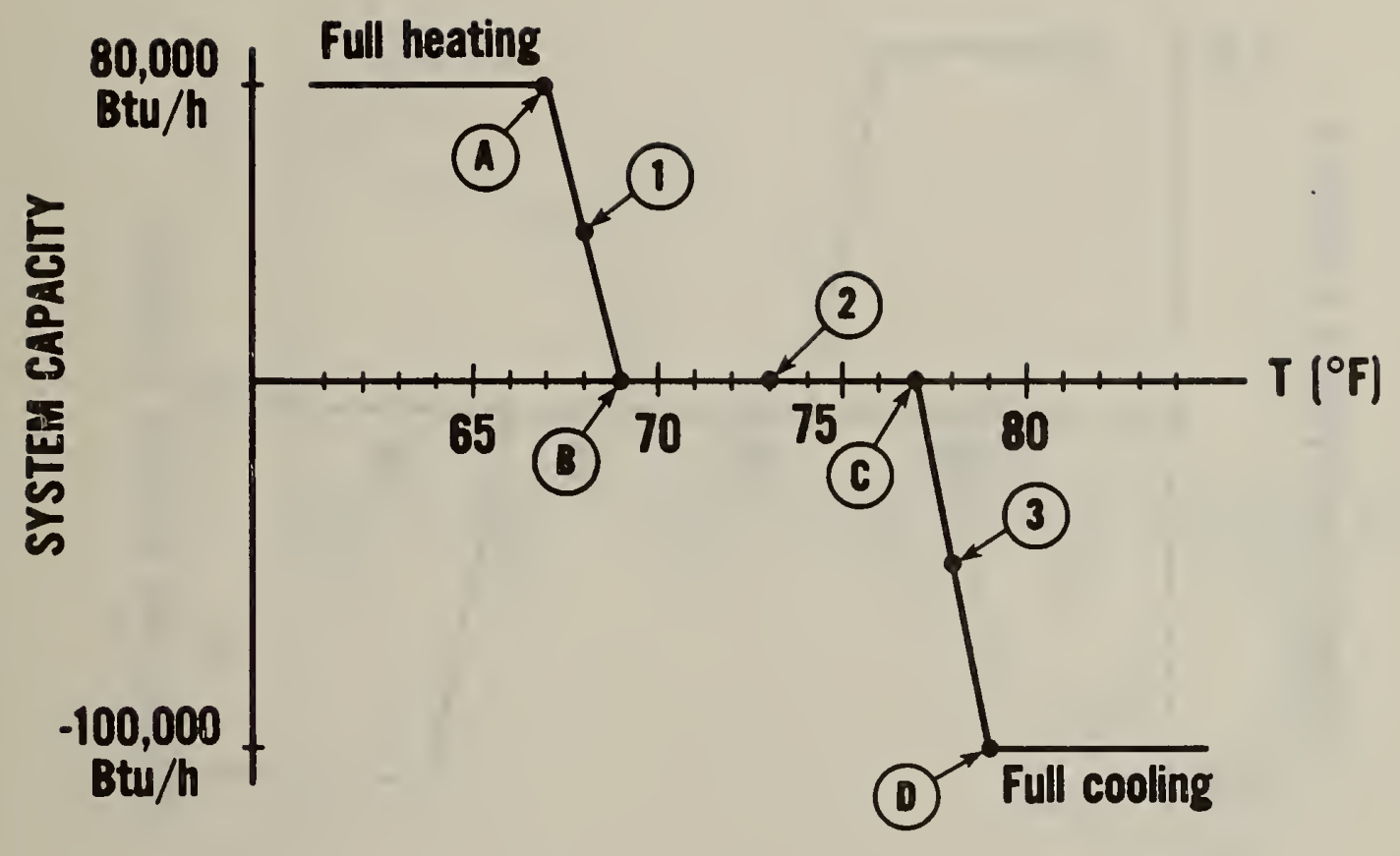

Figure IV.E.1 Simple control profile with deadband 


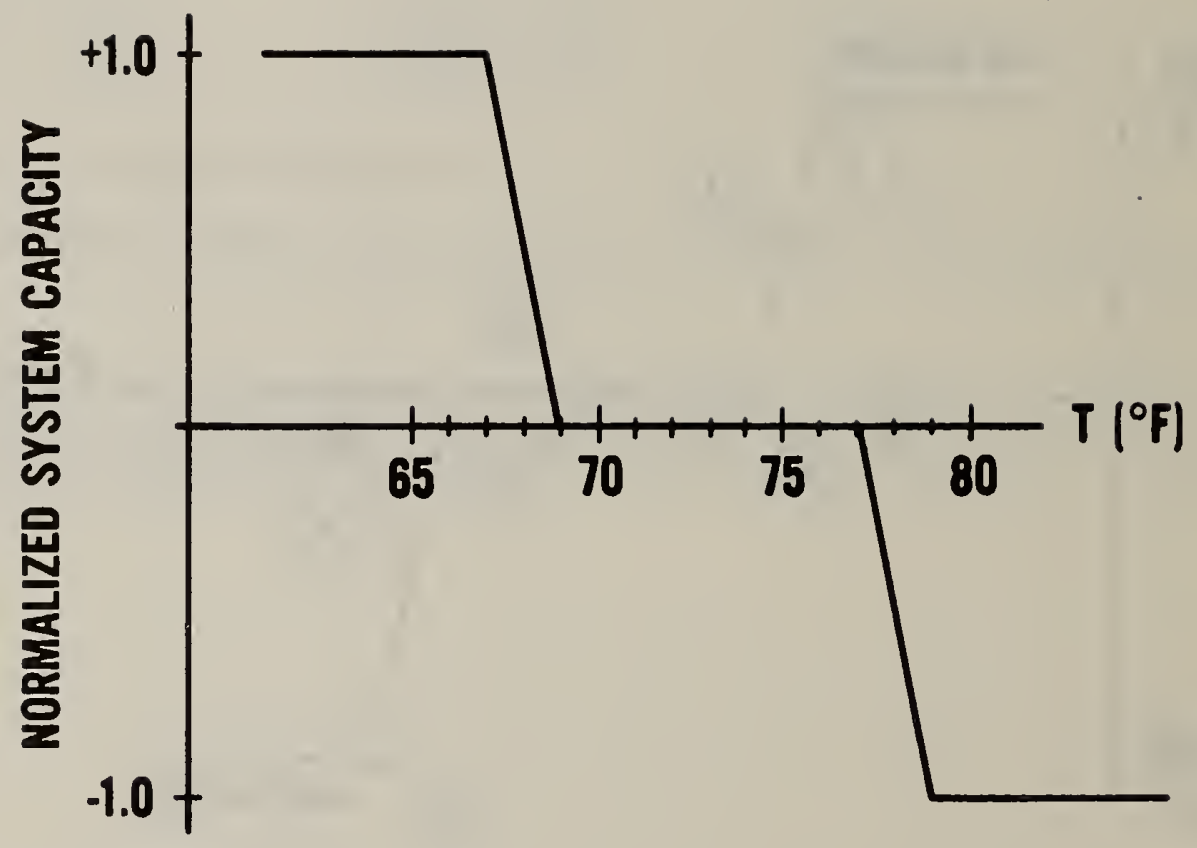

Figure IV.E.2 Normalized control profile 


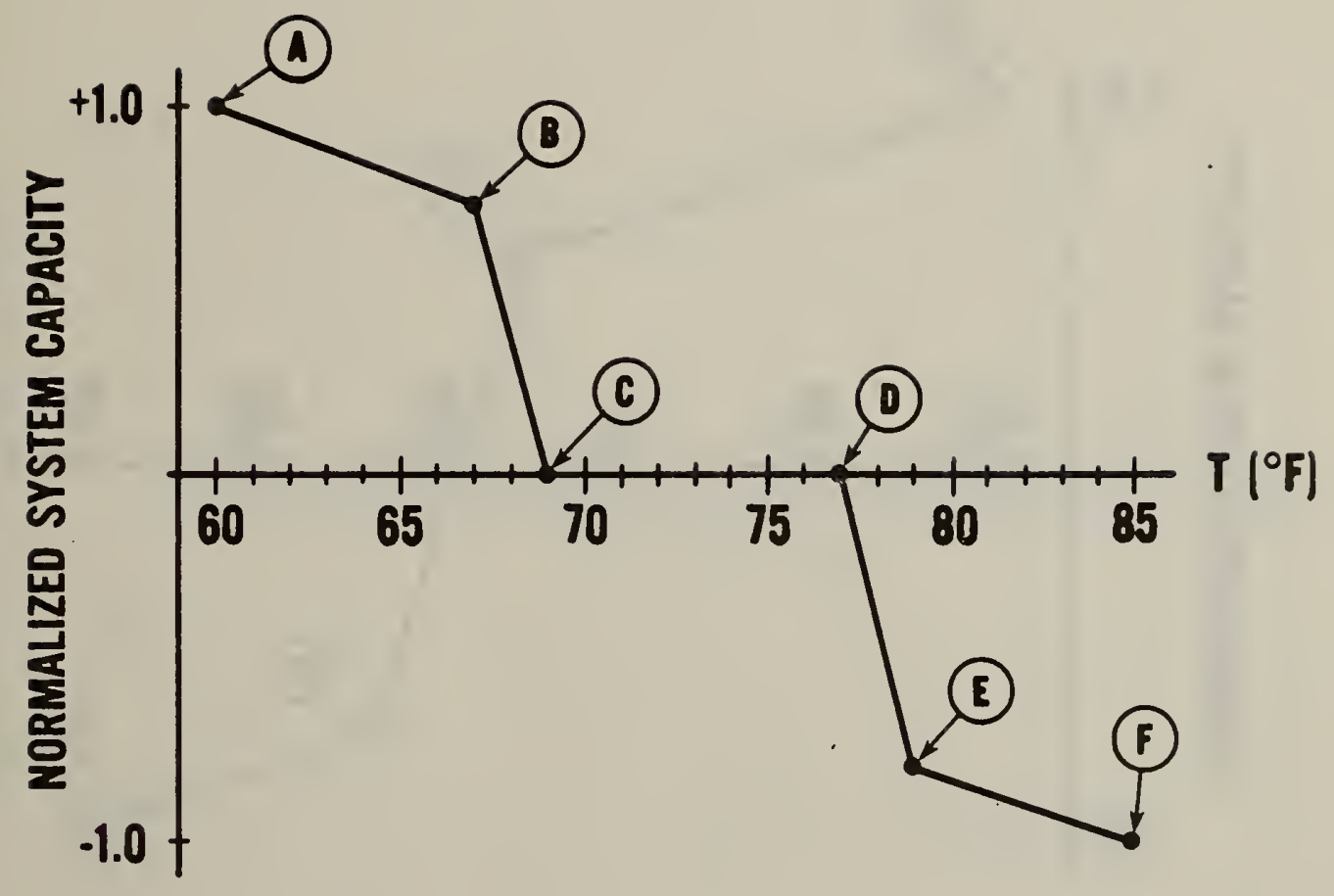

Figure IV.E.3 Control profile for three-deck multizone system 


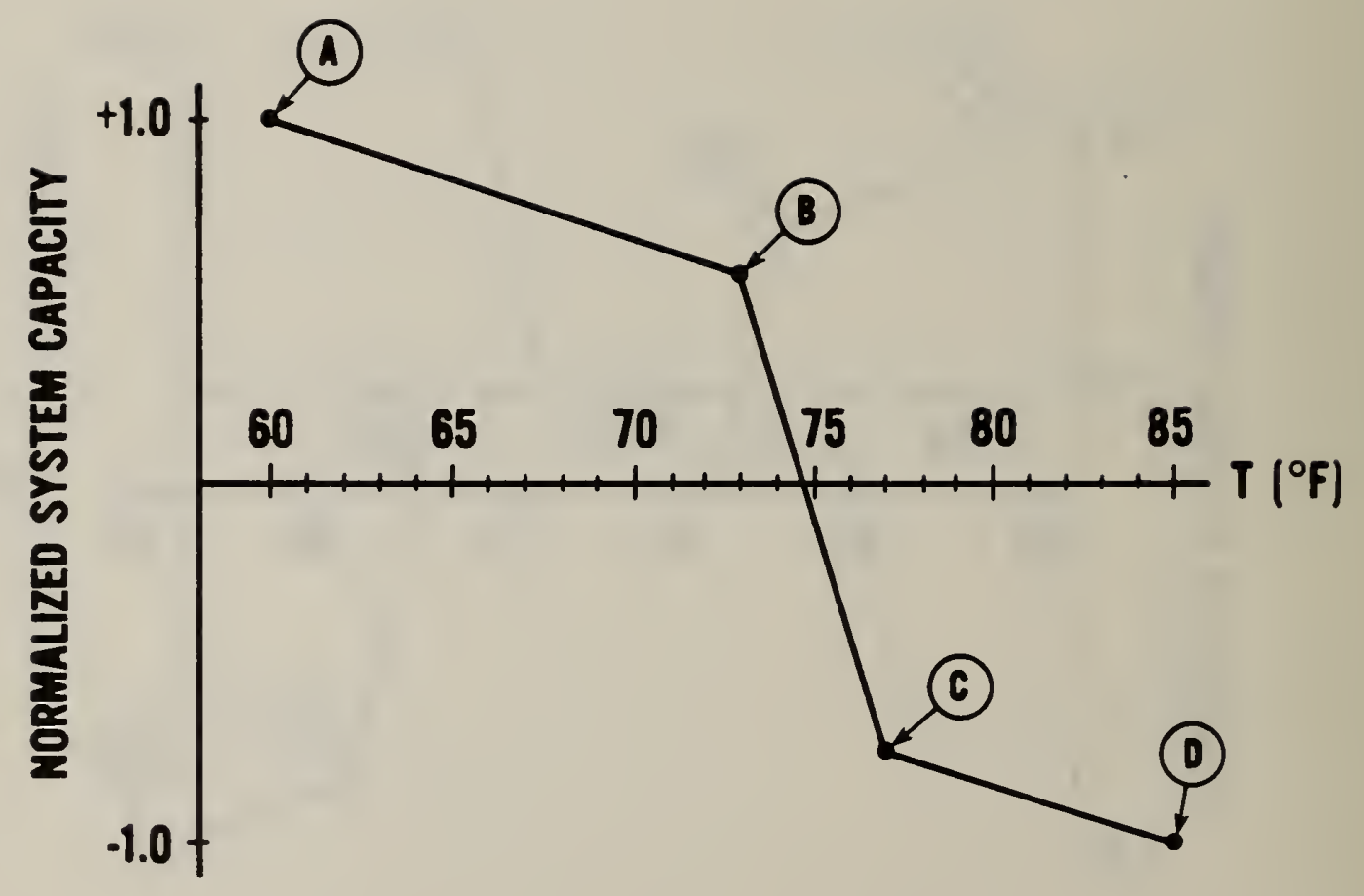

Figure IV.E.4 Control profile for multizone system 


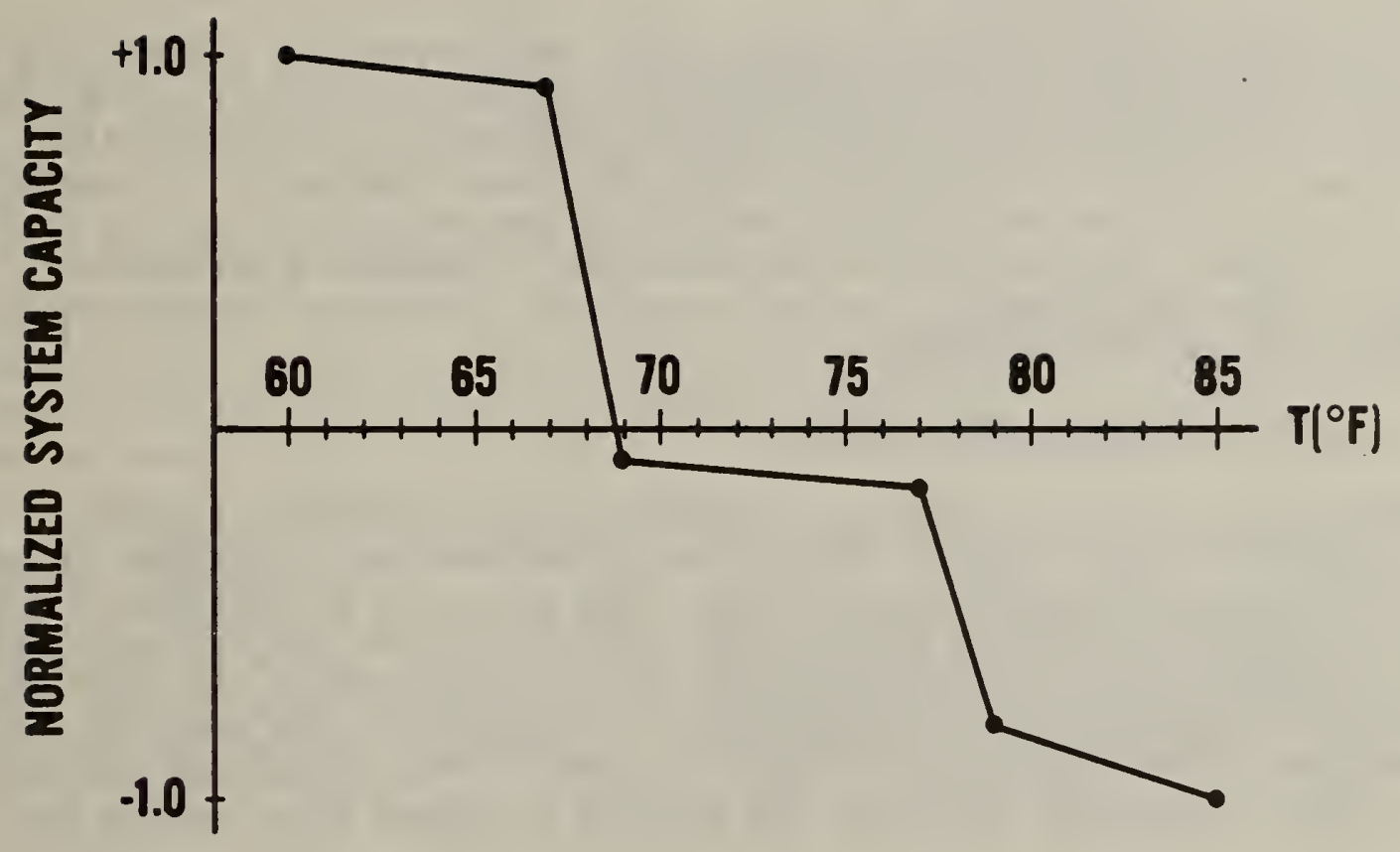

Figure IV.E.5 Control profile for VAV system 
To accurately account for shading, solar gains, and the effects of wind on exterior walls, windows, and roofs, a fairly detailed description of the bullding's geometry is required. Every bullding surface is represented by a plane polygon of three or four sides. Within the program, each polygon is represented by the locations if its vertices in a simple Cartesian coordinate system. In that system, the $\mathrm{X}$ axis points due east, the $\mathrm{Y}$-axis points north, and the Z-axis points upward. The orientation of each surface is maintained by two conventions. First, the vertices are stored in counter-clockwise sequence as the surface is viewed from outside the zone it encloses. (Looking at the surface from the opposite side would give a clockwise sequence.) Second, the orlentation is described in terms of the "azimuth" and "t1lt" angles.

The simplest level (0) of shadowing detall (3.1.2) requires that only the azlmuth and tilt angles be specified. Detailed air flow analysis (3.1.4) and the detalled exterior surface coefficlent algorithm (3.1.6) require correct helghts for every surface. The first and second levels of shadowing detall require that all surfaces of the bullding envelope be correctly positioned in the bullding coordinate system. The third level of shadowing detail requires that internal surfaces also be correctly positioned and that the zone is completely enclosed.

A helrarchy of coordinates systems exists to simplify the positioning of surfaces. The building coordinate system is a simple rotation from the true coordinate system which allows major bullding features to be aligned along the $X-Y$ axes. There is a coordinate system for every zone which is located relative to the bullding system for simplifying the description of the zone geometry. Finally, each surface of the zone has a coordinate system for defining the size and shape of the surface and the location of subfeatures which apply only to that surface.

\section{IV.F.1 SURFACE COORDINATE SYSTEM}

Every wall, roof, or floor of a bullding is represented by a plane surface of three or four sides. The origin of the surface coordinate system is located at one of the surface vertices. The X-axis is a horizontal (relative to the global coordinate system) line in the plane of the surface. The $\mathrm{Y}$-axis is perpendicular to the X-axis and also in the plane of the surface. The $\mathrm{Z}$-axis is perpendicular to the surface. It is used in the descriptions of subsurfaces. The coordinates of the vertices of the surface are described in the surface coordinate system as the surface is viewed from outside 1 ts zone.

Input (4.13.5) allows a simple description of rectangular surfaces. For example a rectangular wall 12 feet wide by 8 feet high ( $W=12 / \mathrm{H}=8$ or equivalently $S I Z E=12,8$ ) would be described by figure F.1. This representation of rectangles places the origin at the lower left corner so that all vertices are positive numbers. 
Non-rectangular surfaces can also be described by giving the coordinates of the vertices. For example, VRTS $=10,0,5,30$ describes the triangle in figure F.2. Negative coordinates like VRTS $=12,-3,7,7,-5,10$ are also possible (figure F.3). In the description of non-rectangular surfaces, a vertex at the origin $(0,0)$ is assumed. The remaining vertices are given by their $X-Y$ coordinates going counter-clockwise around the surface. Only convex surfaces (no interior angle greater than 180 degrees) with 3 or 4 vertices are permitted. Other surfaces should be divided into two or more convex surfaces. The reasons for this are discussed in III.E.4.

\section{IV.F.2 WINDOW AND DOOR SUBSURFACES}

The location and size of these features are described in the coordinate system of the base surface (wall, roof, etc.) on which they lie. The size of each window or door is given by 1 ts width and height (for example, $W=4$ / $\mathrm{H}=6$ or equivalently $\mathrm{SIZE}=4,6$ ). The subsurface is located on the base surface by giving the coordinates of its lower left corner relative to the origin of the base surface (for example $X=4 / Y=1.5$ or $O R G=4,1.5,0$ ). Coordinates are given relativve to the base surface coordinate system. Figure F.4 shows the window thus described placed on the wall from figure F.1. The subsurface must lie completely within the base surface. Nonrectangular subsurfaces must be described as equivalent rectangles.

It is common for windows and doors to be set back slightly behind the plane of the base surface. This causes shadowing of the subsurface, especially as the sun's rays become nearly parallel to the surface. The setback 1 s described by the $\mathrm{Z}$ coordinate $(\mathrm{Z}=-.5$ ) of the location of the subsurface. (A "set forward" is not permitted.)

\section{IV.F.3 SHADOWING SUBSURFACES}

TARP input (4.15) provides a simple way to describe rectangular shadowing features which are parallel to the major axes of the base surface coordinate system. There are four conflgurations:

1. An overhang (OHNG) lies parallel to the $X-Z$ plane and can cast shadows downward onto the surface (figure F.5).

2. A left fin (LFIN) lies parallel to the $Y-Z$ plane and is to the left of its shadow (figure F.6).

3. A right fin (RFIN) also lies parallel to the $Y-Z$ plane but lies to to the right of 1 ts shadow (figure F.7). Section III.E.2 explains why TARP surfaces cast shadows to one side but not the other. It is necessary to use an LFIN and an RFIN to describe a feature which can shade both directions.

4. A projection ( $P R O J$ ) lies parallel to the $X-Y$ plane in front of the surface which it shadows (figure F.8).

Figures F.5 through F.8 show how the size and position of these shadowing features are described in terms of $W, H$ (or SIZE) and X, Y, Z (or ORG).

A shadowing subsurface will shade the base surface and all its window or door subsurfaces. It will not shade any other base surface. 
The surfaces of a zone are located relative to each other in the zone coordinate system. It is a Cartesian coordinate system with a vertical $\mathrm{Z}$-axis and the $\mathrm{X}$ and $\mathrm{Y}$ axes orlented parallel to major zone features to simplify placement of surfaces. A surface is located in the zone coordinate system by giving the coordinates of the surface origin relative to the zone orfgin ( $X=r / Y \approx r / Z=r$ or $O R G=r, r, r[4.13 .6]$ ) and the azimuth ( $A Z M=r$ [4.13.3]) and t1lt ( $T I L T=r[4.13 .4]$ ) angles of the surface.

The tilt angle is the angle from the Z-axis to the normal to the surface. A vertical surface has a tilt of 90 degrees. A horizontal roof has a tilt of 0 . A floor has a t1lt of 180 (the outward normal points down).

Azlmuth is the clockwise angle between the Y-azis and the horizontal profection of the outward normal of the surface. For vertical surfaces this is simply the direction the wall faces. Figure F.9 shows the locations, azlmuths and tilts of three vertical and three t1lted surfaces. For horlzontal surfaces the true azlmuth angle is undefined, but one must be given to properly locate the surface vertices in the zone coordinate system. This is most easily done by imagining the horizontal surface rotated about an edge until it is vertical to allow identification of origin, width, and helght as in figure F.10 for a flat roof and figure F.11 for a floor.

\section{IV.F.5 BUILDING COORDINATE SYSTEM}

The bullding coordinate system is chosen to simplify the placement of zones relative to each other. The $X$ - and $Y$-axes are usually chosen to lie along the axes of most of the zones. Each zone 1s located in the bullding coordinate system by giving the coordinates of the zone origin relative to the bullding origin ( $X=r / Y=r / Z=r$ or $O R G=r, r, r[4.1 .3])$ and the angle from the bullding $Y$-axis to the zone $Y$-axis ( $N=n[4.1 .2])$. Figure F.12 shows the location of three zones in a bullding coordinate system.

Because of the general orlentation of the bullding, the Y-axis may not IIne up with true north. The angle from true north to the Y-axis of the bullding coordinate system ( $N=r$ [3.1.1]) must be given to allow TARP to compute the true coordinates of the surface vertices.

It is common for bulldings to have two or more zones which are geometrically 1dentical except for their location and orientation as shown by the four zone examples in figure F.13. TARP allows two ways to describe zones in terms of others already defined. First is rotation and translation. The description of zone 3 can be produced by duplicating the description of zone 2 and adding a rotation of 180 degrees about the zone origin and shifting the origin to $O R G=24.5,55,0$. This process is 1llustrated in f1gure F.14. Use the text editor to duplicate the geometric features of zone 2, and do the rotation and origin translation of the origin in the GEOM (4.1) key. Th1s reduces the number of new lines that must be typed to describe a similar zone. 
Zone 4 in figure F.13 is very similar to zone 1, but its geometric description cannot be obtained by any combination of rotations and translations. It is a mirror 1mage of zone 1. Its description must use one of the mirror image commands (MIRX [4.1.5] or MIRY [4.1.6]). F1gure F.15 shows how zone 1 is first mirrored in the $Y$ direction ( $Y$ coordinates in the zone system are replaced by their negatives) and then translated to a new origin to produce the description of zone 4. Figure F.16 shows that the same results could have been obtained by mirroring in the $\mathrm{X}$ direction, rotating 180 degrees, and translating the origin. Mirror imaging works for all surfaces and subsurfaces except those cases where a subsurface is on a non-rectangular base surface which was described with the first vertex not lying on the $X$-axis (such as the base surface in figure F.3).

\section{IV.F.6 DETACHED SHADOWING SURFACES}

The geomerty described thus far will allow calculation of shadowing from subsurfaces like fins and overhangs, and from other zone surfaces. In addition the user may wish to describe adjacent bulldings or other significant shadow casting features which are not part of a particular zone and which can shade more than one zone or surface. This is done with the "detached shadowing surface" (DSS [3.2]). The description of such a surface invloves defining its size and shape ( $W=r / H=r$ or SIZE=r, $r$ or VRTS $=r, r, r, r, r, r$ [3.2.4]) as described above for a zone surface and then locating $(\mathrm{X}=\mathrm{r} / \mathrm{Y}=\mathrm{r} / \mathrm{Z}=\mathrm{r}$ or $\mathrm{ORG}=\mathrm{r}, \mathrm{r}, \mathrm{r}$ [3.2.3]) and orienting ( $\mathrm{AZM}=\mathrm{r}$ [3.2.1] and $T I L T=r[3.2 .2]$ ) the surface in the bullding coordinate system. The critical consideration in locating and orienting the surface is that it casts a shadow only into the hemisphere which it faces. 


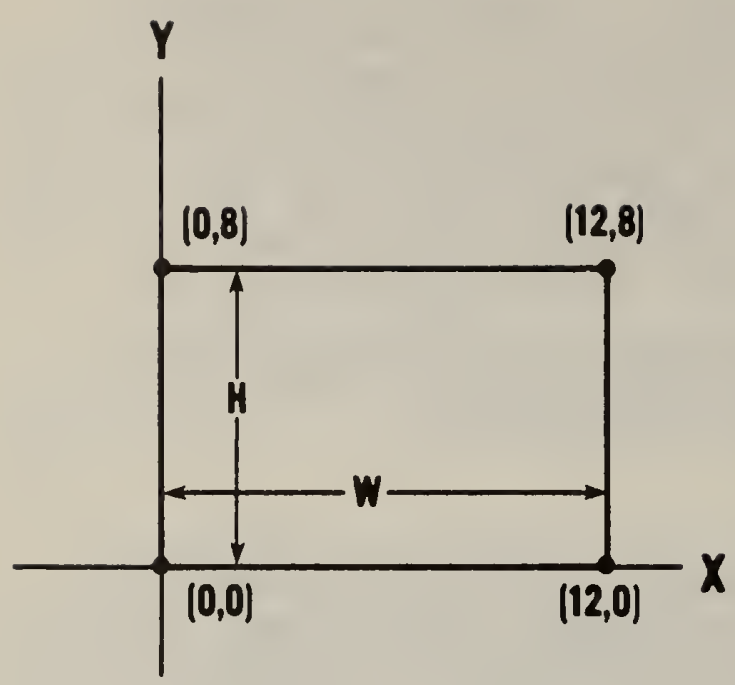

Figure IV.F.1 Rectangle

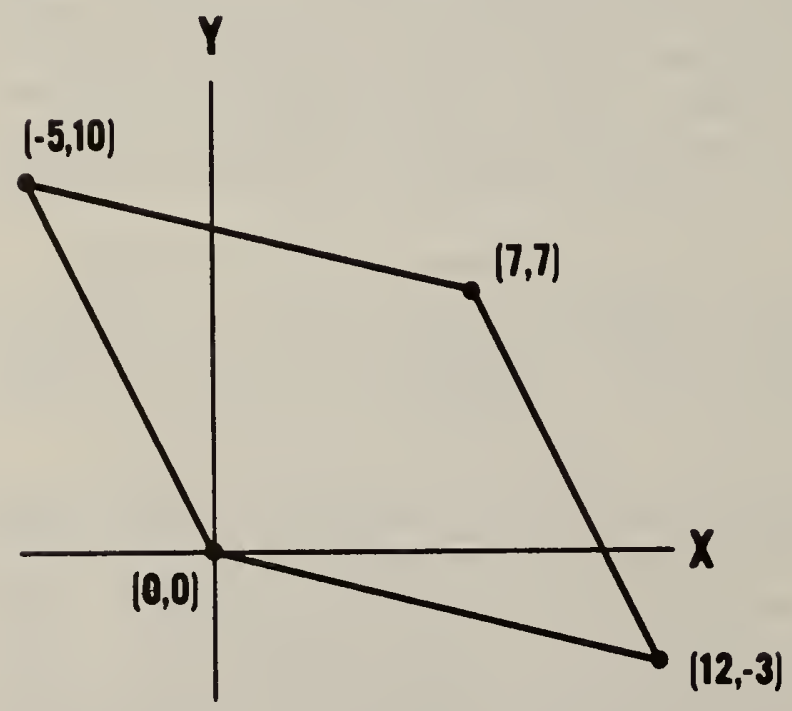

Figure IV.F.3 Quadrilateral

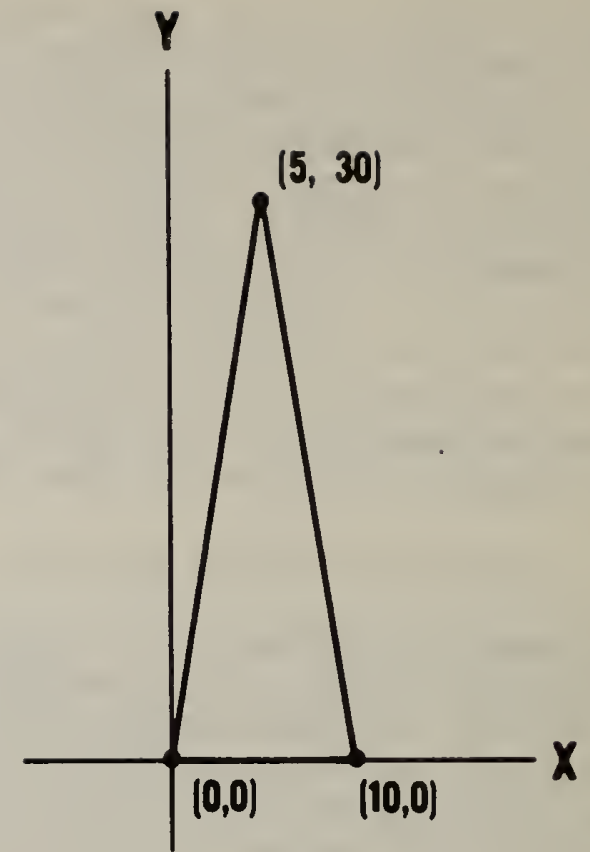

F1gure IV.F.2 Triangle

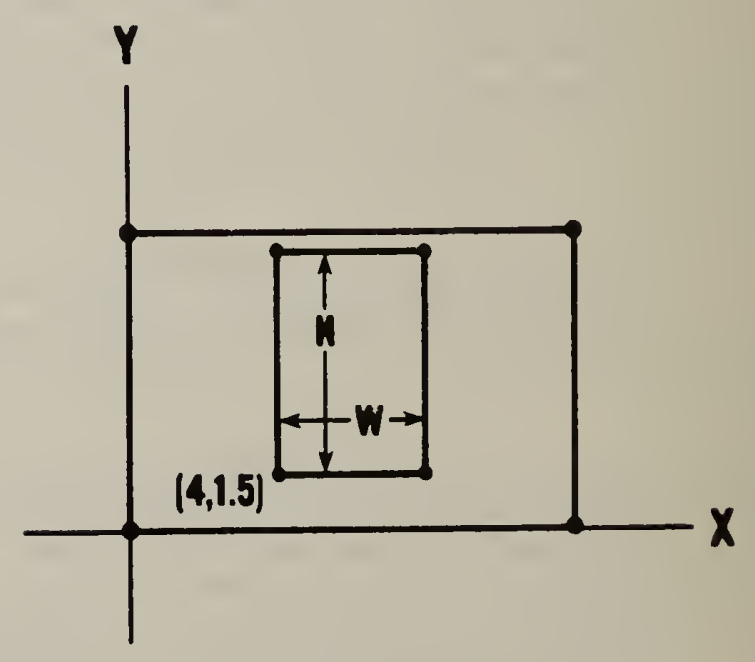




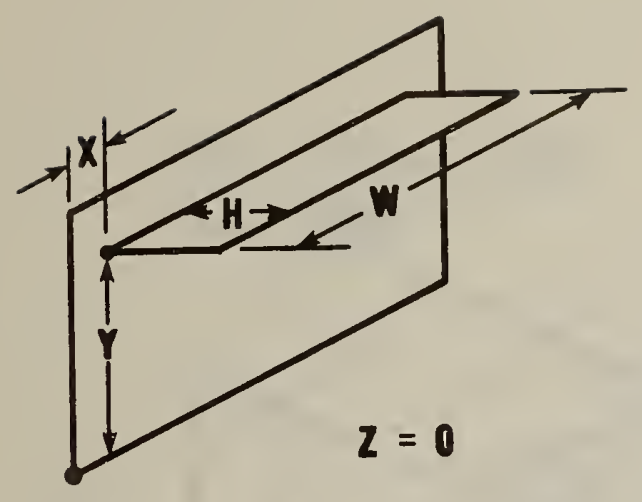

Figure IV.F.5 Overhang

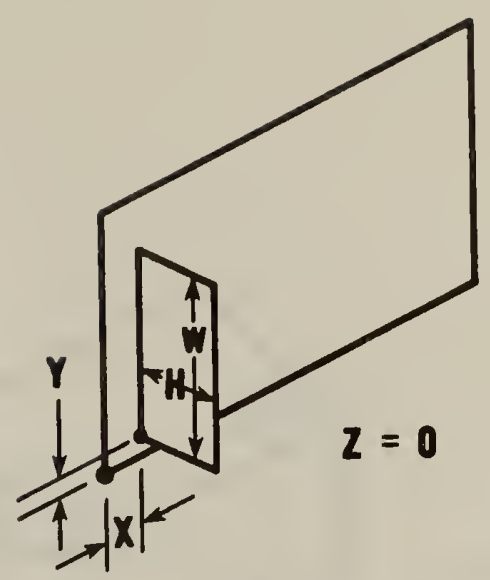

Figure IV.F.6 Left fin

- Subsurface origin

- Base surface origin

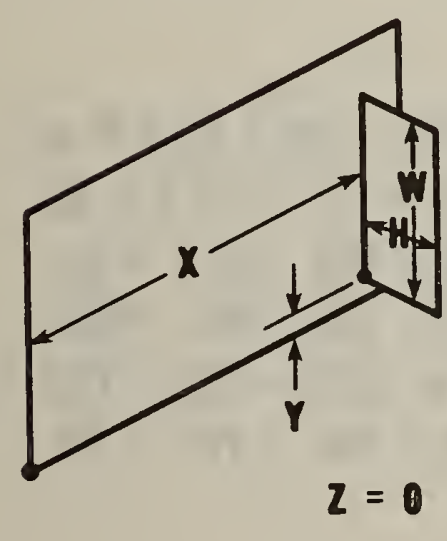

Figure IV.F.7 Right fin

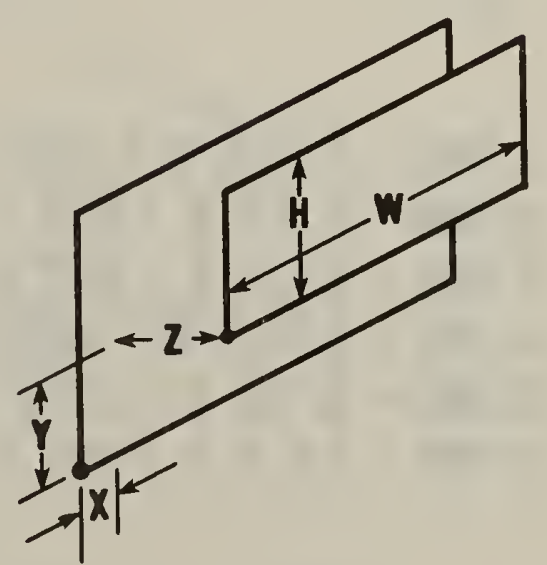

Figure IV.F.8 Projection 


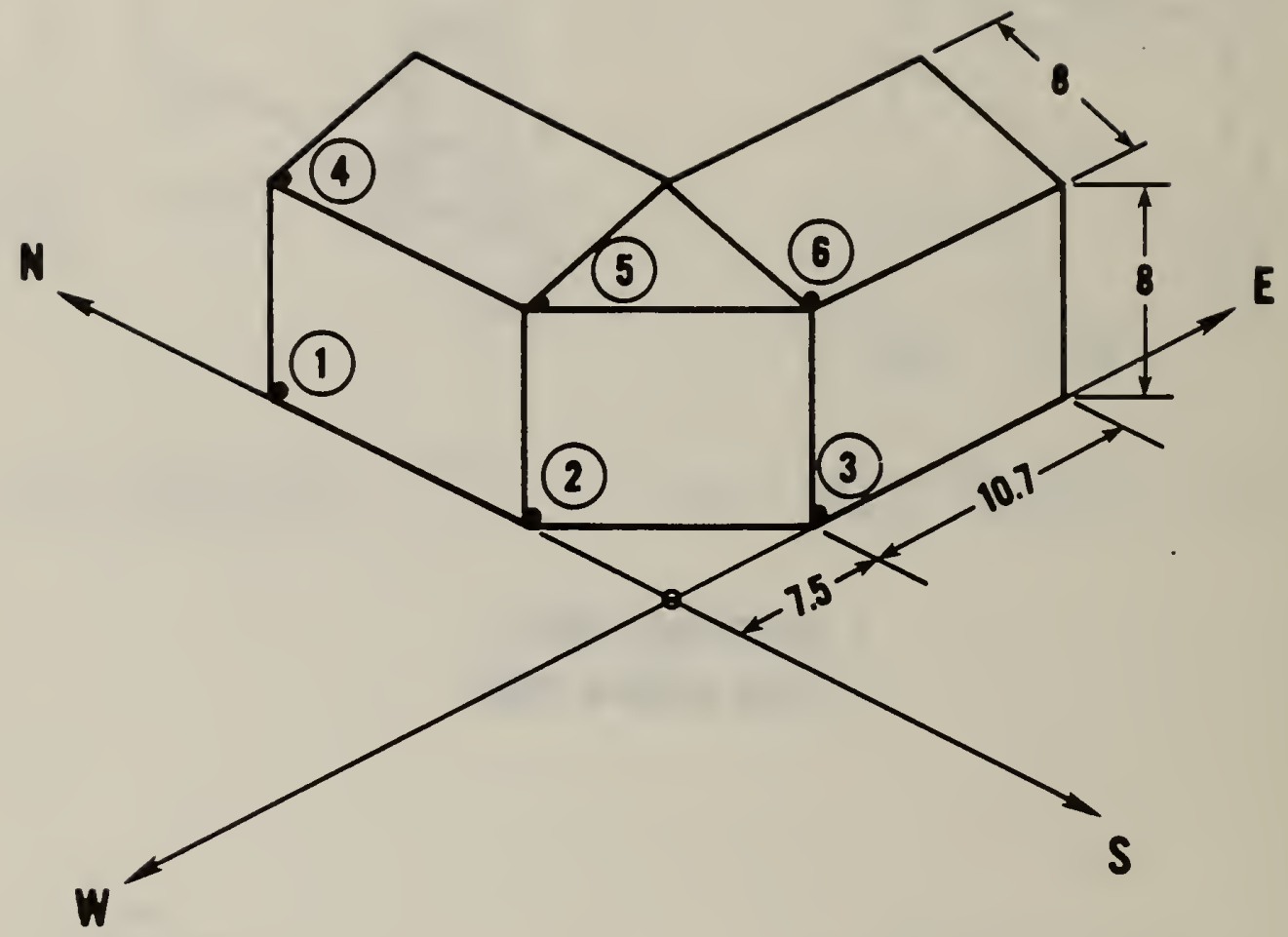

$$
\begin{aligned}
& \text { 1: } \text { ORG }=0,18.2,0 / \text { SIZE }=10.7,8 / \text { AZM }=270 / \text { TILT }=90 \\
& \text { 2: } \text { ORG }=0,7.5,0 / \text { SIZE }=10.7,8 / \text { AZM }=225 / \text { TILT }=90 \\
& \text { 3: ORG }=7.5,0,0 / \text { SIZE }=10.7,8 / \text { AZM }=180 / \text { TILT }=90 \\
& \text { 4: ORG }=0,18.2,8 / \text { SIZE }=10.7,8 / \text { AZM }=270 / \text { TILT }=20 \\
& \text { 5: ORG }=0,7.5,8 / \text { VRTS }=10.7,0,5.3,4 / \text { AZM }=225 / \text { TILT }=20 \\
& \text { 6: ORG }=7.5,0,8 / \text { SIZE }=10.7,8 / \text { AZM }=180 / \text { TILT }=20
\end{aligned}
$$

Figure IV.F.9 Zone coordinate system: tilted surfaces 
- Base surface origin

- Zone origin
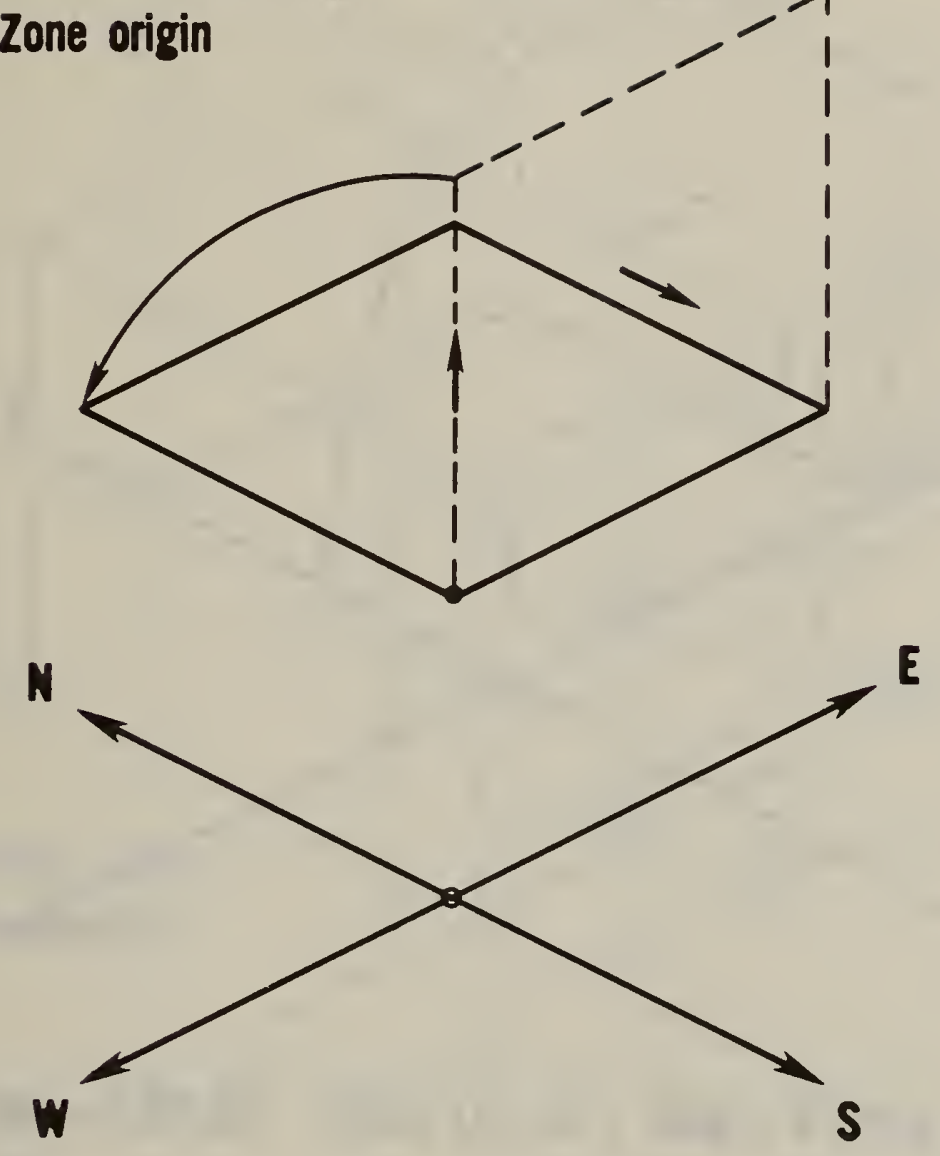

$$
\text { ORG }=0,0,8 / \text { SIZE }=12,12 / A Z M=180 / \text { TILT }=0
$$

Figure IV.F.10 Zone coordinate system: flat roof 


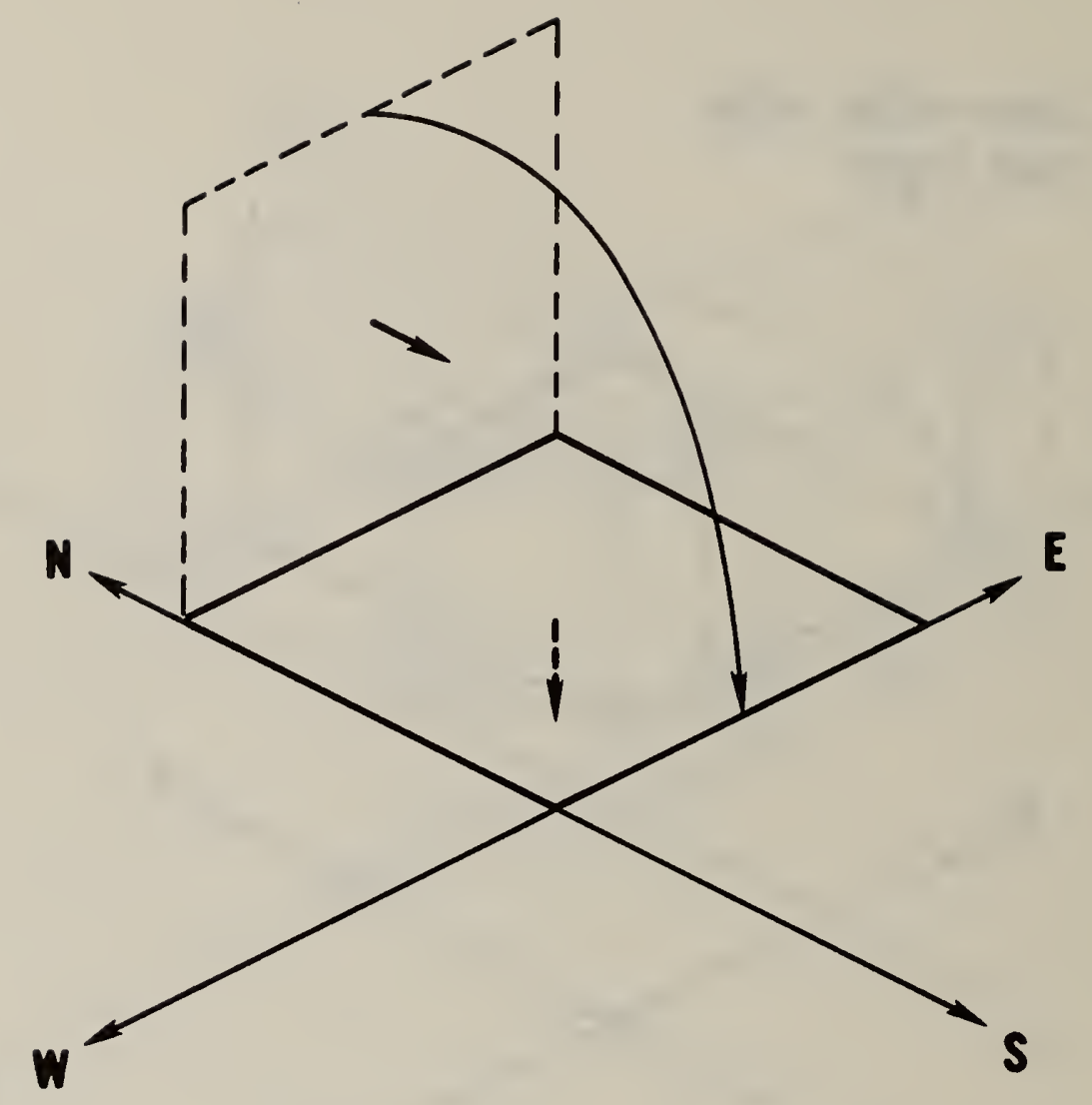

ORG $=0,12,0 /$ SIZE $=12,12 /$ AZM $=180 /$ TILT $=180$

Figure IV.F.11 Zone coordinate system: floor 


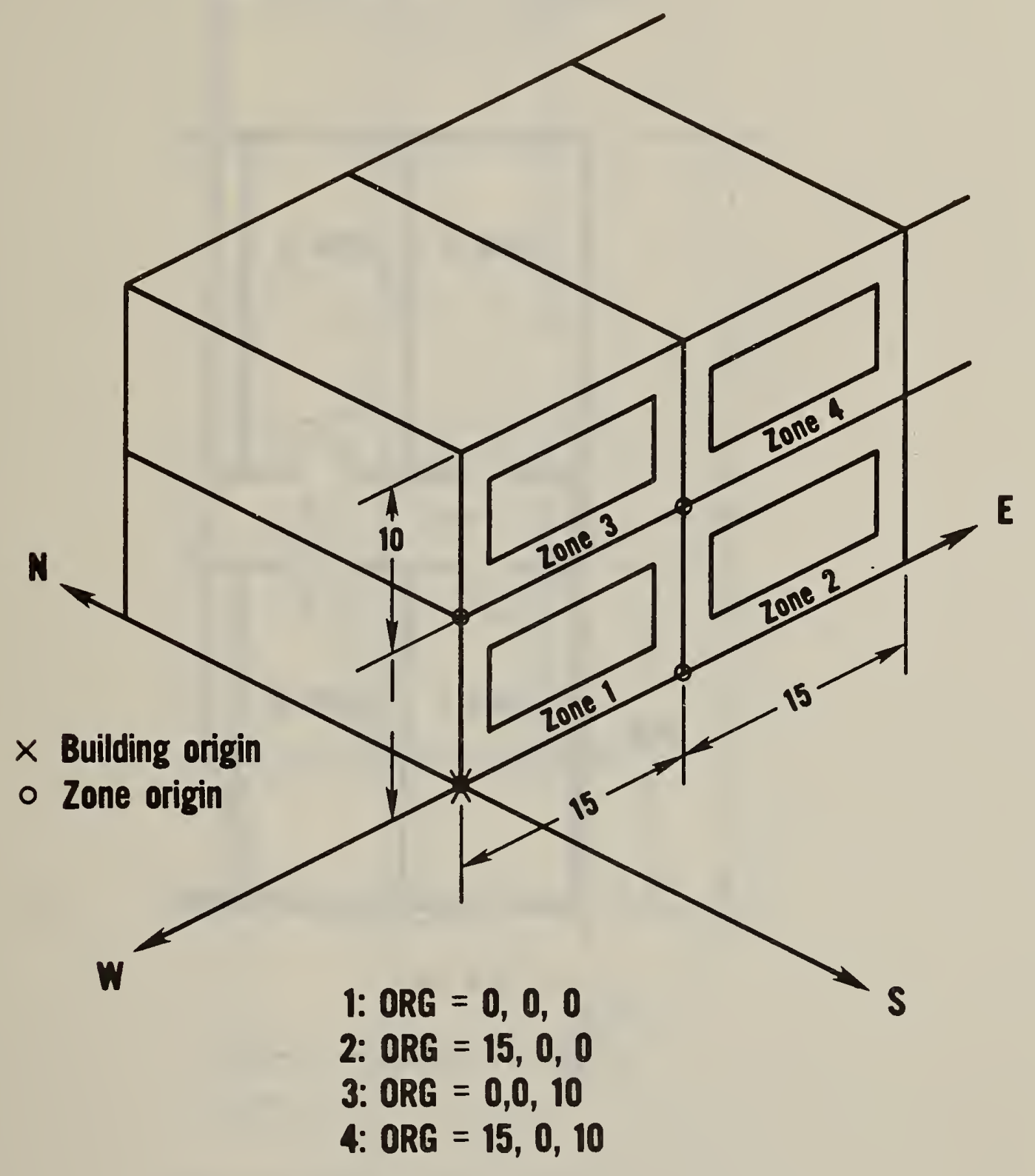

Figure IV.F.12 Building coordinate system: four zones 


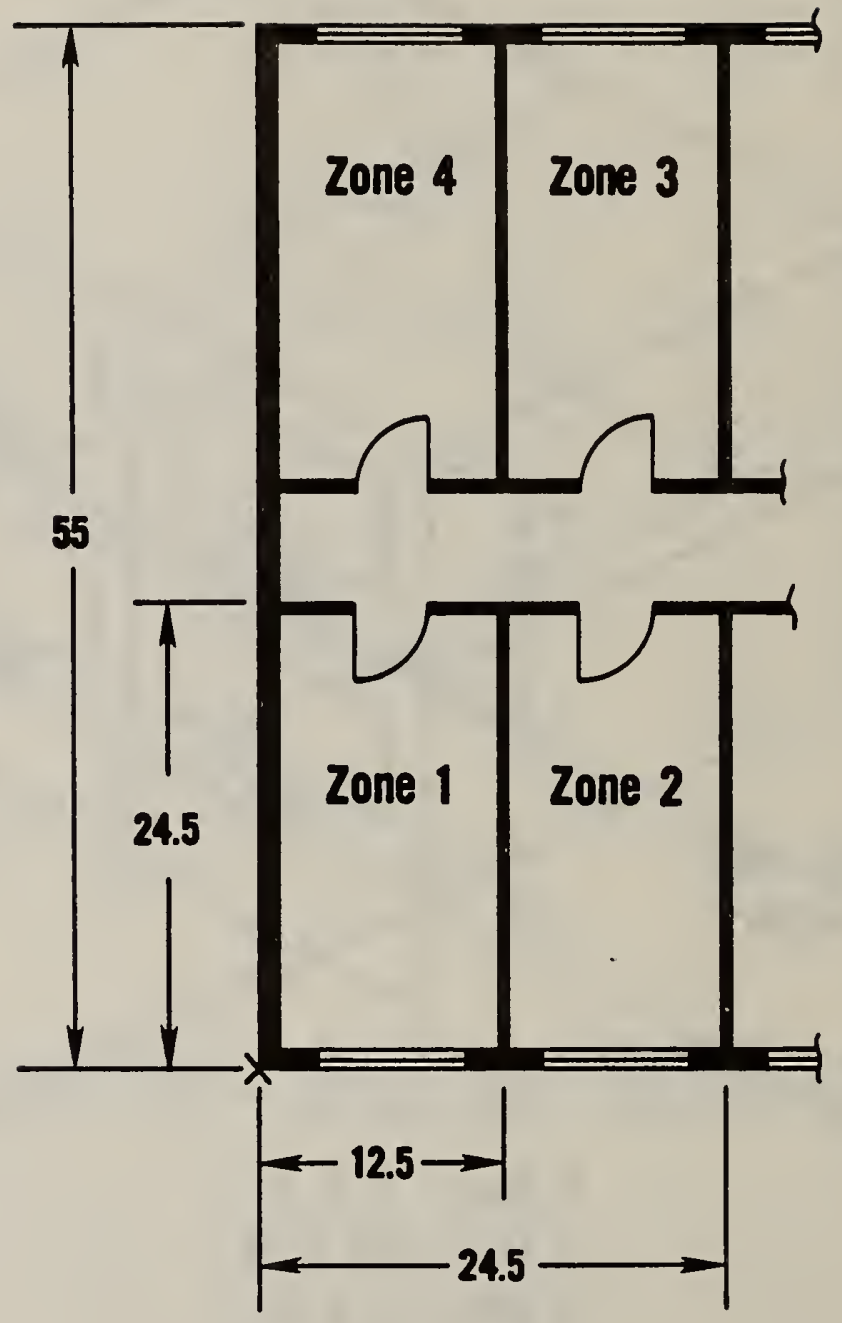

Figure IV.F.13 Portion of building with similar zones 


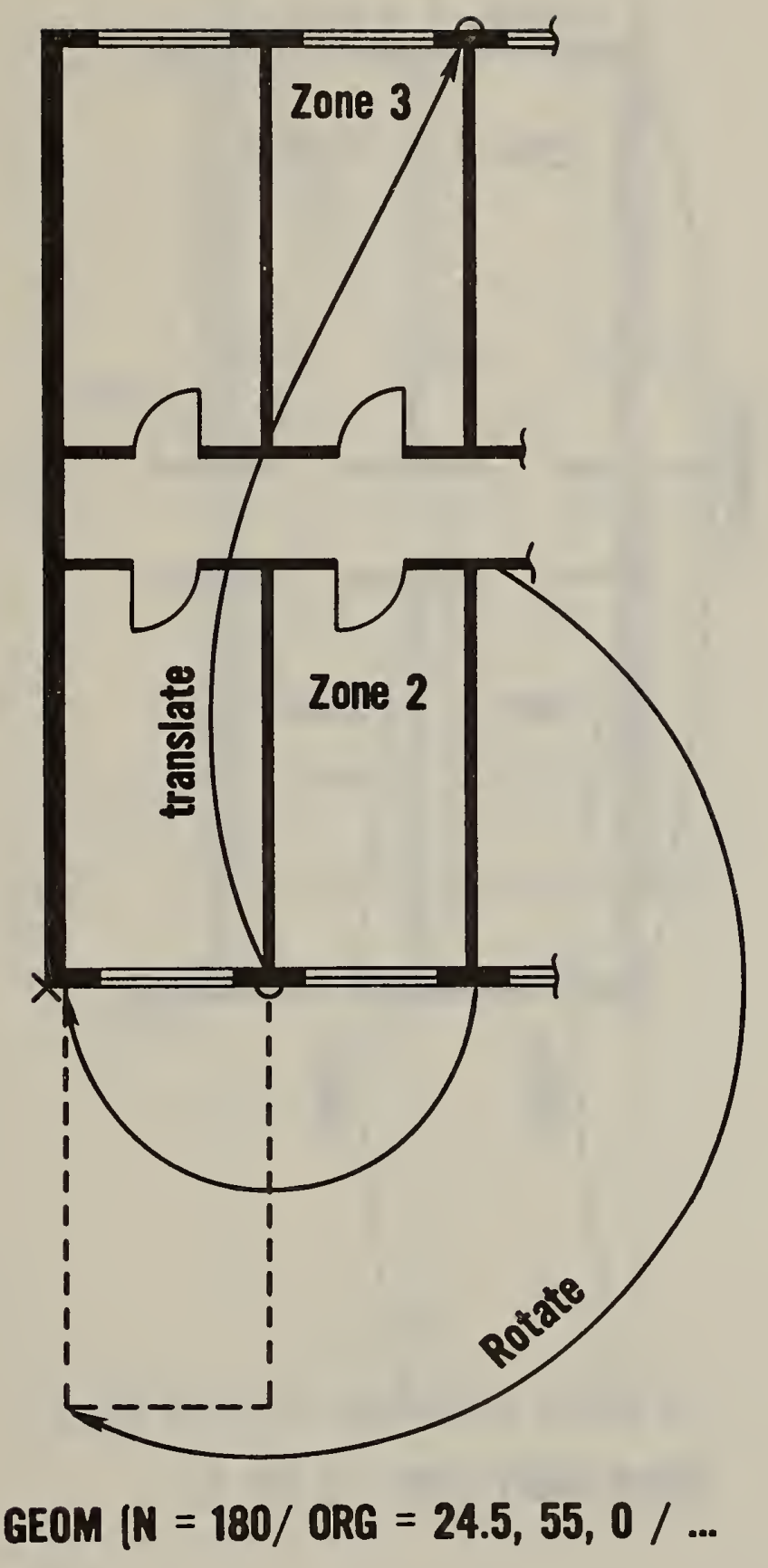

Figure IV.F.14 Zone 3 described by rotation and translation of zone 2 


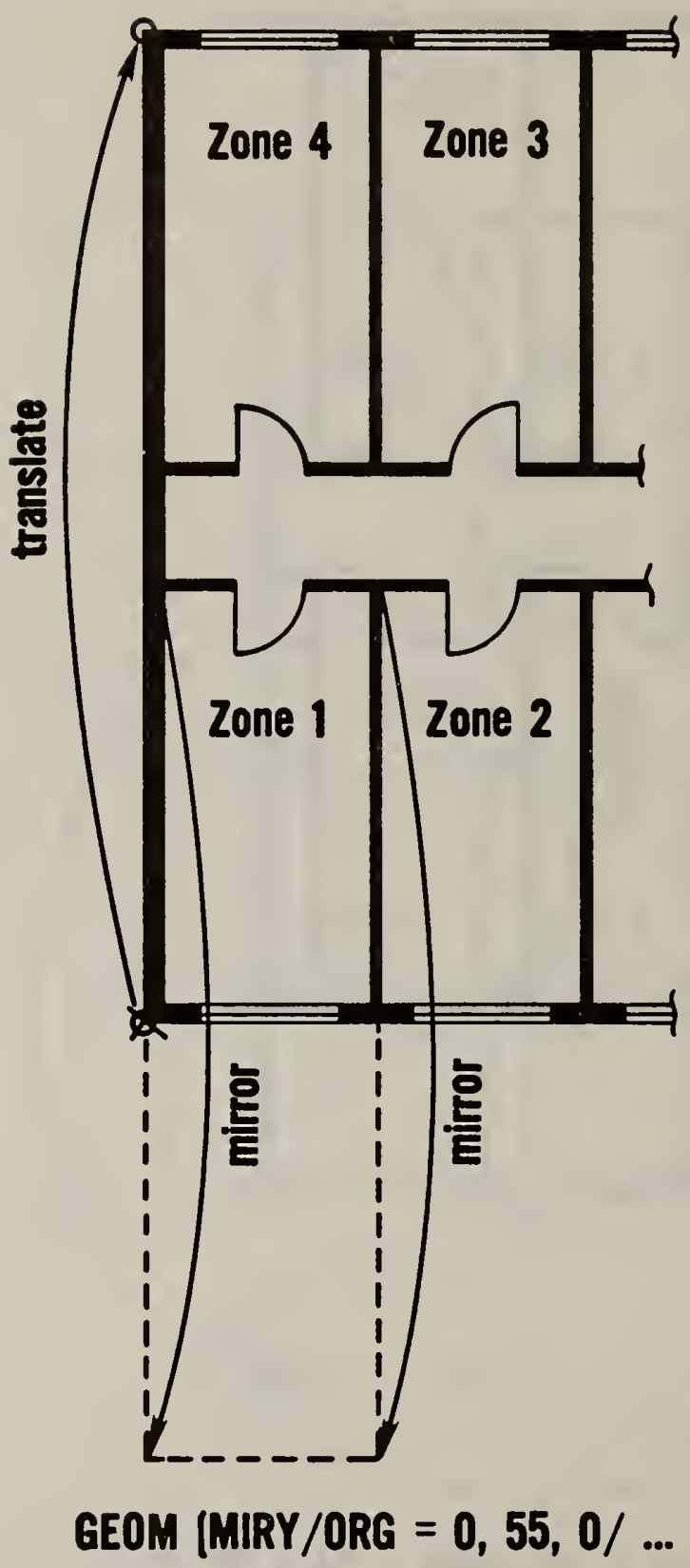

Figure IV.F.15 Zone 4 described by mirror imaging and translation of zone 1 


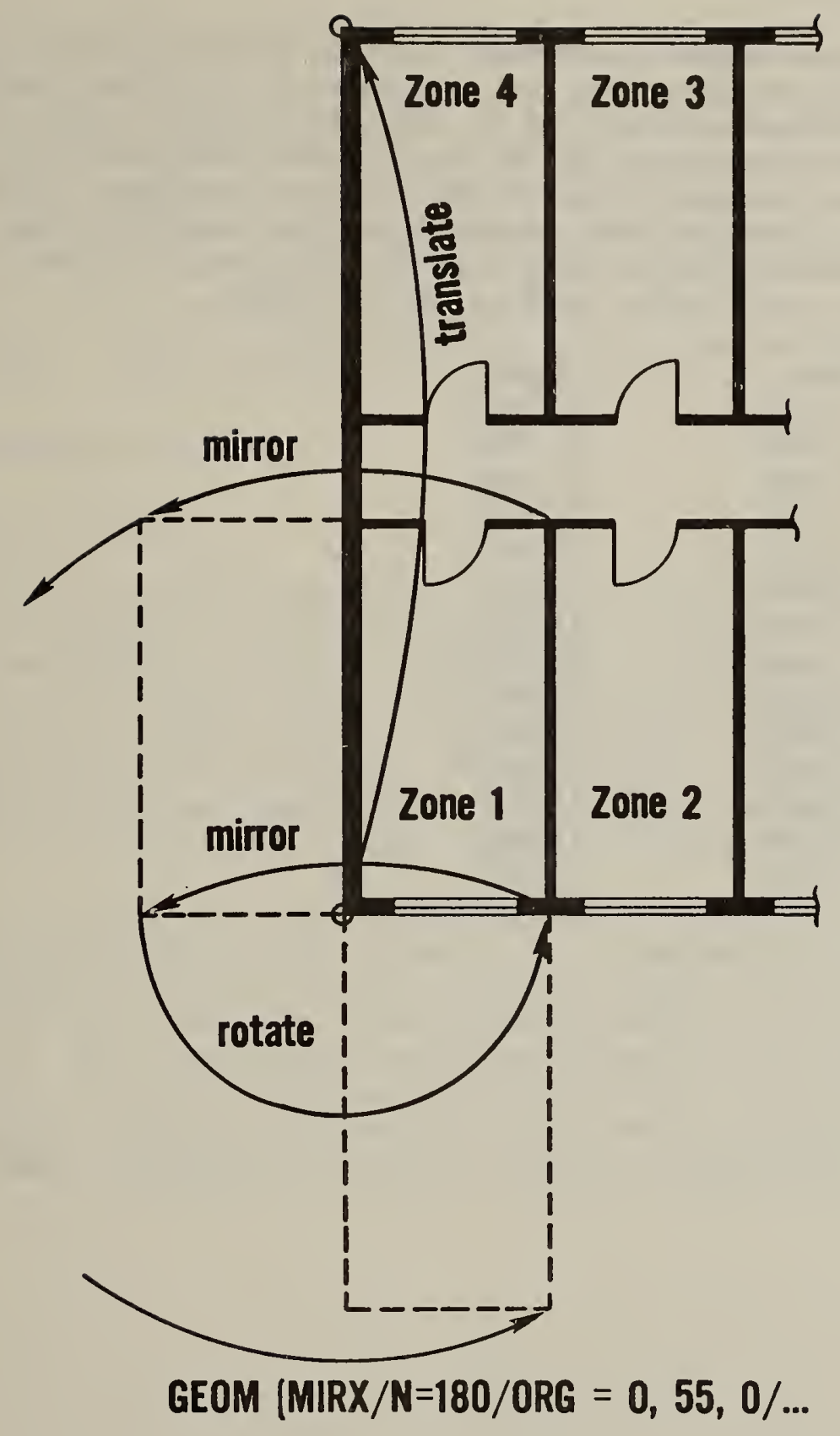

Figure IV.F.16 Zone 4 described by mirror imaging, rotation and translation of zone 1 


\section{IV.G.1 SHADOWING DATES}

Shadow patterns are normally computed for the 14 time periods 11 sted below. These periods were chosen so that the error in the solar position would be less than 2 degrees on any day in the period. Th1s causes the perlods to be shorter around March 21 and Sept 21 when the solar declination angle changes rapidly. Shading features which do not use these dates will Increase the number of time perlods and therefore the amount of time necessary to calculate shadowing. Most shading features w1ll occur over several time periods, e.g. FROM $=16 \mathrm{MAY} / \mathrm{THRU}=30 \mathrm{SEP}$.

\begin{tabular}{|c|c|c|}
\hline PERIOD & FROM & THRU \\
\hline 1 & $1 \mathrm{JAN}$ & $31 \mathrm{JAN}$ \\
\hline 2 & 1 FEB & 20 FEB \\
\hline 3 & 21 FEB & $12 \mathrm{MAR}$ \\
\hline 4 & 13 IMAR & $31 \mathrm{MAR}$ \\
\hline 5 & $1 \mathrm{APR}$ & $20 \mathrm{APR}$ \\
\hline 6 & 21 APR & $15 \mathrm{MAY}$ \\
\hline 7 & $16 \mathrm{MAY}$ & $31 \mathrm{JUL}$ \\
\hline 8 & 1 AUG & 24 AUG \\
\hline 9 & 25 AUG & 12 SEP \\
\hline 10 & 13 SEP & $30 \mathrm{SEP}$ \\
\hline 11 & 1 OCT & 20 OCT \\
\hline 12 & $21 \mathrm{OCT}$ & $15 \mathrm{NOV}$ \\
\hline 13 & 16 NOV & $15 \mathrm{DEC}$ \\
\hline 14 & $16 \mathrm{DEC}$ & 31 DEC \\
\hline
\end{tabular}


The Thermal Analysis Research Program produces output in various levels of detail as directed by the user. Output reports generally consist of tables of numbers suitable for printing or display at a terminal. Development of more elegant graphic output has not been pursued because of the TARP emphasis on the fundamental heat transfer algorithms and computational methods. Almost every intermediate result that TARP calculates can be printed. Most of these intermediate results are available through "dumps" which have minimal descriptive information with the numbers and are in metric units -- the internal data representation. Several "reports" are also available. Reports present summary data and can be in either English or metric units. The following sections discuss the various output options.

V.A INPUT REPORTS

\section{V.A.1 Default Reports}

The input processor produces an "echo" of the user input. This echo is organized by numbered lines on numbered pages as shown in the report for the sample problem from II.C shown in figure 1 on the following pages. Each page heading includes a page number, title, date, time of day, and central processor execution time. This last number is based on a non-ANSI function and may not be available on all computers. The input lines are numbered primarily to aid in editing the user input file. If user lines are not over about 72 characters long, the output will appear on most terminals without "wrap-around".

The last page of the input processor report tells the unused library elements and the required array dimensions (parameters) for the load calculator. The report of unused library names can help to identify typing errors which cause library elements to not be found when they are referenced later in the input. The report also identifies elements which can be removed from the input deck (possibly by commenting - \$) to use less array space. The array dimensions report tells the minimum parameter sizes (see VI.C for a complete list of parameters) necessary to run the simulation. 


\section{PROJECT [}

RC $($ DEM/UIN =ENGLISH/UOUT =ENGLISH/

IIESC='THERMAL MASS TEST - SIMULTANEOUS ZONES, DIRECT SUN')

R'FT (RNOS $=9,21)$

LOC ( DESC $=$ ' COLUMBIA, MO.'/LATI=38.9/LONG $=92.3 / T Z=6$ )

GRND (GRT $=40,42,48,55,62,67,70,69,63,55,48,42)$

IIIYY $(I I E S C=$ 'MILD WINTER' $/ \mathrm{HIGH}=50 / \mathrm{LOW}=30 / \mathrm{WB}=40 / \mathrm{DATE}=21 \mathrm{FEB} /$

$C L R=1 . / M O N / W S=1320 / D I R=315$ ) J

\section{LIBRARY}

DS (NAME $=$ NONE $/$ DESC $=$ 'ZERO ALL HOURS'/FFC $=24 * 0)$

DS (NAME $=F U L L / I I E S C=$ ' ONE ALL HOURS'/FFC=24*1)

IIS ( NAME $=O N /$ IIESC $=$ ' NOR'TH OCCUPANCY',

FFC $=6 * 1, .5, .16,8 * 0,4 *, 16,2 * .33, .67,1)$

DS (NAME $=0 \mathrm{C} /$ IIESC $=$ ' CENTER OCCUF'ANCY',

$F F C=16 * 0,3 * .17, .67, .5, .67, .17,0)$

DS $(N A M E=0 S /$ INSC $=$, SOUTH OCCUPANCY'

$F F C=6 * 0, .5, .5,8 * 0,2 * .33, .67,2 * .16,3 * 0)$

WS (NAME $=O C C N / D E S C=$ 'NORTH OCCUPANCY'/W $\Pi=O N$ )

WS (NAME $=O C C, C /$ LESC $=$ ' CENTER OCCUPANCY'/WD=OC)

WS ( NAME = OCCS/IIESC $=$ ' SOUTH OCCUPANCY'/WD=OS)

[IS ( NAME $=$ LN/DESC $=$ ' NORTH LIGHTING',

FFC $=6 * 0, .7, .7,8 * 0,2 * .33,4 * .7, .4,0)$

IIS (NAME = LC / DESC = ' CENTER LIGHTING' /

FFC $=16 * 0, .5,5 * .7, .3,0)$

[IS (NAME $=$ LS $/$ IIESC $=$ ' SOUTH LIGHTING'/

FFC $=6 * 0, .7, .7,8 * 0,5 * .7,3 * 0)$

WS : NAME $=1 . I T N / I I E S C=$ ' NORTH LIGHTING'/WR=LN)

WS (NAME = LITC/IIESC $=$ 'CENTER LIGHTING'/WI =LC)

WS (NAME =LITS/IIESC = ' SOUTH LIGHTING'/WD=LS)

IIS (.NAME =EN/IIESC = 'NORTH EQUIPMENT', FFC $=20 * 0,3 * 1,0)$

IIS (NAME =EC / DESC = ' CENTER EQUIFMENT' / $F F C=16 * 0,4 * 1,4 * 0)$

IIS (NAME =ES/IESC = ' SOUTH ERUIPMENT' /

FFC $=6 * 3,2 * 1,8 *, 3,2 * 1,3 *, 7,3 *, 3)$

WS (NAME =ERF' $/$ IIESC $=$ ' NORTH EQUIF'MENT'/WD=EN)

WS (NAME $=E Q P C / I I E S C=$ ' CENTER EQUIPMENT'/WD=EC)

WS (NAME $=E Q F \cdot S /$ IIESC $=$ ' SOUTH EQUIFMENT'/WD=ES)

WS (NAME $=$ CONST/DESC $=$ ' CONSTANT $100 \%$ ' /ALL $=$ FULL)

MATL (NAME $=$ GYF'IIESC = 'GYFSUM WALLBOARD'/K=.42/R=45, /CF $=.3$ )

MATL (NAME $=W D-S / R E S C=\prime$ SOFTWOOD'/K $=.0675 / \Pi=32, / C P=.33$ )

MATL (NAME $=$ SHTH/IIESC = ' INTERMEIIATE IENSITY RUILDING BOARD SHE.ATHING', $K=.034 / D=22 . / C P=.31)$

MATL (NAME $=C-H W /$ IIESC $=$ ' HEAUY CONCRETE' $/ K=1.0 / C F=.2 / D=140$.

MATL (NAME $=B 1 /$ IIESC = 'AIRSFACE RESISTANCE'/R=.91/AIR)

MATL (NAME $=R 5 /$ IIESC $=$ 'R.5 FOLYSTYRENE'/R=5.)

MATL (NAME $=R 19 /$ RESC $=$ 'R19 INSULATION'/R=19.)

MATL (NAME $=R 30 /$ IIESC $=$ 'R'30 INSULATION'/R=30,)

MATL (NAME = SFDS/IIESC ='STANDARD GLASS' / GLASS/R $=.0236 /$ TRNS $=.86$ )

MATL (NAME $=A S H / D E S C=$ ' ASFHALT SHINGLES' $/ K=18.16 / D=70 / C P=.3$ )

MATL $(N A M E=\Pi I R T / K=.1 / D=65 . / A=.70)$

Figure V.1 Sample default output 
MATL $\left(N A M E=A L /\left[I E S C={ }^{\prime}\right.\right.$ ALUMINUM SIIING'/K=128/[1=171,/CP=.2)

MATL (NAME =CF'T $/$ LESC $=$ ' CAF'F'ET \& $F A D ' / R=2.08)$

CONS SAME =WL-I/IIESC = 'EXTEFIOR WALL - INSULATION AREA' MATL $=.0052, A L, .0417,5 H T H, 0, R 19, .0521$, GYF $)$

CONS SNAME $=$ WL - S/IIESC = 'EXTERIOR WALL - STUR AREA', MATL $=.0052, A L, .0417,5 H T H, .292, W I I-5, .0521, G Y P)$

CONS (NAME =F'TN-A/DESC = 'F'ARTITION - AIR SPACE AREA'/ MATL $=.0521$, GYF, $0, B 1, .0521$, GYF)

CONS ( NAME =FTN-S/IIESC = 'FARTITION - STUI AREA'/ MATL $=.0521$, GYF, .292, WR-S, .0521, GYF)

CONS (NAME =WIW $2 /$ IIESC $=$ ' 2 FANE WINIIOW', MATL $=0, S F[I S, 0, B 1,0, S F[I S)$

CONS (NAME =FRAME/[IESC = 'WINIOW FRAME'/MATL $=0.1354$, WR-5)

CONS (NAME = KFF - T/IIESC = 'CEILING/RODF - TRUSS AREA', MATL. $=.0104, A S H, .0417$,WII-S, .625, WD-S, .0417, GYP)

CONS (NAME =FIF - I/DESC = 'CEILING/ROOF - INSULATION AREA') MATI $=.0104, A S H, .0417$,WII-S, 0,R30, .0417, GYP)

CONS (NAME $=F^{\prime}$ TN-M/IIESC = 'MASSIVE FAFTITION'/MATL $=.667, C-H W$ )

CONS (NAME:-SL.AE-C/LIESC='SLAB WITH CARFET'/ MATL $=.5$, IIFT, O,RS, .333,C-HW, O,CPT)

CONS (NAME $=$ SLAB-T/IIESC = 'SLAB WITH TILE' / MATL $=.5$, IIIRT, O, KIS, .333,C-HW)

CFFL (NAME = F' $1 /$ IIESC $=$ ' HEATING SETEACK'/CAF $=1,0 /$ TMP $=60,62$ )

CF'FL (NAME $=F^{\prime} 2 /$ IIESC $=$ ' STANIAR II HEATING' $/$ CAF $=1,0 /$ TMF' $\left.=68,70\right)$

CIIS (NAMF $=$ HN $/$ IIESC $=$ ' NORTH HEATING'/CPFL $=6 * P 1,2 * P 2,8 * P 1,6 * P 2,2 * P 1)$

CIIS (NAME $=H C$, IIESC = ' CENTEK HEATING' /CFFL $=16 * F^{\prime} 1,6 * F^{\prime} 2,2 * P 1$ )

CIIS (NAME $=H S /$ IIFSC $=$ ' SOUTH HEATING'/CFFL $=6 * P 1,2 * F 2,8 * F 1,5 * P 2,3 * P 1)$

CWS ( NAME = HEATN/IIESC $=$ 'NOFTH HEATING' /W[I=HN)

CWS (NAME $=$ HEATC/IIESC $=$ ' CENTER HEATING'/WI=HC)

CWS (NAME = HEATS/IIESC ='SOUTH HEATING'/W[I=HS) ]

EUILIING [

SIM(SLIIS $=3 / H T E=0 / F L O W / C N U G=.1, .01, .34,12)$

IISS ( AZM $=130 . / T$ ILT $=153,4 / O R G=0,12,16 / S I Z E=44,2$ )

IISS ( $A Z M=180 . / T$ ILT $=206,6 / O F G=0,0,8 / S I Z E=44,2$ )

IISS ( $A Z M=0 . / T I L T=116,6 / 0 K G=0,36,8 / S I Z E=44,2$ )

]

ZONE

GEOM ( NAME =NOF:TH)

C.TFL ( CWS $=$ HEATN $/$ HEAT $=12$ )

$F E O(W S=O C C N / C A F=3$ )

LIT (WS $=$ L I TN $/ C A F=1,4)$

$E Q F(W S=E Q F N / C A F=1,0)$

MASS ( $C O N S=P T N-A / A R E A=480)$

SFF ( $E X / O F, B S / C O N S=W L-I / A Z M=0 / O R G=44,36,0 / S I Z E=41,8)$ $S R F(E X / T R / S S / C O N S=W I W 2 / O R G=12,5,-.25 / S I Z E=20,2)$

AFS (AREA $=0.2 / E X F=.65)$

$S R F(E X / O F / B S / C O N S=W L-S / A Z M=0 / O F G=3,36,0 / S I Z E=3,8)$

$S R F(E X / O F / B S / C O N S=F F-T / A Z M=0 / O R G=44,36,8 / S I Z E=41,8.95 / T I L T=26.6$ ) AFS (AF'EA $=0.1 / E X F=.65$ )

SFF ( $E X / O F^{\prime} / E S / C O N S=F^{\prime} F-I / A Z M=0 / O R G=3,36,8 / S \mathrm{JZE}=3,8,95 / \mathrm{TLT}=26.6$ )

SFF ( IN $/ O F / B S / C O N S=F \cdot T N-M / A Z M=180 / O R G=0,24,0 / S I Z E=44,12 / Z O N E=C E N T E R$ )

Figure V.l (continued) 
$A F S(A F E A=0.5 / E X P=.50)$

SRF ( IN $/ O F / B S / C O N S=P T N-M / A Z M=270 / 0 R B=0,36,0 / U R T S=12,0,12,12,0,8)$ SRF (IN/OP/BS/CDNS =PTN-M/AZM $=90 / O R G=44,24,0 / U R T S=12,0,12,8,0,12)$ $S R F(E X / O F / B S / C O N S=S L A B-C / A Z M=180 / O R G=0,36,0 / S I Z E=44,12 / T I L T=180)$ 3 $O S C(T G P=1)$

109

110

111

112

ZONE [

GEOM (NAME =CENTER)

CTRL ( CWS = HEATC $/$ HEAT $=12$ )

F. $E O(W S=O C C C / C A F=3$ )

LIT (WS $=L I T C / C A P=1,4)$

$E Q F$ ( WS $=E Q F \cdot C / C A F=1.0$ )

MASS ( $C O N S=F$ 'TN-A/AFEA $=480$ )

SRF (EX/OF/BS/CONS =FRAME /AZM $=180 / O R G=0,12,12 / S I Z E=44,3$ ) $S R F(E X / T R / S S / C O N S=W D W 2 / O R G=2,0,-.25 / S I Z E=40,3)$ AF S (AREA $=0.25 / E X F=.65$ )

$S R F(E X / O F / B S / C O N S=R F-T / A Z M=0 / O R G=44,24,12 / S I Z E=41,8,95 / T I L T=26,6)$ AFS ( $A R E A=0.1 / E X P=.65$ )

SFF (EX/OF/BS/CONS =RF - I/AZM $=0 / O F G=3,24,12 / S I Z E=3,8,95 / T I L T=26.6)$

SEF (IN/DF $/ B S / C O N S=F T N-A / A Z M=180 / O R G=3,12,0 / S I Z E=41,12 / 20 N E=S O U T H$ ) $A F S\left(A K^{\prime} E A=0.5 / E X F=.50\right)$

SRF ( IN/OF /BS/CONS=FTN-S/AZM=180/ORG =0,12,0/SIZE=3,12/ZONE=SOUTH) SRF ( IN $/ O P / B S / C O N S=P T N-M / A Z M=O / O R G=44,24, O / S I Z E=44,12 / Z O N E=N O R T H)$ AFS (AREA $=0.5 / E X P=.50)$

SRF ( IN/OF / BS /CONS =FTN-M/AZM $=270 / O R G=0,24,0 /$ URTS $=12,0,12,16,0,12$ ) SRF (IN/OF/BS/CONS =PTN-M/AZM=90/ORG $=44,12,0 /$ VRTS $=12,0,12,12,0,16$ ) $S R F(E X / O P / E S / C O N S=S L A B-C / A Z M=180 / O R G=0,24,0 / S I Z E=44,12 / T I L T=180)$ ] $O S C(T G F=1)$

ZONE C

GEOM (NAME $=$ SOUTH)

CTRL ( $C W S=H E A T S / H E A T=12$ )

F'EO(WS $=0$ CCS $/ C A F=3$ )

LIT (WS $=L I T S / C A P=1.4$ )

$E Q F$ ' $(W S=E R F S / C A P=9.4 / L O S T=.4$ )

MASS $(C O N S=P T N-A / A R E A=480)$

SFF (EX/OF / BS /CONS $=W L-I / A Z M=180 / 0 R G=0,0,0 / S I Z E=41,8)$

SRF $(E X / T R / S S / C O N S=W D W 2 / O R G=12,3,-.25 / S I Z E=20,4)$ AFS (AREA $=0.2 / E X F=.65$ )

$S R F(E X / D P / R S / C O N S=W L-S / A Z M=180 / O R G=41,0,0 / S I Z E=3,8)$

SRF ( $E X / O F / B S / C O N S=R F-T / A Z M=180 / O R G=0,0,8 / S I Z E=41,8.95 / T I L . T=26.6$ ) AFS (AREA $=0.1 / E X F=.65$ )

$S R F$ ( $E X / O F / E S / C O N S=F F-I / A Z M=180 / O R G=41,0,8 / S I Z E=3,8,95 / T I L T=26,6)$ SRF ( IN/DP / BS /CONS $=P T N-A / A Z M=0 / O R G=44,12,0 / S I Z E=41,12 / Z O N E=C E N T E R$ ) AF $S(A K E A=0.5 / E X F=.50)$

SFF ( IN/OF' $/$ BS /CONS =F'TN-S/AZM=0/ORG $=3,12,0 / S I Z E=3,12 / Z$ INE =CENTER ) SFF ( IN/OP/RS/CONS =F'TN-M/AZM=270/ORG $=0,12,0 /$ VRTS $=12,0,12,8,0,12$ ) SFF (IN/OF /ES/CONS =F:TN-M/AZM $=90 / O R G=44,0,0 /$ VT S $=12,0,12,12,0,8$ ) $S R F(E X / D P / R S / C O N S=S L A B-T / A Z M=180 / O R G=0,12,0 / S I Z E=44,12 / T I L T=180)$ OSC (TGF' $=1)$

Figure V.1 (continued) 


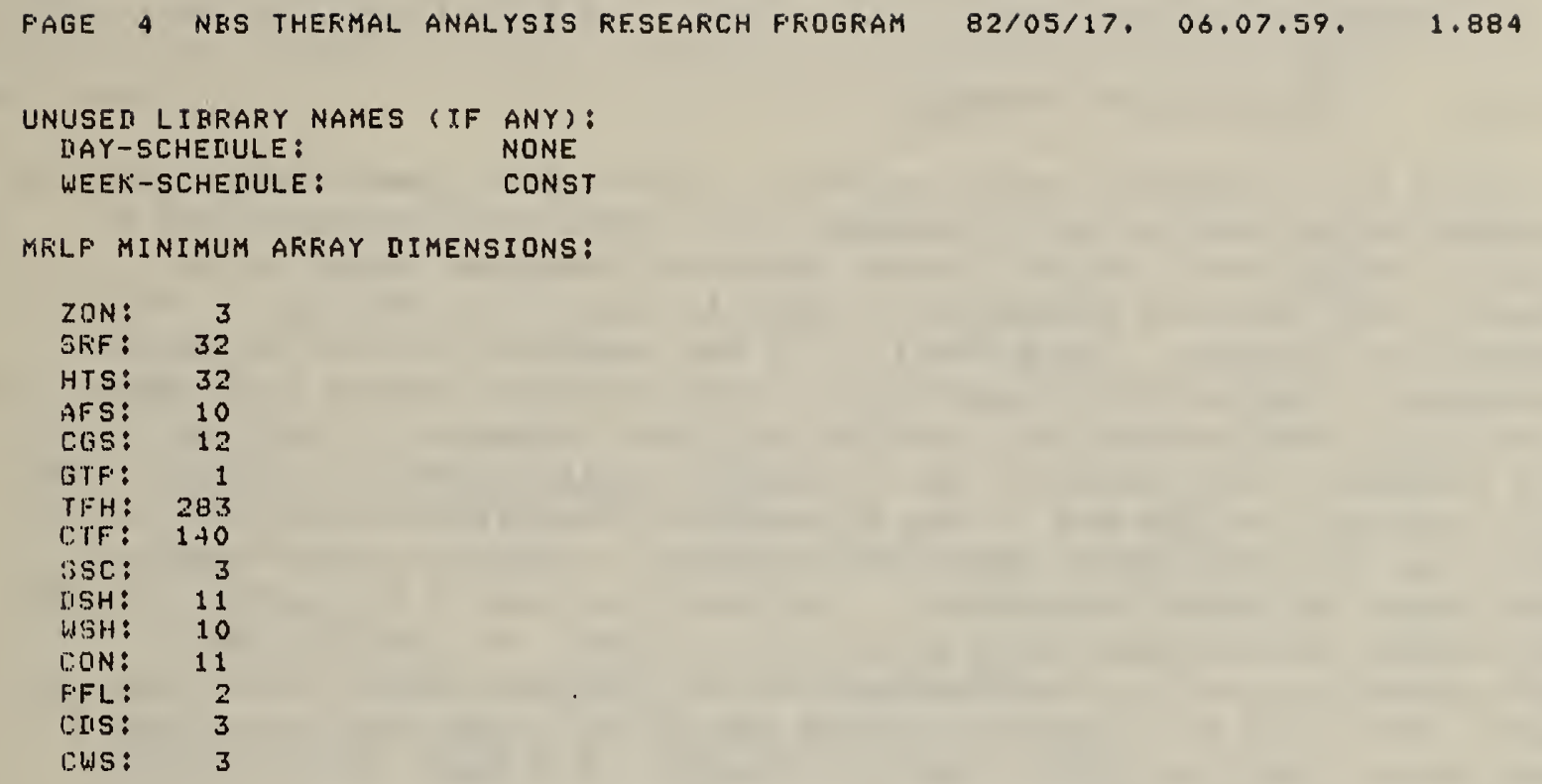

Figure V.l (concluded) 


\section{V.A.2 RUN CONTROL MODIFICATIONS}

The run control statement (1.1) Includes four optional modifications of the output.

V.A.2.1 DEM and error messages.

TARP does extensive input checking. Incorrect or questionable input is reported to the user by error messages which begin with two stars and a severity descriptor. Flgure 2 shows how error messages appear in the output. NAME has been misspelled as NAEM in line 15 of the input. This is Immediately reported. Since DEM (1.1.3) was specified in the run control statement, a list of valid key words $1 \mathrm{~s}$ also printed. Errors that might occur due to bad punctuation, causing the input processor to believe it is in a different input section, can be quickly spotted from the SECTION: and KEY: entries. At the end of the day-schedule description (1ine 16) it is noted that the user did not give this schedule a name (since the required NAME subkey was never recognized). The error in line 15 propagates through the program causing some other errors to be noted. At line 20, the week-schedule 18 not created because the day schedule named OC could not be found. The final error message at the end of the output indicates that a loads input file (the SINPFL) was not created. All input which produces SEVERE errors must be corrected before the SINPFL 18 created.

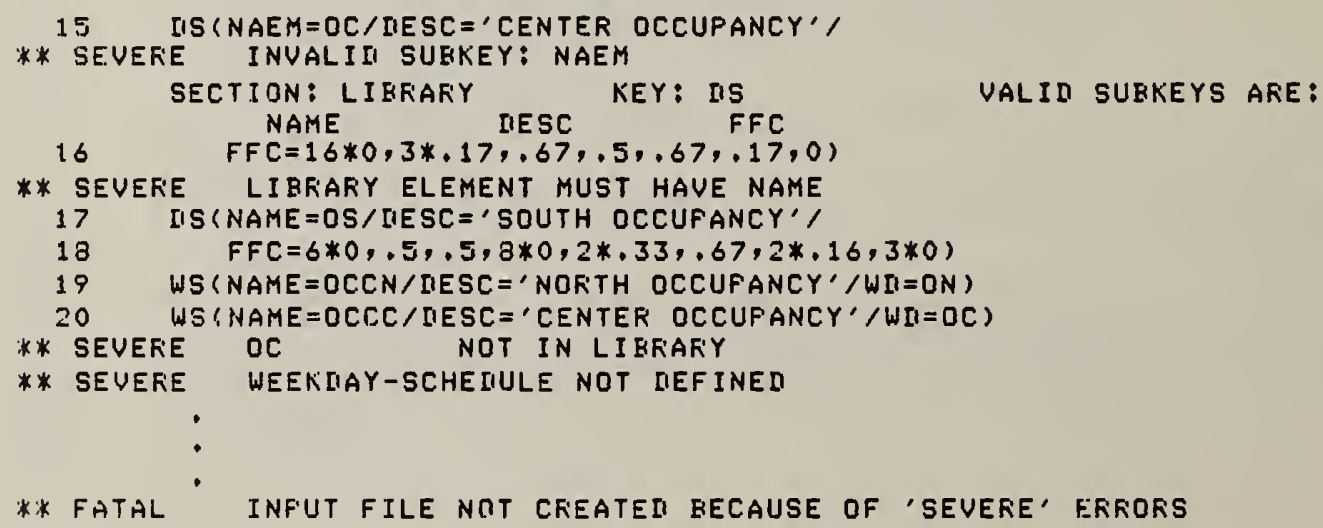

F1gure V.2 Sample error messages 


\section{V.A.2.2 Double spacing}

The 2SPC command $(1.1 .4)$ causes a blank line to be printed before every input line echo as shown in figure 3. Note that double spacing does not begin unt11 the command has been recognized, so there is no skip between lines 1 and 2 .

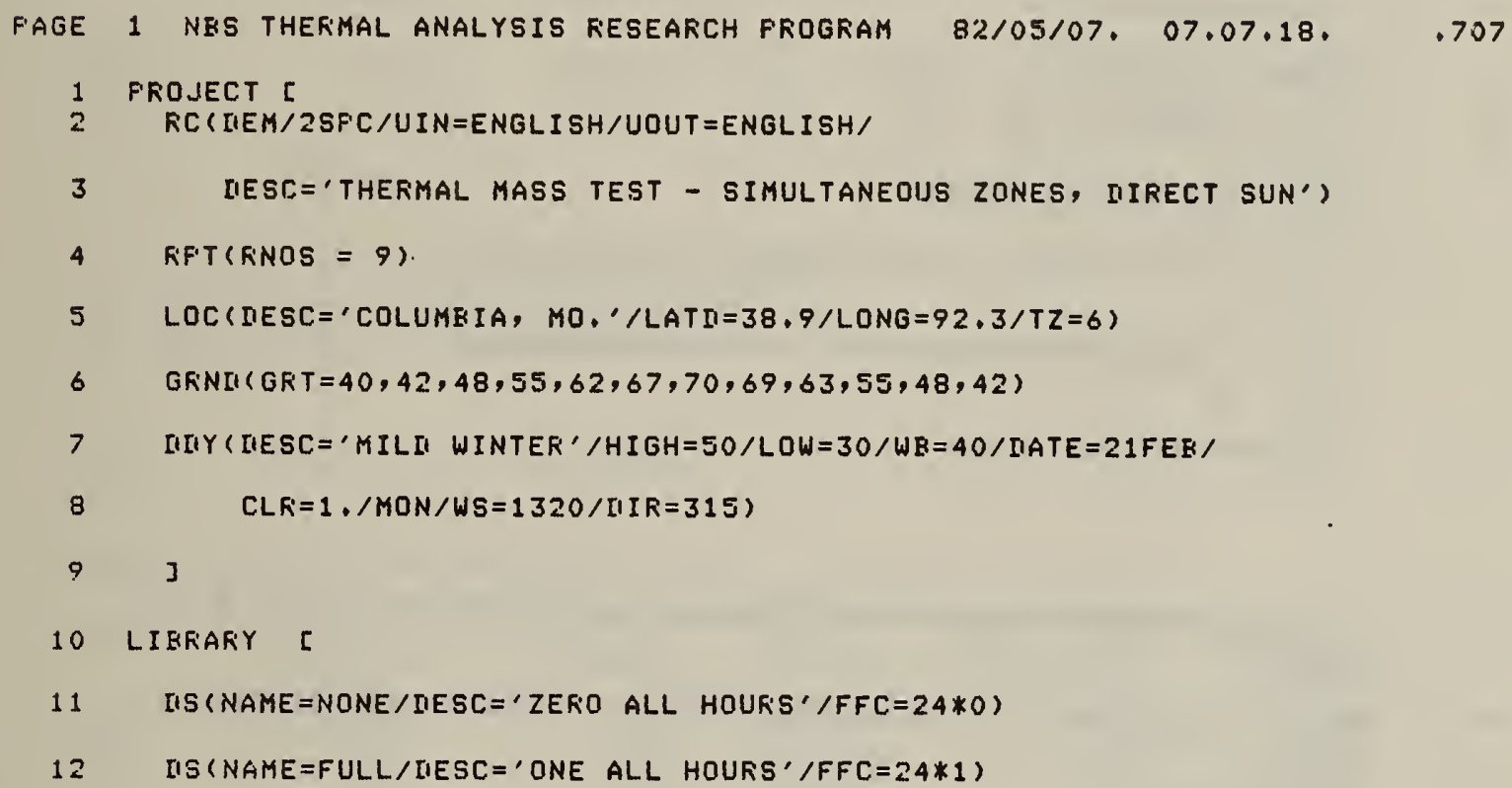

\section{Figure V.3 Double spacing}

\section{V.A.2.3 Cross referencing}

The XREF command (1.1.5) allows the user to match the data in the reports and, especially, the dumps to his input. In general, the input is read and organized into various arrays. The XREF reports the array locations. In figure 4, line 87 describes a detached shadowing surface (3.2). Information about this surface will be stored as element 2 in arrays having a MAXSRF parameter dimension. The next DSS ( 1 ine 88 ) is stored as element 3 in those arrays. Zone controls and scheduled loads (1ines 92-95) are stored in arrays with MAXCGS dimensions. The MASS is the first heat transfer surface, so its data goes into the MAXHTS dimensioned arrays at location 1. The surface description (line 97) has two cross references because both geometric data (in MAXSRF dimensioned arrays) and heat transfer data (in MAXHTS arrays) must be stored. The zone number appears after the zone description is completed (1ine 110). 


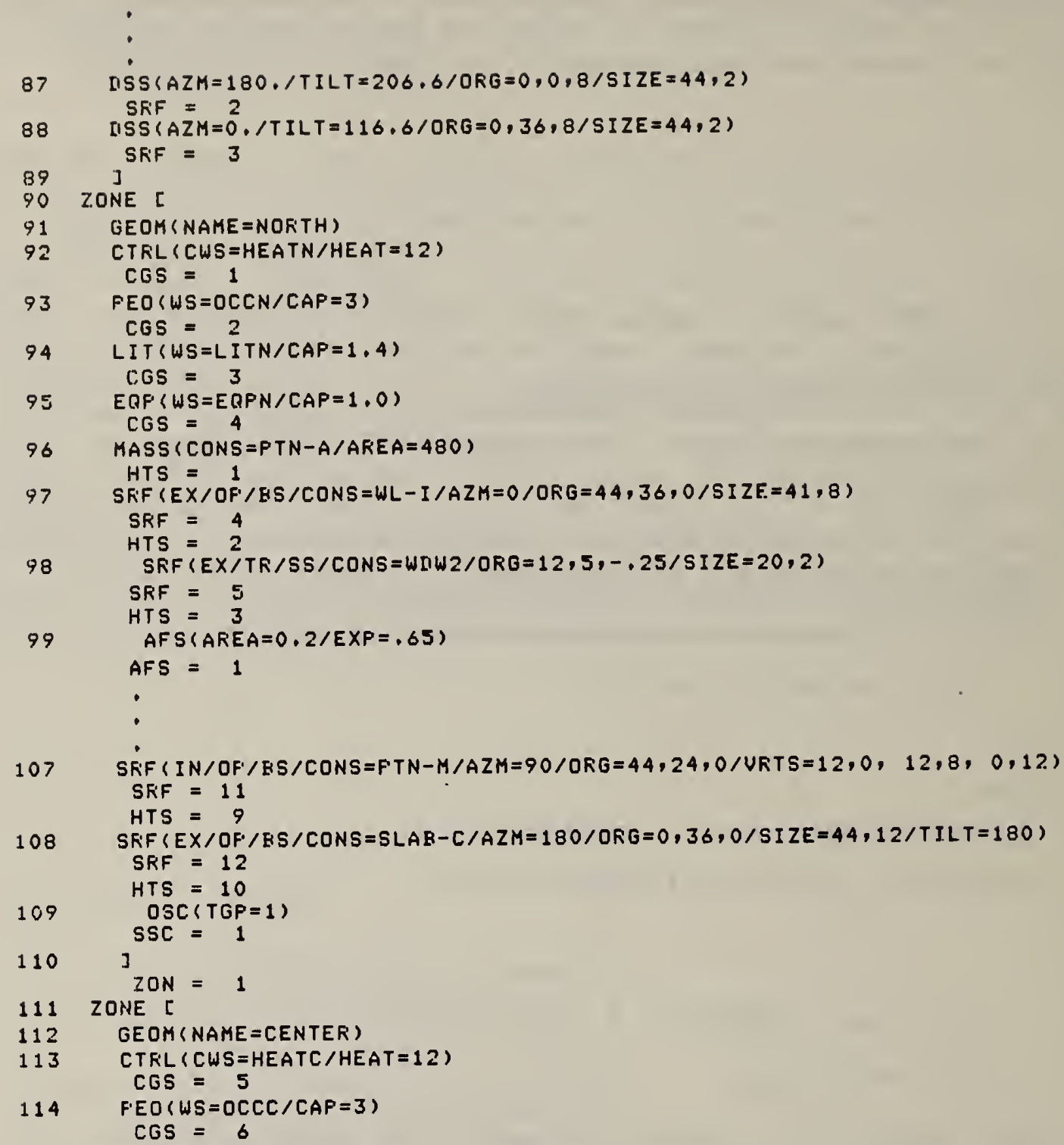

\section{F1gure V.4 Cross references}

V.A.2.4 Metric units

TARP processes input and writes reports in English units by default. The user can request that the input or output or both be in metric units $(1.1 .7)$. Two samples of metric reports are shown in figure 5. The first is the final loads summary described in V.B.1. Second is a wall and conduction transfer function report described in V.A.4.4. 


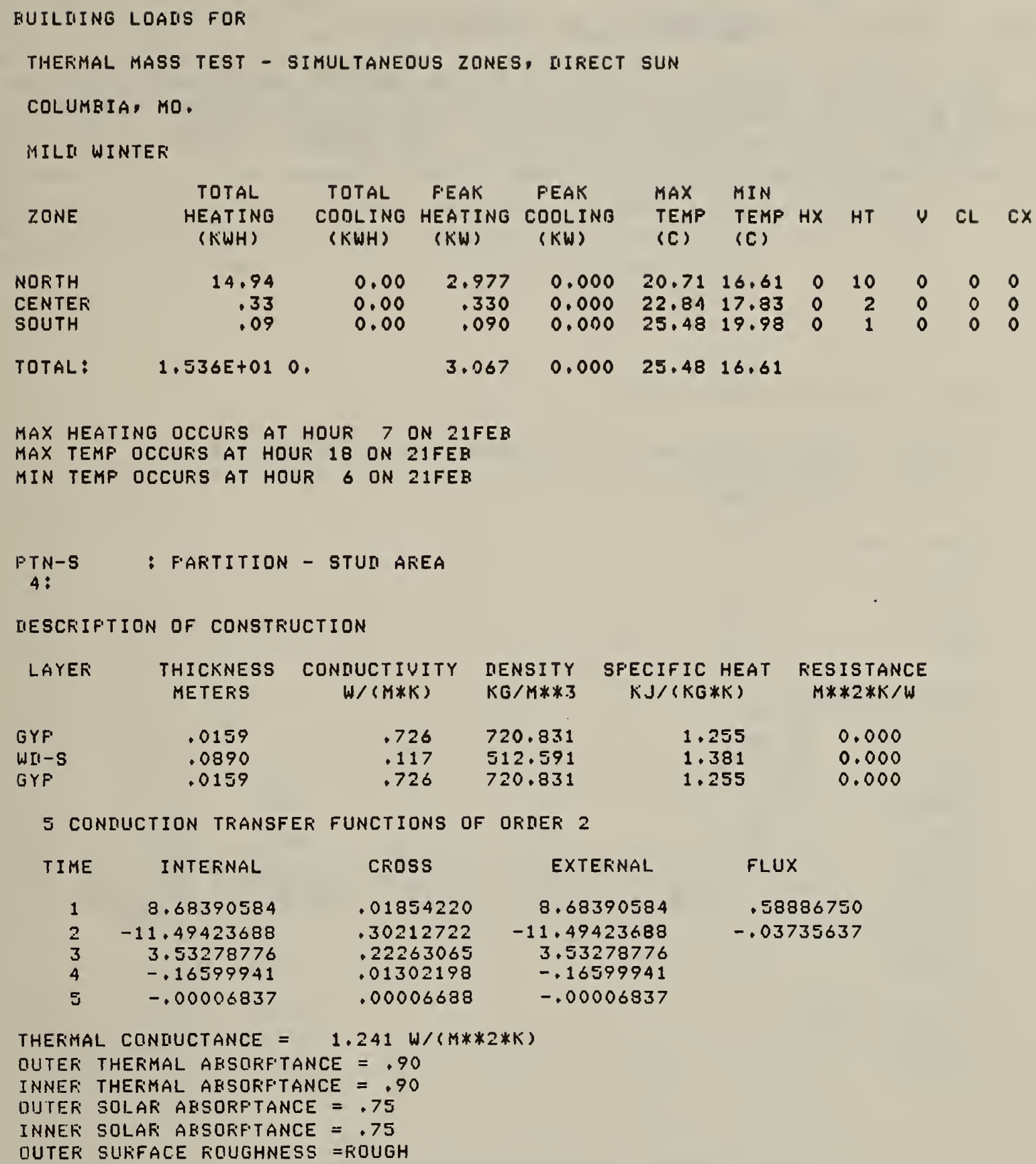

5 CONDUCTION TRANSFER FUNCTIONS OF ORDER 2

\begin{tabular}{rrcrr} 
TIME & INTERNAL & CKOSS & EXTEFNAL & \multicolumn{1}{c}{ FLUX } \\
1 & 8.68390584 & .01854220 & 8.68390584 & .58886750 \\
2 & -11.49423688 & .30212722 & -11.49423688 & -.03735637 \\
3 & 3.53278776 & .22263065 & 3.53278776 & \\
4 & -.16599941 & .01302198 & -.16599941 & \\
5 & -.00006837 & .00006688 & -.00006837 &
\end{tabular}

THEFMAL CONIUUCTANCE $=1.241 \mathrm{~W} /(M * * 2 * K)$

OUTER THERMAL AESORFTANCE $=.90$

INNEF: THERMAL AESORF'TANCE $=.90$

OUTEF SOLAR ABSORFTANCE $=.75$

INNEF SOLAR ARSORF'TANCE $=.75$

DUTER SULFACE FOUGHNESS = ROUGH

Figure V.5 Two reports using metric units 
V.A.3 NUMBERED REPORTS

Seven data dumps can be requested by spectfying report numbers $(1.2 .1)$.

V.A.3.1 RNOS $=1$; dumP PROJECT and LIBRARY data

This provides summarles at the end of the PROJECT and LIBRARY sections. The DUMP OF PROJECT CONTROL DATA shown below lists the values associated with different variables which can be set in the PROJECT section. Refer to VI.C for a description of the individual variables.

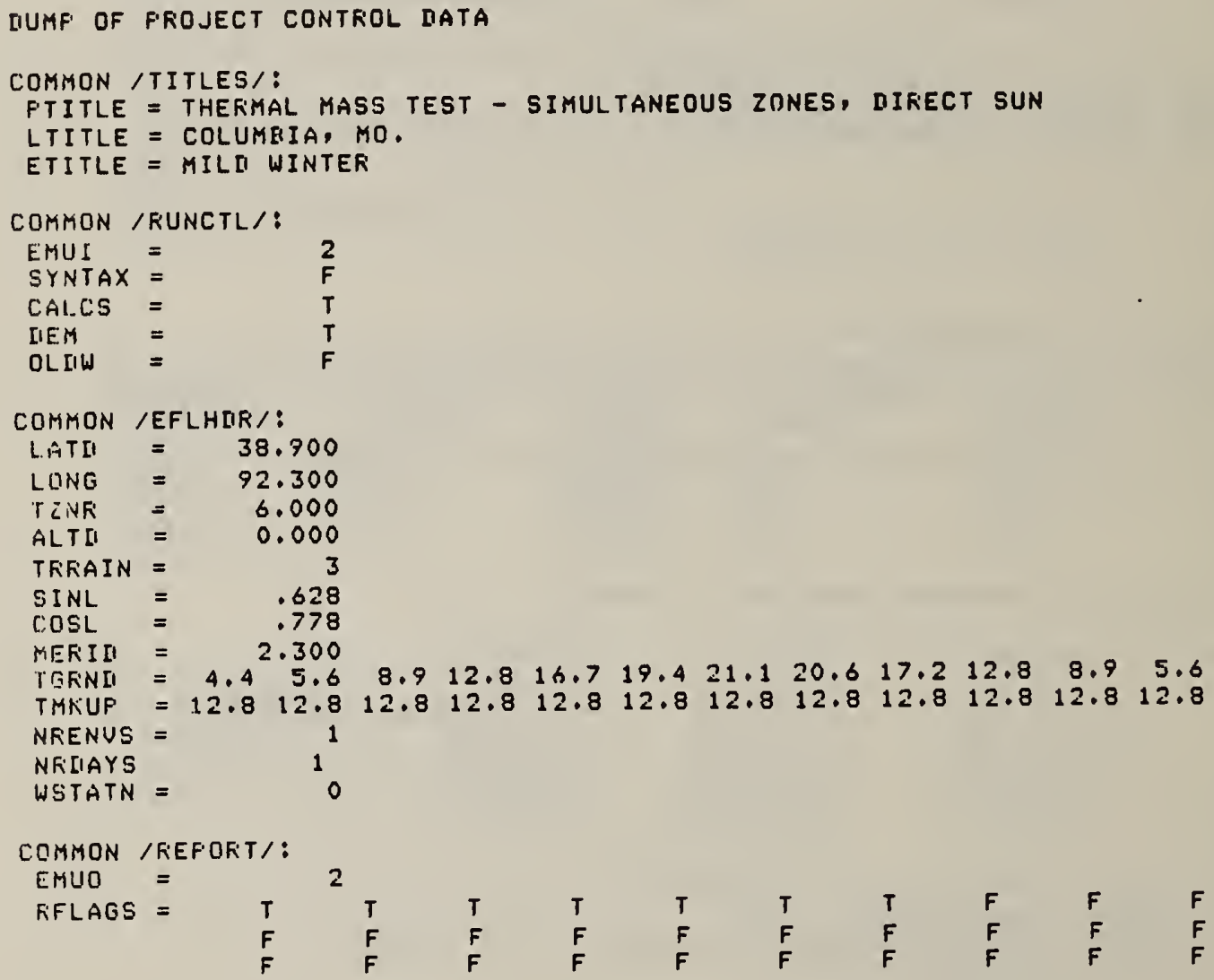


The DUMP OF LIBRARY CONTROL DATA shown below gives the number and names of all library entries. First, summary data is given for each of the seven libraries. This data is taken from common block LIBCTL. It begins with the day-schedule (DS) by giving the 0 location (DSO), the number of schedules defined (NDS), and the maximum number of schedules permitted (MXDS). This last number can be set by the user (2.1.2). Similar data is presented for the other six libraries. Next comes a 11 st of all 11brary element names (LNAMES) presented in eight names per row in sequence. The list of numbers can be used to determine to which 11 brary the names belong. For example, the first 16 names are day-8chedules. DS names occupy the first two rows including the five undefined (blank) names in the second row. Week-schedules (WS) names occupy the net two rows with ten names defined and six left undefined, etc.

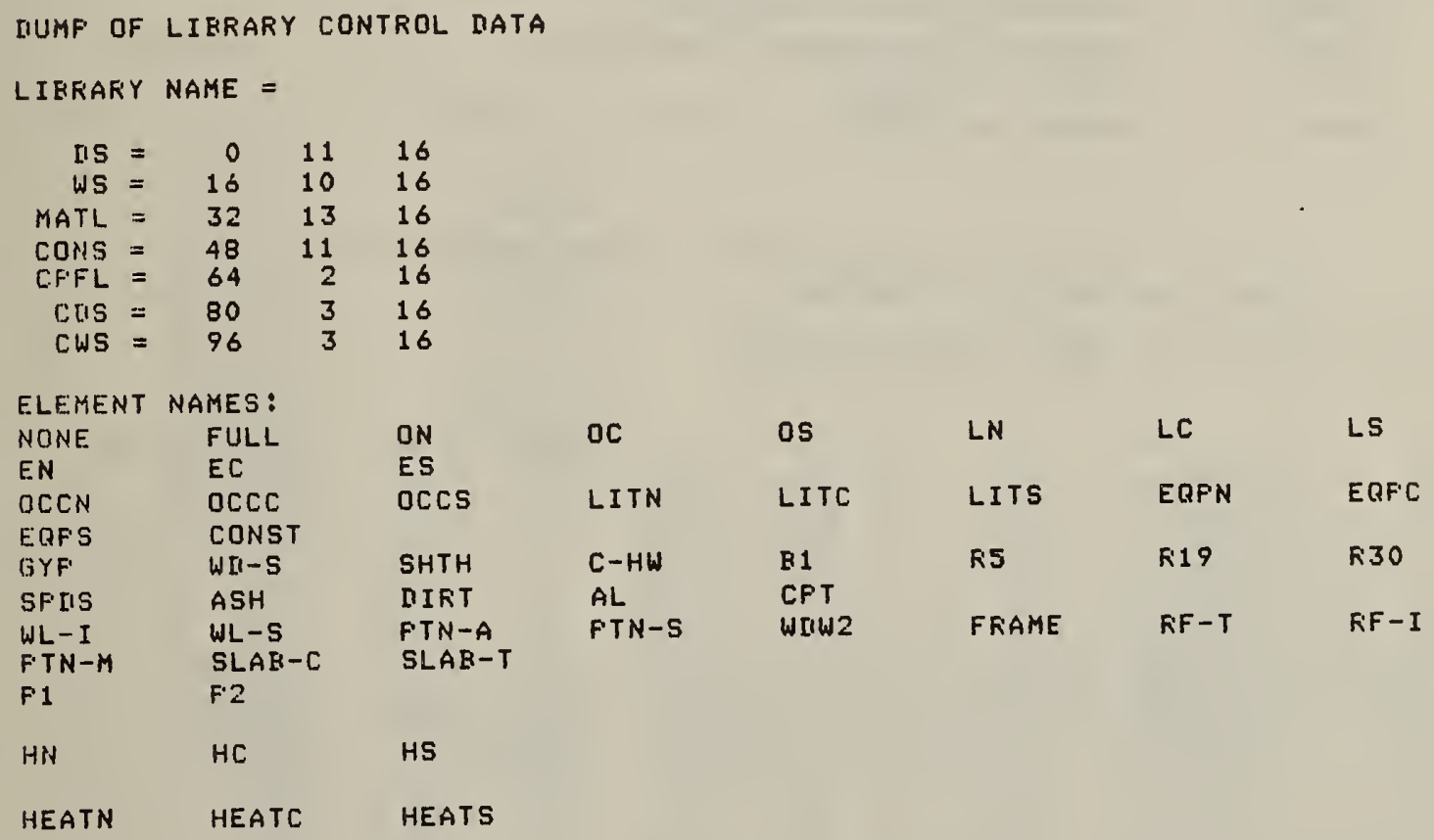

Figure V.7 Dump of library control data

V.A.3.2 RNOS $=2$; dump of DDY and WTAP data

This is a dump of all weather data for every day described in the DDY (1.6) and WTAP (1.5) keys. It is a dump of data in the EVDAT common block. The data names are summarized as follows: 


\begin{tabular}{|c|c|c|}
\hline NAME & VARIABLE & DESCRIPTION \\
\hline YEAR & YEAR & year \\
\hline MO & MONTH & month number \\
\hline DY & DYOFM & day of month \\
\hline $\mathrm{DW}$ & DAYOFW & day of week number \\
\hline HOL & HOLIND & holiday and spectal days indicator \\
\hline DST & DSTIND & daylight saving time indicator \\
\hline SSDECL & SSDECL & sine of the solar declination angle \\
\hline CSDESL & CSDECL & cosine of the solar declination angle \\
\hline EQTIME & EQTIME & equation of time (h) \\
\hline TD & ODB & dry bulb temperature (C) \\
\hline TW & OWB & wet bulb temperature (C) \\
\hline$B P$ & OBP & barometric pressure $(\mathrm{Pa})$ \\
\hline $\mathrm{H}$ & OHR & humidity ratio \\
\hline WS & SPD & wind speed $(\mathrm{m} / \mathrm{s})$ \\
\hline WD & DIR & wind direction ( deg) \\
\hline TS & SKY & sky radiative temperature (C) \\
\hline QB & SRADBM & direct normal (beam) solar flux (W/m**2) \\
\hline QD & SRADDE & sky brightness $(W / m * * 2)$ \\
\hline$Q R$ & SRADGR & ground brightness (W/m**2) \\
\hline RN & RAIN & rain indicator \\
\hline SN & SNOW & snow Indicator \\
\hline
\end{tabular}

7 IIIY (IIESC='MILD WINTER'/HIGH=50/LOW=30/WB=40/DATE $=21 \mathrm{FEB} /$

$8 \quad C L R=1, / M O N / W S=1320 / D I R=315$ )

YEAF MO IIY DW HOL IST SSDECL CSDECL ERTIME

$\begin{array}{llllllllll}1958 & 2 & 21 & 2 & 0 & 0 & -.184 & .983 & -.229\end{array}$

\begin{tabular}{|c|c|c|c|c|c|c|c|c|c|c|c|}
\hline TI & $T W$ & BP & $H$ & WS & WD & TS & QB & QD & QR & RN & SN \\
\hline $\begin{array}{r}.33 \\
-.22 \\
-.67 \\
-1.00\end{array}$ & $\begin{array}{r}-.87 \\
-1.19 \\
-1.45 \\
-1.64\end{array}$ & $\begin{array}{l}100000 \\
100000 \\
100000 \\
100000\end{array}$ & $\begin{array}{l}.0031 \\
.0031 \\
.0031 \\
.0031\end{array}$ & $\begin{array}{l}6.7 \\
6.7 \\
6.7 \\
6.7\end{array}$ & $\begin{array}{l}315 . \\
315 . \\
315 . \\
315 .\end{array}$ & $\begin{array}{l}-16.16 \\
-16.69 \\
-17.10 \\
-17.42\end{array}$ & $\begin{array}{l}0.0 \\
0.0 \\
0.0 \\
0.0\end{array}$ & $\begin{array}{l}0.0 \\
0.0 \\
0.0 \\
0.0\end{array}$ & $\begin{array}{l}0.0 \\
0.0 \\
0.0 \\
0.0\end{array}$ & $\begin{array}{l}0 \\
0 \\
0 \\
0\end{array}$ & $\begin{array}{l}0 \\
0 \\
0 \\
0\end{array}$ \\
\hline $\begin{array}{r}-1.11 \\
-.89\end{array}$ & $\begin{array}{l}-1.71 \\
-1.58\end{array}$ & $\begin{array}{l}100000 . \\
100000 .\end{array}$ & $\begin{array}{l}.0031 \\
.0031\end{array}$ & $\begin{array}{l}6.7 \\
6.7\end{array}$ & $\begin{array}{l}315 . \\
315 .\end{array}$ & $\begin{array}{l}-17.52 \\
-17.31\end{array}$ & $\begin{array}{l}0.0 \\
0.0\end{array}$ & $\begin{array}{l}0.0 \\
0.0\end{array}$ & $\begin{array}{l}0.0 \\
0.0\end{array}$ & $\begin{array}{l}0 \\
0\end{array}$ & \\
\hline $\begin{array}{r}-.33 \\
.67 \\
2.11\end{array}$ & $\begin{array}{r}-1.25 \\
-.67 \\
.09\end{array}$ & $\begin{array}{l}100000 . \\
100000 . \\
100000 .\end{array}$ & $\begin{array}{l}.0031 \\
.0031 \\
.0031\end{array}$ & $\begin{array}{l}6.7 \\
6.7 \\
6.7\end{array}$ & $\begin{array}{l}315 . \\
315 . \\
315 .\end{array}$ & $\begin{array}{l}-16.79 \\
-15.85 \\
-14.49\end{array}$ & $\begin{array}{r}0.0 \\
307.4 \\
734.5\end{array}$ & $\begin{array}{r}0.0 \\
18.6 \\
44.5\end{array}$ & $\begin{array}{r}0.0 \\
10.2 \\
51.1\end{array}$ & $\begin{array}{l}0 \\
0 \\
0\end{array}$ & 0 \\
\hline 3.78 & 1.05 & 100000 . & .0031 & 6.7 & 315. & -12.93 & 875.8 & 5.3 .1 & 88.0 & 0 & \\
\hline $\begin{array}{l}5.67 \\
7.44\end{array}$ & $\begin{array}{l}2.12 \\
3.09\end{array}$ & $\begin{array}{l}100000 \\
100000\end{array}$ & $\begin{array}{l}.0031 \\
.0031\end{array}$ & $\begin{array}{l}6.7 \\
6.7\end{array}$ & $\begin{array}{l}315 . \\
315 .\end{array}$ & $\begin{array}{r}-11.15 \\
-9.48\end{array}$ & $\begin{array}{l}937.7 \\
965.4\end{array}$ & $\begin{array}{l}56.8 \\
58.5\end{array}$ & $\begin{array}{l}116.1 \\
133.2\end{array}$ & $\begin{array}{l}0 \\
0\end{array}$ & \\
\hline $\begin{array}{r}8.78 \\
9.67 \\
10.00\end{array}$ & $\begin{array}{l}3.80 \\
4.27 \\
4.44\end{array}$ & $\begin{array}{l}100000, \\
100000 . \\
100000 .\end{array}$ & $\begin{array}{l}.0031 \\
.0031 \\
.0031\end{array}$ & $\begin{array}{l}6.7 \\
6.7 \\
6.7\end{array}$ & $\begin{array}{l}315 . \\
315 . \\
315 .\end{array}$ & $\begin{array}{l}-8.23 \\
-7.39 \\
-7.08\end{array}$ & $\begin{array}{l}972.2 \\
961.0 \\
927.0\end{array}$ & $\begin{array}{l}58.9 \\
58.2 \\
56.2\end{array}$ & $\begin{array}{l}138.0 \\
130.2 \\
110.4\end{array}$ & $\begin{array}{l}0 \\
0 \\
0\end{array}$ & \\
\hline $\begin{array}{l}9.67 \\
8.89 \\
7.67\end{array}$ & $\begin{array}{l}4.27 \\
3.86 \\
3.21\end{array}$ & $\begin{array}{l}100000 . \\
100000 \\
100000 .\end{array}$ & $\begin{array}{l}.0031 \\
.0031 \\
.0031\end{array}$ & $\begin{array}{l}6.7 \\
6.7 \\
6.7\end{array}$ & $\begin{array}{l}315 . \\
315 . \\
315 .\end{array}$ & $\begin{array}{l}-7.39 \\
-8.12 \\
-9.27\end{array}$ & $\begin{array}{l}852.7 \\
675.5 \\
107.0\end{array}$ & $\begin{array}{r}51.7 \\
40.9 \\
6.5\end{array}$ & $\begin{array}{r}80.0 \\
41.5 \\
2.6\end{array}$ & $\begin{array}{l}0 \\
0 \\
0\end{array}$ & \\
\hline $\begin{array}{l}0.22 \\
4.78 \\
3.56\end{array}$ & $\begin{array}{r}2.43 \\
1.62 \\
.93\end{array}$ & $\begin{array}{l}100000 \\
100000 \\
100000\end{array}$ & $\begin{array}{l}.0031 \\
.0031 \\
.0031\end{array}$ & $\begin{array}{l}6.7 \\
6.7 \\
6.7\end{array}$ & $\begin{array}{l}315 . \\
315 . \\
315 .\end{array}$ & $\begin{array}{l}-10.63 \\
-11.99 \\
-13.14\end{array}$ & $\begin{array}{l}0.0 \\
0.0 \\
0.0\end{array}$ & $\begin{array}{l}0.0 \\
0.0 \\
0.0\end{array}$ & $\begin{array}{l}0.0 \\
0.0 \\
0.0\end{array}$ & $\begin{array}{l}0 \\
0 \\
0\end{array}$ & \\
\hline $\begin{array}{r}2.44 \\
1.56 \\
.89\end{array}$ & $\begin{array}{r}.28 \\
-.17 \\
-.55\end{array}$ & $\begin{array}{l}100000 \\
100000 \\
100000\end{array}$ & $\begin{array}{l}.0031 \\
.0031 \\
.0031\end{array}$ & $\begin{array}{l}6.7 \\
6.7 \\
6.7\end{array}$ & $\begin{array}{l}315 . \\
315 . \\
315 .\end{array}$ & $\begin{array}{l}-14.18 \\
-15.02 \\
-15.64\end{array}$ & $\begin{array}{l}0.0 \\
0.0 \\
0.0\end{array}$ & $\begin{array}{l}0.0 \\
0.0 \\
0.0\end{array}$ & $\begin{array}{l}0.0 \\
0.0 \\
0.0\end{array}$ & $\begin{array}{l}0 \\
0 \\
0\end{array}$ & \\
\hline
\end{tabular}

Figure V.8 Dump of weather data 


\section{V.A.3.3 RNOS $=3$; dump of conduction transfer function calculations}

Detalls of the CTF calculations are presented beginning with a 11st of the layers and their thermal properties ( $\mathrm{L}=$ thickness, $\mathrm{K}=$ conductivity, $C P=$ specific heat, $D=$ density, $R=$ thermal resistance value). SUMB, CND, RR, and CC are varlable names (see VI.C). The RR value is calculated only for single layer constructions. The number of roots (NRT) found and the search increment (SINC) are reported as well as the values of the ROOTs and the variable RATIO. From the ROOTs and RATIOs the CTF are computed for orders zero ( 00$)$ through ( $\left.\begin{array}{l}0 \\ 0\end{array}\right)$ unt1l the convergence criteria have been met. The $X, Y, Z$, and $J$ CTF are reported for all orders. This report is simplified for massless constructs since no CTF (only the U value) are calculated.

IUUMF OF CONHUCTION CALCULATIONS FOR:

FARTITION - STUII AREA

$\begin{array}{llllll}\text { LAYER } & \text { L } & K & \text { CF } & \text { II } & R \\ \text { GYF } & .016 & .726 & 1.255 & 720.831 & 0.000 \\ \text { WII-S } & .089 & .117 & 1.381 & 512.591 & 0.000 \\ \text { GYF } & .016 & .726 & 1.255 & 720.831 & 0.000\end{array}$

SUMB $=254.58173 \mathrm{CND}=1.24059 \mathrm{KF}=\quad-\mathrm{I} \quad \mathrm{CC}=14368.09$

NUMEER OF RDOTS $=9 ;$ SEARCH INCREMENT $=.007856$

$\begin{array}{ccc}N & \text { FOOT } & \text { FATIO } \\ 1 & .013546079 & .516548286 \\ 2 & .027011651 & .072319215 \\ 3 & .040288196 & .002899261 \\ 4 & .053198718 & .000037605 \\ 5 & .065446912 & .000000201 \\ 6 & .076662966 & .000000001 \\ 7 & .036835154 & .000000000 \\ 8 & .096795305 & .000000000 \\ 9 & .007590765 & .000000000\end{array}$

NUMEEF OF RESFONSE FACTORS = 5; ORIIER = 2

$\begin{array}{rrrrrrr}N & 00 & 01 & 02 & 03 & 04 & 05 \\ 1 & 8.683909 & 8.683909 & 8.683906 & 8.683909 & 8.683909 & 8.683909 \\ 2 & -6.380569 & -10.866227 & -11.494237 & -11.519418 & -11.519744 & -11.519746 \\ 3 & -.548920 & 2.746952 & 3.532788 & 3.566114 & 3.566547 & 3.566549 \\ 4 & -.250886 & .032658 & -.165999 & -.176242 & -.176376 & -.176377 \\ 5 & -.127301 & .002293 & -.000068 & 0.000000 & 0.000000 & 0.000000 \\ 1 & .018542 & .018542 & .018542 & .018542 & .018542 & .013542 \\ 2 & .313046 & .303468 & .302127 & .302073 & .302073 & .302073 \\ 3 & .406281 & .244577 & .222631 & .221755 & .221743 & .221743 \\ 4 & .240573 & .030710 & .013022 & .012377 & .012368 & .012368 \\ 5 & .126555 & .002288 & .000067 & 0.000000 & 0.000000 & 0.000000 \\ 1 & 8.083909 & 8.683909 & 8.0683906 & 8.683909 & 8.683909 & 8.683909 \\ 2 & -6.380569 & -10.866227 & -11.494237 & -11.519418 & -11.519744 & -11.519746 \\ 3 & -.548920 & 2.746952 & 3.532788 & 3.566114 & 3.566547 & 3.566549 \\ 4 & -.250886 & .032658 & -.165999 & -.176242 & -.176376 & -.0176377 \\ 5 & -.127301 & .002293 & -.000068 & 0.000000 & 0.000000 & 0.000000 \\ 2 & .588868 & -.037356 & 0.000000 & 0.000000 & 0.000000 & \end{array}$

Figure V.9 Dump of CTF calculations for massive construct 
V.A.3.4 RNOS = 4; dump of glass calculations

Detalls of the optical calculations are presented beginning with the DESCription of the construction and a list of the normal transmittance, Index of refraction, film transmittance, and reflectance of the GLASS or SHADE layers (AIR layers are assumed between each optical layer). The optical properties for the individual panes are:

$\operatorname{EXTC}=k * L$ from $(D .3 .5)$

$\mathrm{GN}=$ index of refraction

$\mathrm{FN}=\mathrm{f} 1 \mathrm{~m}$ index or refraction (D.4.1)

$\mathrm{FK}=$ film extinction coefficient (D.4.1)

$F D=f 11 m$ thickness.

Then the computed reflectances and transmittances of the panes are reported at various angles of incidence:

$\mathrm{Tl}=$ transmittance for $\mathrm{TE}$ light

R11 = reflectance for TE light incident from outside

R12 = reflectance for $T E$ light incident from inside

$\mathrm{T} 2$ = transmittance for TM light

$\mathrm{R} 21$ = reflectance for $\mathrm{TM}$ 11ght incident from outside

R22 = reflectance for TM 11ght incident from inside

The polynomial coefficients are the least squares fit values for (D.1.7b) and (D.1.7a). T refers to transmittance, A to absorptance, 0 to outside, I to inside, and $S$ to shade.

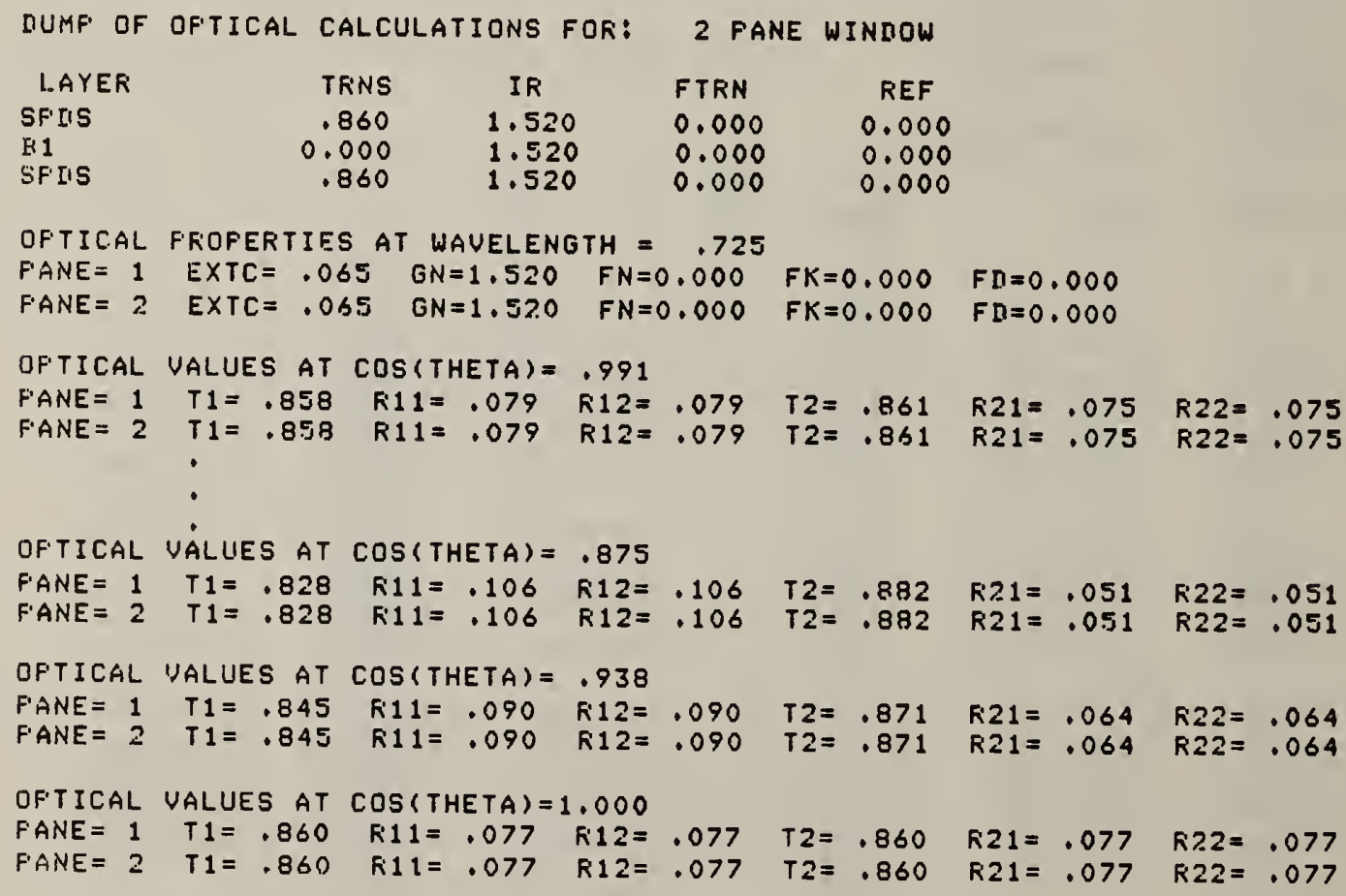

Figure V.10 Dump of optical calculations 
FOLYNOMIAL COEFFICIENTS:

$\begin{array}{cc}1 & T 2 \\ 1 & 3.8544537 E-01 \\ 2 & 1.0308017 E+01 \\ 3 & -3.3949733 E+01 \\ 4 & 5.0154231 E+01 \\ 5 & -3.9590559 E+01 \\ 6 & 1.4092558 E+01 \\ I & T 1 \\ 1 & -3.8380648 E-01 \\ 2 & 4.4021943 E+00 \\ 3 & -6.7817725 E+00 \\ 4 & 4.8351028 E+00 \\ 5 & -1.3277812 E+00\end{array}$

$\mathrm{AO2}$

2. $4276461 \mathrm{E}+00$

$-2.2363210 E+01$

1. $0021852 \mathrm{E}+02$

$-2.3554957 E+02$

$2.7725274 \mathrm{E}+02$

$-1.2867078 E+02$

A01

$1.2150528 E-01$

$-1.3248196 E-01$

1. $6526246 \mathrm{E}-01$

$-1.2219971 \mathrm{E}-01$

$3.5232619 E-02$
A I 2

$5.7576912 \mathrm{E}-01$

$-3.6428286 E+00$

$1.4986929 \mathrm{E}+01$

$-3.4400820 E+01$

$3.9841064 E+01$

$-1.8204343 E+01$

\section{AI 1}

1. $2238673 E-02$

2. $4052260 E-01$

$-4.1181869 E-01$

$2.9334734 E-01$

$-7.9688593 E-02$
AS2

$$
\begin{aligned}
& -I \\
& -I \\
& -I \\
& -I \\
& -I \\
& -I
\end{aligned}
$$

AS1

$$
\begin{aligned}
& -I \\
& -I \\
& -I \\
& -I \\
& -I
\end{aligned}
$$

Figure V.10 (continued)

V.A.3.5 RNOS $=5$; dump of DSS data

This dump begins with the surface number (same as SRF number in V.A.2.3). Then the coordinates of the vertices of the surface are presented as $X, Y$, and $Z$ values (in meters) arranged in the same order as the surface is viewed. For example, $(-.0003 .1135 .150)$ are the $X, Y$, and $\mathrm{Z}$ coordinates respectively of the upper left vertex. (13.411 3.6584 .877$)$ refers to the lower corner. Several individual values are then presented: $\mathrm{CA}=$ cosine of the aximuth (global coordinate system) angle $\mathrm{SA}=$ sine of the aximuth angle

$\mathrm{CT}=$ cosine of the tilt angle

ST = sine of the tilt angle

TRNS = surface transmittance

$\mathrm{ON}=$ start date in cyclic date $($ B.1.4) form

OFF = end date

$\operatorname{S1}, \mathrm{S} 2=\operatorname{variables} \operatorname{SHdSRF}(I, 1)$ and $\operatorname{SHdSRF}(I, 2)$. See VI.C.

85 BUILIING [

$86 S \operatorname{SIM}(S L I I S=3 / H T B=0 / F L O W / C N \cup G=.1, .01, .34,12)$

87 IISS ( AZM $=180 . / T I L T=153,4 / O R G=0,12,16 / S I Z E=44,2$ )

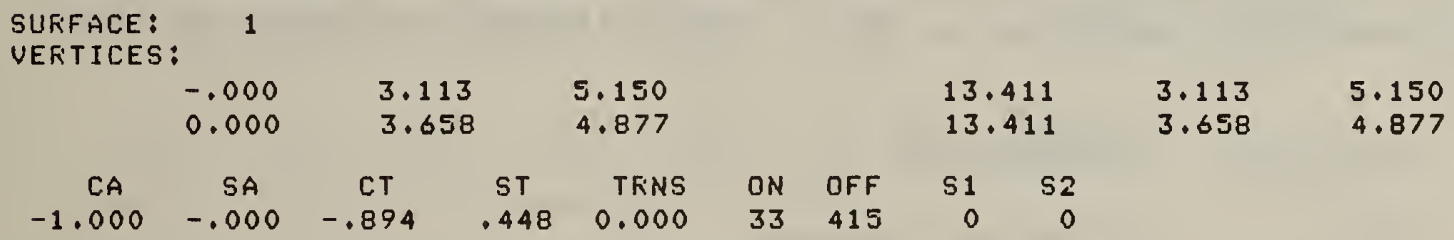

88 IISS (AZM $=180 . / T I L T=206.6 / O F G=0,0,8 / S I Z E=44,2$ )

SURFACE: 2

UEFTTICES :

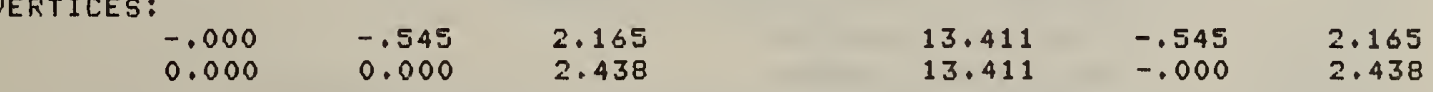

$\begin{array}{cccccccrr}\text { CA } & S A & \text { CT } & \text { ST } & \text { TFNS } & \text { ON } & \text { OFF } & \text { S1 } & \text { S2 } \\ -1.000 & -.000 & -.894 & -.448 & 0.000 & 33 & 415 & 0 & 0\end{array}$

Figure V.11 Dump of shadowing surface data 
The zone data dump produces output as shown in figure 12. There are different data formats corresponding to the many different elements of zone data. Controls and scheduled loads produce simflar output as shown for lines 92 through 95. First the schedule number (corresponding to CGS in V.A.2.3) is given. Then the contents of CGSZON (zone number), type of load), GGSON (on date), CGSOFF (stop date), CGSDX (week-schedule pointer), and elements 1 to 5 of RCGS (see VI.c) are given order.

Lines 96 and 101 produce dumps of heat transfer surface data. They begin with the heat transfer surface number (corresponding to HTS in V.A.2.3). On the next two lines the following values are given:

\begin{tabular}{|c|c|c|}
\hline NAME & VARIABLE & DESCRIPTION \\
\hline AREA & AREA & Area of surface (m2) \\
\hline INV & ISENV & Zone number \\
\hline ONV & OSENV & Outside environment / far side zone number \\
\hline FSS & FSS & View factor to sky \\
\hline FSG & FSG & Vlew factor to ground \\
\hline $\mathrm{K}$ & KPTR & Polnter to construct data \\
\hline AZM & SFAZIM & Azimuth angle (degrees) \\
\hline CTILT & CTILT & Cosine of tilt angle \\
\hline HоC & HOC & Factor for detalled outside convection \\
\hline THE & TMPHPR & Polnter to external temperature histories \\
\hline THI & TMPHPI & Polnter to internal temprature histories \\
\hline QHE & FLXHPE & Polnter to external flux historles \\
\hline QHI & FLXHPI & Polnter to internal flux histories \\
\hline
\end{tabular}

The surface described in line 101 is part of the envelope of the zone. Therefore, 1t also has shadowing surface data 1dentical to that described in V.A.3.5.

The air flow opening at line 102 produces another dump beginning with the XREF number (corresponding to AFS). Then following varlables are dumped in order:

$\begin{array}{lll}\text { NAME } & \text { VARIABLE } & \text { DESCRIPTION } \\ \text { AREA } & \text { FAREA } & \text { Effective flow area } \\ \text { EXP } & \text { FEXP } & \text { Flow exponent } \\ \text { ZS } & \text { ZS } & \text { Helght of opening } \\ \text { ZT } & \text { ZT } & \text { Helght of top of base surface } \\ \text { COS1 } & \text { FCOS1 } & \text { Direction cosine } \\ \text { COS2 } & \text { FCOS2 } & \text { Direction cosine } \\ \text { PTR } & \text { AFSPTR } & \text { Number of adjacent zone }(0=\text { ambient }) \\ \text { ZONE } & \text { ZNMOUT } & \text { Name of adjacent zone }\end{array}$

Other side coefficients (1ine 109) also produce a data dump beginning with the XREFF number (corresponding to OSC). Then the following varlables are dumped in order: 


$\begin{array}{lll}\text { NAME } & \text { VARIABLE } & \text { DESCRIPTION } \\ \text { HO } & \text { RSSC }(2, I) & \text { Convection coefficient } \\ \text { TZP } & \text { RSSC }(3, I) & \text { Zone air temperature part } \\ \text { TAP } & \text { RSSC }(4, I) & \text { Ambient air temperature part } \\ \text { HO } & \text { RSSC }(5, I) & \text { Constant temperature } \\ \text { TZP } & \text { RSSC }(6, I) & \text { Constant temperature part } \\ \text { TAP } & \text { RSSC }(7, I) & \text { Ground temperature part } \\ \text { WSP } & \text { RSSC }(8, I) & \text { Wind speed factor } \\ \text { HTS } & \text { ISSC }(9, I) & \text { HTS number of the base surface }\end{array}$

Movable insulation also produces a data dump from the RSSC/ISSC arrays:

NAME VARIABLE DESCRIPTION

$\begin{array}{lll}\text { R } & \text { RSSC }(1, I) & \text { Thermal resistance of insulation } \\ \text { A } & \text { RSSC }(3, I) & \text { Outside solar absorptance } \\ \text { E } & \text { RSSC }(4, I) & \text { Outside thermal emittance } \\ \text { RGH } & \text { ISSC }(5, I) & \text { Outside roughned number } \\ \text { ON } & \text { ISSC }(6, I) & \text { Start date for movable insulation } \\ \text { OFF } & \text { ISSC }(7, I) & \text { Stop date } \\ \text { CTL } & \text { ISSC }(8, I) & \text { Control type or pointer to day-schedule } \\ \text { HTS } & \text { ISSC }(9, I) & \text { HTS number of the base surface }\end{array}$

V.A.3.7 RNOS $=7$; dump of cross reference values

The matching of interzone partitions and openings can become difficult, so the following dump has been provided (figure V.13). As the input processor encounters interzone partitions (IZP) and openings (AFO) it checks data in two match-up lists. If the IZP/AFO does not match one of the entries in the 1ist, it is added to the 1ist. Otherwise, if it does match, the matched element in the list is removed. This dump monitors that process.

The first interzone partition is defined at line 104. No match for this IZP is found, so the number of unmatched IZP's is now 1. The far side and near side zone names are CEITTER and NORTH, respectively. The surface area is $449.053 \mathrm{~m}^{2}$; the U-value is $8.5074 \mathrm{~W} / \mathrm{m}^{2} \mathrm{~K}$; the number of temperature CTF terms is 3 ; and the number of flux CTF terms is 2 . These numbers and names will be used to find the matching description of the IZP from the adjacent zone.

The air flow opening at line 105 also created an entry in the AFO table. The count and zone names are simllar to those used for the IZP. The number are the opening area, flow exponent, and opening height, respectively.

The input processor continues to not find matches ( 1 ines 124, 125, 126, 148, and 149) or to match IZP and AFO (1ines 127, 128, and 150). When a match is found, the reduced number of 1tems IZP or AFO tables is reported as well as the HTS or AFS of the match. In this particular example, there is a typing error in the name of the adjacent zone at line 148. This error prevents a match of both IZP and AFO. At the conclusion of input processing 
this fallure to match is reported as SEVERE errors. The data accompanying the error messages (produced by default) should be sufficient to determine the incorrect or missing surfaces and openings.

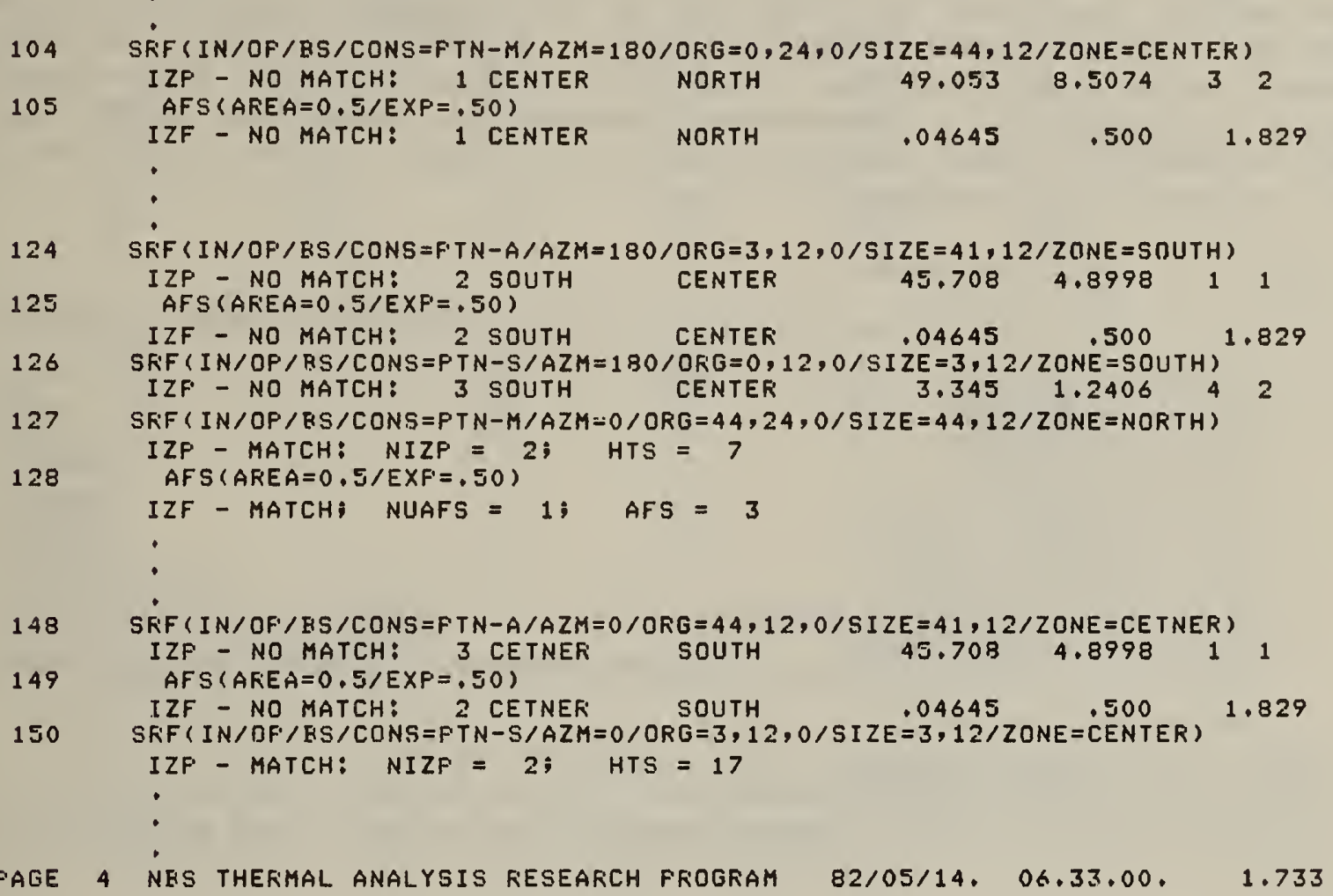

** SEUERE UNMATCHEII INTER-ZONE SUFFACES :

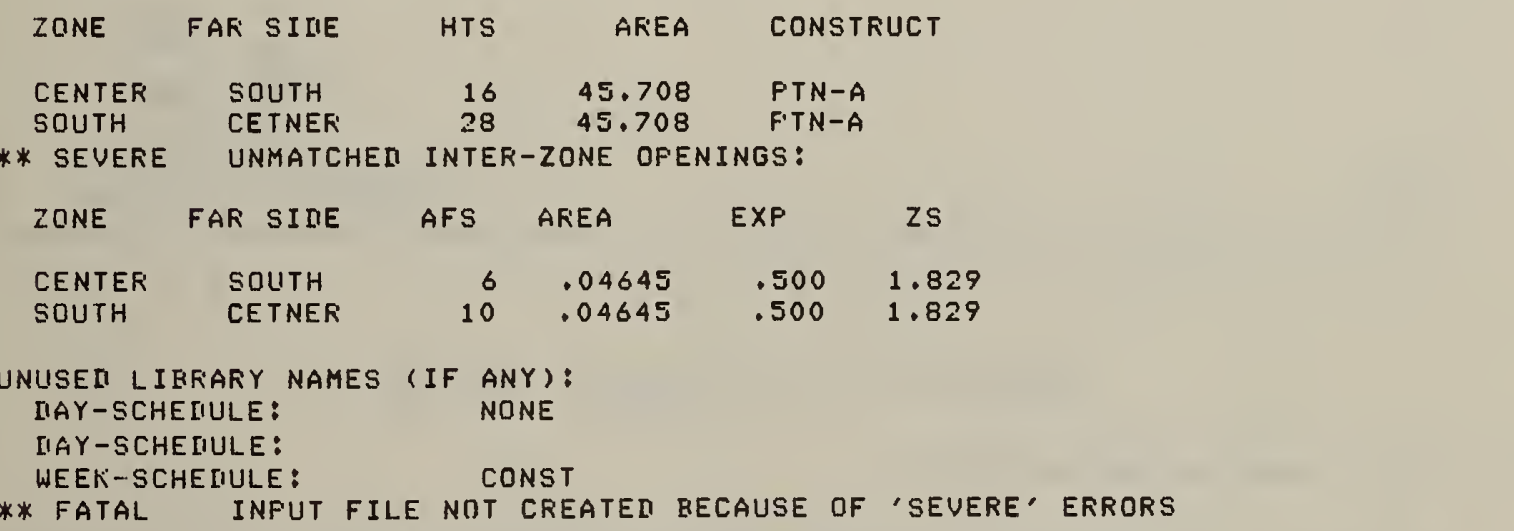

Figure V.13 Dump of cross reference values 


\section{V.A.4 LIBRARY REPORTS}

The library data can be reported by 11 brary commands (2.1.3).

\section{V.A.4.1 Day-schedules (DS)}

Figure 14 shows typical reports for two day-schedules. A simple graph 18 provided with the data. The first line of the DS report is the user defined name (ON) and description (NORTH OCCUPANCY). The next line gives the schedule number / array 1ndex (3). Then comes a l1st of hour numbers. Below these the hourly fractions of full capacity are presented by a simple bar graph. Each hour is three X's wide. The final line of a DS report is the hourly fractions as a percent of full capacity.

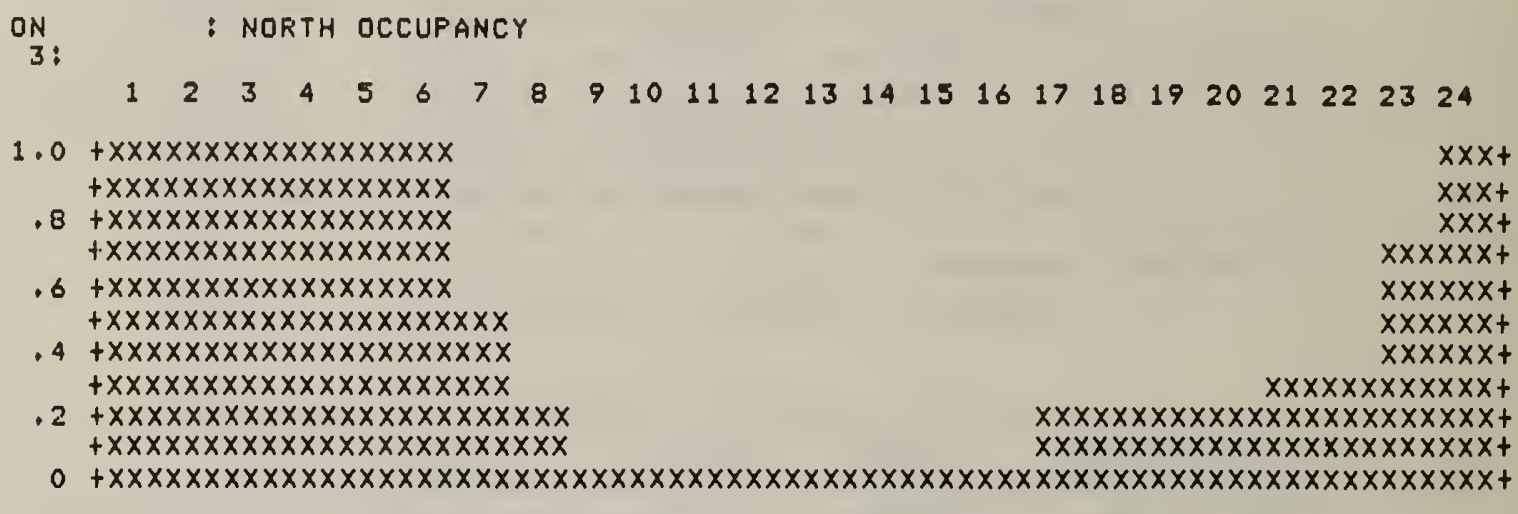
$1001001001001001005016 \quad 0 \quad 0 \quad 0 \quad 0 \quad 0 \quad 0 \quad 0016 \quad 0 \quad 1616 \quad 16 \quad 33 \quad 33 \quad 67100$

OC : CENTER OCCUPANCY

$\begin{array}{llllllllllllllllllllllll}1 & 2 & 3 & 4 & 5 & 6 & 7 & 8 & 9 & 10 & 11 & 12 & 13 & 14 & 15 & 16 & 17 & 18 & 19 & 20 & 21 & 22 & 23 & 24\end{array}$

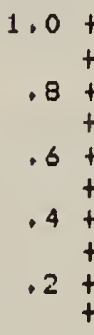

$0+x x x x x x x x x x x x x x x x x x x x x x x x x x x x x x x x x x x x x x x x x x x x x x x x x x x x x x x x x x x x x x x x x x x x x x x x x x x x x x x x x x x x x x x x+$

$\begin{array}{llllllllllllllllllllllll}0 & 0 & 0 & 0 & 0 & 0 & 0 & 0 & 0 & 0 & 0 & 0 & 0 & 0 & 0 & 0 & 17 & 17 & 17 & 67 & 50 & 67 & 17 & 0\end{array}$

\section{F1gure V.14 Day-schedule reports}

\section{V.A.4.2 Week-schedules (WS)}

The first two lines of the week-schedule report give the user defined name, description, and the schedule number. These are followed by a list of 12 days: SUN through FRI on one line and SAT through SP 4 ines below. Below each day name is the name of the day-schedule in effect on that day. Below that is the day-schedule number. Figure 15 shows three week-schedules. 


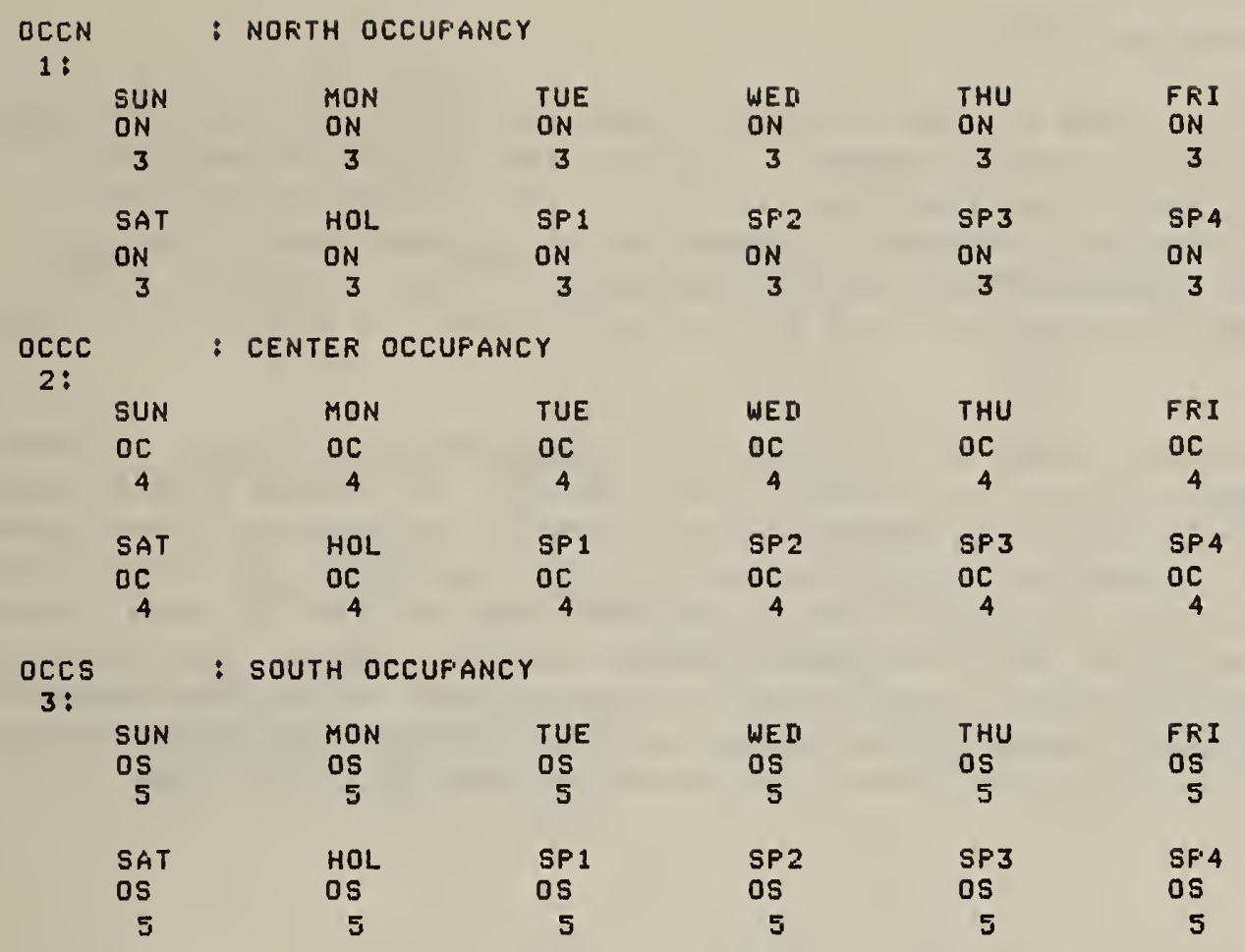

Figure V.15 Week-schedule reports

\section{V.A.4.3 Materials (MATL)}

The first two lines of the materials report give the user defined name, description, and the schedule number. The thermal properties of the material are given below the names (using the input subkey names) of those properties. Optical properties are also reported when they apply.

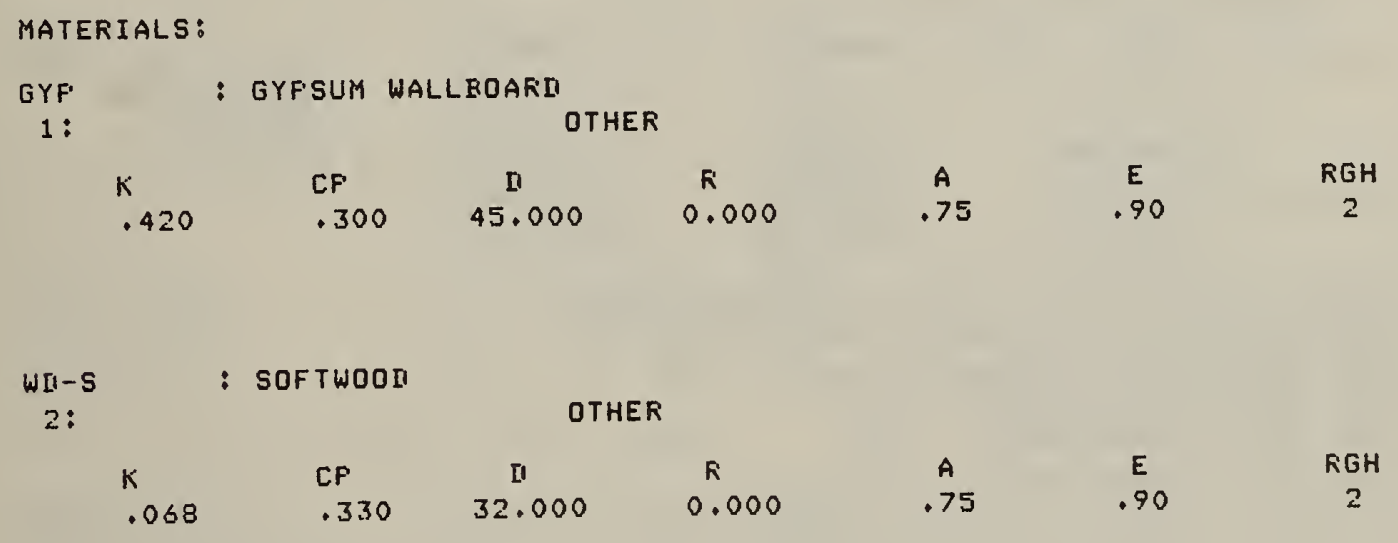

Figure V.16 Materials report 


\section{V.A.4.4 Constructs (CONS)}

The first two lines of the construct report give the user defined name, description, and the schedule number. The name and thermal properties of each layer are given. The number and values of the conduction transfer functions are reported. "Internal" refers to the $\mathrm{Z}$ functions, "cross" to the $Y$ functions, "external" to the X functions, and "flux" to the $J$ functions. The thermal conductance and surface properties are reported as shown below in figure 17.

Considerably more data is reported for transparent constructs. Figure V.18 shows a sample report for a double pane window. It begins with a report of the conductive propertles. There is only one CTF because the layers have no thermal mass. Then the optical properties are reported. The transmittance, reflectance, and absorptances of the window are reported for 16 evenly spaced values of the cosine of the angle of incidence and for diffuse radiation. The program computes polynomial coefficients to approximate the angular dependence of these properties. These fitted values are reported for the window transmittance and absorptances at the outer and Inner surfaces of the window.

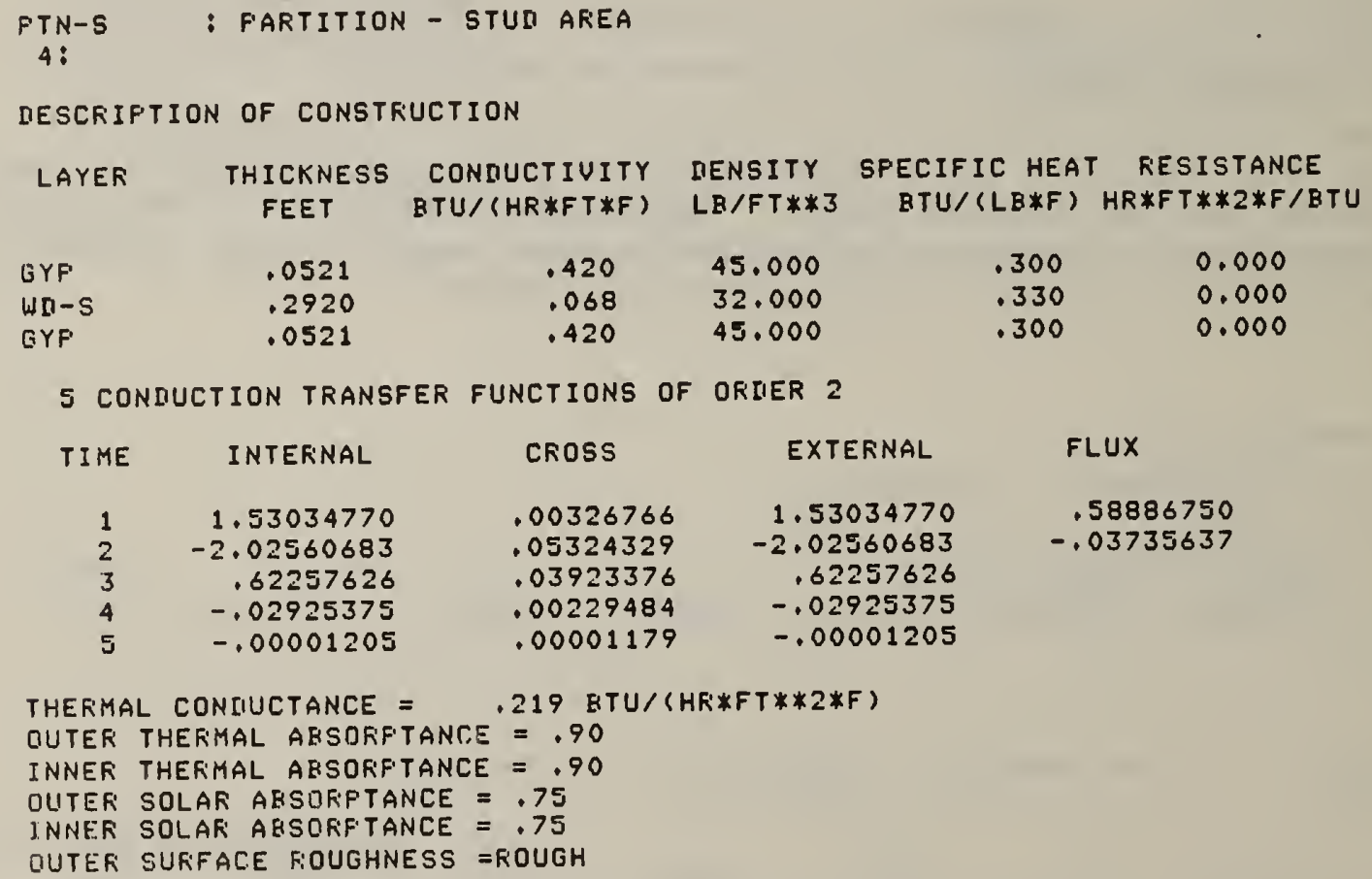


WIW 2

: 2 FPANE WINDOW

$5:$

IIESCRIFTION OF CONSTRUCTION

LAYER THICKNESS CONIUUTIUITY IIENSITY SFECIFIC HEAT RESISTANCE FEET ETU/(HR*FT*F) LB/FT**3 BTU/(LB*F) HR*FT**2*F/ETU

$\begin{array}{llllll}\text { SFIIS } & 0.0000 & 0.000 & 0.000 & .200 & .024 \\ \text { B1 } & 0.0000 & 0.000 & 0.000 & .200 & .910 \\ \text { SFIIS } & 0.0000 & 0.000 & 0.000 & .200 & .024\end{array}$

1 CONDUCTION TRANSFER FUNCTIONS OF ORDER O

TIME INTEFINAL CFOSS EXTERINAL FLUX

$1 \quad 1.04471375 \quad 1.04471375 \quad 1.04471375$

THEFMAL CONIUCTANCE $=1.045 \mathrm{ETU} /(\mathrm{HF} * \mathrm{FT} * * 2 * \mathrm{~F}$ )

OUTER THERMAL AESORPTANCE $=.90$

INNEF: THEFMAL AESORFTANCE $=.90$

OUTER SOLAR ABSORFTANCE $=.75$

INNER SOLAR AESORFTANCE $=.75$

OUTER SUR'FACE ROUGHNESS $=$ ROUGH

OFTICAL VALUES

$\begin{array}{llcrrr}\text { LAYER } & \text { TRNS } & \text { IR } & \text { FTRN } & \text { TRNS } & \text { REF } \\ \text { SFIIS } & .860 & 1.520 & 0.000 & \\ \text { SFIIS } & .860 & 1.520 & 0.000 & \end{array}$

ANGULAR IIEFENIIENCE OF VALUES:

$\begin{array}{lllllllll}\text { COS(THETA): } & .0625 & .1250 & .1875 & .2500 & .3125 & .3750 & .4375 & .5000 \\ \text { TFANSMITTANCE: } & .0563 & .1548 & .2639 & .3705 & .4647 & .5415 & .6003 & .6434 \\ \text { REFLECTANCE: } & .8314 & .7109 & .5932 & .4830 & .3875 & .3109 & .2532 & .2119 \\ \text { ABSOFFTANCE: } & .0872 & .0975 & .0982 & .0959 & .0926 & .0893 & .0862 & .0835 \\ \text { ABSORFTANCE: } & .0251 & .0368 & .0447 & .0507 & .0552 & .0584 & .0603 & .0612\end{array}$

FITTER UALUES FOR LOADS CALCULATIONS:

TFANSMITTANCE: $\quad .0568 .1540 .2643 .3708 .4645 .5412 .6004 .6436$

QUTEF ABSORFTANCE: .0855 .1002 .0971 .0944 .0932 .0906 .0859 .0822

INNEF AESORF'TANCE: $\quad .0249 .0371 .0446 .0505 .0553 .0585 .0603 .0611$

ANGULAR IIEPENIIENCE OF VALUES:

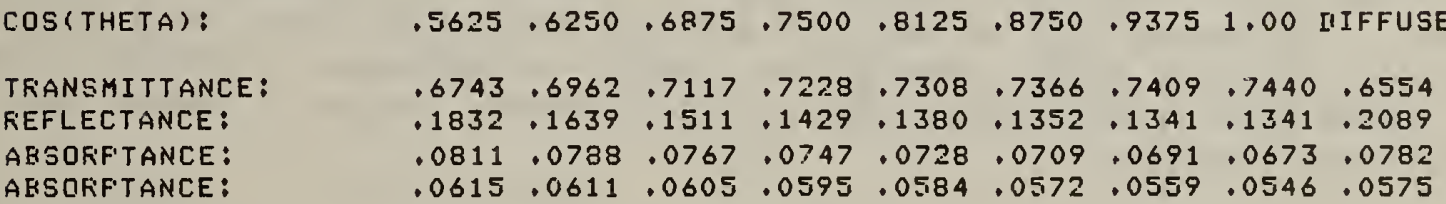

FITTEII VALUES FOR LOAIS CALCULATIONS:

TFANSMITTANCE: $\quad .6742 .6963 .7118 .7228 .7307 .7366 .7410 .7439 .6554$

QUTER AESOFFTANCE: .0811 .0788 .0767 .0747 .0728 .0709 .0691 .0673 .0782

INNER AESOFFTANCE: $\quad .0615 .0612 .0605 .0595 .0584 .0572 .0559 .0546 .0575$

Figure V.18 Construct report for a window 


\section{V.A.4.5 Control profiles (CPFL)}

The first two lines of the control profile report give the user defined name, description, and the schedule number. The next line is a 11 st of the user defined control temperatures followed by a line of matching fractions of full capacity. The number of control points 18 determined by the user subject to array dimension constraints. Figure 19 shows this report for two control profiles.

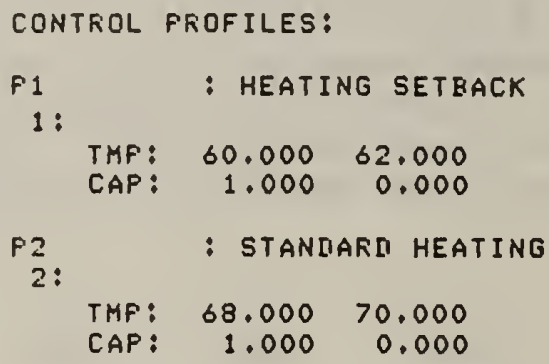

Figure V.19 Control profiles reports

V.A.4.6 Control day-8chedules (CDS)

After the two line of standard heading information the CDS report gives a list of 24 hours (on four lines) with the profile name and index reported below each hour. Figure 20 shows a CDS report for two control day-schedules.

V.A.4.7 Control week-schedules (CWS)

The first lines of the control week-schedule report give the user defined name, description, and the schedule number. These are followed by a list of 12 days: SUN through FRI on one 11 ne and SAT through SP4 four 11 nes below. Below each day name is the name of the control day-schedule in effect on that day. Below that is the control day schedule number. Flgure 21 shows two control week-schedules. 
CONTROL IIAY-SCHEIIULES:

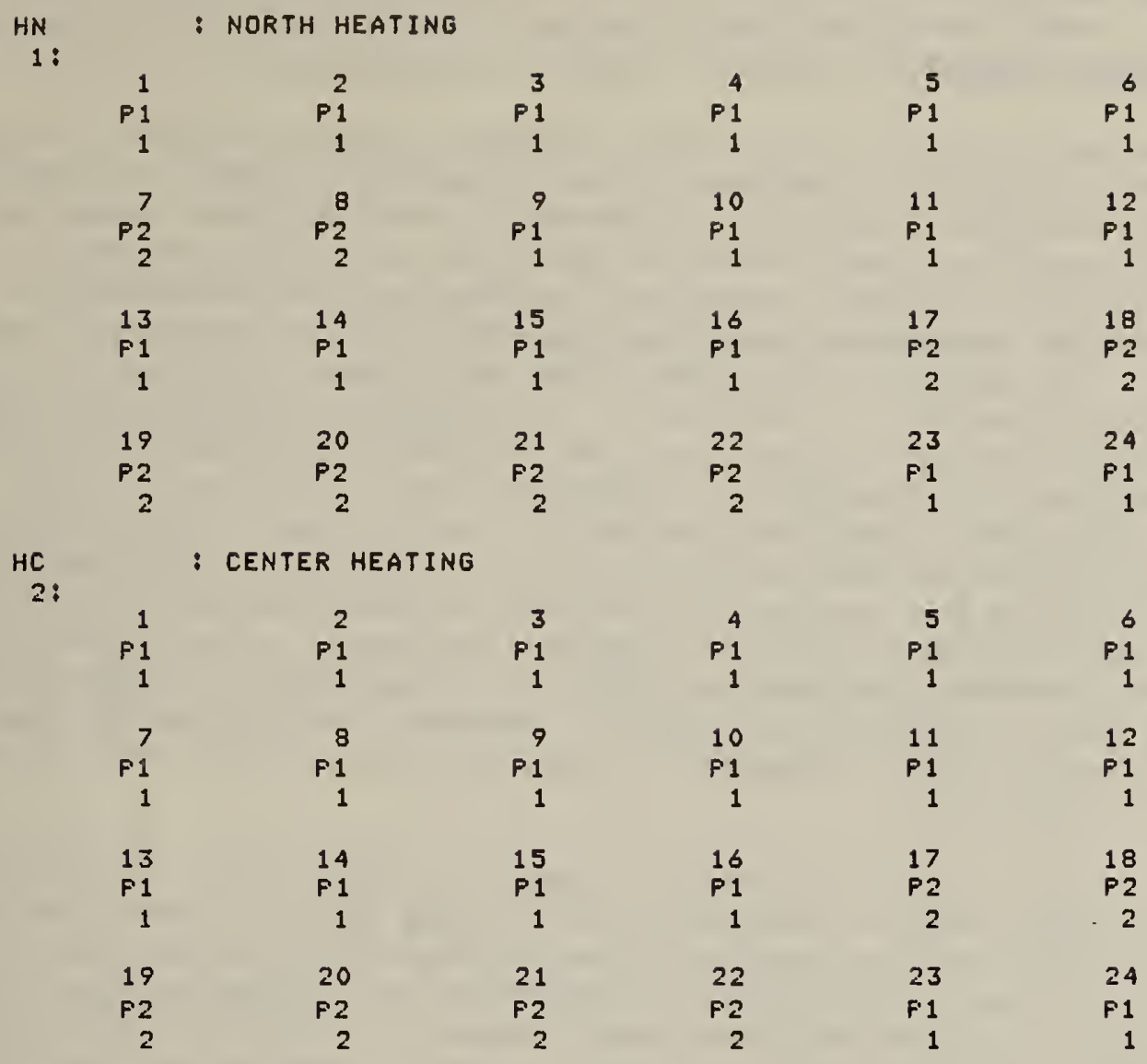

Figure V.20 Control day-schedule reports

CONTROL WEEK-SCHEIULES:

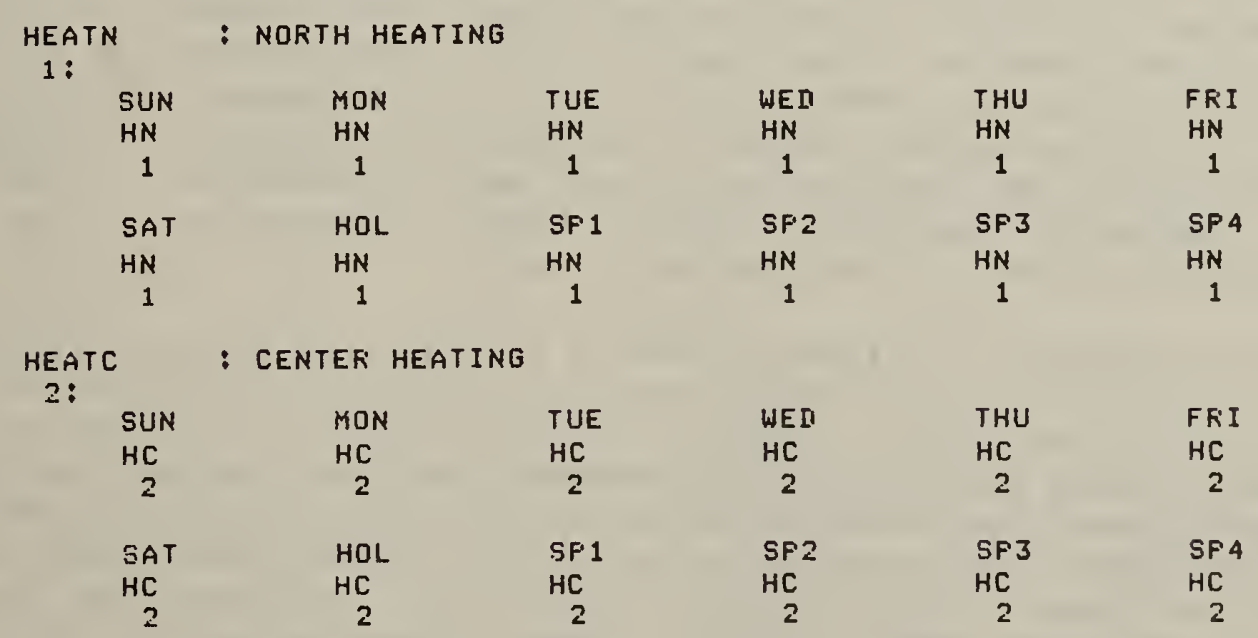

Figure 21. Control week-schedule reports 
Sample default output of the loads calculator program is shown in figure 22. The loads calculator is designed to be recomplied to match the specific problem being simulated. The user may decide to store different compilations on tape. Therefore, the first action of the loads calculator program is not to print the maximum avallable array space so the user can determine the capabilities of the program by executing 1t, even without a simulation input file (SINPFL). The names for the array sizes match those reported by the input processor as described in V.A.I and VI.C. If the user has attached a SINPFL, the program prints the array space required to solve the current simulation. If insufficient space is avallable, a warning is given, and execution is terminated. Otherwise, simulation begins. If the avallable array space is much too large, it may be desirable to compile so that just sufficient space is available and charges for program size during execution are minimized. During the calculation of the solar gain multipliers, two other array requirements are reported: the shadowing combinations (CMB) and homogeneous coordinate space (HCS). These sizes depend on the number of surfaces, the shadowing algorithm (3.1.2), and the specific arrangement of surfaces and so they cannot be known before program execution.

The next default report is shown as page 2 in figure 22 . It describes the calculational effort used to determine the bullding loads. First; the temperature and flux history initialization period is reported. The execution time for initialization can be determined by comparing the completion time with the start time (which was given with the page 2 header). Inftialization proceeds until load and temperature extreme values for two successive days are within the convergence limits. In this example that required seven days. There were 635 surface and air heat balances, or about 3.78 1terations per hour. This number can be reduced by widening the convergence limits. That will also result in fewer days for initialization. Wider convergence limits tend to change peak values more than they change the total loads. There were 2181 Newton's method 1terations to compute air flows. That is about 3.43 iterations per heat balance iteration. There were no heat balance iterations which failed to converge. Fallure to converge may be due to an inadequate iteration limit (3.1.3) or to cycling between points on two different segments of a control profile. The loads for that hour may or may not be reasonable. Check the peak loads (below) for impossible values. Similar information on time, days, and iterations is given for the simulation period.

The final summary of bullding loads is presented as page 3 of the example. The report is headed by three descriptions: project (1.1.1), location (1.3.1), and weather $(1.5 .1$ or 1.6 .1$)$. Then the following values are presented for each zone: Total heating and cooling requirements, peak heat and cooling loads, maximum and minimum zone air temperatures, hours at peak heating capacity (HX), other heating hours (HT), ventilating hours (V), cooling (below peak capacity) hours (CL), and hours at peak cooling capacity (CX). Building-wide values are summarized by the line labeled "TOTAL:" These values include the total heating and cooling requirements for all zones, the peak coincident heating and cooling 
loads, and the maximum and minimum of all zone temperatures. The hour and day are reported for the occurrence of the peak loads and temperatures. In the example, there is no time reported for peak cooling since there was no cooling load.

F'AGE 1 NES THERMAL ANALYSIS RESEARCH FROGRAM 82/05/17. $05.38 .06 . \quad 3.004$

MRLF MAXIMUM ARRAY DIMENSIONS:

$\begin{array}{rr}\text { ZON: } & 4 \\ \text { SRF: } & 36 \\ \text { HTS: } & 36 \\ \text { AFS: } & 24 \\ \text { CGS: } & 16 \\ \text { GTF: } & 4 \\ \text { TFH: } & 512 \\ \text { CTF: } & 192 \\ \text { SSC: } & 16 \\ \text { IISH: } & 16 \\ \text { WSH: } & 16 \\ \text { CON: } & 16 \\ \text { FIIL: } & 8 \\ \text { CIS: } & 8 \\ \text { CWS: } & 8\end{array}$

MFILF ARRAY SFACE USEI:

ZON: 3

SFF: 32

HTS: 32

AFS: 10

CGS: 12

GTF: 1

TFH: 283

C.TF: 140

SSC: 3

USH: 11

WSH: 10

CON: 11

FFL: $\quad 2$

CIIS: 3

CWS: 3

FERUIREI CMB $=82$
FEQUIFEI HCS $=10$

Figure V.22 Default loads calculation output 


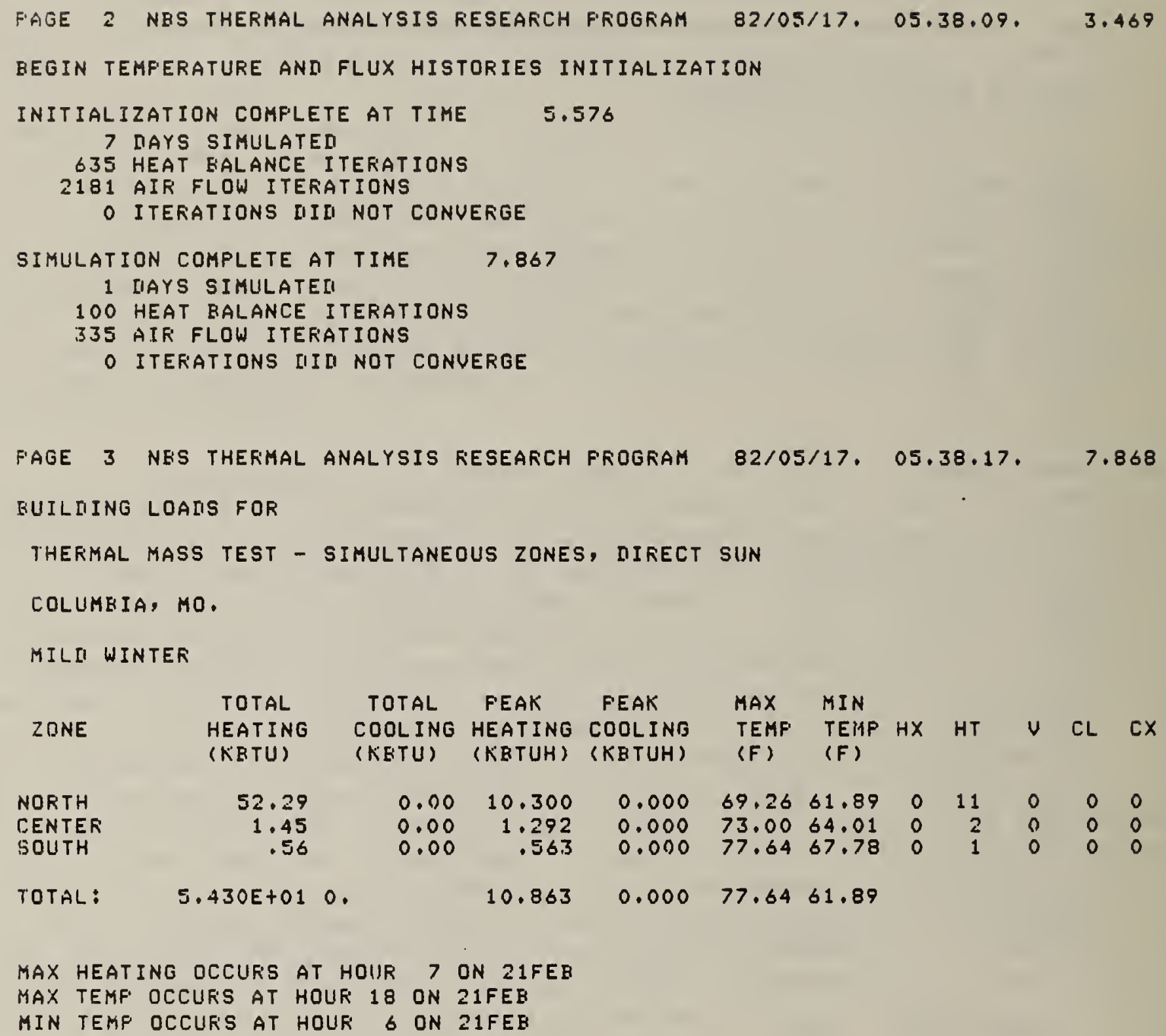

Figure V.22 (continued) 
Several reports and data dumps can be requested by specifying report numbers $(1.2 .1)$.

V.B.2.1 RNOS $=8$; Dump of SINPFL as read by loads program

This is a dump of every value transferred from the input processor to the loads calculator by the simulation input file (SINPFL). It includes all project data except the weather and can, therefore, be rather long. Figure 23 for a SINPFL dump of the sample problem data is four pages long.

The SINPFL dump begins with a dump of variables which can be described as run control data. Refer to VI.C for a description of the individual variables. Next comes a dump of library data beginning with the day-schedules. The data for each day-schedule consists of the array index, the schedule name, and 24 hours of capacity fractions expressed as percents. The week-schedules are dumped in a similar manner. Each line describes one schedule and consists of an array index, the schedule name, and 12 pointers to day-schedule array indices.

There is no data for materials. All materials have been used in constructs. The headings for the constructs data are:

$\begin{array}{lll}\text { NAME } & \text { VARIABLE } & \text { DESCRIPTION } \\ \text { NT } & \text { NTRTFC } & \text { Number of temperature CTF terms } \\ \text { PE } & \text { TRTFPE } & \text { Pointer to external }(X) \text { CTF terms } \\ \text { PC } & \text { TRTFPC } & \text { Pointer to cross (Y) CTF terms } \\ \text { PI } & \text { TRTFPI } & \text { Pointer to internal ( } \text { CTF terms } \\ \text { NF } & \text { NFRTFC } & \text { Number of flux CTF terms } \\ \text { PF } & \text { FLRTFP } & \text { Pointer to flux CTF terms } \\ \text { XO } & \text { CTFXO } & \text { X CTF for time }=0 \\ \text { YO } & \text { CTFYO } & \text { Y CTF for time=0 } \\ \text { ZO } & \text { CTFZO } & \text { Z CTF for time }=0 \\ \text { AO } & \text { OSABS } & \text { Outside solar absorptance } \\ \text { EO } & \text { OTABS } & \text { Outside thermal emittance } \\ \text { AI } & \text { ISABS } & \text { Inside solar absorptance } \\ \text { EI } & \text { ITABS } & \text { Inside thermal absorptance } \\ \text { VF } & \text { IVABSF } & \text { Multiplier for diffuse solar absorptance } \\ \text { U } & \text { UVAL } & \text { Thermal conductance of construct } \\ \text { R } & \text { OROUGH } & \text { Outside roughness number } \\ \text { W } & \text { WTYPE } & \text { Pointerr to window array index }\end{array}$

The conduction transfer functions are listed directly from the CTF array at ten numbers per line. The construct pointer values ( $P E, P C$, and PI) point to the location 1mmediately before CTF location. For example, the X(1) value of WL-S is -6.3074297 ( $\mathrm{PE}=7$; therefore CTF index $=8$ ). The $X(0), Y(0)$, and $\mathrm{Z}(0)$ values are stored separately. The window pointer, WTYPE, points to the array index of the window coefficients. In this example, there is only one window type, but each type has four line of data: one each for transmittance 
and outside, inside, and shade absorptance. Each line of data consists of the window type index, data abbreviation, value for diffuse radiation, and polynomial coefficients for angular properties.

Control profile data consists of the array index, profile name, number of control points, and control temperatures and capacity fractions. In the example, the capacities for $\mathrm{Pl}$ are 1.0 at $\mathrm{T}=15.56$ and 0.0 at $\mathrm{T}=16.67$. The control day-schedule data consists of the array index, schedule name, and 24 pointers to control profile array indices. The control week-8chedule data consists of the array index, schedule name, and 12 pointers to control dayschedule array indices.

Inputs (4.2) through ( 4.11 ) create scheduled loads and activities. Each line of the scheduled loads dump consists of the array index, zone number (CGSZON), type (CGSTYP), start and stop dates (CGSON and CGSOFF), schedule pointer (CGSDF), all 5 values of RCGS, and zone names (CGSZON). See VI.C for descriptions of these variables.

Next the surfaces involved in shadowing and solar gains (SRF) are described. This consists first of the array index, number of vertices, and $X, Y$, and $Z$ coordinates of the vertices for each surface. Then comes the subsurface data previously described in V.A.3.5.

The heading for the columns of data for the heat transfer surfaces (HTS) are:

\begin{tabular}{|c|c|c|}
\hline NAME & VARIABLE & DESCRIPTION \\
\hline AREA & AREA & Area of surface \\
\hline 2 & ISENV & Zone number \\
\hline ONV & OSENV & Outside environment / far side zone number \\
\hline FSS & FSS & View factor to sky \\
\hline FSG & FSG & View factor to ground \\
\hline SSC & SSCPTR & Pointer to special coefficients \\
\hline K & KPTR & Pointer to construct data \\
\hline THE & TMPHPE & Pointer to external temperature histories \\
\hline THI & TI:PHPI & Pointer to internal temperature histories \\
\hline FHE & FLXHPE & Pointer to external flux historles \\
\hline FHI & FLXHPI & Pointer to internal flux histories \\
\hline AZM & SFAZIM & Azinuth angle (degrees) \\
\hline CTILT & CTILT & Cosine of tilt angle \\
\hline HOC & HOC & Factor for detailed outside convection \\
\hline
\end{tabular}

The special coefficient data consists of the array index and nine values from ISSC or RSSC (see VI.C) depending on the type of data being described (see also V.A.3.6). Special surface coefficients are stored at the bottom of the array and movable insulation data are stored at the top. 


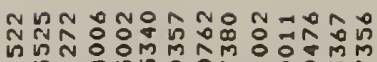

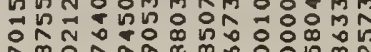

舟品

-

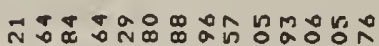

mon

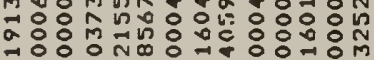

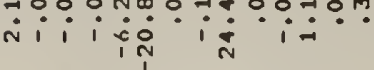

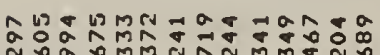

广

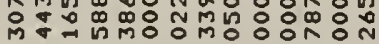

i $i \underset{n}{\cos }$ i

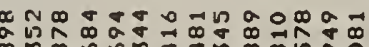

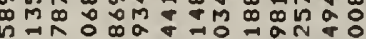

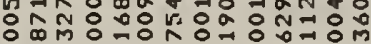

N

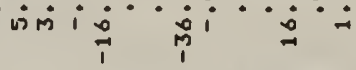

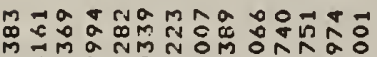
传

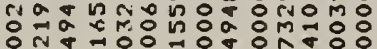

íti

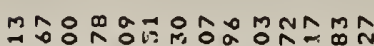

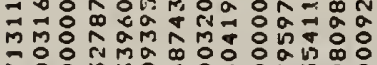
స:융 $\dot{m} \dot{m}_{\dot{1}} i$ isi $i$

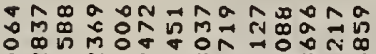

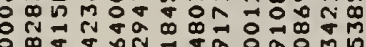
:웅 in
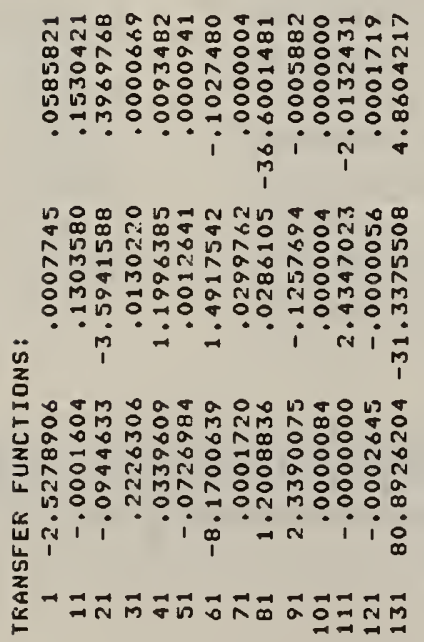

กำก๊ำ

\%ำ

$\underset{\sim}{\infty} \stackrel{\infty}{1}$

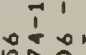

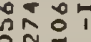

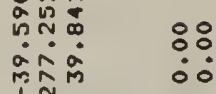

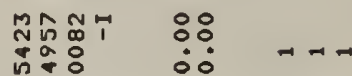

䧟菂

i

Mำ

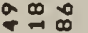

ลำ:

m:

Nim

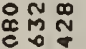

的。

¿iํ

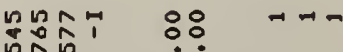

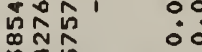

$\therefore:$

n N

m?

$\because \because \quad N N-$

N N N

NNN

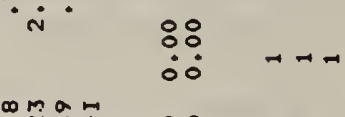

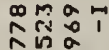

$\therefore:$

m?ㅇํㅇ

$\because i$

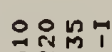

旅茼

赵

$\therefore 8$

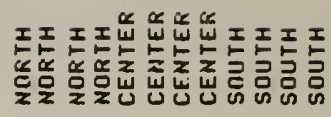

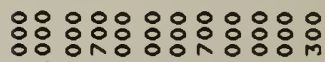
$\therefore \circ 0^{\circ} \circ 0^{\circ} \circ 0^{\circ}$

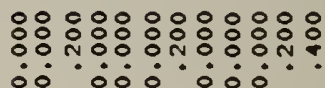

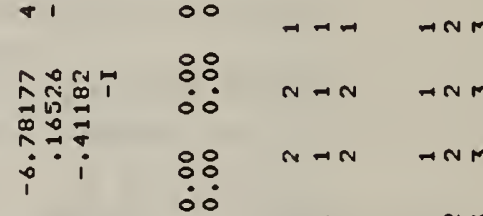

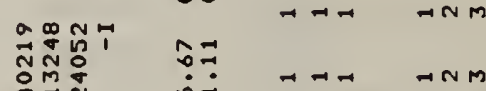
$\underset{+i}{\stackrel{M}{*}}$

ธีที丶ด mi:
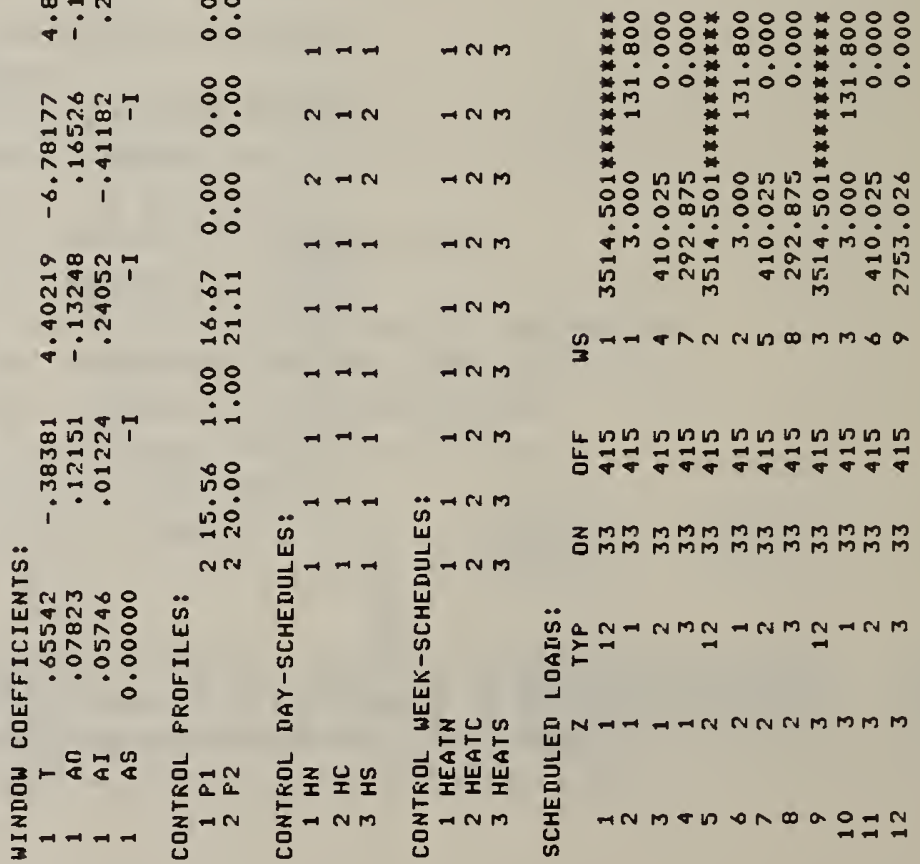

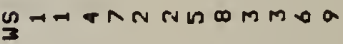

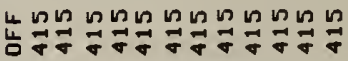

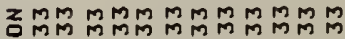

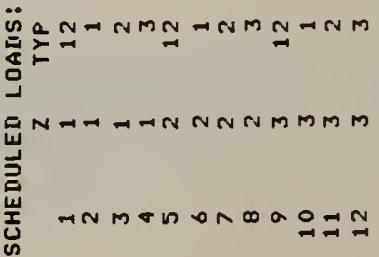

Figure V.23 (continued) 
แก๊์ मित्Ni

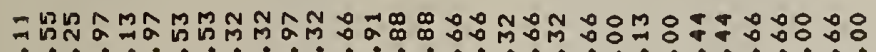
मि

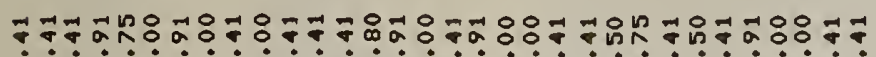

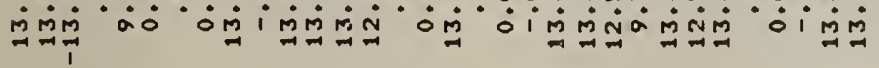

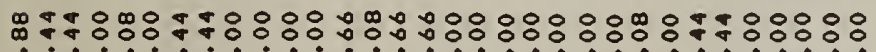

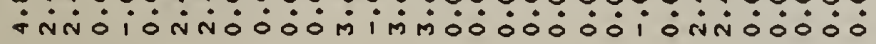

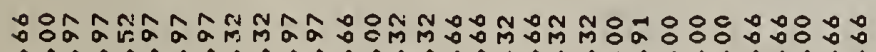

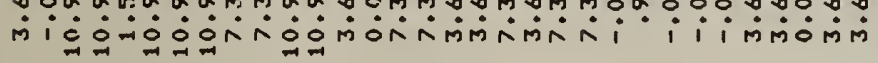

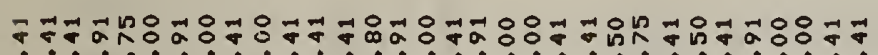
min

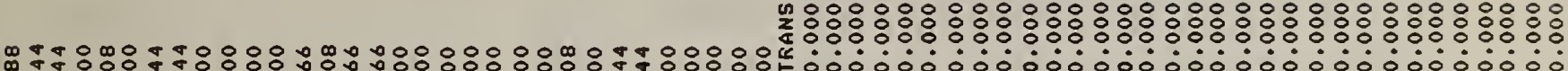

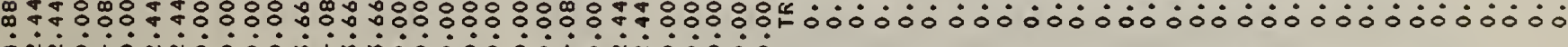

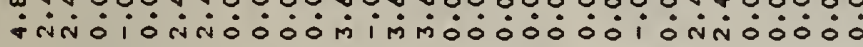

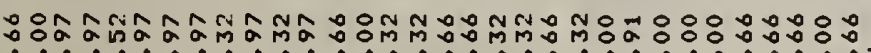

Ln $\ln _{0} \ln 0000000000000000000000000000$ món

:우유. $\circ 00$ mp m

แำ

以ก⿻上丨

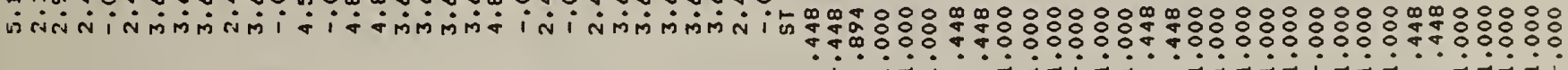

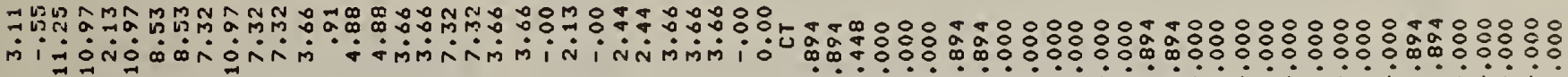
i i i i i i

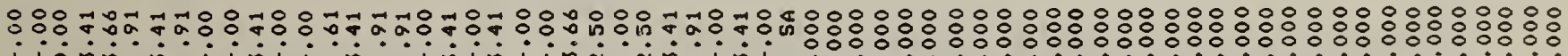
i iom mim $i$ imi $i$ mimimi im 
บํำกำฒ์

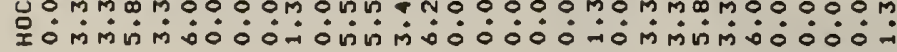

ઍ:웅 Loii i i i

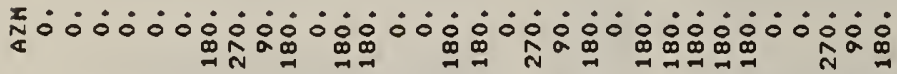

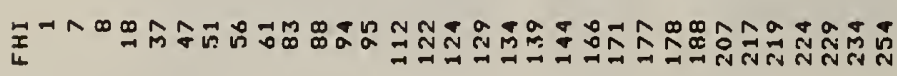

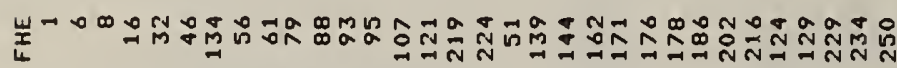

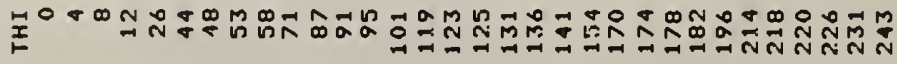

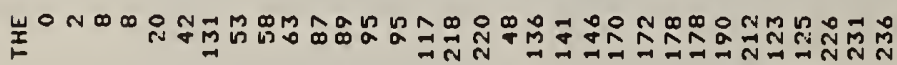

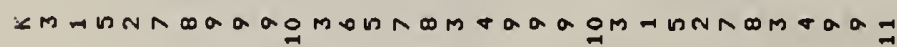

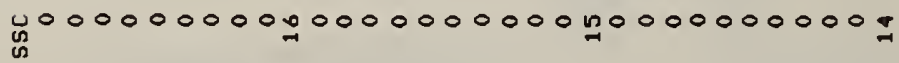

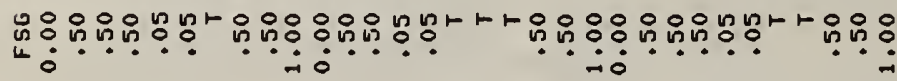

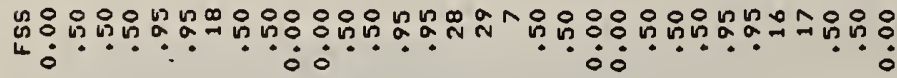

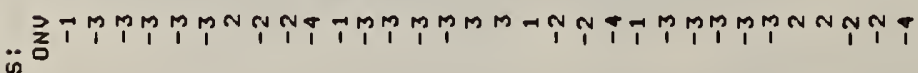
$\because \because:$ 压 के

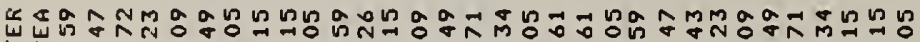

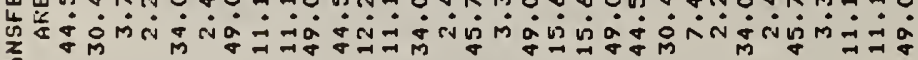

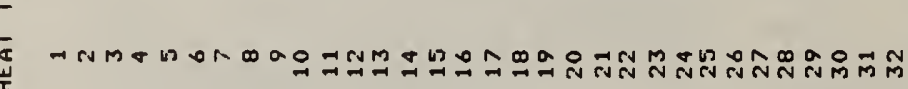
ㅇำก $\because::$

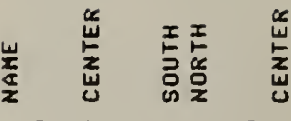

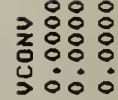
$\stackrel{\leftarrow}{a}$

$\because: 8$

-

$\therefore::$ $\therefore \circ:$

$\therefore::$ $\therefore \circ 0^{\circ}$

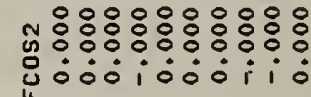

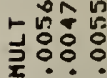
경유융유유유

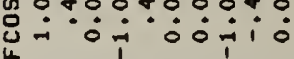

LMN

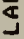

$\omega \rightarrow \infty$

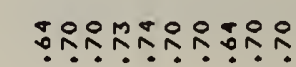

으뉴

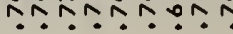

迹

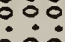

$N$

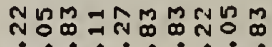

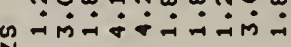
Mํำ מี $\frac{1}{4}$ แ in ज岕: MMM

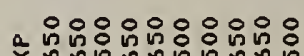

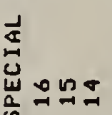


The headings for the air flow opening data are:

$\begin{array}{lll}\text { NAME } & \text { VARIABLE } & \text { DESCRIPTION } \\ \text { FAREA } & \text { FAREA } & \text { Effective flow area } \\ \text { FEXP } & \text { FEXP } & \text { Flow exponent } \\ \text { ZS } & \text { ZS } & \text { Height of opening } \\ \text { ZV } & \text { ZVMOD } & \text { Factor for wind pressure calculation } \\ \text { FCOS1 } & \text { FCOS2 } & \text { Direction cosine } \\ \text { FCOS2 } & \text { FCOS2 } & \text { Direction cosine } \\ \text { PTR } & \text { AFSPTR } & \text { Number of adjacent zone (O=ambient }) \\ \text { NAME } & \text { AFSNAM } & \text { Name of adjacent zone }\end{array}$

The zone related values consist of the array index, the zone name, the indices of the first and last surfaces which are part of the zone, the first and last heat transfer surface numbers, the first and last air flow surface numbers, the height of the zone for pressure calculations, and multipliers for visible and convective gains.

V.B.2.2 RNOS $=9$; Zone description report

This report gives a description of each zone (one zone per page). It begins with the zone name, for example, NORTH in figure V.24. Next is a listing of the scheduled loads and controls. The data is presented using the input variable names. The surfaces of the zone are described next. The first zone includes a description of the detached shadowing surfaces. The reported U-values do not include surface coefficients. Finally, the air flow openings are described. ZONE is the name of the zone on the other side of the opening. 


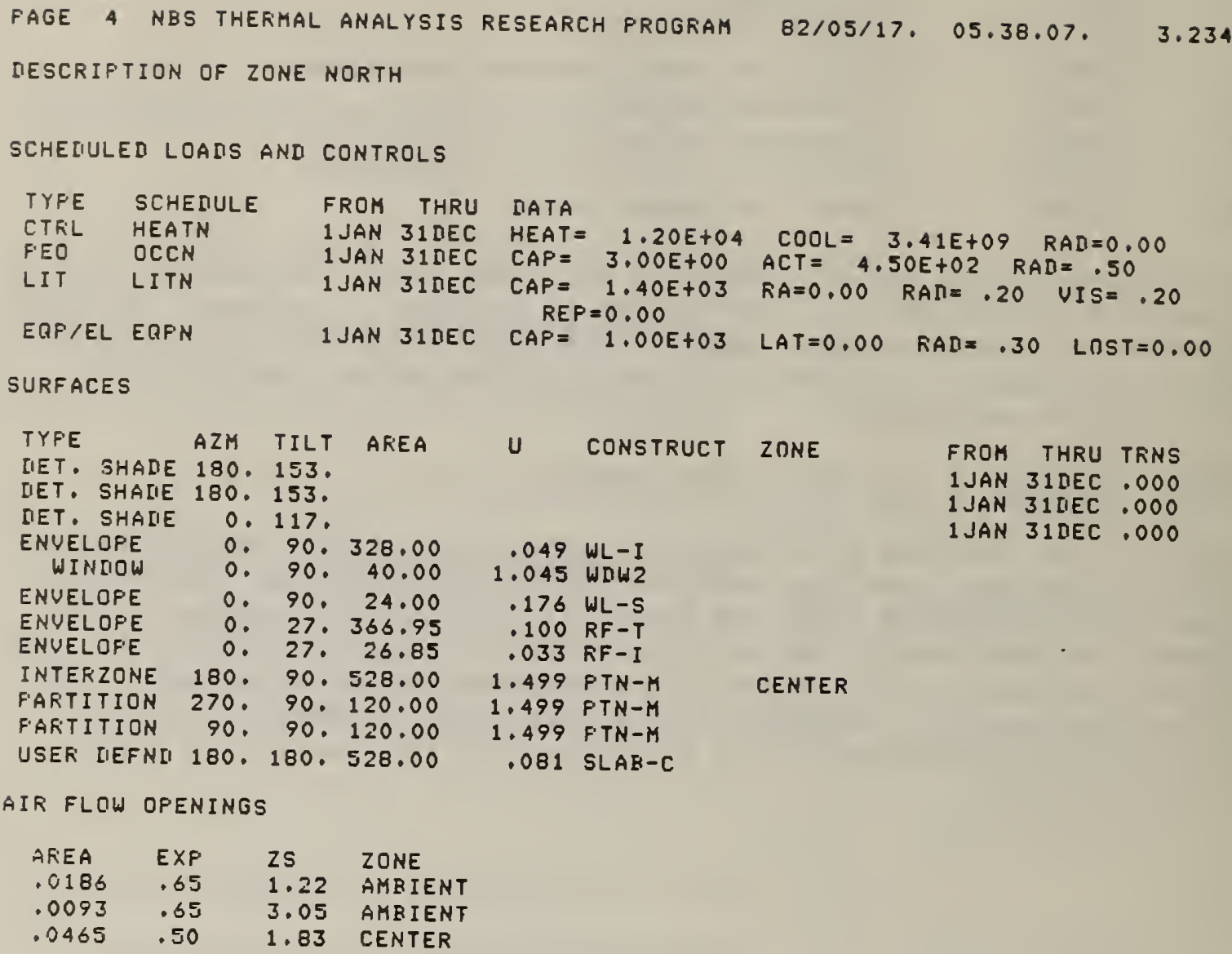

Figure V.24 Zone description report

V.B.2.3 RNOS $=13$; Report of sunlit fractions

This report gives the fraction sunlit area for all heat transfer surfaces. It begins with the date and solar declination and equation of time values used in computing the solar position. The values of the cosine of the angle of incidence on each surface and the sunlit fraction are presented for 24 hours on the half hour. Nine values from ISSC or RSSC (see VI.C) depending on the They are in the HTS number sequence. The sunlit fractions apply only to the outside of envelope surfaces, so partitions and such cannot have sunlit fractions but are reported to maintain the sequence of surfaces. 


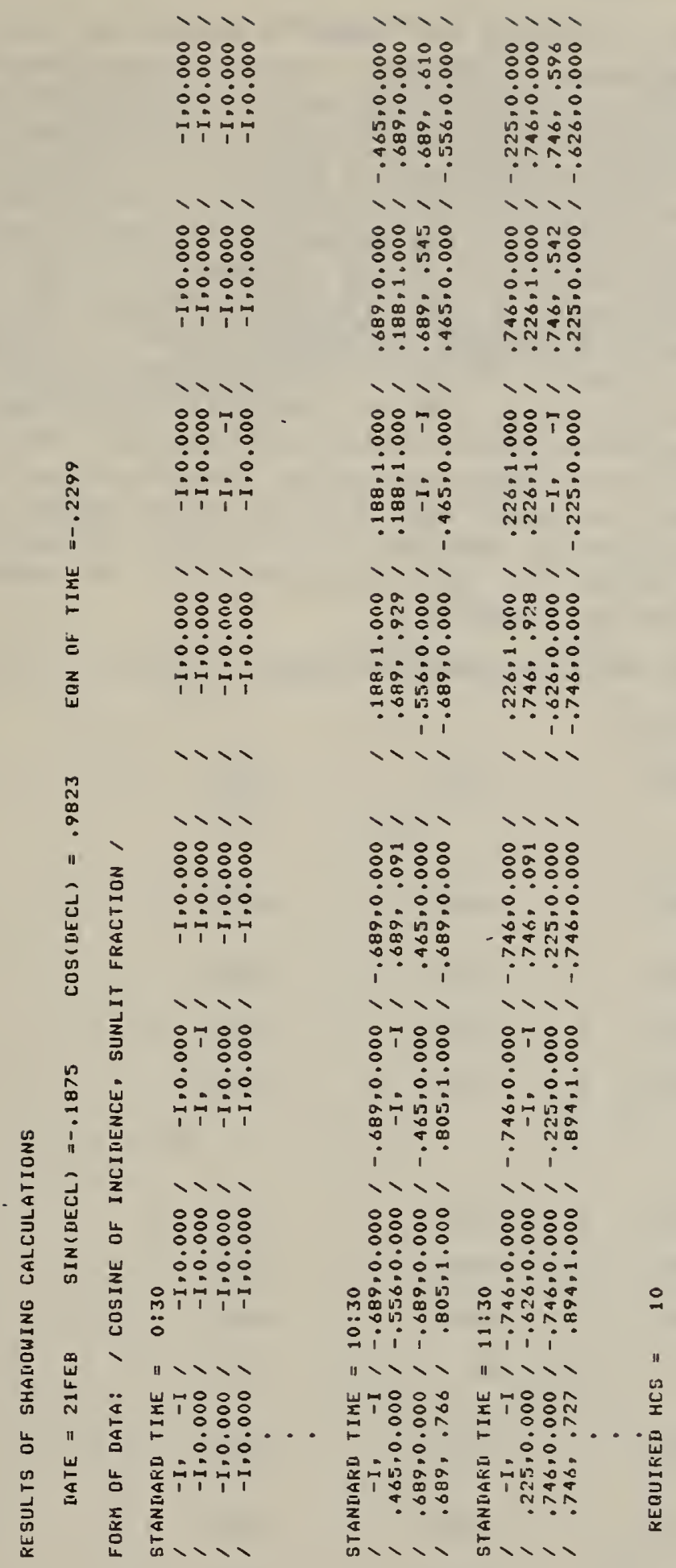

Figure V.25 Results of shadowing calculations 


\section{V.B.2.4 RNOS $=14$; Report of shadowing combinations}

Some surfaces of the bullding can never be shaded by others because of various geometric constraints. TARP does a one-time determination of which surfaces can possibly be shaded by others and stores the results to save time in long term or multiple environment runs. The shadowing combinations report for the example problem is shown in figure 26. Information is presented for each General shadow Recelving Surface (GRS), that is, each EXterfor, Base Surface (4.13.2) of the bullding. Surfaces are referred to by their SRF numbers. The first such surface 18 GRSNR $=4$. For this surface there is one possible shadowing surface (NGSS $=1$ ), seven intertor surfaces which may recelve direct sun through the window (NBKS $=7$ ), and one subsurface $($ NSBS $=1)(4.13 .2)$. A general shadowing surface (GSS) is elther a GRS or a detached shadowing surface (3.2). The one GRS which might shade GRS 非 1 s SRF \#3. The detalled solar distribution within the zone must refer to the EXterior of INterfor (4.13.2) surfaces which are called back surfaces (BKS) during shadowing calculations. The seven back surfaces which might recelve beam sunlight through the window are SRFs $⿰ ⿰ 三 丨 ⿰ 丨 三 6,7,8,9,10,11$, and 12 . The only subsurface of the GRS 1s SRF 非. Note that GRS \#6 has no (transparent) SBS and therefore no BKS need be computed.

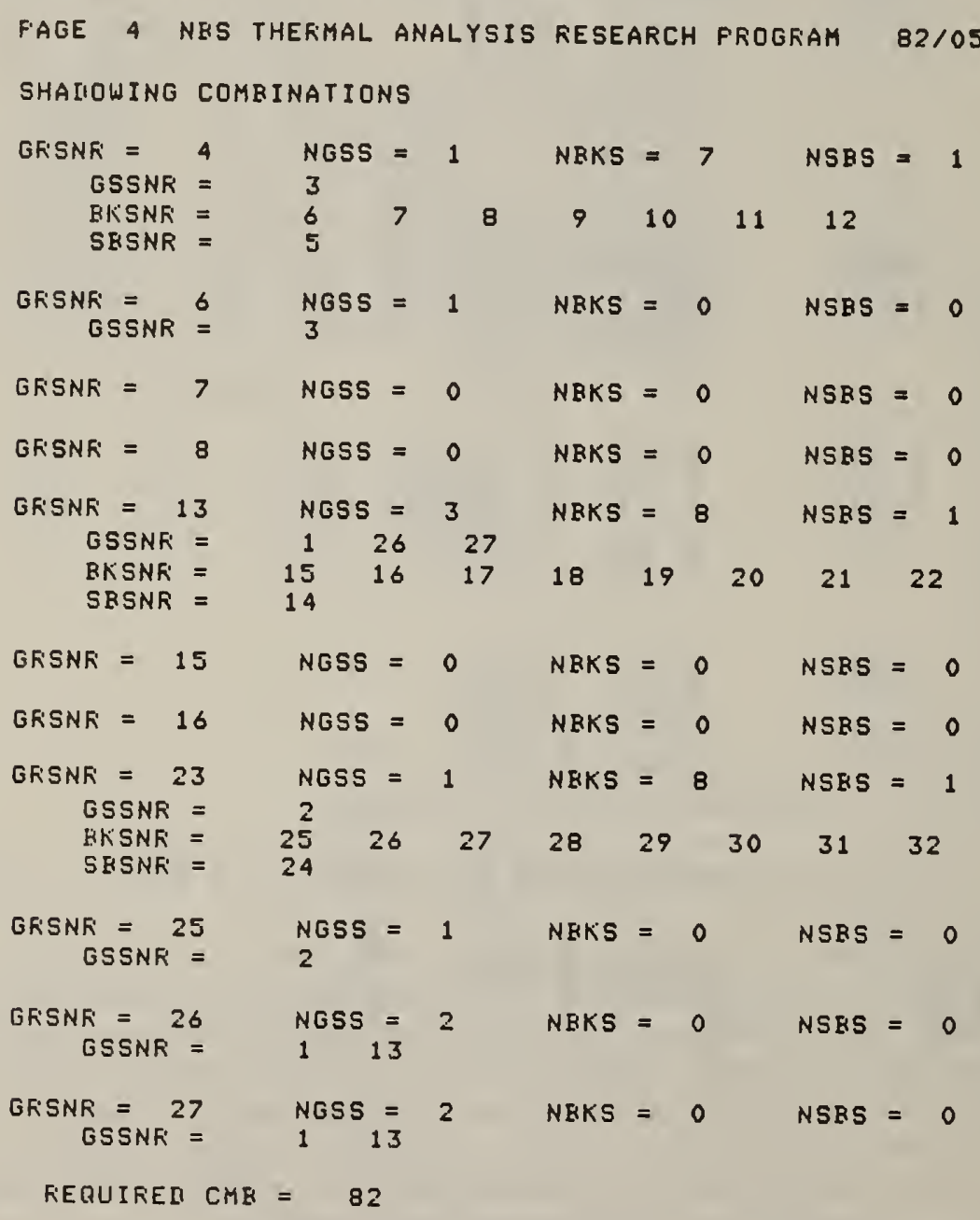

Figure V.26 Shadowing combinations report 


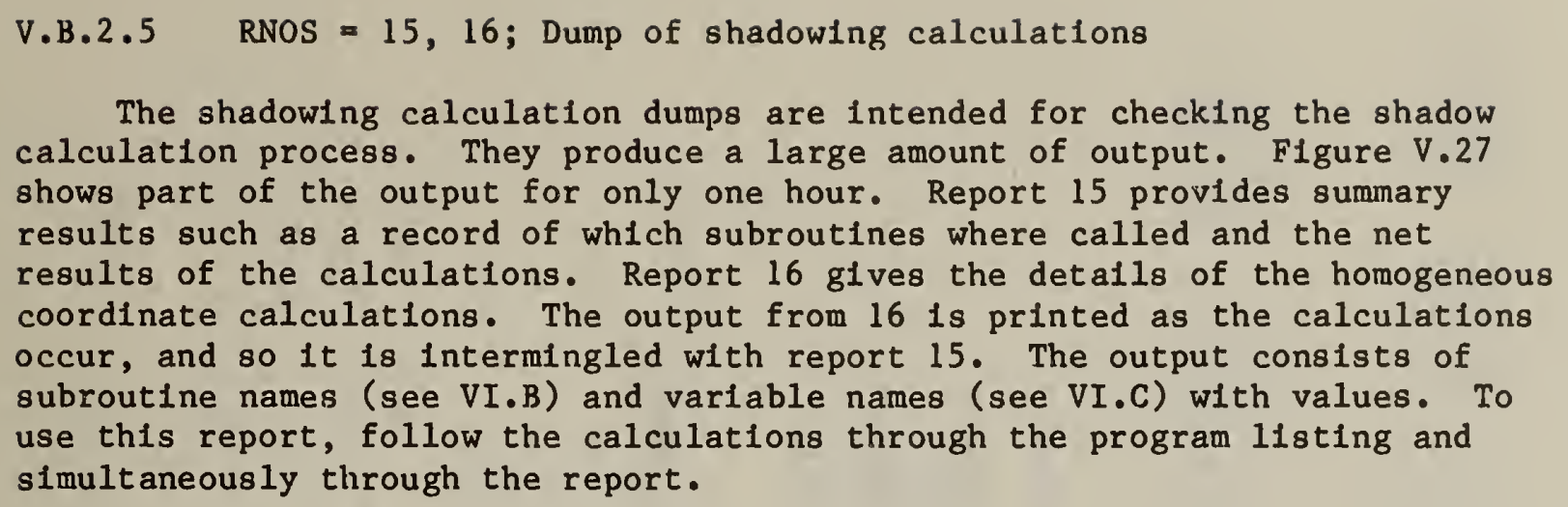

The shadowing calculation dumps are intended for checking the shadow calculation process. They produce a large amount of output. Figure V.27 shows part of the output for only one hour. Report 15 provides summary results such as a record of which subroutines where called and the net results of the calculations. Report 16 gives the detalls of the homogeneous coordinate calculations. The output from 16 is printed as the calculations occur, and so it is intermingled with report 15. The output consists of subroutine names (see VI.B) and variable names (see VI.C) with values. To use this report, follow the calculations through the program 11 sting and simultaneously through the report. 


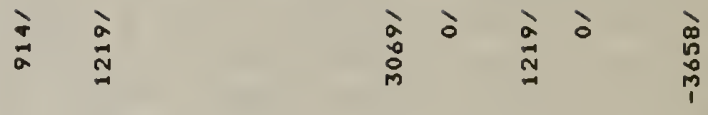

융 $1:$

के

$\stackrel{\infty}{\because} \div$

:ำㅇำ

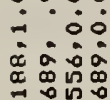

$\because \frac{1}{i} i$

以.

N.

:ํํㅇํำ

$\circ: \dot{0}$

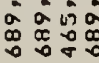

i.

N.

:ง:ㅇํำ

$\dot{0} \dot{0}$

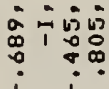

N.

::ㅇำ

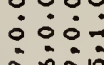

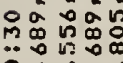

Oii

" \ソ

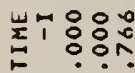

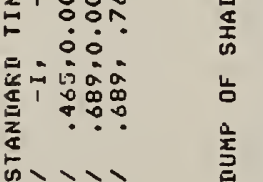

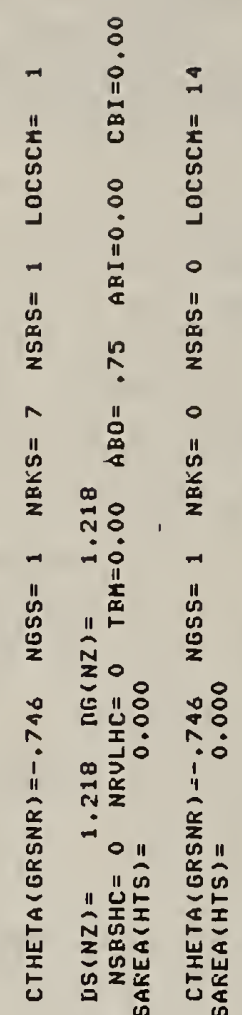

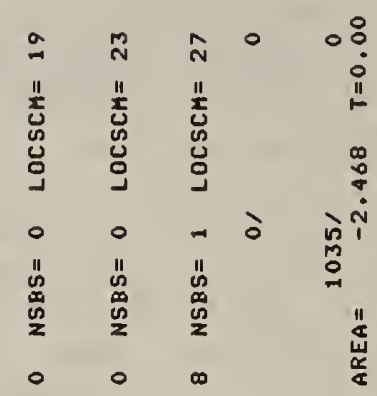

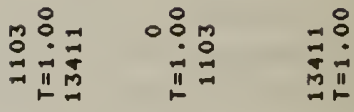

究

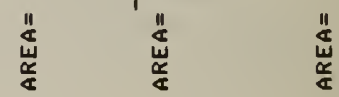

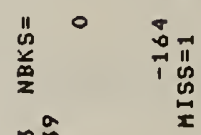

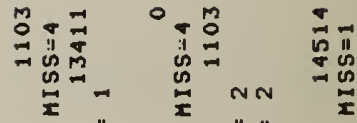

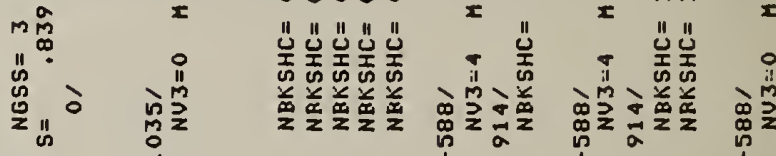

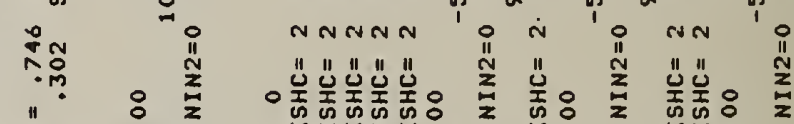

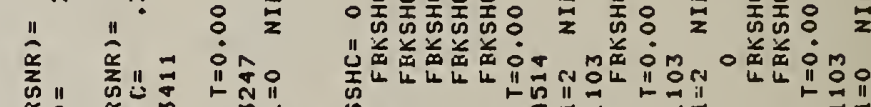

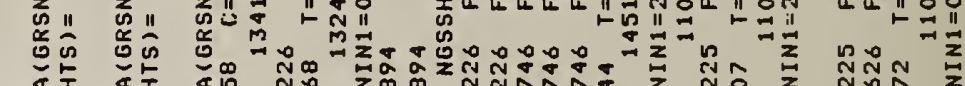

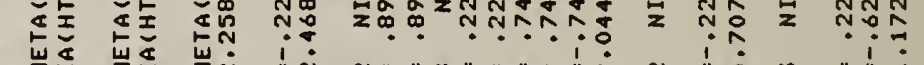

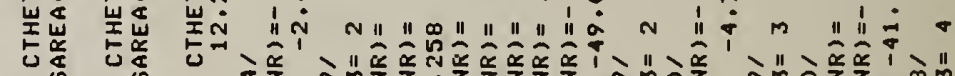
N 


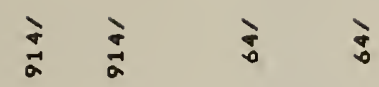

$$
\begin{aligned}
& \text { ำ }
\end{aligned}
$$

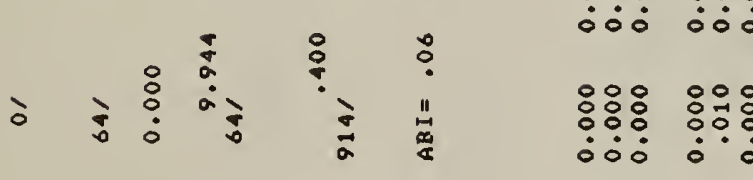

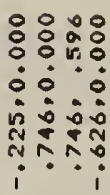

$$
\begin{aligned}
& >> \\
& \therefore: ํ \\
& \circ- \\
& \text { i.j. }
\end{aligned}
$$

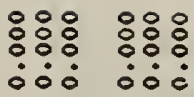

$$
\begin{aligned}
& \text { 以八 }
\end{aligned}
$$

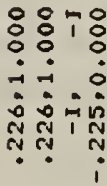

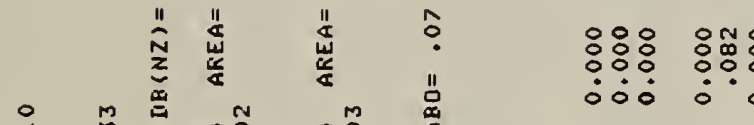

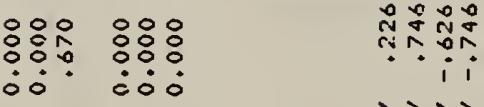

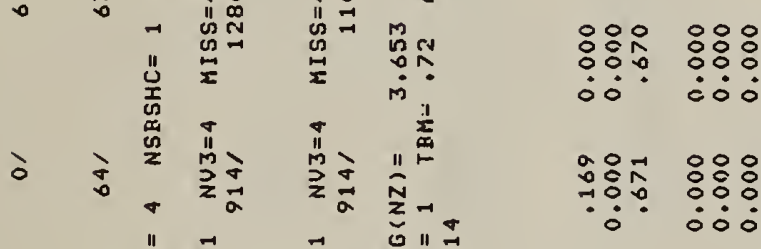

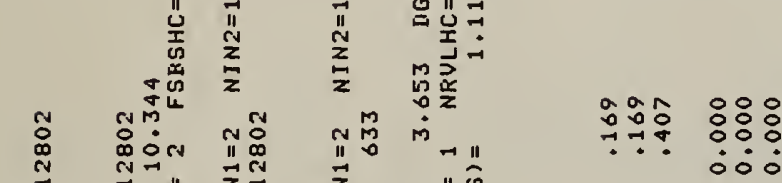

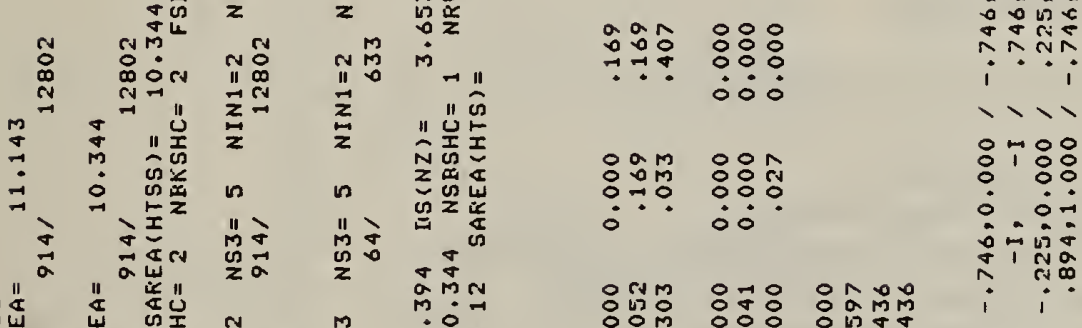

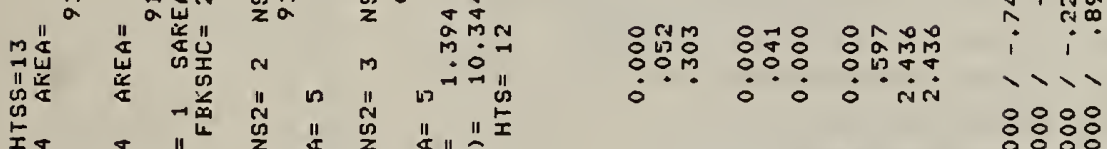

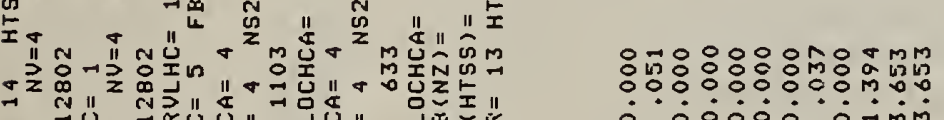

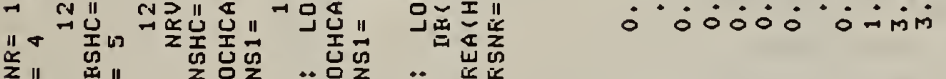

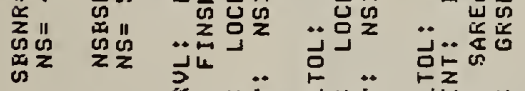

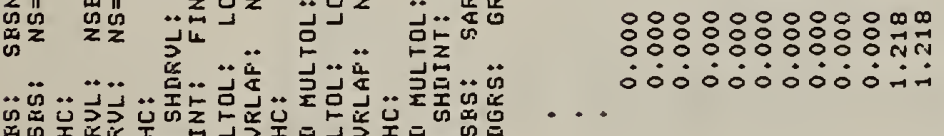

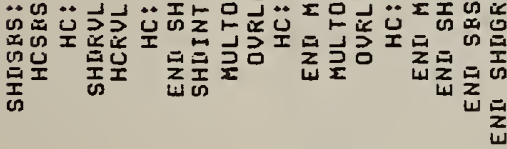

$$
\begin{aligned}
& \text { 䑰: }
\end{aligned}
$$

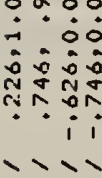

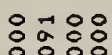

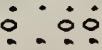

$$
\begin{aligned}
& \text { 융유유 } \\
& \text { mo: } \\
& \because \div \\
& \text { แ八 } \\
& \text { 岂 }
\end{aligned}
$$

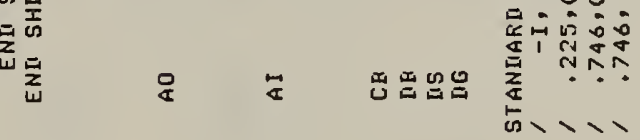

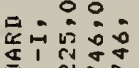

Figure V.27 (continued) 
V.B.2.6 RNOS $=21$; Hourly dump of primary zone loads data

This report provides hourly loads data. It consists of a line of time data, a line of weather data, and a line of loads data for each zone (see figure V.28). All data are in metric units. The time data consists of:

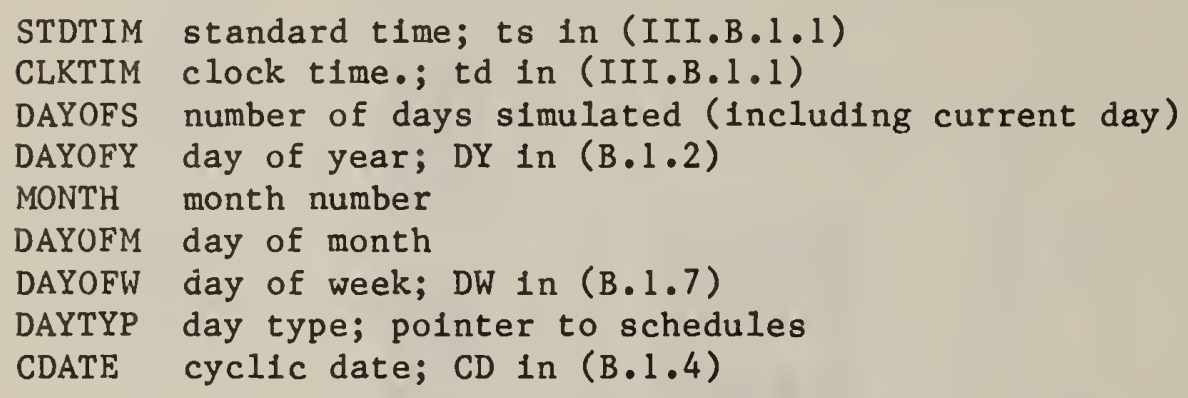

The weather data consists of:

$\begin{array}{ll}\text { DB } & \text { dry-bulb temperature } \\ \text { WB } & \text { wet-bulb temperature } \\ \text { BP } & \text { barometric pressure } \\ \text { SPD } & \text { wind speed } \\ \text { DIR } & \text { wind direction } \\ \text { TS } & \text { sky temperature } \\ \text { HB } & \text { direct normal solar flux } \\ \text { HD } & \text { sky brightness } \\ \text { HR } & \text { ground brightness } \\ \text { TG } & \text { ground temperature }\end{array}$

The zone loads data consists of:

$\begin{array}{ll}\text { TZ } & \text { zone air temperature } \\ \text { TR } & \text { zone radiant temperature } \\ \text { SN } & \text { sensible load } t=\text { heating, }-=\text { cooling } \\ \text { LA } & \text { latent gain from internal sources } \\ \text { EE } & \text { energy for lights and electric equipment } \\ \text { GE } & \text { energy for steam equipment } \\ \text { ST } & \text { energy for gas equipment } \\ \text { HW } & \text { energy for hot water equipment } \\ \text { OT } & \text { energy for other equipment } \\ \text { RA } & \text { energy direct to return air } \\ \text { BB } & \text { baseboard load } \\ \text { OAMFL } & \text { mass flow rate of outside air into zone }\end{array}$




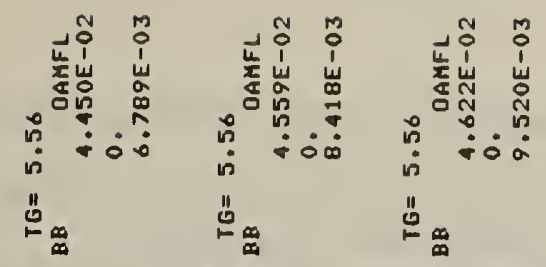

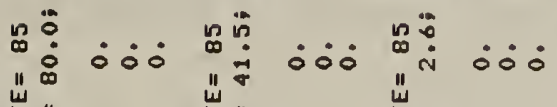

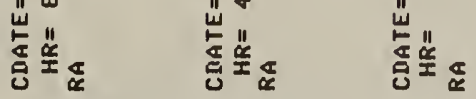

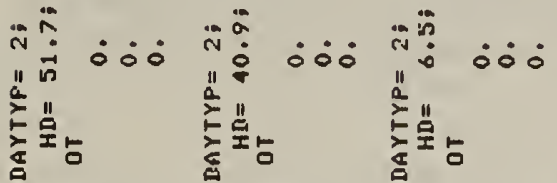

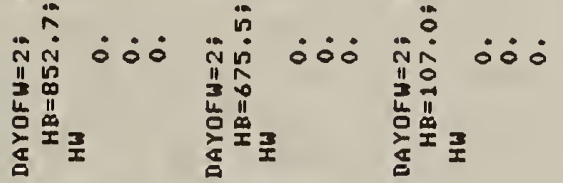

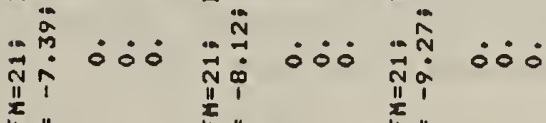

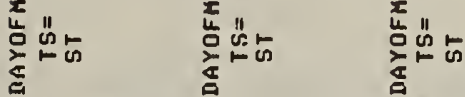

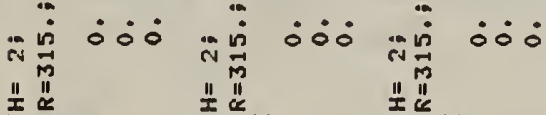

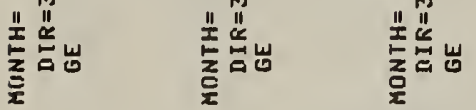

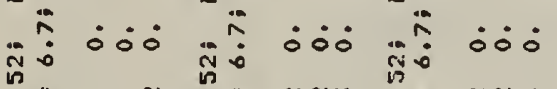

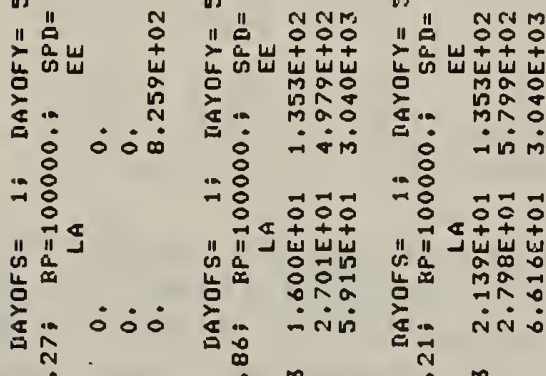

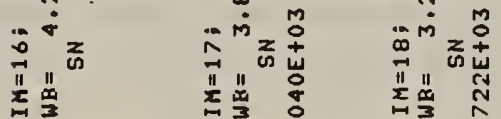

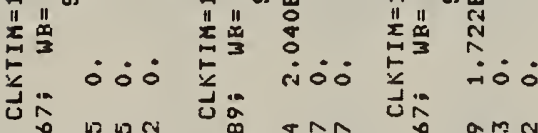

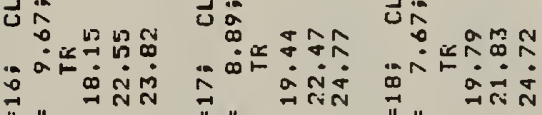

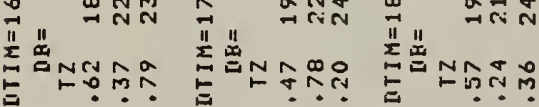

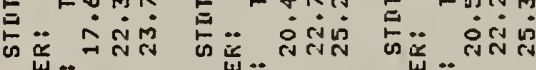

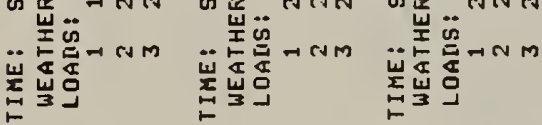

Figure V.28 Hourly dump of zone loads 
V.B.2.7 RNOS $=21,22,23,24 ;$ Dump of zone loads calculations

Reports 22, 23, and 24 give detalls of the loads calculation process. All are in metric units. These dumps can be quite lengthly. Figure 29 shows part of the output generated for one hour. Report 21 should be specifled to report times for the other reports.

Report 22 describes the control profiles and solar gains for the hour. The report of control values describes the control profile (IV.E) for each zone. It consists first of the zone number, the number of control temperature ranges (NRCTR), and the temperature range which will be used for the first air heat balance (EFSTR). The second line is a list of control point temperatures. It is followed by the QFSTDC and QFSTIF variables for the control ranges between the indicated temperatures. The solar gains data consists first of the total short wavelength (including from lights) flux (W/m ${ }^{2}$ ) absorbed by each heat transfer surface on the outside (QSO), the inside (QSI), and on any movable insulation (QSM). Then the radiant gains converted directly to convection (QC), the total diffuse solar gain (QD), the total diffuse shortwave radiant gain (QS), the total beam sunlight into the zone (QBV), and the total diffuse sunlight into the zone (QDV).

The following dumps (23) describe the heat balance calculations. They begin with the alrflow calculations. The following data is presented for each alrflow opening (I).

$\mathrm{N} \quad$ (inside) zone number

M (far side) zone number $(0=a m b i e n t)$

PS stack pressure (G.2.3)

PW wind pressure (G.1.3)

$\mathrm{PZ} \quad$ zone pressure

UP pressure difference across opening

FLOW mass flow rate through opening $(+=1 \mathrm{n},-=$ out $)$

Then the partial outside (KOP) and partial inside (KIP) conductive fluxes (C.1.7 and C.1.5) are presented for each heat transfer surface. These values are constant for the hour. The convection coefficients (HC) are also presented for each surface followed by the outside surface temperatures (TO) and then the inside surface temperatures (TI). The results of the zone air heat balances are summarized under $\mathrm{ZON}$ :

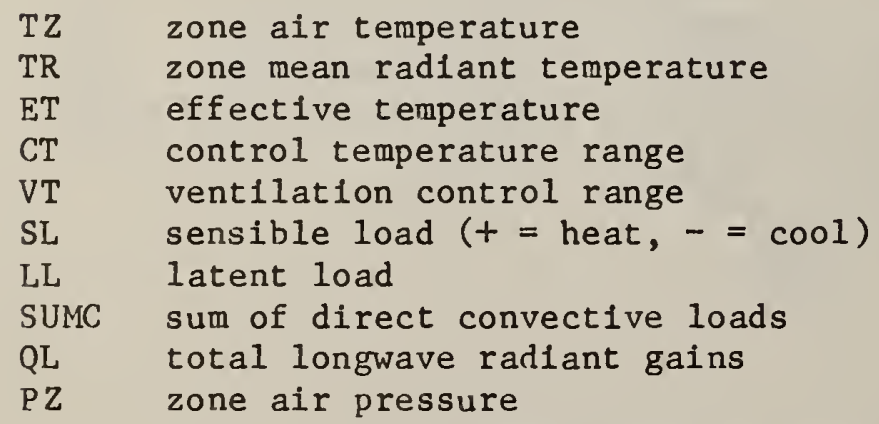


The FLOW, TI and ZON values are dumped for each heat balance iteration. HC and TO may also be dumped if new values are computed.

Report 24 is a dump of the contents of the temperature and flux historles array. It occurs after heat balances have converged. The hourly shift of the histories is accomplished by the TSHIFT variable until it equals zero and the histories are moved. NTFH is the number of temperature and flux histories. The histories are matched to their respective heat transfer surfaces by the TMPHPE, TMPHPI, FLXHPE, and FLXHPI pointers which can be obtalned by reports 6 or 8. Report 21 then summarizes the zone loads for the hour.

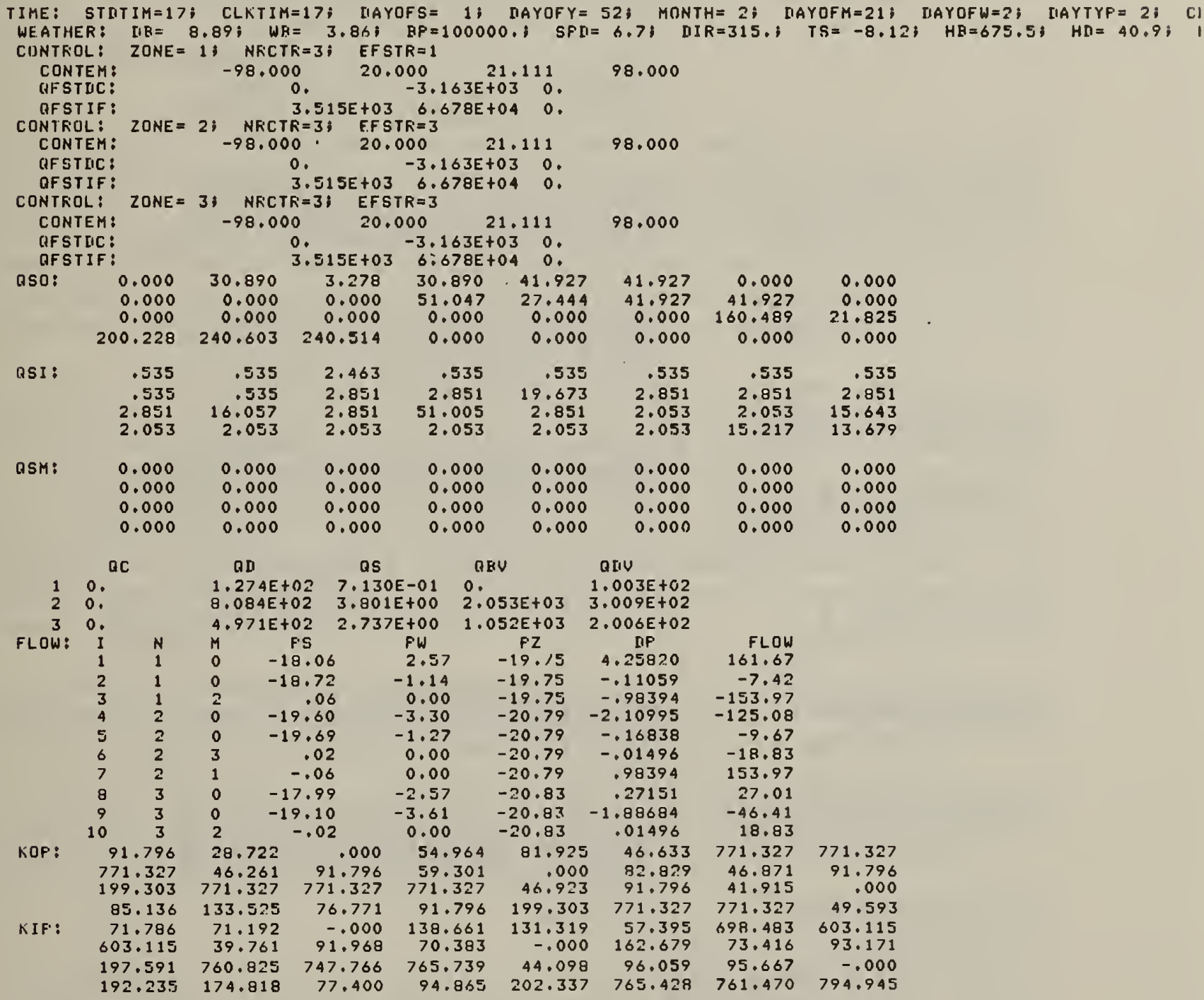




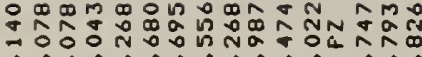

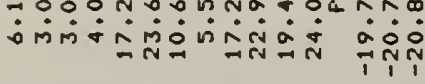

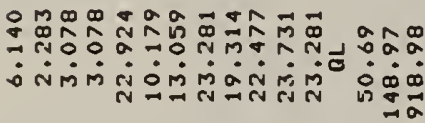

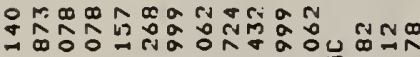

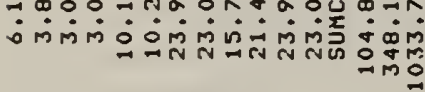

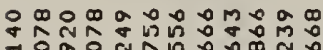

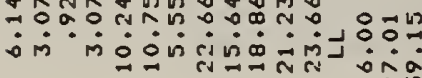

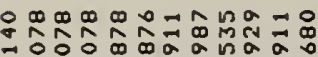

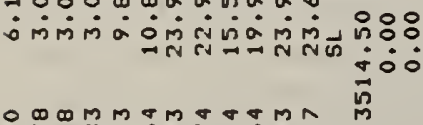

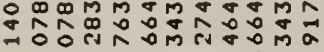

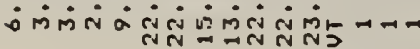

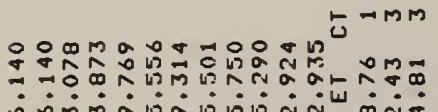

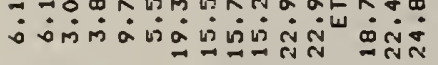

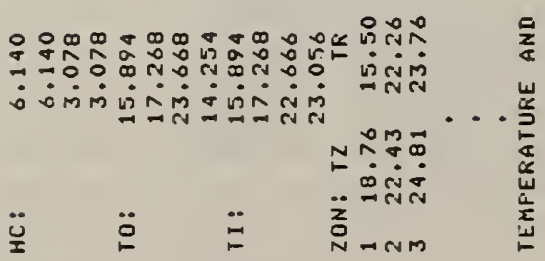

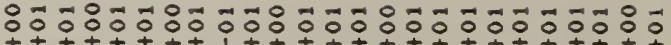

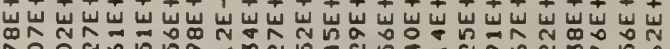

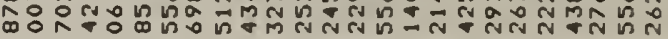

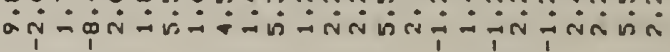

$\stackrel{\infty}{\infty}$

这 $\overrightarrow{0}$

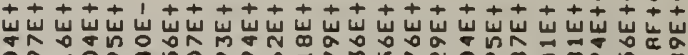

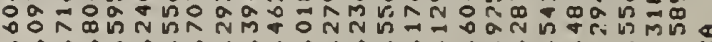

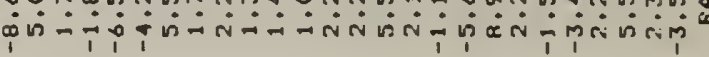

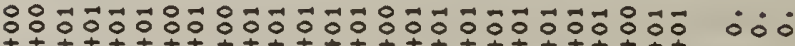

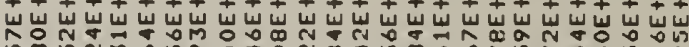

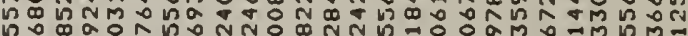
内人月-

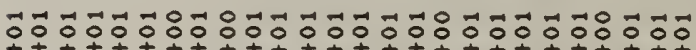

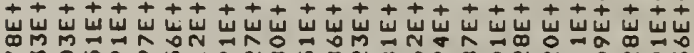

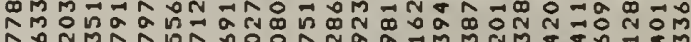

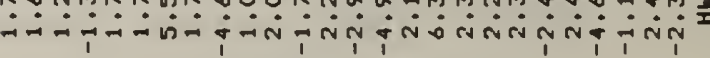

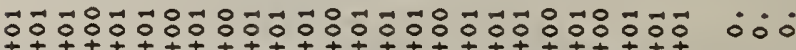

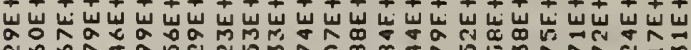

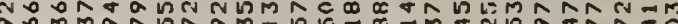

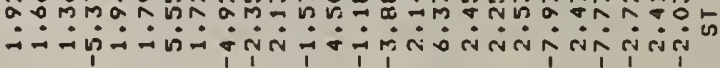

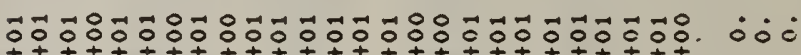

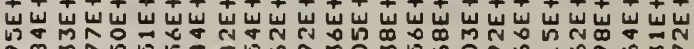

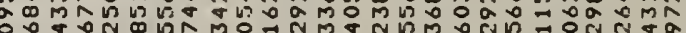

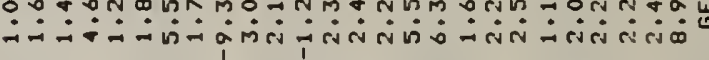

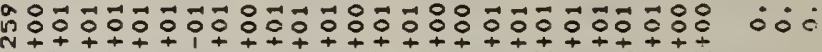

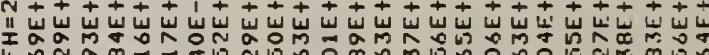

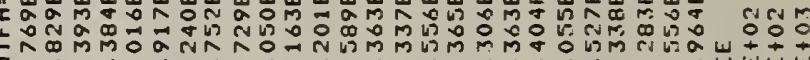

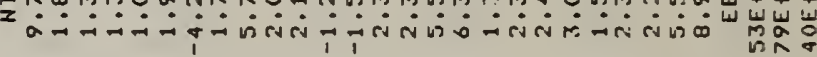

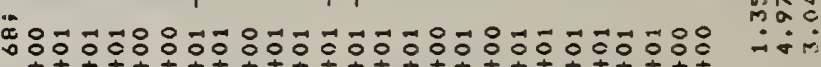

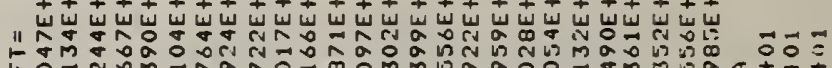

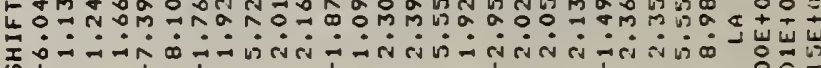

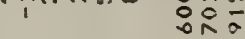

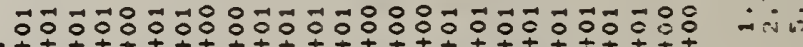

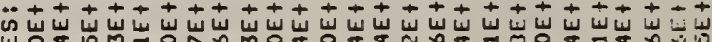

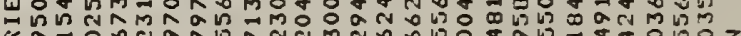

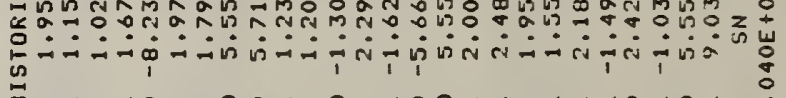

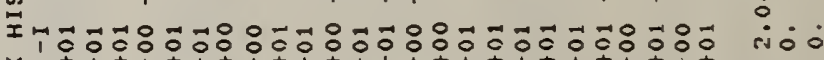

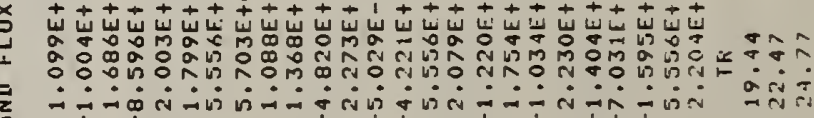
Figure V.29 (continued) 
The general structure of the Thermal Analysis Research Program was described in chapter II.B and figure II.1. This chapter expands upon that introduction by describing the program subroutines, variables, and files.

VI.A INPUT PROCESSOR

The input processor (IP) is the first of the two TARP subprograms. It checks and interprets the user input, creates the input files for the loads calculator (LC), and writes various reports. This processing involves all of chapter IV and primarily sections B, C, and D of chapter III. Data about the location and weather goes to the LC in the ENVTFL (environment file). The description of the building, including library data, goes in the SINPFL (simulation input file).

The IP is divided into four major sections corresponding to the input language sections. These sections may be used to reduce core requirements by overlay (or segmentation). A small input processor will help to give fast job turn-around necessary to quickly debug the user input deck. Each section is headed by a subroutine that is called when a section name and "[" is encountered in the input. The name of that routine is similar to the section name. The section processor subroutines all have similar structures, especially for how they handle incorrect input.

Each section contains several subroutines which process the input language keys. The names of these routines are the same as the key names. Most of the key processing routines also have similar structures consisting of: initialization, decoding the subkeys, error checking, calculation of derived data, output to SINPFL, reports and dumps. The output to SINPFL consists of an identifier record containing two integers and one or (sometimes) more data records. The data records usually have values for a single surface, schedule, etc., which is read by the LC into arrays for all surfaces, schedules, etc.

Some key processing subroutines call other groups of subroutines for complex calculations. The largest of these groups are those that compute the conduction transfer functions and the window optical coefficients.

A short description of each of the 130 input processor subroutines is given below. After the descriptions is a diagram (figure VI.A.1) showing the general relationship of the IP routines and the segment structure.

Evaluate the subkeys of AFS (4.14). The AFSDAT common block contains data to match interzone openings. Data is output in the AFSIL common block. 
Evaluate the subkeys of BBH (4.11). Data is output in the SSCISL common block.

BDLIB

block data

Set initial values for library processing.

BDPROJ

block data

Set initial values for project processing.

BDSLR

block data

Set initial values for processing user input.

BEAM

subroutine

Evaluate window optical properties for beam sunlight at 16 angles of incidence.

BLANK (ARRAY, LEN) subroutine

Blank (set to ' ') an ARRAY of character strings of length LEN. BUILDG subroutine

Evaluate the keys of BUILDING (section 3 ). This is the root subroutine of the building segment.

CDS

subroutine

Evaluate the subkeys of CDS (2.7). Convert control profile names to pointers.

CHKCP

subroutine

Check description of control profile: number, range, and order of temperatures and normalized capacities.

subroutine

Compute the optical properties for the pane-shade system for both polarizations of light incident from the outside. Compute overall transmittance and reflectance and individual absorptances. 
Evaluate the subkeys of CONS (2.5). Evaluate the thickness of each layer, and convert its material name to a pointer to retrieve materail data from unit 4. Compute conduction transfer functions. Compute optical coefficients for constructs having no opaque layers. Data is written to the constucts file (unit 5) for reference by zone surfaces. Data is output to the SINPFL in common blocks CONDAT, GLAS, and GLASO.

CPFL subroutine

Evaluate the subkeys of CPFL (2.6). Call CHKCP to check the control profile. Data is output in the CNTPFL common block.
CREPT(SCRFL)
subroutine

Transfer constructs reports (2.1.3) from unit SCRFL to the output file.

CTRL subroutine

Evaluate the subkeys of CTRL (4.9). Data is output in the CGSIL common block.
$\operatorname{CTF}(I, \operatorname{CONVG})$
subroutine

Calculate the higher order conduction transfer functions from the response factors (order $0 \mathrm{CTF}$ ) and the RATIO's. Check convergence by $(\mathrm{C} .2 .1)$.

CWS

subroutine

Evaluate the subkeys of CWS (2.8). Convert control day-schedule names to pointers.

DCHXYZ

subroutine

Compute conduction transfer functions of a single layered slab using the algorithm of D. C. Hittle.

DDY

subroutine

Evaluate the subkeys of DDY (1.6). Data is output as a single day in the ENVTFL.

Calculate the total construct and total derivative matrices for a single value of the Laplace parameter. 
This subroutine operates in one of two modes. It may compute the optical properties of a combination of glass panes for both polarizations of diffuse light of a given wavelength incident from both sides (D.6.2). Or 1t may compute the optical properties af a pane-shade system for both polarizations of diffuse of a given wavelength incident from the outside only. A Simpson's rule integration is used.

DIFSHD

subroutine

Compute the reflectance of an interior shading device for both polarizations of diffuse light.

DLT

subroutine

Evaluate the subkeys of DLT $(4 \cdot 10)$. Data is output in the CGSIL common block.

DMPAFS

subroutine

Dump air flow opening data in the AFSIL common block. Dump initiated by RNOS $=6(1.2 \cdot 1)$.

DMPCGS

subroutine

Dump zone control and general schedule data in the CGSIL common block. Dump initiated by $\operatorname{RNOS}=6(1.2 .1)$.

DMPHTS

subroutine

Dump heat transfer surface data in the HTSIL, HTSIS, and HTSISL common blocks. Dump initiated by RNOS=6 (1.2.1).

DMPSRF

subroutine

Dump surface geometry data in the SRFIS common block. Dump inftiated by RNOS=6 $(1.2 \cdot 1)$.

DMPSSC

subroutine

Dump special surface data in the SSCISL common block. Dump initiated by RNOS $=6(1.2 \cdot 1)$.

DS

subroutine

Evaluate the subkeys of DS (2.2). Check number and range of profile values. 
Evaluate the subkeys of DSS (3.2). Coordinates are converted from the building to the global coordinate system by (E.1.1) and (E.1.4). Data is output in the SRFIS common block.
DUMPGL (MODE)
subroutine

Dump optical calculations according to MODE. $M O D E=1$ : describe optical layers.

$M O D E=2$ : report optical properties.

$M O D E=3$ : report optical values ( $T, R, A$ ) for each layer.

MODE $=4$ : print polynomial coefficients.

Initiated by RNOS=4 $(1.2 .1)$.

DUMPLB

subroutine

Dump library control data initiated by RNOS=1 (1.2.1).

DUMPNV

subroutine

Dump one day of weather data. Initiated by RNOS=2 (1.2.1).

DUMPPJ

subroutine

Dump project data: common blocks TITLES, RUNCTL, EFLHDR, and REPORT. Initiated by RNOS=1 $(1.2 .1)$.

DUMPRF (MODE)

subroutine

Dump conduction transfer calculations according to MODE.

$M O D E=1$ : describe conductive layers.

$M O D E=2$ : print roots and ratios.

MODE $=3$ : Print al1 orders of conduction transfer functions.

Initiated by $\mathrm{RNOS}=3(1.2 .1)$.

$\operatorname{DUPLIB}($ LO ,LEN)

subroutine

Check for duplicate name in library.

DYS (JFLAG , DY , MO , DM, LY) subroutine

If JFLAG $=1$, compute day-of-year (DY) from month number (MO), day-of-month (DM), and leap year indicator (LY) (B.1.1). Otherwise, compute MO and DM from DY and LY.

EMI

subroutine

Evaluate the subkeys of EMI (4.17). Data is output in the SSCISL common block. 
Evaluate the subkeys of EQP (4.4). Data is output in the CGSIL common block.

ERROR(MSG ,ETYPE)

subroutine

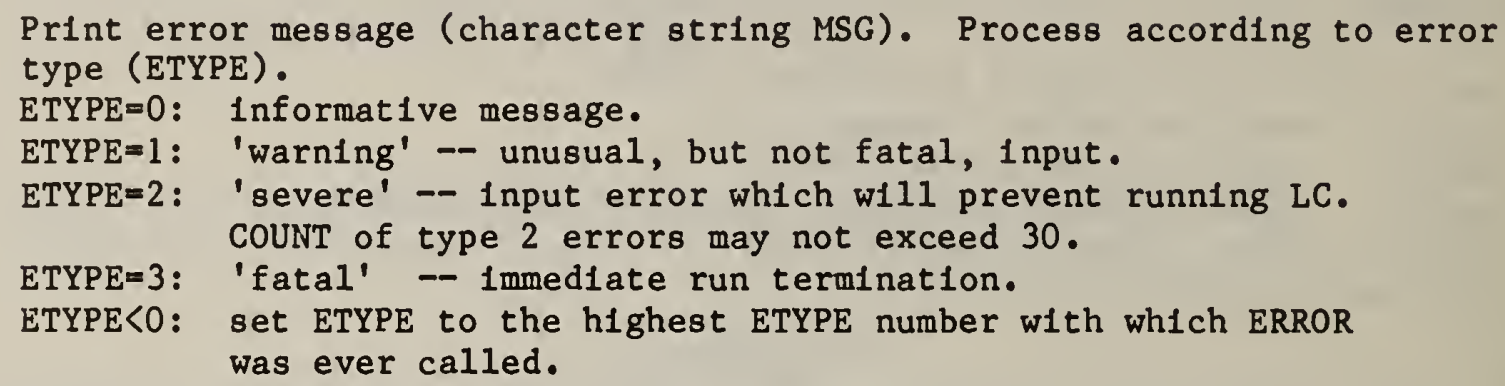

Compute $k^{*} \mathrm{~L}$ (extinction coefficient times thickness) of glass pane $\mathrm{N}$ with normal incidence transmittance TO (D.3.11).

FAN

$$
\text { subroutine }
$$

Evaluate the subkeys of FAN (4.8). Data is output in the CGSIL common block.

FILM(J, N, LAMBDA, CTHETA, STHETA, CPHI) subroutIne

Compute the optical properties of a thin reflective film on side $\mathrm{J}$ ( 1 =outside, $2=1$ nside) of glass pane $N$.
FINDFD(N, TPLAIN , TFILM)
subroutine

Determine the thickness of a thin reflective film on pane $N$ by 1 ts normal transmittance with (TFILM) and without (TPLAIN) the film.

Finish input processing. Check for and report unmatched interzone surfaces and openings. Check for and report unused library names. Terminate run if there were any 'severe' errors. Report minimum LC array sizes (PARAMETERS). Write the last SINPFL record - common block RUNCTL.

Evaluate the subkeys of GEOM (4.1). Values are set for the subsequent geometric processing of zone surfaces. 
Skip NSKIP days of weather data from the BLAST 3.0 weather file (WTHRTP, unit 3). Transfer the following NDAYS of data to the ENVTFL.

GETLIN subroutine

Get the next line on user input from the INPUT file. Echo the line in the output file. Print error message if data is being skipped.

GLASSX

subroutine

Compute the total transmittance and reflectance of a system of up to four panes of glass and the absorptance of each pane for both polarizations of light and both directions of incidence (at a given wavelength and angle of incidence).

GRND subroutine

Evaluate the subkeys of GRND (1.4). Data goes into ENVTFL header record.

ICTF subroutine

Initialize arrays for conduction transfer function calculations. $\operatorname{IDSTF}(\mathrm{MO}, \mathrm{DM}, \mathrm{DW})$ integer function

IDSTF $=1$ when daylight savings time is in effect, and it equals 0 otherwise. IDSTF is based on the month number (MO), the day-of-month (DM), and the day-of-week (DW). Daylight savings time begins on the last Sunday in April, and it continues until standard time resumes on the last Sunday of October.

$\operatorname{ILLINI}(A, B, T O L, R T, R E P E A T) \quad$ subroutine

Use modified false position method to compute root (RT) in the interval bounded by $A$ and $B$. Convergent solution is found the upper bound lower bound < TOL. If solution is not found, set REPEAT to true.

IMI

subroutine

Evaluate the subkeys of IMI (4.18). Data is output in the SSCISL common block.

subroutine

Evaluate the subkeys of INF (4.5). Data is output in the CGSIL common block. 
Compute the units conversion factors. Most factors are derived from $\operatorname{CFL}(2)=.3048, \operatorname{CFM}(2)=.45359237$, and $\operatorname{CFC}(2)=4.184$ to give a consistant set of conversion factors.

INITGL

subroutine

Direct the calculation of window optical coefficients. Set up properties of optical layers (no alr layers). Set coefficients of shading coefficients window directly. Otherwise, evalaute optical properties (SPCTKM) and compute polynomial coefficients (WDWPOL). Print dumps and reports as required. This is the root subroutine of the optical calculations segment.

INITRF

subroutine

Direct calculation of conduction transfer functions. Compute properties of conductive layers (no interior shades). Evaluate CTF for multi-layer (RESPNS) or single layer (DCHXYZ) constructs and report results. This is the root subroutine of the conduction calculations segment.

$\operatorname{INTCON}(A N U M, E F L A G)$

integer function

Evaluate character string ANUM as an integer (syntax rule [IV.B.1] 8). If ANUM is a proper integer, return EFLAG set to 0 . Otherwise, set INTCON to 0 , set EFLAG to 1 , and print error message.

I SHADE

subroutine

Add the effect of an interior shade to optical properties of the glass panes in the window (D.7).

IZERO(ARRAY,LEN) Subroutine

Set ARRAY (length LEN) of integers to 0 .

JDS (JFLAG , JD, YR , MO ,DM) subroutine

If JFLAG $=1$, compute the Julian date (JD) from the year (YR), month (MO), and day-of-month (DM) (B.1.2). Otherwise, compute YR, MO, and DM from YR (B.1.3).

subroutine

Evaluate the subkeys of LIB (2.1). Data is used to control the processing of library input. Open the library report scratch files. 
Evaluate keys of LIBRARY (section 2.). Insure sequence of key input. This is the root subroutine of the library segment.

LIT

subroutine

Evaluate the subkeys of LIT (4.3). Data is output in the CGSIL common block.

LOC

subroutine

Evaluate the subkeys of LOC (1.3). Data is stored in the weather file header (common block EFLHDR).

LOCLIB (ITEM, LO, LEN, LOC) subroutIne

Determine location (LOC) of ITEM in the library relative to LO. The library consists of seven groups of named elements. All names in the seven groups are stored in the LNAMES array beginning at various locations. LO is the array location before the first entry in the group of interest. LEN is the number of elements of that group. LOC records the sequence in which the 11 brary entries were defined and in which they exist on scratch files or will exist in the loads calculator arrays. If ITEM is not found, set LOC to zero.

LOCORD (LIST, LEN, ITEM) Integer function

Determine the location of ITEM in a LEN long array (LIST) of alphabetically ordered words. If ITEM is not found, return the value zero. A bisection search is used.

LOCRAN (LIST , LEN, ITEM) integer function

Determine the location of ITEM in a LEN long array (LIST) or unordered words. If ITEM is not found, return the value zero. A linear search is used.

LREPT ( SCRFL, NLINES, TI'TLE) Subroutine

Transfer 11 brary reports (2.1.3) from unit SCRFL to the output file. Each report element is NLINES long and is given a TITLE. Close the SCRFL when finished.

LSQFIT (ITYPE, N,N1,N2) subroutine

Compute the polynomial coefficients of the optical properties equations (D.1.7a and b). A standard least squares fit is used. ITYPE $=1$ does the polynomial which is evaluated by POLYlF. ITYPE $=2$ does the polynomial which is evaluated by POLY2F. $\mathrm{N}$ is the order of the polynomial.

$\mathrm{N} 1$ is the location in $X$ and $Q$ of the first data value.

$\mathrm{N} 2$ is the location in $X$ and $Q$ of the last data value. 
Compute the leap year indicator from the four digft year number (YR). If YR is a leap year, set LYF to 1 . Otherwise set LYF to 0 .

MASS

subroutine

Evaluate the subkeys of MASS (4.12). Thermal properties are read from UNIT 5. Data are output in common blocks HTSIL and HTSISL.

MATL

subroutine

Evaluate the subkeys of MATL (2.4). The input data are checked against approprlate ranges. The materlal properties are written to UNIT 4 for reference by the CONS subroutine. The materlals report (MATL - 2.1.3) is written to UNIT 23.

$\operatorname{MATRIX}(W)$

subroutine

Evaluate the conduction matrix for a multi-layered slab.

MIX

subroutine

Evaluate the subkeys of MIX (4.7). Data is output in the CGSIL common block.

MODY(DATE , EFLAG)

integer function

Evaluate character string DATE as a date (syntax rule [IV.b.1] 10). Compute MODY in the cyclic date form (B.1.4). If DATE is a valld date, return EFLAG set to 0 . Otherwise, set MODY to 0 , set EFLAG to 1 , and print error message. Note that day-of-month numbers from 1 through 31 are considered valld for all months.

\section{subroutine}

Evaluate the subkeys of OSC (4.16). Data is output in the SSCISL common block. Error checking includes (1) OSC not permitted with interior surface, (2) OSC not permitted with EMI on same surface, and (3) multiple definitions of OSC for the same surface not permitted. 
Write output report page headings. This routine can be used to count the number of lines being printed on issue page eject commands at appropriate intervals according to the use of IACT and NEED. IACT $=0$ : Inftialize page routine. Set page length to NEED. IACT $=1$ : NEED lines are to be printed. If there is insufficient space remalning on the page, eject page and print heading.

"IACT=2: Return page number in NEED.

IACT=3: Return number of lines left on page in NEED.

IACT $=4$ : Eject page and print heading if NEED lines not left on page. Do not increment line count.

The page heading includes a report of cumulative program execution time determined froin the non-ANSI function SECOND. This function can be removed without otherwise affecting the program.

subroutine

Compute the transmittance, reflectance and absorptance of pane number $\mathrm{N}$ (counted from the outside). This routine uses the optical algorithms of III.D.3.

PEO

subroutine

Evaluate the subkeys of PEO (4.2). Data is output in the CGSIL common block.

$\operatorname{POLY} 1 \mathrm{~F}(\mathrm{X}, \mathrm{A}, \mathrm{N})$ real function

Evaluate simple polynomial expression (D.1.7a):

$P=A(1)+A(2) * X+A(3) * X^{2}+\ldots+A(N) * X^{N-1}$

$\operatorname{POLY2F}(X, A, N)$

real function

Evaluate simple polynomial expression (D.1.7b):

$P=A(1) * X+A(2) * X^{2}+\ldots+A(N) * X^{N}$

PROJCT

subroutine

Open the simulation input (SINPFL) and environment (ENVTFL) files. Evaluate the keys of PROJECT (section 1.). Write the weather file header record and close the weather file. Write the first records on the simulation input file. Initiate dump of "project" data (RNOS=1 1.2.1). This is the root subroutine of the project segment.

PSYCH

subroutine

This routine may be used to test the psychrometric package. It is not called by TARP. 
Compute the dew point temperature (TD) from the humidity ratio (W) and the barometric pressure (PB) (B.2.6).

$\operatorname{PSYHTW}(\mathrm{TA}, W) \quad$ real function

Compute the enthalpy (H) from the dry bulb temperature (TA) and humidity ratio (W) (B.2.9).

PSYRHT(TA,TD)

real function

Compute the relative humidity (RH) from the dry bulb (TA) and dew point (TD) temperatures (B.2.7). Check for $0<\mathrm{RH}<1$.

$\operatorname{PSYTWD}(\mathrm{TA}, \mathrm{W}, \mathrm{PB})$

real function

Compute the wet bulb temperature (TW) from the dry bulb temperature (TA), humidity ratio (W), and the barometric pressure (PB). TW is computed by iteration of function PSYWTP to a convergent solution. The first set is to check for saturated alr which means TW $=$ TA. Falling that, an initial guess for TW $1 \mathrm{~s}$ made at TA-1. Th1s inftial guess is increased if it produces an impossibly low humidity ratio. The initial guess is used in a secant 1teration. If the secant 1teration should fall, a slower but more rellable bisection iteration is avallable.

$\operatorname{PSYVTW}(T A, W, P B)$

real function

Compute the specific volume $(V)$ of molst alr from the dry bulb temperature (TA), humldity ratio $(W)$, and barometric pressure (PB) (B.2.8). Check for reasonable range: $0.58<\mathrm{V}<3$.

PSYWDP (TD, PB)

real function

Compute humldity ratio (W) from dew point temperature (TD) and barometric pressure (PB) (B.2.2). Check for $W>1.61 \mathrm{E}-6$ ( $W$ for $T D=$ $-70 \mathrm{C})$.

$\operatorname{PSYWTH}(\mathrm{TA}, \mathrm{H})$

real function

Compute humidity ratio (W) from dry bulb temperature (TA) and enthalpy (H) (B.2.5). Check for $W>1.61 E-6$ ( $W$ for $T D=-70 C$ ).

PSYWTP(TA,TW,PB)

real function

Compute humidity rat1o (W) from dry bulb (TA) and wet bulb (TW) temperatures and barometric pressure (PB) (B.2.3). Check for $W>$ $1.61 \mathrm{E}-6$ ( $W$ for $\mathrm{TD}=-70 \mathrm{C})$. 
$\operatorname{PSYWIR}(T A, R H, P B) \quad$ real function

Compute humidity ratio (W) from dry bulb temperature (TA), relative humidity (RH), and barometric pressure (PB) (B.2.4). Check for $W>$ $1.61 \mathrm{E}-6(\mathrm{~W}$ for $\mathrm{TD}=-70 \mathrm{C})$.

QTF

subroutine

Compute flux conduction transfer coefficients from RATIO values.

RC

subroutine

Evaluate the subkeys of RC (1.1). Data are stored in the RUNCTL common

block and used in subsequent processing of user input.

READER

subroutine

Decode the user input (in UINREC) according to input syntax rules

(IV.B.1). Output is current status (UISTAT) and individual words in

the AWORD array. The longest element of input processed in one call to

this routine is a subkey with data.

RELCON(ANUM,EFLAG)

real function

Evaluate character string ANUM as a real number (syntax rule [IV.B.1] 9). If ANUM is a valid number, return EFLAG set to 0 . Otherwise, set RELCON to 0.0 , set EFLAG to 1 , and print error message.

REP'TGL (LSC)

subroutine

Report on the calculation of window optical coefficients. This report is initiated by CONS $(2.1 .3)$. The report is in two formats: one for detailed optical calculations and the other if a shading coefficient was used (LSC true).

REPTRF

subroutine

Report on the calculation of conduction transfer functions. This

report is initiated by CONS (2.1.3). Also report surface properties.

RESPNS

subroutine

Direct the calculation of conduction transfer functions for multi-layered slabs.

RFCOMP

subroutine

Compute conduction transfer functions for multi-layered slab from the roots and residues. 
Evaluate the subkeys of RPT (1.2). Data is stored in the RFLAGS array. $\operatorname{RSBF}(I, \operatorname{COSINC}, \mathrm{WL})$ real function

Compute reflectance of an interior shading device. This returns the value of RSO whlch was computed from user 1nput REF (2.4.12). Th1s routine is a program stub to allow computation of reflectance from polarization (I), angle (COSINC), and wavelength (WL) when data for such a calculation exists.

Compute the saturation pressure of water at temperature ( $T$ ) by the detalled ASHRAE correlation (B.2). This subroutine is not called by TARP. It is used with PSYCH to test the psychrometric package.

$\operatorname{SATUPT}(\mathrm{T})$

real function

Compute the saturation pressure of water at temperature (T) (B.2.1). Check for $-70<T<100$.

$\operatorname{SATUTP}(\mathrm{P})$

real function

Compute the saturation temperature of water at pressure (P) (B.2.1). Check for $\mathrm{P}$ in the range corresponding to $-70<\mathrm{T}<100$.

SEARCH

subroutine

Determine upper and lower bounds within which a root must exist. Call ILLINI to converge to root. Trigonometric identities are used (with APPROX) to evaluate AS and BS as PT is incremented. The search for roots of $B S$ is helped by the fact that roots of BS must lie between roots of AS.

SETUPV

subroutine

Compute vertices of polygon. Vertices of rectangular and non-rectangular base surfaces are evaluated in the global coordinate system by equations (E.1.4). Rectangular subsurfaces have vertices computed in the base surface coordinate system. Subsurface azimuth and t1lt angles are computed from the base surface angles.

subroutine

Evaluate the subkeys of SHD (4.15). Data is output in the SRFIS common block. 
Evaluate the subkeys of $\operatorname{SIM}(3.1)$. Data is stored in the RUNCTL common block and output as one of the last steps of input processor operation.

SLR

program

SLR stands for "simplified language reader". This is the root program of the input processor. It inftiallzes program variables and opens files, directs the processing of input sections, prints final reports and closes files. The variable SEQ is used to insure that sections are not used out of sequence.

$\operatorname{SKYTF}(T A, T D, N)$

real function

Compute sky temperature from dry bulb (TA) and dew point (TD) temperatures and tenths cloud cover ( $N$ - integer) (B.3.1 through B.3.4)

SPCTRM

subroutine

Use the detalled optical algorithms to compute the window optical properties. This routine includes a loop to integrate the optical properties over wavelength. The loop is executed for only one average wavelength. This was found to give sitisfactory results for typical window materials.

subroutine

Evaluate the subkeys of SRF (4.13). Data is output in the SRFIS, HTSIL, and HTSISL common blocks. The subkey names (In KEYS) are sequenced according to frequency of occurrance to speed the INDEX operation in SUBKEY. The large number of options in the SRF description make this the most complex input subroutine. There are several error messages relating to syntax requirements. Then the sky and ground view factors are computed by (E.5.2a) and (E.5.2b), unless the user chose to provide his own values by $(4.13 .7)$ and $(4.13 .8)$. The surface area (gross area for base surfaces) is computed from (E.4.1). The conductive and radiative properties of the surfaces are read from unit 5. If the surface is an interzone partition (IZP), and attempt is made to match it to previously defined IZP's. An IZP must be described in two zones. RNOS=7 (1.2.1) reports on this matching process. The surface geometric data (primarily coordinates of vertices) is computed. Values are stored in the BASES common block for the geometric description of subsurfaces. 
This subroutine evaluates the subkey name (syntax element [IV>B>1] 4). The subkey name is always the first word in ALIST. KEYS is a single string of all subkey names, each no more than LKEYS characters long. The number of names in KEYS is NKEYS. LOC is the word number location of the subkey name in KEYS. The INDEX function is used in determining LOC. If the name is not found, an error message is printed. All valid subkey names are optionally (DEM - 1.1.3) printed.

This routine fills a single day of weather data in common block ENVDAT from the user's dedign day description (DDY - 1.6). Calendar values are computed. A dew point temperature (TD) for the day is computed. It is used in computing the hourly wet bulb temperatures, humidity ratios, and sky temperatures. Solar intensities are computed.

SUN2 (DAYYR, A , B , C , AVSC)

subroutine

Compute the ASHRAE A, B, and C values from the day-of-year (DAYYR). These are computed from truncated Fourler serles computed from data in ASHRAE 1981 Fundamentals, page 27.2.

SUN5 (HOUR)

subroutine

Compute the solar direction cosines at standard time HOUR.
SURFIN( ZAVG, ZTOP)
subroutine

Compute coordinates of surface vertices. Determine avarage and maximum height of surface from ground.

$\operatorname{TSBF}(I, \operatorname{CosINC}, \mathrm{WL})$

real function

Compute transmittance of an interior shading device. This returns the value of TSO which was computed from user input TRNS (2.4.9) and REF $(2.4 .12)$. This routine is a program stub to allow computation of transmittance from polarization ( $I$ ), angle (COSINC), and wavelength (WL) when data for such a calculation exists.

VALID(KEYS, LKEYS, NKEYS, LEVEL) subroutine

List valid input names. LEVEL (equals 1, 2, or 3) determines whether section, key, or subkey names are being listed. The names are all in the single string KEYS. The number of names is NKEYS. Each is LKEYS characters long.

VENT

subroutine

Evaluate the subkeys of VENT (4.6). Data is output in the CGSIL common block. 
WDWPOL

subroutine

This routine directs the calculation of the polynomial coefficients

(D.1.7a and $b$ ) describing the optical properties of the window.

WS

subroutine

Evaluate the subkeys of WS (2.3). Data is output in the local array PTR and the optional report is on unit 22. The day schedule pointers can be filled from a single weekday pointer.

WTAP

subroutine

Evaluate the subkeys of WTAP (1.5). Get weather from the BLAST weather file unless SYNTAX $(1.1 .2)$ or OLDW $(1.1 .6)$ are in effect.

$\operatorname{WXREF}(\mathrm{A}, \mathrm{I}) \quad$ subroutine

Write cross reference data consisting of the array name (A) and the location ( $I$ ) in that array. WXREF is initiated by XREF (1.1.5). It relates the input keys to the arrays reported by DUMPIN in the loads calculator. DUMPIN is caused by $\operatorname{RNOS}=8(1.2 .1)$.

ZERO (ARRAY,LEN) subroutine

Set ARRAY (length LEN) of real numbers to 0 .

ZERORE

subroutine

ZERORE calculates the residues related to the double pole at zero.

ZONE

subroutine

Evaluate keys of ZONE (section 4.). Insure sequence of KEY input. Data is output in the ZONISL common block. Key names (in KEYS) are approximately in the order of frequency of occurrence to speed execution of the INDEX function. This is the root subroutine of the zone segment. 
This diagram (continued over several pages) shows the general relationship of the input processor subroutines to each other. A subroutine calls other subroutines which are to the right and below it on the diagram. Multiple calls to the same subroutine are not shown, only the first. Circled letters are continuation points for of ten used groups of subroutines and for large groups of subroutines. Not all subroutines and functions are included. The intrinsic FORTRAN 77 routines have been left out. Several simple utility routines which are called from many places are not always shown. These include: ERROR, INTCON, I ZERO, LOCLIB, MODY, PAGE, RELCON, WXREF, and ZERO.

BDSLR

BDPROJ

BDLIB

SLR

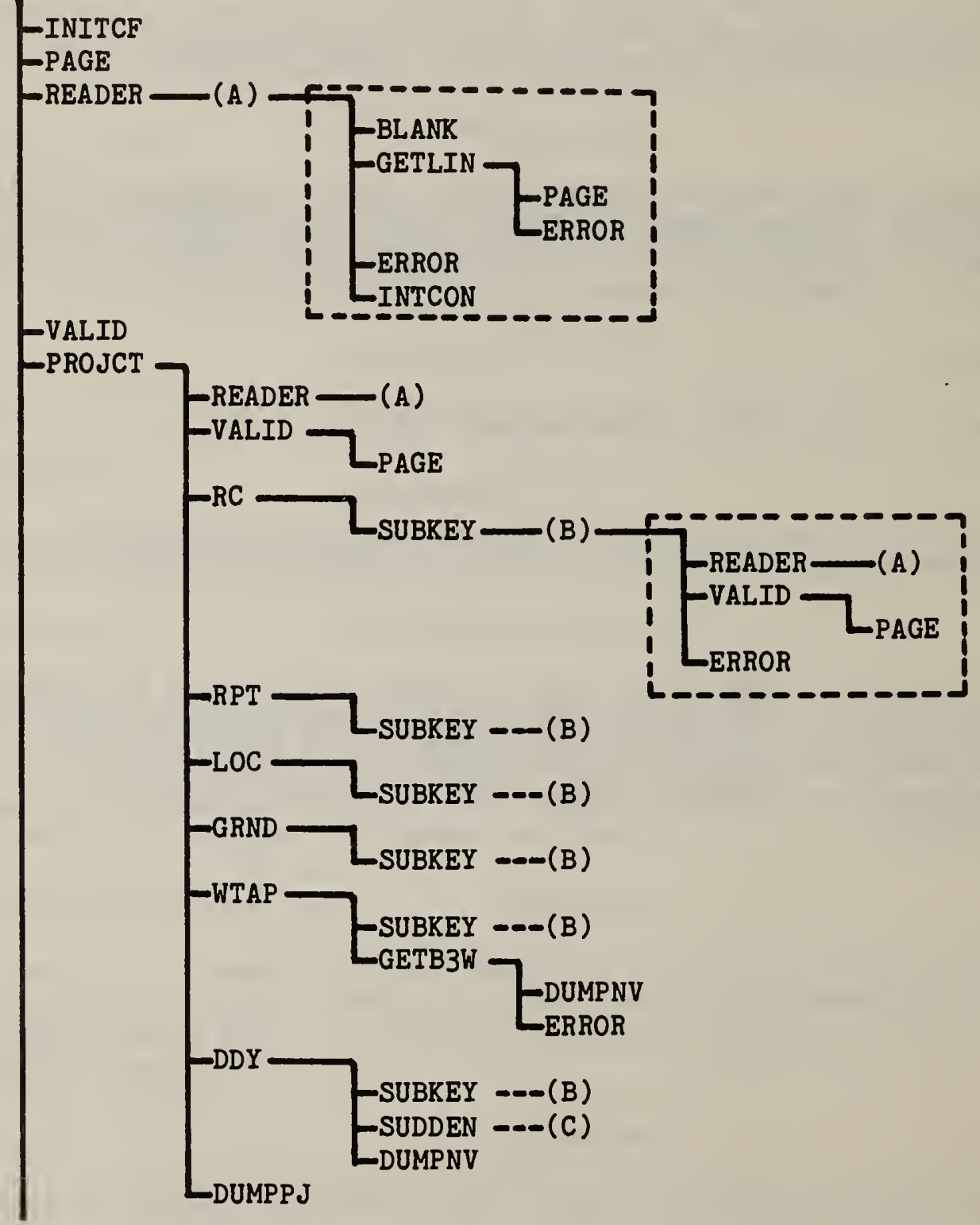

Figure VI.A.l Tree structure of input processor program 


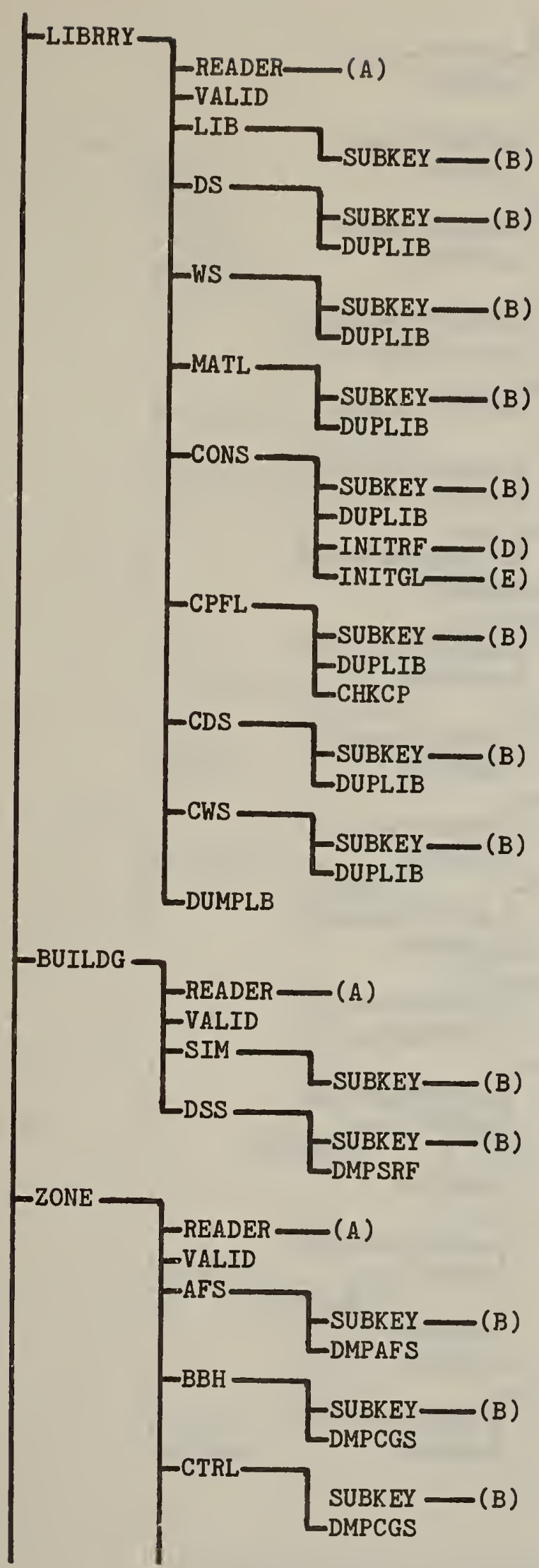

Figure VI.A.I (continued) 


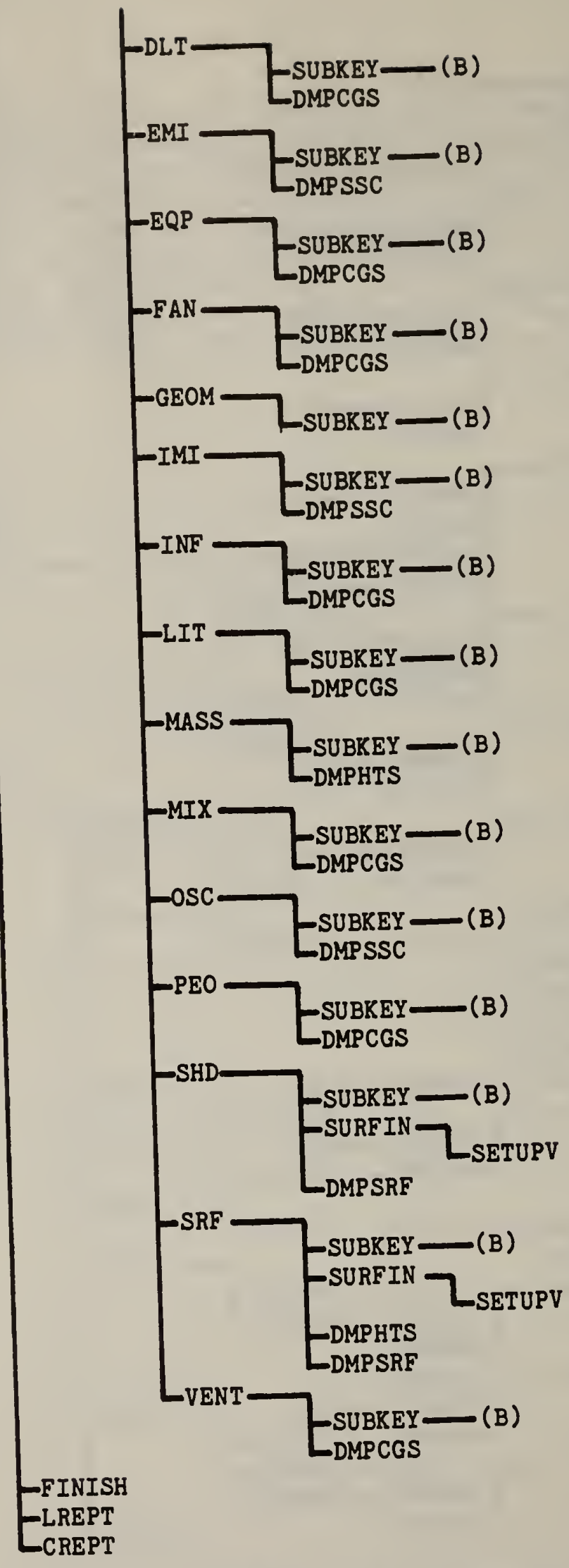

Figure VI.A.1 (continued) 


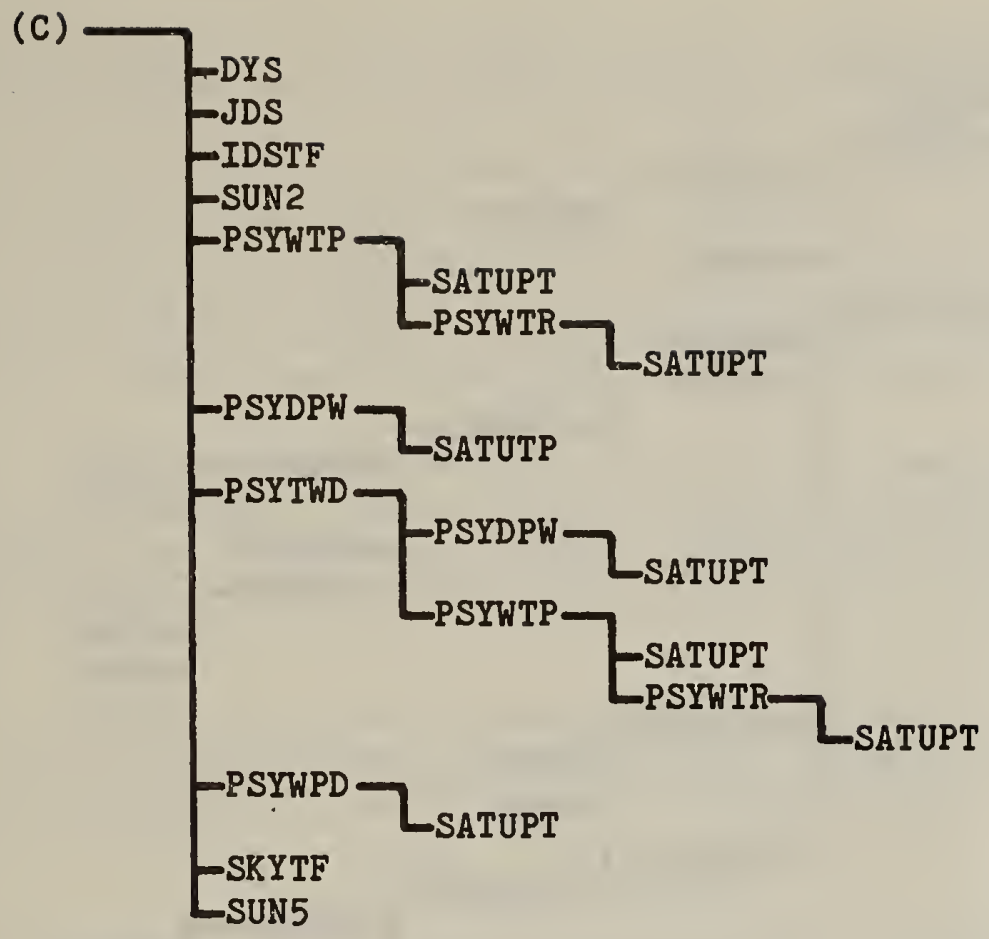

(D)

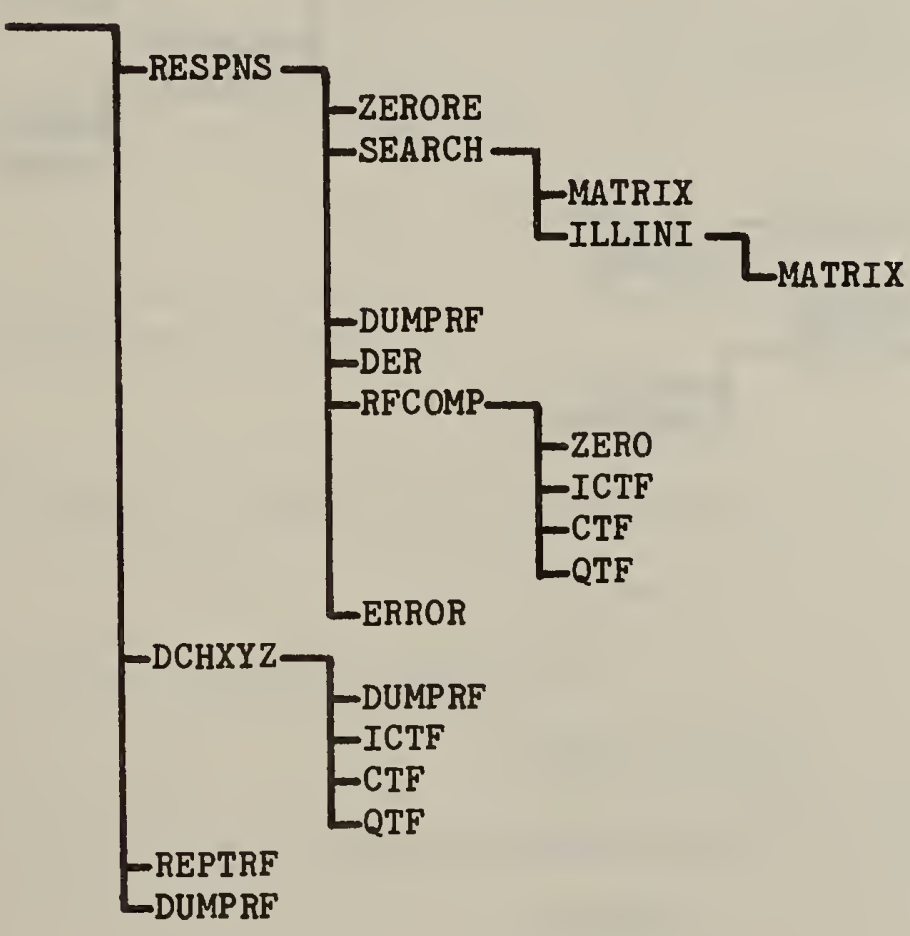

Figure VI.A.1 (continued) 


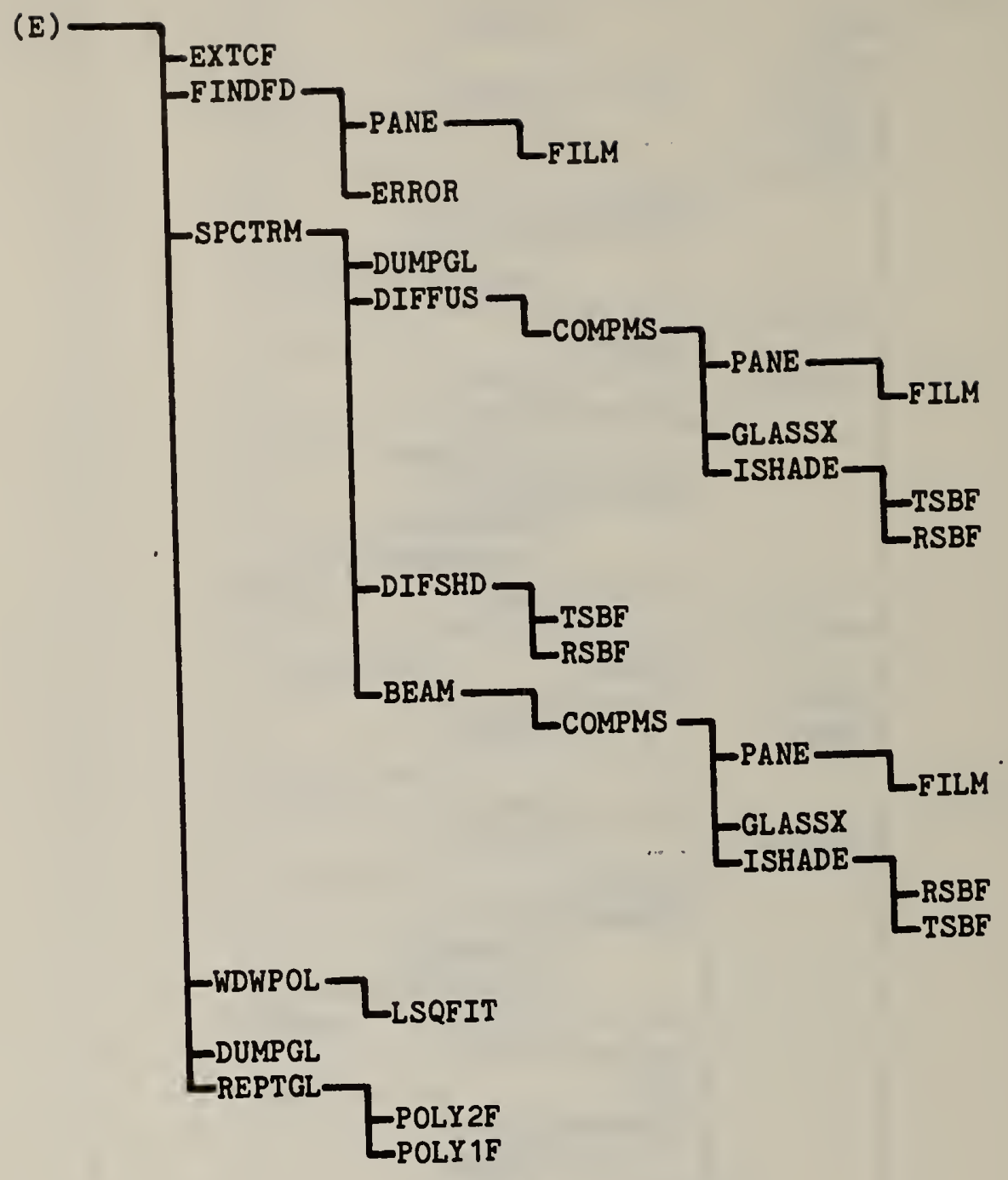

Figure VI.A.1 (concluded) 
The loads calculator (LC) subprogram of TARP computes the zone loads based on the algorithms in chapter III, primarily sections $\mathrm{E}$ through $\mathrm{L}$. It is divided into three sections. The first reads the SINPFL created by the IP and fills the LC arrays. It checks for sufficient array space and performs some checks and calculations which require that the entire building description be present in the arrays. The second section section uses the geometric and optical descriptions of the bullding surfaces to compute solar gain factors for various periods of the year. The third section computes the zone loads by simultaneous, hour-by-hour heat balances.

The three segment structure of the LC is used to name many of the common blocks. For example, common block HTSISL is composed of variables dimensfoned MAXHTS and is used in the Input, Shadowing, and Loads segments. Common block ZONL has variables dimensioned MAXZON and is used in only the Loads segment.

A short description of each of the 90 loads calculator subroutines is given below. After the descriptions is a diagram (figure VI.B.1) showing the general relationship of the LC routines and the segment structure.

AIRMVO

subroutine

Compute air movements for the simple algorithms: infiltration (INF $4.5-\mathrm{K} .2$ ), two zone mixing (MIX $-4.7-\mathrm{K} .3$ ), and whole house fan (FAN - 4.8 - K.4). The mixing and fan models may not be used when other ventilation (VENT - 4.6) is possible.

AIRHV 1

subroutine

Compute infiltration and interzone air flows using the detailed air movement algorithms in III.G.

BDMRL

block data

Set initial values for loads calculator program.

BDSIM

block data

Set initial values for loads simulation.

$\operatorname{BTWEEN}(\mathrm{N1}, \mathrm{NO}, \mathrm{N} 2)$

logical function

Determine if cyclic date N1 lies between dates NO and N2 (B.1.6).

CALOAD

subroutine

Calculate values for the bullding loads report including system status hours, zone loads, zone peaks, building loads, and building peak values. 
Set up the control points and coeficients of the system performance (K.1) and vent1lation models (K.3).

CHKBKS (NRS, NBS)

subroutine

Check that a convex zone has been defined. No vertex of surface number NBS may lie in front of surface number NRS.

CHKGSS(NRS, NSS, ZMIN, NOSHAD) subroutine

Determine if surface number NSS can possibly shade surface NRS. If it can, set NOSHAD false. NSS cannot shade NRS if any of the following conditions are true:

(1) No point of NSS is above the lowest point (helght ZMIN) of NRS.

(2) NSS is horizontal and faces up.

(3) NSS is entirely behind NRS.

(4) NRS is entirely behind NSS.

CHKSBS

subroutine

Check that a subsurface is completely enclosed by 1ts base surface. This routine uses the shadow overlap technique.

CISAF

subroutine

Compute the fraction absorbed by each surface of the total beam solar energy transmitted into the zone. This is for the simple solar distribution which assumes all beam solar galns are incident on the floors of the zone. The fraction absorbed 18 proportional to the solar absorptance of each floor.

CIVAF

subroutine

Compute the distribution of diffuse short wavelength radiation on all surfaces. Each surface absorbs a fraction of the total diffuse energy in the zone in proportion to its area and solar absorptance with an allowance for loss through transparent surfaces (F.2.1).

CLIP

subroutine

'Cl1p' the shadowing surface polygon so that none of 1 t lies below the plane of the shadow recelving surface (E.2). This prevents the casting of false shadows.

$\operatorname{CROSS}(A, B, C) \quad$ subroutine

Compute $\mathrm{C}$ as the cross product of $\mathrm{A}$ and $\mathrm{B}$. $\mathrm{All}$ are three element vectors. 
Transform the coordinates of the vertices of surface NS from the global coordinate system to the surface coordinate system relative to surface NR (E.1.5).

DAILY

subroutine

Perform all operations which can be done once per day. Read the weather data and set date values. Set the solar gains file group number. Check external movable insulation and set pointers if the date is in effect. Set the schedule and control pointers according to the date. Set the monthly report flags.

$\operatorname{DOT}(A, B)$

real function

Compute the dot product of $A$ and $B$ which are each vectors of 3 elements.

DUMPAF subroutine

Dump air flow values ( $\mathrm{RNOS}=23-1.2 .1$ ).

DUMPEH subroutine

Dump values in the environment file header (RNOS=8 - 1.2.1).

DUMPHW subroutine

Dump weather values for the hour (RNOS=21-1.2.1).

DUMPIN subroutine

Dump all values read from the simulation input file (RNOS=8 - 1.2.1). DUMPQB subroutine

Dump results of the zone loads calculations (RNOS=23 - 1.2.1).

DUMPSC subroutine

Report shadowing combinations ( $R$ NOS=14 - 1.2.1).

DUMPSG subroutine

Dump solar gain values ( $R N O S=22-1.2 .1$ ).

DUMP ST subroutine

Dump Surface temperatures and other surface related values (RNOS=23 1.2 .1 ). 
Print the solar incidence angles and sunlit fractions for all heat transfer surfaces for hour number I (RNOS=13 - 1.2.1).

DUMPS2(MODE)

subroutine

Dump the numbers which are controlling the shadowing calculations ( $R N O S=15-1 \cdot 2.1$ ). MODE is set by the calling to routine to tell which values to print.

DUMPS3(MODE)

subroutine

Dump details of the shadowing calculations (RNOS=16 - 1.2.1). These are primarily the coordinates of the shadow and overlap figures. MODE determines which values to print.

$\operatorname{DUMPTC}(\mathrm{N} Z)$

subroutine

Dump temperature profile control points for zone NZ (RNOS=22 - 1.2.1). DUMPTH subroutine

Dump all temperature and flux history values (RNOS=24 - 1.2.1). DUMPT:1 subroutine

Dump time and date values ( $R N O S=21-1.2 .1)$. $\operatorname{DUMPVC}(\mathrm{NZ})$ subroutine

Dump ventilation profile control points for zone NZ (RNOS=22 - 1.2.1). DUMP ZL subroutine

Dump zone load values for all zones (RNOS=21 - 1.2.1). ERROR(MSG, ETYPE) subroutine

Print error message (character string MSG). Process according to error type (ETYPE). ETYPE $=0$ : informat 1ve message.

ETYPE=1: 'warning' - unusual, but not fatal, value or action. ETYPE=2: 'severe' -- unusual value or action usually leading to incorrect answers or ETYPE=3 error.

ETYPE=3: 'fatal' -- immediate run termination usually caused by exceeding iteration limit, exceeding valid control range, or Invalid arithmetic operation (division by 0 , etc.). 

$\operatorname{GAUSSY}(A, B, X, N, \operatorname{MAX})$
subroutine
Solve a system of simultaneous linear algebraic equations ( $A * X=B$ )
by Gauss elimination. There are no safety check or pivoting in this
routine: it will not fail gracefully for an invalid set of equations.
It is used in the Newton iteration for pressure where the A matrix
is diagonally dominant and known to produce valid equations.

$\operatorname{HBAIR}$ (CNVG)

subroutine

Compute the zone air temperatures for normal control (K.1.4) or

ventilation control (K.3). Check heat balance convergence and set CNVG false if it has not been achieved.

HBOUT

subroutine

Compute surface outside temperatures for building envelope surfaces.

Use the algorithms in I.4.

HBSRF

subroutine

Compute surface inside temperatures according to algorithms in J.3, $\mathrm{J} .4$, and $\mathrm{J} .5$.

HTRANS ( I, NS, NV) subroutine

Convert Cartesian coordinates to homogeneous coordinates (E.3) and compute the area $(\mathrm{E} .4 .1)$ of the figure.

IBLRPT subroutine

Initialize the building loads report varaibles.

IMRTNW

subroutine

Initialize the nean radiant temperature network algorithm. Compute the MRT view factors $(H .2 .2)$ and the constant part of the radiative conductance $(H .2 .3)$.
$\operatorname{IMVINS}(I, \mathrm{~N})$
subroutine

Determine presence of inside movable insulation for heat transfer surface I in zone $N$. If present, set UM(I) to the insulation U-values. otherwise, set UM(I) to zero.
$\operatorname{INCLOS}(\mathrm{N1}, \mathrm{NV} 1, \mathrm{~N} 2, \mathrm{NV} 2, \mathrm{NV} 3, \mathrm{NIN})$
subroutine

Determine which vertices of HC figure N1 lie within figure N2. N1 has NV1 vertices, and N2 has NV2 vertices. NIN is the number of enclosed vertices. NV3 is a running count of the number of vertices in the overlap of $\mathrm{N} 1$ and $\mathrm{N} 2$. The algorithm is described in E.4. The coordinates of the inclosed vertices are stored in XTEMP and YTEMP. 
Direct the set-up of the simulation data. This is the root routine in the initallization segment. The segmentation is helped by temporary storage of data on units 4 and 5. The report of array limits is the f1rst action. It w1ll occur even if there is no SINPFL or ENVTFL attached. Next, those files are opened and the environment header is read. Then the SINPFL is read [READER] and the required array space reported. Some calculations are made that require data simultaneously for all zones and surfaces [SETIZP, CISAF, and CIVAF]. Dumps [DUMPEH, DUMPIN] (RNOS=8, 1.2.1) and reports [REPTZD] (RNOS=9, 1.2.1) are written. Inter-segment scratch files 4 and 5 are written.

INITSG

subroutine

Direct the calculation of the solar gains multipliers. This is the root routine of the solar gains segment. The segmentation is helped by the temporary storage of data on unit 5. Determine shadowing combinations [SGCOMB]. Read the environment file to determine solar position and days to be simulated.

INITTH

subroutine

Initallize temperatures and temperature/flux histories. INIT ZP

subroutine

Initialze values for computing zone pressures. In particular, set the $\mathrm{ZZ}(0)$ and $\mathrm{PZ}(0)$ values (for ambient air) to zero. Set system flows to zero. Set wind pressures to zero (needed to allow inclusion of PW term in the equation for internal surfaces).

INTCPT

subroutine

Determine all intercepts between the sides of figure NS2 and the sides of figure NS1 (E.3.4 and E.4).

IZERO (ARRAY, LEN) subroutine

Set ARRAY (length LEN) of integers to 0.

JDS (JFLAG , JD , YR , MO ,DM) subroutine

If JFLAG $=1$, compute the Julian date (JD) from the year (YR), month (MO), and day-of-month (DM) (B.1.2). Otherwise, compute YR, MO, and DM from YR (B.1.3).

LOCRAN (LIST, LEN, ITEM) integer function

Determine the location of ITEM in a LEN long array (LIST) of unordered words. A linear search is used. An unsuccessful search returns the value zero. 
Multi-room loads program. This is the main (or root) program of the loads calculator. It calls the three segments of the loads calculation.

MRTNET

subroutine

Compute the zone mean radiant temperatures for the second and subsequent heat balance 1terations. Use the simple (H.2.3) or the detalled (H.2.4) algorithm. This routine includes equations to improve heat balance convergence.

MRTNT1

subroutine

Compute the zone mean radiant temperatures for the first heat balance 1teration of the hour. Use the simple (H.2.3) or the detalled (H.2.4) algorithm. This routines includes equations to improve convergence of the MRT on the first iteration. Development of those equations is not complete.

MULTOL (NNN, LOCO,NRFIGS)

subroutine

Determine the overlaps of figure NNN with previous figures stored in locations LOCO+1 through LOCO+NRFIGS of the HC arrays.

OCNVCO ( I , HM, OABS , TO, HO, HS , HG) subroutine

Evaluate the heat exchange coefficlents HA (=HO), HS, and HG for heat transfer surface number $I$. Input also includes the U-value of movalbe insulation, if present, the solar absorptance of the surface/movable insulation, and the most recently computes surface outside temperature TO. Use the algorithms in (I.2). The surface temperature of movable insulation is estimated from (I.3.8) with HO as input computed from the simple algorithm.

$\operatorname{OMVINS}(I, \mathrm{OABS})$

subroutine

Evaluate external movable insulation for heat transfer surface number $I$. If it is present, return its solar absorptance in OABS and set UM(I). Otherwise, set UM(I) to zero.

ORDER(NS3,NV3)

subroutine

Sort the unordered vertices found by enclosure [INCLOS] and intercept [INTCPT] into clockwise sequence for use by subsequent overlap calculations. Results are placed in location NS3 in the HC arrays.

OVRLAP subroutine

Use homogeneous coordinate techniques (E.4) to compute the overlap between two convex polygons. 
Write output report page heading. See PAGE description in the list of IP subroutines.

$\operatorname{POLY} 1 \mathrm{~F}(\mathrm{X}, \mathrm{A}, \mathrm{N})$ real function

Evaluate simple polynomial expression (D.1.7a): $P=A(1)+A(2) * X+A(3) * X^{2}+\ldots+A(N) * X^{N-1}$

$\operatorname{POLY} 2 F(X, A, N)$ real function

Evaluate simple polynomial expression (D.1.7b): $P=A(1) * X+A(2) * X^{2}+\ldots+A(N) * X^{N}$

QINSRC subroutine

Compute (or set up parameters and pointers) for scheduled internal loads. First initialize the loads arrays. Then process every element in the CGS arrays (that is not off for the day) according to type (CGSTYP).

Distribute short wavelength radiant gains (solar and lights) on the inside surfaces of the zones. This includes a single pass of light through transparent interzone partitions and calculation of the light converted to instantaneous convective gain on internal shades. Determine if the radiant gain should be placed on movable insulation instead of the surface. Include the transmission of light through windows ut of the zone and to the environment.

\section{subroutine}

Determine solar gains. Use the solar gains multipliers and the solar radiation intensities to determine the diffuse solar gains in the zones, the solar gains on outside surfaces, and the beam soalr gains on inside surfaces. Also evaluate placement of movable insulation for the hour [IMVINS and OMVINS].

Read the simulation input file (SINPFL) and determine the array space used. Data which was prepared in single element arrays in the IP is read into multiple element arrays. The reading is directed by two-element records that tell which arrays will be filled when the next record is read. The unformatted read statements must match the IP write statements. Note that each data read is protected to prevent array overflow. Also note that a simulation control information (created in FINISH) must be the last record read. Otherwise, an end-of-file is encountered which terminates the run. 
Report building loads (a default action).

$\operatorname{REPTSM}(K E Y)$

subroutine

Report simulation values like numbers of iterations and execution time. Time is determined by the non-ANSI function SECOND. This function can be removed without otherwise effecting the program.

REPT ZD subroutine

Report a description of the zone (RNOS=9 -1.2 .1 ). RPTASU(NR, MAX, NANE, LIMIT) subroutine

Report array space utilization. For PARAMETERized arrays, print a message giving the number (NR) of elements utilized and the short parameter name (NAME). If NR is greater than the size (MAX) of the arrays, print a string of stars to highlight the message and set LIMIT true.

SETIZP subroutine

Set interzone pointers for interzone partitions, MIX and FAN operations, and interzone air flow openings. Unmatched items cause run termination.

SCACTN

subroutine

Determine which groups of days are used for shadowing calculations. This is based on the shadowing group dates (Table IV.G.1) and the dates of any shadowing surface or movable insulation actions which change the building shadowing configuration. The angles (declination and equation of time) from which solar position is calculated are determined by averaging the values for all days in the period.

SGBEAM subroutine

Direct the calculation of solar gains multipliers for a day. For each hour, compute the angle of incidence of the sun's rays on every surface (E.2.2); compute the solar multipliers [SHADOW]; store the results on unit 3 for later heat balance calculations.

subroutine

Determine which surfaces can shade each other. This is constant for the entire simulation and can, therefore, be used to avoid,recomputing such data at every hour. Data is stored in the SHDCMB array and is used to direct the calculation sequence of the SHADOW subroutine. Shadowing combinations are computed for heat transfer, exterior, base surfaces. All surfaces which can shade the base surface are determined [CHKGSS]. All heat transfer subsurfaces are determined [CHKSBS]. For 
the detailed solar distribution algorithm, all inside surfaces which might receive beam sunlight are determined [CHKBKS]. Complex building configurations which cause SHDCMB to overflow are handled by reducing the level of shadowing detail, if possible.

SHADOW(IHOUR)

subroutine

Compute the sunlit areas and solar gains multipliers for all building envelope surfaces at time IHOUR. From the shadow combinations array, determine the number of shadowing surfaces (NGSS), inside (back) surfaces (NBKS), and heat transfer subsurfaces (NSBS). If the surface faces away from the sun, its sunlit area (and all subsurfaces) must be zero. If it faces the sun and there are no shadowing surfaces, it must be totally sunlit. Otherwise, compute the shadow patterns on the surface [SHDGSS]. For window subsurfaces and the detailed solar distribution call SHDBKS. Then process the subsurfaces [SHDSBS] to compute their sunlit areas and solar gains multipliers and to determine how they modify the gross sunlit area of the base surface. Finally, compute the solar gain multiplier of the base surface.

SHDBKS (NGRS)

subroutine

Project the zone inside surfaces along the sun's rays to the plane of the current general shadow receiving surface. This is done for the detailed internal solar distribution (3.1.2) if there are windows on the base surface and if the sun might shine through the window onto the inside surface. This is not possible if the inside surface faces the sun. The projected figure of the inside surface is reduced to $f i t$ within the base surface by the overlap algorithm (E.4) [OVRLAP].

\section{SHDGSS(NGRS)}

subroutine

Compute the shadow figures on surface (base surface - 4.13.2) number NGRS. If there are no shadowing surfaces, the surface must be fully sunlit. Otherwise, determine the shadows from all shadowing surfaces. If the shadowing surface is sunlit, it cannot be casting a show (E.2) so skip it. Also skip if indicated by shadowing surface dates. Transform and clip the coordinates of the shadowing surface to the receiving surface coordinate system (E.2). Determine the overlap of the shadow on the surface (E.4). Also determine how it overlaps any previous shadows. Add (signed) shaded areas to compute the gross sunlit area of the base surface. The effects of subsurfaces is not yet computed.

\section{$\operatorname{SHDINT}(L)$}

subroutine

Determine the distribution of solar gains from a single window of optical type L (index to optical coefficients). Compute multipliers for zone diffuse gains. Compute multipliers for beam gains using detailed or simple internal solar distributions. The detailed distribution involves overlapping the window sunlit pattern with the 
projections of the internal surfaces along the sun's rays to the plane of the base surface and computing the sunlit area of each internal surface. If the internal surface is transparent, its diffuse transmittance is used to pass sunlight into the adjacent zone. The simple distribution puts the sunlight on the floor(s) of the zone according to ISABSF [CISAF]. In either case, that portion of the sunlight which is not directly absorbed by the internal surface becomes a diffuse gain for the entire zone.

SHDRVL

subroutine

Evaluate the shadowing effect of a subsurface setback (4.13.6). The shadow from the setback reduces the potential sunlit area of the subsurface. This potential area is still rectangular. It is overlapped with the shadow figures already known to lie within the subsurface opening [SHDSBS] to compute the actual sunlit area.

SHDSBS ( IHOUR)

subroutine

Evaluate the sunlit areas of the subsurfaces (windows, doors). The shadow patterns have already been accurately determined on the base surface and stored in the homogeneous coordinate arrays [SHDGSS]. The subsurfaces are evaluated one at a time. Each subsurface figure is overlapped with the shadow figures. This determines a sunlit area which must be removed from the gross sunlit area of the base surface. Check for movable insulation [SMVINS] and if it applies skip most of the following calculations. Evaluate the shadowing effect of a setback [REVEAL]. If the surface is transparent, compute its optical properties and determine the windows contribution to the distribution of sunlight in the zone [SHDINT]. Finally, compute the solar multipliers for the subsurface.

S IMBLD

subroutine

Simulate the building thermal performance. This is the root routine of the loads segment. The segmentation is helped by temporary storage of data on unit 4. There are several initializations [IMRTNW, REPTSM(1), and IBLRPT]. The largest initialization requires several days simulation [SIMDAY] to remove the transients in the temperature histories. This initialization is terminated in accordance with the hourly heat balance convergence criteria. Then the actual simulation [SIMDAY] is done for the number of days required. A summary report is printed [REPTBL].

subroutine

Do the simultaneous multizone heat balance calculations for one day. This involves an initialization of values which are constant for the day [DAILY] followed by a loop of heat balance calculations for 24 (standard time) hours. The loop involves setting up the constant values for the hour (weather data, solar gains [QSUN], scheduled loads 
[QINSRC], control profiles [CHACS], distribution of short wavelength radiation [QSDIST]), doing the first iteration of the multizone heat balance (compute variable coefficlents [VARTMP], alr movements [AIRMVO or AIRMVI], surface outside heat balances [HBOUT], mean radiant temperatures [MRTNTI], surface inside heat balances [HBSRF], the zone air heat balances [HBAIR]), do subsequent 1terations to convergence, summarize the hour's loads data [CALOAD], and prepare for the next hour [UTHRMH]. Varlous data dumps are avallable as the calculations proceed.

subroutine

Evalaute exterior movable insulation (EMI). K is the pointer stored in SSCPTR(heat transfer surface number). It points to data about the EMI in the ISSC/RSSC arrays. Time (IHOUR), environmental conditions, and the type of control will determine if the EMI is applied or if $1 \mathrm{t}$ is not. If it is not, OABS is set to zero. If it is applied, OABS is set to the solar absorptance of the EMI.

subroutine

Solve the detalled air flow equations for the zone pressures. On the first 1teration of the hour approximate the zone pressures (PZ) by solving a linear set of equations (flow exponents set to one). This gives a reasonable set of starting values for PZ. Then use a. modified Newton's method to solve the simultaneous non-linear algebraic equations ( $\mathrm{G} .3 .5, \mathrm{G} .4 .1 \mathrm{a}$ to $\mathrm{c}$ ). This method always produces a diagonally dominant matrix which can be solved by GAUSSY, a simplified Gauss elimination routine.

subroutine

Print the status of unit number UNIT as determined by the FORTRAN INQUIRE function. This routine is used for prograin debugging purposes only.

subroutine

Compute the sine of the solar declination angle (SINDEC) and the equation of time value (EQTIM) for a given day-of-year (DAYYR).

subroutine

Compute the solar direction cosines for a given HOUR.

Update the surface temperature and flux history values. All historles are stored contiguously in the TFH array. New values of temperature and flux are added to the array by overwriting old values (that will not be needed next hour) of other surfaces. This causes the histories 
to "crawl" slowly through the TFH array. Compute the inside (C.1.4)

and outside (C.1.6) conductive fluxes and store in the TFH array.

Compute KIP (C.1.5) and KOP (C.1.7) for the next hour. Shift the

history values back one hour by incrementing TSHIFT. If the histories

have reached the bottom of the TFH array, shift all values back to the

top of the array and reset TSHIFT.

VARTMP subroutine

Evaluate variables that are directly influenced by zone air

temperature. These variables are the occupant sensible/latent gains

$(F .1 .1)$, and the interior convection coefficients (J.1 and J.2).

ZERO(ARRAY,LEN) $\quad$ subroutine

Set ARRAY (length LEN) of real numbers to 0. 
This diagram (continued over several pages) shows the general relationship of the loads calculator subroutines to ech other. A subroutine calls other subroutines which are to the right and below it on the diagram. Multiple calls to the same routine are not shown, only the first. Circled letters are continuation points for often used groups of subroutines. Not all subroutines and functions are included. The intrinsic FORTRAN 77 have been left out. The simple utility routines ERROR and PAGE which are called from many places are not always shown.

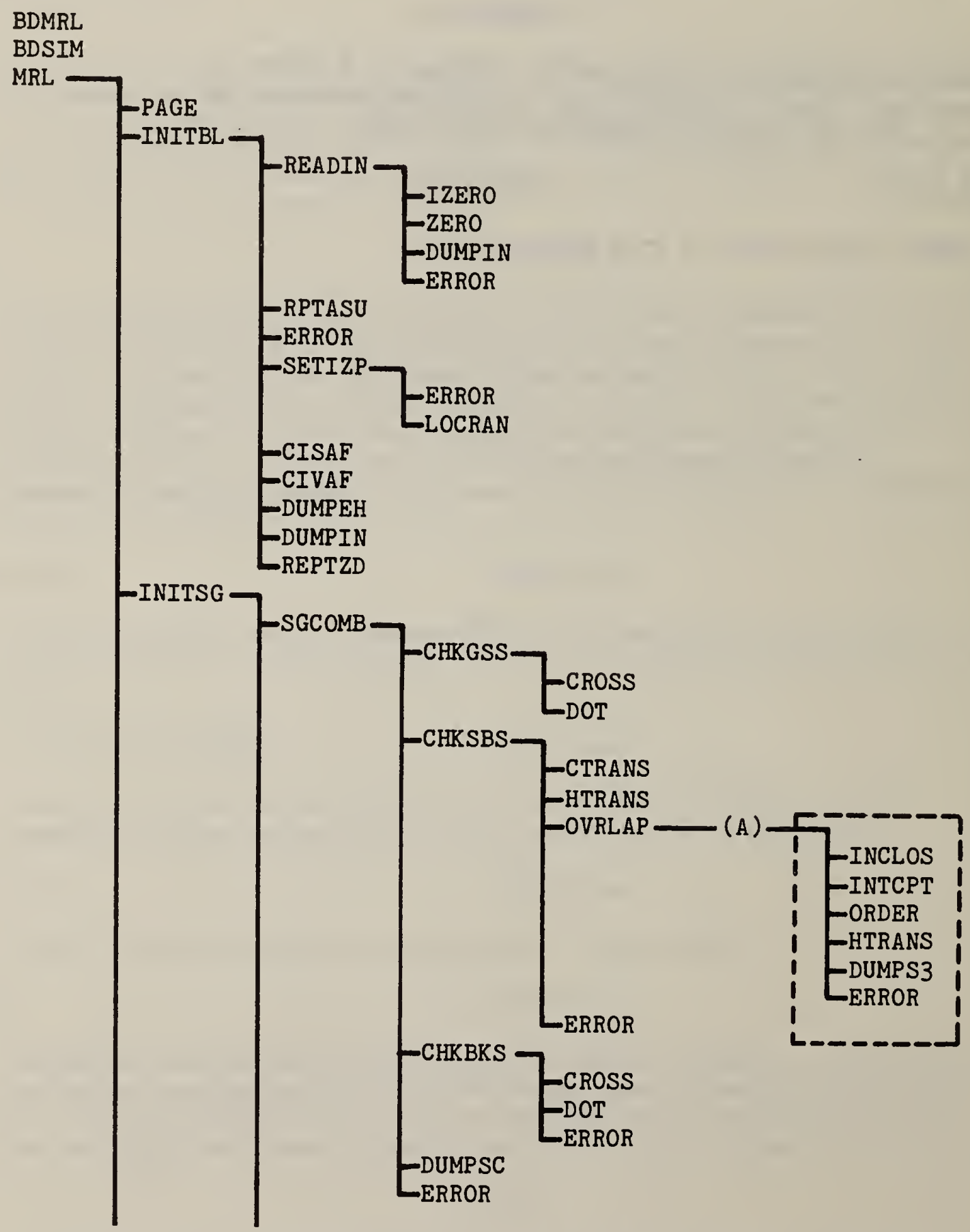

Figure VI.B.1 Tree structure of the loads calculator program 


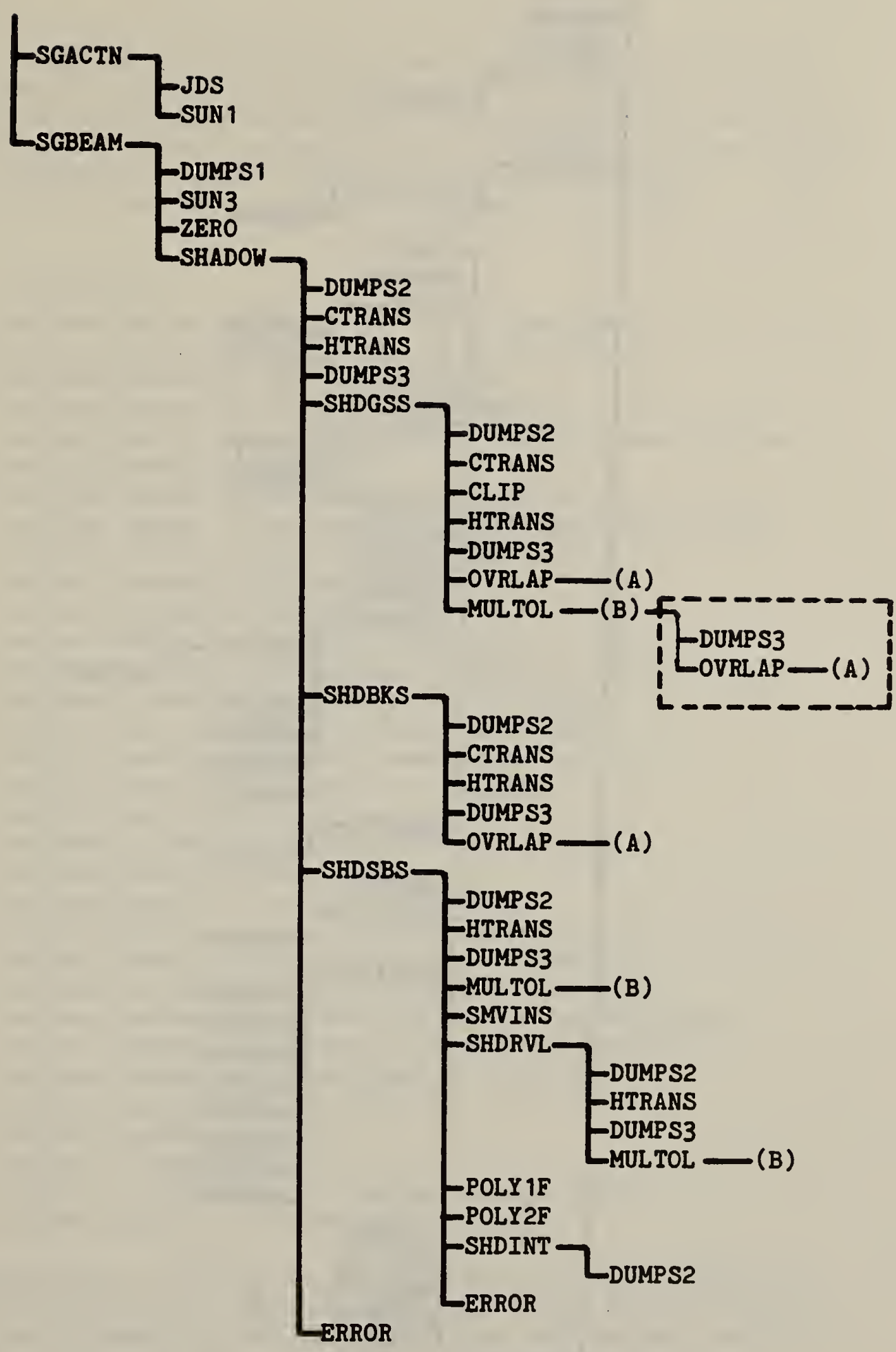

Figure VI.B.I (continued) 


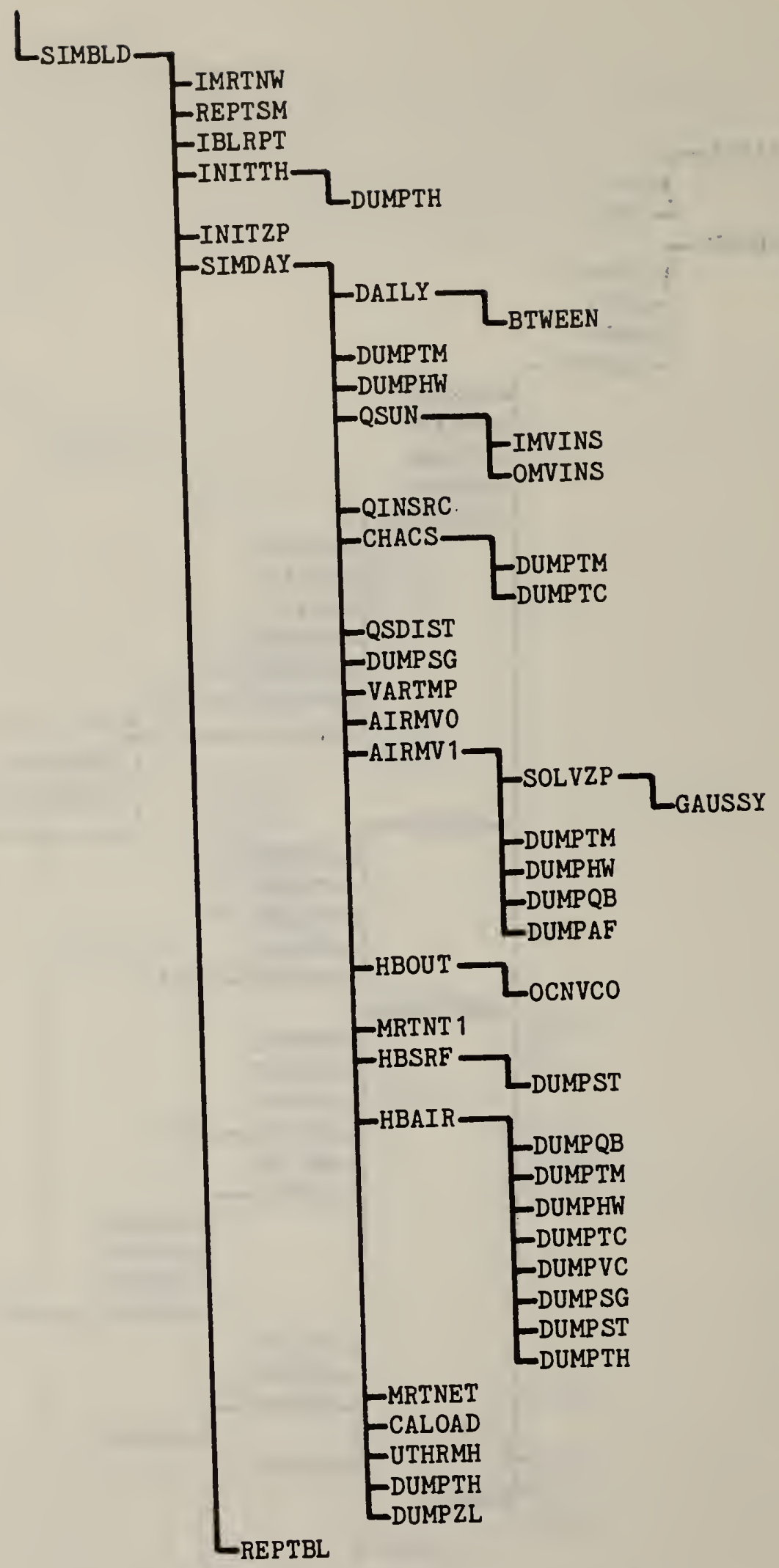

Figure VI.B.1 (concluded) 
PARAMETERS are extensively used to set array dimensions. This allows the same common block to describe only a single surface, schedule, etc., in the IP program and hold all surfaces, schedules, etc. in the LC. The IP computes the required dimensions necessary for the LC to simultaneously hold all descriptions. The following list describes the TARP parameters. "Short names" are those used to describe parameters in IP and LC reports.

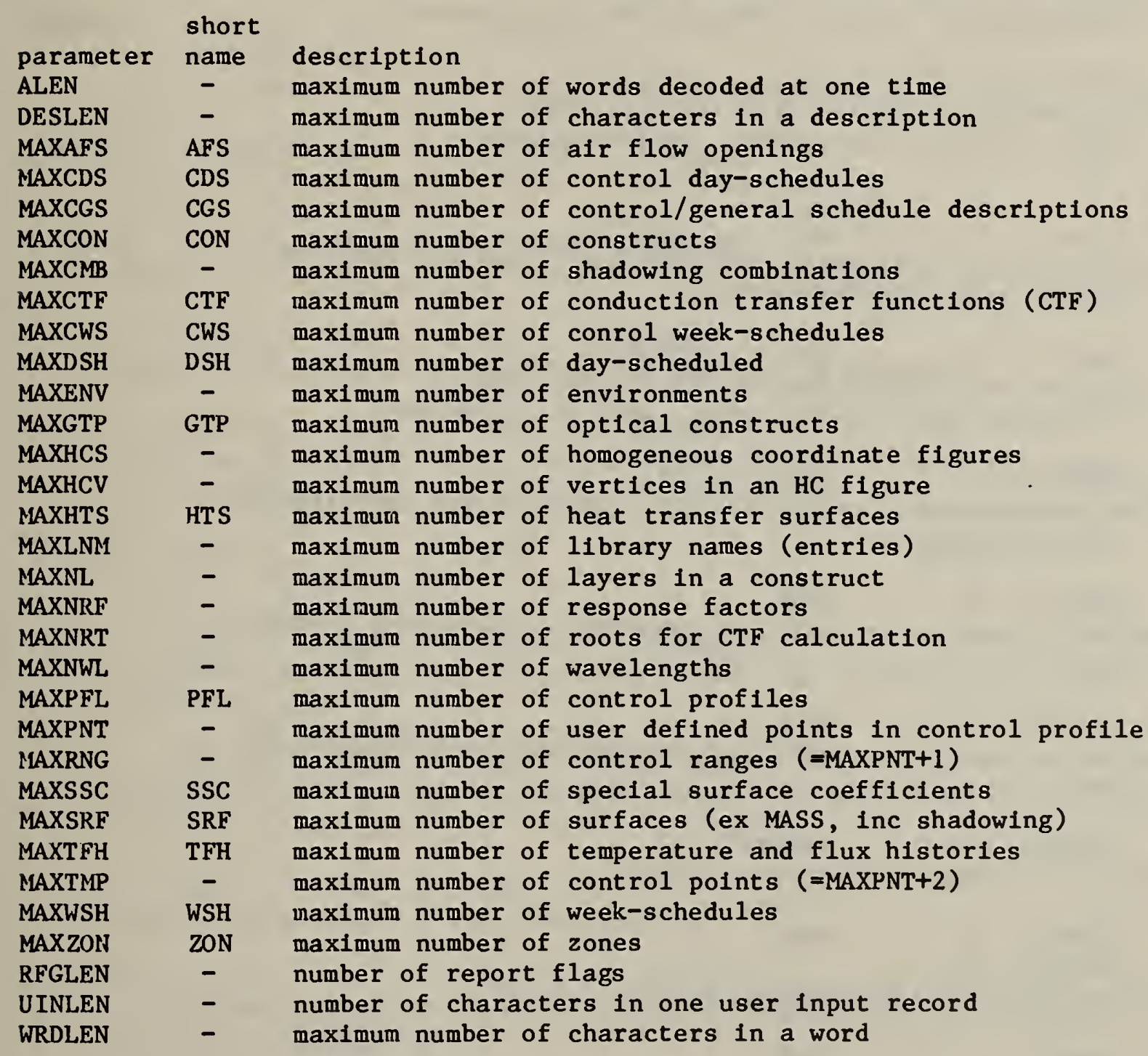

Nearly all significant variables in the TARP are in common blocks. The list below describes all such variables by giving the name, comron block, subprogram using the variable (IP, LC, or BOTH), type, dimensions (including parameters), and units on one line followed by a verbal description. 
/GLAS3/ IP real $(2,4,2)$

Absorptances of single panesof glass

(polarization, pane number, side of incidence).

A

$$
\text { /ZONL/ LC real (MAXZON) C/W }
$$

Temperature independent part of the zone heat balance equation.

For example $(K .1 .4)$ and $(K .4 .1)$.

AA

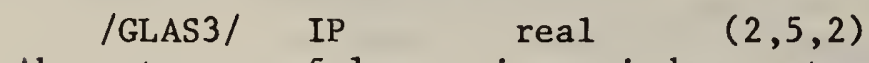

Absorptances of layers in a window system

(polarization, surface number, side of incidence).

$\mathrm{AAB}$

/GLAS6/ IP real $(16,2,5)$

Absorptances of a window system for beam light

(angle number, polarization, surface number).

AABW /GLAS8/ IP real $(16,5)$

Beam absorptances integrated over wavelength and polarization

(angle number, surface number).

$\mathrm{AAD}$
/GLAS5/ IP
real
$(2,5,2)$

Absorptances of a window system for diffuse light

(polarization, surface number, side of incidence).

AADW

/GLAS7/ IP real

(5)

Diffuse absorptances integrated over wavelength and polarization

(surface number).

$\mathrm{ABI}$

/SHDCTL/ LC real -

Fraction of beam solar radiation absorbed at the inside surface of

a window.

$\mathrm{ABO}$

/SHDCTL/ LC

real -

Fraction of beam solar radiation absorbed at the outside surface of

a window.

ACHAR /UINDAT/ IP integer -

Pointer to current character in AWORD.

ACNVGl /RUNCTL/ IP real

/SIMCTL/ LC

Relative air flow convergence $(3 \cdot 1.4)$.

ACNVG2 /RUNCTL/ IP real - $\mathrm{m}^{3} / \mathrm{s}$

/SIMCTL/ LC

ACNVG3 /RUNCTL/ IP $\quad \mathrm{real} \mathrm{m} / \mathrm{s} \quad \mathrm{Pa}$

/SIMCTL/ LC

Minimum pressure across any opening (3.1.4). 
$A D$ $/$ RF4/ IP real -

Upper left element of the layer derivative matrix.

AFAREA /AFSDAT/ IP real - $\mathrm{m}^{2}$

Air flow opening area for matching interzone openings.

AFEXP /AFSDAT/ IP real -

Air flow opening exponent for matching interzone openings.

AFLOW /RUNCTL/ IP integer -

/SIMCTL/ LC

Flag for detailed (1) or simple (0) air flow modeling (3.1.4).

AFSNAM /AFSNAM/ LC chr*WRD (MAXAFS)

Name of $z$ one on opposite side of interzone opening.

AFSPTR /AFSIL/ LC integer (MAXAFS)

Number of the zone on the opposite side of the opening ( 0 means ambient).

AI /SOLFAC/ LC real (MAXHTS)

Beam solar radiation factor for the inside of a surface.

AID /GLASO/ BOTH real (MAXGTP)

Fraction of diffuse solar radiation absorbed at the inside surface of a window.

AIRDEN /AIR/ LC real - $\mathrm{kg} / \mathrm{m}^{3}$

Density of ambient air.

AI1 /GLAS/ BOTH real (5,MAXGTP)

Polynomial coefficients for window inside beam solar absorptance

(ci in D.1.7a).

AI2 /GLAS/ BOTH real (6, MAXGTP)

Polynomial coefficients for window inside beam solar absorptance

(ci in D.1.7b).

$\mathrm{AL} / \mathrm{RF} 4 /$ IP real

Upper left element of the layer matrix.

ALIST /ALIST/ IP char*WRD (ALEN)

List of words decoded from user input: a section name, key name, or subkey name and data.

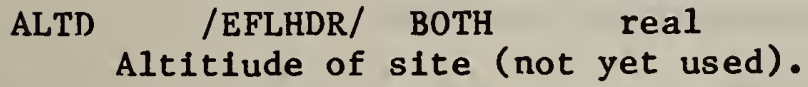

AMAXIT /RUNCTL/ IP integer -
Maximum number of air flow iterations for convergence $(3.1 .4)$. 
/GLAS9/ IP
Index of refraction of air $(=1.0)$.

AO

$$
\text { /SOLFAC/ LC real (MAXHTS) }
$$

Beam solar radiation absorption factor for the outside of a surface.

AOD

$$
\text { /GLASO/ BOTH real (MAXGTP) }
$$

Fraction of diffuse solar radiation absorbed at the outside surface of a window.

A01

$$
\text { /GLAS/ BOTH real (5,MAXGTP) }
$$

Polynomial coefficients for window outside beam solar absorptance

( $c_{i}$ in D.1.7a).

$\mathrm{AO} 2$

$$
\text { /GLAS/ BOTH real (6,MAXGTP) }
$$

Polynomial coefficients for window outside beam solar absorptance

( $c_{i}$ in D.1.7b).

AP

/IZPDAT/ IP

real

$\mathrm{m}^{2}$

Area of interzone partition.

AREA

/HTSISL/ BOTH real

Area of heat transfer surface.

(MAXHTS)

$\mathrm{m}^{2}$

AS

/RF4/ IP real -

Upper left element of the total construct matrix.

ASD
/GLASO/ BOTH
real
(MAXGTP)

Absorptance for diffuse radiation of the interior shading device.

AS 1
/GLAS/ BOTH
real
(5, MAXGTP)

Polynomial coefficients for beam absorptance of the interior shading device $\left(c_{i}\right.$ in $\left.D .1 .7 a\right)$.

AS2
/GLAS/ BOTH
real
$(6$, MAXGTP)

Polynomial coefficients for beam absorptance of the interior shading device $\left(c_{i}\right.$ in $\left.D .1 .7 b\right)$.

AT
/RF4/ IP
real

Upper left element of the total derivative matrix.

AWORD /UINDAT/ IP $\quad$ integer -
Pointer to current word in ALIST.

AZS /AFSDAT/ IP real - m

Height of air flow opening for matching interzone openings.

B
/ ZONL/ LC
real
(MAXZON)
W

Temperature dependent part of the zone air heat balance equation.

For example (K.1.4) and (K.4.1). 


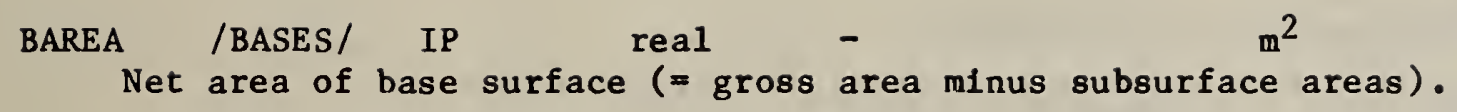




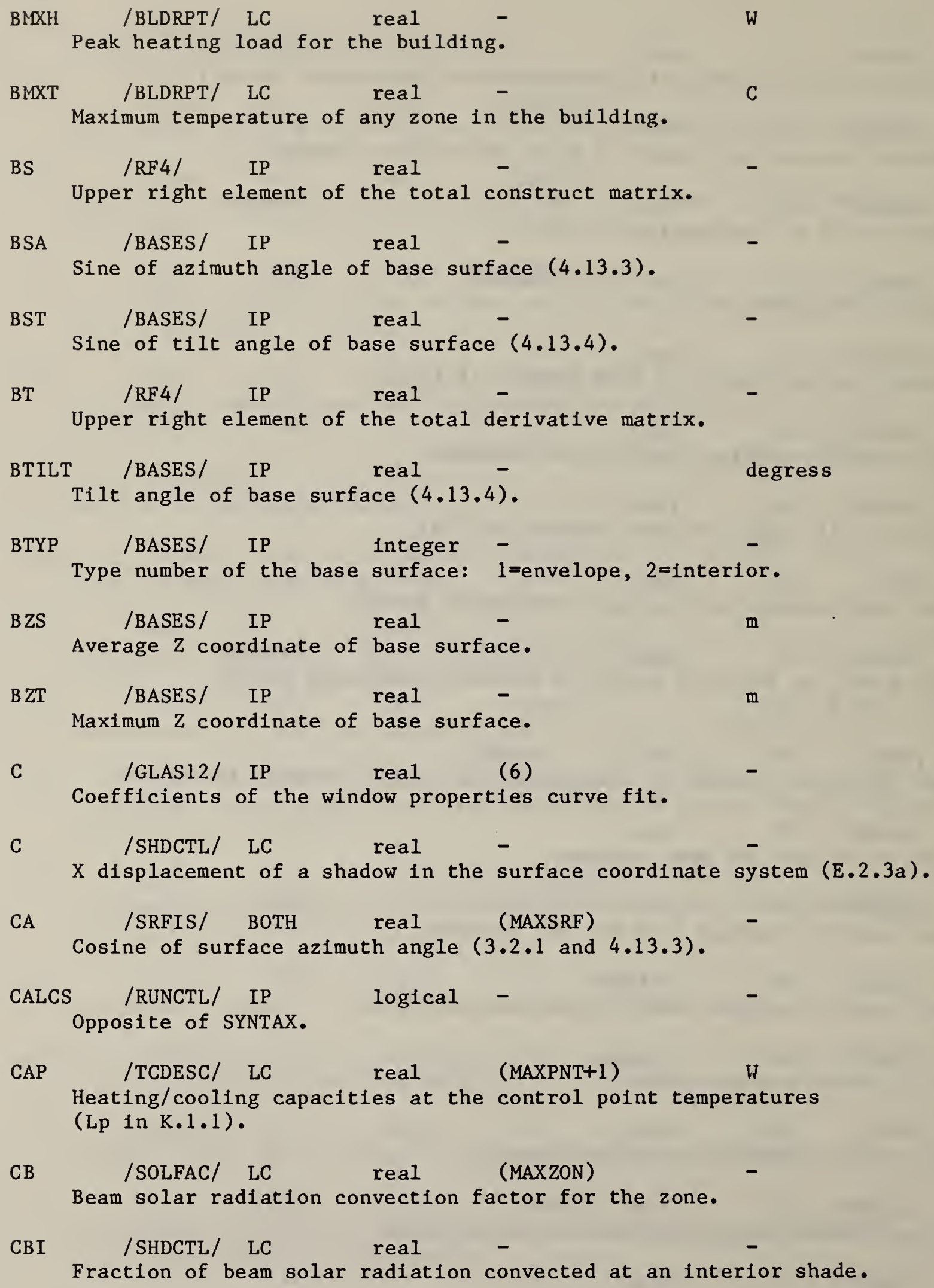




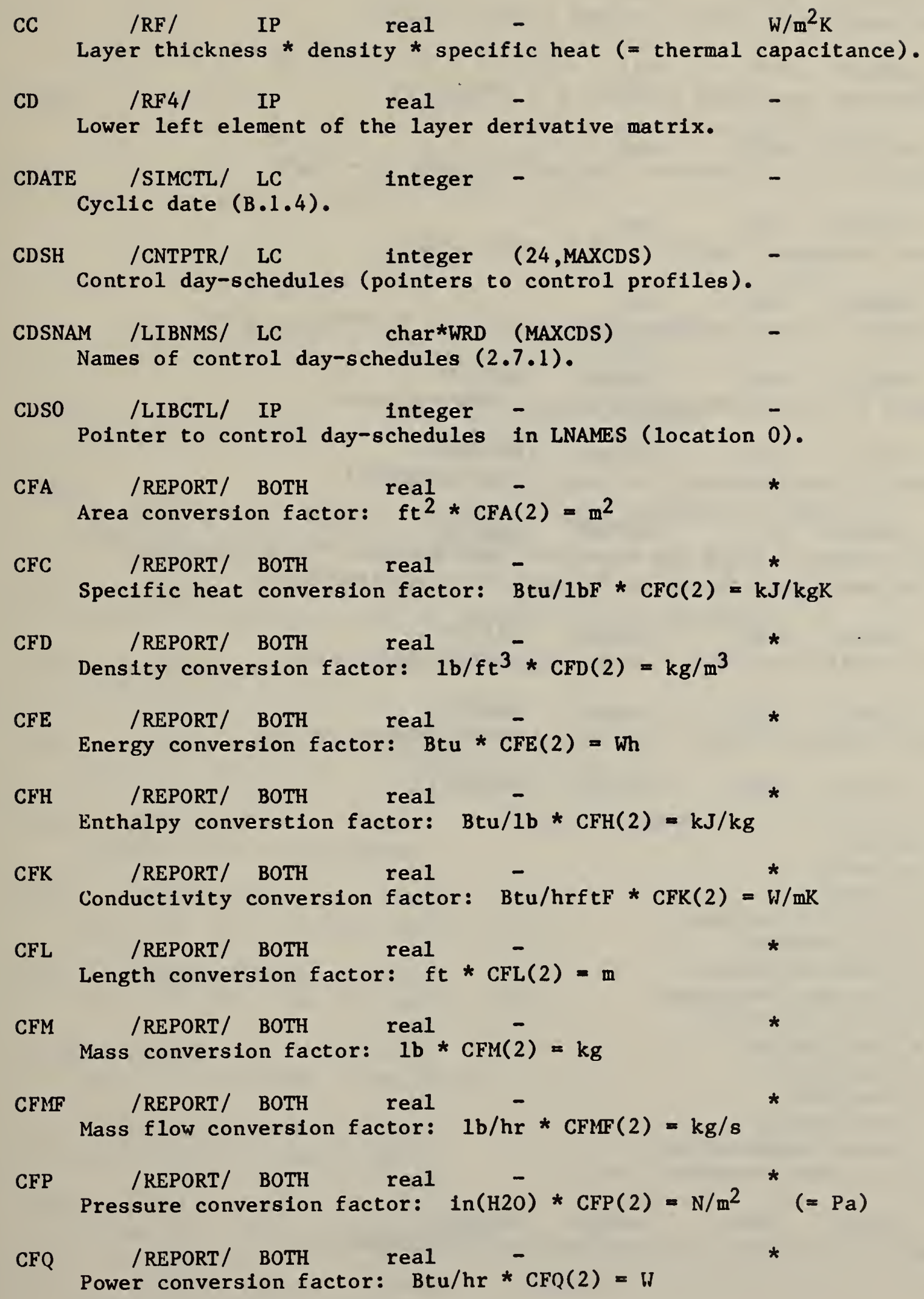

CD /RF4/ IP real -

Lower left element of the layer derivative matrix. 


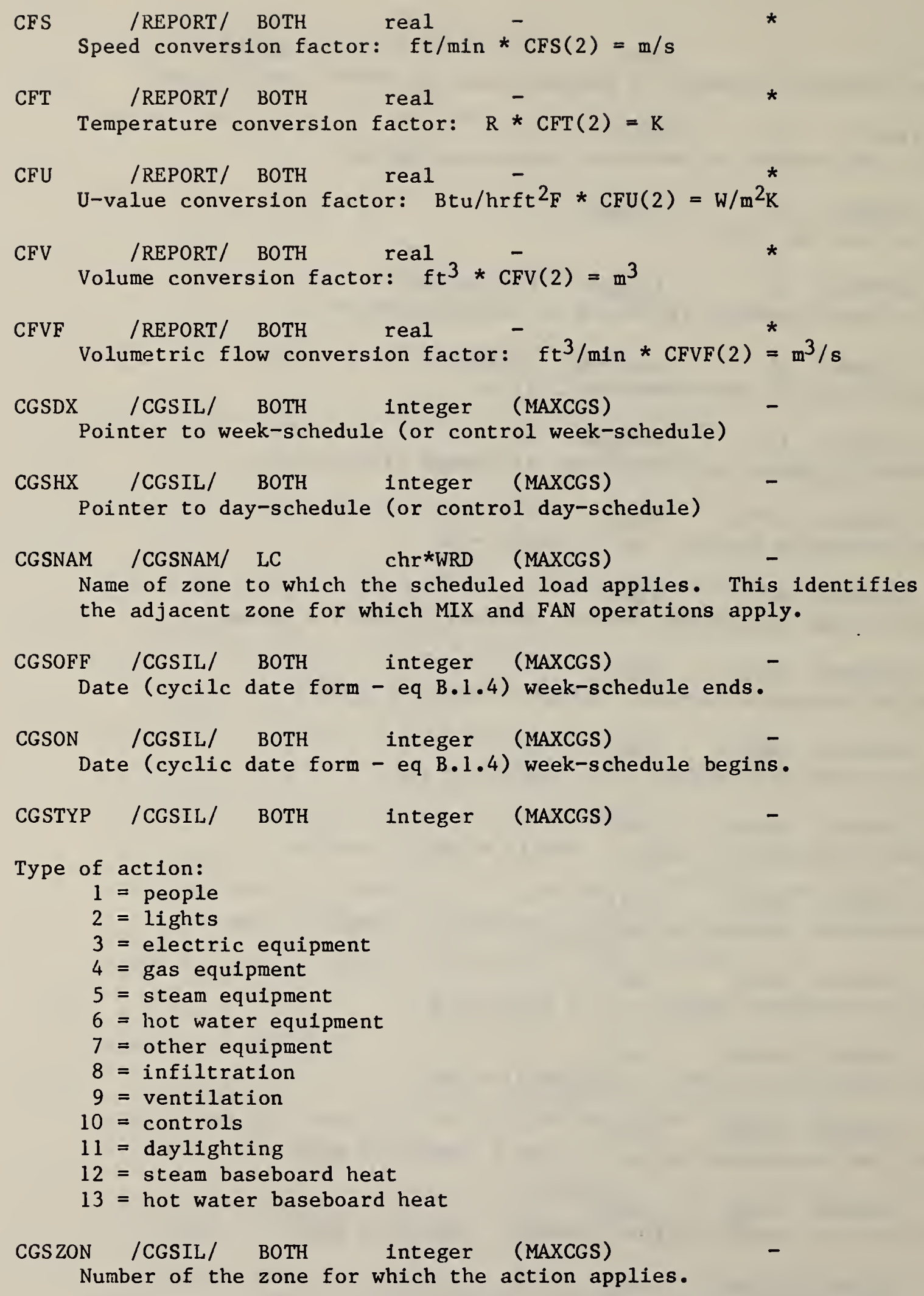




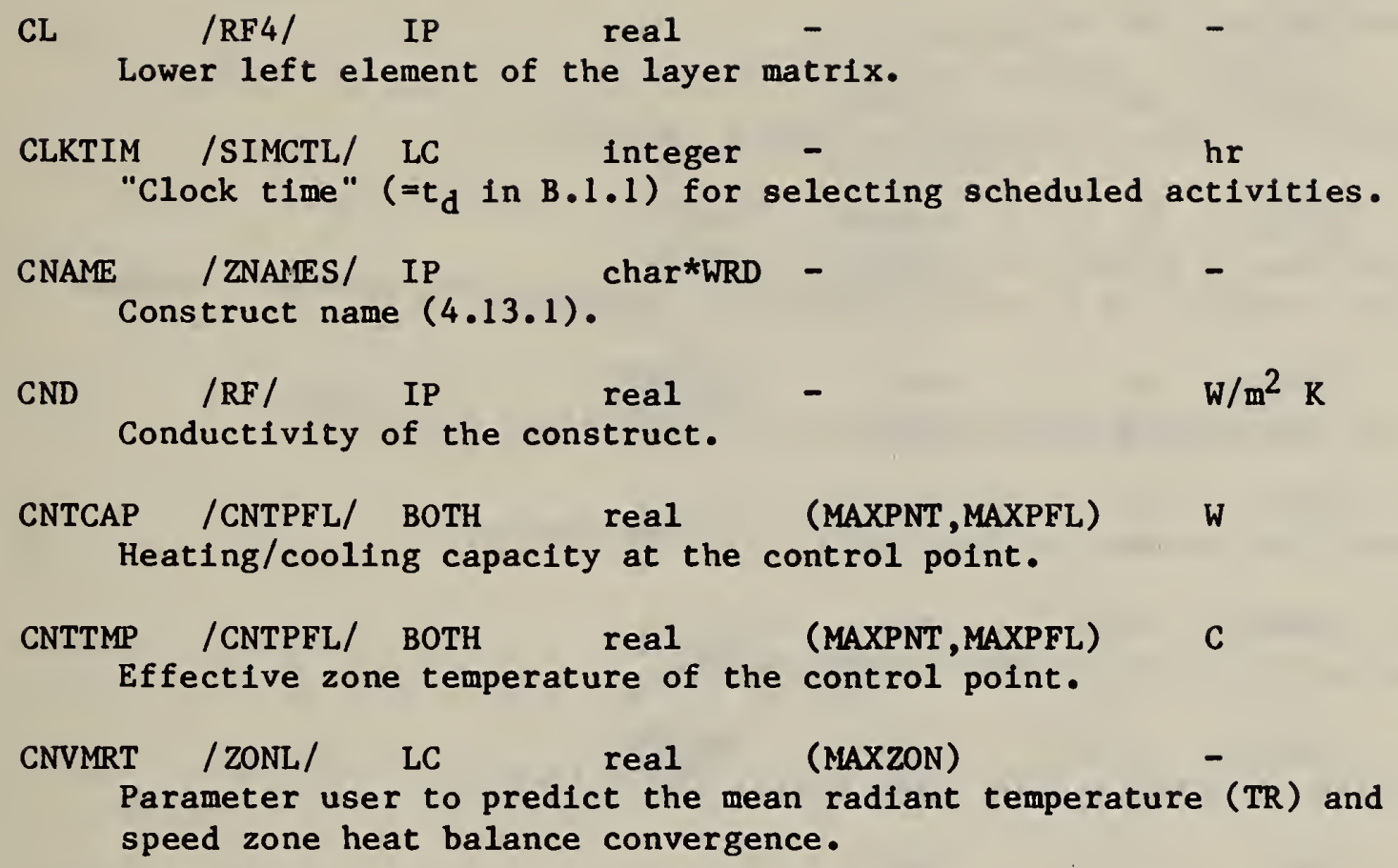




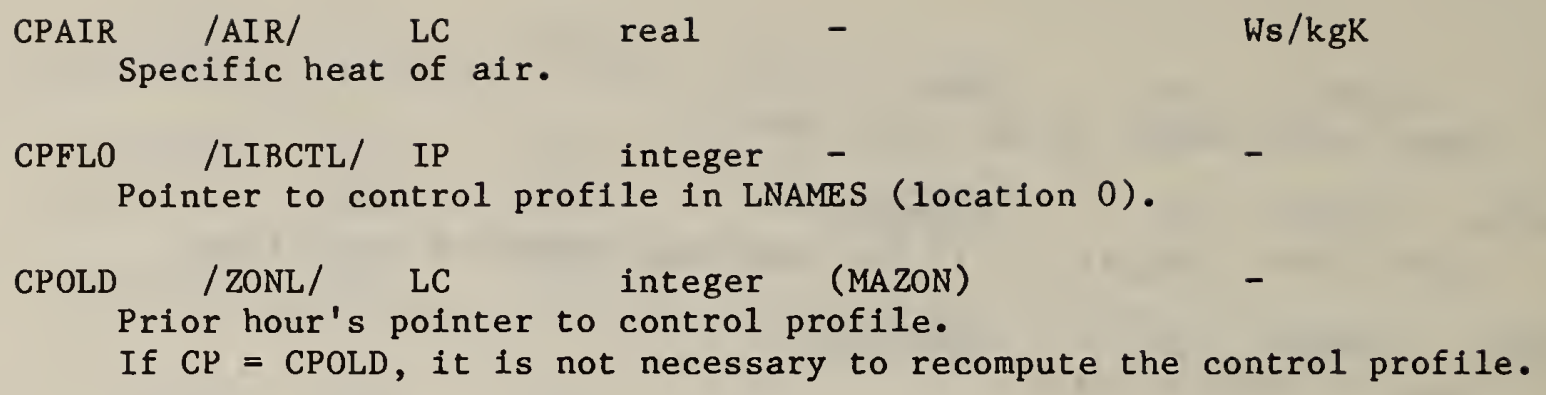

CT

$$
\text { /RF4/ IP real }
$$

Lower left element of the total derivative matrix.

CTF /BLDCTF/ LC real (MAXCTF)

Array of conduction transfer fucntions for all constructs.

CTFXO /CONDAT/ BOTH real (MAXCON) $\mathrm{W} / \mathrm{m}^{2} \mathrm{~K}$ $X$ conduction transfer function for each construct for time $=0$.

CTFYO /CONDAT/ BOTH real (MAXCON) $\mathrm{W} / \mathrm{m}^{2} \mathrm{~K}$ $\mathrm{Y}$ conduction transfer function for each construct for time $=0$.

CIFZO /CONDAT/ BOTH real (MAXCON) $\mathrm{W} / \mathrm{m}^{2} \mathrm{~K}$ $\mathrm{Z}$ conduction transfer function for each construct for time $=0$.

CTHETA /SRFIS/ BOTH real (MAXSRF) Cosine of the angle of incidence of the sun's rays on the surface.

CTILT /HTSISL/ BOTH real (MAXHTS) Cosine of the heat transfer surface tilt anlge.

CTQ /RF1/ IP real (5) Flux conduction transfer functions (orders 0 through 5).

CTX IPF1/ real (0:5,0:MAXNRF $) \quad \mathrm{W} / \mathrm{m}^{2} \mathrm{~K}$ $X$ (external) conduction transfer functions (orders 0 through 5 ).

CTY /RF1/ IP real (0:5,0:MAXNRF) $\mathrm{W} / \mathrm{m}^{2} \mathrm{~K}$ $\mathrm{Y}$ (cross) conduction transfer functions (orders 0 through 5 ). 
CTZ $/ \mathrm{RF} 1 /$ IP real $(0: 5,0: \mathrm{MAXNRF}) \quad \mathrm{W} / \mathrm{m}^{2} \mathrm{~K}$

$\mathrm{Z}$ (internal) conduction transfer functions (orders 0 through 5 ).

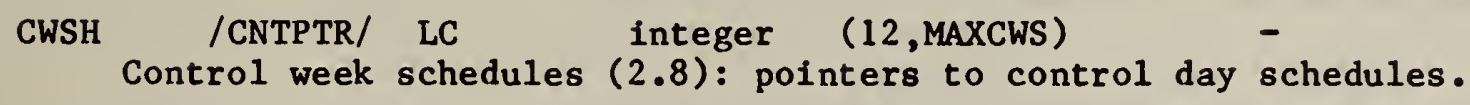

CWSNAM /LIBNMS/ LC char*WRD (MAXCWS)

Names of control week shcedules $(2.8 .1)$.

CWSO /LIBCTL/ IP Anteger -
Pointer to control week-schedules in LNAMES (location 0 ).

D $1.0-$ RATIO IP real (5)

DAYOFM /ENVDAT/ BOTH integer -

Day of the month number (DM in B.1.2)

DAYOFS /SIMCTL/ LC integer -

Number of days simulated.

DAYOFW /ENVDAT/ BOTH integer -

Day of the week number (DW in B.1.2).

DAYOFY /ENVDAT/ BOTH integer -

Day of the year number (DY in B.1.2).

DAYTYP /SIMCTL/ LC integer -

Day type number (used to select schedules).

DB /SOLFAC/ LC real (MAXZON)

Beam radiation factor for zone (beam converted to diffuse by shade).

DD /RF4/ IP real -

Lower right element of the layer derivative matrix.

DDBP /DDENVT/ IP real - Pa

Design day barometric prpessure $(1.6 .6)$.

DDCLR /DDENVT/ IP real -

Design day clearness number $(1,6.9)$.

DDDOFM /DDENVT/ IP integer -

Design day day-of-month number $(1 \cdot 6 \cdot 5)$.

$\begin{array}{cc}\text { DDDTYP /DDENVT/ IP } & \text { integer } \\ \text { Design day type number }(1.6 .12)\end{array}$

DDMDBT /DDENVT/ IP real -

Design day maximum dry bulb temperature (1.6.2). 


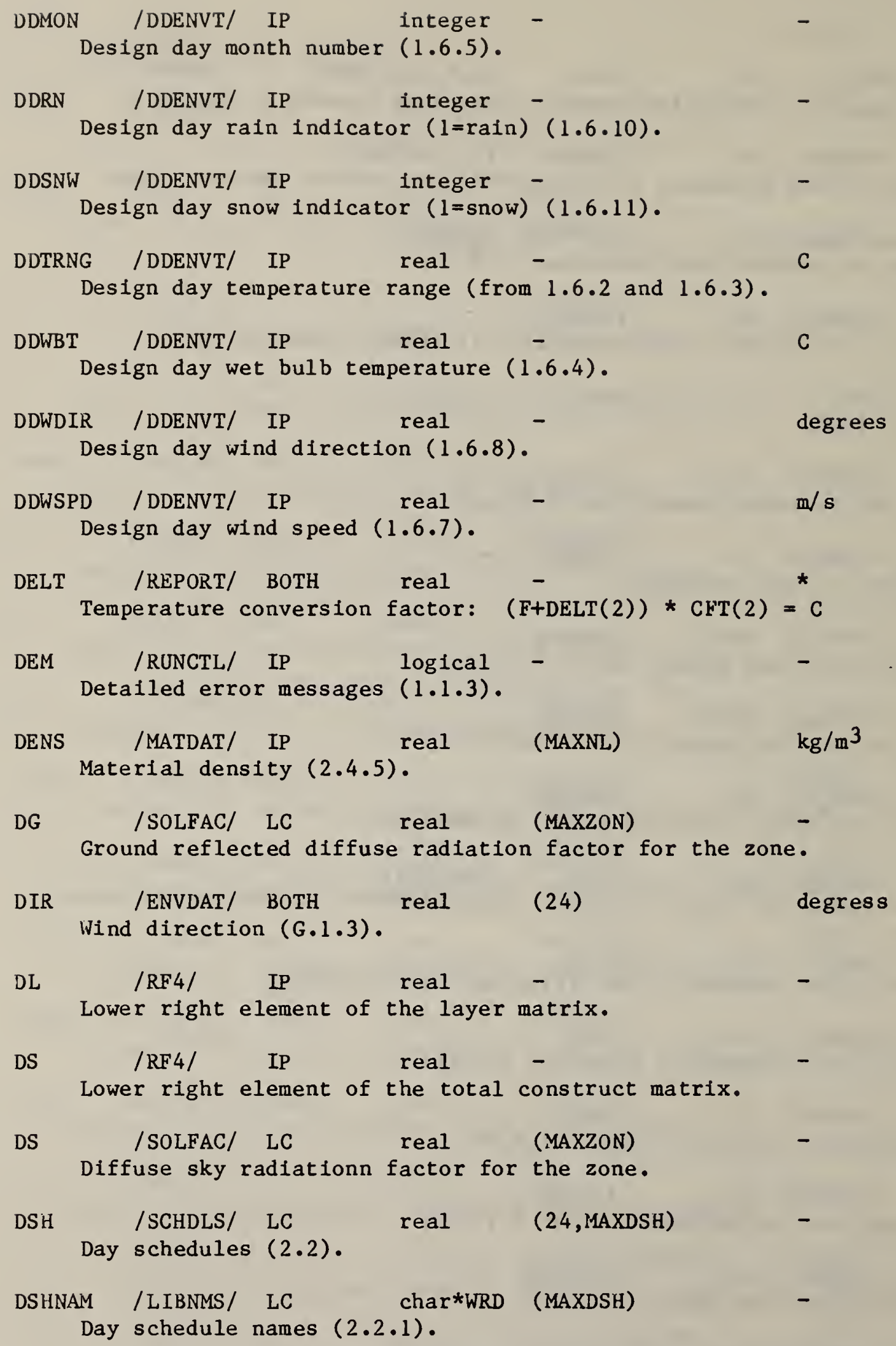


DSTIND /ENVDAT/ BOTH integer -

Daylight savings time indicator.

DSO /LIBCTL/ IP integer -

Pointer to day schedules in LNAMES (location 0 ).

DT /RF4/ IP real

Lower right element of total derivative matrix.

DTR /REPORT/ BOTH real

Conversion factor: degrees * DTR = radians.

DYS /CALNDR/ BOTH

Names of day types (2.3.3).

EELOAD / ZONL/ LC real (NAAZON) Wh

Zone electric load (lights plus electric equipment).

EFILL /ENVDAT/ BOTH integer (3)

Array filler.

EFSTR /TCDESC/ LC integer (MAXZON)

Pointer to temperature control range ( $p$ in $K .1 .1$ ).

EMIT $\begin{gathered}\text { /MATDAT/ IP } \\ \text { Emittance o material for thermal wavelength radiation }\end{gathered}$

EMUI $\begin{gathered}\text { /RUNCTL/ IP } \\ \text { Input in English (2) or metric (1) units (1.1.7). }\end{gathered}$

EMUO /REPORT/ BOTH
Output in English (2) or metric (1) units (1.1.7).

ENDATE /SIMCTL/ LC integer -

Cyclic date on which current shadowing data ends.

ENVDAT /ENVDAT/ BOTH integer (256)

Environment data - all equivalenced to this array.

ENVREC /SIMCTL/ LC A integer -
Environment record number (index to ENVTFL direct access file).

ENVTNR /SIMCTL/ LC integer -

Environment number.

EQTIME /ENVDAT/ BOTH real -

Equation of time.

EQTM /SLPSSH/ BOTH real -

Equation of time. 
ETITLE /TITLES/ BOTH char ${ }^{\star D E S C}$ (13)

Environment titles $(1.5 .1$ and 1.6 .1$)$.

EVDATE /ENVDAT/ BOTH integer -

Julian date (JD in B.1.2).

EXTC /GLAS9/ IP real (4)

Product of pane extinction coefficient times thickness.

EXTCW /GLAS10/ IP real (4, MAXNW) -
Product of pane extinction coefficient times thickness for each wavelength.

EVTR. /TCDESC/ LC integer (MAXZON)

Pointer to ventilation control temperature range.

FACTOR / ZONL/ LC real (MAXZON) C

Intermediate result for computing mean radiant temperature

$\left(T R L_{n}\right.$ if $\mathrm{H} .2 .4 \mathrm{C}$ ).

FAFS /ZONISL/ BOTH integer (MAXZON)

Number of the first air flow opening in the zone description.

FAHS /ZONL/ LC real (IAXZON) $\mathrm{m}^{3} / \mathrm{s}$

Net air flow from the air handling system into the zone (set to 0 ).

FAREA /AFSIL/ BOTH real (MAXAFS) $\mathrm{m}^{2}$

Air flow opining area $(4 \cdot 14 \cdot 1)$.

FBKSHC /SHDCTL/ LC integer -

Pointer to HC location for inside (back) surface calculations.

FCOS1 /AFSIL/ BOTH real (MAXAFS)

Direction cosine of opening for computing relative wind direction.

FCOS2 /AFSIL/ BOTH real (MAXAFS)

Direction cosinf of opening for computing relative wind direction.

FCOUNT /SIMCTL/ LC integer -

Number of air flow iterations from start of simulation.

FEXP /AFSIL/ BOTH real (MAXAFS)

Air flow opening exponent $(4.14 .2)$.

FD /GLAS9/ IP real $(2,4)$

Thickness of reflective films ( $D$ in $D .4 .4 a$ ).

(side, pane number)

FGSSHC /SHDCTL/ LC integer -

Pointer to HC location for general shadowing surface calculations. 


\section{FHTS /ZONISL/ BOTH integer (MAXZON)
Number of the first heat transfer surface in the zone description.}

\section{FINSHC /SHDCTL/ LC integer -}

Pointer to HC location for inside solar distribution calculation.

FK

$$
\text { /GLAS9/ IP real }(2,4)
$$

Reflective film extinction coefficient ( $k_{2}$ in $\mathrm{D.4.1}$ ). (side, pane number)

FKW

$$
\text { /GLAS10/ IP real (4, MAXNWL) }
$$

Reflective film extinction coefficient ( $k_{2}$ in $\left.D .4 .1\right)$. (pane number, wavelength)

FLRTFP /CONDAT/ BOTH integer (MAXCON)

Pointers to flux components of conduction transfer functions.

FLXHPE /HTSIL/ BOTH integer (MAXHTS)

Pointers to external flux histories.

FLXHPI /HTSIL/ BOTH integer (MAXHTS)

Pointers to internal flux histories.

FN /GLAS9/ IP real $(2,4)$

Reflective film index of refraction ( $n_{2}$ in $\left.D .4 .1\right)$. (side, pane number)

FNW /GLAS10/ IP real (4,MAXNWL)

Reflective film index of refraction ( $n_{2}$ in $\left.D .4 .1\right)$. (pane number, wavelength)

FP / ZONL/ LC integer (MAXZON)

Pointer to scheduled fan action (RCGS).

FRVLHC /SHDCTL/ LC integer -

Pointer to HC location for setback (reveal) calculations.

FSBSHC /SHDCTL/ LC integer -

Pointer to HC location for subsurface calculations.

FSG /HTSISL/ BOTH real (MAXHTS)

Angle factor between the surface and the ground $(4.13 .8$ and E.5.1 and I. $2.6 \mathrm{c}$ ).

FSRF / ZONISL/ BOTH integer (MAXZON)

Number of first surface in zone description.

FSS /HTSISL/ BOTH real (MAXHTS)

Angle factor between the surface and the sky $(4.13 .7$ and E.5.1 and I.2.6a,b). 


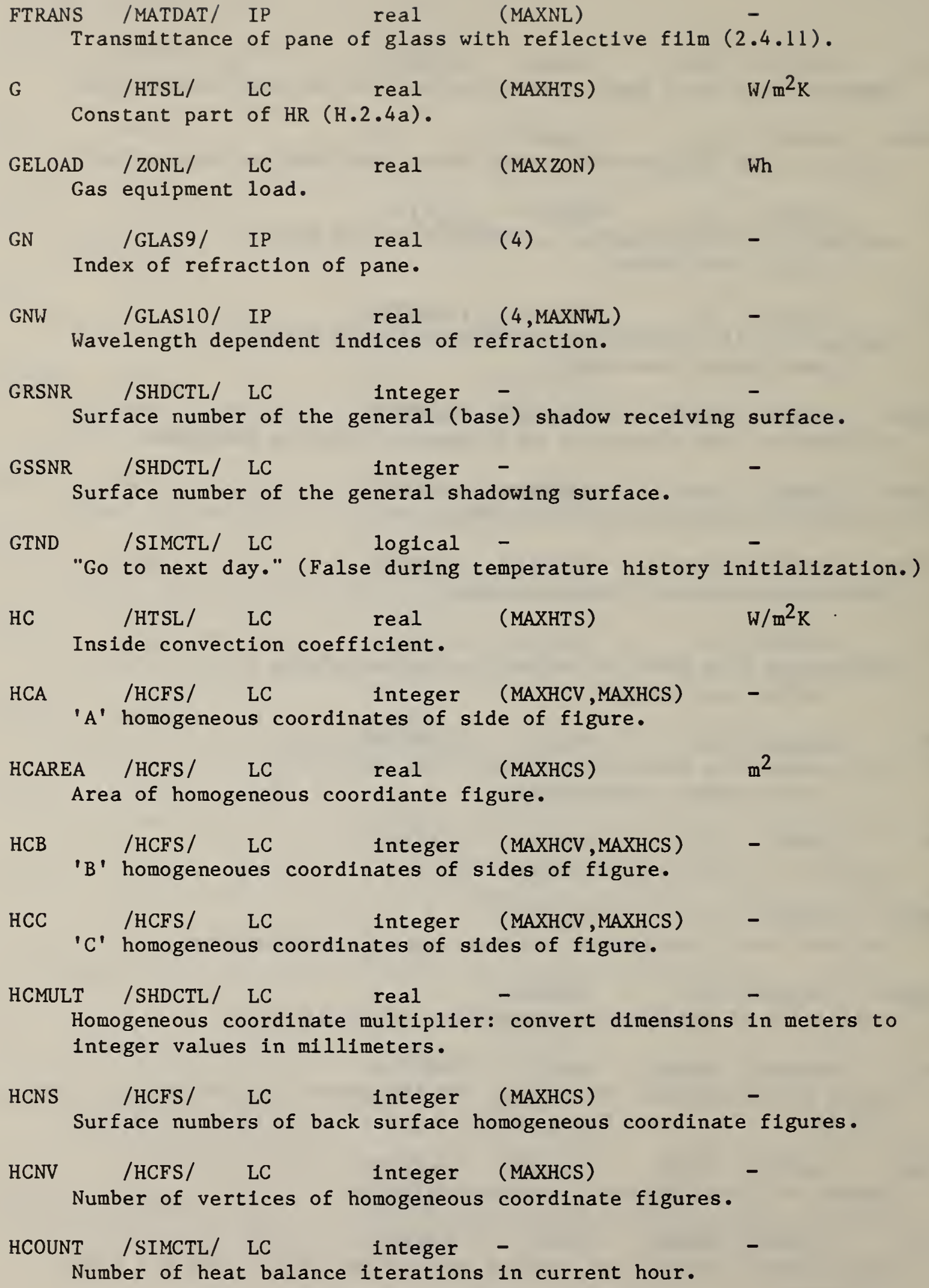




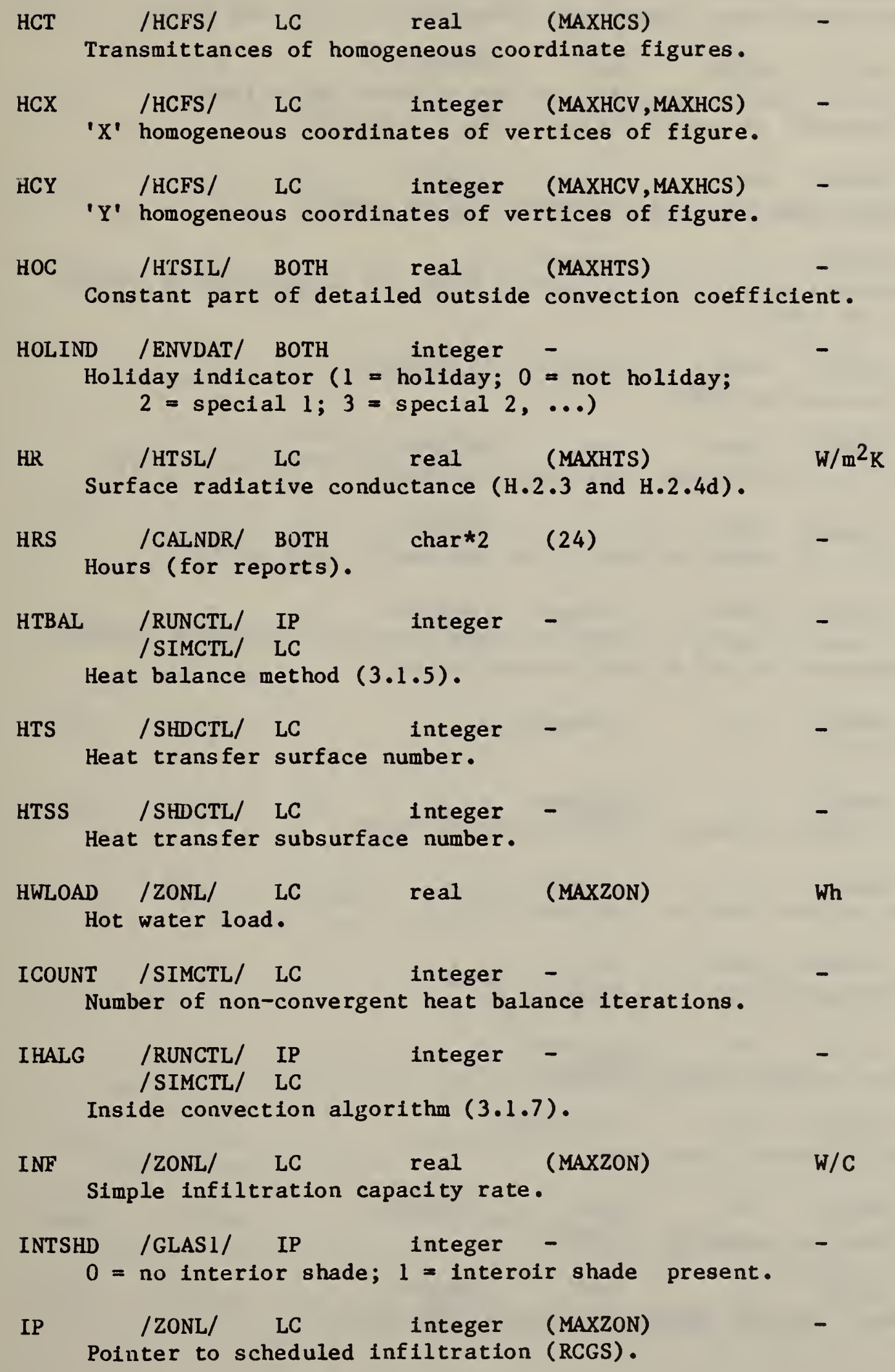




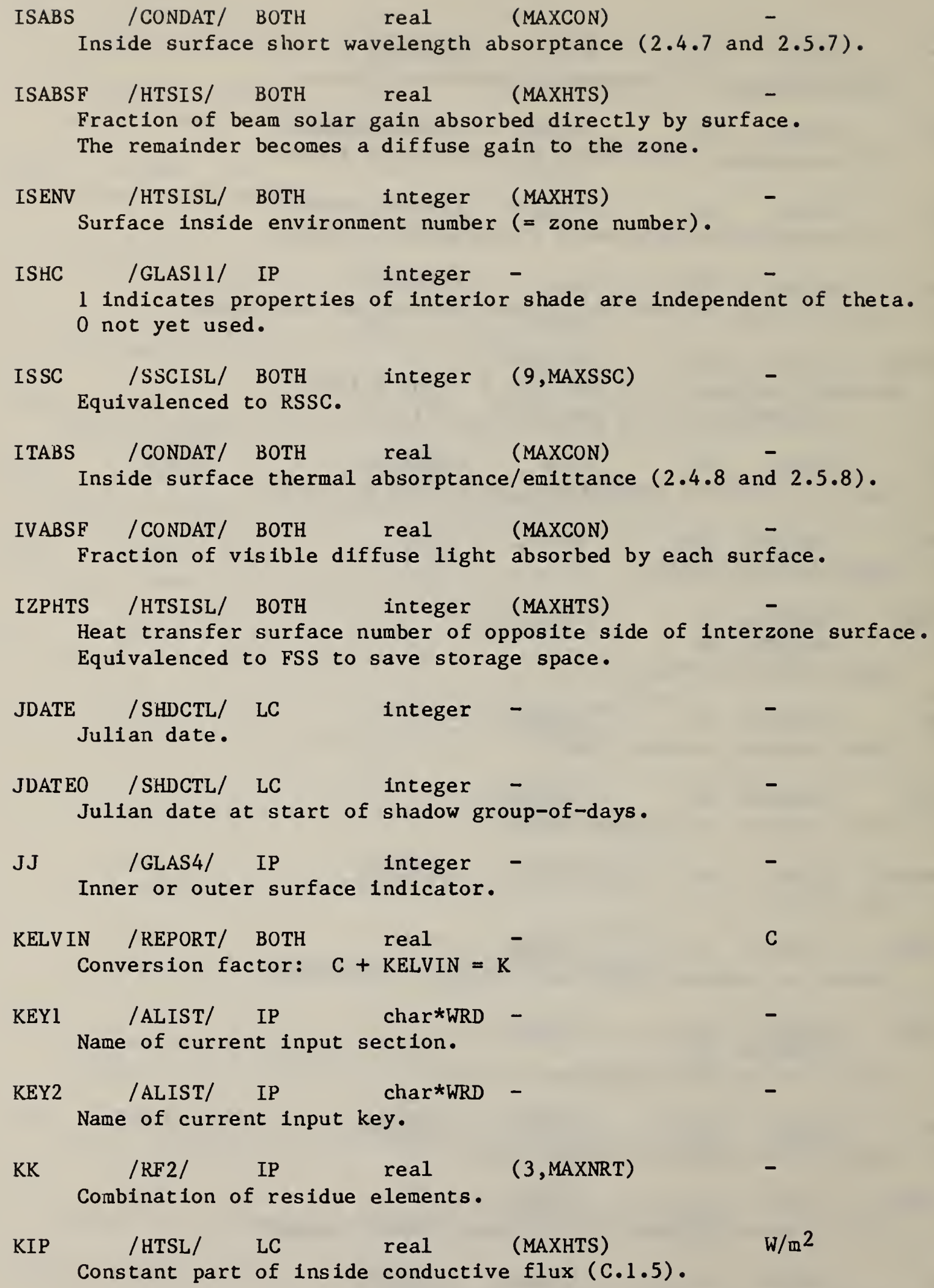




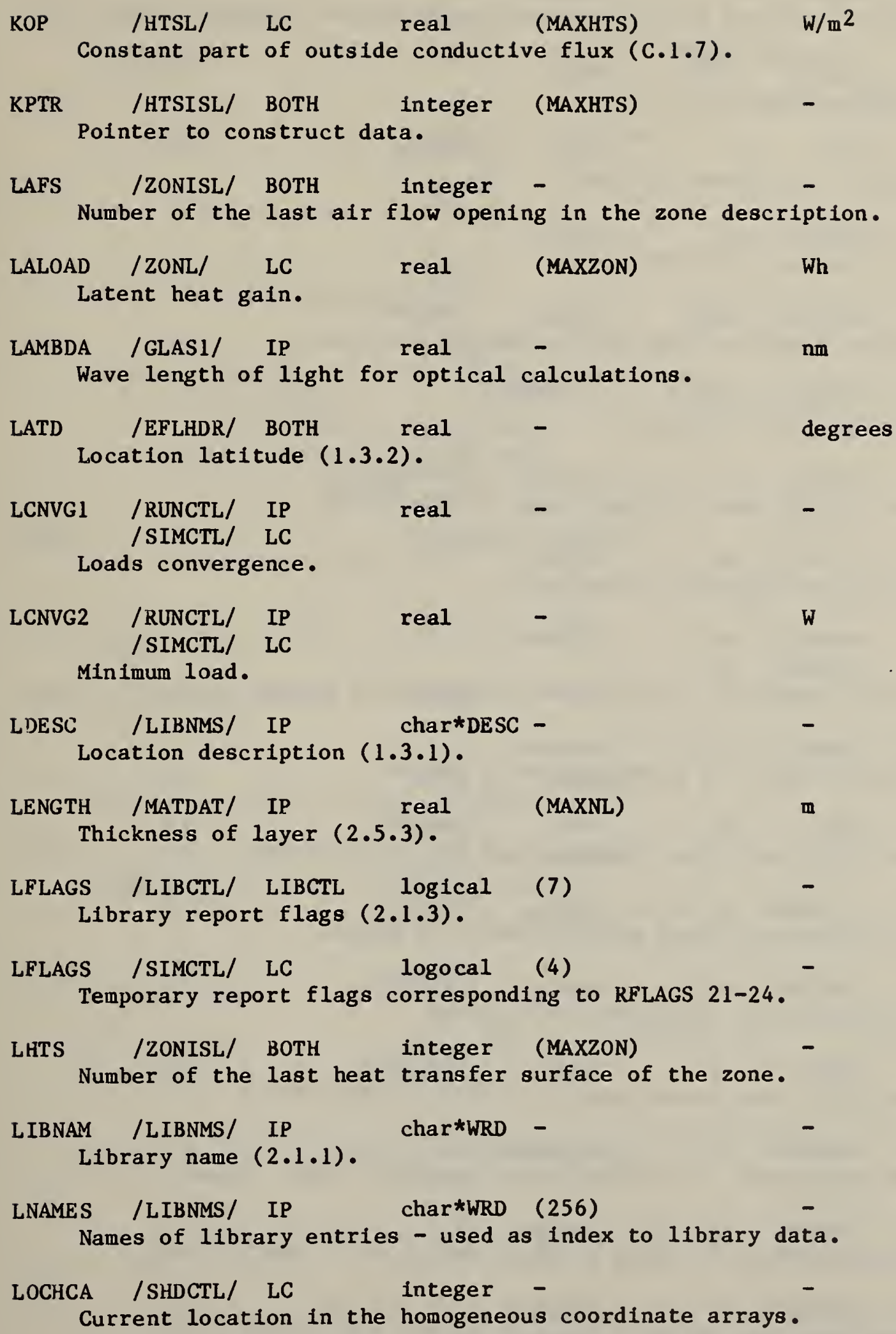




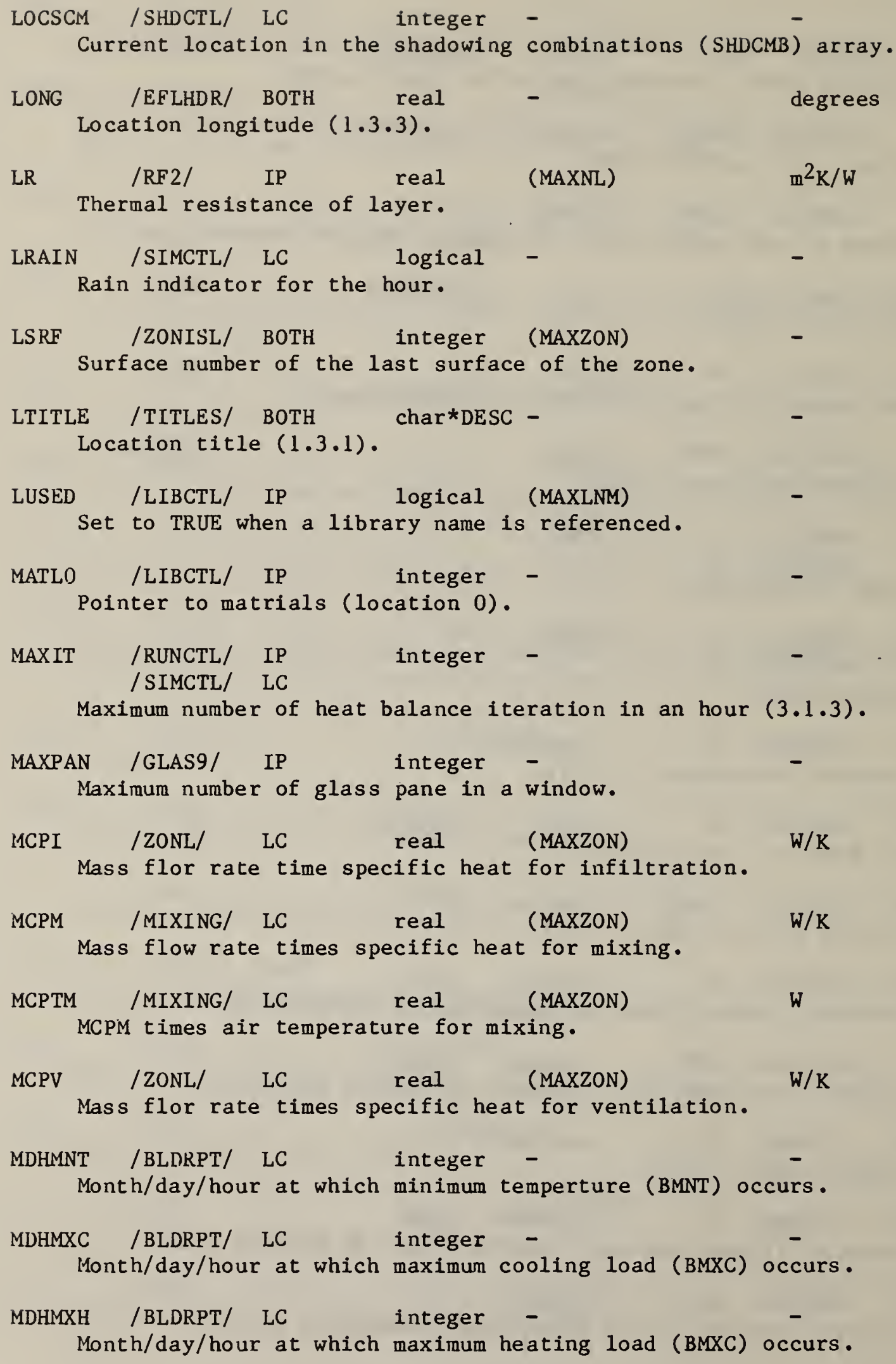




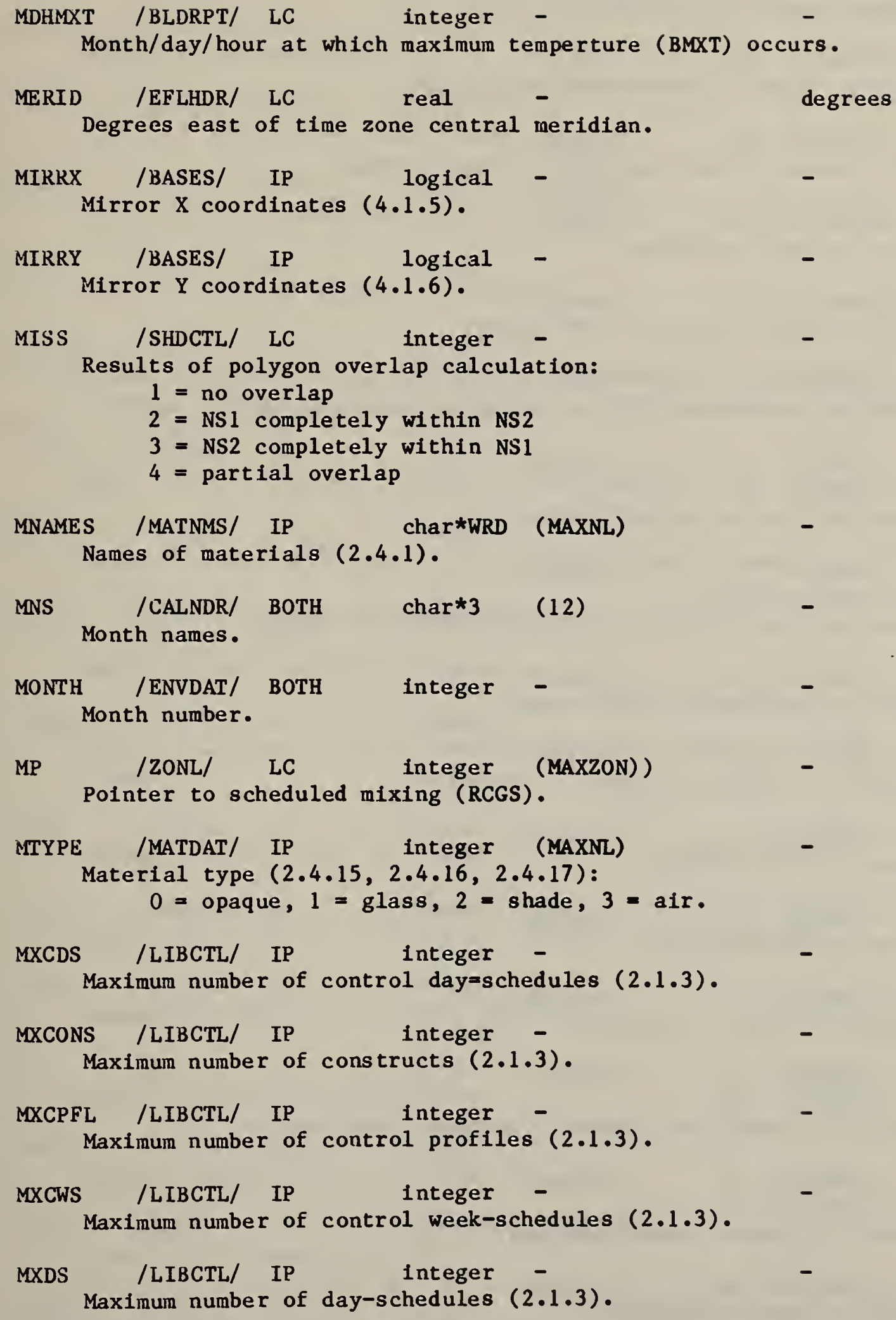




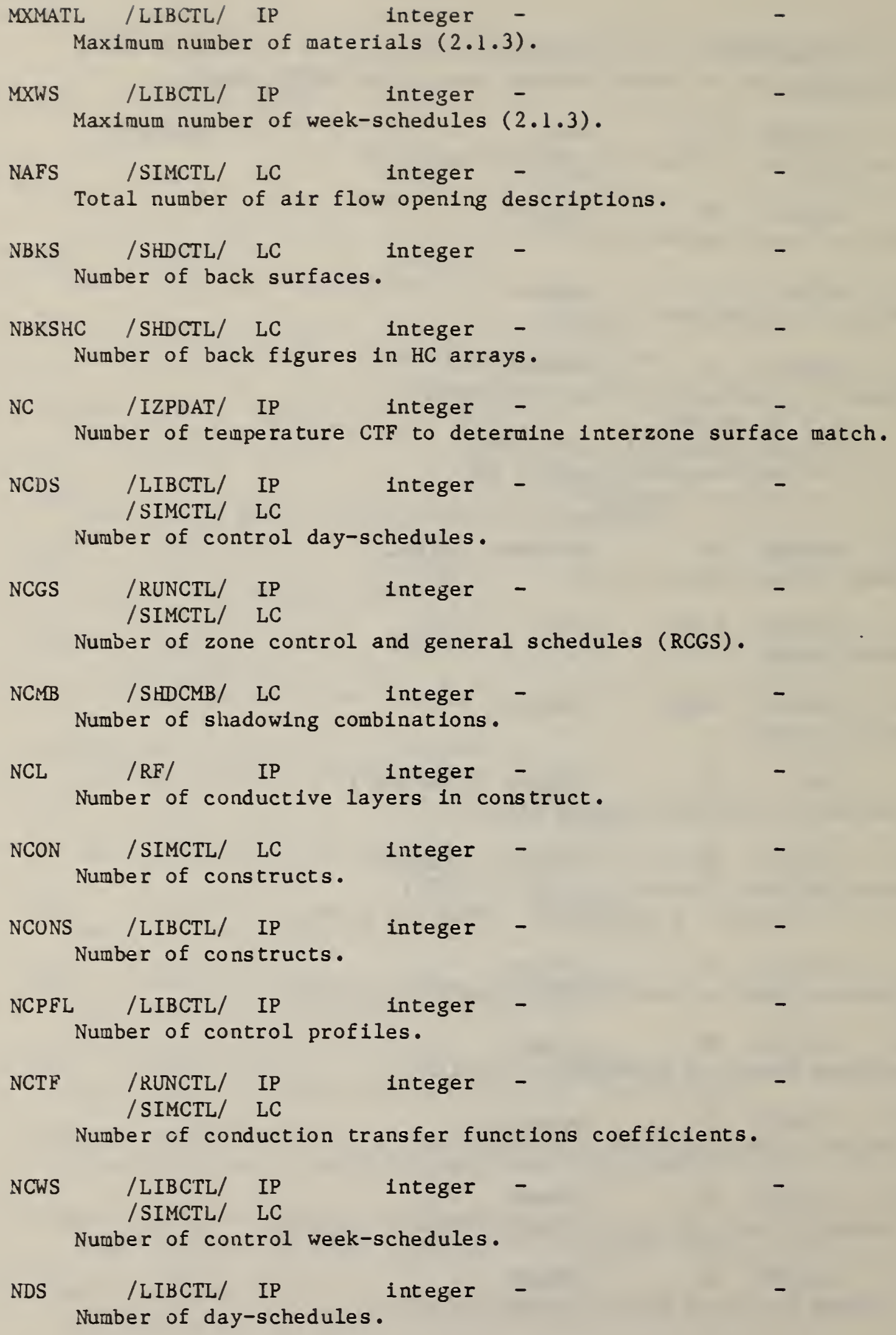




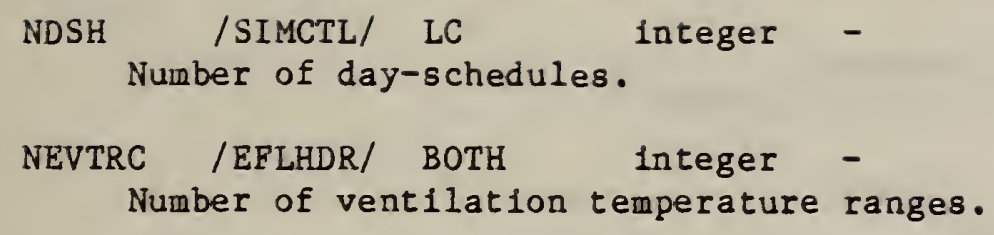




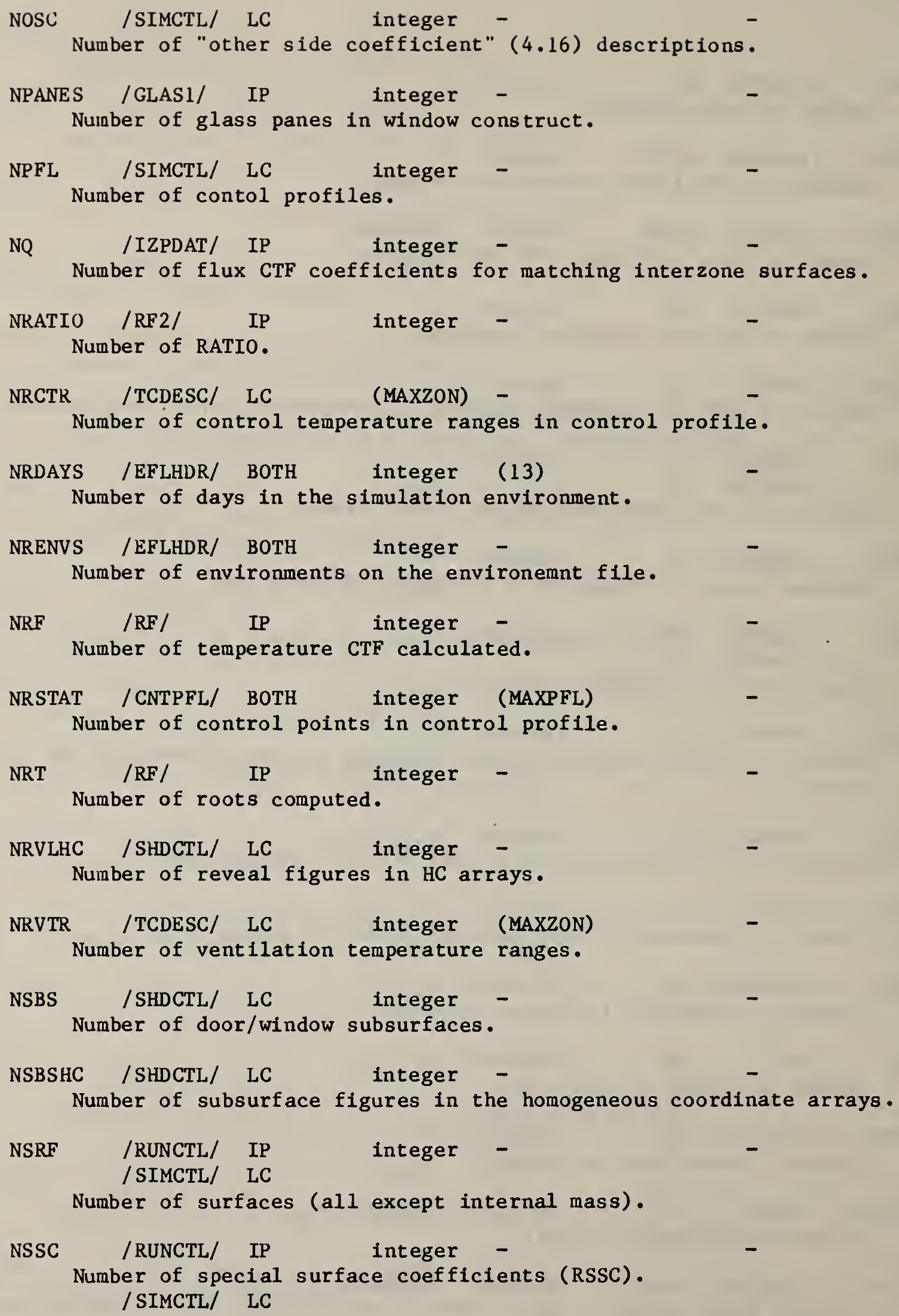




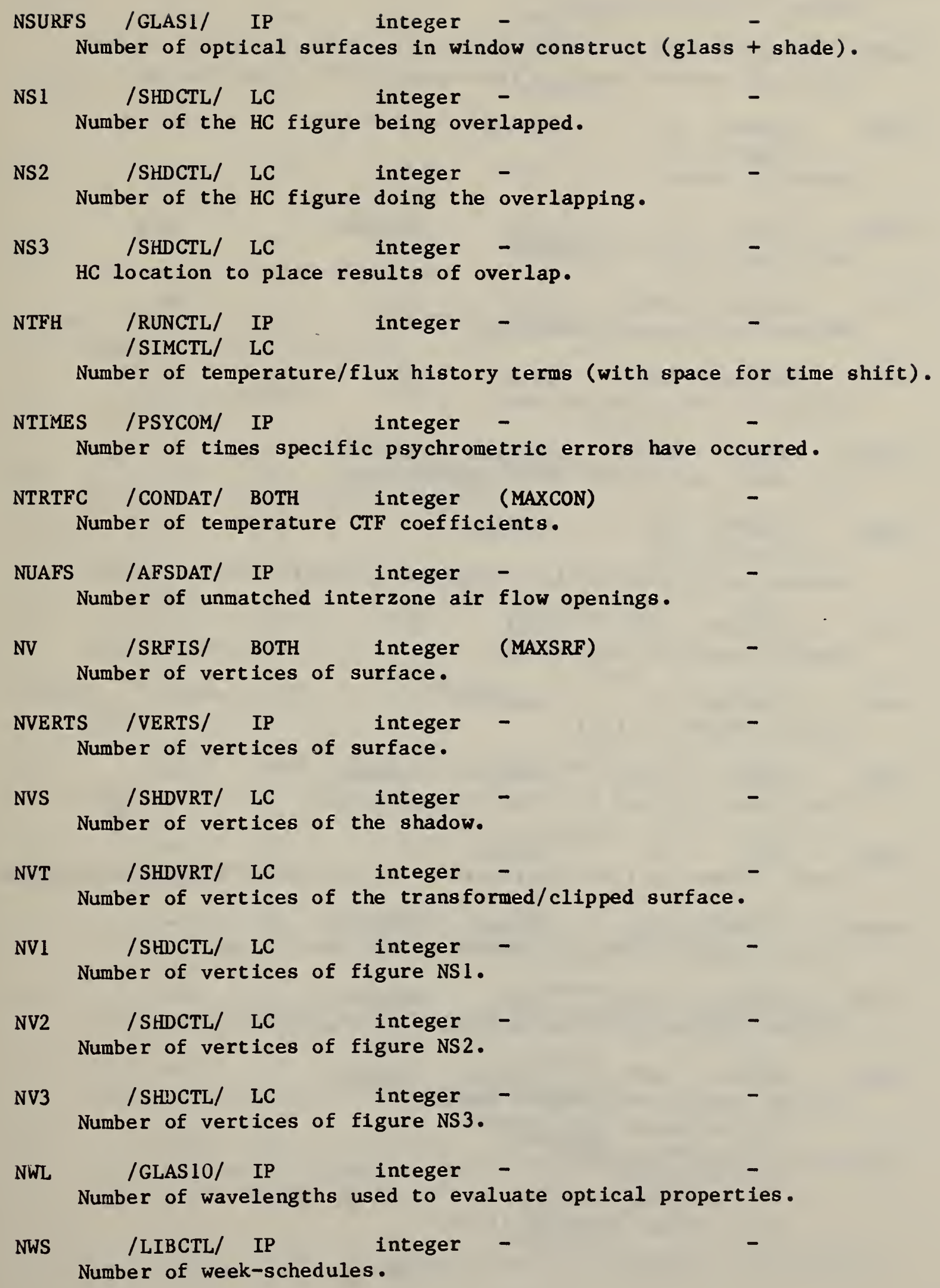




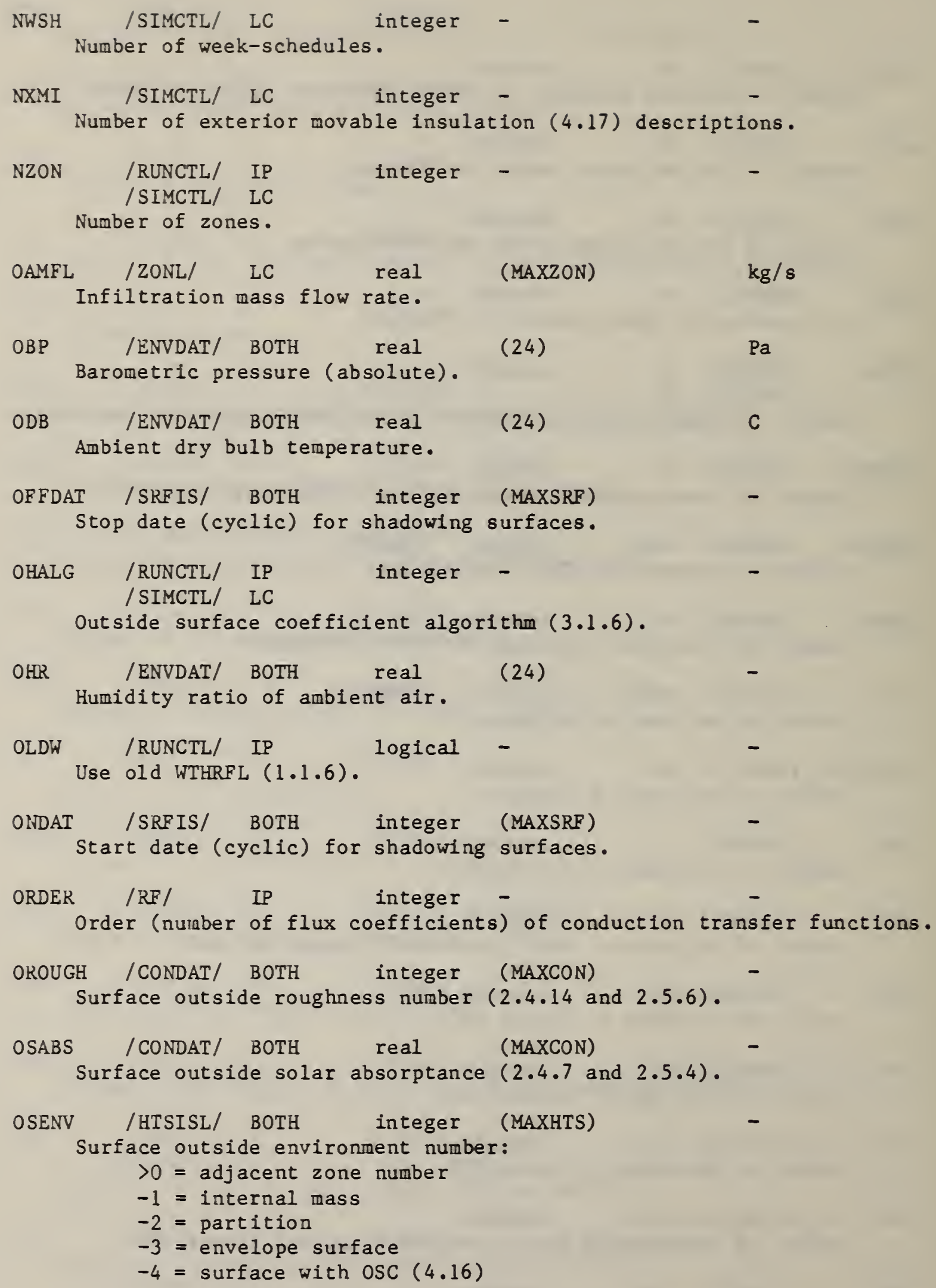




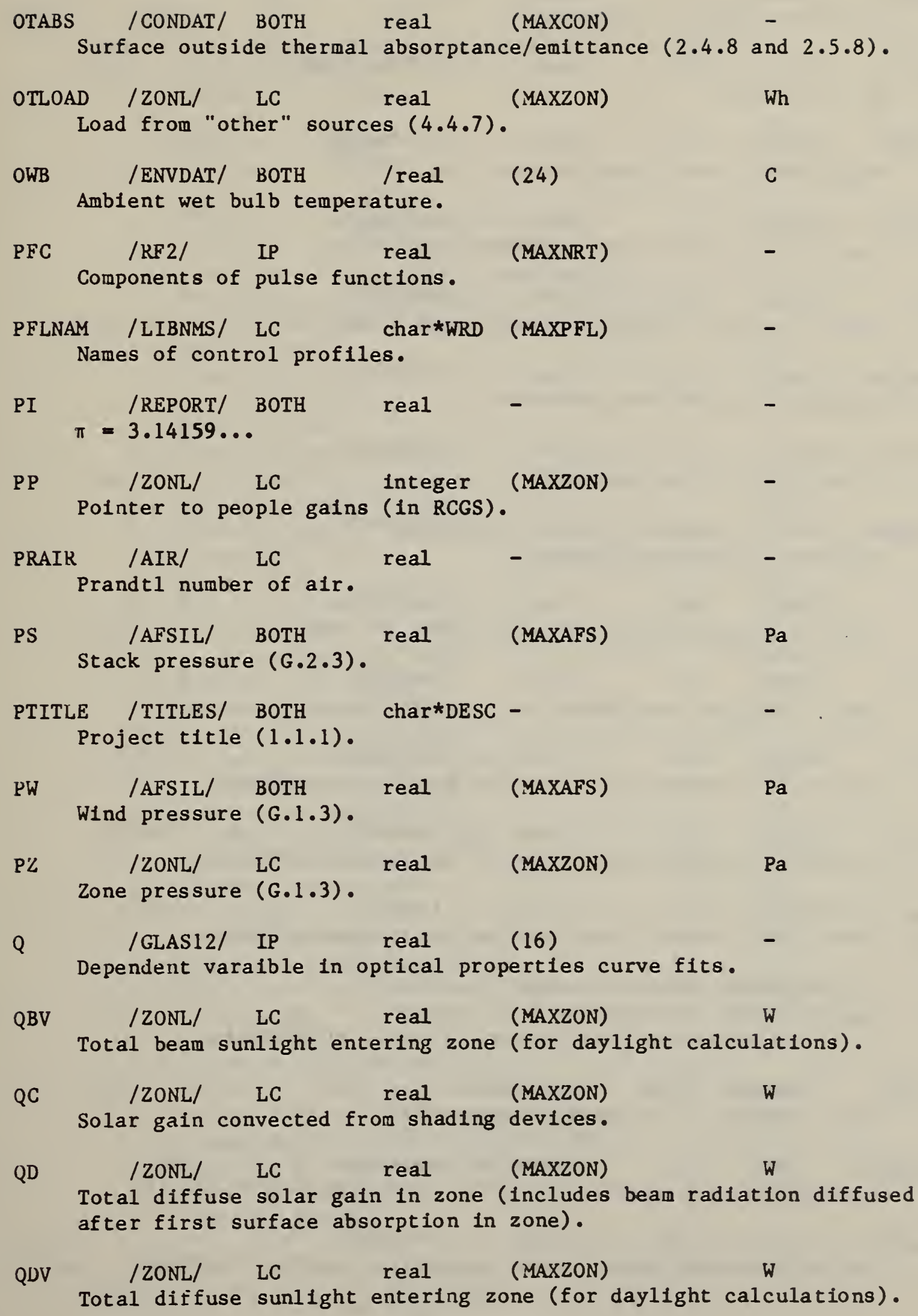




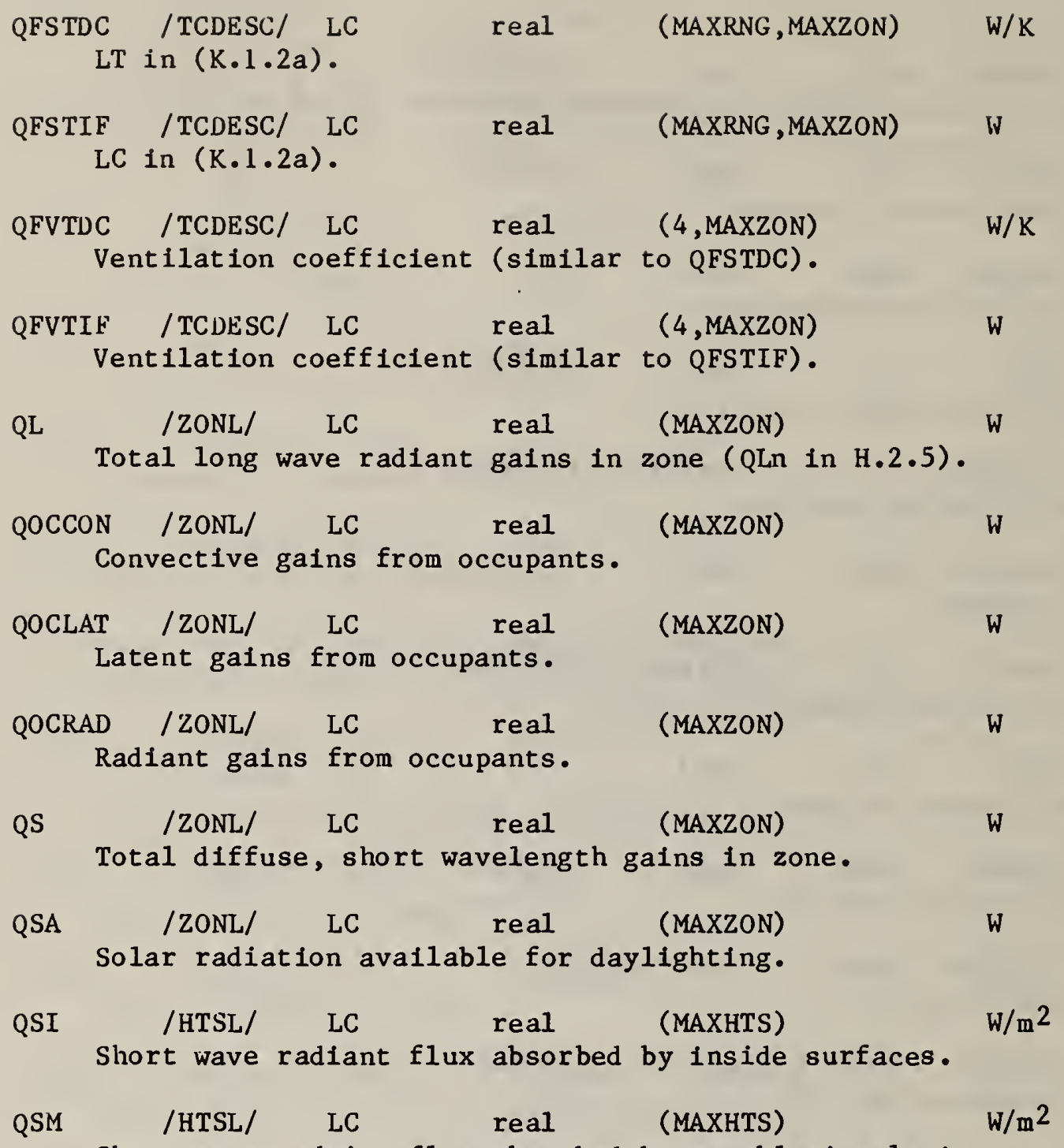




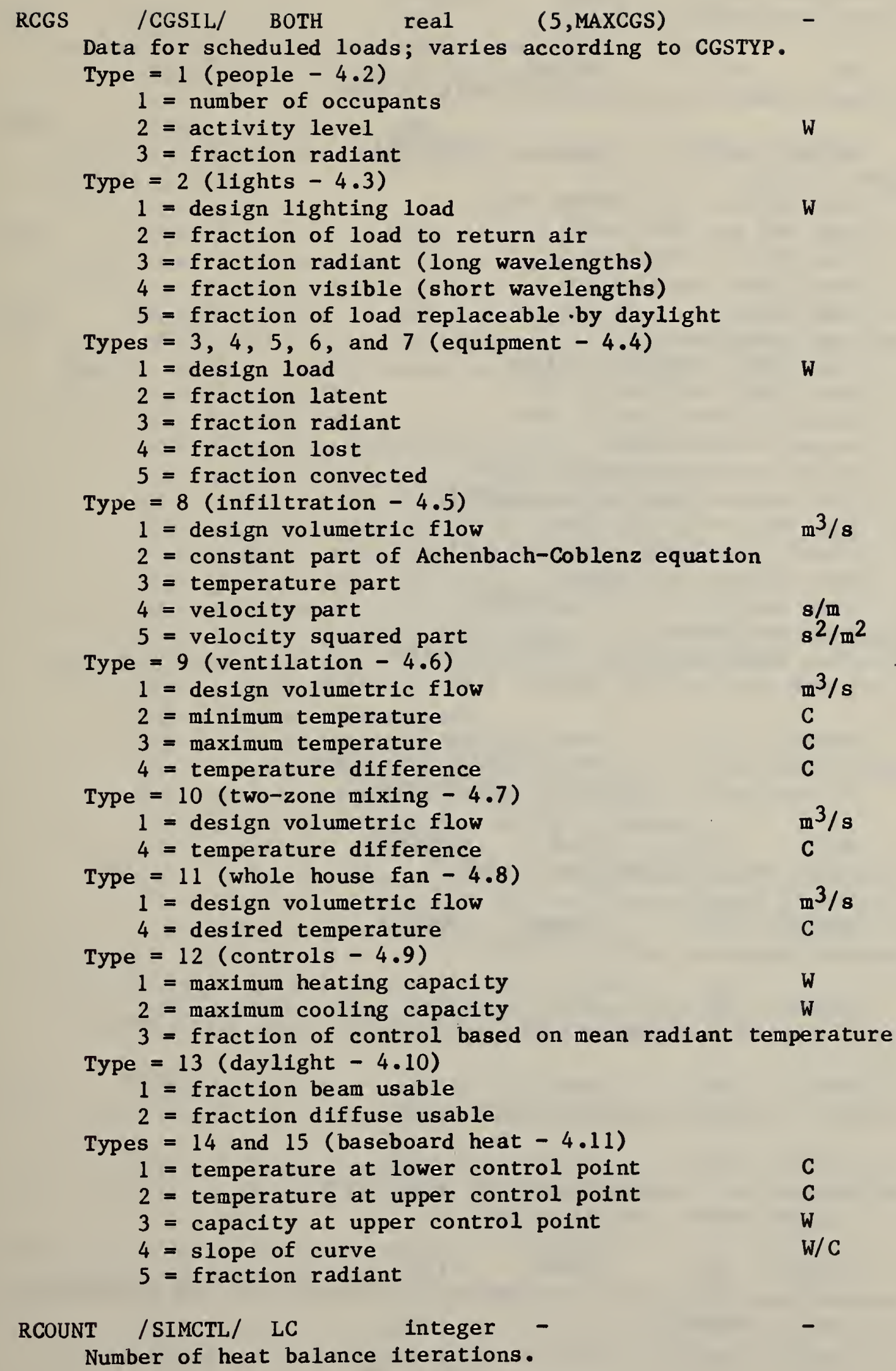




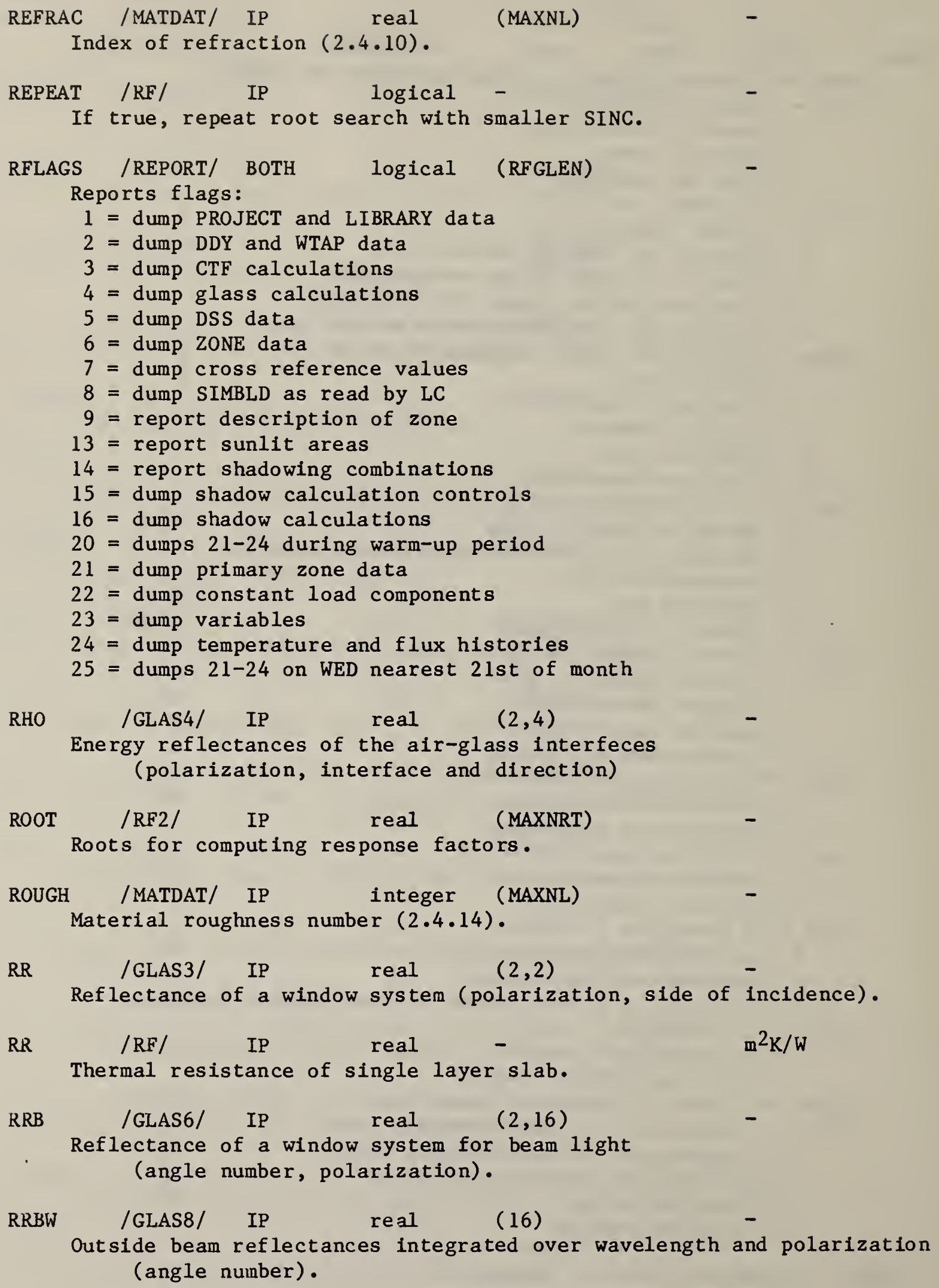


$\mathrm{RRD}$

$\begin{array}{ccc}\text { /GLAS5/ IP } & \text { real }(2,2) \\ \text { Reflectances of a window system for diffuse 1ight }\end{array}$ (polarization, side of incidence).

RRDW /GLAS7/ IP $\quad$ real -
Outside diffuse reflectance integrated over wavelength and polarization.

RSD

$$
\text { /GLAS11/ IP real }
$$

Reflectance of shade for diffuse 1ight.

RSSC
/SSCISL/ BOTH
real
$(9$, MAXSSC)

Array of special surface coefficients created by OSC (4.16), EMI (4.17)

and IMI (4.18). Equivalenced to ISSC for integer values.

For OSC, $\operatorname{RSSC}(\mathrm{N}, \mathrm{SSC})=$

$\mathrm{N}=1: \quad 3$ (integer)

$\mathrm{N}=2$ : convection coefficient $(4 \cdot 16 \cdot 1)$

$\mathrm{N}=3$ : zone air temperature part $(4 \cdot 16.2)$

$\mathrm{N}=4$ : ambient air temperature part $(4 \cdot 16 \cdot 3)$

$\mathrm{N}=5$ : constant temperature $(4 \cdot 16.4)$

$\mathrm{N}=6$ : cons tant temperature part $(4 \cdot 16.5)$

$\mathrm{N}=7$ : ground temperature part $(4 \cdot 16.6)$

$\mathrm{N}=8$ : wind speed factor $(4 \cdot 16.7)$

$\mathrm{N}=9$ : heat transfer surface number of base surface (integer)

For $\operatorname{EMI}, \operatorname{RSSC}(\mathrm{N}, \mathrm{SSC})=$

$\mathrm{N}=1$ : 1 (integer)

$\mathrm{N}=2$ : U-value of construct

$\mathrm{N}=3$ : outside solar absorptance

$\mathrm{N}=4$ : outside thermal absorptance

$\mathrm{N}=5$ : surface roughness number (integer)

$\mathrm{N}=6$ : start date (cyclic) (4.17.3) (integer)

$\mathrm{N}=7$ : stop date (cyclic) (4.17.3) (integer)

$\mathrm{N}=8$ : positive value = pointer to day-schedule $(4.17 .2)$, -1 = sun up control, -2 = sun down control (integer)

$\mathrm{N}=9$ : heat transfer surface number of the base surface (integer)

For IMI, $\operatorname{RSSC}(\mathrm{N}, \mathrm{SSC})=$

$\mathrm{N}=1$ through $\mathrm{N}=7$ and $\mathrm{N}=9$ : same as EMI

$\mathrm{N}=8$ : positive value = pointer to day-schedule (4.18.2),

-1 = maximum heat gain, $-2=$ maximum heat loss (integer)

RSO

/GLAS11/ IP real

Reflectance of shade at normal incidence (2.4.12).

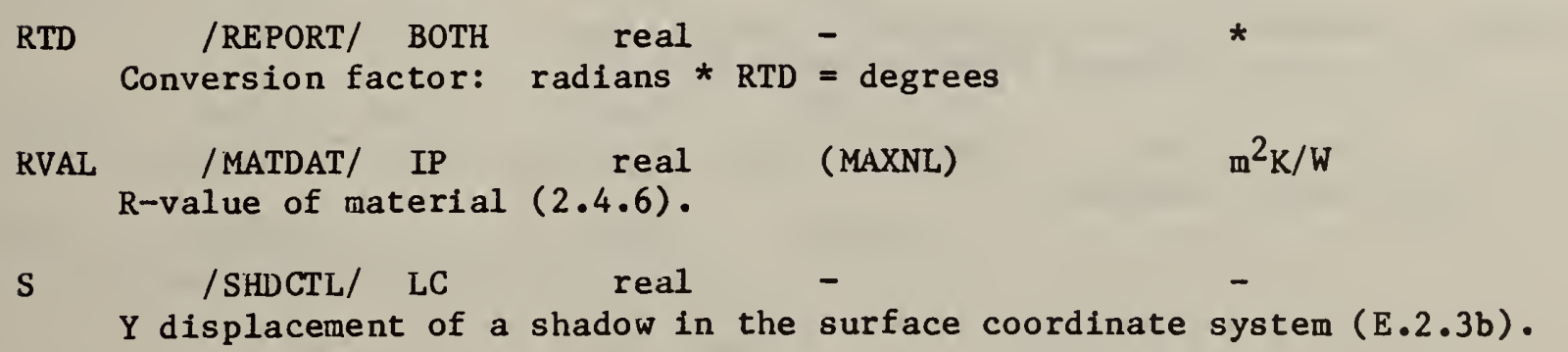


SA

$$
\text { /SRFIS/ BOTH real (MAXSKF) }
$$

Sine of surface azimuth angle (4.13.3).

SABS

$$
\text { /MATDAT/ IP real (MAXNL) }
$$

Solar absorptance of the material (2.4.7).

SAREA /HTSIS/ BOTH real (MAXHTS)

$\mathrm{m}^{2}$

Sunlit area of the surface.

SBSNR /SHDCTL/ LC integer -

Subsurface number; pointer to SRFIS arrays.

SFAZIM /HTSIL/ BOTH real (MAXHTS)

Surface azimuth angle (3.2.1 and 4.13.3).

degrees

$\begin{array}{rlc}\text { SHAPE IPERTS/ IP } & \text { integer - } & - \\ \text { Surface shape number: } & \text { 1=triangle, } 2=\text { quadrilateral, } 3=\text { rectangle, }\end{array}$ $4=$ door/window, 5=overhang, 6=projection, $7=$ left fin, $8=$ right fin .

SHDCF /MATDAT/ IP real (MAXNL)

Shading coefficient of material (2.4.13).

SHDCMB / SHDCMB/ LC integer (MAXCMB)

Shadowing combinations array. For each base, envelope surface:

surface number, number of shadowing surfaces, number of back surfaces, number of subsurfaces, list of shadowing surfaces, list of back surfaces, list of subsurfaces.

SHDGRP /SIMCTL/ LC integer -

Shadow group (of days) number.

SHDREC /SIMCTL/ LC integer -

Shadow file record. number.

SHDSRF /SRFIS/ BOTH integer (2,MAXSRF)

Surface data array (for shadowing).

$\operatorname{SHRSRF}(1, \mathrm{NS})=$

+1 to +MAXHTS: Heat transfer surface number (HTS or I) of surface NS.

0 : Detached shadowing surface.

$-1 \quad$ : Shadowing subsurface.

$\operatorname{SHRSRF}(2, \mathrm{NS})=$

+1 to +MAXHTS: Coordinates are relative to global origin.

-1 to -MAXHTS: Coordinates are relative to surface-HTS.

SINBR /RUNCTL/ IP real

Sine of the building rotation angle (3.1.1).

SINC /RF/ IP real

Root search increment. 
SIND /SLPSSH/ BOTH real -
Sine of the solar declination angle.

SINL /EFLHDR/ BOTH real

Sine of the location latitude (1.3.2).

SINZR /BASES/ IP real

Sine of the zone rotation angle (4.1.2).

SKY /ENVDAT/ BOTH real (24)

C

Sky temperatures (B.3.4).

SNAME /ZNAMES/ IP chr*WRD -

Schedule name.

SNLOAD / ZONL/ LC real (MAXZON) Wh

Sensible heating $(+)$ or cooling $(-)$ load in the zone.

SNOW /ENVDAT/ BOTH integer -

Snow indicator (compressed 24 hours).

SOLDIS /RUNCTL/ BOTH integer -

Solar distribution algorithm $(3 \cdot 1 \cdot 2)$.

SPC2
If true, double space the echo of user input $(1.1 .4)$.

SPD /ENVDAT/ BOTH real (24) m/s

Wind speed.

$\begin{array}{llllll}\text { SPHT } & \text { /MATDAT/ } & \text { IP } & \text { real } & \text { (MAXNL) } & \mathrm{kJ} / \mathrm{kgK} \\ \text { Specific heat } & \text { of material } & (2.4 .4) & \\ \text { SQTRDZ } & \text { /ZONL/ } & \text { LC } & \text { real } & \text { (MAXZON) } & \sqrt{\mathrm{kg} / \mathrm{m}^{3}}\end{array}$

Square root of zone air density.

SQRTV /AIR/ LC real - $\quad \sqrt{(\mathrm{m} / \mathrm{s})}$

Square root of wind velocity.

SRADBM /ENVDAT/ BOTH real (24) $\mathrm{W} / \mathrm{m}^{2}$

Intensity of beam solar radiation.

SRADDF /ENVDAT/ BOTH real (24) W/m²

Intensity of diffuse solar radiation (sky brightness).

SRADGR /ENVDAT/ BOTH real (24) W/m²

Intensity of ground reflected solar radiation.

SREF /MATDAT/ IP real (MAXNL)

Reflectance of shade $(2 \cdot 4 \cdot 12)$. 


\section{SSCPTR /HTSISL/ BOTH integer (MAXHTS)}

Pointer to special surface coefficients.

SSDECL /ENVDAT/ BOTH real

Sine of the solar declination angle.

ST

$$
\text { /SRFIS/ BOTH real (MAXSRF) }
$$

Sine of the surface tilt angle (3.2.2 and 4.13.4).

STATM /BLDRPT/ LC integer (6,MAXZON)

System status hours: Total for run in 6 categories.

1 = heating capacity exceeded.

2 = in heaing mode.

3 = in ventilation mode.

4 = in cooling mode.

5 = cooling capacity exceeded.

6 = no heating, cooling, or ventilating.

STDTIM /SIMCTL/ LC integer -

Standard time $\left(t_{s}\right.$ in $\left.\sec B .1 .1\right)$.

STLOAD /ZONL/ LC real (MAXZON) Wh

Steam load in zone (steam equipment plus steam baseboard heat).

SUMB /RF/ IP real

Sum of BETA values for all layers.

SUMC /ZONL/ LC real (MAXZON) W

Sum of scheduled convective gains.

SUMDTI /ZONL /LC real (MAXZON)

Sum of outside temperature derivatives.

SUMHA /ZONL/ LC real (MAXZON) W/K Sum of (HI*AREA) for zone surfaces ( $\mathrm{HCi}$ *Si in $\mathrm{K.2.2}$ ).

SUMHAD /ZONL/ LC real (MAXZON)

Sum of air temperature derivatives (J.3.4a, J.4.2a, J.5.8a, J.5.10a).

SUMHAT /ZONL/ LC real (MAXZON) W

Sum of $\left(H I^{*} A R E A * T\right)$ for zone surfaces $\left(H C_{1} * S_{1} * T_{1}\right.$ in $\left.K .2 .2\right)$.

SUMUA /ZONL/ LC real (MAXZON) W/K

Sum of (HR*AREA) for zone surfaces $(H .2 .5)$.

SUMUAD /ZONL/ LC real (MAXZON)

Sum of radiant temperature derivatives (J.3.4b, J.4.2b, J.5.8b, and $\mathrm{J} \cdot 5 \cdot 10 \mathrm{~b}$ ).

SUMUAT /ZONL/ LC real (MAXZON)

Sum of (HR*AREA*T) for zone surfaces (H.2.5). 


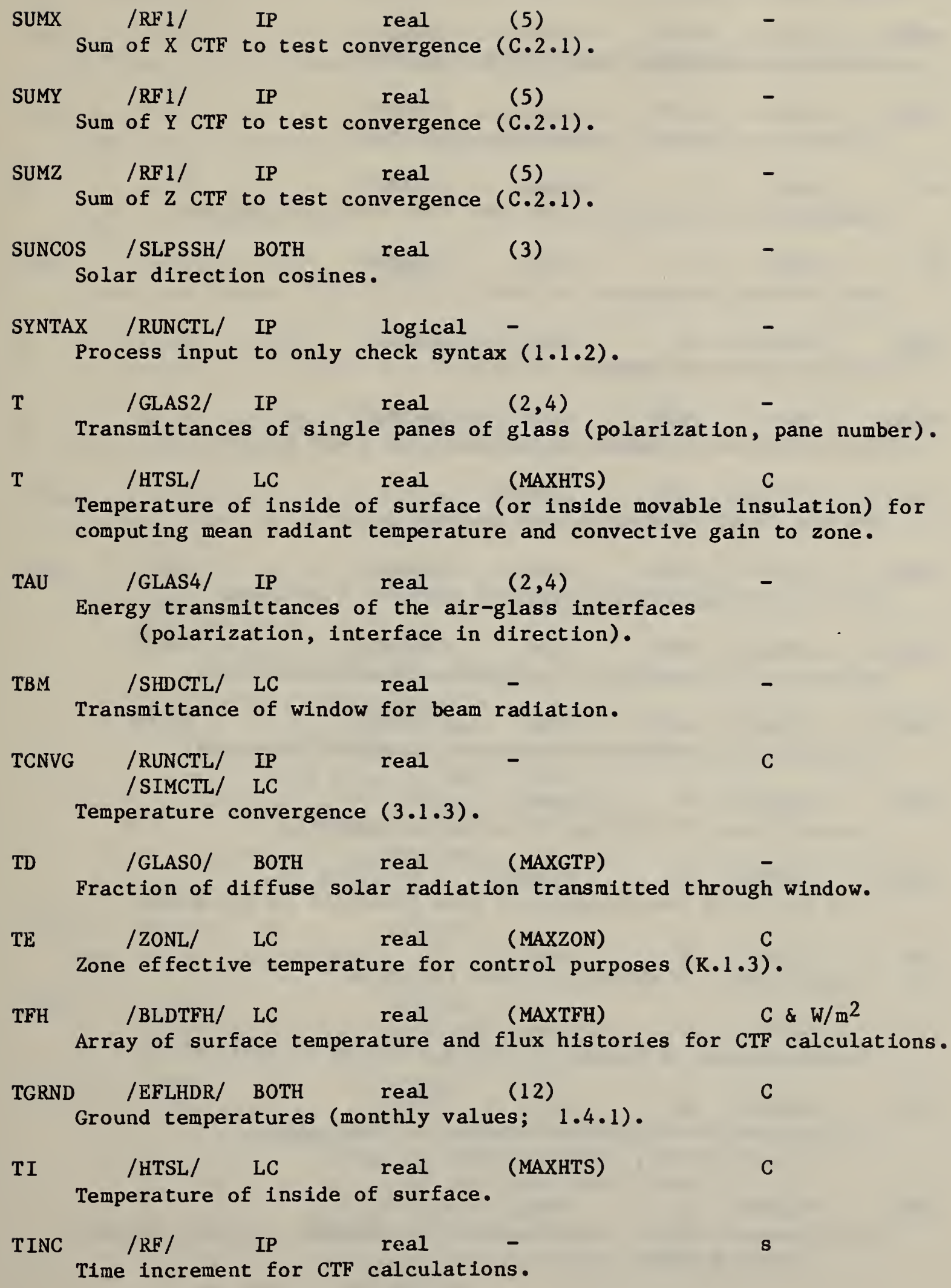

TD

$$
\text { /GLASO/ BOTH real (MAXGTP) }
$$

Fraction of diffuse solar radiation transmitted through window.

$\mathrm{TE}$

$$
\text { /ZONL/ LC real (MAXZON) }
$$

Zone ef fective temperature for control purposes (K.1.3).

TFH

$$
\text { /BLDTFH/ LC real (MAXTFH) C\& W/m } 2
$$

Array of surface temperature and flux histories for CTF calculations.

TGRND /EFLHDR/ BOTH real (12) C

Ground temperatures (monthly values; 1.4.1).

TI /HTSL/ LC real (MAXHTS) C

Temperature of inside of surface.

TINC /RF/ IP
Time increment for CTF calculations. 


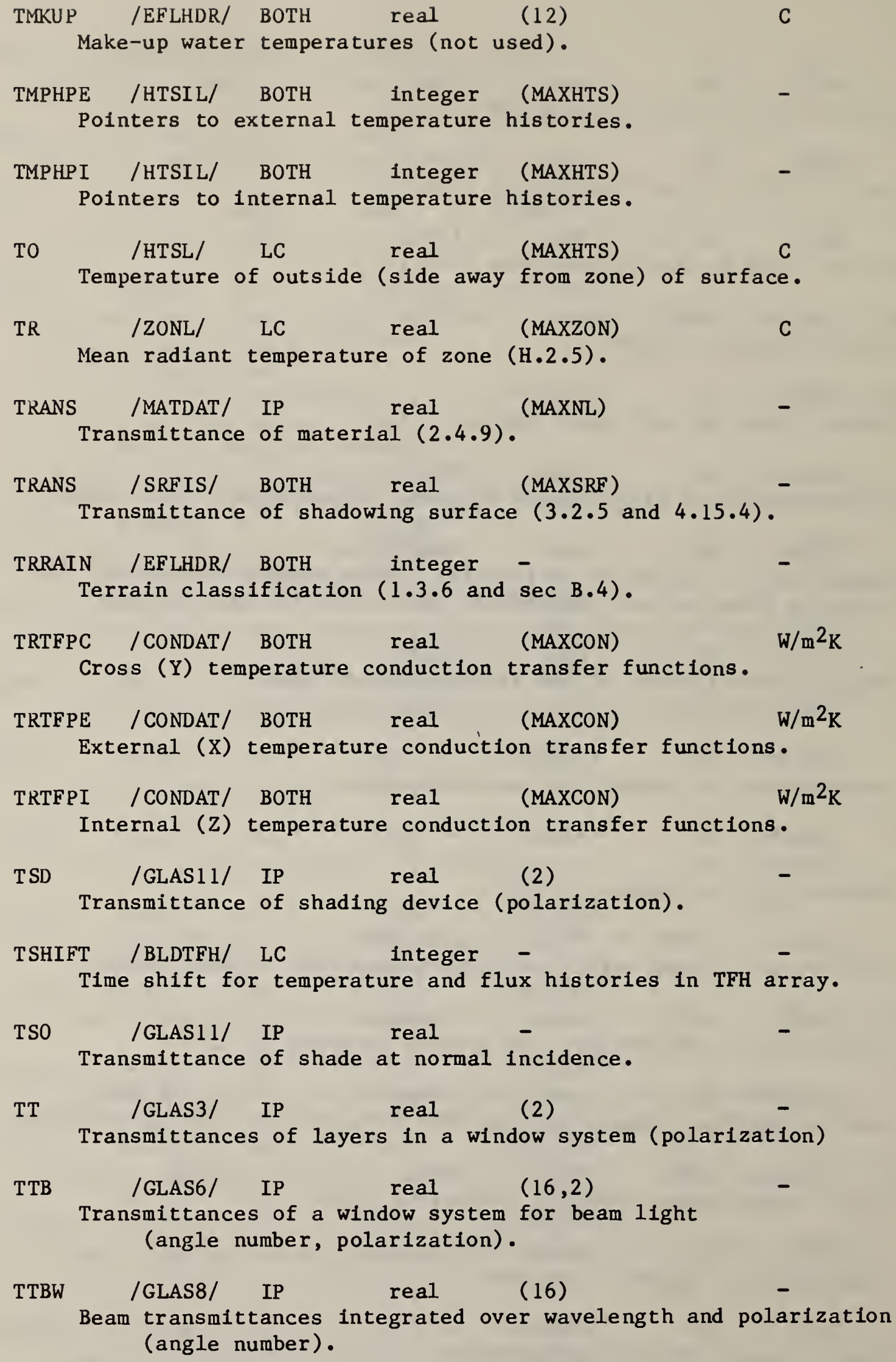


TTD

/GLAS5/ IP real

(2)

Transmittances of a window system for diffuse light (polarization).

TTDW /GLAS7/ IP real -

Diffuse transmittances integrated over wavelength and polarization.

TVENT /TCDESC/ LC real (5,maxzon) C

Ventilation control point temperatures.

$\mathrm{TZ}$

/ZONL/ LC real (MAXZON)

C

Zone air temperature.

TZNR /EFLHDR/ BOTH real

Time zone number $(1.3 .4)$.

T1

/GLAS/ BOTH (5,MAXGTP)-

Polynomial coefficients for beam solar transmittance ( $c_{1}$ in $\mathrm{D.1.7a}$ )

T2

/GLAS/ BOTH (6,MAXGTP)-

Polynomial coefficients for beam solar transmittance ( $c_{1}$ in $D .1 .7 b$ )

UCHAR /UINDAT/ IP Integer -

Current character in line (record) of user input.

UIERR /UINDAT/ IP Integer -

User input error:

0 no error

1 invalid subkey value:

continue processing

2 invalid subkey name:

skip input to next / or ) or ]

3 error in key name processing: skip input to next ) or ]

4 error in section name processing: skip input to next ]

5 at end of information: set $\mathrm{UISTAT}=6$

UILINE /UINDAT/ IP integer -

User input line number.

UINREC /UINREC/ IP char*80 -

User input record ( 1 ine of 80 characters).

UISTAT /UINDAT/ IP integer -

User input status:

0 initial setting in subroutine READER

1 at / at end of subkey

2 at ) at end of key, end subkey also

3 at ( at end of key name

4 at ] at end of section

5 at [ at end of section name

6 at end-of-information 


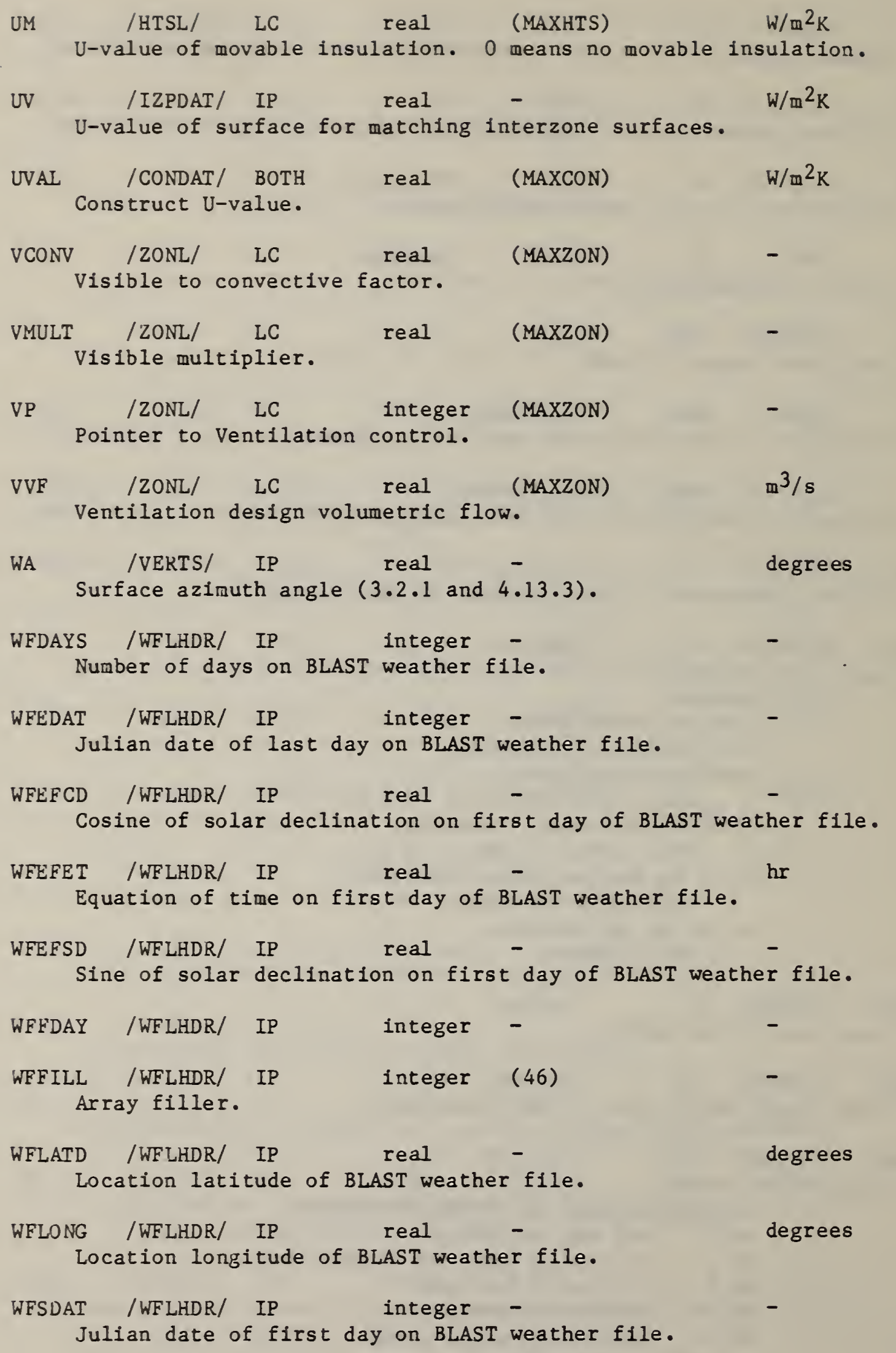




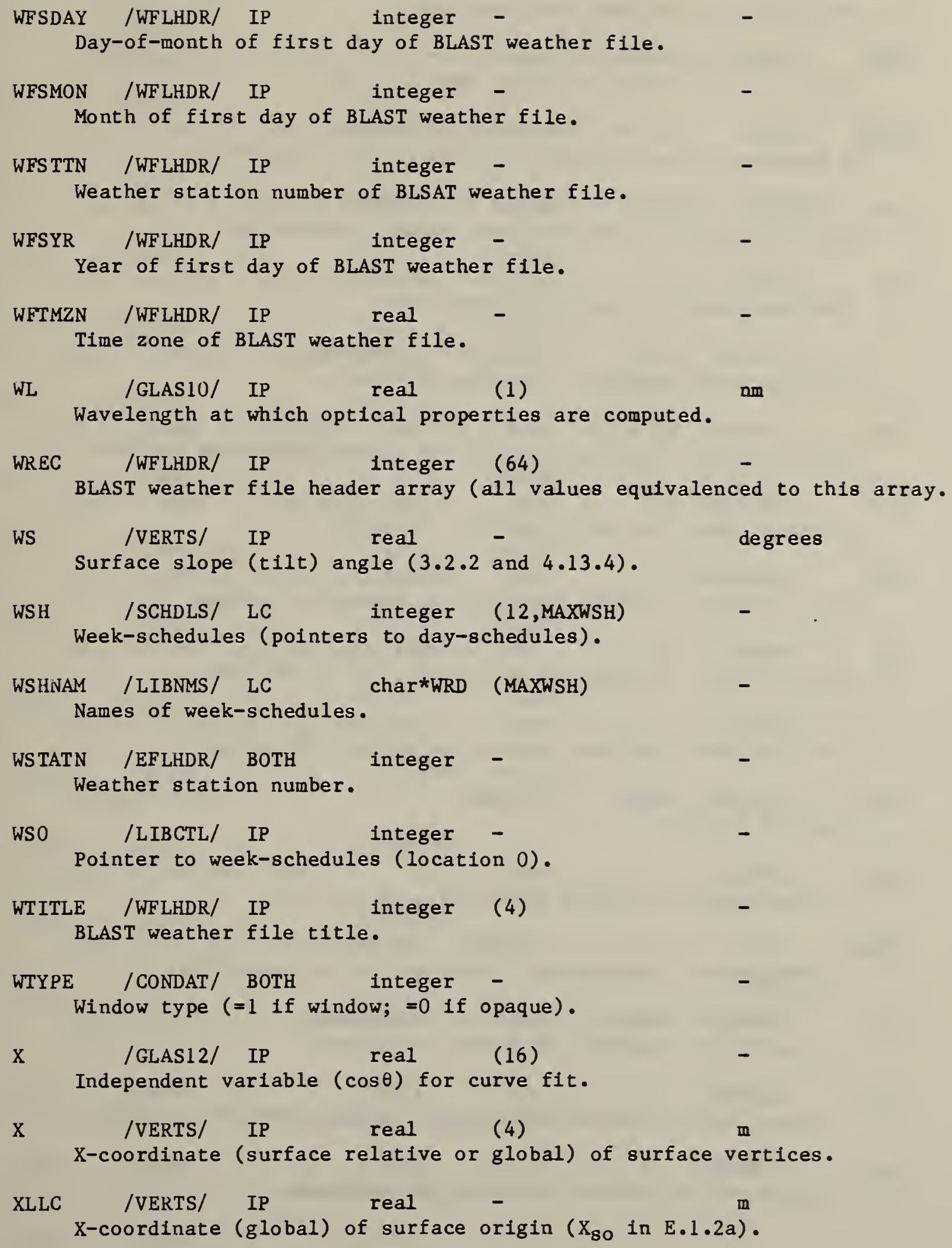




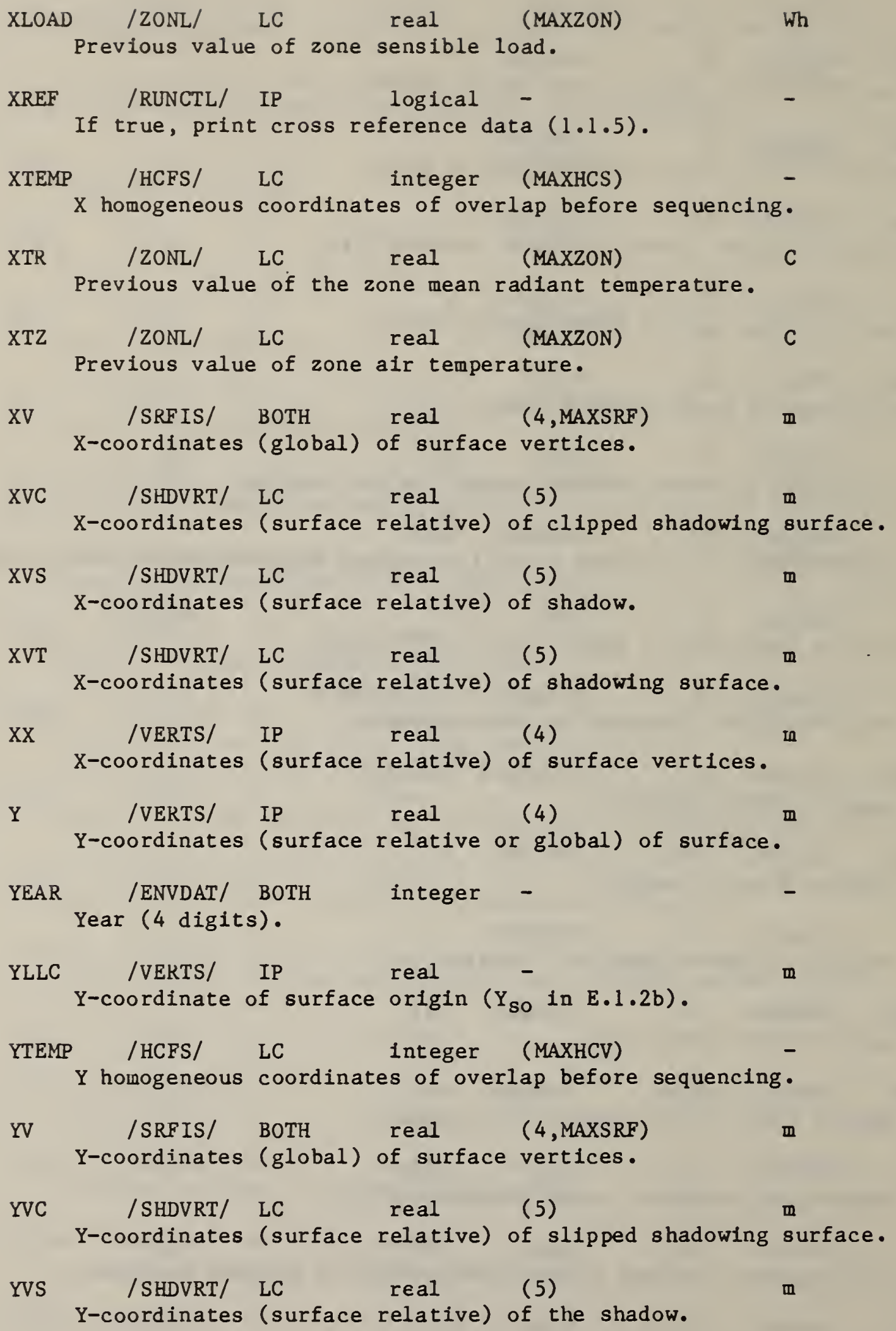




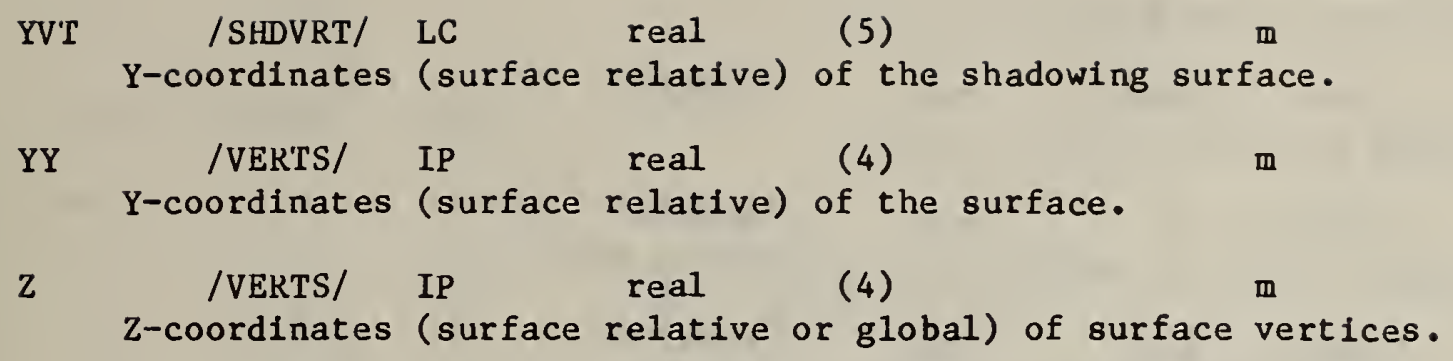




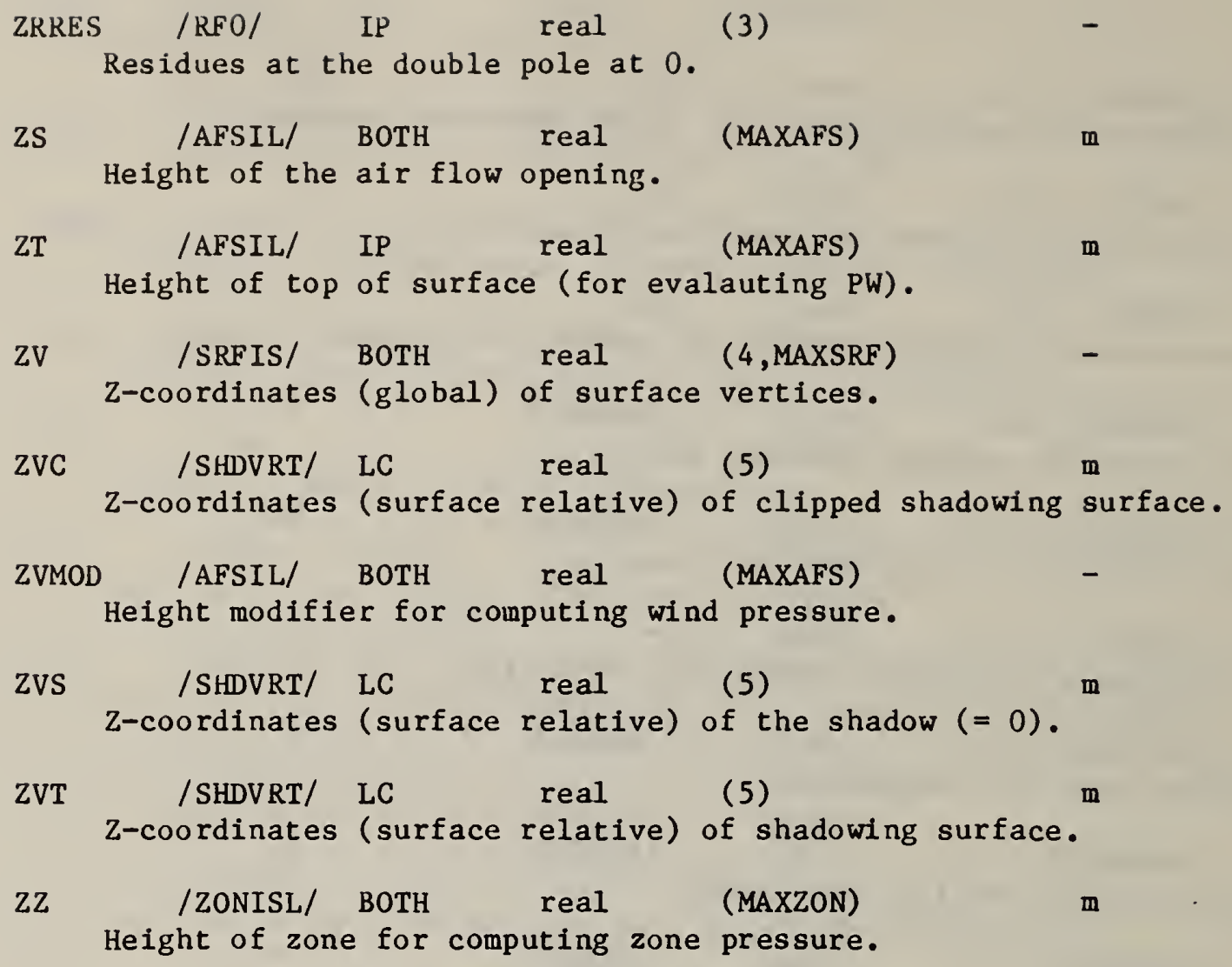


VI.D FILES

INPUT PROCESSOR FILES :

$\begin{array}{cccl}\text { UNIT } & \text { FILE } & \text { ACCESS } & \text { DESCRIPTION } \\ 11 & \text { SINPFL } & \text { seq } & \text { Simulation input file } \\ 12 & \text { ENVTFL } & \text { dir } & \text { Environment file } \\ 13 & \text { WTHRTP } & \text { seq } & \text { Weather tape from BLAST program } \\ 14 & - & \text { dir } & \text { Materials data } \\ 15 & - & \text { dir } & \text { Constructs data } \\ 16 & - & \text { dir } & \text { Interzone surface data } \\ 17 & - & \text { dir } & \text { Interzone opening data } \\ 21 & - & \text { seq } & \text { Day-schedules library report } \\ 22 & - & \text { seq } & \text { Week-schedules library report } \\ 23 & - & \text { seq } & \text { Materials library report } \\ 24 & - & \text { seq } & \text { Constructs library report } \\ 25 & - & \text { seq } & \text { Control profiles library report } \\ 26 & - & \text { seq } & \text { Control day-schedules library report } \\ 27 & - & \text { seq } & \text { Control week-schedules library report }\end{array}$

LOADS CALCULATOR FILES:
11 SINPFL seq
12 ENVTFL dir
Simulation input file
13 - dir
$14 \quad-\quad$ seq
$15 \quad-\quad$ seq
Environment file
Solar gains multipliers
Input segment to loads segment data
Input segment to shadowing segment data 
4. TITLE AND SUBTITLE

Thermal Analysis Research Program Reference Manual

5. AUTHOR(S)

G. N. Walton

6. PERFORMING ORGANIZATION (If joint or other than NBS, see in structlons)

7. ContracU Grant No.

NATIONAL BUREAU OF STANDARDS

DEPARTMENT OF COMMERCE

8. Type of Report \& Period Covered

WASHINGTON, D.C. 20234

9. SPONSORING ORGANIZATION NAME AND COMPLETE ADDRESS (Street, City, Stote, ZIP)

National Bureau of Standards and U.S. Department of Energy

Building Energy Sciences Branch

Office of Building Energy Research and Development

Washington, D.C. 20545

10. SUPPLEMENTARY NOTES

Document describes a computer program; SF-185, FIPS Software Summary, is attached.

11. ABSTRACT (A 200-word or less foctual summary of most significant information. If document includes a significant bibliogrophy or literature survey, mention it here)

The Thermal Analysis Research Program (TARP) has been developed as a research tool for the thermal analysis of buildings. It especially aims to study the interactions of many complex heat transfer phenomena. TARP uses the detailed heat balance method for the simultaneous calculation of the energy requirements of multiple rooms. Interroom conductive and convective processes are simulated in detail. This program reference manual describes the algorithms, input, output, and program structure of TARP. The program is written to be portable and modifiable. It is written in FORTRAN 77 and has run on CDC and UNIVAC computers. Future expansions of the program are anticipated, particularly for the simultaneous simulation of equipment performance and building thermal response.

12. KEY WORDS (Six to twelve entries; alphabetical order: capitalize only proper names; and seporate key words by semicolons) Building energy analysis; load calculation; computer modeling; building heat transfer.

13. AVAILABILITY

- $\mathrm{X}$ Unlimited

For Official Distribution. Do Not Release to NTIS

Order From Superintendent of Documents, U.S. Government Printing Office, Washington, D.C. 20402.
14. NO. OF

PRINTED PAGES

286

15. Price

$\$ 22.50$

- $[\mathrm{X}$ ) Order From National Technical Information Service (NTIS), Springfield, VA. 2216I 

